Volker Bockholt, Matthias Freise, Werner Lehfeldt, Peter Meyer (Hg.)

\title{
FINIS CORONAT OPUS
}

Festschrift für Walter Kroll zum 65. Geburtstag

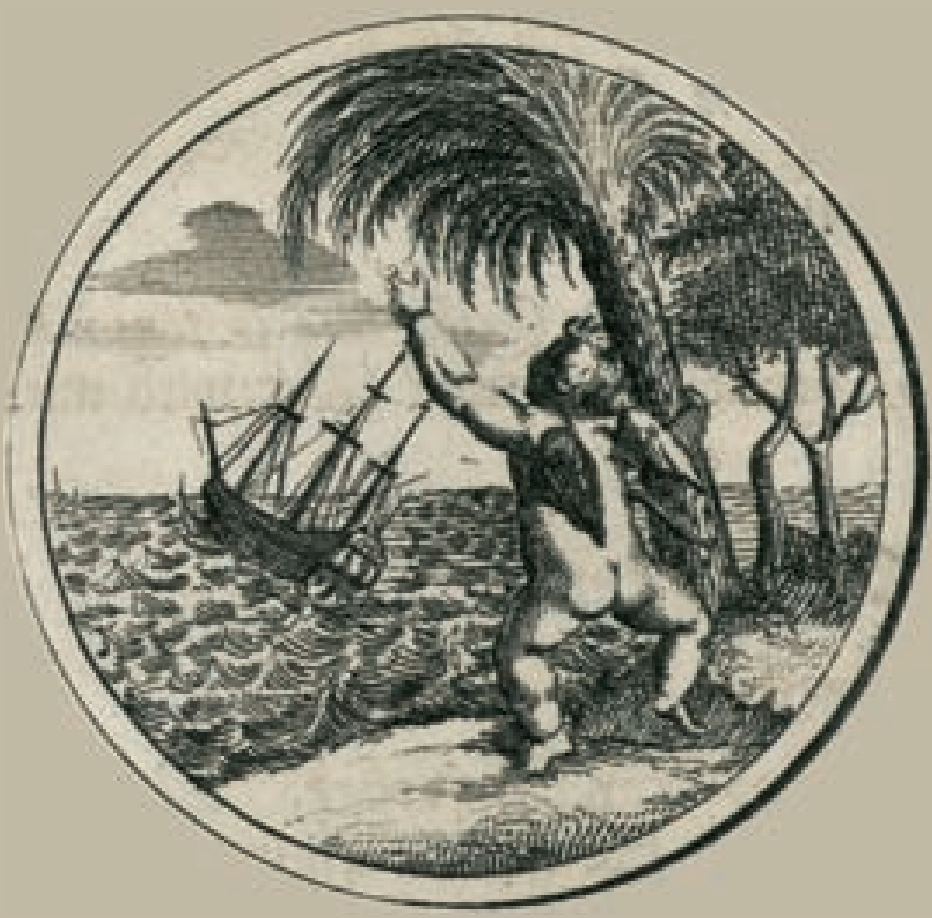

\section{Universitätsverlag Göttingen}



Volker Bockholt, Matthias Freise, Werner Lehfeldt, Peter Meyer (Hg.) Finis coronat opus 
erschienen im Universitätsverlag Göttingen 2006 
Volker Bockholt,

Matthias Freise,

Werner Lehfeldt,

Peter Meyer (Hg.)

Finis coronat opus

Festschrift für Walter Kroll zum 65. Geburtstag

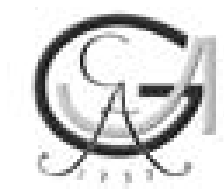

Universitätsverlag Göttingen 2006 


\section{Bibliographische Information der Deutschen Nationalbibliothek}

Die Deutsche Nationalbibliothek verzeichnet diese Publikation in der Deutschen Nationalbibliographie; detaillierte bibliographische Daten sind im Internet über $<$ http://dnb.ddb.de $>$ abrufbar

\section{Anschrift des Instituts}

Seminar für Slavische Philologie

Humboldtallee 19

37073 Göttingen

Dieses Buch ist auch als freie Onlineversion über die Homepage des Verlags sowie über den OPAC der Niedersächsischen Staats- und Universitätsbibliothek (http://www.sub.uni-goettingen.de) erreichbar und darf gelesen, heruntergeladen sowie als Privatkopie ausgedruckt werden. Es ist nicht gestattet, Kopien oder gedruckte Fassungen der freien Onlineversion zu veräußern.

Titelabbildung

Niedersächsische Staats- und Univeristätsbibliothek. „Symbola et emblemata iussu Petri Alexeidis Imperatoris Moscoviae"

Signatur 4 Bibl Uff 508

Satz und Layout: Peter Meyer

Umschlaggestaltung: Maren Büttner, Kilian Klapp

(C) 2006 Universitätsverlag Göttingen

http://univerlag.uni-goettingen.de

ISBN-10: 3-938616-48-2

ISBN-13: 978-3-938616-48-2 


\title{
Liber
}

\author{
Gualterio Regi \\ (vulgo Walter Kroll) \\ LXV annos nato
}

$\mathrm{ab}$ amicis missus

qui inscribitur

\section{FINIS CORONAT OPUS}

Edentibus et curantibus

Volker Bockholt

Matthias Freise

Werner Lehfeldt

Peter Meyer

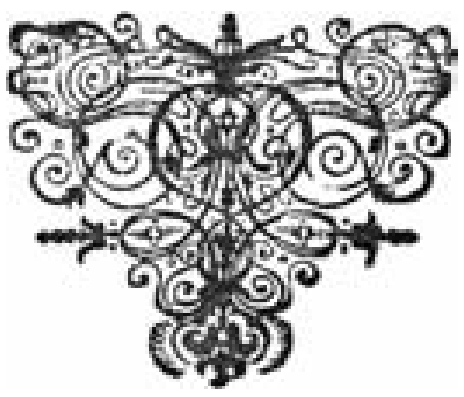

Gottingae MMVI 


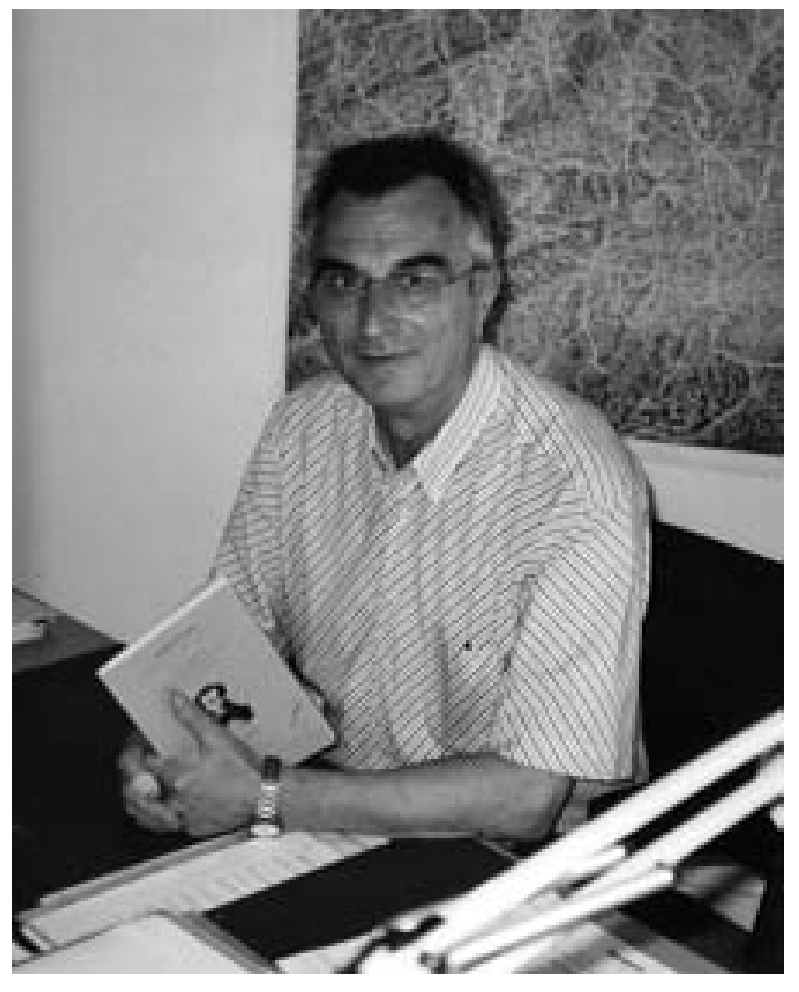

Dr. Walter Kroll 


\section{Inhaltsverzeichnis}

Geleitwort der Herausgeber

VOLKER BOCKHOLT

Zur Entstehung der Formen der Endungen der 3. Person des Präsens in den slavischen Sprachen

DAGMAR BURKHART

Konzeptualisierungen des Ehrbegriffs in der russischen Kultur

АЛЕКСАНДР ДМИТРИЕВИЧ ДУЛИЧЕНКО

Градищанско-хорватские сказки по-штинацски из Южного Бургенланда (Запоздалый отклик)

MARTIN ERDMANN

Unbekannte Wirklichkeit. Die Träume Raskol'nikovs in Fedor M. Dostoevskijs Roman Преступление и наказание

AlEKSANDAR FLAKER

Eine Begegnung an der Ostsee

MATthiAs FREISE

Vier Weisen, nach dem Text zu fragen

PAVEL GAN

„Moja harfa je ceło ślónsko zém“ - Zur lachischen Poesie von Óndra Łysohorsky aus der Euroregion Schlesien

RAINER GRÜBEL

Lehren, Übersetzen und Forschen in Jeletz (1887-1891). Ein

Kapitel aus Wassili Rosanows Biographie

ULRIKE JEKUTSCH

„Der Tod und das Mädchen“ in den Versionen Maksim Gor'kijs und Nikolaj Zabolockijs

ZvONKO KovAČ

Göttinger Elegien 
KATERINA KROUCHEVA

Arkadij Bartov, Muchiniada. Ein fiktiver Kindler-Artikel

REINHARD LAUER

Grundlegung der Metametrik

143

WERNER LEHFELDT

Moltke über Polen

Josip MATEŠIĆ

Friedrich Hölderlin u prijevodu Dragutina Tadijanovića na hrvatski jezik

Peter Meyer

Ist Herr Kroll ein Gehirn im Tank?

Andrea Meyer-FraAtz

Zur Rezeption deutschsprachiger Literatur bei den Kroaten in den 30er Jahren des 20. Jahrhunderts

AnNegret MidDEKe

Philippopolis - Filibe - Plovdiv: Plovdivbilder in der bulgarischen Literatur

Hans-Michael Miedlig

Gewalt und Gewaltvorstellungen im russischen und osmanisch-südosteuropäischen Raum vom späten Mittelalter bis ins 19. Jahrhundert

Ewa Skorupa

Ansichten von Bolesław Prus zu Preußen und Deutschland (am Beispiel der Kroniki)

Maxim I. Stamenov

Ambivalente Aspekte des assertiven sozialen Verhaltens, ausgedrückt durch türkische Lehnwörter im Bulgarischen

JÜRGEN UDOLPH

Anmerkungen zum Familiennamen Kroll 


\section{ASTRID Winter}

Stumme Poesie. Zur Poetik des nonverbalen Ausdrucks in der tschechischen experimentellen Literatur

INGEBORG WOLF

Wird die deutsche Sprache der tschechischen immer ähnlicher? Beobachtungen beim Hörfunk

VIKTOR ŽMEGAČ

Aspekte der Verfremdung

Schriftenverzeichnis von Dr. Walter Kroll 



\section{Geleitwort der Herausgeber}

Die vorliegende Festschrift ist Walter Kroll zur Vollendung seines 65. Lebensjahres gewidmet. Dieses Datum markiert - leider - zugleich das Ausscheiden von Walter Kroll aus seiner Stellung als Wissenschaftlicher Mitarbeiter am Seminar für Slavische Philologie und den Eintritt in den sogenannten Ruhestand. Die Herausgeber und die Autoren verfolgen mit der Festschrift das Ziel, Walter Kroll mit dieser Freundschaftsgabe beim Übergang in den neuen Lebensabschnitt zu begleiten und ihm auf diese Weise die hohe Wertschätzung und Achtung zu bezeugen, die ihm im Göttinger Seminar und weit darüber hinaus entgegengebracht wird.

Walter Kroll ist Oberschlesier. Am 10. Oktober 1941 wurde er in Horneck (Kreis Gleiwitz) geboren. In seiner Heimat, die nach dem II. Weltkrieg zu Polen gekommen war, besuchte er die polnische Grundschule und das polnische Gymnasium, bevor er im Jahre 1958 Schlesien verließ und im Rahmen der Familienzusammenführung nach Deutschland übersiedelte. Im Jahre 1963 legte er am Neusprachlichen Gymnasium der Stadt Elze das Abitur ab. Im selben Jahr nahm er an der Berliner Freien Universität das Studium der Fächer Philosophie und Germanistik auf, wechselte 
1965 nach Göttingen, um an der Georgia Augusta bei Maximilian Braun Slavistik zu studieren, und zwar „Vollslavistik“ im Sinne der Beschäftigung mit den ost-, den west- und den südslavischen Sprachen und Literaturen. 1972 erwarb er in den Fächern Slavistik und Germanistik den Magistertitel.

Nach dem Abschluß des Studiums war Walter Kroll von 1972 bis 1978 an der Abteilung für Germanistik der Universität Zagreb als DAAD-Lektor für die deutsche Sprache tätig und konnte in dieser Zeit seine Kenntnis der kroatischen Sprache vervollkommnen. Nach der Rückkehr aus Kroatien arbeitete er von 1978 bis 1983 als Wissenschaftlicher Mitarbeiter am Slavischen Seminar der Universität Mannheim. 1983 wurde er in Göttingen bei Reinhard Lauer mit der Dissertation „Heraldische Dichtung bei den Slaven“ zum Doktor der Philosophie promoviert. Der Titel der Dissertation bezeichnet ein Arbeitsfeld, auf dem Walter Kroll seitdem unaufhörlich und intensiv tätig gewesen ist.

Nachdem Walter Kroll von 1983 bis 1986 als Hochschulassistent in Mannheim tätig gewesen war, wechselte er 1986 endgültig nach Göttingen über, wo er seitdem am Lehrstuhl von Reinhard Lauer die Stellung eines Wissenschaftlichen Mitarbeiters innehatte. In dieser Position hatte er vor allem an den zahlreichen Lehrstuhlprojekten mitzuarbeiten sowie die Reihen „Opera Slavica“ und „Der Blaue Turm“ redaktionell zu betreuen. Außerdem war er im akademischen Unterricht tätig und leistete auf diese Weise einen wichtigen Beitrag zur slavistischliteraturwissenschaftlichen Lehre an unserem Seminar. Und zwar erstreckte sich diese Lehrtätigkeit auf die russische, die polnische, die kroatische, die serbische und die bosnische Literatur. All diese Literaturen bildeten und bilden auch den Gegenstandsbereich der Forschung von Walter Kroll. Nennen wir einige Schwerpunkte seiner literaturwissenschaftlichen Forschungstätigkeit: slavische Literaturtheorie, slavische Barockliteratur (Emblematik bei den Slaven), Romantik und Moderne bei den Slaven, kroatische und bosnische Gegenwartsliteratur, Komparatistik. Von der Beschäftigung mit diesen Forschungsschwerpunkten hat Walter Kroll in zahlreichen im In- und Ausland gehaltenen Vorträgen sowie am nachhaltigsten in zahlreichen Publikationen Zeugnis abgelegt. So ist er nicht nur zu einem engagierten und geachteten akademischen Lehrer geworden, sondern auch zu einem hochgeschätzten Forscher auf dem Gebiet der slavischen Literaturwissenschaft. Die vorliegende Festschrift, mit der Herausgeber und Autoren Walter Kroll eine Freude bereiten wollen, versteht sich - wir haben es bereits erwähnt - als Zeichen dieser Hochschätzung. 
Glücklicherweise für das Göttinger Slavische Seminar bedeutet Walter Krolls Ausscheiden aus dem sogenannten aktiven Dienst nicht das Ende seiner Tätigkeit als akademischer Lehrer. Als Lehrbeauftragter wird er unseren Studentinnen und Studenten weiterhin die von ihm beackerten slavischen Literaturen vermitteln und auf diese Weise einen höchst erwünschten Beitrag zur Aufrechterhaltung des literaturwissenschaftlichen Lehrangebots leisten. Wir hoffen und wünschen, daß er uns in dieser Stellung noch viele Jahre verbunden bleiben wird. Unsere besten Wünsche begleiten ihn in seiner neuen Lebensphase.

Volker Bockholt Matthias Freise Werner Lehfeldt

Peter Meyer 



\section{Zur Entstehung der Formen der Endungen der 3. Person des Präsens in den slavischen Sprachen}

0. Über die Entstehung der Formen der Endungen des slavischen Verbs der 3. Person des Singular und des Plural im Präsens ist bereits sehr viel publiziert worden (vgl. u.a. den Übersichtsartikel von Miller 1988, 7-33). Hierfür gibt es gute Gründe. Es besteht eine Formenvielfalt, die innerhalb der indogermanischen Sprachfamilie selten ist: so weisen die west- und die südslavischen Sprachen - mit Ausnahmen, auf die in diesem Artikel noch eingegangen werden wird - zumeist Nullendungen auf (z.B. poln. działa (Singular) und działaja (Plural), während im ostslavischen Sprachraum Endungen auf palatalisiertes $-m s$ und nichtpalatalisiertes $-m$ dominieren (z.B. russ. делаеть, делает (Singular) und делають, делают (Plural), im folgenden auch als Dentalendungen bezeichnet). Auch die semantische Spezialisierung von Nullendungen und von Dentalendungen auf die Bezeichnung von Numerusgrammemen kommt häufig vor: so steht in zahlreichen bulgarischen Dialekten und in der bulgarischen Standardsprache die Nullendung für die Singularform und die Dentalendung für die Pluralform. In den ostslavischen Dialekten und in der 
ukrainischen Standardsprache dient die Nullendung darüber hinaus auch noch zumeist in der Singularform - zur Bezeichnung der Verbklasse; die Bezeichnung der Pluralformen ist in dieser Hinsicht zumeist neutral, z.B. ukr. ходять, идуть. Zur Bezeichnung des Singulars wird bei Verben der $i$-Konjugation die Dentalendung, z.B. ukr. xодums, bei Verben der $e$-Konjugation jedoch die Nullendung verwendet, z.B. ukr. üde. Es kommen zahlreiche weitere kombinatorische Verteilungen beider Endungen vor (vgl. die besonders ausführliche Aufzählung bei Обнорский 1953, 118 ff.).

Lediglich im Hinblick auf den genetischen Ursprung der weichen Dentalendung - $t$ ' besteht Klarheit. Es handelt sich um die ererbte indogermanische Endung des Präsens. Ein ungelöstes Problem bildet hingegen bis heute die Herkunft der harten Dentalendung $-m$ im ostslavischen (Kiparsky 1967, 189) und im makedonischbulgarischen sowie die der Nullendung im west- und im südwestslavischen (serbokroatischen, slovenischen) Sprachraum. Ziel des vorliegenden Beitrages ist es, eine Sichtung der bisher vertretenen Meinungen zu dieser Fragestellung vorzunehmen und eine eigene, neue Hypothese über die Entstehung der Endungsvielfalt und deren Ursprung zu formulieren.

1. Den Anlaß für die Wahl gerade dieses Themas bildet der Beitrag von Jan Ivar Bjørnflaten (Bjørnflaten 2003, 48-56) in der Festschrift für Werner Lehfeldt. Das Anliegen des Beitrages von Bjørnflaten und die dort aufgestellte Argumentation sollen auch den Ausgangspunkt dieses Beitrags bilden. Bjørnflatens Anliegen besteht zum ersten darin, nachzuweisen, daß es auf dem großrussischen Sprachgebiet Dialekte gebe, welche im Singular und im Plural der 3. Person Präsens konsequent die Nullendung (z.В. дела, делаю statt standardsprachlich делает, делают) aufweisen - und sich somit von der Mehrzahl der großrussischen Dialekte und von der Standardsprache unterscheiden, die zumeist Dentalendungen auf - $m$ s oder $-m$, teilweise die Nullendung in der Singularform einer der beiden großen Verbklassen aufweisen (vgl. die Übersicht in Bjørnflaten 2003, 50). J. I. Bjørnflaten findet solche Dialekte mit konsequenter Nullendung im Gebiet von Gdov am Ostufer des Peipussees, im äußersten Nordwesten des großrussischen Sprachgebietes und im heutigen Grenzraum zum estnischen und damit zum finnougrischen Sprachgebiet (Bjørnflaten 2003, 51 f.). Der Nachweis seiner Behauptung ist Bjørnflaten eindrucksvoll und überzeugend gelungen. Bjørnflatens Ausführungen sind vor dem Hintergrund der Einstellung der Dialektologen der Sowjetzeit zu ihren Sprachdaten zu sehen und zu verstehen: es gab einerseits die korrekt arbeitenden Wissenschaftler, die sich genau an die Fakten hielten. Andererseits gab es auch Wissenschaftler, die sich von der Ideologie des an der standardsprachlichen Norm orientierten Sprachunitarismus (als Teilkomponente des gleichgemachten Sowjetmenschen) leiten ließen und die Existenz deutlicher Abweichungen von der Norm hartnäckig leugneten. Letztgenannte Einstellung wirkt bis in die heutige Zeit nach, und es ist eine hoch einzuschätzende Leistung Bjørnflatens, diesen Sachverhalt an einem konkreten und gut geeigneten Beispiel kurz nachgezeichnet (Bjørnflaten 2003, 49-51) und durch eigene, fachgerechte Datenerhebung an Ort und Stelle Textmaterial gewonnen 
zu haben. Es ist nach Bjørnflaten nicht mehr anzuzweifeln, daß es im großrussischen Sprachraum Dialekte gibt, die in der 3. Person des Präsens konsequent die Nullendung aufweisen.

Zum zweiten unternimmt Bjørnflaten den Versuch, eine Chronologie der Entstehung dieser konsequenten Nullendung am Rande des großrussischen Sprachgebietes aufzustellen. Er gelangt zu dem Ergebnis, daß es sich hierbei um eine verhältnismäfig junge Innovation handele, die in die Zeit nach dem 16. Jahrhundert zu datieren sei (Bjørnflaten 2003, 55). Das Schlüsselargument für diese Ansicht besteht darin, daß die Fixierung der reflexiven Partikel - ся auf die Position am Ende des russischen Verbs zeitlich ins 17. Jahrhundert falle und daß die agglutinierte reflexive Partikel in der 3. Person des Präsens im ostslavischen Sprachgebiet ausschließlich an Dentalendungen (also - $m с я$ oder $-m ъ c я$ ) vorkomme. Der Schwund des $-m$ bzw. des - $m$ s und damit die Entstehung der Nullendung könne also erst nach diesem Zeitpunkt eingetreten sein.

Diese von Bjørnflaten entwickelte relative Chronologie der Entstehung der Nullendung im Gdover Gebiet und ihre Datierung ins 17. Jahrhundert ist allerdings vor dem Hintergrund der einschlägigen Daten aus den seit 1951 gefundenen Birkenrindentexten als geschwächt anzusehen. Zwar widerlegen die Daten aus den Birkenrindentexten Bjørnflatens Datierung nicht unmittelbar, weil kein einziger individueller Birkenrindentext Präsensformen mit konsequenter Nullendung im Singular und im Plural aufweist, wie es die von Bjørnflaten erhobenen Gdover Dialekttexte laut Auswertung durch seinen Schüler Honselaar tun (Bjørnflaten 2003, 53; Хонселаар 2001, 18). Bei einer Gesamtbetrachtung der Belege (Янин, Зализняк 1986, 143; Зализняк 1995, 119; Зализняк 2004, 137) kommen die Birkenrindentexte dem Befund in Bjørnflatens Gdover Dialekttexten jedoch schon sehr nahe: es gibt zwar sowohl Dentalendungen als auch Nullendungen, aber die Nullendungen unterliegen keinerlei Beschränkung auf den Singular oder den Plural und weiter auch keinerlei Beschränkung auf die $e$-Verben oder die $i$-Verben, wie man es in den meisten zeitgenössischen großrussischen Dialekten beobachten kann (vgl. Гецова 1963, 107 ff.; Bjørnflaten 2003, 50; Касаткин 2005, 151 f.).

Auch der Befund für die Verbformen mit agglutinierten reflexiven Partikeln im Birkenrindentextkorpus schwächt Bjørnflatens Datierung. Für das gesamte Birkenrindentextkorpus gilt die Regel, daß Verbformen der 3. Person Präsens, denen ein enklitisches Pronomen folgt - hierzu gehört auch die Partikel - $c я$ - zwingend eine Dentalendung, niemals jedoch eine Nullendung, aufweisen (vgl. Янин, Зализняк 1986, 143; unter Berücksichtigung weiterer Textfunde genauso: Зализняк 1995, 120; Зализняк 2004, 138). Gerade dieser Teilbefund aus den Birkenrindentexten fehlt in der Argumentation Bjørnflatens - dieser referiert nach Kiparsky (Kiparsky 1967, 197) eine Arbeit von Gunnarsson aus dem Jahre 1935, die also entstanden ist, als die Birkenrindentexte noch unentdeckt waren. Durch den Ausweis der Sprachdaten der Birkenrindentexte ist die Voraussetzung für Bjørnflatens relative Chronologie und damit auch für die Datierung der Entstehung der Nullendung auf einen relativ späten Zeitpunkt geschwächt. Die Daten aus den Birkenrindentexten 
lassen somit an einer bestimmten, von Bjørnflaten mitvertretenen traditionellen Meinung Zweifel aufkommen. Erkennt man die Bedeutung dieser Daten an, kann man sich auch der gegenteiligen Meinung anschließen, nämlich der, die Entstehung der Nullendung in diesem Teil des ostslavischen Gebietes sei eben nicht neu, sondern im Gegenteil alt. Diese Meinung wird von den mit dem indogermanistischen Stammbaummodell arbeitenden Slavisten jedoch höchst ungern vertreten (s. 2.). Es spielt hier wohl auch ein gewisses Moment der Trägheit des Verlaufes von Wissenschaftsdiskursen eine Rolle: die ersten Funde von Birkenrindentexten haben zwar ein großes Aufsehen erregt - ein intensives Interesse der sprachwissenschaftlichen Russistik ist jedoch nur zögerlich entwickelt worden. Noch in der 1980 erschienenen Sprachgeschichte Issatschenkos (,sprachgeschichtlich bieten sie recht wenig", Issatschenko 1980, 67) wird die Bedeutung der Birkenrindentexte für die Sprachgeschichte des Russischen verkannt. Erst die seit den achziger Jahren publizierten Analysen von A. A. Zaliznjak (vor allem: Янин, Зализняк 1986, 89 ff.) gestützt durch eine bis heute kontinuierlich wachsende Zahl von Funden - haben eine angemessene Einschätzung der Birkenrindentexte durch die Sprachhistoriker eingeleitet.

Angreifbar ist ferner der Umstand, daß Bjørnflaten eine nationalphilologische, ostslavisch-großrussische Sicht der Dinge einer gesamtslavischen Perspektive vorzieht. Natürlich kennt Bjørnflaten die gesamtslavischen Verhältnisse. Er erwähnt kurz, daß „die Nullendung mit den westslavischen Sprachen übereinzustimmen [...] scheint" (Bjørnflaten 2003, 48). Er sagt jedoch nicht ausdrücklich, daß die Nullendung in den westslavischen Sprachen deutlich früher als im 17. Jahrhundert entstanden ist (s. 5.). Er weicht damit der sich aufdrängenden Frage aus, welche Ursache im Gdover Gebiet zu einem wesentlich späteren Zeitpunkt als im westund im südwestslavischen Sprachraum zu genau demselben Ergebnis, nämlich zu der konsequenten Nullendung, geführt hat.

Zaliznjak hingegen vertritt die Ansicht, die Nullendung in den Novgoroder Birkenrindentexten sei erstens alt und zweitens ein genetisch westslavisches Element (Зализняк 1988, 175). Er zieht den grundsätzlichen Schluß, daß der sprachliche Befund der Birkenrindentexte der Vorstellung einer monolithischen genetischen Abzweigung des Urostslavischen vom Urslavischen widerspreche (Зализняк 1988, 176), mit anderen Worten, daß das genetische Prinzip des indogermanistischen Stammbaummodells den Sprachdaten in den Birkenrindentexten nicht gerecht werde. Nach Zaliznjak ist die Sprache der Novgoroder Birkenrindentexte als „Mischtyp von Dialekten“ zu verstehen, in dem ost- und westslavische Merkmale vereint seien (Зализняк 1988, 165), weil Novgorod in einer „Kontaktzone“ beider Dialektgruppen gelegen habe (ebd.). Zaliznjaks Ansicht paßt gut zu den belegten Daten aus dem west- und dem südwestslavischen Sprachraum.

2. Die gesamtslavische Perspektive unseres Problems behandelt ein Überblicksartikel von Raymond H. Miller (Miller 1988, 7-33), den Bjørnflaten leider nicht berücksichtigt hat. Der Artikel enthält einen Bericht über den Befund in den älteren slavischen Handschriften (Miller 1988, Abschnitt 3, 8-9), in den zeitgenös- 
sischen slavischen Dialekten (Miller 1988, Abschnitt 4, 9-16), einen Bericht über die wichtigsten Ergebnisse der Forschung zu unserer Fragestellung (Miller 1988, Abschnitt 5, 16-19), eine eigene Hypothese zur Entstehung der Endungen der 3. Person des Präsens (Miller 1988, Abschnitt 6, 19-24) und einen Exkurs über die von Bjørnflaten behandelte Frage der Entstehung der Nullendung im Ostslavischen (Miller 1988, Abschnitt 7, 25-29). Im Ergebnis kommt Miller zu einer Ansicht, die der von Bjørnflaten vertretenen Meinung entgegensteht. Er hält die konsequente Nullendung in den nordwestgroßrussischen Dialekten für sehr alt (Miller 1988, 23, 25 ff.). Miller kennt die Ergebnisse der Analysen der Novgoroder Birkenrindentexte und die von Zaliznjak hierzu vertretene Ansicht (s. 1.). Zaliznjaks Ansicht ist mit den Ergebnissen von Millers Rekonstruktion der Entwicklung (s.u.) kompatibel, auf konzeptioneller Ebene jedoch klaffen Welten zwischen Zaliznjak und Miller.

Ausgehend von den Verhältnissen in den indogermanischen Sprachen, den slavischen Dialekten und in den alten Handschriften - hier gewinnt Miller seine sprachlichen Daten -, modelliert Miller vier Etappen der Entstehung der heutigen Endungsvielfalt. Er ordnet die gesamte Entwicklung der gemeinslavischen Periode zu. Er arbeitet mit morphologischen Größen, nämlich den Endungen der aus dem Indogermanischen ererbten athematischen und der thematischen Verbklassen (Miller 1988, 20) sowie den Endungen der nicht aus dem Indogermanischen ererbten, von ihm „2. slavische Konjugation“ genannten Klasse der $i$-Verben (Miller 1988, 21). Durch dreimaliges Neuordnen der angenommenen Ausgangskonstellation gewinnt er eine viergliedrige, räumlich angeordnete Konstellation, aus der man die heutige areale Sprachmakrosituation herauslesen kann (Miller 1988, 23). Diese war nach Miller gegen Ende der gemeinslavischen Periode erreicht (ebd.). In einem entscheidenden Punkt deckt Millers Modell jedoch die Wirklichkeit nicht ab: die konsequente Dentalendung ist im Modell nur für den nordöstlichen Quadranten vorgesehen, auf der Ebene der Realität aber in den makedonischen Dialekten um Ohrid sehr vital und vor allem schon in den ältesten altkirchenslavischen Denkmälern des 11. Jahrhunderts als schriftlich fixierter Normalzustand belegt. Diese Denkmäler werden von der gesamten Fachwelt unstrittig dem slavischen Süden zugeordnet. Auch scheint es unvorstellbar, daß der Ausdruck einer im Usus häufig vorkommenden grammatischen Kategorie mehreren sprunghaften Veränderungen unterworfen gewesen sein soll. Das von Miller erarbeitete Modell läßst nicht nur die Frage nach der Entstehung der altkirchenslavischen harten Dentalendungen offen. Es ist grundsätzlich nicht geeignet, die Lösung irgendeiner Problemstellung zu befördern. Wenn Miller schon annimmt, die Endungsvielfalt sei alt und auf einen gemeinsamen Entstehungszeitraum zurückzuführen, läge es auch nahe, zu versuchen, den Ursprung der Endungsvielfalt auf eine gemeinsame Ursache zurückzuführen. Dies geschieht jedoch - wie auch schon bei Bjørnflaten ganz und gar nicht.

Millers Ansatz ist als spezieller Lösungsansatz der Indogermanistik einzuordnen. Ihre traditionellen Lösungsansätze operieren mit Daten der lautlichen Ebene. Auch unsere Frage nach der Entstehung der Endungsvielfalt der Formen für die 
Bezeichnung der 3. Person Präsens ist mit der Wirksamkeit von Lautgesetzen in Verbindung gebracht worden. Da die weiche Dentalendung - $t$ ' unstrittig den historischen Nachfolger des indogermanischen Präsens repräsentiert, wurde sie zumeist als Ausgang für die Lautwandelprozesse angesetzt, die die harte Dentalendung - $t$ und die Nullendung hervorgebracht haben sollen:

„Die Formen beretz, berots haben wir irgendwie als Zwischenstadien [Hervorhebung von mir. V. B.] zwischen *berets, *berots und *bere, *bero zu erklären." (Stang 1942, 218)

Mit anderen Worten: die Indogermanistik nimmt einen lautlichen Prozeß an, der vom Ausgangszustand - $t$ ' über den Zwischenzustand - $t$ (noch die neueste Ausgabe der in Rußland verbreiteten Einführung in die russische Dialektologie formuliert diese Vorstellung einer Entwicklung von älterem südgroßrussischem -mъ zu jüngerem nordgroßrussischem -m; vgl. Касаткин, 2005, 151) zum Endzustand geführt habe. Bei der Suche nach einem Lautwandelprozeß mit diesem Verlauf steht man vor der Hürde des Sachverhaltes, daß hartes $-m$ und weiches $-m s$ im Ostslavischen bewahrt und streng voneinander geschieden werden. Auch das konsequente altkirchenslavische (makedonische) -mø ist lautgesetzlich nicht als Nachfolger eines indogermanischen weichen -t' zu erklären (Kiparsky 1967, 189). Um die Hürde dennoch zu nehmen, referiert z.B. Stang (Meillet und Vaillant folgend) einiges an Sonderkategorien von Lauten: speziell schwacher Jer-Typus, Abglittvokal, Gleitvokal, fakultativer Vokal, unetymologischer Auslautvokal, unregelmäßige Kürzung in der 3. Person, unregelrechte Entpalatalisierung in der 3. Person im Großrussischen, Reaktionsphänomen (Stang 1942, 216 ff.) - die Vielfalt der Erklärungsversuche halte ich für einen deutlichen Indikator der grundsätzlichen Schwäche dieses Erklärungsweges (so auch Обнорский 1953, 117).

Daß die harte Dentalendung -mø einen Normalzustand des ältesten schriftlich belegten Sprachzustandes im slavischen Bereich, nämlich des Altkirchenslavischen, darstellt und daß diese Endung daher als alt zu gelten hat, wird nirgends offen angezweifelt. Das mediävistische Wissen darüber, daß das Erzbistum Ohrid als Mittelpunkt der Herstellung früher altkirchenslavischer Denkmäler zu gelten hat und daß die harte Dentalendung - ms als Merkmal der örtlichen Dialekte in die Texte übernommen worden sein könnte, wird in dem hier behandelten Zusammenhang nirgends ausdrücklich erwähnt. Immerhin weisen die nahezu gleichaltrigen frühesten ostslavischen Denkmäler konsequent die korrespondierende weiche Dentalendung -ms auf, die ebenfalls nur regional, und zwar im südwestlichen Teil des ostslavischen Sprachraumes, verbreitet und ebenfalls dort bis in die heutige Zeit kontinuierlich belegt ist. Über dieses kulturgeschichtliche Wissen läßt sich die konsequente harte Dentalendung als wohl bereits gegen Ende des 9. Jahrhunderts in den Ohrider Dialekten anzutreffendes Merkmal bestimmen.

Grundsätzlich ist zu Millers Arbeit zu sagen, daß der Autor zwar zu Beginn seiner Ausführungen bestimmte morphosemantische Ansätze zur Lösung der Fragestellung ausschließst (Miller 1988, 8: „There will be no discussion of the 3pers dual, or the aorist and imperfect."), daß aber weite Teile seiner Berichte und 
eigenen Forschungen mit teilweise unklarer Abgrenzung zwischen lautlicher und morphologischer Perspektive hin- und herschwanken. Im Ergebnis bricht Miller mit der traditionellen Lehrmeinung von der Priorität von - $t$ ' und hält die Endung auf harten Dental - $t$ sowie die Nullendung gleichfalls für sehr alt (Miller 1988, 30). Die Kriterien der Entscheidungsfindung sind nicht besonders klar: wie die diskutierten Belege in den Denkmälern, das Vorkommen aller Endungen in sämtlichen slavischen Sprachgruppen sowie die Koexistenz aller Endungen auf engem Raum in bestimmten ostslavischen Gebieten genau zu bewerten sind, ist für mich nicht deutlich geworden. Ein theoretisches Modell, auf dem Millers Schlußfolgerungen basieren, wird aus seinen Ausführungen nicht erkennbar. Ich stimme Miller zu, wenn dieser sich die Ansicht V. N. Toporovs zueigen macht, daß Sprachhistoriker sich mit der Formulierung von Hypothesen begnügen müßten (Miller 1988, 30). Sicherlich wird die Erforschung der Entstehung von Sprachvarianz auf Ewigkeiten an Hypothesen gebunden sein. Der entscheidende Punkt ist jedoch ein ganz anderer: Ist das Stammbaummodell, das zwei einander diametral entgegenstehende Antworten (Bjørnflaten und Miller) auf eine konkrete Fragestellung zuläßt - dies habe ich bisher vorgeführt - ein geeignetes Modell für solche Forschung, oder gibt es nicht doch andere, mehr versprechende Modelle? Und weist nicht Zaliznjak mit seiner Annahme einer Sprachkontaktzone für das alte Novgorod einen Weg zu einem alternativen Modell?

3. Bevor ich auf den Sprachkontakt und seine mögliche Eignung zur Modellierung der Entstehung von Sprachvarianz näher eingehe, möchte ich der Vollständigkeit halber noch einige morphosemantische Ansätze zur Erklärung der Entstehung der Endungsvielfalt in der 3. Person des Präsens am slavischen Verb nachzeichnen und kommentieren. Miller schließt diesen Aspekt der Fragestellung aus seinem Bericht ausdrücklich aus (Miller 1988, 8), macht jedoch im Laufe der Darstellung eine Kehrtwende (S. 17-19).

Schon ein erster Blick in eine Gesamtschau der Tempusformenentwicklung der indogermanischen Sprachen zeigt, daß die Herausbildung der Präsens- und der Aoristformen einen Prozeß darstellt, der von gegenseitigen Austauschvorgängen geprägt ist (Hirt 1928, 177-192). Stang z.B. hat mit Meillet erwogen, die harte Dentalendung -mø sei ein Nachfolger der Endung für die 2. Person Singular des indogermanischen Perfekt (Stang 1942, 221). Für seine Annahme führt er das Argument an, die Endung -mø sei auf athematische und asigmatische Wurzelaoriste beschränkt (S. 222).

Die vereinzelte Verwendung der weichen Dentalendung - $m$ s und der Nullendung neben der regelmäßigen harten Dentalendung -mø in Denkmälern des altkirchenslavischen Textkanons ist bereits mehrfach beschrieben worden (van Wijk 1931, 213 f.; Обнорский 1953, 117). Koch beschreibt darüber hinaus eine Reihe von Fällen, in denen in altkirchenslavischen Denkmälern aufgrund der griechischen Textvorlage eine Aoristform zu erwarten ist, tatsächlich jedoch eine Präsensform verwendet wurde (z.B. naдљm statt zu erwartendem naдљ, Koch 1985, 47 ff.). Diese von Koch ermittelten Vorkommen fehlerhaft verwendeter Präsensformen 
sind beschränkt auf Verben mit identischer Lautgestalt in der Aoristform und in der um die Dentalendung reduzierten Präsensform (Koch 1985, 63). Solche Verhältnisse gibt es nur bei einem Teil der Verben der ersten Leskienschen Klasse (z.B. идетг - иде) und bei den Verben der vierten Leskienschen Klasse mit Infinitivstammauslaut auf - $и$ (z.B. хвалитг - хвали).

Fortunatov nahm an, die harte Dentalendung im Ostslavischen setze ein altes Pronomen ${ }^{*} m$ శ fort (Stang 1942, 219; Miller 1988, 19, 24). Obnorskij dehnte Fortunatovs Ansicht auch auf die weiche Dentalendung aus (!) und nahm ferner an, die Nullendung habe die Funktion, ein unbestimmtes Subjekt anzuzeigen, wohingegen die Dentalendung die Funktion habe, ein bestimmtes Subjekt anzuzeigen (Обнорский 1953, 135). Ferner wurde die Meinung vertreten, daß innerhalb eines noch weiter gefaßten Rahmens der Ausgleichsprozesse indogermanischer Verbformen für Tempora und Modi die ostslavischen Endungen -mə und -ms ursprünglich verschiedene Modi bezeichnet hätten (Fortunatov nach Miller 1988, 17-18). Großrussische Dialekte des Nordwestens im Gebiet von Tver', in denen nach diesem Prinzip die meisten Verben sowohl die Nullendung als auch die Dentalendung annehmen können, wobei die Nullendung eine konditionale, die Dentalendung eine indikativische Bedeutung bezeichnet, sind zuletzt von Ryko beschrieben worden (Рыко 2000, 114-133).

Von diesen morphosemantischen Ansätzen möchte ich die von Stang formulierte Hypothese, die harte Dentalendung - $m$ z sei ein Nachfolger der indogermanischen Form für die 2. Person Singular des Perfekt (Stang 1942, 221) wieder aufgreifen, neu diskutieren und erweitern (s. 5).

4. Die Bedeutung und die Beurteilung von Sprachwandel auf der Grundlage des indogermanistischen Stammbaummodells stößt in komplexen und schwierigen Fällen wie dem der Entstehung der Endungen der 3. Person des Präsens am slavischen Verb offenkundig an Grenzen. In unserem Kontext überwindet allein Zaliznjak diese Grenzen mit der Annahme einer Sprachkontaktzone in Novgorod, indem er für die Nullendung eine westslavische Herkunft annimmt. Auf die Diskussion diverser moderner theoretischer Ansätze zur Beschreibung des Sprachwandels soll hier aus Platzgründen verzichtet, der Ansatz zur Erklärung von Sprachwandel als Folge eines Sprachkontaktes soll jedoch aufgegriffen werden.

Theoretische Aussagen über Sprachwandel, die auf konkrete Sprachdaten beziehbar sind, werden von de Saussure oder Paul über den Sprachgebrauch bzw. die „parole“ bei de Saussure oder den „Usus“ bei Paul konstruiert (Boretzky 1977, 34; Paul 1960, 32). Dieser Usus ist immer an einen individuellen Sprecher gebunden, so daß jedwede Sprechtätigkeit zwischen zwei individuellen Sprechern als „Sprachmischung“ aufzufassen ist (Paul 1960, 390).

Der häufigere Fall im realen Leben dürfte derjenige sein, in dem individuelle Sprecher in einer Sprachgemeinschaft leben und daher einen hochgradig ähnlichen Usus pflegen. Unter dieser Voraussetzung dürfte wenig Sprachwandel entstehen, der den Kernbereich grammatischer Kategorien und ihrer formalen Ausdrücke erfaßt. Im seltener vorkommenden Extremfall des realen Lebens können zwei 
unterschiedliche Sprachen von individuellen Sprechern einer Gemeinschaft benutzt werden. Hier ist wohl die Voraussetzung für die Entstehung eines bisher nicht praktizierten Usus und damit für radikalen Sprachwandel gegeben. Einen solchen Extremfall präsentiert Zybatow mit dem sogenannten Mednyj-Aleutischen, einer Sprache, die aus dem Kontakt zwischen Sprechern des Russischen und solchen des Bering-Aleutischen entstanden ist (Zybatow 1988, 325; vgl. auch: Comrie 1981, 252-258). Dieses Bering-Aleutische ist eine Eskimosprache und als solche mit dem Russischen genetisch nicht verwandt:
Bering-Aleutisch
Russisch
3. Sg. Präs.
uүuс̌ $i-k u-x$
[dt.: er sitzt]
cuд - um
3. Pl. Präs.
uүuči $-k u-s$
[dt.: sie sitzen]
сид - ят

\section{Mednyj-Aleutisch}
3. Sg. Präs.
uүuči - it
3. Pl. Präs.
uүuči-jat

Die Formen des Mednyj-Aleutischen sind zu beschreiben als Verbindung einer aus dem Bering-Aleutischen übernommenen Verbwurzel mit einer aus dem Russischen übernommenen - synkretistisch Verbklasse, Tempus, Numerus und Person bezeichnenden Kombination aus Formans und Endung. Aus diesen Formen wird ersichtlich, daß die elementare Ebene des „Umbaus“ sprachlicher Strukturen die morphologische Ebene zu sein scheint. Diese Ansicht wird von Boretzky ganz grundsätzlich vertreten, indem dieser für den morphologischen Bereich einen höheren Grad an Ausnahmslosigkeit des Sprachwandels als für den lautlichen feststellt (Boretzky 1977, 27). Die Qualität der Innovation läßt erkennen, daß diese eine genaue Kenntnis beider Sprachen voraussetzt, der Sprachkontakt also sehr intensiv sein muß. Das Ergebnis eines solchen Sprachwandels ist nicht aus Qualitäten eines einzigen Systems (im Sinne des Strukturalismus) zu erklären, dem gewisse Neigungen zu Entwicklungsrichtungen zugeschrieben werden. In der Kommentierung von Zybatow lautet die entsprechende Aussage folgendermaßen:

Auch Roman Jakobsons These, daß eine Sprache fremde strukturelle Elemente nur dann akzeptieren, d.h. entlehnen würde, wenn sie den inneren Entwicklungstrends dieser Sprache entsprächen, entkräften Thomason, Kaufmann (1991: 234-35) mit einem recht eindrucksvollen Beispiel aus dem Eskimo-Aleutischen. (Zybatow 1998, $325)$

Theoretische Modelle des Sprachwandels auf der Grundlage strukturalistischer Vorstellungen von sprachsysteminternen Steuerungs- und Beschränkungsmechanismen führen offenkundig nicht weiter, werden jedoch bis heute immer noch angesetzt (vgl. z.B. Riehl 2004, 69-73, 95-98, 115). 
Daß das Bild einer Sprache als direkter Nachfolgerin einer älteren Sprache (Mutter-Tochtersprachenbeziehung der Indogermanistik) nie völlig adäquat ist, sondern daß Fremdeinflüsse in Rechnung gestellt werden müssen, die auch im Falle der indogermanischen Sprachfamilie mit ihren sehr verschiedenen Tochtersprachen (z.B. Englisch vs. Persisch vs. Neuindisch) Sprachwandel hervorgerufen haben können, ist keine ganz neue Erkenntnis (Boretzky 1973, 153-154). Die Entstehung des angeführten Beispiels aus dem Mednyj-Aleutischen paßt gut zu Boretzkys Meinung, und sie zeigt, daß Sprachwandel einen Sitz im Leben solcher Menschengruppen hat, die in einer zweisprachigen Umgebung miteinander auskommen müssen. Es ist also sinnvoll, zu versuchen, die Entstehung von Formen, deren Herleitung aus einer genetischen Prozedur heraus Schwierigkeiten bereitet, aus der Annahme einer geeigneten Sprachkontaktsituation herzuleiten. Dabei ist von der Erwartung auszugehen, daß das Ergebnis des zu beschreibenden Sprachwandels Eigenschaften zweier verschiedener Vorläufersprachen enthalten kann.

5. Unter den von Stang referierten und diskutierten morphosemantischen Erklärungsansätzen möchte ich zwei herausgreifen. Erstens stellt er die Erwägung vor, die harte Dentalendung - mo sei ,aus dem Aorist (Typus jętz) [in das Präsens, V.B.] übernommen“ (Stang 1942, 216) worden. Diese Annahme verwirft Stang ohne weitere Argumentation: „Eine solche Übernahme der Aoristendung wäre an sich nicht sehr wahrscheinlich.“ (ebd.) Zweitens diskutiert er die „den Sprachhistorikern Schwierigkeit machenden" (S. 219) Wurzelaoriste auf -tð wie z.B. jętð, mrěto usw. Nach Vondrák u.a. erörtert er die Ansicht, diese Endungen seien möglicherweise „Vom Präsens entlehnt“ (ebd.). Auch diese Ansicht wird verworfen, statt Argumente vorzutragen werden an dieser Stelle meinem Erachten nach sinnvolle Fragen gestellt, die als Begründung für Stangs ablehnende Ansicht gedacht sind, aber nicht weiter verfolgt werden:

Warum sollten zwei funktionell verschiedene Formen einander angeglichen werden? Und ferner: falls man neben $d a$ sogar eine dem Präsens gleichlautende Form dastz geschaffen hat, warum hat sich die Sprache gegen Formen wie *bitz, *tratz gesträubt? (S. 220)

Um diese Fragen angemessen beantworten zu können, habe ich zunächst den Usus für Präsens- und Aoristformen der 3. Person in den ältesten ostslavischen Denkmälern genau untersucht. Methodisch hat die Wahl dieser Denkmalgruppe den Vorteil, daß die Endung mit der unumstrittenen Herkunft, also die weiche Dentalendung $-m s$, konsequent zur Bezeichnung des Präsens verwendet wird. Analysiert wurden die gut edierten Evangeliare des ostslavischen Kulturraumes, also das Ostromir-Evangeliar (1056/57), das Archangel'sker Evangeliar (1092) und das Mstislav-Evangeliar (vor 1117). Es zeigt sich, daß die beiden ältesten Denkmäler in bezug auf die hier interessierenden Formen sehr homogen sind. Neben der regelmäßig weichen Dentalendung -ms für das Präsens, die auch auf die homophonen Präsens-/Aoristformen der athematischen Verben дасть (Востоков 1843, Грамматическия правила, 95) und псть/ясть (dtsch. er, sie ißt/aß, ebd. 
313) und sogar бысть (ebd., 51; nur Aorist!, s.u.) ausgreift, findet sich im OstromirEvangeliar für die Derivate des Verbs яmu und bestimmte andere Verben die harte Dentalendung -тг für Aoristformen: ятъ (ebd., 315), налтг (ebd., 173), поятг (ebd., 219), приятг (ebd., 227), вгзятг (ebd., 70), начятг (ebd., 172), зачятг (ebd., 117), повитг (ebd., 206 - Archang. Evang.: пови), обитг (ebd., 183), умрпто (ebd., 297 - Archang. Evang.: умгре). Das heißt, im OstromirEvangeliar und im Archangel'sker Evangeliar bezeichnet -mø eindeutig den Aorist, - $m$ s hingegen das Präsens. Aufgehoben ist diese Bedeutungsunterscheidung für die athematischen Verben $\partial a c m s$ und $n c m s$ / яcms (dtsch. er, sie i $\beta t / a \beta$ ), im Falle von бъсть und есть (dtsch. er, sie ist) trägt die Wurzel die Bedeutungsunterscheidung. Die harte Dentalendung -mø ist in diesen Denkmälern beschränkt auf wenige Verben der ersten und der vierten Leskienschen Klasse. Die überwiegende Mehrzahl der Verben bildet Aoristformen der 3. Person mit einer Nullendung. Die Verben, in denen die Opposition - $m$ s (Präsens) zu -mə (Aorist) vorkommt, sind identisch mit denen, die nach Koch eine altkirchenslavische Präsensform für einen von der griechischen Vorlage geforderten Aorist aufweisen können (s. 3.). Vorläufig zusammenfassend ist festzuhalten: das Ostromir-Evangeliar und das Archangel'sker Evangeliar weisen alle drei uns interessierenden Endungen mit folgender Semantik auf: die weiche Dentalendung steht für das Präsens, die harte Dentalendung und die Nullendung stehen für den Aorist, bestimmte athematische Verben haben formal präsentische Gestalt, tragen jedoch beide Bedeutungen. Im Mstislav-Evangeliar (vor 1117) und in noch jüngeren Denkmälern des ostslavischen Sprachraumes finden sich nur noch spärliche Belege von Aoristformen auf harte Dentalendungen.

Betrachten wir nun den im Detail recht gut beschriebenen Verlauf des Sprachwandels für die Präsensformen im Serbokroatischen, also in einem Sprachraum, wo sich die Nullendung konsequent durchgesetzt hat (Даничић 1874, 272 ff.). Die Richtung des Wandels ist klar erkennbar: seltenen alt belegten Dentalendungen steht eine große Menge an Formen mit Nullendung entgegen, wobei an Beispielen von thematischen Formen der dritten Leskienschen Verbklasse (z.B. znajets) deutlich wird, daß der Wandel nicht lautlicher Natur (Schwund eines silbenschließenden - $t$ als Folge des Jerausfalls in schwacher Position mit dem Ergebnis znaje), sondern morphologischer Natur ist (Analogiebildungen zu Aoristformen mit dem Ergebnis zna). Die letztgenannte Form stellt den heutigen Zustand der Dialekte und den der Standardsprachen dar. Die schon im Ostromir-Evangeliar in eine Sonderkategorie fallenden athematischen Verben dastb/da, jastb/ja stellen auch im Serbokroatischen Ausnahmen dar, weil sie ihre Doppelformen bewahrt haben. In den westslavischen Sprachen ist ein vergleichbarer Prozeß abgelaufen (Соболевский 1907, 160), mit dem Ergebnis, daß der Aorist als Kategorie geschwunden und im Präsens die Nullendung zum Regelfall geworden ist. Diese Zustände gelten heute auch im Slovenischen und in den nördlichen Gebieten Kroatiens und Serbiens, die ebenfalls keinen Aorist bewahrt haben. Das heißt, im Ergebnis liegt für die Gebiete mit konsequenter Nullendung ein Zustand vor, der durch den Schwund 
der Aoristkategorie und die Übertragung der formalen Aoristmarkierung - $\varnothing$ auf das Präsens gekennzeichnet ist.

Übertragen wir das Prinzip des Verlaufes des Sprachwandels in den west- und den südwestslavischen Gebieten und dessen Ergebnis auf die ostslavischen Gebiete mit partiell und konsequent vorhandener Dentalendung, z.B. auf das Russische, so kann man einen analog strukturierten Vorgang erkennen. Der Schwund der Aoristkategorie, verbunden mit der Übertragung der zweiten zur Verfügung stehenden Aoristmarkierung -mø auf das Präsens, führt zu den heutigen Verhältnissen. Im Gegensatz zu den westslavischen und den westlichen südslavischen Sprachen werden die Formantien - $e$ - und - $i$ - der Präsensstämme in den ostslavischen Dialekten nicht vom Sprachwandel erfaßt. Die Sonderkategorie enthält in diesem Fall für die moderne russische Standardsprache ein einziges Element, und zwar die historisch athematische Verbform ecms (dtsch. er, sie ist). Der Zustand im Altkirchenslavischen und in den westmakedonischen Dialekten um Ohrid kann ebenso erklärt werden. Die in der bulgarischen und der ukrainischen Standardsprache, den bulgarischen und den ostslavischen Dialekten zu beobachtende Ausbildung von semantischen Spezialisierungen von Nullendungen auf den Singular und Dentalendungen auf den Plural mit ihren verschiedenen Variationen in den Verbklassen läßt sich ebenfalls in dieses Bild einfügen.

Stangs oben zitierte Fragen wären also etwa folgendermaßen zu beantworten: Zwei funktionell verschiedene Formen [Präsens und Aorist] könnten ohne weiteres einander angeglichen werden, wenn eine dieser Formen funktionslos geworden ist. Nun ist der Aorist vom nordöstlichen bis zum südwestlichen Teil des slavischen Sprachraums tatsächlich aus dem Usus geschwunden. Seine Funktion ist in diesen Gebieten auf eine analytische Konstruktion, bestehend aus dem Hilfsverb byti und dem $l$-Partizip, übertragen worden. Die Form dieser Konstruktion ist von der Präsensform hinreichend sicher unterscheidbar. Im genannten Sprachgebiet sind in konsequenter Weise Nullendungen oder Endungen auf harten Dental -mø für die 3. Person des Präsens entwickelt worden. Im südlichen Teil des ostslavischen Sprachgebietes und im östlichen Teil des südslavischen Sprachgebietes war die Entwicklung konservativer - hier wurde die indogermanische weiche Dentalendung -mъ für das Präsens, dort die Aoristkategorie bewahrt. Die Sprache hatte die

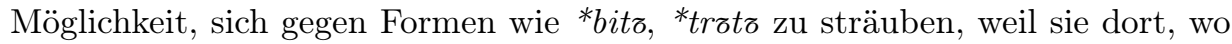
die Aoristkategorie bewahrt wurde, eine Wahl zwischen der Endung auf harten Dental -mø und der Nullendung hatte. Die Neigung zur Nullendung war dominant, die Durchsetzung dieser Endung erfaßte nahezu alle Verben. Einen archaischen Kern an unregelmäßig gebildeten Formen im hochfrequenten Grundwortschatz wie z.B. bystz, dasto usw. leisten sich viele Sprachen. Warum konkrete Verben in der Formenbildung zum archaischen Kern oder zum progressiveren Rand tendieren, läßt sich im Einzelfall nicht begründen.

Vorläufig zusammenfassend kann man sagen, daß die generalisierende Aussage Hirts über gegenseitige Austauschvorgänge bei der Herausbildung indogermanischer Präsens- und Aoristformen (s. 3.) auf den Fall der slavischen Sprachen 
anwendbar ist. Es zeigt sich, daß die Entstehung der Endungsvielfalt der 3. Person Singular und Plural im Präsens am slavischen Verb über morphologische Daten erklärbar ist. Dieser Erklärungsweg erlaubt es, die Entstehung der Formenvielfalt auf eine einzige strukturelle Ursache zurückzuführen und einen frühen und gemeinsamen Entstehungszeitraum der „neuen“ Präsensendungen, nämlich der harten Dentalendung -mø und der Nullendung anzunehmen.

6. Nachzugehen bleibt noch der Frage, welche Sprache mit dem Slavischen in einer hinreichend intensiven Sprachkontaktsituation gestanden haben könnte, um einen größeren Umbau im Formenbestand des Präsensparadigma und den Schwund des Aorists bewirkt zu haben. Zu fragen ist hierzu zunächst nach solchen Merkmalen des Slavischen, die dieses innerhalb der indogermanischen Sprachfamilie isolieren, die also nicht genetisch erworben sein können. Solche Merkmale sind der Verbalaspekt und das $l$-Partizip. Beide sind gemeinslavisch. Die Eigenschaft, mit Hilfe einer analytischen Konstruktion aus einem Hilfsverb und einem Partizip verbale Temporabezeichnungen zu bilden, ist im Indogermanischen weit verbreitet und daher unspezifisch.

Der Fall des Verbalaspekts ist unstrittig, der Fall des $l$-Partizips bedarf einer Erläuterung. Leskien folgend, halten Issatschenko und Kiparsky das Suffix -l- für ein ursprüngliches indogermanisches Wortbildungssuffix. Mit Hilfe dieses Suffixes werden Verbalnomina, deverbale Adjektive und auch Namen gebildet, z.B. russ. чита-л-нъя, зре-л-ьй, Погоре-л-ов, Чка-л-ов, tschech. Nezva-l, Navrati-l usw. (Issatschenko 1983, 406). Direkte Entsprechungen solcher slavischer Bildungen in anderen indogermanischen Sprachen sind sehr selten, z.B. lat.: tepula aquaslavisch: tepla voda (Kiparsky 1967, 250). Die Grammatikalisierung dieses Suffixes im Paradigma der verbalen Tempusbezeichnungen ist in der indogermanischen Sprachfamilie jedoch ausschließlich slavisch (ebd.).

Einen semantisch mit dem Slavischen vergleichbar organisisierten Verbalaspekt weisen die Turksprachen auf. Die Verwendung des Suffixes $-l^{(4)}-($ mit großer bzw. weiter Vokalharmonie) zur Bildung von Adjektiven ist in dieser Sprachfamilie durchaus partiell mit den Wortbildungsverhältnissen im Slavischen vergleichbar (z.B. türkeitürkisch yǎs - dtsch.: das Alter zu yaš-lı-dtsch.: alt, bejahrt). Für die hier zu behandelnde Fragestellung ist wichtig, daß die Turksprachen mit einem lautlich ähnlichen Suffix, nämlich -(4) $l$ - (mit großer bzw. weiter Vokalharmonie) das Paradigma der verbalen Passivformen (z.B. türkeitürkisch: gör-ül-mek - dtsch.: gesehen werden zu gör-mek - dtsch.: sehen) bilden. Ich halte diese Passivformen für das Vorbild des slavischen $l$-Partizips. In polnischen Formen des $l$-Partizips wie z.B. zosta-t-e-m, zosta-t-a-m ist das agglutinierende Prinzip der türkischen Formenbildung vollständig erhalten. In den übrigen slavischen Sprachen wird die Bezeichnung von Person und Numerus in der in den indogermanischen Sprachen regelmäßigen Form am Hilfsverb ausgedrückt. Da die Turksprachen für die Bezeichnung der 3. Person des Präsens eine Nullendung verwenden (z.B. gör-ü-yor- $\varnothing$ dtsch.: er, sie, es sieht), kommt diese Endung auch als direktes Vorbild für die slavischen Nullendungen im Präsensparadigma in Betracht. 
Da das Slavische mit der Aspektkategorie und dem l-Partizip zwei verschiedene, im gesamten Sprachgebiet verbreitete Merkmale aufweist, die sonst im Indogermanischen nicht vorkommen und die aus einer Turksprache stammen können, erscheint die Annahme eines frühen türkisch-slavischen Sprachkontaktes auch als Ursache für die Entstehung der Vielfalt der Endungen der 3. Person Singular und Plural im Präsens des Verbs plausibel. Diese Sprachkontaktsituation könnte unter anderem für den Schwund des Aorist als Teil eines größeren Umbaus eines indogermanischen zu einem speziellen, slavischen System verbaler Temporalparadigmen ursächlich sein. Die in diesem Aufsatz behandelte Fragestellung ist in diesem Zusammenhang zu sehen, bildet jedoch nur einen kleinen Teilbereich am Rande dieses großen und komplexen Vorganges. Natürlich steht die Annahme eines frühen türkisch-slavischen Sprachkontaktes unter dem Vorbehalt der Vorläufigkeit, sie bedarf der Überprüfung durch weitere Untersuchungen.

7. Der betrachtete Fall zeigt, daß die Annahme von Sprachkontaktsituationen grundsätzlich geeignet ist, Fragestellungen einer sinnvollen Antwort zuzuführen, die die Indogermanistik nicht befriedigend lösen kann. Darüber hinaus ergibt sich aus der Annahme von Sprachkontakten die Möglichkeit, Ursachen für Sprachwandel zu ermitteln, die auf andere Weise nicht gewonnen werden können. Ferner arbeitet man mit der Annahme von Sprachkontaktsituationen als Ausgangspunkt für Sprachwandel auf einer guten Datenbasis, weil Sprachdaten aus einer zweiten Quelle ermittelt werden müssen, die die fraglichen Daten aus der ersten Quelle gewissermaßen kontrollieren. Daten der morphologischen Ebene sind für solche Untersuchungen besser geeignet als Lautdaten, weil sie Form- und Bedeutungseigenschaften aufweisen. Morphologische Daten sind daher leichter identifizierbar, sofern sie im Sprachwandelprozeß erhalten bleiben und nicht geschwunden sind. Lautdaten haben den potentiellen und vermutlich oft realen Nachteil, zu viele identische Eigenschaften aufzuweisen. Sie dürften daher in den seltensten Fällen einer von zwei Kontaktsprachen eindeutig zuzuordnen zu sein.

\section{Literaturverzeichnis}

Востоков, А. (изд.): 1843, Остромирово Евангелие 1056-57 года, Санкт Петербург (Reprint: Wiesbaden 1964).

Гецова, О.Г.: 1963, „К вопросу о формах 3-го лица глагола в русских говорах“, Славянская Филология, вып. 5-ый, 105-131.

Даничић, Ђ.: 1874, История облика српскога или хрватскога језика до свршетка XVII вијека, Београд.

Жуковская, Л.П., Миронова, Т.Л. (изд.): 1997, Архангельское Евангелие 1092 года. Исследования, Москва.

Жуковская, Л.П., Владимирова, Л.А., Панкратова, Н.П. (изд.): 1983, Апракос Мстислава Великого, Москва.

Зализняк, А.А.: 1988, „Древненовгородский диалект и проблемы диалектного членения позднего праславянсого языка', Славянское языкознание. $X$ 
международный съезд славистов, София, сентябрь 1988 г. Доклады советской делегаиии, Москва, 164-177.

Зализняк, А.А.: 1995, Древненовгородский диалект, Москва.

Зализняк, А.А.: 2004, Древненовгородский диалект. Второе издание, переработанное с учетом материала находок 1995-2003 гг., Москва.

Касаткин, Л.Л. (ред.): 2005, Русская диалектология, Москва.

Обнорский, С.П.: 1953, Очерки по морфологии русского глагола, Москва.

Рыко, А.И.: 2000, ,Семантическое распределение окончаний 3-го лица презенса в северозападных русских говорах“, Балто-славянские исследования 19981999, 14, 114-133.

Соболевский, А.И.: 1907, Лекции по истории русского языка, Москва. (Reprint in: Соболевский, А.И. 2004: Труды по истории русского языка. Том $I$, Москва)

Хонселаар, 3.: 2001, Говор деревни Островци Псковксой области, Амстердам.

Янин, В.Л., Зализняк, А.А.: 1986, Новгородские грамоты на бересте (из раскопок 1977-1983 гг.) Комментарии и словоуказазатель к берестяным грамотам (из раскопок 1951-1983 гг.), Москва.

Bjørnflaten, J.I.: 2003, ,Bemerkungen zur Ausbreitung und Chronologie der Nullendung der 3. Person Präsens in den russischen Mundarten', in: S. Kempgen, U. Schweier, T. Berger (Hrsgg.): Rusistika, Slavistika, Lingvistika. Festschrift für Werner Lehfeldt zum 60. Geburtstag, München, 48-56.

Boretzky, N.: 1973, ,Sprachkontakte‘, in: W.A. Koch (Hrsg.): Perspektiven der Linguistik I, Stuttgart, 134-158.

Boretzky, N.: 1977, Einführung in die historische Linguistik, Reinbek bei Hamburg

Comrie, B.: 1981, The Languages of the Soviet Union, Cambridge, London, New York, New Rochelle, Melbourne, Sydney.

Hirt, H.: 1928, Indogermanische Grammatik. Teil IV: Doppelung, Zusammensetzung, Verbum, Heidelberg.

Issatschenko, A.: 1980-83, Geschichte der russischen Sprache. 1. u. 2. Band, Heidelberg.

Kiparsky, V.: 1963, Russische historische Grammatik. Band 1: Die Entwicklung des Lautsystems, Heidelberg.

Kiparsky, V.: 1967, Russische historische Grammatik. Band 2: Die Entwicklung des Formensystems, Heidelberg.

Koch, C.: 1985, ,Die Ausbreitung des -tъ der aksl. Präsensendungen der 3. Sg. und Pl.', Wiener Slavistisches Jahrbuch 31, 47-68.

Miller, R.H.: 1988, ,The Third Person Present Tense and Common Slavic Dialectology', International Journal of Slavic Linguistics and Poetics 37, 7-33.

Paul, H.: 1960, Prinzipien der Sprachgeschichte, Tübingen

Riehl, C.M.: 2004, Sprachkontaktforschung. Eine Einführung, Tübingen.

Stang, C.S.: 1942, Das slavische und baltische Verbum, Oslo. 
Van Wijk, N.: 1931, Geschichte der altkirchenslavischen Sprache. Erster Band: Lautund Formenlehre, Berlin u.a.

Zybatow, L.N.: 1998, ,Zu neuen Horizonten der slavistischen Sprachkontakt- und Sprachinselforschung;, Die Welt der Slaven 43, 323-338. 


\section{Konzeptualisierungen des Ehrbegriffs in der russi- schen Kultur}

Wertbegriffe werden in einer Kultur diskursiv vermittelt. Insofern lässt sich auch von einer kommunikativen Verfasstheit der Ehre als symbolischem Kapital sprechen (Burkhart 2002). In einer Diskursgemeinschaft oder einem Diskursensemble, wie man die Schnittstelle zwischen privatem und öffentlichem Kommunikationssystem nennen könnte, stellt Ehre eine „cultural unit“ (Eco 1972, 36, 74-76), eine „,kulturelle Struktureinheit“ (Frithjof 1975, 115) dar, die in variablen lexikalischen Feldern sowie - neben sprachlichen - auch gestisch-szenischen, vestimentären, spatial-proxemischen, architektonischen u.a. Zeichen diachron und synchron kommuniziert wird. Im Weltmodell nach Jurij Lotman und anderen Semiotikern des Moskau-Tartuer Kreises haben Normbegriffe einen semantisch wie psychosozial bedeutsamen Stellenwert, der auch die Möglichkeit einer Differenzierung von Kultursphären bietet, denn „Beschreibungen, die auf der Hervorhebung von Normen basieren, deren Verletzung in einem bestimmten Kollektiv beschämend gilt, und 
von Normen, deren Erfüllung von Angst diktiert wird, können eine geeignete Grundlage zur typologischen Klassifizierung von Kulturen bilden" (Lotman 1986, 836). Axiologische Werte, unter ihnen auch die Ehre), bestimmen also das kollektive Weltmodell und legen das ungeschriebene Gesetz fest, nach dem das Sozium bestimmtes Verhalten als moralisch-rechtlich akzeptabel oder inakzeptabel wertet. Eine historische Betrachtungsweise der Ehre auf der Linie der Diachronie muss deshalb mit Zustandsbeschreibungen auf der Ebene der Synchronie kombiniert werden, um die konstituierenden Konstanten und Variablen des Ehrbegriffs bestimmen zu können.

Der Ehrbegriff (russisch čest', čestnost'; počët, počitanie, počtenie; naročityj,

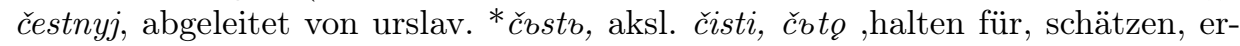
achten $^{6}$ ) hat im Laufe der russischen Geschichte und der sozialen Differenzierung unterschiedliche Konzeptualisierungen erfahren. Grundsätzlich gilt die Dichotomie innere Ehre im Sinne von Selbstachtung, Würde und Integrität versus äußere Ehre in der Bedeutung von Ansehen, Reputation und Ehrung in der Gesellschaft, wobei im kollektiven Wertekanon des Sprichworts der inneren vor der äußeren Ehre Priorität eingeräumt wird: „Čestej mnogo, a čest' odna“. Interne und externe axiologische Wertungen sind allerdings miteinander verknüpft, weil Individuen in ihrer Subjektivität und Selbstschätzung eng an die Wertschätzung durch das Sozium gebunden sind. Georg Simmel sieht gerade darin den Wirkmechanismus von Ehre im Unterschied zu Recht und Moral, dass es ihr gelingt, ,,dem Individuum die Bewahrung seiner Ehre als sein innerlichstes, tiefstes, allerpersönlichstes Eigeninteresse zu infundieren. Es gibt vielleicht keinen Punkt, an dem sich das Sozialund Individualinteresse derart verschlingt" (Simmel 1992, 602). Die Partizipation eines Menschen an Werten als Begründung für seine Ehre und Würde und die von den Mitmenschen geschuldete Anerkennung dieser Ehr-Würdigkeit als Instrument zur Erlangung eines adäquaten sozialen Status bilden die Konstanten oder, anders gesagt, die kategoriale Struktur des Phänomens. Welche Ziele dagegen den historischen Ehrvorstellungen semantisch zugeordnet werden bzw. in welchen Ausdrucksformen sie auftreten, ist durch Variabilität bestimmt, d.h., sie werden durch axiologische Regeln diktiert, die in verschiedenen Kulturen, historischen Epochen und sozialen Gruppen jeweils stark variieren können. Vieles was einst Ehren-Wert besaß - beispielsweise die Ausübung von Blutrache als Mittel zur Wiederherstellung verletzter Familienehre (Leitwert: Stolz), die Versklavung besiegter Völker oder Kriegsgefangener (Stärke), die Anprangerung und Verstümmelung von Delinquenten (Recht) u. ä. m. -, gilt nach modernen, d.h. humanistischen und aufklärerischen ethischen Maßstäben als axiologisch inakzeptabel. Die zugrunde liegenden Werte bilden also - semiotisch gesprochen - die Signifikate (das Bezeichnete), die variablen Ausdrucksformen indes die Signifikanten (das Bezeichnende). Dabei gelten für die Variablen zweierlei Faktoren: der Zeit-Faktor, der unterschiedliche Ehre- und Wertungsformen auf der temporalen Linie der Diachronie relativierbar macht, und andererseits der soziale Faktor, der auf der synchronen Ebene der Gleichzeitigkeit gruppenspezifische, genauer gesagt: inter- und intraso- 
ziale Wertungen ermöglicht. Ehrgefühl als solches stellt also eine Konstante dar, nur worin die Menschen jeweils ihre Ehre setzen, kann von Subjekt zu Subjekt, von Gruppe zu Gruppe, von Epoche zu Epoche variieren. So war es für einen radikalen russischen Sozialrevolutionär des 19. Jahrhunderts (narodnik) Ehrensache, Repräsentanten des zaristischen Regimes durch Attentate zu beseitigten (Leitwert: volja), während die Ehre des Zaren (Leitwert: samoderžavie) es verlangte, dass er dieses autokratische System mit allen Mitteln verteidigte und Attentäter hinrichten ließ. Weitere ideologische Dichotomien, denen eine konträre Konzeptualisierung des Ehrbegriff geschuldet ist, fanden sich später bei den Repräsentanten der Weißen (Leitwerte: Treue, Zar und Vaterland) und der Roten im Bürgerkrieg sowie bei den Revolutionären und den „Konterrevolutionären“ der Sowjetzeit.

\section{Vom Mittelalter bis zum 18. Jahrhundert}

Ehre und Ruhm (čest' $i$ slava) waren v. a. in der vorchristlichen Zeit und in der feudalen Gefolgschaftssphäre von Fürst und družina die axiologischen Werte, die das weltliche Leben bestimmten. Ein Beispiel für diesen Ehrbegriff liefert die Povest' vremennych let, wo unter dem Jahr 945 der Eintrag Smert' Igorja zu lesen ist: Fürstin Ol'ga lockt die Mörder ihres Gatten Igor', dessen Ehre sie verteidigt (Leitwert: Rache für obida), in eine Falle, indem sie ihnen ,große Ehre“ verspricht (,choču vozdat' zavtra čest' pered ljud'mi svoimi“; ,zovoet vas Ol'ga dlja česti velikoj“). Nachdem sie dadurch eine Vertrauensatmosphäre geschaffen hat, verhöhnt sie die ehrsüchtigen Männer, bevor sie sie lebendig begraben lässt, mit der Frage: „Wie gefällt euch diese Ehre?“ („choroša li vam čest'?“). Zwei weitere Male gelingt es der Fürstin, durch Ehrversprechen (,prišlite dvuch lučšich mužej, čtoby s velikoj čest'ju pojti za vašego knjazja“) die Feinde ihres ermordeten Gatten einem ehrlosen Tod zuzuführen. In Kontrast zu Erzählungen dieser paganen Art, wo sich Ehrenlohn für den Vasallen auch materiell in Form von Kriegsbeute ausdrücken konnte, stehen Narrative, die nach der 988 unter Fürst Vladimir erfolgten Christianisierung Russlands entstanden. Statt Vergeltung von Menschenhand zu üben, werden Mörder nun dem göttlichen Zorn ausgeliefert. So wird in dem hagiographischen Bericht über die Ermordung von Boris und Gleb durch ihren machtgierigen älteren Bruder Svjatopolk dieser von Gott dadurch bestraft, dass Dämonen von ihm Besitz ergreifen, er ,in Unehren“ stirbt („,tam končil besčestno žizn’ svoju“) und von seinem Grab (im Gegensatz zu dem wohlriechenden Grabstätten russischer Märtyrer) ein übler Geruch ausgeht.

Die in Kriegserzählungen und Städteklagen geschilderte Eroberung von christlichen Städten des Heiligen Russlands (Povest' o razorenii Rjazani Batyem, Slovo o pogibeli russkyja zemli u.a.) durch die heidnischen Tataren (zlaja čest' tatarskaja) kam einer nationalen Entehrung gleich (besčestie Russkoj zemli), der die Bewohner durch apotropäische und den Gegner demütigende Gesten zu begegnen suchten. So steht beispielsweise in der Tverskaja letopis' des 14. Jahrhunderts, dass die Stadtbewohner den Belagerern Schande zufügten, ,kažušče im sramy svoi“ (,indem sie ihre Schamteile zeigten“). Andererseits heißt es z.B. in der Zadonščina nach 
dem Sieg der christlichen Gefolgsleute des Großfürsten, „česti my, brat dobyli i slavnogo imeni. Bogu našemu slava!“

Seit dem Barock und Klassizismus wird in Russland eine aus der Antike (Menander) stammende rhetorische Tradition begründet, Städte und deren Erbauer zu glorifizieren: Es entstand das Genre des „Städtelobs“, laudatio urbis. Vertreter dieser Art von Preisliteratur („pochvala“) waren Polockij, Bužinskij, Tred’jakovskij, Sumarokov und Deržavin, die in ihrem Lob der Stadt Petersburg erst durch Puškins Vanitas-Verspoem Mednyj vsadnik dekonstruiert wurden. Es war eine auf höfisches Ehren-Zeremoniell, Reputation und Repräsentation bedachte Zeit, in der Hofdichter wie Lomonosov nicht nur die Größe Gottes priesen, sondern auch regelmäßig Preisoden auf die Thronbesteigung bzw. die glorreichen Werke der Zaren oder Zarinnen verfassten.

Der Dienst für den Zaren, der die Quelle von Ehre und Rang jedes Untertanen darstellte, fundierte die Existenz wie auch das Selbstverständnis des hauptstädtischen Adels, der dafür mit Landbesitz und Geld belohnt wurde. Wer als Bevollmächtigter des Zaren für Steuern, Polizei und Gericht in den Landkreisen, als Wojewode (voevoda) amtierte, ,profitierte nicht nur von dem ihm rechtmässig zustehenden Verwaltungsgebühren und Ehrengeschenken, sondern nutzte in der Regel seine Machtmittel auch, um sich darüber hinaus widerrechtlich zu bereichern" (Goehrke I 2003, 324). Die nach dem Ehrverteilungsprinzip funktionierende Rangplatzordnung (mestničestvo), welche bis zu ihrer Abschaffung im Jahr 1682 jedem Adligen nach Ehrenwert der Familienherkunft (otečestvo, rodoslovnost'), Verdiensten (činovnost', razrjadnost') und Gunst des Monarchen einen bestimmten Rang in Gesellschaftsgefüge zuwies, war zwar einer auf Karriere und Einzelinteressen orientierten Mentalität förderlich, hielt aber als Errungenschaft des Adels auch das ganze, auf der Gnade des Zaren und dem aristokratischen Selbstbewusstsein basierende Dienstsystem in Balance (Rüß 1994, 391). Der jeweilige Rang und die möglichst geringe Distanz zum Zaren bildete den Kern der individuellen Ehrenstellung. Rangstreitigkeiten wegen vermeintlich oder tatsächlich verletzter Ehre, z.B. bei der Verweigerung von Ehrenplätzen beim Bankett (vgl. die Byline Suchman und ihren Niederschlag in der Povest' o gore $i$ zločastii, 17. Jh.), waren deshalb für den Alltag der Adligen bestimmend, wobei - laut Olearius Bericht über seine Russlandreise im Jahr 1636 - selbst jegliche Rücksichtnahme auf die Gegenwart hoher ausländischer Gäste entfiel. Im Ehrverteidigungsverhalten galten, dem Zeitgeist in Russland entsprechend, körperliche Angriffe in der Regel nicht als ehrenrührig, außer sie hätten ehrsensible somatische Zeichen wie den Bart zum Ziel gehabt. Ehrenrührig dagegen waren Brachialattacken in Verbindung mit Beleidigungen und übler Nachrede. In einer auf die Staatsspitze ausgerichteten Dienstgesellschaft konnte - im Gegensatz zum Westen - allein der autokratische Herrscher eine verloren gegangene Ehre wiederherstellen.

Entehrung wurde vom Zaren bzw. seinen Organen „durch Geldbussen, in schweren Fällen durch Körperstrafen, Verbannung etc. gesühnt. Der Preis der Entehrung war dabei nach der unterschiedlichen Nähe zum Herrscher abgestuft" 
(Goehrke I 2003, 325), wovon die zuerst in dem Statut (ustav) Jaroslavs und des Metropoliten Ilarion aus der Mitte des 11. Jahrhunderts festgelegten Summen für Ehrverletzung Zeugnis ablegen: Entschädigung für eine hohe Bojarentochter betrug 5 Grivnen Gold, die gleiche Summe wie für den Metropoliten, während Frauen von niederen Bojaren oder einfachen Leuten mit Silber- oder Fellgrivnen zu entschädigen waren (Rüß 1994, 235.) Auch im Gesetzbuch (Sudebnik) von 1550 ist die Höhe des Strafmaßes je nach Person und Art der Ehrverletzung abgestuft. In dem Gesetzbuch aus dem Jahr 1589 betrafen allein 33 von 231 Artikeln die Höhe des Ehrengeldes für die einzelnen Ränge der weltlichen und der kirchlichen Hierarchie. Noch detaillierter wurde die Frage von Ehrverletzungen in dem 1649 von Zar Aleksej erlassenen Gesetzeskodex Sobornoe uloženie geregelt: 73 von 287 Paragraphen des 10. Kapitels befassten sich mit der Ahndung von Ehrenkränkungen, die im Einzelnen für die Beleidigung eines Metropoliten 400 Rubel Sühnegeld (bezčestie) vorsahen, für die eines Popen 5 Rubel und für die eines bei kirchlichen Würdenträgern beschäftigten Kochs oder Pferdeknechts je einen Rubel. Für die Verletzung der Ehre einer verheirateten Frau musste doppelt so viel an Strafe bezahlt werden wie für die Beleidigung des Mannes, bei Beschimpfungen von Jungfrauen (Leitwert: Virginität), deren Tauschwert als Heiratspartnerinnen dadurch geschmälert wurde, betrug sie das Vierfache, und nur der Beleidiger eines minderjährigen Sohnes kam mit der Hälfte der Einschätzungssumme (oklad) davon (Meiske 1985, 94-104). Im Falle von Beleidigungen, denen keine Aussöhnung gefolgt war, wurde eine für die Beteiligten und die Zeugen geltende Anzeigepflicht eingeführt. Ein Ehrengericht musste binnen sechs Wochen eine Sühne festsetzen: bei Verbalinjurien Haft bis zu drei Monaten sowie die Verpflichtung, den Beleidigten auf Knien um Verzeihung zu bitten; bei Körperverletzungen sollte der Beleidiger nach dem Talionsprinzip vor dem Gericht bereit sein, von dem Geschlagenen die gleiche Behandlung zu erfahren (Polnoe Sobranie Zakonov Rossijskoj Imperii.)

In der Kiever Rus' und im Moskauer Reich gab es zwei Formen des Zweikampfs: den stellvertretenden militärischen, durch den zwei Einzelkämpfer über das Schicksal des Heeres entschieden (in der Povest' vremennych let unter den Jahren 992 und 1022 belegt), sowie den gerichtlichen Zweikampf (sudebnyj poedinok, metonymisch pole) in der Funktion eines Gottesurteils als Beweismittel (früheste Erwähnung in russischen Quellen 1229). Während sich jedoch in Westeuropa aus dem Gerichtszweikampf und dem Ritterturnier seit dem 16. Jahrhundert das moderne Duell entwickelte, starb in Russland der gerichtliche Zweikampf, an dessen Stelle das Los und der Eid als Beweismittel getreten waren, aus, ohne durch neue Zweikampfformen ersetzt worden zu sein (Brang 1961, 321). Der spezifische Ehrbegriff des vom Rittertum geprägten Feudalwesens in den westeuropäischen Ländern waren der mittelalterlichen und frühneuzeitlichen Rus' im wesentlichen fremd geblieben (Gercen 1954, 156, 158). Das Fehlen des Duellwesens bei den Russen versetzte Fremde wie den im Dienst von Boris Godunov stehenden Jacques Margeret in Erstaunen. Wurden im Russland des 17. Jahrhunderts Duelle ausgetragen, so handelte es sich um Ehrstreitigkeiten zwischen Ausländern. Als Zar Peter I. das Land 
den westlichen Lebensformen geöffnet hatte, befürchtete er, dass damit auch das Duell importiert würde. Deshalb verbot er kurioserweise das Duell (duél'; poedinok, abgeleitet von der Vorstellung ,je einer“), bevor es überhaupt aufgetaucht war (Scholle 1977, 9). Durch die im 49. Kapitel des ersten Teils seines Militärreglements (Voinskij Ustav) von 1716 formulierte Verordnung sollte das Zustandekommen von Duellen durch eine juristische Ahndung von Beleidigungen verhindert werden: Duellforderungen wurden mit Aberkennung der Dienstgrade und partiellem Vermögenseinzug bestraft. Teilnehmern an einem Duell drohte, lebend oder tot mit den Füßen nach oben auf besonders schimpfliche Weise gehängt zu werden. Trotzdem wurde das Duell - ein verabredeter Kampf zwischen zwei standesgleichen Personen, der mit Säbel oder Pistole unter Einhaltung bestimmter Regeln und im Beisein von Sekundanten ausgetragen wird mit dem Ziel, die verletzte Ehre des einen oder beider Duellanten wiederherzustellen - im Laufe des 18. Jahrhunderts zu einer am Ehrenkodex des französischen Adels orientierten üblichen Erscheinung. Auch das 1787 erlassene Manifest von Katharina II. bedeutete eher eine Anerkennung der Existenz des Duellwesens als ein adäquates Mittel zu seiner Eindämmung dar, weil es die Strafbestimmungen erheblich milderte.

\section{Vom 18. Jahrhundert bis zum 20. Jahrhundert}

1722 wurde von Zar Peter I. als Ersatz für die alte Rangplatzordnung eine Rängetabelle (Tabel' o rangach) eingeführt., die - allerdings mit Modifikationen bis 1917 gültig sein sollte und trotz der Zugeständnisse an Leistungskriterien vor allem Prinzipien und Gepflogenheiten übernahm, welche das Primat der Aristokratie im Staat auch fernerhin sicherte (Rüß 1994, 408). Diese Ehrenordnung parallelisierte Militär und Zivilverwaltung und ordnete sie in 14 Stufen an, die ,im Prinzip auch als Etappen einer Laufbahn gelten konnten, faktisch aber standen die Privilegien des Erbadels einer wirklichen Durchlässigkeit im Wege. So wurde im Laufe der Jahrzehnte die Schwelle, ab der ein Amtsinhaber den erblichen Adel erhielt, von der 6. über die 5. auf die 4. Stufe verschoben“" (Franz 2002, 365; 502). Und das mit höherem Sozialprestige besetzte Militär kannte die 14., die unterste Stufe, gar nicht. Streng reglementiert waren die Kleidungsordnungen, die schon auf den ersten Blick den jeweiligen Rang signalisierten, und geregelt war auch die sprachliche Etikette: Angehörige der unteren sechs Ränge mussten mit „Euer Wohlgeboren“ (Vaše blagorodie) angeredet werden, Inhaber der Ränge 8 bis 5 mit „Euer Hochwohlgeboren“ (Vaše vysokoblagorodie), der Ränge 4 und 3 mit „Euer Exzellenz" (Vaše prevoschoditel'stvo) und die höchsten Ranginhaber mit „Eure Exzellenz" (Vaše vysokoprevoschoditel'stvo). Die Signifikanz der Rangordnung für die russische Kultur lässt sich u. a. an der Literatur ablesen: Zahllose Werke, angefangen von Gogol's Erzählung Der Mantel (Šinel'), wo eine „,bedeutende Persönlichkeit" karikiert wird, welcher der Generalsrang zu Kopf gestiegen ist und sie gefühllos gemacht hat, beschreiben die Ehrversessenheit und Karrieresucht der russischen Beamten und Militärs, indem sie das semiotische Potential der Rängetabelle nutzen. 
Vergleicht man das absolutistische Preussen mit dem Russland Katharinas II., zeigt sich, wie wenig sich das russische Reich trotz einer ähnlichen staatlichen Fassade in seinen internen Strukturen den Monarchien im Westen angenähert hatte und wie wenig gegliedert die Gesellschaft immer noch war. Zwar wurden vom Staat nach und nach durchaus „Stände“" (soslovija) geschaffen, „die der sozialen Abstufung und den Rechten nach in den erblichen und persönlichen Adel, die Ehrenbürger, die Geistlichen, die Kaufleute, die «Städter», das Militär und die Bauern zerfiel; wer in dieses Schema nicht hineinpasste, firmierte unter «Angehörige verschiedener Ränge» (raznočincy). Aber diese «Ständegesellschaft» basierte auf einer Dienstpflicht gegenüber dem Staat, ohne als Gegenleistung dafür ständisch abgestufte, verbriefte Mitwirkungsmöglichkeiten zu erhalten, die ihre Repräsentanten anspornten, am Prozess der von oben eingeleiteten sozialen Disziplinierung und Modernisierung auch ihrerseits aktiv teilzunehmen" (Goehrke II 2003, 18).

Nach Ludgera Vogt ist die Entwicklung der Ehre gekennzeichnet durch „eine Reihe von Verschiebungen, die der Ehrbegriff im Prozess der Modernisierung von Gesellschaften durchlaufen hat: eine Verschiebung von〈außen〉 nach 〈innen〉, von partikularer zu universaler Geltung, von klaren Status- und Rollenzuschreibungen zur Pluralisierung und letztlich auch Verunsicherung des Status, schließlich von der (geburts-)ständischen Askription zum leistungsabhängigen Erwerb von Ehre“ (Vogt 1997, 59). Die russische Aufklärung und ihre Literatur zeugt unter dem Einfluss von Montesquieu, Voltaire und Rousseau von einer Internalisierung des Ehrbegriffs, der nun zu einem moralischen Phänomen wird. Diese Verinnerlichung der Ehre geht einher mit einer Kritik am Duell und an den Standesprivilegien des russischen Adels als einer rein genealogischen Nobilität, welcher nun ein Ehrbegriff gegenüber gestellt wird, der (wie z.B. in Sumarokovs Satire O čestnosti) mit Pflichtmaximen, Tugendhaftigkeit (dobrodetel', dobronravie) und Nützlichkeit für die Gesellschaft (Ideal des blagorodnyj graždanin) semantisiert wird: „Cena i čest' est' to že. Sej, kto ne imeet vnutri sebja, priemlja lživoe svidetel'stvo snaruži, tot nedevaet vid ložnogo almaza i vorovskoj monety", heißt es in den Basni Char'kovskie (1774) von Skovoroda, und „Prosveščenie ili vera božija, miloserdie, velikodušie, spravedlivost', postojannost', celomudrie - Vot cena naša i čest'!“ (Borisov 1997, 9091). Fonvizin, der die Regierungszeit Katharinas II. als eine Ära ehrgeiziger Höflinge und schamloser Günstlinge kritisierte, der er die Zeit Peters I. gegenüberstellte, lässt in seiner Komödie Nedorosl' (1781) den die alten Tugendwerte verkörpernden Starodum das Leben eines Höflings ohne Auszeichnungen und Ämter verlassen, weil er angesichts des agonalen Wettbewerbs um Reputation am Hof um seine innere Ehre fürchtet: „Prines domoj neprovreždenno moju dušu, moju čest', moi pravila".

Um äußere Ehre bzw. Ehrung, in welcher der Staat mit den von ihm hypostasierten Werten sinnlich greifbar wird, geht es bei der Ordensverleihung. Obwohl der erste Orden (ordena) der des hl. Andreas, auf das Jahr 1699 zurückgeht und die Verleihung des Georgsordens („Für Treue und Mut“) auf das Jahr 1769, wurde erst 
1797 unter Paul I. ein Gesetz Über die Verleihung von Orden erlassen. In diesem Gesetz stand als Begründung und Zielsetzung: Orden „werden zur Ehrung und zur Auszeichnung wahrer Verdienste auf dem Feld ziviler und militärischer Tapferkeit und Heldentaten und als Ansporn für den Dienst und zum Wohl des Vaterlandes verliehen“ (Franz 2002, 333). Während der Orden des hl. Aleksandr Nevskij „Für Taten und Vaterland“ verliehen wurde, war der Orden des hl. Fürsten Vladimir eine Auszeichnung „Für Nutzen, Ehre und Ruhm“. Seit 1849 (bis 1917) wurden die Namen aller Kavaliere des Georgsordens, die eine ganz besondere Verehrung genossen, im Großen Kremlpalast auf Marmortafeln verewigt.

Für Aleksandr Puškin, der die geistige Elite Russlands im 19. Jahrhundert repräsentiert, ist eine ambivalente Ehrauffassung charakteristisch, die nicht nur in literarischen und paraliterarischen, sondern auch in historischen und literatursoziologischen Texten zum Ausdruck gelangt. Basierend auf einem adligen Ehrdiskurs, der das genealogische Standes- und Ehrbewusstsein der Bojaren als sozialpolitischer Elite ( $O$ dvorjanstve, 1830, u.a.) formuliert, thematisiert Puškin in Gedichten, Dramen und narrativen Texten die Opposition ,echte“ innere Ehre (den point d'honneur eines „Mannes von Ehre und Verstand“) versus Ehrbegriff der „Narren“, deren Triebfedern Vorurteil und die öffentliche Meinung, „unser Götze“ („naš kumir" in Evgenij Onegin), darstellen. In Epigrammen und Briefen fand Puškin eine Möglichkeit des „Duellierens“ mit verbalen Mitteln, die er gegen Verleumder und Geheimpolizeispitzel wie den Publizisten Faddej Bulgarin einsetzte, welche seine professionelle Ehre als Schriftsteller in einem vom „edlen, aristokratischen Wirkungsfeld“ zum „,verlausten Markt" („všivyj rynok“) heruntergekommenen Literaturbetrieb zu beschädigen suchten.

Signifikant ist auch Dostoevskijs Opposition von wahrer, innerer Ehre (verkörpert z.B. durch Figuren wie den Fürsten Myškin in Idiot oder Sonja Marmeladova in Prestuplenie $i$ nakazanie) und falscher, aus Machtgier (wie Raskol'nikov) oder sozialem Egoismus und Übermenschentum entsprungener Sucht nach äußerer Ehre, die den Skandal für sich nutzt (Stavrogin in Besy). Lev Tolstojs Ehrauffassung äußert sich nicht nur in einer (auch von Schopenhauer beeinflussten) moralischen Verurteilung von Verstößen gegen Ehrprinzipien (wie u.a in Anna Karenina, Voskresenie, Krejcerovaja sonata), sondern auch in der Gegenüberstellung von synchron existierenden und konfligierenden Ehrkonzepten der kaukasischen Schamkultur und der russischen Schuldkultur in Texten wie der (1904 abgeschlossenen) Erzählung Hadži Murat (Hartmann 2004), die eine von Puškin in seinem Verspoem Tazit (1829) begründete Tradition der Kaukasus-Literatur und ihrer Alteritätskonzepte fortsetzte.

Um eine Tradition zu unterlaufen, welche die entehrende Prügelstrafe durch die zaristischen Autoritätsorgane tolerierte, und um dem fatalistischen Lebensgefühl bzw. Lebensüberdruss des adligen „lišnij čelovek“ Ausdruck zu verleihen (Brang 1961, 326-327), kam es zu einer Hochkonjunktur des Duells. Die russischen Duellanten nahmen die - vom Staat monopolistisch betriebene - Ausübung von Gewalt auf, inkorporierten sie in die ritualisierte Duellprozedur und ersetzten 
auf diese Weise die hierarchische Gewalt in Form von Körperstrafen durch die gleichstellende, auf Ebenbürtigkeit beruhende Gewalt des Duells. Die Zunahme der Duellpraxis spiegelte die tiefgehende Abneigung von Adligen (unter ihnen Šeremet'ev, Puškin und Lermontov, die 1817, 1839 bzw. 1841 im Duell fielen) gegenüber der staatlichen Macht über ihren persönlichen Raum und über ihre Körper wider, wobei der Ehrenzweikampf als ausdrucksstarke Geste dazu diente, staatliche Gewalt durch Selbstjustiz zu konterkarieren. Die russische Literatur des 19. Jahrhunderts (von Bestužev-Marlinskij, Puškin, Lermontov bis Dostoevskij, Turgenev und Tolstoj, wobei Gogol's satirisch-groteske Duell-Darstellung eine Ausnahme bildet; Brang 1961, Scholle 1977, Schultz 1996, 319-354) wie auch die Trivialliteratur und wissenschaftliche Arbeiten transportierten den hohen Prestigewert, den das Duell und der auf einen strengen Ehrkodex bedachte, tapfere und großmütige Gentleman-Duellant genossen (Reyfman 1999, 1-3). Das Duell, dem für den Adel eine „sozial bestimmende Rolle“ (Lotman 1997, 174), weil nach außen abschließende Rolle zukam, gestaltete sich in Russland allerdings brutaler als in Westeuropa. So wurde beispielsweise der für damalige medizinische Verhältnisse absolut tödliche Bauchschuss bevorzugt. Außerdem hatte derjenige, der als Zweiter schoss, das Recht, seinen Kontrahenten (der nach westeuropäischen Duellregeln auf der Stelle stehen bleiben musste) an die Barriere zu rufen, um ihn dann als unbewegliche Zielscheibe zu erschießen. Während im Westen der Abstand zwischen den Barrieren mindestens 15 Schritt betrug, waren in Russland acht bis zehn Schritt üblich (Gordin 1996, 93-97).

Spätestens durch kritische, nichtadelige Schriftsteller wie Anton Čechov, in dessen Credo persönliche Integrität (im Gegensatz zum Ehrverlust durch Käuflichkeit wie in Ivanov) und die „Freiheit von Gewalt und Lüge, worin sich beide auch äußern mögen", höchsten Stellenwert besitzt (vgl. seine Dramen und v.a. seine Erzählung Duèl', 1891), setzte eine Infragestellung oder Ablehnung des Duells ein. In Kuprins Roman Poedinok (1905), wo der Protagonist durch ein vom Offiziersgericht angeordnetes Duell in den Tod getrieben wird, fand das 1894 von der russischen Regierung (in Anlehnung an die preussische Gesetzgebung) geänderte Militärstrafrecht seinen Niederschlag, das Duelle zur Offizierspflicht erklärte und Duellverweigerung mit Ausstoßung aus der Armee bedrohte.

Obwohl es in der Moderne zu einer Destruktion der traditionellen Moralnormen und zur Schaffung von exzentrischen Erosmodellen kam, die sich in Bloks symbolistischen Gedichten über die schöne Unbekannte in Gestalt einer Großstadthure genau so ausdrückte wie in den Dreiecksbeziehungen, mit denen Belyj in seinem Roman Peterburg die göttliche Trinität wie auch Tolstojs rigide Moralauffassung persiflierte, war Belyj durchaus in seinem Ehrgefühl verletzlich und ließ sich in skandalöse, für ihn selbst schockartige Rede-Duelle mit seinen Kritikern verwickeln (Schahadat 2001, 54-56). Noch 1922 wurde Kaverin von Zoščenko zu einem „echten“ Duell gefordert, obwohl der sozialistischen Moral, wie es in der Bolšaja sovetskaja énciklopedija lakonisch hieß, das „Duell fremd ist“" (Brang 1961, 345). 
Die kommunistische Lehre in der Sowjetunion vertrat eine utopische Ideologie, die verbindliche Direktiven hinsichtlich der Formung des neuen Menschen und der Gesellschaft aufstellte, wobei sie den von ihr entwickelten Ehrbegriff zu einem Politikum machte. Das auf dem XXII. Parteitag von Chruščev vorgelegte Programm der KPdSU enthält (im Unterschied zu den Parteiprogrammen von 1903 und 1919) explizite Formulierungen dessen, was man unter einem kommunistischen Ehrkodex und sozialistischer Ehre verstand: „Die Partei ist das Hirn, die Ehre und das Gewissen unserer Epoche“, denn sie „weist dem Volk die wissenschaftlich fundierten Wege des Fortschritts, weckt in den Massen gigantische Energien und führt sie zur Lösung grandioser Aufgaben" (Schultes 1964, 549). Während die Nationalsozialisten biologistisch argumentierten, indem sie die Ehre blut- und rassegebunden ansahen, so erklärten die russischen Kommunisten die Ehre als identisch mit der Partei, denn nur sie allein sei in der Lage, axiologische Wertungen zu setzen. Der ethische Kodex der „Erbauer des Kommunismus“ basiert in dem Parteiprogramm von 1961 auf zwölf Prinzipien, die von der „Treue zur Sache des Kommunismus" und „Liebe zur sozialistischen Heimat" über „humanes Verhalten und gegenseitige Achtung der Menschen“, „Ehrlichkeit und Wahrheitsliebe, sittliche Sauberkeit, Schlichtheit und Bescheidenheit im gesellschaftlichen wie im persönlichen Leben“ bis zur „brüderlichen Solidarität mit den Werktätigen aller Länder" reichen (Meißner 1962, 227-228). Ehrenhaftes Verhalten nach diesen Grundsätzen der „,kommunistischen Moral“ heißt, „die Macht, die Ehre und den Ruhm der Sowjetunion“" zu vergrößern (Meißner 1962, 244).

Ihren Niederschlag fand die sozialistische Ehrauffassung zunächst in der revolutionären Kunst bzw. Literatur der Avantgarde (z.B. Majakovskijs Oda revoljucii), dann in der Produktionsliteratur und in moral-ästhetischen Werken wie Gladkovs Énergija (1933), Ostrovskijs Kak zakalilas' stal' (1932-34) und Fadeevs Kriegsroman Molodaja gvardija (1945), die dem Dogma des Sozialistischen Realismus verpflichtet waren. Dem mit teilweise hagiographischen Formen ausgestatteten Lenin-Kult folgte seit den dreißiger Jahren ein von bildenden Künstlern, Schriftstellern und Publizisten praktizierter Ehren-Kult bzw. Götzendienst um Stalin, der den Diktator als Hypostasierung der Partei zum alleinigen Hüter von Wahrheit und Ehre stilisierte und zum multimedialen „Gesamtkunstwerk“ (Groys 1988) formte. Die durch Autoren wie Aleksandr Solženicyn (Odin den' Ivana Denisoviča), 1962, Archipelag GULag), Varlam Šalamov (Kolymskie rasskazy, 1975, 1978) und andere vertretene Lagerliteratur zeigt allerdings eine konträre Konzeptualisierung von Ehre, die sich auch von der im GULag dominierenden, auf dem Recht des physisch Stärkeren basierenden Ganovenehre des „blat" abgrenzen muss, um moralischen Distinktionsgewinn zu erzielen.

Obwohl in der nachstalinistischen Tauwetter-Periode der Personenkult und die Schönfärberei (lakirovka) der abgebildeten Wirklichkeit Kritik erfuhren, blieb die Diskrepanz zwischen Propaganda-Ideologie und der von dem offiziell verordneten Ehrkodex weitgehend unberührten Realität einer „Fassadengesellschaft“ (Goehrke III, 249, 270-274) über weitere Jahrzehnte bestehen. Vasil' Bykovs Anfang der 
siebziger Jahre publizierte und mit dem Staatspreis ausgezeichnete Kriegserzählung Obelisk mit ihrer Thematisierung des genuin heroischen Ehrbegriffs ist ein exemplarisches Beispiel für diese gelenkte Literatur.

Nachdem unter der Sowjetmacht zunächst sämtliche Orden abgeschafft worden waren, kam es bald als Werkzeug der totalen Indoktrination zur Wiedereinführung von Statussymbolen und Auszeichnungen in Form von Kampf- und Arbeitsorden. Als Ehrenzeichen mit dem höchsten Prestigewert galten der Lenin-Orden, der Rotbannerorden und der Goldene Stern eines Helden der Sowjetunion (für militärische Verdienste). Titel wie „Held der sozialistischen Arbeit“, „Volkskünstler“ oder „Verdienter Wissenschaftler" sollten als Ansporn dienen, mit aller Kraft am Aufbau des Sozialismus mitzuwirken (Goehrke III, 189).

\section{Gegenwart}

In der postkommunistischen Ära setzte nicht nur eine politisch-wirtschaftliche Perestrojka, sondern auch eine Umwertung der sozialistischen Normen und eine Devaluation aller staatlichen Auszeichnungen ein. Es kam zu einer - schon in den Jahrzehnten vorher durch die Dissidenten (Daniel, Sinjavskij u. a.) praktizierten - Abkehr vom verordneten moral-politischen Ehrkodex und in der Kunst und Literatur zur Dekonstruktion des moral-ästhetischen Kanons. Signifikant hierfür ist u. a. die Indexikalität von Anti-Sprichwörtern im gegenwärtigen russischen Sprachgebrauch. Valerij Mokienko und Harry Walter haben Sprichworttransformationen und Spott-Sentenzen gesammelt, deren Sarkasmus demonstriert, welche Umwertung so relevante Konstanten der russischen Kultur wie Ehre und Moral heute erfahren: Dostovernost' - nevozmožnost' ne verit'; Čestnost' dlja politika eto kak klejmo „profneprigoden“! (Walter, Mokienko 2002, 55,152). Auch das u.a. von Puškin häufig verwendete Sprichwort Beregi čest’ smolodu („Hüte deine Ehre von Jugend auf!" ) hat eine Reihe von Umformungen erfahren, die einer Entwertung gleichkommen: Beregi brjuki szadi, a jubku speredi; Beregi čeljust' smolodu! Beregi čest' smolodu, koli roža kriva; Beregis' testja s molotom; Gotov' sani letom, a čest' smolodu; Obchodi tramvaj speredi, a čest' smolodu, und in der bitteren Wahrheit gipfeln: Esli čest' bereč' smolodu, na čto že žit' v starosti?

Die SocArt und die postmoderne Literatur in Russland, vertreten u.a. durch Vladimir Sorokin, Viktor Erofeev und Vladimir Makanin, wird durch eine Entwertung sozialistischer Werte, auch der Arbeiter-, der Parteiführer- und der IntellektuellenEhre, gekennzeichnet und äußert sich in einem sprachlichen Experimentieren an den Tabugrenzen der totalitären Wirklichkeit der alten Sowjetunion. So hat beispielsweise Sorokin in seinen Erzählungen Obelisk oder Pervyj subbotnik (1992), in denen er den einzigen von der Literatur der Sowjetzeit nicht vereinnahmten Diskurs der Substandard-Sprache und ihrer skatologischen Lexik einsetzt, die Monstrosität des Heldengedenkens und des sozialistischen Ehrbegriffs in ihrer Verlogenheit dekuvriert. Und Makanin zeigt in seinem Roman Undegraund ili Geroj našego vremeni (1998), wie ein heruntergekommener Schriftsteller, der eine „Philosophie des Schlags“ (filozofija udara) vertritt, ohne Gewissensbisse zwei Morde „im Namen 
der Ehre" begeht: den einen an dem Kaukasier, der von ihm auf einer Bank vor dem Wohnheim Geld fordert, wobei er ihn mit seinem Messer provokativ am Arm „kitzelt“, und den der Schriftsteller in einem (parodistischen) „Sitz-Duell“ sein Klappmesser in den Rücken stößt; den anderen an einem früheren Parteispitzel, dem er selbst, durch Alkohol bestochen, Informationen über Autoren-Kollegen geliefert hat.

Während sich 1991 in Russland eine Vereinigung des Adels konstituiert hat mit dem Ziel, die traditionellen Werte (u.a. die aristokratische Ehre) zu pflegen, folgt in der Postperestrojka-Periode ein anderer Teil der Bevölkerung der „dem Kriminaljargon entnommenen Formel žit' po ponjatijam" (Koreneva 2004, 65). Als Verkörperung und Hauptprofiteure der neuen Marktwirtschaft gelten die einer Elite sehr heterogener Herkunft entstammenden „novye russkie“, die „ihren plötzlich gewonnenen Reichtum wie Parvenüs schamlos zur Schau stellen" (Goehrke III, 436-437) und auf Grund ihrer moralischen, aber auch bildungsmäßigen Defizite zum Gegenstand zahlloser Witze geworden sind (Engel 2001). In Anlehnung an die im Westen gesendeten Formate Big Brother I-III wurde 2001 die russische TV-Serie Za steklom ausgestrahlt, die im Gegensatz zu der Rezeption von Big Brother, wo in erster Linie Fragen der Menschenwürde diskutiert wurden, heftige mediale Auseinandersetzungen über Moral und Nicht-Moral (z.B. Voyeurismus als „Entehrung“ der Beteiligten) auslöste. Ob Filme wie Aleksej Balabanovs Brat I und Brat II, in denen die Figur des ,ehrenwerten“ Killers zur Identifikation einlädt, einen neuen Trivialmythos begründet, wird sich zeigen.

\section{Literatur}

Arutjunova, N. D.: 2000, ,O styde i sovesti‘, in: N. D. Arutjunova, T. E. Janko, N. K. Rjabceva (Hrsg.), Jazyki etiki, Moskva, 54-78.

Borisov, S. B.: 1997, Čest' kak kul'turno-antropologičeskij fenomen: Évoljucija filosofskich interpretacij, Ekaterinburg.

Bourdieu, P.: 1979, Entwurf einer Theorie der Praxis auf der ethnologischen Grundlage der kabylischen Gesellschaft, Frankfurt a. M.

Brang, P.: 1961, ,Der Zweikampf im russischen Leben und in der russischen Literatur', Zeitschrift für Slavische Philologie 29, 315-345.

Burkhart, D.: 2002, Ehre. Das symbolische Kapital, München.

Eco, U.: 1972, Einführung in die Semiotik, München.

Engel, Ch.: 2001, ,Novyj russkij pojmal zolotuju rybku... Ökonomie und Ökonomiepriinzip in den Witzen über die „neuen Russen“", Wiener Slawistischer Almanach, Sonderband 54, 231-245.

Fleischer, M.: 1997, Das System der russischen Kollektivsymbolik. Eine empirische Untersuchung, München.

Franz, N. (Hrsg.): 2002, Lexikon der russischen Kultur, Darmstadt. 
Frithjof, R.: 1975, ,Anspielungen. Zur Theorie der kulturellen Kommunikationseinheiten', Poetica VII, 115-134.

Gercen, A. I.: 1954, ,Neskol'ko zamečanij ob istoričeskom razvitii česti' (1848), in: A. Gercen, Sobranie sočinenij v tridcati tomach, tom 2, Moskva, 151-176.

Gesemann, G.: 1943, Heroische Lebensform. Zur Literatur und Wesenskunde der balkanischen Patriarchalität, Berlin.

Goehrke, C.: 2003-2005, Russischer Alltag. Eine Geschichte in neun Zeitbildern, 3 Bde., Zürich.

Gordin, Ja. A.: 1996, Dueli i duéljanty, Sankt-Peterburg.

Hartmann, A.: 2004, ,Zur Axiologie der Ehre in Lev Tolstojs Chadži Murat', in: www.jfsl.de/publikationen/2004/hartmann.html

Kacura, A.: 1999, Poedinok česti. Duèl'v istorii Rossii, Moskva.

Kiernan, V. G.: 1988, The Duel in European History. Honour and the Reign of Aristocracy, Oxford, New York.

Kissel, W. S.: 2004, Der Kult des toten Dichters und die russische Moderne, Köln, Weimar, Wien.

Kollmann, N. S.: 1988, ,Was there Honor in Kiev Rus'?', in: Jahrbücher für Geschichte Osteuropas 36, H. 4, 481-492.

Koreneva, M.: 2004, Ehre und Würde als Verhaltenscodes in der russischen Kultur', in: B. Menzel (Hrsg.), Kulturelle Konstanten Russlands im Wandel, Bochum, Freiburg, 50-67.

Lotman, Ju. M.: 1986, ,Zur Semiotik der Begriffe Scham und Angst im Mechanismus der Kultur' (1970), in: K. Eimermacher (Hrsg.), Semiotica sovietica. 2. Sowjetische Arbeiten der Moskauer und Tartuer Schule zu sekundären modellbildenden Zeichensystemen (1962-1973), Aachen, 835-838.

Lotman, Ju. M.: 1993, ,Ob oppozicii čest' - slava v svetskich tekstach kievskogo perioda', in: Ju. M. Lotman, Izbrannye stat'i $v$ trech tomach, Tallin, III, 111-126.

Lotman, Ju. M.: 1997, Russlands Adel, Köln.

Meiske, Ch. (Hrsg.): 1985, Das Sobornoe Uloženie von 1649, Halle.

Meißner, B.: 1962, Das Parteiprogramm der KPdSU 1903-1961, Köln.

Neckel, S.: 1991, Status und Scham. Zur symbolischen Reproduktion sozialer Ungleichheit, Frankfurt a. M. - New York.

Nicolosi, R.: 2002, Die Petersburg-Panegyrik: russische Stadtliteratur im 18. Jahrhundert, Frankfurt a. M.

Reyfman, I.: 1999, Ritualized Violence Russian Style. The Duel in Russian Culture and Literature, Stanford.

Rüß, H.: 1994, Herren und Diener. Die soziale und politische Mentalität des russischen Adels. 9.-17. Jahrhundert, Köln, Weimar, Wien.

Simmel, G.: 1992, Soziologie (1908), Frankfurt a. M.

Schahadat, Sch.: 2001, ,Ohrfeigen und andere Normverletzungen. Über den Skandal in Lebens- und Kunsttexten von Dostoevskij und Belyj', in: S. K. Frank u. a. 
(Hrsg.), Gedächtnis und Phantasma. Festschrift für Renate Lachmann, München, 48-63.

Scholle, Ch.: 1977, Das Duell in der russischen Literatur, München.

Schultes, H.: 1964, ,Die Ehrauffassung im Wandel der Gesellschaft', Geschichte in Wissenschaft und Unterricht, Jg. 15, 540-552.

Urban, P.: 1996, , «in Baron mehr oder weniger...»-Variationen des Duells im Werk von Anton Čechov', in: U. Schultz (Hrsg.), Das Duell. Der tödliche Kampf um die Ehre, Frankfurt a. M., 337-354.

Vogt, L.: 1997, Zur Logik der Ehre in der Gegenwartsgesellschaft, Frankfurt a. M.

Walter, H., Mokienko, V.: 2002, Wörterbuch russischer Anti-Sprichwörter, Greifswald. 


\section{Градищанско-хорватские сказки по-штинацски из Южного Бургенланда (Запоздалый отклик)}

Более двадцати лет тому назад вышел первый сборник сказок градищанских хорватов, живущих в Южном Бургенланде, в селе Штинац - Stinatz (Erzählgut 1983). Занимаясь исследованием языка градищанских хорватов Австрии, я как-то сразу обратил внимание на эту книгу, неоднократно читал ее и делал из нее всевозможные выписки. Чтение этой книги доставляет мне удовольствие до сих пор. Потому хотелось бы кратко поведать, о чем идет речь.

Градищанские (или бургенландские) хорваты проживают в земле Бургенланд в Австрии. В 20-е гг. 20 века основоположник градищанско-хорватской микролитературы Мате Милорадич предложил для немецкого Burgenland славянский эквивалент Градище - Gradišće. С этого времени в славистической литературе и утвердилось название градищанские хорваты, градищанu, - Gradišćanski Hrvati, Gradišćanci. Предки этого островного микроэтноса, 
преследуемые турками, оставили в 16 веке свои родные места (районы Лики и Покупля, западной части Славонии, верхней Посавины, северной и северозападной Боснии, Хорватского Приморья) и поселились на землях тогдашней Западной Венгрии. Поскольку наиболее мощная миграционная волна наблюдалась в 1533 году, то этот год взят за основу отмечавшегося в 1983 г. в Градище 450-летия переселения (специально к этой дате написана и издана параллельно на немецком и градищанско-хорватском языках солидная монография, см.: Schreiner 1983).

В настоящее время в Австри проживает приблизительно 35-40 тыс. градищанских хорватов (по официальной статистике на начало 70-х годов - 28 тыс., поскольку в переписях учитывается только так наз. „контактный, или повседневный, язык“; по подсчетам эйзенштадтского епископата - 39 тыс.; cм.: Gradišćanski Hrvati 1973, 299; Symposion Croaticon 1974, 20). В историкокультурном и этно-социальном плане близки к ним хорваты, населяющие некоторые места современных Венгрии и Словакии.

C 16 века градищанские хорваты имеют свой литературный язык, базирующийся, в отличие от штокавского литературного языка Хорватии, на чакавской диалектной основе. Их культурным центром является город Эйзенштадт, по-градищанско-хорватски - Железно (Željezno), где выходит основная печатная продукция на градищанско-хорватском литературном языке (периодика, книги, учебники для школы и т. д.) и сосредоточены культурнопросветительные и прочие общества.

Несмотря на сильные, наблюдавшиеся как в прошлом, так и в настоящее время ассимиляционные процессы, градищанские хорваты упорно сохраняют свою традиционную культуру и свой язык. Уже в прошлом веке произведения их устного народного творчества собрал и опубликовал Ф. Курелац (Kurelac 1871), затем - В. Кухач (опубликовано в загребском журнале Vienac в 70е годы 19 века). В середине 20 века много в этом плане сделали известные деятели градищанско-хорватской культуры Я. Добрович и М. Мершич (см. соответственно: Dobrović 1964; Meršić 1964). Однако все это (или преимущественно все) были произведения поэтического творчества.

Книга, о которой мы хотим рассказать, представляет нам образцы прозаического творчества, записанного в 1964-1965 годах в селе Штинац, которое градищанские хорваты называют Cтиняки - Stinjaki. Текстам предполсано обширное введение, в котором содержатся данные об историческом прошлом и современном социальном и культурном состоянии Штинаца (1300 жителей). Это село, в отличие от других хорватских мест Южного Градища, представляет собою стойкий в этническом и языковом отношении славянский остров. В нем практически нет старого немецкого населения. Традиционное занятие здесь - сельское хозяйство, причем мужская часть населения занимается также отхожим промыслом. В силу этого мужчины, как правило, дву- и даже трехъязычны - владеют, кроме родного языка, также немецким и/или вен- 
герским. Женщины, напротив, как правило, одноязычны, в лучшем случае владеют также местным немецким диалектом.

Именно женщины являются основными хранителями и создателями народной словесной культуры. Один из составителей книги пишет, что за все время его работы в Штинаце он так и не смог услышать из уст мужчин какой-либо истории. Примечательной особенностью техники записывания материала является так наз. свободный разговор - freies Gespräch, когда „история" рассказывается не лично исследователю, а всем слушателям, которые в этом случае собираются в доме рассказчицы. Видной рассказчицей, памяти которой посвящена книга, была Мария Киризич - от нее записано наибольшее число „историй“. Характеристика каждой рассказчицы (всего их четыре) представлена в книге в виде графика, в котором отражены данные о месте рождения, занятиях (в пределах села и вне его), образования и т. д. родителей и предков, а также самой рассказчицы. Это дает возможность объяснить появление тех или иных культурыных, социально-политических и прочих инноваций в сказочном тексте. Всего в книге 57 текстов различного объема, причем каждый текст подается штинацским говором с переводом на немецкий.

Штинацский говор весьма специфичен в кругу хорватских говоров Южного Градища. Он относится к чисто икавскому типу ( $\check{e}>i$ : cista ,улица; дорога', želizo ,железо') и отличается от градищанско-хорватского литературного языка особенностями ударения и интонации, растяжкой закрытых слогов, дифтонгизацией, лексическим составом. Потому за ним закрепилось также название штинацский язык - die Stinatzer Sprache, Stinatzerisch. Записи поштинацски осуществлены с магнитофонной ленты практической транскрипцией, которая, тем не менее, достаточно точно передает истинное звучание слова (образцы акцентированных текстов, сделанные научной транскрипцией, приведены во введении, с. LXVIII-LXX). Перед каждым текстом сообщается номер фонотеки (Phonogrammarchiv) Австрийской Академии наук, хранящей живую запись; здесь же указывается сюжетное соответствие штинацской сказки сказкам других народов, проверенное по известному каталогу А. Аарне и С. Томпсона (Aarne, Thompson 1961), а также по венгерскому каталогу Й. Берзе Надя (Berze Nagy 1957). Это дает возможность четче осознать специфику так наз. „культурной экологии“ - Kulturökologie Штинаца, т. е. состояние традиционных форм народной культуры и их связей с иноэтническими культурами, чему собиратели градищанско-хорватского фольклора придают большое значение. Выявляется, что большая часть сюжетов - 34 из 57 - имеет четкие параллели в сказках других народов. Следует, однако, иметь в виду, что они взяты из одного источника. В этом случае можно говорить о генетико-типологической связи сюжетов, а не об их заимствовании. В большинстве случаев такая ситуация характеризует сюжеты на известные библейские темы (странствия и страдания Иисуса Христа, деяния апостола Петра и под.). Если учесть этот фактор, то оказывается, что почти половина 
представленного в сборнике штинацского прозаического фольклора имеет по крайней мере региональное или локальное происхождение. Как правило, это обработанные под сказку острые события жизни, например, „Кто выстрелит в сердце отца?“ - „Do će striljit ocu u serce?“, всевозможные трактирные, бытовые, военные и прочие истории („Счастье бедного крестьянина“ - „Srića bedavoga paora“, „Голубая роза“ - „Plava ruža“, „Девушка-уточка“ - „Divuojkakača“" и др.). Народная память хранит события из времен турецкого нашествия, связывая их с воспоминаниями о прародине (например, небольшая сказка „Брат-турок“ - „Turski brat“). Отдельные сказочные сюжеты возникли под влиянием местных немецко-австрийских. В ряде сказок, например, персонажи носят немецкие имена: в сказке „Дети ищут родителей“ - „Dica na iskanju starljiev“ выступает Hans; ср., однако, сказку „Жестокая сестра“ („Ločiesta sestra“) из уст одной и той же рассказчицы Анны Живкович, где персонаж выступает под именем Iva (что соответствует немецкому Hans).

Книга Прозачческое благо (= сказки) хорватов из Штинача в Южном Бургенланде, составленная австрийскими славистами - специалистом по фольлору К. Гаалом, диалектологом Г. Невекловским в сотрудничестве с М. Грандич, рожденной в Штинаце, является ценным вкладом в изучение славянского островного фольклора. И не только: это еще и увлекательное чтение...

Составители этого интересного сборника продолжили свою работу: в 1987 г. и в 1991 г. они издали еще два тома штинацского фольклора (Neweklowsky, Gaál 1987; Neweklowsky, Gaál 199).

\section{Лumepamypa}

Aarne A., Thompson, S.: 1961, The Types of the folktale, Helsinki.

Berze Nagy, J.: 1957, Magyar népmesetipusok, Pécs.

Dobrovich J., 1950, 1964, Pjesmarica. Narodne jačke Gradišćanskih Hrvatov, Štikapron; Druga pjesmarica. Narodne jačke Gradišćanskih Hrvatov, Štikapron.

Erzählgut der Kroaten aus Stinatz im südlichen Burgenland kroatisch und deutsch. Hrsg. von K. Gaál und G. Neweklowsky unter Mitarbeit von M. Grandits, Wien 1983.

Gradišćanski Hrvati, Zagreb 1973.

Kurelac, F.: 1871, Jačke ili narodne pěsme prostoga i neprostoga puka po župah Šopronjskoj, Mošonjskoj i Željeznoj na Ugrih, Zagreb.

Meršić, M.: 1964, Jačkar. Hrvatske narodne jačke iz Gradišća, Čakovec.

Neweklowsky, G., Gaál, K.: 1987, Totenklage und Erzählkultur in Stinatz kroatisch und deutsch, Wien.

Neweklowsky, G., Gaál, K.: 1991, Kroatische Märchen und Totenklagen aus Stinatz im Burgenland (Croatian Literature Series, vol. 7), Zagreb.

Symposion Croaticon. Gradišćanski Hrvati, Beč/Wien 1974. 
Schreiner, B.: 1983, Das Schicksal der burgenländischen Kroaten durch 450 Jahre / Sudbina Gradišćanskih Hrvatov kroz 450 ljet, Eisenstadt/Željezno. 



\section{Unbekannte Wirklichkeit. Die Träume Raskol'nikovs in Fedor M. Dostoevskijs Roman Преступление и наказание}

Fedor Michajlovič Dostoevskijs $1866^{1}$ erschienener Roman Преступление и наказание schließt mit dem Hinweis auf eine „,vollkommen unbekannte Wirklichkeit“, die für sich wieder den Stoff einer neuen Erzählung bilden könne: „Но тут уж начинается новая история, история постепенного обновления человека, история постепенного перерождения его, постепенного перехода из одного мира в другой, знакомства с новою, доселе совершенно неведомою действительностью. Это могло бы составить тему нового рассказа, - но теперешний рассказ наш окончен“ (PSS 6, 422). Für Dostoevskij ist die Möglichkeit der moralischen Erneuerung des gefallenen Menschen ein Teil der Lebenswirklichkeit; er ist überzeugt, daß es auch für den Mörder Raskol'nikov noch eine Wende geben kann hin zu einer ganz neuen Geschichte, die sich freilich stufenweise („постепенно“) vollzieht, als Bekanntschaft mit einer neuen Wirklichkeit, die gleichwohl nicht 
Utopie zur emotionalen Beruhigung, sondern (vorläufig noch) unbekannt, ja unbewußt ist. Alles das ist Thema seines Romans, und ausgehend von der Übertretung (преступление) zeichnet der Autor nun ein Bild der positiven Transition hin zu dieser schon angelegten, aber eben noch unbekannten Wirklichkeit: Er spricht vom Übergang (переход) aus einer Welt in die andere, ja sogar von einem „Umgeborenwerden" - перерождение. Der ganze ausgedehnte, höchst schmerzhafte und sehr eigentümlich bereits vor der Tat einsetzende Sühneprozeß (наказание) Raskol'nikovs, der die Fabel des Romans bildet, ist also zunächst lediglich die Vorbereitung auf diese nun stufenweise zu erwartende Umwandlung, die jedoch zugleich bereits in dem konkreten Sühneprozeß präfiguriert ist.

Über das im Schlußsatz des Romans enthaltene sprachkünstlerische und philosophische Potential ${ }^{2}$ ließe sich trefflich eine eigene Abhandlung schreiben. Ich möchte mich aber in der folgenden Betrachtung einem zentralen Verfahren Dostoevskijs zur Modellierung dieser geschichteten Wirklichkeit zuwenden: den Traumdarstellungen des Titelhelden Raskol'nikov. Wie setzt der Autor Träume innerhalb seiner eigenen Realismuskonzeption literarisch ein, und wie verwebt er sie in die Motivebene?

Dostoevskij hat sich selbst in einem berühmten Ausspruch kurz vor seinem Tod als „Realist im höheren Sinne“ bezeichnet: „При полном реализме найти в человеке человека. Это русская черта по преимуществу, и в этом смысле я конечно народен (ибо направление мое истекает из глубины христианского духа народного) [...] Меня зовут психологом: неправда, я лишь реалист в высшем смысле, то есть изображаю все глубины души человеческой“ (PSS 27, 65). Die Psychologie steckte vor 125 Jahren noch ganz in den Kinderschuhen, aber Dostoevskij war schon so weit zu erkennen, daß sich ernsthafte Psychologie mit dem ungeteilten Menschen beschäftigen müsse, daß auch das Unbewußte, und die Seele zumal, der ungeteilten menschlichen Realität angehören. Für ihn ist dies sogar ein spezifisch russischer Zug des Denkens, der untrennbar mit dem christlichen Menschenbild ${ }^{3}$ verbunden ist. So möchte er gerade nicht eine Spannung zwischen im Wachzustand erlebter Wirklichkeit und den „Hirngespinsten“ des Träumenden gelten lassen; für Dostoevskij ergibt sich daraus auch literarisch gesehen kein Antagonismus zwischen Realistik und Phantastik. So verstanden, verwendet Dostoevskij die Begriffe „Psychologe“ und „Realist im höheren Sinne“ als Synonyme. Der Psychologe befaßst sich folglich nicht mit Phantastik, sondern mit dem Menschen als ganzem, und so bedient er sich aller menschlichen Erfahrungsebenen als Hilfsmittel. Insofern ist menschliche geschichtliche Wirklichkeit immer geschichtete Wirklichkeit. Wenn man dies nicht nur von der konkreten Person und den verschiedenen Schichten der Persönlichkeit (zum Beispiel im Sinne der Tiefenpsychologie) ausgehend sieht, sondern auch von der konkreten Existenz in Zeit und Raum, dann bedeutet es, daß Menschsein für Dostoevskij nicht als eine nur punkthafte Existenz auf dem Zeitstrahl zu beschreiben ist, sondern daß die immer nur im Augenblick der Gegenwart sich vollziehende Existenz ihre Verbindung zu Vergangenheit und Zukunft hat, nämlich durch die spezifisch menschlichen Fähigkeit zu Erinnerung und Hoffnung. Damit widerspricht der Dichter jeder 
empirisch-positivistischen Engführung des literarischen Realismusbegriffs und öffnet ihn geradezu in jene Weite hinein, die Michail Bachtin (Bachtin 1971) seiner Konzeption des „polyphonen Romans“ vorausgesetzt hat. Die Polyphonie, das werden wir an den Traumdarstellungen sehen, ist nicht nur konstituiert als Dialog autonomer Romanfiguren und als Autonomie der Figuren wiederum vom Autor, sondern setzt schon tiefer (oder ,höher") an, nämlich in den Personen selbst. ${ }^{4}$ Die geschichtliche Existenz der Personen vollzieht sich eben nicht nur als bloße Aufeinanderfolge von Ereignissen monophon, sondern auch in der Interpretation derselben gleichsam polyphon, und in dieser Beziehung, so besagt es Dostoevskijs Konzeption des „Realisten im höheren Sinne“, sind Träume nicht nur rein inhaltlich berichtenswert, sondern sie sind ein Teil der wirklichen Existenz des Menschen und tragen spezifisch zur Konstitution und zum Verständnis seiner eigenen Geschichte bei.

\section{Von der ,anklagenden Literatur" zum ,Instrument anklagen- der Selbsterkenntnis"}

Mit den einleitenden Ausführungen zu Dostoevskijs Realismuskonzeption habe ich zweifellos vorgegriffen auf die schon über den Roman hinausführende Deutung des Dostoevskijschen Menschen- und Weltbildes. Auf diese philosophische Reflexionshöhe hatte der Dichter seine zunächst geplante Erzählung wohl noch nicht hinaufschwingen wollen, ja noch nicht einmal - so ist zu vermuten - auf diejenige der reinen Fabel von Преступление и наказание, wie sie der dann gedruckten Version des Romans entspricht. Im Sommer 1865 hatte Dostoevskij noch einen Roman mit dem Titel P'janen'kie geplant, der eine deutlich sozialkritische Ausrichtung haben sollte. ${ }^{5}$

Aus den Entwürfen zu diesem Roman erwuchs nach und nach ein ganz anders ausgerichtetes Werk, das sich in zunehmendem Maße existenzphilosophischen Fragen widmete und das ursprüngliche Thema des Alkoholismus und seiner Folgen für die Gesellschaft in den Nebenhandlungsstrang der Marmeladov-Familie verlegte. Das zeigte sich auch schon an den Titelvarianten Dostoevskijs für diesen Roman: Erst nach Pod sudom und Rasskaz perestupnika gelangte er zu dem endgültigen Titel, dem bis dahin das entscheidende, komplementäre Element im positiven Menschenbild Dostoevskijs noch gefehlt hatte. Doch verlief die Arbeit nicht nur kontinuierlich, sondern sie war durch einen entscheidenden Bruch gekennzeichnet, der allgemein als Beginn einer neuen Schaffensperiode Dostoevskijs angesehen wird. Noch Ende November 1865 ist er von Grund auf unzufrieden mit dem Manuskript und wirft es ins Feuer: „В конце ноября было много написано и готово; я все сжег; теперь в этом можно признаться: Мне не понравилось самому. Новая форма, новый план меня увлек; и я начал сызнова.“6

Welcher neue Plan hatte ihn gepackt und befähigt, das Werk innerhalb weniger Wochen von neuem auszuarbeiten, so daß bereits Ende Januar 1866 der erste Teil erscheinen konnte? Es war die ,philosophisch vertiefte Thematik vom 
Schicksal des genialen Individuums, das sich an die leer gewordene Stelle Gottes setzt und souverän über Leben und Tod seiner Mitbürger entscheidet" (Neuhäuser 1979, 161), die sich an dem ebenfalls 1865 in Paris erschienenen Werk Histoire de César Napoleons III. entzündet hatte. Diese Ideologie des genialen Individuums findet sich dann auch in dem Aufsatz Raskol'nikovs, der die Thematik des ersten Gesprächs mit dem Untersuchungsrichter Porfirij bildet (Kapitel III, Abschnitt $5)^{7}$. Literarisch gesehen, vollzog sich in diesem Bruch Dostoevskijs die Umbildung der ,anklagenden Literatur" zum „Instrument einer anklagenden Selbsterkenntnis“, worauf der Theologe Martin Doerne (1962, 22) im Zusammenhang seiner vier religösen Motivkreise, die er aus der Beschäftigung mit Dostoevskijs antropologischem Grundentwurf erarbeitet hatte, hingewiesen hat. Das Thema sozialer Randbereiche blieb zwar erhalten, wurde nun aber Motivation und Ausgangspunkt eines Kriminalromans, in dessen Mittelpunkt hinwiederum nicht die Aufdeckung der Tat in ihren Einzelheiten im Vordergrund steht, sondern „die Analyse eines Erkenntnisprozesses, der sich nach vollbrachter Tat im Täter vollzieht und ihn selbst nach Strafe verlangen läßst." (Neuhäuser 1979, 166). Dostoevskij gelangte damit von seinem sozialkritischen Ausgangspunkt ${ }^{8}$ über die aktuelle Ideologie der napoleonischen Idee zu einer Konzeption des Tests am Individuum, woraus Neuhäuser $(1979,170)$ vier Hauptthemen formuliert hat, die der Entstehungsgeschichte des Romans folgen:

I. die sozialen Übel der Zeit;

II. das Verbrechen als humanitäre Tat;

III. die napoleonische Idee;

IV. das autonome Individuum.

Während die ersten beiden Themen die Oberfläche des Romans beschreiben (Raskol'nikov will sich durch die Ermordung einer in seinen Augen nichtswürdigen Wucherin aus seiner materiellen Not befreien), nehmen die Themen III und IV die ideologisch-philosophische Weiterentwicklung im oben schon beschriebenen Sinne auf. So spiegelt sich die Werkgeschichte im Aufbau der Fabel wider und sie kristallisiert sich in der Hauptperson Raskol'nikov, an dem sich der Test am Individuum vollzieht, nämlich die Beantwortung der Frage, ob auf dem Fundament durch und durch niederer Mordmotive nicht doch ein hehrer Überbau gegründet werden könnte.

Doch Dostoevskij will ,im Menschen den Menschen finden“, will ihn aus einer ausweglosen Rolle als vermeintlicher Funktionär der Geschichte herauslösen und zeigen, daß die Autonomie des Individuums nicht zwangsläufig im Scheitern der Hybris endet, sondern aus dem Scheitern heraus wieder ein Heilungs- und Heilsprozeß entstehen kann. Wir wollen nun sehen, wie dies anhand von Raskol'nikovs Traumdarstellungen deutlich und im Roman wirksam wird. 


\section{„Eine Klarheit, die sich kein Dichter ausdenken kann“}

Dem großen Kenner der ostkirchlichen Kultur Konrad Onasch verdanken wir eine wesentliche Einsicht in die Bedeutung der Traumdarstellungen für die Komposition von Преступление и наказание, denn er hat anhand eines Grundgerüstes aufgezeigt, daß die von Dostoevskij zur Darstellung gebrachte ,anklagende Selbsterkenntnis" auf drei verschiedenen Ebenen verläuft: zum einen in den vier ${ }^{9}$ Träumen Raskol'nikovs, zum anderen in den Porfirij- und den Sonjagesprächen (vgl. Onasch 1976, 112). An diesem Grundgerüst lassen sich die Haupthandlungsstränge des Romans, die sich um die Hauptfigur gruppieren, sehr deutlich aufzeigen: auf der moralisch-religiösen Ebene die Beziehung Raskol'nikovs zu Marmeladovs Tochter Sonja, auf der kriminalistisch-psychologischen Ebene die Gespräche Raskol'nikovs mit dem Untersuchungsrichter Porfirij. Diese „Zweiheit“ hat Doerne (1962, 30ff.) sehr gut herausgearbeitet und deshalb sein Kapitel über Преступление и наказание mit dem markanten Titel überschrieben: „Richterliche und schöpferische Menschenerkenntnis". Die Träume kommen im Gegensatz zu Onasch bei Doerne nicht zur Sprache, wohingegen auch N. Reber (1981) ihre Bedeutung für den Bewußtwerdungsprozeß, also für die Selbsterkenntnis Raskol'nikovs, erkannt und herausgestellt hat. Sowohl durch die religiös-emotionale Zuwendung Sonjas, als auch durch die kriminalistisch-psychologische Kunst Porfirijs wird dieser Selbsterkenntnisprozeß gefördert; ${ }^{10}$ es ist im wesentlichen ein dialogischer Prozeß, und selbst die inneren Vorgänge im Titelhelden vollziehen sich dialogisch, nämlich vermittels der Träume, die gerade der Gefahr der Verdrängung, die rational-intellektuelle Auseinandersetzung mit eigener Schuld immer mit sich bringt, entbehren und erst in dieser Sicht als innere autonome Stimme im Konzept des polyphonen Romans ihre wahre Funktion enthüllen.

Um dies zu erkennen, müssen wir allerdings keine spekulativen theoretischen Überlegungen anstellen, sondern müssen nur dem Dichter selbst zuhören, der dem ersten Traum ein kurzes, aber vollständiges Konzept in philosophischer wie in sprachkünstlerischer Hinsicht vorangestellt hat: „В болезненном состоянии сны отличаются часто необыкновенною выпуклостью, яркостью и чрезвычайным сходством с действительностью. Слагается иногда картина чудовищная, но обстановка и весь процесс всего представления бывают при этом до того вероятны и с такими тонкими, неожиданными, но художественно соответствующими всей полноте картины подробностями, что их и не выдумать наяву этому же самому сновидцу, будь он и такой художник, как Пушкин или Тургенев. Такие сны, болезненные сны, всегда долго помнятся и производят сильное впечатление на расстроенный и уже возбужденный организм человека." (PSS 6, 45f.)

Es mag zunächst überraschen, mit welcher Vehemenz Dostoevskij gerade jenen Träumen, die einem Krankheitszustand entspringen, den Fieberträumen (vgl. Bachtin 1971, 190), eine besondere Klarheit und Deutlichkeit, ja eine besondere Ähnlichkeit mit der Wirklichkeit zuspricht. Dies gelte selbst dann, wenn das Traumbild als solches, wenn der Gegenstand des Traums ein ungeheuerlicher sein sollte, 
selbst dann seien das Zusammenspiel und die Glaubwürdigkeit der Einzelheiten unerwartet genau. Was bedeutet das aber aus der Sicht des Träumenden? Offenbar wird er im Traumzustand aus seiner raumzeitlichen Verankerung herausgelöst; er erfährt, daß er nicht nur, wie oben schon angedeutet, ein Punkt auf dem Strahl der Zeit ist, daß sein Schicksal nicht nur vom ewigen Fluß des Chronos mitgerissen wird, sondern er erfährt im Traum das Einbrechen des Kairos, „ein Augenblick bedeutet Billionen von Jahren“, wie es in Dostoevskijs Erzählung Son smešnogo čeloveka heißt. ${ }^{11}$ Vor seinen geistigen Augen verbinden sich Vergangenheit und Zukunft, indem der Traum als eine Interpretation der gegenwärtigen Situation empfunden wird. Ja, die Krankheit ist gewissermaßen die Vorbereitung für diesen Erkenntnisprozeß, sie schwächt die manipulative Willenskraft, sie öffnet einen Raum für die nicht willensgesteuerte Interpretation und Selbsterkenntnis. Entscheidend ist der Träumende selbst, der sich in seinem krankhaften Bewußtsein zurechtfindet, ja, die unter den Sonderbedingungen des Traums nur scheinbar subjektiv ist, in Wirklichkeit aber in dem Willen des Subjekts entzogener Objektivität die Krankhaftigkeit des Bewußtseins entlarvt. Dostoevskij faßt also die Krankheit als krisenhaft-kathartischen Prozeß auf, der mit dem besonders klaren Erkennen der Wirklichkeit im Traum sich ganz wesentlich gegenüber der im gesunden Wachzustand vorgenommenen Analyse, die sich der Gefahr der Subjektivierung niemals ganz entziehen kann, objektiviert. Der Leser indes kann an diesem Bewußtseinsprozeß nur teilnehmen, indem die Raum-Zeitmodellierung im Roman vom Bewußtsein Raskol'nikovs ihren Ausgang nimmt, ansonsten müßten ihm die Traumbilder unverständlich bleiben. ${ }^{12}$

In diesem Zusammenhang steht auch die alte Frage nach dem Verhältnis von Dichtung und Wahrheit, die der Autor hier berührt. Im Wachzustand könne der Träumende, so schreibt er, niemals ein Bild aus ,künstlerisch zum Ganzen so passenden Einzelheiten" ersinnen, mag er auch ein Dichter sein wie Puškin oder Turgenev. Was ist die Aufgabe des Dichters? Die Darstellung der Wirklichkeit, würde sicher Dostoevskij auch und gerade unter seiner differenzierten Selbstcharakterisierung als Realist im höheren Sinne antworten. Ja, hier verhält es sich sogar so, daß er die zuvor genannte Ähnlichkeit mit der Wirklichkeit gleichsetzt mit den „künstlerisch zum Gesamtbild passenden Einzelheiten“. Kapituliert die Kunst vor der Wirklichkeit? Aus der Sicht Dostoevskijs sicherlich nicht, wenn sie sich der Kraft der Wirklichkeit und ihrer Aufgabe im Dienst derselben bewußt ist. Nicht Ausdenken ist die Aufgabe des Schriftstellers, sondern Zur-Sprache-Bringen von Wirklichkeit, ihre verschiedenen Schichten zu durchsuchen; dort nicht Phantastik zu ersinnen, wo die Wirklichkeit selbst Instrumente zur ihrer eigenen Interpretation bereithält. Dies um so mehr, wenn es sich um das Innerste der menschlichen Person handelt, um einen Bewußtwerdungsprozeß, dessen Gegenstand die dabei behilfliche Krankheit ebenso ausgelöst hat. Noch einmal: der „Realist im höheren Sinne" läßt sich nicht auf einen bloßen Positivisten reduzieren; das wäre für ihn kein Künstlertum, welches er untrennbar mit dem spezifisch russischen (und das ist für ihn synonym mit christlichem) Menschenbild verbunden sieht. 
Träume von solcher Klärungskraft entspringen nur dem geschwächten Organismus, der keine Energie verschwenden wird, es sei denn, sie könnte seiner Heilung nützlich sein. Solche Träume prägen sich dem Bewußtsein ganz deutlich und langanhaltend ein - im Gegensatz zu gewöhnlichen Träumen -und entfalten ihre starke Wirkung. Nimmt es wunder, daß Dostoevskij sich gerade ihrer bedient, um den heilsamen Prozeß der Selbsterkenntnis Raskol'nikovs zu beschreiben und so dem kriminalistischen Einzelfall eine über ihn hinausweisende, exemplarische Dimension zu verleihen?

\section{„Es geht uns nichts an“ (Erster Traum)}

Wie es scheint, ist der erste Traum Raskol'nikovs, der sich unmittelbar vor dem Mord an der Pfandleiherin ereignet, nicht eigentlich ein solcher Fiebertraum, wie ihn Dostoevskij in der oben erörterten und diesem Traum vorausgeschickten Stelle beschrieben hat. Raskol'nikov war auf dem Heimweg in Gedanken herumgelaufen, unschlüssig, ob er noch seinen Freund Razumichin besuchen solle. Ein Glas Wodka, nach längerer Abstinenz unterwegs genossen, tut sein übriges; er legt sich in ein Gebüsch auf den Rasen und schläft ein (PSS 6, 45). Daß der Traum doch schon Anzeichen einer nervlichen Überreizung sein könnte, wird Raskol'nikov erst nach dem Aufwachen langsam bewußt, während die zu Beginn des Traums näherliegende Motivation die Müdigkeit infolge des Alkoholgenusses ist und es dem Leser plausibel erscheinen läßt, daß Raskol'nikov einschläft und träumt. Diesen Kunstgriff wendet Dostoevskij gezielt an: Eine Vermischung von Wach- und Traumzustand, wie sie für einen Fiebertraum bezeichnend ist und sich als Verunklärung der Grenze zwischen beiden in der chronotopischen Modellierung niederschlägt, ist hier nicht gegeben; direkt, unmittelbar und ausdrücklich leitet Dostoevskij die Traumerzählung ein: „Страшный сон приснился Раскольникову“ (PSS 6, 46). Im Traum erlebt Raskol'nikov eine Kindheitsszene oder aber, eigentlicher, „seine Kindheit", denn Dostoevskij gebraucht die Formulierung: „Приснилось ему его детство" (PSS 6, 46), er spricht also offensichtlich von einer Kristallisation seiner Kindheit in einer einzelnen, schrecklichen Traumszene. ${ }^{13}$ Die Unmittelbarkeit des Traums wird durch die Verwendung des historischen Präsens unterstützt, und im Traum erscheint die ganze vorgestellte Situation für Raskol'nikov noch klarer als in seinem bewußten Gedächtnis, also ganz im Sinne der schon besprochenen Konzeption Dostoevskijs: „Даже в памяти его она гораздо более изгладилась, чем представлялась теперь во сне“ (PSS 6, 46).

Im kompositorischen Aufbau der Traumszene lassen sich zwei Ebenen oder Abschnitte unterscheiden. Zunächst wird die eigentliche Handlung, der ungeheuerliche Gegenstand des Traumes, hinausgezögert durch eine Schilderung der Örtlichkeit, der Heimatstadt Raskol'nikovs und der großen Schenke vor der Stadt, die ihm stets einen unangenehmen, ja angsteinflößenden Eindruck gemacht hatte. Dieser Eindruck indes rührte weniger von dem Gebäude selbst her als vielmehr von der großen Menge Betrunkener, die sich dort aufzuhalten pflegte, und von deren Verhalten: Lachen, Schreien, Prügeln. Dostoevskij geht nun aber über eine rein 
deskriptive Darstellung schon hier zu Beginn hinaus und entwirft ein Stimmungsbild des kindlichen Raskol'nikov, das interpretative Elemente miteinbezieht. Vom Ort der Handlung, der Schenke, führt nämlich eine Straße zu einem Ort seiner Kindheit, der mit positiven Gefühlen verbunden ist: zu der Kirche, mit der er die Totenmessen für die verstorbene, ihm unbekannt gebliebene Großmutter assoziiert und darüberhinaus auch den Friedhof mit dem Grab seines ihm gleichfalls nicht erinnerlichen kleinen Bruders.

Diese Erinnerung, die zeichenhaft über die Straße vom Ort des Schreckens der Schenke - hinführt zu einem Ort des Friedens, der Ehrfurcht und religiösen pietas, ist die Gefühlswelt seiner Kindheit, und es ist bezeichnend, daß Dostoevskij in diesem Abschnitt sehr häufig das Adverb „всегда“ verwendet. In der kindlichen Welt verbinden sich bestimmte Orte, Dinge oder Situationen zumeist mit beständigen Erfahrungen und Emotionen, welche wenig differenziert und zugleich scharf konturiert erscheinen. (Und macht nicht jeder irgendwann die Erfahrung, daß ihn die Erinnerung mit zunehmendem Abstand von einer Lebensperiode zu diesem „immer" zurückkehren läßt: „Als wir Kinder waren, hatten wir im Winter immer viel Schnee“, „war es im Sommer immer sehr heif", „mußten wir immer viel arbeiten" und so fort? Die Erfahrungen und Emotionen erscheinen eingeschmolzen, aber ihr Ausgangspunkt ist die gegenwärtige Situation des sich Erinnernden, in die sich auch schon Vergessen mischt. Ist also die interpretative Reduktion im vergessenden Erinnern nicht auch ein Auslöser der besonderen Klarheit?) Jedenfalls zeigt sich hier bereits jene charakteristische Antinomie, die den ganzen Roman durchzieht und im Charakter Raskol'nikovs begründet ist.

Nach dieser Vorbereitung setzt nun die Traumhandlung von neuem ein: „И вот снится ему“ (PSS 6, 46). In der Art des Bachtinschen Karnevalskollektivs ist vor der Schenke ein Haufen betrunkener Männer und Frauen versammelt; eine Konzentration derjenigen Gestalten und Verhaltensweisen, die Raskol'nikovs Kindheitserinnerungen mit der Schenke verbinden. Ein betrunkener Grobian, Mikolka genannt, schickt sich an, seine Zechkumpanen auf seinem Wagen zu fahren, und fordert sie auf, hinaufzusteigen. Vor den Wagen, der von seiner Größe her an sich für kaltblütige Lastpferde bestimmt ist, ist eine altersschwache Stute gespannt. Hierin liegt vor allem die Ungeheuerlichkeit des Traumbildes, das dennoch nicht völlig unrealistisch ist. Die Stute soll nach dem unsinnigen Willen ihres Besitzers mitsamt der ungeheuren Last Galopp laufen, was zu einer immer mehr sich steigernden Wut Mikolkas und seiner Mittäter führt, die das Tier mit Peitschenhieben peinigen, bis es schließlich, unter den Schlägen Mikolkas, der sich am Ende einer Deichselstange und auch noch einer eisernen Brechstange bedient, qualvoll verendet. Lärmen und Lachen der Beteiligten und der Umstehenden steigern sich ebenso wie die Wut Mikolkas und seine Gewalttätigkeit, die sich wiederum in der Steigerung der Peinigungswerkzeuge manifestiert (vgl. Reber 1981, 191). Der kleine Raskol'nikov, zusammen mit seinem Vater Zeuge der grausamen Szene, reißt sich voller Entsetzen vom Vater los und küßt das tote Pferd, bevor er sich in kindlicher Wut mit geballten Fäusten auf Mikolka stürzt. Der Vater zieht 
ihn weg und versucht ihn zu beschwichtigen: „Пьяные, шалят, не наше дело, пойдем!“" (PSS 6, 49).

Raskol'nikov deutet diesen Traum, nachdem er schweißgebadet erwacht ist, für sich selbst als die Stimme seines Gewissens, die sich gegen die Elementargewalt der Aggression erhebt (vgl. Reber 1981, 192), also als Gegenüberstellung von Über-Ich und Trieben, ${ }^{14}$ die während der Planung der Tat in Konkurrenz miteinander treten. Es wird ihm klar, daß er seinen Plan nicht wird ausführen können: „Слава Богу; это только сон! [...] Господи, неужели?“ (PSS 6, 50). Der Traum hat seine Wirkung nicht verfehlt, und Raskol'nikov, im Traum noch der kindliche Beobachter, fühlt sich selbst am ganzen Leibe zerschlagen.

Außer diesen Emotionen Raskol'nikovs und der Auseinandersetzung mit seinem Gewissen enthält der Traum aber noch mehr Hinweise auf die komplexe Thematik des Romans, und er enthält auch eine scharfe Gesellschaftskritik. Zum einen ist es Mikolka, der sich die napoleonische Idee bar jeder ideologischen Überhöhung zu eigen macht und damit entlarvt: Immer wieder weist er darauf hin, die Stute sei sein Eigentum, er könne mit ihr tun, was er will. Das autonome Individuum in seiner Verblendung zeigt sich hier unbeschönigt, und mehr noch, es tritt in krassen Gegensatz zum christlichen Glauben der Erlösung durch das Leiden des Gottessohnes, dessen Integrität gerade in der Preisgabe der Autonomie durch sein Leiden in der Auferstehung unversehrt bewahrt worden ist. ${ }^{15}$ So halten einige Umstehende denn auch Mikolka entgegen: „Да что на тебе креста, что ли, нет, леший! - кричит один старик из толпы“ (PSS 6, 48) - „Ну и впрямь, знать, креста на тебе нет! - кричат из толпы уже многие голоса“" (PSS 6, 49). Indes, niemand hält den rasenden Gewalttäter zurück, man läßt ihn gewähren, äußert zwar Empörung, bleibt aber tatenlos. „Es geht uns nichts an“, diese Beschwichtigung von Raskol'nikovs Vater nimmt man allzu leicht hin, weil sie zu einem Kind gesprochen wird, aber dennoch steckt darin gefährlich verborgen jene philiströse Mittäterschaft, deren Wirksamkeit ebenso wie die Frage nach ihrer Anrechenbarkeit als persönliche Schuld zu den ethischen Grundfragen und nicht nur, wenngleich dort besonders scharf, in der Situation der totalitären Gesellschaft zutage tritt.

Das scheint auch Raskol'nikov, wenn auch nur implizit, bewußt geworden zu sein, denn er erkennt: „Боже! - воскликнул он, - да неужели ж, неужели ж я в самом деле [...] Господи, неужели?“ (PSS 6, 50) Und er betet: „Господи! [...] покажи мне путь мой, а я отрекаюсь от этой проклятой ... мечты моей!“ (PSS 6, 50) Diese zweifache Hinwendung Raskol'nikovs zu Gott ist unter der Beachtung des Dostoevskijschen Menschenbildes sicherlich nicht nur eine rhetorische Phrase; sie zeigt Raskol'nikovs existenzielles Ringen mit seinem Gewissen und die klar eingestandene Erkenntnis, daß die Idee des autonomen Individuums scheitern wird. Aber ist denn das Christentum der Gesellschaft seines Vaters nicht doch zu schwach gewesen, als daß er sich der Erlösung des leidenden Gottesknechtes wird anvertrauen können? Seine Assoziationen, die er im Traum mit der Kirche der Kindheit verbindet, belegen es: es sind Totenmessen, Begräbnisse und ein alter, zitternder Priester. Es ist eine gedämpfte Frömmigkeit, die eher im gesellschaftlich- 
familiären Ritual steckenbleibt, vielleicht auch eine verbürgerlichte, mit Kraft wohl zur Empörung, aber nicht zur Tat. Insofern sind in diesem ersten Traum sowohl die Tat als auch ihr Scheitern, sowohl die Auseinandersetzung Raskol'nikovs mit seiner eigenen Person als auch die flankierende Gesellschaftskritik Dostoevskijs miteinander verschränkt. Im Traum war es einzig der kindliche Raskol'nikov, der persönliches Mitleid mit der geschundenen Kreatur empfand und sich aller Machtlosigkeit zum Trotz vom Widerstand gegen den Peiniger nicht abhalten ließs ${ }^{16}$ Diesen Weg wieder aufzunehmen ersehnt er nun, aber der Mord läßt sich dennoch nicht mehr verhindern.

\section{„Hatte sich die Welt umgedreht?“ (Zweiter Traum)}

Am Abend nach dem Mord besucht Raskol'nikov seinen Freund Razumichin und macht auf dem Polizeirevier Bekanntschaft mit dem Leutnant Il'ja Petrovič. Den Heimweg des Protagonisten gestaltet Dostoevskij bereits als änigmatischsymbolischen Parcours, auf dem Raskol'nikov beinahe unter die Pferde einer Kutsche gerät und für seine Ungeschicklichkeit zu allem Überfluß auch noch einen Peitschenhieb kassiert, der ihn buchstäblich mit einem Schlag ,wieder völlig zur Besinnung" bringt (PSS 6, 89f.). Seiner Aufmachung und seinem merkwürdigen, orientierungslosen Verhalten verdankt er es, daß er von einer Passantin ein Zwanzigkopekenstück erhält, und im Weitergehen versenkt er sich in die Betrachtung des Petersburger Panoramas, wie es schon früher seine Gewohnheit gewesen ist. Daß er indes noch dieser alten Gewohnheit, nun, nach der Ausführung des Mordes, nachzuhängen vermag, kommt ihm durchaus verwunderlich vor: „Уж одно то показалось ему дико и чудно, что он на том же самом месте остановился, как прежде, как будто и действительно вообразил, что может о том же самом мыслить теперь, как и прежде, и такими же прежними темами и картинами интересоваться, какими интересовался ... еще так недавно. Даже чуть не смешно ему стало и в то же время сдавило грудь до боли. В какой-то глубине, внизу, где-то чуть видно под ногами, показалось ему теперь все это прежнее прошлое, и прежние мысли, и прежние задачи, и прежние темы, и прежние впечатления, и вся эта панорама, и он сам, и всё, всё... Казалось, он улетал куда-то вверх всё исчезало в глазах его ..." (PSS 6, 90). Nach diesen Empfindungen, die ihn bereits aus der raumzeitlichen Verankerung im Hier und Jetzt lösen, in denen alles eins und zugleich aufgelöst erscheint, die ihm eine Unterscheidung zwischen seiner Person, seinen Gedanken und Handlungen einerseits und der Umgebung anderseits nicht mehr ermöglichen, die sein Leben und ihn selbst hinabziehen in die Tiefe, während er doch hinaufzufliegen vermeint, wird er noch einmal recht „,materialistisch“ ins Bewußtsein zurückgerufen, denn er fühlt das Zwanzigkopekenstück wieder in seiner Hand, die es krampfhaft umklammert. Dieses letzte Unterpfand - wenngleich bürgerlicher - Barmherzigkeit schleudert er in die Newa, und dann: „Ему показалось, что он как будто ножницами отрезал себя сам от всех и всего в эту минуту“ (PSS 6, 90). 
In diese unklare, polyphone Situation hinein gestaltet Dostoevskij den zweiten Traum Raskol'nikovs. Dem Leser erscheint es plausibel, daß Raskol'nikov infolge seiner aufgewühlten Stimmungslage und seines psychisch dramatischen Heimwegs zuhause wie bewußtlos auf sein Sofa sinkt. Ja, Raskol'nikov fühlt sich wie ein "gehetztes Pferd“, und in dieser Parallele zum ersten Traum wird zugleich die offenbarende Krise deutlich, denn Täter und Opfer erscheinen vertauscht. Nach dem ersten Traumerlebnis fühlte sich Raskol'nikov bereits wie zerschlagen, nur hatte er da noch das ganze Leid und die Qual der geschundenen Kreatur absorbiert und mit seinem kindlichen Mitleid zu erlösen versucht.

Daß er nun mitten in der Nacht wieder aus dem Schlaf aufschreckt, nachdem er ein fürchterliches Geschrei im Hause wahrgenommen hat, muß dem Leser gleichfalls nicht ungewöhnlich erscheinen. Dostoevskij gestaltet die Geräuschkulisse ebenso eindringlich wie diffus durch insistierende Aufzählung: „Таких неестественных звуков, такого воя, вопля, скрежета, слез, побой и ругательств он никогда еще не слыхивал и не видывал. Он и вообразить не мог себе такого зверства, такого исступления" (PSS 6, 90). Die russische Sprache hält für solcherlei Qualund Wutgeschrei etliche lautmalerische Worte bereit, deren Wirkung der Dichter noch durch Alliteration zu verstärken weiß. Hier ist im Kern die ganze Modellierung dieses zweiten Traums enthalten, welche sich ausschließlich akustischer Mittel bedient. Nach und nach wird es Raskol'nikov bewußt, daß seine Wirtin verprügelt wird, und zwar von niemand anderem als dem Polizeitleutnant Il'ja Petrovič. Diese Erkenntnis ist jedesmal mit dem Dostoevskijschen Signalwort „вдруг" gekennzeichnet. Wieder, wie im ersten Traum, gibt es offensichtlich auch Schaulustige, denn Raskol'nikov hört außerdem die Gegenrede offenbar auf der Hausflurtreppe anwesender Personen, die allerdings diesmal nicht lachen, sondern in Aufregung umherlaufen, Türen schlagen, das Geschehen kommentieren.

Der ungeheuerliche Gegenstand formt sich ebenfalls in Raskol'nikovs interpretativem Lauschen aus der gewalttätigen Geräuschkulisse: Zugleich fragt er sich, weswegen wohl seine Wirtin von der Polizei verprügelt werde, und erkennt, daß jedenfalls die Anwesenheit der Polizei nur mit seiner eigenen Tat im Zusammenhang stehen könne: „Но за что, за что же, и как это можно! -повторял он, серьезно думая, что он совсем помешался. Но нет, он слишком ясно слышит! ... Но, стало быть, и к нему сейчас придут, если так, потому что... верно, все это из того же, из-за вчерашнего ... Господи!“ (PSS 6, 91). Schon zuvor hat er sich gefragt: „Что это, свет перевернулся, что ли?“ (PSS 6, 91).

Ja, so ist es, offensichtlich hat sich die Welt umgedreht unter den Bedingungen seines Genialitätsexperiments. Er hatte sie noch am Abend unter seinen Füßen gehabt, aber das war nur seine kleine, beschränkte Persönlichkeit gewesen, die er für das ganze Panorama gehalten hatte. Er wollte fliegen und klammerte sich an eine Münze, er hatte sich selbst losgeschnitten, und nun erlebt er die erbärmliche Gewissensangst des Täters, der noch gar nicht enttarnt ist, aber der drohenden Strafe unentrinnbar ausgeliefert ist. Dostoevskij hat diese Aspekte der umgedrehten Welt nicht nur durch die rätselhafte Verprügelung der Hauswirtin gestaltet, sondern 
auch raumzeitlich durch die Illusion des nächtlichen Aufschreckens Raskol'nikovs. Dieses nächtliche Wiederzusichkommen ist in Wirklichkeit der Fiebertraum, aber es ist in einem ,höheren Sinne“ der Beginn des Wiederzusichkommens der Zurechtweisung. Es ist der Beginn des Heilungsprozesses, der sich stufenweise vollzieht und mit dem Hören beginnt, wenngleich in diesem Stadium die Verdrängung der Tat noch im Vordergrund steht, denn noch ist es nicht Raskol'nikov, der die Strafe erleidet, sondern rätselhafterweise seine Wirtin.

Daß es sich bei der ganzen Szene um einen Traum gehandelt hat, darüber wird der Leser zwar im Unklaren gelassen; er muß, ähnlich wie Raskol'nikov, aus der Geräuschkulisse den raumzeitlichen Zusammenhang erschließen. Indes gewinnt er nun einen interpretativen Vorsprung vor Raskol'nikov, dessen autonome Stimme im polyphonen Gefüge dadurch deutlich abgeschwächt erscheint. Dennoch entspricht es sicherlich Dostoevskijs christlichem Menschenbild, daß er die Traumverrätselung nicht bis ins Unkenntliche treibt, denn bei allem Kopfstehen der Welt bricht immer wieder auch die beginnende Selbsterkenntnis des Mörders ein. Im ersten Traum hat Raskol'nikov im Nachhinein die Tat interpretativ antizipiert, nun ist er mitten darin und sieht sich in der Rolle des machtlosen Zuhörers gegenüber ungerechter Gewalt und unausweichlicher Strafe.

\section{„Der Mond gibt gerade ein Rätsel auf“ (Dritter Traum)}

Der dritte Traum ist mit einigem Recht auch als die „Achse des Romans“ (Reber 1981, 193) bezeichnet worden, denn er enthält alle Deutungselemente desselben in kristallisierter Form und ist ebenso realistisch wie symbolisch ausgestaltet. Zudem ziehen sich von ihm aus interpretativ verstärkende Verbindungslinien zu den ersten beiden Träumen. Dabei muß man gewärtigen, daß die Traumszene vielleicht einem positivistischen Realisten überflüssig vorkommen könnte, denn sie schließst sich unmittelbar an ein Selbstgespräch Raskol'nikovs an, in dem er sich die wahren Beweggründe seiner Tat klar verdeutlicht und sich am Ende selbst verlacht: „Да, я действительно вошь, - продолжал он, с злорадством прицепившись к мысли, роясь в ней, играя и потешаясь ею, - и уж по тому одному, что, во-первых, теперь рассуждаю про то, что я вошь; потому, во-вторых, что целый месяц всеблагое провидение беспокоил, призывая в свидетели, что не для своей, дескать, плоти и похоти предпринимаю, а имею в виду великолепную и приятную цель, - ха-ха!"“ (PSS 6, 211). Damit ist zwar der Ausgang des Napoleonischen Experimentes klar und deutlich entlarvt, doch eine innere Verwandlung Raskol'nikovs läßt noch auf sich warten, noch hat er die kindliche Stufe des Mitleids, die sich im ersten Traum zeigte, nicht wieder erreicht, denn die getötete Wucherin erscheint ihm geradezu als Auslöser aller seiner Leiden: „О, ни за что, ни за что не прощу старушонке!“ (PSS 6, 212). Noch ist Raskol'nikov also in seiner verkehrten, kopfstehenden Welt befangen, und hier nun zeigt sich, daß in Dostoevskijs Konzeption die ganze symbolisch-realistische Szene des dritten Traums keinesfalls überflüssig ist, denn er gibt Raskol'nikov nicht verloren, er sucht weiter „den Menschen im Menschen“. 
Auch dieser Traum wird durch die raumzeitlich unklare Wendung „Он забылся“ eingeleitet, und abermals ist der Leser im Unklaren, ob es sich um eine reale, die Handlung weiterführende Situation handelt. Raskol'nikov findet sich auf der Straße wieder, in einer für ihn typischen Situation, in der er nicht genau weiß, warum und zu welchem Ziel er sich aufgemacht hat. Plötzlich - zweimal kommt hier wieder das stark markierende „вдруг" vor - sieht er einen Mann und vermeint, dieser winke ihm zu. Etwas unsicher folgt er ihm und erkennt ihn dann als jenen Kleinbürger, den er schon einmal auf der Straße getroffen hat. Jener führt Raskol'nikov an den Ort seines Verbrechens zurück, um dann zu verschwinden. Diese erste Szene ist von drei Elementen geprägt: Unsicherheit, Dunkelheit und Stille. Keinerlei Geräusche sind zu hören, wenngleich doch Scharen von Menschen sich auf den Straßen befinden. Die ganze Geräuschkulisse ist für Raskol'nikov, der wie hypnotisiert dem Kleinbürger folgt, ausgeblendet. In der Wohnung der Wucherin angekommen, wird es Raskol'nikov langsam bewußt, daß er sich am Ort seines Verbrechens befindet. Die Stille ist ihm unheimlich und, mehr noch, seine eigenen Schritte: „И какая там тишина, даже страшно ... Но он пошел. Шум его собственных шагов его пугал и тревожил" (PSS 6, 213). Doch es bleibt unklar: Kehrt hier der Verbrecher nach begangener Tat an den Tatort zurück, wie es ein gängiges, zum kriminalistischen Sujet gehörendes Motiv verlangt, oder ist es ein Nacherleben der Tat, das jetzt zu erwarten steht? In diese Stille hinein fügt Dostoevskij ein retardierendes Moment, eine meisterhafte, änigmatische Synästhesie: „Огромный, круглый, медно-красный месяц глядел прямо в окна. ,Это от месяца такая тишина, - подумал Раскольников, - он, верно, теперь загадку загадывает.' Он стоял и ждал, долго ждал, и чем тише был месяц, тем сильнее стукало его сердце, даже больно становилось. И все тишина“" (PSS 6, 213). Diese Mondesstille ist gewiß der unerhörte Gegenstand dieses Traumes, denn die dann folgende Szene, in der Raskol'nikov vergeblich die Alte zu töten versucht, ist zwar grotesk in ihrer Ausgestaltung, besonders durch das Lachen des Mordopfers, doch kommt in ihr die Welt bereits wieder ihrer Wirklichkeit näher. Der schweigende Mond indes, der immer stiller wird, also nicht heller oder dunkler, steht am Wendepunkt. Was für ein Rätsel ist es, das er aufgibt? Es ist die Situation, die Chronos und Kairos voneinander scheidet. Wird Raskol'nikov den Kairos erkennen und von seinem Vorhaben ablassen? Wird er zugleich die niederen, philiströsen Beweggründe entlarven, die ihn an den Ort des Verbrechens geführt haben: seine Habgier einerseits und seine Hybris anderseits? Oder wird er mitgerissen werden vom Strom des einmal durch eigenen Entschluß begonnenen bösen Werkes, unfähig, der Tat im letzten Moment auszuweichen? Wird aus seinem Wunsch, Herr der Geschichte zu sein, das Desaster, ihr Sklave zu sein zu müssen? Plötzlich ein kurzes Knacken, das Aufsummen einer Fliege und - dadurch vielleicht motiviert - die Entdeckung eines Mantels, hinter dem sich jemand verbirgt - sein Opfer.

Das Rätsel wird gelöst. Raskol'nikov findet die Wucherin, erhebt das Beil, schlägt auf sie ein. Aber sein Tun hat keinen Erfolg. Die Alte erscheint nicht nur 
wie aus Holz und so immun gegen seine Schläge zu sein, zu allem Überfluß lacht sie ihn aus. Es ist ein lautloses Lachen, das sich proportional zu seiner Wut darüber steigert, daß er sie nicht töten kann. Die Szene erinnert an den ersten Traum und an die sich steigernde Wut Mikolkas, doch ist die dort vorgestellte Szene, in der das Pferd zu Tode geprügelt wird, sehr ausführlich und wirklich brutal gestaltet. Hier nun ist alles verdichtet auf den Mord als solchen, die Handlung ist konzentriert, und dies scheint mit der Abnahme der Geräuschkulisse zu korrespondieren (vgl. auch Reber 1981, 194). Raskol'nikovs Experiment ist gescheitert, alle seine vorherigen Berechnungen brechen in sich zusammen. Er ist nicht der Herr der Geschichte, kein Napoleonischer Typus, unfähig, den Kairos zu ergreifen und im letzten Moment das Gute zu tun. Ja, der Kairos ist nur auf das Gute bezogen und nur durch Selbstverleugnung zu ergreifen. Für seine eigentlichen, niederen Beweggründe wird Raskol'nikov deshalb jetzt vom Opfer seiner Tat ausgelacht. ${ }^{17}$

Diese karnevaleske Szene mit ihrer verkehrten Welt (vgl. Bachtin 1971, 190f.) ist nun der Ausgangspunkt, die Welt wieder auf die Beine zu stellen. Sie ist der Ausgangspunkt der Wirklichkeitserkenntnis und der Selbsterkenntnis Raskol'nikovs, und der Ausgang des Traums ist schon ein erster Schritt zur Heilung hin, denn er enthält einen Topos des Traums, nämlich vor einer Situation nicht weglaufen zu können: „Он бросился бежать, но вся прихожая уже полна людей, двери на лестнице отворены настежь, и на площадке, на лестнице и туда вниз - всё люди, голова с головой, все смотрят, - но все притаились и ждут, молчат ... Сердце его стеснилось, ноги не движутся, приросли ... Он хотел вскрикнуть и - проснулся" (PSS 6, 213). Die Menge lacht Raskol'nikov nicht aus, das hatte schon das Opfer selbst getan. Doch nun ist seine Tat offenkundig geworden, und das Schauen und Schweigen der Menge ist vielleicht noch grausamer als das Lachen zuvor. ${ }^{18}$ Hatte der erste Traum die Grausamkeit nackter Gewalt thematisiert, so ist diese im zweiten verschleiert worden und tritt nun wieder, im dritten Traum, deutlich hervor. Der Schritt zur Selbsterkenntnis und zur Heilung Raskol'nikovs ist nun getan und die Perspektive geöffnet für die „richterliche und schöpferische Menschenerkenntnis", die Thema der nun einsetzenden Sonja- und Porfirij-Gespräche sein wird.

Da wir nun die Romanhandlung für lange Zeit verlassen, sei noch auf eine intertextuelle Parallele zu Raskol'nikovs Napoleon-Experiment hingewiesen, nämlich auf die Figur des Hermann in Puškins Pikovaja Dama. Hermann träumte insgeheim davon, ,жертвовать необходимым в надежде приобрести излишнее “19, und in seiner Geisteshaltung steht er derjenigen Raskol'nikovs nicht fern. Bachtin (1971, 190f.) hat in diesem Zusammenhang auf die ähnliche Motivation beider Gestalten hingewiesen: auf den Wahnsinn Hermanns und auf den Fiebertraum Raskol'nikovs. Doch ist gerade diese scheinbar nahe nebeneinanderliegende Motivation in Wirklichkeit dasjenige Element, das beide Figuren am deutlichsten voneinander scheidet. Denn bei Puškin ist der Wahnsinn seines Helden zugleich dessen Ende, bei Dostoevskij ist der Fiebertraum Ausgangspunkt und Remedium auf dem Weg zum Menschen. 


\section{„Diese Menschen hatte zuvor niemand erkannt" (Vierter Traum)}

Raskol'nikov geht seinen Weg als verurteilter Mörder im sibirischen Zuchthaus. Während die richterliche Menschenerkenntnis mit Strafprozeß und Vollstreckung der Strafe abgeschlossen ist, vollzieht sich die schöpferische Menschenerkenntnis in immer tieferer Weise, denn Sonja ist Raskol'nikov gefolgt und kümmert sich um den Gefangenen, besucht ihn, insbesondere auch während seiner Krankheit, die sich über die ganze Fastenzeit und die erste Osterwoche erstreckt. In diese Zeit fallen fiebrige Träume, derer er sich nicht mehr im Einzelnen erinnert; Dostoevskij entwirft hier ein apokalyptisches Panorama, in dem sich einzelne Traumeindrücke zu einem Gesamtbild ordnen und verdichten: „Он припомнил свои сны“ (PSS 6, 419). Hier ist der Traum also nicht mehr als Teil der Handlung explizit oder implizit in den Roman verwoben, sondern als symbolisch-philosophische Reflexion eingefügt.

Die Weltuntergangsvision Raskol'nikovs spricht von einer Seuche, die von bisher nicht dagewesenen Trichinen ausgelöst wird, jedoch nicht den körperlichen Verfall zur Folge hat, sondern zunächst eine geistige Verseuchung: „Но эти существа были духи; одаренные умом и волей“ (PSS 6, 419). ${ }^{20}$ Infolge dieser Trichinenepidemie verbreitet sich unter den Menschen rasender Wahnsinn, der auf dem Irrglauben an die eigenen Klugheit und den Alleinbesitz der Wahrheit basiert. Daraus entspringen gesellschaftlich-moralische Zwietracht, Verlust der Unterscheidung zwischen Gut und Böse und damit das desorganisierte Erlahmen des täglichen Lebens, gesteigert in gegenseitigen Haß, Mord und Totschlag. Ja, man kann sagen, Dostoevskij spricht hier nicht nur vom Widerstreiten einzelner Gruppen und Glaubensüberzeugungen, nicht von einem Kampf der Kulturen (so könnte man zunächst annehmen, da die genannten Trichinen ihren Weg aus Asien nach Europa genommen haben), sondern von einem das Gemeinschaftsleben vollständig zersetzenden Individualismus. Anklänge an das Neue Testament sind hier unübersehbar, vor allem an Mt 24, 23f., wo vom Auftreten der Pseudomessiasse und der Pseudopropheten die Rede ist, aber auch, in der gesamten Diktion und in den Motiven von Zwietracht und Verfall, an die Apokalypse, ${ }^{21}$ wenngleich nicht unter Verwendung direkter Zitate. ${ }^{22}$ Dostoevskij erreicht so eine raumzeitlich maximale Ausdehung: Zeit und Raum des Geschehens sind „die Welt“, die Handelnden: „die Menschen“. Raskol'nikov steht dieser Szenerie als unbeteiligter Beobachter gegenüber. Aber es gibt eine Rettung: Die Begründung eines neuen Menschengeschlechtes durch diejenigen Auserwählten, die nicht von den Trichinen befallen worden sind, und das sind Menschen, die für solcher Art zerstörerischen Individualismus oder exentrischen Egoismus keine Disposition besitzen: „[. . . это были чистые и избранные, [...] но никто и нигде не видал этих людей; никто не слыхал их слова и голоса“" (PSS 6, 420).

$\mathrm{Zu}$ diesen Stillen und Unbemerkten gehört zweifellos Sonja, die Raskol'nikov einst in einem seiner barmherzigen Momente, die doch sein wahres Wesen offenbarten, das gleichwohl immer wieder von ihm niedergehalten worden war in seinen 
Napoleonischen Wahnvorstellungen, für immer gewonnen hat. Jetzt erst wird er sich seiner Liebe bewußt, und es ist bemerkenswert, wie Dostoevskij hier noch einmal auf das semantische Gefüge der Träume zurückgreift, indem er von der überpersönlichen und überzeitlichen Schreckensvision der Apokalypse wieder hinführt zu Raskol'nikovs persönlicher Apokalypse und diesen Moment nun umdeutet zu seiner persönlichen Rettung. Wir erinnern uns: Als sich Raskol'nikov dem Rätsel des Mondes stellen mußte, in absoluter Stille, da schlug ihm das Herz so sehr, daß es schmerzte. Dies wiederholt sich nun, nachdem er sich voller Unruhe nach Sonjas Gesundheit erkundigt hat und zur Antwort einen Zettel erhält, der ihren baldigen Besuch ankündigt: „Когда он читал эту записку, сердце его сильно и больно билось“" (PSS 6, 420). Damit ist er an die Achse des Romans zurückgekehrt, nun kann er den Kairos ergreifen, eine ganz unbekannte Wirklichkeit, die er dennoch von Kindheit an in seinem Herzen verborgen hatte.

\section{Zusammenschau}

Die vier großen Traumdartstellungen Raskol'nikovs bilden nicht nur einen wesentlichen Bestandteil des kompositiorischen Grundgerüstes des Romans, sondern sie bilden isoliert auch ein eigenes Koordinatensystem, ja, ein philosophisches Paradigma: 


\begin{tabular}{|c|c|c|c|c|}
\hline & 1. Traum & 2. Traum & 3. Traum & 4.Traum \\
\hline $\begin{array}{l}\text { Relation zur } \\
\text { Handlung }\end{array}$ & $\begin{array}{l}\text { vorzeitig } \\
\text { (Kindheit) }\end{array}$ & gleichzeitig & $\begin{array}{l}\text { parallel und } \\
\text { nachzeitig }\end{array}$ & (Reflexion) \\
\hline Situation & realistisch & realistisch & $\begin{array}{l}\text { realistisch und } \\
\text { phantastisch }\end{array}$ & abstrakt \\
\hline Realisation & Erinnerung & Akustik & $\begin{array}{l}\text { phantastisches } \\
\text { Nacherleben }\end{array}$ & $\begin{array}{l}\text { Prophetie } \\
\text { (Symbolik) }\end{array}$ \\
\hline $\begin{array}{l}\text { Literarisie- } \\
\text { rung }\end{array}$ & Autobiographie & intratextuell & $\begin{array}{c}\text { intratextuell / } \\
\text { intertextuell } \\
\text { (Puškin) }\end{array}$ & $\begin{array}{l}\text { intertextuell } \\
\text { (Bibel) }\end{array}$ \\
\hline$\underset{\text { Text }}{\text { Einfügung im }}$ & explizit & $\begin{array}{l}\text { fortlaufend } \\
\text { (Bewußtlosig- } \\
\text { keit) }\end{array}$ & $\begin{array}{l}\text { fortlaufend } \\
\text { (Bewußtlosig- } \\
\text { keit) }\end{array}$ & $\begin{array}{c}\text { explizit } \\
\text { (nachträglich) }\end{array}$ \\
\hline $\begin{array}{l}\text { Geräuschkulis- } \\
\text { se }\end{array}$ & Lärm / Lachen & Lärm & Stille / Lachen & - \\
\hline $\begin{array}{c}\text { Beteiligung } \\
\text { Raskol'nikovs }\end{array}$ & $\begin{array}{c}\text { passiv } \\
\text { (Zuschauer) }\end{array}$ & passiv (Zuhörer) & aktiv & unbeteiligt \\
\hline $\begin{array}{c}\text { Emotionen } \\
\text { Raskol'nikovs }\end{array}$ & Mitleid & Angst & Wut & Qual \\
\hline $\begin{array}{l}\text { psychologi- } \\
\text { sche } \\
\text { Kategorien }\end{array}$ & $\begin{array}{l}\text { Über-Ich / } \\
\text { Triebe }\end{array}$ & Verdrängung & $\begin{array}{l}\text { Über-Ich / } \\
\text { Bewußtes }\end{array}$ & (Apokalypse) \\
\hline $\begin{array}{l}\text { moralische } \\
\text { Kategorien }\end{array}$ & Verbrechen & Strafe & Schuld & Mahnung \\
\hline \multirow[t]{2}{*}{ Hauptthemen } & I & II & III & IV \\
\hline & \multicolumn{2}{|c|}{ „Der erniedrigte Mensch“ } & \multicolumn{2}{|c|}{$\begin{array}{c}\text { „Frage der } \\
\text { Selbstbehauptung“، }\end{array}$} \\
\hline
\end{tabular}

Ein Blick auf die Horizontale erlaubt Rückschlüsse auf die Entwicklung Raskol'nikovs, die wiederum den vier Haupthemen nach Neuhäuser (s.o.) und gruppierend zwei der drei Leitlinien Doernes ${ }^{23}$, nämlich „dem Modell des erniedrigten Menschen“ und „der Frage der Selbstbehauptung“, zugeordnet werden kann.

Auf einer Ebene befinden sich die beiden ersten Träume, denn sie umrahmen den Mord und variieren zwei seiner Aspekte, nämlich Grausamkeit und verbrecherische Agression auf der einen, Angst vor der zu erwartenden Strafe auf der 
anderen Seite. Sie enthalten keine phantastischen Elemente, und Raskol'nikov ist in ihnen nur passiver Zuschauer bzw. Zuhörer, worin zu erkennen ist, daß die mahnende Stimme des Gewissens Hand in Hand einhergeht mit dem nach der Tat einsetzenden Verdrängungsprozeß. Beide Träume sind vor dem Hintergrund einer lauten Geräuschkulisse modelliert, denen starke Emotionen oder Triebausbrüche zugrunde liegen.

Zwischen dem zweiten und dem dritten Traum vollzieht sich der Übergang von Lärm zu vollkommener Stille, und es ist genau diese Schnittstelle, welche die erstmalige deutliche Einführung des Napoleonthemas markiert, das im ersten Porfirijgespräch anklingt. An dieser Schwelle von Verdrängung und Bewußtwerdung schlägt die Angst in Wut um, der Lärm in Stille, die Passivität in Aktivität.

Dieser ideologischen Überhöhung entspringt die in den beiden letzten Träumen wirksame „Frage der Selbstbehauptung“, das Thema der Autonomie des Individuums. Mit dieser gestiegenen Abstraktionshöhe mischen sich nun phantastische, die Realistät verfremdende Elemente in die Träume, also etwa das Lachen der Wucherin, die trotz größter Kraftanwendung nicht erschlagen werden kann, oder die apokalyptische Szenerie im Epilog.

Im dritten Traum kommt es zudem zu einem äußersten antinomischen Spannungsaufbau zwischen der Stille und der aktiven Beteiligung Raskol'nikovs, der seine Tat wiederholt. Im vierten Traum hinwiederum wird die Apokalypse zur psychologischen Kategorie, mir Hilfe derer der Autor die autonome Stimme des Protagonisten zurückdrängt ${ }^{24}$ und das polyphone Gefüge des Romans davor bewahrt, zu einer babylonischen Kakophonie auszuarten. Die Lösung und Loslösung ${ }^{25}$ von seiner Ideologie, von seiner egozentrischen Hybris, gelingt Raskol'nikov eben nicht auf dem Wege einer neuen Theorie, sondern nur in der Zurkenntnisnahme prophetisch dargebotener, eschatologischer Wahrheit und in der Hinwendung zu einem Du. In der Qual, die ihm diese apokalyptischen Träume hinterlassen, gelangt er wieder zu einer Verbindung mit dem kindlichen Mitleid, das er im ersten Traum empfunden hat. Noch ist er nicht geheilt, aber der Weg dorthin scheint, wenn auch offen, so doch gebahnt.

\section{Anmerkungen}

\footnotetext{
1 Erstmals erschienen ab Januar 1866 in der von M. N. Katkov herausgegebenen Zeitschrift Русский Вестник (vgl. PSS 7, 323). Von Nekrasovs Современник war der Roman zuvor abgelehnt worden (Braun 1976, 117). Erstmalig als zweibändige Buchausgabe erschien der Roman in Sankt-Peterburg 1867, zu welcher Gelegenheit Dostoevskij den ganzen Roman nochmals durchgesehen und redigiert hatte (vgl. PSS 7, 328).

2 Dies ließe sich noch theologisch ausweiten auf die alte, zentrale Frage nach dem Verhältnis von Gnade und freiem Willen.

3 Vgl. 1 Thess 5, 23: „Der Gott des Friedens heilige euch ganz und gar und bewahre euren Geist, eure Seele und euren Leib unversehrt, damit ihr ohne Tadel seid, wenn Jesus Christus, unser Herr, kommt."

${ }^{4}$ Vgl. Neuhäuser $(1979,166)$ : „In diesem Romantypus [dem polyphonen] sind die Personen nicht mehr ,Objekte' eines dominierenden Autorbewußtseins, sondern autonome Bewußtseinsobjekte, die dem Autorbewußtsein als von ihm unabhängige, fremde gegenüberstehen."
} 
${ }^{5}$ Diese Vorstellung von seinem Roman hatte Dostoevskij Mitte 1865: Буданова, Фридлендер (1994, 32); vgl. auch PSS 7, 309: „[Роман будет связан] с теперешним вопросом о пьянстве. Разбирается не только вопрос, но представляются и все его разветвления, преимущественно картины семейств, воспитание детей в этой обстановке и проч. и проч."

6 In einem Brief an A. E. Vrangel' vom 18. Februar 1866; s. Буданова, Фридлендер (1994, 45); vgl. auch PSS 7, 309, Neuhäuser (1979, 169).

7 Hier und im folgenden: Teil III des Romans, Abschnitt 5.

8 Für die Entstehung der Fabel ist interessant zu bemerken, daß am 30. September 1865 in der Zeitung Голос (Nr. 270) ein ausführlicher Bericht über den Mord an dem Pfandleiher Bek und dessen Köchin, verübt durch den neunzehnjährigen Fürsten Mikeladze, erschienen ist. Der Mord geschah nach Aussage des Täters wegen einer Beleidigung, die er durch Bek erfahren hatte, und wegen der Grobschlächtigkeit von dessen Köchin (s. Буданова, Фридлендер 1994, 42). Ein ähnlicher Fall ereignete sich bemerkenswerterweise am 12. Januar 1866, als der Student A. M. Danilov in Moskau den Pfandleiher Popov und dessen Hausangestellte umbrachte (s. Буданова, Фридлендер 1994, 51). Zu diesem Zeitpunkt befand sich der erste Teil des Romans mit der Schilderung des Verbrechens bereits im Druck, und als im Februar im Verlauf des Strafprozesses die Ähnlichkeit mit der Dostoevskijschen Schilderung sogar in einer Reihe von Einzelheiten deutlich wurde, verblüffte dies auch den Dichter. Später hat Dostoevskij diesen Fall dann wieder zur Verteidigung seiner Realismuskonzeption gegenüber Vorwürfen des Idealismus und der Fantastik herangezogen: „А мы в нашим идеализмом пропочили даже факты. Случилось." (Буданова, Фридлендер $(1994,55))$.

9 Neben dem Traum Svidrigajlovs (VI, 6; vgl. PSS 6, 391f.) ist auch der sogenannte „Oasentraum" Raskol'nikovs, den man eher als retardierendes Moment auffassen kann, hier außer Acht gelassen, da er kompositorisch nicht stark ins Gewicht fällt.

${ }^{10}$ Es wäre eine interessante, hier nicht weiter zu verfolgende Frage, inwieweit die Beteiligung Sonjas und Porfirijs auf einer gleichwertigen Ebene angesiedelt ist oder ob sich der Dichter doch zugunsten Sonjas entscheidet, weil sie auf ihre Weise den letzten Grund der Persönlichkeit Raskol'nikovs besser zu erreichen vermag. Unter dem Gesichtspunkt sprechender Namen ist steht sie jedenfalls dem traumhaften Erkenntnisprozeß Raskol'nikovs näher.

11 Bachtin $(1971,168 f$.) hat diese Stelle in Сон смешного человека näher analysiert. Dostoevskij spricht dort ausdrücklich von der Aufhebung von Raum und Zeit und der Gesetze der Vernunft.

12 Vgl. hier das oben Gesagte bzgl. der Autonomie der Romanfiguren vom Autorenbewußtsein im polyphonen Roman.

13 Dostoevskij verarbeitete hier eine persönliche Kindheitserinnerung, wie aus seinen vorbereitenden Notizen zu ersehen ist: „Как одна загнанная лошадь, которую я видел в детстве“ (PSS 7, 368, Anm. zu S. 46).

14 Eine hierüber hinausgehende Deutung der Traumsymbolik im Sinne der Tiefenpsychologie vermeide ich ausdrücklich. Wohin dies im Extremfall führen kann, sieht man, bei allem Respekt, in dem Aufsatz von Lower (1969): „Analysis of Raskol'nikovs dreams reveals the murder of the old woman to be the defensive acting out of an unconcious sado-masochistic oedipal fantasy. In the murder he identified with the castrating father in order to avoid his anxiety in identifying with the passive, castrated mother, and with the axe he actively attempted to destroy the projected passive-feminine paft of himself. The effort failed, because, in addition, the woman unconciously represented his dead father, and the resulting guilt forced him back into a vicious guilty-shame-cycle." In tiefenspsychologischer Hinsicht ist Kaus (1926) schon viel weiter und differenzierter.

15 Vgl. Phil 2, 6-11.

16 Reber (1981, 192), weist auf die Aufspaltung des Ichs Raskol'nikovs hin, auch im Zusammenhang mit der Namenssymbolik; s. hierzu auch Lehrmann (1977, 107).

17 Das Gute ist nach der mittelalterlichen Philosophie das Wirklichkeitsgerechte. S. hierzu: Pieper, J.: 1934, Die Wirklichkeit und das Gute, München.

18 Bachtin 1971, 190f. hat hier sehr anschaulich auf eine Parallele hingewiesen: das Verlachen des Karnevalskönigs, das sich hier vor allem aus den räumlichen Verhältnissen heraus ergibt, 
denn Raskol'nikov befindet sich ja oben auf der Treppe. Auch auf die Parallelität dieser Szene zur späteren öffentlichen Beichte Raskol'nikovs weist er hin.

19 Zit. Nach Alexander Puschkin: Pique Dame. Übersetzung und Nachwort von Kay Borowsky. Stuttgart 1971, S. 30.

20 Vgl. PSS 7, 399, Anm. z. S. 419. Über solche Trichinen handelten Zeitungsberichte in den Jahren $1865 / 66$.

21 Es ist interessant zu bemerken, welche Begriffe Dostoevskij mit der Apokalypse verband. So schrieb er in sein Neues Testament an den Rand von Offb 13, 11: „социал[изм]“ und von Offb 17, 9: „цивилизации“ (vgl. Kjetsaa 1984, 74, 77; Reber 1981, 196). Dostoevskij selbst hatte sich in Sibirien gewandelt. „Wohl träumte er noch immer von einer sozialen Erneuerung, doch Revolution, Sozialismus und Materialismus, die er [...] dem verderblichen Einfluß Westeuropas zuschrieb, lehnte er ab" (Neuhäuser 1976, 163).

22 Vgl. PSS 7, 399; Reber (1981, 196).

23 Doerne 1962, 10. Die erste Leitlinie bildet die „dichterische Menschenschau“, ein Oberbegriff, der dem Problem der Psychologie Dostoevskijs insgesamt zuzuordnen wäre und der Integration der Traumdarstellungen in sein sprachkünstlerisches Konzept zugrundeliegt.

24 Vgl. Braun $(1976,145)$.

25 Braun $(1976,144)$ ist der Meinung, Raskol'nikovs Theorie bleibe im Roman unwiderlegt. Sicherlich ist dies so auf der expliziten Ebene, doch hat er gerade die Träume nicht in seine Interpretation miteinbezogen, was ihn offenbar zu dieser Auffassung geführt hat.

\section{Literatur}

\section{Textausgaben}

$\mathrm{PSS}=$ Ф.М. Достоевский. Полное собрание сочинений в тридиати томах. Выд.

В. Г. Базановым и др., Ленинград 1972 и след.

Том 6: Преступление и наказание, Ленинград 1973.

Том 7: Преступление и наказание. Рукописные редакции, Ленинград 1973.

Том 27: Дневник писателя 1881. Автобиографическое. Дубия, Ленинград 1984.

\section{Forschungsliteratur}

Bachtin, M.: 1971, Probleme der Poetik Dostoevskijs, München.

Braun, M.: 1976, Dostojewskij. Das Gesamtwerk als Einheit und Vielfalt, Göttingen.

Буданова, Н. Ф., Фридлендер, Г. М. (Ред.): 1994, Летописъ жизни и творчества Ф. М. Достоевского. Том второй: 1865-1874, Санкт-Петербург.

Doerne, M.: 1962, Gott und Mensch in Dostojewskijs Werk, Göttingen.

Гедройц, А.: 1981, ,Сон и бред у Достоевского', Записки русской академии ческой группы в США 14, 214-230.

Jackson, R. L.: 1981, The Art of Dostoevsky: Deliriums and Nocturnes, Princeton/New Jersey.

Kaus, O.: 1926, Die Träume in Dostojewskys „Raskolnikoff“, München.

Kjetsaa, G.: 1984, Dostoevsky and His New Testament, Oslo, New Jersey.

Lehrmann, E. H.: 1977, A „Handbook“ to the Russian Text of Crime and Punishment, Mouton. 
Lower, R. B.: 1969, ,On Raskol'nikovs Dreams in Dostoevsky's Crime and Punishment', Journal of the American Psychoanalytic Association 17.

Mortimer, R.: 1956, ,Dostoevsky and the Dream', Modern Philology 54, 106-116.

Neuhäuser, R.: 1979, ,Fjodor Dostojewskij. Schuld und Sühne', Zelinsky, B. (Hg.), Der Russische Roman, Düsseldorf, 161-187.

Onasch, K.: 1976, Der verschwiegene Christus, Berlin (Ost).

Pachmuss, T.: 1960, ,The Technique of Dream-Logic in the Works of Dostoevskij', The Slavonic and East European Journal, New Series, Vol. IV (XVIII), 3, 220-242.

Reber, N.: 1981, ,Die Tiefenstruktur des Traumes in Dostoevskijs Werk und ihre Bedeutung für den Bewußtwerdungsprozeß des Menschen', Rothe, H. (Hg.), Dostoevskij und die Literatur, Köln, Wien, 188-204.

Shaw, J. T.: 1973, ,Raskol'nikov's Dreams', Slavic and East European Journal 17, Nr. 2, 131-145. 



\section{Eine Begegnung an der Ostsee}

Milan Begović (1876-1948) gehört zu den wichtigsten Vertretern der kroatischen Moderne der neunziger Jahre. Er stellte sich dem Leser zuerst als Neuerer im Bereich der Lyrik vor, wurde aber bald durch seine Theaterstücke bekannt, und in den 20-er Jahren offenbarte sich sein Ästhetizismus auch in Erzählungen. Leider war sein großer Roman Giga Barićeva als Buch erst seit 1940 zugänglich und wurde durch zwei gegensätzliche namenhafte Autoren an die Peripherie der Literaturgeschichte verdrängt: Mile Budak und Miroslav Krleža waren Ideologen, Begović war es nicht. Im Grunde genommen, blieb er dem Ästhetizismus der Moderne an der Jahrhundertwende treu.

Die lyrische Dichtung des 19. Jahrhunderts blieb im allgemeinen von der nationalen Funktion der Literatur abhängig. Der Aufbruch des Spätromantikers Silvije Strahimir Kranjčević zu Fragen des europäischen Umsturzes, ja zum Weltall stand am Anfang der kroatischen Moderne, aber ihm konnten die Poeten des „jungen“ Ästhetizismus nicht folgen: die Kluft zwischen der Heimat und dem Kosmos war zu groß. Begović wollte keine philosophischen Fragen stellen, keine 
„Ideale“ wie Kranjčevićs Moses „in Zweifel ziehen“. Er kam aus dem dalmatinischen Hinterland, das der oralen Epik bis heute treu geblieben ist und sich immer wieder an den Quellen der štokavischen Mundart der Karstregion nähren kann. Aber Begović verließ bald das Heimatliche zugunsten des Allgemeineuropäischen. Erst in späteren Prosawerken und besonders in dem Libretto zu der Oper Ero s onoga svijeta (Musik: Jakov Gotovac, 1935) konnte man seine Ursprünge erkennen.

Nach dem Schulbesuch in Split, einer Stadt, die unter der österreichischen Verwaltung Dalmatiens durch die Bevorzugung der italienischen Sprache und Kultur geprägt war, weilte Begović später in Wien, wo er Romanistik und Slavistik studierte. Seit 1894 veröffentlichte er Theaterstücke, die meistens, besonders die 1903-1920 geschriebenen Male komedije, unter dem Einfluß der Wiener Moderne entstanden waren (Batušić 2001, 253-261), aber in seiner lyrischen Dichtung lehnt er sich meistens an italienische und französische Vorbilder an. Das Theater wählte Begović zu seinem Beruf: Seit 1910 arbeitete er am Hamburger Deutschen Schauspielhaus und seit 1912 an der Neuen Wiener Bühne. Damit erklärt sich seine Bindung an die deutsche Literatur und Kultur. Demnach wurde Begović zu einem wahren Europäer der kroatischcen Wort- und Theaterkunst.

In der früheren Phase seiner Dichtung gehörte Begović zu den Autoren, die „literarische Gegenwelten“ (Književni protusvjetovi ist der Titel eines Buches zur Geschichte der kroatischen Moderne, s. Batušić, Kravar, Žmegač 2001) der sozialen und nationalen Gegenwart entgegenstellten. Das wichtigste Buch Begovićs war damals Knjiga Boccadoro (1900), im Grunde genommen eine ,intertextuelle Übertragung der Vergangenheit in die Gegenwart", die dem ,formellen Inventar der altitalienischen Dichtung" folgte und auch die lyrischen Gattungen der romanischen Dichtung übernahm (Batušić, Kravar, Žmegač, 2001, 157, 202).

Das Buch Boccadoro besteht aus mehreren Gedichtzyklen. Der Zyklus Soneti godišnjih doba ist nach den Jahreszeiten gegliedert und folgt somit den Schemata musikalischer Kompositionen (Vivaldi, Haydn) oder der bildenden Kunst des französischen Barock und Klassizismus (Poussin, Maillol). Idilički intermezzo zeigt verschiedene Gattungen der galanten Dichtung (Pastourelle, Romanca, Ballata), und in Muzika versucht Begović die Maler (fra Beato Angelico, Carlo Dolce, Rafael d'Urbino) mit der Musik zu verbinden und ihre Bilder mit der Wortkunst zu verknüpfen (vgl. Flaker 1995, 18-26). Das Prinzip der Zyklisierung entspricht einem Canzoniere, und Begović darf sich selbst auf die Tradition der kroatischen Renaissance, besonders auf Hanibal Lucić (vgl. Begović 2002, 357), berufen. Wir wissen: Petrarca wirkte ja nicht nur während der kroatischen Renaissance, sondern wurde auch von den kroatischen Romantikern (Vraz) als Vorbild betrachtet. Begović entfernt sich von dem petrarkistischen Kanon, kostümiert das lyrische Subjekt als Xerex de la Maraja, einen spanischen Ritter, und zu seiner Geliebten wählt er eine Marquise: Zoé Boccadoro. Das bekannteste Gedicht der Sammlung wird seit 1933 als Menuet Boccherini betitelt und weist deutlich auf die Epoche des Rokoko hin. Dabei versteht Begović sich selbst als einen Dichter des befreiten Eros: Manches, so behauptet er, sei „ein absichtlicher Protest gegen die Prüderie, die 
Hypokrisie und den Zelotismus der damaligen offiziellen Kritik und der Bewahrer der spießbürgerlichen Moral" (Begović 2002, 357).

Das Gedicht Liddy ist nicht zyklisiert; durch den Titel Les Passagères bildet es zwar ein Diptychon, aber die beiden Gedichte sind stilistisch kaum verwandt. Der Titel weist zwar auf das Motiv der vorübergehenden Begegnungen zweier Frauengestalten, aber während der erste Text nicht nur eine flüchtige, sondern seitens des lyrischen Subjekts eine fluchtartige Begegnung Evas - der Verführerin - aufweist, so ist die Begegnung Liddys melodramatisch und nostalgisch geprägt. Liddy ist datiert, und der locus des Treffens wird genannt. Eva ist fast völlig im Bereich des Seelischen situiert und versucht, den Liebesdrang, polnisch chuć bei Przybyszewski (vgl. zum Verhältnis Begović-Przybyszewski auch Kornhauser 1978, 59), durch ekstatische Bewegungen der passagère wiederzugeben, aber die Szenerie der (seelischen) Begegnung spielt sich doch in einem gotischen Kirchenraum ab und weist somit auch auf den norddeutschen Raum des Geschehens hin.

Liddy bildet eine semantische und stilistische Opposition zu Eva. Eva ist ein biblischer Name, Liddy gehört zur modernen Zivilisation. Eva ist abstrakt, Liddy konkret. Das ganze Gedicht umrahmt die Abschiedszene am Bahnhof Travemünde, und es bietet eine nostalgische Erinnerung an drei am Strand verbrachte Tage. Der Bahnhof als Ort der Begegnungen wird um 1911 zum Topos der lyrischen Dichtung:

Вокзал, несгораемый ящик

Разлук моих, встреч и разлук $/ \ldots$ /

(Pasternak 1985, 1, 34)

So evoziert nach seiner Marburger Episode der russische Dichter die Bahnhofsituationen. Und eben 1911 finden wir in Heyms Zyklus Berlin die Szenerie der Berliner Bahnhöfe im Kontrast zur suburbanen Idylle. Hinweise auf andere Beispiele der „Eisenbahndichtung“" vgl. bei Flaker (1984, 219-234; 1999, 77-78).

Laut Rapacka (2001) erlaubt die Eisenbahnmotivik zwei Deutungen: die erste ist katastrophisch; die zweite „besteht aus bittersüßen Gefühlen der Vergänglichkeit und Zufälligkeit der Liebesbegegnung und Nostalgie nach den entfernten Welten" und wird „populär" in der Trivialliteratur und im Film der 30-er Jahre. In diesem Kontext erwähnt die polnische Forscherin auch Begović (10-11).

Im Rahmen der urbanen Zivilisation wird auch die Mädchenfigur geschildert. Die Szenerie des mondänen Badeortes, Eleganz und Koketterie (wobei das französische pleurese die Traurigkeit der dekorativen Weiden betont) wird vom lyrischen Subjekt mißachtet, und da erscheint Liddy, völlig mit der Natur durch Vergleiche verbunden, wobei „račić morski“ einen zarten, fast durchsichtigen Leib einer Garnele (kroat. kozica) vor unsere Augen bringt. Die Begegnung geschah ja an einer Sandbank (im Orig. pržina), und die goldene Farbe beherrscht das ganze Bild. Erst bei der Wiedererscheinung Liddys kommen andere Farben in Sicht: dem ,roten Kostüm“ korrespondieren jetzt „zwei schwarze Augen“, die mit „,schwarzen Sonnen“ verglichen werden. Begović, der uns in seiner Boccadoro-Lyrik nicht den Reichtum 
seiner Ikonizität ersparen will, wird lakonisch, skizzenhaft und - theatralisch. Er nähert sich Munch an.

Im Dialog mit Liddy beantwortet der Anonyme die Fragen des neugierigen Kindes. Das lyrische Subjekt stellt sich als einen Abenteurer (pustolov), einen „Glücksjäger" auf der ständigen Suche „nach einem Land“ (jedan kraj, Mignon wird zitiert!) vor und führt seine Partnerin in eine symbolische Seelenlandschaft, die der Bezeichnung rasipnik - luda-pijanac eine mystische Vertikale verleiht. Die Selbststilisierung als Bohémien (vgl. ,Strolch“ in der ersten deutschen Übersetzung!) und Abenteurer entfaltet sich später in dem Theaterstück Pustolov pred vratima (Abenteurer vor dem Tor, 1926) in einer inversiven Situation - den Träumen eines sterbenden Mädchens, das die Realisierung des Unbekannten erwartet. Das Stück entsprach den Erwartungen: man wies auf Freud, die Ikone des Surrealismus hin. Wenn wir aber zu Liddy zurückkehren, so weisen wir auf einen Text des Kunsthistorikers Zidić (2000) hin, der besonders die Prager Arbeiten (1908-1922) des Sezessionisten Vlaho Bukovac hervorgehoben hat: Zidić bezeichnet die Vorliebe des Malers für helle und manchmal pointilistische Mädchenakte als „Lolitismus“. Diesen Begriff können wir auch auf das in derselben Zeit entstandene Gedicht von Begović anwenden, mit der Anmerkung, daß wir diese Neigung auch anderswo in der Malerei und der Literatur der Sezession finden können. Wenn wir aber, dem Beispiel Zidićs folgend, auf den großen Erfolg des Films Kurze Begegnung (David Lean, 1945) hinweisen, wo sich die hoffnungslos Liebenden an einem Bahnhof begegnen, so tun wir das nur, um die Modernität des Gedichtes zu bekräftigen. Den Erfolg Leans kann man nämlich in einer Situation verstehen, wo das Publikum am Kriegsende von der Kunst auch das Ewige im Trivium des Alltages erleben wollte. Ja, Begović hat in diesem Gedicht body and pressure of time gut verstanden. In der Lyrik war es seine einmalige Leistung: Liddy wurde in fast alle Anthologien der kroatischen Lyrik aufgenommen und überlebte auch die schwersten Zeiten.

\section{Unverbindlicher Epilog}

In dem neuesten Roman des auch in Deutschland bekannten kroatischen Prosaautors Zoran Ferić, in dem ein Gymnasiallehrer die Geschichte seiner Liebe zu einer 17-jährigen Schülerin erzählt, wird in einer kurzen Vorgeschichte auch über eine andere Reise berichtet:

Sie hat mir alles erzählt. Wie die beiden vor seinem Selbstmord den Sommer in Lübeck verbracht haben /.../ Jeden Tag gingen sie nach Travemünde baden und spazierten später am linken Ufer der Bucht /.../ (Ferić, 2005, 170)

Travemünde wird hier als ein vom Meer bedrohter verhängnisvoller Ort evoziert, der einem Selbstmord vorausgeht, erscheint aber im Kontext einer Liebesgeschichte mit einer Teenagerin. Der Autor unterrichtet kroatische Literatur am Gymnasium... 


\section{Literatur}

Begović, M.: 2002, Pjesme I. Hrsg. und Anmerkungen V. Flaker, Zagreb.

Batušić, N., Kravar, Z., Žmegač, V.: 2001, Književni protusvjetovi, Zagreb.

Ferić, Z.: 2005, Djeca Patrasa, Zagreb.

Flaker, A.: 1984, Poetika osporavanja, Zagreb.

Flaker, A.: 1995, Riječ, slika, grad, Zagreb.

Flaker, A.: 1999, Književne vedute, Zagreb.

Kornhauser, J.: 1978, Od mitu do konkretu, Kraków.

Rapaska, J.: 2001, ,Željeznica, kolodvor, vlak. Iz imaginarija hrvatske moderne ${ }^{6}$, Dani hrvatskoga kazališta. Književnost $i$ kazalište hrvatske moderne - bilanca stoljeća, Split, 5-13 (unvollendet).

Zidić, I.: 2000, ,Bukovčev „lolitizam““, Fokus, Zagreb 12.05.

Пастернак, Б. Л.: 1985, Izbrannoe v dvux tomax, Moskva.

\section{Anhang}

\section{Liddy}

\section{Von Milan Begović}

Noch zwei, drei kleine Minuten - - -

Durch's schmale Fenster des Wagens

Blick' ich zur Bahnhofspforte

Und warte. Voll Ungeduld - traurig...

Sie kommt nicht, ach nein, sie kommt nicht!

Wohl füllt des Bahnsteiges Enge

Der Badegäste Gedränge.

Doch lockt mich wenig das Bunte

Dieser fremden, wimmelnden Welt.

Mich kümmern nicht zierliche Gesten

Und nicht elegante Allüren,

Ich sehe kein Grazien-Lächeln

Und pfeif' auf kokettes Gescherze

Und such' nicht die wissenden Blicke.

Die sich verbergen im Schatten

Prunkender Luxus-Pleureusen.

Ich warte nur und ich seufze:

- Sie kommt nicht, ach nein, sie kommt nicht! - - -

Oh kleine, oh süsse Liddy!

Oh du eilig-huschlige Krabbe,

Oh kleine feinfeine Alge,

Oh Körnchen glitzernden Sandes, 
Oh du heiter duftende Seele,

Du goldenes Sonnenscheinen -

Leb wohl!

Rasch sind drei Tage vergangen,

Drei Tage unserer Liebe,

Drei Tage unseres Lebens.

Doch die Sonne von dreihundert Jahren

Kann nicht soviel Freude versammeln,

Als ich allein durfte finden

In deinem kindlichem Blick!

Es könnten, Liddy, drei Welten

Soviel an Glück nicht erblicken,

Wie ich aus der offenen Schale

Deiner kleinen Hände empfing.

Drei Tage unseres Lebens,

Drei Tage, ach, unserer Liebe

Lebt wohl!

Ich traf dich an Meere Ufer!

Goldene Sonne - und goldig

Der Sand - und auch du warst wie Gold.

- Wie heissen Sie? -

Und Sie, Monsieur? -

$$
\text { - Liddy! }
$$

- Ich habe nicht Namen, Liddy ...

Oder besser - ich hab' ihrer viele,

So viele, wie vielviele Leben

Ich erleb' auf der Jagd nach dem Glück.

Was ist das: ein Name? Das Schicksal

Macht erst den Menschen zum Menschen,

Macht erst das Leben zum Leben.

Kommt aber einst die Sekunde,

Bringend den Kampf und die Wünsche,

Bringt sie auch unseren Namen.

Und Liddy pascht in die Hände

Und jubelt in Kinderentzücken:

- Sie sind ein Strolch ohne Namen? -

Und krabbelt sich näher zu mir her,

Fest auf dem feuchtwarmen Sande,

Wie eine Krabbe.

- Doch woher sind Sie, Monsieur? -

- Ich weiss nicht. Oder besser - ich weiss,

Oh Liddy, ich komme von dorten,

Von wo auch mein Glück entstammt:

Heut' aus der Welt, aus der grossen,

Morgen aus düsterer Wüste. -

- Und ist das dem Glück einerlei?

Können wir's überall finden? - 
- Überall. Dort auf der grausen,

Treulosen Welle des Meeres,

Ebenso wie auf dem Händchen,

Deinem lieblichen Händchen.

Wahres Glück ist wie wir sind:

Hat weder Namen noch Heimat!

- Heimatlos? Habt Ihr nicht Heimat? -

Jubelt sie auf. - Oh, Ihr Strolch Ihr!. . .

Aber, wenn Ihr, so wandernd

Durch die Welt, einmal fändet

Jene, die Euch im Herzen

Die Nächste von Allen ist -

Wohin wollt Ihr sie führen? -

- Oh Liddy, oh kleine Liddy!

Dann, dann gibt es ein Land

Ausserhalb weltlicher Grenzen,

Schöner noch, schöner als jenes

Das einst sich erträumte Mignon...

Wo menschliche Wünsche schweigen,

Wo's Schmerz nicht gibt, und nicht Hoffen,

Wo alles Vergessen ist

Weitgeöffnet und gierig

Blickten auf mich ihre Augen,

Wie zwei schwarze Sonnen,

Wie zwei Wünsche!

Und wir verlebten drei Tage

In jenem verzauberten Reiche.

Um uns: Die See und die Sonne,

In uns: Das Glück und das Leben.

Jetzt aber - ach, lebe wohl, Du!

Weiter wandert der Strolch nun

Von einem Lande zum nächsten,

Strolchend, schlendernd und suchend,

Wo er sein Herz könnt zerbrechen,

Wo seine Seele zerreissen.

Ein Prasser - ein Narr - ein Berauschter...

Aber du, du wirst bleiben,

Weiter träumend am Meere,

Unter der Sonne, die niemals

Von deinem duftenden Leibe

Löschen wird können die heissen

Brandmale all meiner Küsse...

Oh Liddy!

Oh kleine, oh süsse Liddy!

Oh du eilig-huschlige Krabbe,

Oh kleine feinfeine Alge,

Oh Körnchen glitzernden Sandes,

Oh du heiter duftende Seele, 
Du goldenes Sonnenscheinen -- -

Da fliegt durch die Bahnhofspforte

Plötzlich ein rotes Kostüm,

Ein breiter Panama-Strohhut

Und unter ihm schwarze zwei Augen,

Wie zwei schwarze Sonnen,

Wie zwei sehnende Wünsche...

Sie ist es! - Sie ist es!

Stolz das Näschen gehoben

So sucht sie und schaut sie und zittert -

Und nach einem Augenblick hingen

Um meinen Hals ihre Arme,

Pressend sich fester und fester

In wildem, verzweifeltem Schmerz.

Ein Schluchzen verschlug ihr den Atem.

Da gab man das letzte Zeichen:

Schon rollten die eisernen Räder.

Und ein kleines Händchen, ein schlankes,

Das winkte zum äussersten Abschied,

Wie ein junger, gebrochener Zweig...

Niemals mehr, niemals mehr - - -

Oh Liddy! Liddy!

Adieu!

Adieu!

Adieu!

Travemünde a.d. Ostsee, Juli 1911.

Aus dem Kroatischen übertragen von P. v. P.

Die erste deutsche Übersetzung des Gedichtes wurde mit Petars v. Preradović Glückwunsch zum 50. Geburtstag des Dichters am 7. Januar 1926 in der Agramer Zeitung „Der Morgen“ (Nr. 914, S. 9-10) gedruckt. Hier ist sie ohne Korrekturen nach den Zeitungsspalten abgedruckt. 
Matthias Freise

\section{Vier Weisen, nach dem Text zu fragen}

Jahrhunderte lang haben sich die Geisteswissenschaften immer weiter ausdifferenziert. Ein ursprünglicher, anscheinend naiver Synkretismus des Fragens wurde durch eine immer engere Spezifik überwunden. Was bei dieser Erfolgsgeschichte der Wissenschaften zunächst keine Rolle spielte, war eine gleichzeitige Entfremdung zwischen den Disziplinen. Vom Anspruch her derselbe Gegenstand, löste sich dieser in immer mehr Gegenstände des Fragens auf. So kann ein und dasselbe Gedicht zum Gegenstand von Soziologie, Geschichtswissenschaft, Psychologie, Philosophie und Philologie werden. Das Ding, das doch durch die Einheit der Wahrnehmung überhaupt zustande kommt, scheint sich aufzulösen. Es ist kein Was mehr, sondern nur noch ein als was. Man könnte diesem Befund entgegnen, die sinnliche Wahrnehmung bringe doch den Gegenstand in seiner unfraglichen ,primären“ Identität zu Stande, und alle wissenschaftlichen Zugriffe, alles Verstehen als was sei dem gegenüber nur abgeleitet. Eine solche Unterscheidung zwischen primären und sekundären Qualitäten, zwischen Essenz und Akzidenzien eines Forschungsobjektes lässt sich jedoch nicht mehr aufrechterhalten, seitdem deutlich geworden 
ist, dass auch die raumzeitliche Strukturierung der Welt, ja selbst die sinnlichen Füllungen der Materialität der Gegenstände kulturelle und damit wandelbare Größen darstellen. Dies gilt um so mehr für kulturelle Gegenständlichkeiten im engeren Sinne, deren Zeichenhaftigkeit und damit Interpretationsbedürftigkeit außer Frage steht. Man vergisst aber oft, dass ein vermeintlich identischer Gegenstand z.B. des Historikers und des Philosophen, etwa die Freiheit, im strengsten nur denkbaren Sinne verschiedene Gegenständlichkeiten darstellen, zwischen denen freilich eine Beziehung hergestellt werden kann. Welcher Art eine solche Beziehung sein kann, wenn Wissenschaft eine gemeinsame Aufgabe darstellen soll, wenn also Forschungsergebnisse über das eigene Spezialistentum überhaupt von Relevanz sein soll, davon wird im folgenden die Rede sein.

Ein Ausweg aus der Entfremdung zwischen dem unterschiedlichen Verstehen als was scheint die interdisziplinäre Zusammenarbeit zu sein. Das Gedicht wird z. B. in einer ad-hoc-Kommission von Soziologen, Historikern, Philologen usw. untersucht. Dieser Weg der Interdisziplinarität ist sicherlich der derzeit gängigste, er wird z.B. von Jürgen Mittelstraß in seinem kürzlich erschienenen Büchlein ${ }^{1}$ empfohlen. Nur werden solche ad-hoc-Kommissionen, und das betont auch Mittelstraß, aus einer aktuellen Problemsituation heraus gebildet, es geht ihnen gar nicht um die Rekonstruktion oder das Verstehen des Gegenstandes, sondern es gibt eine Problemstellung, der sich die beteiligten Disziplinen unterzuordnen haben, etwa in Ethik-Kommisssionen, an denen außer Medizinern auch Theologen und Philosophen beteiligt werden. Die beteiligten Disziplinen reflektieren hier nicht über ihren spezifischen Zugang zu der Problematik, und es gibt auch keine übergeordnete Stelle, auf der eine solche Reflexion angestellt und durch die die jeweiligen Disziplinen zueinander in ein Verhältnis gesetzt würden. Dazu ist die auftraggebende Institution solcher Kommissionen überhaupt nicht in der Lage.

Nun könnte man sagen, der Gegenstand sei einfach die Summe seiner Aspekte, Wissenschaft produziere eine „spannende Vielfalt", jede Harmonisierung wissenschaftlicher Zugänge sei autoritär und marginalisiere Alternativen. Dieses Argument muss zunächst einmal ausdifferenziert werden. Zum einen kann damit die Vielfalt von Zugängen innerhalb einer Disziplin gemeint sein. Diese Zugänge stehen idealiter gegenseitig in einem Wettbewerb um das Produzieren relevanter Forschungsergebnisse. Doch was in den Naturwissenschaften selbstverständlich ist - dass nämlich der bessere Zugang die ganz offensichtlich relevanten Forschungsergebnisse produziert -, ist in den Geisteswissenschaften äußerst umstritten. In der Regel produzieren die Zugänge die Kriterien für ihre eigene Relevanz gleich mit, bis hin zu der postmodernen Botschaft, dass relevant sei, was sich auf dem Jahrmarkt der wissenschaftlichen Eitelkeiten propagandistisch durchsetzt.

Nun ist aber der Gegenstand als Summe seiner Aspekte gerade nicht wissenschaftlich verstanden, da Wissenschaft die Einordnung in Zusammenhänge fordert. Wir können zwar sagen, dann gebe es eben kein wirkliches wissenschaftliches Verstehen und wir verzichten darauf. Aber es ist auf diese Weise noch nicht einmal möglich, die verschiedenen eigenen Ergebnisse in eine Beziehung zueinander zu 
bringen. Es wäre eine petitio principii, zu sagen, das seien Erkenntnisse in Bezug auf dieses konkrete Gedicht, denn was dieses Gedicht wissenschaftlich betrachtet ist, steht ja gerade in Frage. In der Praxis wird dieses Problem meistens so gelöst, dass eine der Wissenschaften ihren Fragegesichtspunkt für leitend erklärt und damit die anderen zu ihren Hilfswissenschaften macht. Das funktioniert, solange eine Wissenschaft die Führungsrolle zu Recht beansprucht. Die dafür notwendige Hierarchie zwischen den Disziplinen gibt es jedoch nicht mehr, jeder Streit der Fakultäten wird heutzutage vermieden.

Da sich aber die Geisteswissenschaften nicht nach dem Was, sondern nach dem als Was voneinander geschieden haben, ist jede von ihnen im Grunde allzuständig, jede erklärt die Welt vollständig, jede Methode ist universal. Man ist nicht interdisziplinär, sondern transdisziplinär, und so ist nun der eigentümliche Zustand erreicht, dass alle alles machen. Die Chiffre für dieses Alles lautet „Kultur“, verstanden als die Summe aller menschlichen Lebensäußerungen. Das sieht dann so aus: es gibt eine soziologische Kulturwissenschaft, eine historische Kulturwissenschaft, eine philologische Kulturwissenschaft, eine anthropologische Kulturwissenschaft, eine psychologische Kulturwissenschaft, und die Philosophie war ja überhaupt schon immer Kulturwissenschaft. Damit sind wir nun heute so synkretistisch wie die archaischsten Archaiker, das Wort Kultur ist unser Mantra, es ist unser kollektiv dahingemurmeltes „OM“. Dieses undifferenzierte Alles über alles zwingt uns, wieder nach den Unterschieden des wissenschaftlichen Fragens zu suchen, um in Vergessenheit geratene Spezifika freizulegen. Das Ziel wäre ein systematischer Zusammenhang innerhalb einer begrenzten Zahl grundsätzlicher Fragen. Aber gibt es nicht die eine Frage, die alles erfasst? Ja, auch die Literaturwissenschaft denkt das vielleicht noch. Dabei hat sie sich, um überhaupt Wissenschaft zu werden, zu Beginn des 20. Jahrhunderts auf die nur ihr gehörenden spezifischen Phänomene besonnen, auf die Fiktionalität und Konstruktivität literarischer Texte. Inzwischen aber hat sie diese Phänomene nicht nur an literarischen Texten, sondern überall entdeckt und hält sich darum jetzt, wie die anderen Geisteswissenschaften auch, für allzuständig. Egal, ob Gedichte, Gerüche, Gartenzwerge oder Gottesdienste, alles ist inzwischen Gegenstand der Literaturwissenschaft als Kulturwissenschaft. Ihren Anspruch als Universalwissenschaft der geistigen Phänomene begründet die Literaturwissenschaft in der Semiotik. Die semiotische Lehre von der Zeichenhaftigkeit aller Phänomene scheint alle Parameter von Kultur in sich zu bergen, bis auf einen, allerdings einen ganz entscheidenden - ihre Zeitlichkeit. Die Semiotik muss von der Koexistenz der Zeichen ausgehen, um sie aufeinander beziehen zu können. Operiert sie diachron, kann sie nur den Wandel isolierter Phänomene begründen, der Wandel des Systems bleibt arbiträr und damit unverstanden.

Um dem offensichtlichen Mangel der synchronen Starre der semiotischen Beschreibung abzuhelfen, hat man versucht, Zeichen prozessual zu verstehen. So wurden die geschlossenen Zeichensysteme, die man zunächst konstruiert hatte, für die offenen Bedeutungsprozesse der Signifikantenverschiebung geöffnet. Doch die als Zeichenpraxis verstandene Semiose ist nicht zeitlich, sondern lediglich expansiv. 
Auf diese Weise wird nur beschrieben, was die allzuständigen geisteswissenschaftlichen Einzeldisziplinen gerade tun: sie überwuchern sich gegenseitig, oder, wie es so schön heißt, sie rhizomisieren. Auf der Grundlage einer solchen in alle Richtungen wuchernden Semiose kann das Phänomen Kultur nicht zu einer Geschichte oder zu einem Kulturraum verknüpft werden. So etwas wie eine Epoche kann nicht einmal mehr gedacht werden. Die notwendige Konsequenz daraus, dass es also auch keine diachrone Geschichte, sondern nur die semiotische Praxis des Geschichtsdenkens gibt, hat dann der New Historicism gezogen.

Die Semiotik ist nur eine Spielart des Verlustes von Zeitlichkeit in der Kultur des 20. Jahrhunderts. Auf andere kann ich hier nicht eingehen. Da aber das 20. Jahrhundert häufig auch das semiotische Zeitalter genannt wird, mag dieses Beispiel als repräsentativ gelten. Natürlich gibt es im 20. Jahrhundert ein immenses historisches Wissen, aber die Zeitstelle eines Phänomens ist kein semantisch relevanter Faktor mehr, und damit ist die Zeit auch kein Operator des Verknüpfens mehr, sondern nur noch Prinzip der Reihung. Die Zeitpunkte haben die semantische Kohäsion untereinander verloren, durch die sich Geschichte erst herstellt.

Eine der Folgen der Austreibung der Zeit aus der Kultur sind die zentralen Aporien in den Kulturtheorien des 20. Jahrhunderts - der unendliche Regress jedes Legitimationsversuches und die Unmöglichkeit eines Außen- oder Metastandpunktes. Beides hängt natürlich zusammen. Jedes sinnhafte oder gar hierarchisierende Verbinden erscheint als Usurpation der Diskurse. Von innen in bezug auf ein Innen Position beziehend, ist man ja immer nur Partei. Wissenschaft kann sich so nicht mehr legitimieren. Aus dieser Falle befreit uns allein die Zeit, denn die Zeit ist jenseits aller Bedeutungspraxis. Als Zukunft lässt sie das radikal Unverstandene über uns hereinbrechen, als Vergangenheit gibt sie uns eine Bindung vor, die von keiner Semiose aufgelöst werden kann.

Wie aber macht die Zeitlichkeit des Denkens ein echtes Außen und eine Legitimation möglich? Das geschieht dadurch, dass der Rekurs zu einer anderen Zeit erfolgt und darum eine Distanz hat. Die Zeit stellt die Differenz her zwischen mir und dem begegnenden Anderen, zwischen Aussage und Metaaussage. Alle glückende Begegnung im Bereich der Kultur enthält die Dimension der Zeit: die Sozialisation, der ödipale Konflikt, die kulturelle Selbstfindung einer Generation in einer Querelle, die Überwindung der Einflussangst. Dabei setzt sich das Außen des Begegnens nicht absolut. Die Beziehung, die hier zustandekommt, situiert uns ja beide, mich und mein Gegenüber, in der Zeit. Ich bin damit nicht nur Metastandpunkt für den Anderen, sondern zugleich immer schon drinnen im selben Zeitstrom. Zeit wird kulturell wirksam über die erlebte Differenz zwischen Zeiten. Ich muss Zeitverhältnisse semantisieren und hierarchisieren, dann kann ich Zeit kulturell wieder wahrnehmen, und dann kann ich die Kultur überhaupt zeitlich, d.h. geschichtlich wahrnehmen.

Die Semiotik hat keinen zeitlichen und damit keinen dialogischen Kulturbegriff. Sie kann darum nicht die übergreifende Theorie der Geisteswissenschaften sein. Ohne die Dimension der Geschichtlichkeit ist sie für die Geschichtswissenschaft 
unannehmbar, ohne den Begegnungsaspekt hat sie der Psychologie nichts zu sagen. Gleichwohl muss jede Kulturtheorie die Einsicht der Semiotik berücksichtigen, dass die uns begegnende Welt durch und durch zeichenhaft ist und dass sie als solche vielfach überdeterminiert ist, weil an dasselbe Material zugleich verschiedene Fragen zu stellen sind. Wie aber wird verhindert, dass sich kulturelle Praxis und Kulturtheorie auf den propagandistischen Kampf zwischen den Perspektiven des Fragens reduzieren? Alle Zeichendeuter sind offenbar durch den gleichen Zaubertrank unbesiegbar geworden, und so prügeln sie sich bis zum Weltende um die Diskurshegemonie. Wenn man aber das wissenschaftliche Fragen auf eine begrenzte Zahl grundsätzlicher Möglichkeiten zurückführen könnte, dann würde sich zwischen diesen eine Beziehung ergeben. Damit würden keine Claims abgesteckt, sondern es würde der spezifische Beitrag ersichtlich, den jede Geisteswissenschaft zu einem Ganzen leistet. Dieses Ganze wäre nicht die Einzelwissenschaft, die die anderen unterjochen würde, sondern es wäre das Korrelationsprinzip zwischen ihrem Fragen. Aber geht denn das? Ja, das geht.

Es gibt vier solche grundsätzlichen Möglichkeiten des Fragens. Ich nenne sie das historische, das technische bzw. linguistische, das ästhetische bzw. philosophische und das kulturelle Warum. Man kann natürlich viele Fragen stellen, warum ist nicht das einzige Fragewort, aber das Wort warum ist konstitutiv für Wissenschaft. Wissenschaft ist, zu fragen, warum. Das ist nicht selbstverständlich. Wissenschaftler stellen viele andere Fragen: wann oder was oder wo oder wer mit wem. Aber das ist alles nur wissenschaftliche Propädeutik. Wer nicht schließlich warum fragt, betreibt keine Wissenschaft.

Das provoziert sofort die Frage: warum gerade vier Möglichkeiten? Reinhard Brand argumentiert in seinem Büchlein über die Vier als Ordnungsprinzip der europäischen Kulturgeschichte, diese Zahl sei aus Gründen der visuellen Vorstellbarkeit für begriffliche Bestimmungen der Wirklichkeit verwendet worden. Moderne, an der mathematischen Unendlichkeit orientierte Wissenschaft bedürfe ihrer nicht mehr, denn die Vierteilung sei für die Zwecke quantitativer Wissenschaft ohne jede Auszeichnung. Dazu ist zu sagen, dass zum einen wahrnehmungspsychologisch die höchste visuell vorstellbare Zahl die Fünf ist, die aber als Ordnungsprinzip nicht verwendet wird. Zum anderen gibt es eine Mathematik von den möglichst großen und eine von den möglichst kleinen Zahlen. Wissenschaft ist Komplexitätsreduzierung, darum steht für sie auch und gerade die möglichst kleine Zahl zur Debatte. So auch hier. Die Beziehung zum Text sieht sich vor zwei Alternativen gestellt: Die Alternative zwischen immanenter und grenzüberschreitender Betrachtung und die Alternative zwischen digitaler und analoger Kommunikation. Die Kombination der beiden Alternativen ergibt vier Klassen. Zur ersten Alternative: Technisches und ästhetisches Fragen sind immanente Begründungszusammenhänge für das Sosein des Textes, historisches und kulturelles Fragen sind grenzüberschreitende Begründungszusammenhänge für den Text. Diese Alternative hat in slavischen bzw. slavistischen Texttheorien eine gewisse Tradition. Die russischen Formalisten unterschieden zwischen der ästhetischen und der realistischen Motivierung des lite- 
rarischen Textes. Erstere betraf die künstlerische Organisation des Textes, war also immanent, letztere seine Beziehung zur Wirklichkeit, war also grenzüberschreitend. Die Formalisten unterschieden nicht zwischen immanentem ästhetischem Sinn und immanenter technischer Form, weil sie die ästhetische Funktion als Selbstverweis des Zeichens deuteten. Das ist dann unausweichlich aber auch nur dann möglich, wenn der Signifikant zuvor „,vergessen“ wurde, wenn er transparent war in einer ungebremst-automatisierten Wahrnehmung des bloßen Wiedererkennens. Diesen Aspekt eines jeden Textes profiliert zu haben, ist bleibendes Verdienst der russischen Formalisten, ihn zu verabsolutieren, ist, oder kann man schon sagen: war, die epochenbedingte Betriebsblindheit des „semiotischen Zeitalters“. Auch zwischen historischer Abhängigkeit und kultureller Wirksamkeit des Textes konnten die Formalisten nicht unterscheiden. Darum verfielen sie, die doch angetreten waren, um die Eigengesetzlichkeit des Literarischen zu beweisen, auf dieser Seite auf soziologistische Erklärungen. Auch Igor' Smirnovs Unterscheidung zwischen primären, auf die Wirklichkeit gerichteten Kulturmodellen wie z.B. dem Realismus und sekundären, auf das Zeichen gerichteten Modellen wie dem Symbolismus verarbeitet nur die erste Alternative und vermag darum z.B. nicht zwischen den gleichermaßen sekundären Modellen des Symbolismus und der Postmoderne zu unterscheiden.

Die andere Alternative ist die Unterscheidung zweier Kommunikationsformen, derer sich der Text wie überhaupt jede kulturelle Äußerung bedient: der digitalen (logischen) und der analogen (assoziativen) Kommunikationsform. Ich entnehme diese Unterscheidung dem Buch Pragmatics of Human Communication der Psychologen Watzlawick, Beavin und Jackson. Nach diesen Autoren operiert digitale Kommunikation mit Namen, d.h. mit arbiträren Zuweisungen. Sie liefert die elementaren logischen Operatoren des Denkens. Die analoge Kommunikation verwendet dagegen Analogien. Diese erlauben keine eindeutigen Festlegungen, weil analoger Kommunikation wie z.B. Mimik und Gestik die Syntax fehlt. Weil sie damit keinen Operator für die Negation hat, sind ihre Aussagen unaufhebbar ambivalent, zweideutig. Die genannten Psychologen weisen darauf hin, dass digitale Kommunikation das entscheidende Instrument der Wissensübermittlung und -aufbewahrung ist, im Bereich menschlicher Beziehung ist sie jedoch fast bedeutungslos. Hier funktioniert nur die analoge Kommunikation. Das gilt, so füge ich hinzu, nicht nur für individuelle Beziehungen, sondern auch für das kollektive Beziehungsphänomen „Kultur“. Technisches und historisches Fragen operieren digital, sie isolieren die Form bzw. das Thema und kommen in Bezug darauf zu eindeutigen Ergebnissen, die aber ohne kulturelle oder ästhetische Relevanz sind. Ästhetisches und kulturelles Fragen operieren dagegen analog. Hier sind keine eindeutigen oder streng logischen Antworten zu erwarten, doch wenn Beziehungsphänomene nur auf diese Weise zu erfassen sind und der ästhetische und kulturelle Aspekts von Welterfahrung ein Beziehungsphänomen ist, dann gibt es hier zu analogem Fragen keine Alternative. 
Die Entgegensetzung von digitaler und analoger Kommunikation wird implizit von Jurij Lotman vorausgesetzt, wenn er zwischen primären und sekundären modellbildenden Systemen unterscheidet. Aber auch in den Sprachursprungstheorien des 18. Jahrhunderts sind ihre Spuren zu finden. Nach Rousseau liegt der Ursprung der Sprache im Schreien und Singen. In sozialer Verwendung wurde sie dann zum Instrument der Verstellung und Lüge. Für die Aufklärung, vertreten z.B. durch Moses Mendelssohn, steht der Ursprung der Sprache jedoch im Zusammenhang mit der Entwicklung unserer Erkenntnisfähigkeit. Wir sehen, dass beide Recht haben: Rousseau verabsolutiert den Beziehungsaspekt von Sprache, und analoge Kommunikation ist, wenn sie sozial konventionalisiert wird, tatsächlich Lüge und Verstellung. Rousseau argumentiert ästhetisch und kulturell. Mendelssohn verabsolutiert dagegen den Erkenntnisaspekt von Sprache. Er argumentiert technisch und historisch. Ohne digitale Kommunikation gibt es tatsächlich keinen Erkenntnisfortschritt und keinen Wahrheitsbegriff.

Erst in der Kombination beider Alternativen ergeben sich alle Aspekte, unter denen ein Text zu befragen ist. Jeder Text hat also vier Dimensionen - die historische ist grenzüberschreitend digital, die technische immanent digital, die ästhetische ist immanent-analog und die kulturelle grenzüberschreitend analog. Häufig werden der historische und der technische Aspekt als „Textoberfläche“ bezeichnet und der ästhetische und kulturelle Aspekt als Substruktur. Das ist natürlich der Konvention des Logozentrismus geschuldet. Deren Macht ist so groß, dass Autoren, denen der ästhetische und kulturelle, d.h. der Beziehungsaspekt ihrer Texte wichtiger ist als der historische und technische Aspekt, immer wieder nach Wegen suchen, die digitale Rezeption zu verhindern oder wenigstens zu behindern. Das führt zu mehr oder weniger hermetischen, zu rätselhaften Texten, die aber auf der analog-assoziativen Beziehungsebene hoch funktional sind. Ich gehe jetzt auf jedes der vier Warums näher ein.

Dem historischen Warum liegt das Prinzip der Kausalität zu Grunde. Die Kausalität ist zuständig für die Verkettung der Denotate, also der ,realen Gegenständlichkeiten“. Das bedeutet natürlich nicht, dass für jeden Gegenstand seine Kausalität vollkommen geklärt würde. Die Verkettungen der Denotate sind viel zu komplex, als dass dies möglich wäre. Das gilt im Übrigen für alle vier Warums: ihrer Frageperspektive ist grundsätzlich horizonthaft, d.h. offen, sie ist durch die Möglichkeit, immer tiefer in die Horizonte einzudringen und ganz neue Gesichtspunkte einzubeziehen, falsifizierbar im Popperschen Sinne. Die historische Beobachtung von Verkettungen führt zum Konstatieren relativer Abhängigkeiten. Diese können unterschiedlich bewertet werden: ein Faktor erscheint als Ausdruck bestimmter anderer Faktoren, etwa das Literarische als Ausdruck des Politischen oder Sozialen, oder innerhalb desselben Faktors als Einfluss bzw. Abhängigkeit, z.B. von literarischen Vorbildern oder stilistischen Konventionen. Das zeigt den grenzüberschreitenden Charakter des historischen Warum. Der Text ist eingebettet in ein synchrones und diachrones Beziehungsgefüge, das sein Entstehen plausibel macht. Die Argumentation weist immer über den Text hinaus. 
Für das historische Warum ist zweifellos die Geschichtswissenschaft zuständig, aber nicht sie allein. Empirische Sozialforschung, empirische Psychologie, auch Politologie und Wirtschaftswissenschaft können hier ebenfalls ihre Plausibilisierungsstrategien einbringen. Eine historische Kulturwissenschaft ist dagegen ein sehr problematisches Unternehmen, denn das historische Warum kontextiert nur, bettet nur ein. Jeder Text ist für sie in einer Kultur situiert. In den 80er Jahren standen die Umweltschützer mit Plakaten an der Autobahn: du stehst nicht im Stau, du bist der Stau. Genau so verhält es sich mit dem Text. Als das Kulturphänomen schlechthin ist er nicht in der Kultur, er ist die Kultur. Nur das kulturelle Warum vermag seine aktive, seine konstitutive Rolle für die Kultur erfassen. Die historische Einbettung verschiebt dagegen die Frage nach der kulturellen Rolle des Textes in den Kontext, so wie jeder Autofahrer die Verantwortung für den Stau auf die anderen Autofahrer schiebt. Auch den kulturellen Verlust der Zeitlichkeit kann das historische Warum nicht rückgängig machen. Es ist ja im New Historicism selbst eines seiner Opfer. Die Zeit ist erst als verstandene, als semantisierte Zeit wieder Teil der Kultur, und zwar als ihr Entwicklungsaspekt. Die Einwirkung des Kontextes auf den Text beschreibt aber gerade keine Entwicklung des Textes selbst. Kultur als zeitliches Phänomen kann darum vom historischen Warum nicht erfasst werden.

Dem technischen Warum liegt das Prinzip der Rationalität zugrunde. Es rekonstruiert den Text im weiteren oder im engeren sprachlichen Sinne hinsichtlich seiner innertextuellen Komposition. Damit begreift dieses Warum den Text als System, in dem sich die einzelnen Parameter gegenseitig in ihrer Systemstelle definieren. Jeder Parameter ist funktional von allen anderen abhängig, und damit ist auch dieser Bereich unendlich komplex und nicht restlos zu verifizieren, und das, obwohl die Abhängigkeiten, nach denen das technische Warum fragt, aufgrund der vollständigen Immanenz der Parameter logisch beschreibbar sind. Für das technische Fragen nach dem Text ist die Linguistik, oder, wenn es sich um nichtsprachliche Texte handelt, die Semiotik zuständig.

Das ästhetische Warum fragt nach dem Text als Sinnzusammenhang. Das ist eine, nein: es ist die finalistische Kategorie, weil jeder Zusammenhang als gemeinsamer Ursprung oder als gemeinsames Ziel erscheint. Damit führt ästhetisches Fragen nach dem Text analytisch auf einen absoluten Ursprung zurück, auf ein „Sinnzentrum“, das sich perspektivisch mit der hypothetischen Hervorbringungsinstanz deckt. Diese Instanz unterscheidet sich natürlich von der realen Autorperson, nach der das historische Warum fragt. Man nennt sie darum den Abstrakten Autor. Bei aller Abstraktheit ist das ästhetische Warum als Ausrichtung auf einen Punkt gleichwohl personalistisch, denn der Punkt auf den aller Zusammenhang zurückgeht, ist das Ich der Apperzeption. Sinn ist also ohne die Kategorie der Person nicht darstellbar. Personalistisch heißt aber nicht psychologisch, denn dem Ursprung und Ziel allen Sinns fehlt die Bedingtheit und Beschränktheit des psychischen Subjekts. Der Abstrakte Autor ist als Ursprung und Garant allen Sinns 
göttlicher Natur, was zeigt, dass das ästhetische Warum nicht nur philosophisch, sondern zugleich theologisch ist.

Die Methode zur Rekonstruktion des Textsinns ist die Annäherung an den nie ganz zu erreichenden Punkt seines Ursprungs, es ist die Hermeneutik im Sinne Schleiermachers und Heideggers. Im Zuge dieser Annäherung an das Sinnzentrum werden die Signifikate, die Zeichenbedeutungen, immer enger, bis zur höchstmöglichen Plausibilität, miteinander vernetzt, und zwar nach dem Prinzip der Klassifikation, d.h. nach dem immanent-analytischen Prinzip der Analogie und des Gegensatzes. Die Methode ist die Analytik bzw. Deduktion, wozu auch die semantische Deutung formaler Äquivalenzen innerhalb des Textes, wie ich sie bei Wolf Schmid gelernt habe, zu zählen ist. Das Ergebnis ist die Sinnstruktur, und Sinnstruktur ist die Antwort auf das Fragen der Philosophie, unabhängig davon, ob diese nominalistisch wie die Sprachanalytik oder realistisch wie die Phänomenologie operiert. In beiden Fällen, wie auch in Scholastik, Hegelscher Dialektik, Kantscher Kritik usw. wird von den Denotaten abgesehen und auf die Vernetzung der sie aus philosophischer Perspektive konstituierenden Signifikate zurückgefragt. So gelangt man von der Physik zur Metaphysik, von der natürlichen Einstellung zur Epoché usw. Das Ergebnis dieser Abstraktion, die reinen Beziehungen zwischen den Signifikaten, kann selbst nicht erkannt werden, denn Erkenntnis ist ja eine Beziehung zu den Denotaten. Darum gibt es kein Erkennen des Erkennens und darum ist Sinn auch nur durch analogische Vernetzung und nicht durch digitale Logik zu erschließen. Doch wie kann etwas immanent und zugleich analogisches Beziehungsphänomen sein? Sinn ist die verinnerlichte Seite von Beziehung, er ist Korrespondenz im Sinne Baudelaires, Beziehung zum Absoluten. Keine literarische Richtung eignet sich im Übrigen so gut für die immanent-ästhetische Sinndeutung wie die symbolistische Dichtung, so wie überhaupt einzelne Epochen jeweils ein Warum in den Vordergrund stellen. Das ästhetische Warum fragt also philosophisch nach dem Text.

Da das kulturelle Fragen die Grenze des Textes überschreitet, muss es auf seine Epochenbedeutung bezogen sein. Das kulturelle Warum fragt darum immer nach dem Epochenzusammenhang. Dieser Zusammenhang ist nur, wie schon anlässlich der Frage nach einer historischen Kulturwissenschaft erörtert wurde, als Entwicklung des Gesamtsystems Kultur darstellbar. Das leistet das historische Warum nicht. Doch das kulturelle Warum ist als Wissenschaft noch gar nicht existent, und darum landet mancher, der kulturell fragen will, fälschlicherweise beim historischen Warum. Es gibt aber einen Vorreiter echten kulturellen Fragens, und das ist die Psychoanalyse. Sie hat die Begrifflichkeit entwickelt, mit der man die Entwicklung eines komplexen Systems im Dialog mit seinem Kontext darstellen kann, nämlich die Entwicklung des Systems der menschlichen Psyche in der Sozialisation des Kindes. Die Etappen der psychischen Entwicklung des Kindes sind die Epochen der Psyche, und man kann nach der Psyche nicht anders fragen als in solchen Epochenbegriffen. Der Zugang zu diesem Entwicklungsprozess ist die analoge Beziehungs-Kommunikation, mit deren Hilfe das kulturelle Warum 
wie das ästhetische analogisch, d.h. assoziativ ein Netzwerk von Analogien und Gegensätzen rekonstruiert. Dieses Netzwerk ist jedoch nicht immanent auf den Einheitspunkt des eigenen Systems gerichtet, sondern es besteht im Dialog mit dem Text. In solche Zuwendung zum Text fließst natürlich die eigene kulturelle Situation ein. Gleichwohl wird der Text auf diese Weise nicht missbraucht, sondern seine Zeit bekommt im Dialog mit meiner Zeit überhaupt erst eine Chance sichtbar zu werden. Epoche ist immer Epochenbeziehung und dabei eben kein willkürliches Konstrukt. Der eigene Anteil am Epochendialog müsste im Übrigen durch eine Art kulturelle Gegenübertragungsanalyse sichtbar gemacht werden können. Kulturell gesehen ist jeder Anachronismus eigentlich ein Diachronismus, Ausdruck einer zeitlichen Beziehung.

Kulturelles Fragen ist nun keineswegs gleichbedeutend mit strukturellem Denken. Mancher meint vielleicht, wenn er strukturell argumentiert, betreibe er schon Kulturwissenschaft. Tatsächlich aber denken und argumentieren alle vier Warums strukturell. Der Historiker spricht von Handels- oder Machtstrukturen, der Linguist von Sprach- oder Zeichenstruktur und das ästhetische Warum des Philosophen enthüllt die Sinnstruktur. Die Struktur, die das kulturelle Warum sichtbar macht, ist die Epoche im Sinne einer immanenten Zeitlichkeit von Kultur. Der Strukturbegriff ist in allen diesen Fragestellungen notwendig, weil die Verkettungen, die sie herstellen, niemals im metaphysischen Sinne wahr werden können, sondern nur ziemlich plausibel, denn der Gegenstand, um den es ihnen geht, ist unendlich komplex. Damit hat sein Verstehen zwar eine Richtung, kann aber nie abgeschlossen werden. Das gilt für die Verkettung der Denotate, die das historische Warum leistet, ebenso wie für die Verkettung der Signifikanten, die der Linguist oder Semiotiker herstellt, es gilt für die Verkettung der Signifikate, mit denen der Philosoph sich befasst ebenso wie für die Verkettung der Texte, die die Aufgabe der Kulturwissenschaft ist. Der Strukturbegriff ist damit die Regelantwort auf die geisteswissenschaftliche „Regelanfrage" warum?

Meine Systematik der vier Warums hat mehrere Vorbilder. Da wäre als erstes der vierfache Schriftsinn der mittelalterlichen Schriftexegese zu nennen, mit dem z.B. Dante in einem Widmungsbrief die Polysemie seiner Göttlichen Komödie klassifiziert. Der buchstäbliche Sinn, sensus litteralis, bezieht sich auf die Denotate, entspricht also meinem historischen Warum. Der tropologische Sinn, sensus moralis, verweist auf das, „was wir tun sollen“, er entspricht als Handlungsanweisung dem technischen Warum. Der symbolische Sinn, sensus anagogicus, erhebt den Geist zu Gott und findet darum seine Entsprechung im ästhetischen Warum. Der allegorische Sinn, sensus allegoricus, ist als vermeintlich willkürliche Textauslegung verpönt. Die allegorische Deutung stellt jedoch als, ich zitiere, „Beziehung auf das, was nach dem neuen Gesetz zu glauben ist" die kulturelle Bedeutung des Textes in Relation zur Kultur der eigenen Epoche her. Es handelt sich hierbei also genau um das kulturelle Warum. Die allegorische Methode ist die Methode der grenzüberschreitenden Analogiebildung, d.h. der Rekonstruktion der typologischen 
Intertextualität. Wer das als unsinnig abtut, verpasst die Chance, kulturelles Selbst- und Fremdverständnis zu leisten.

Mit seiner Lehre von den vier Textsinnen greift August Boeckh unter dem Einfluss der Hermeneutik Schleiermachers diese mittelalterliche Klassifikation auf. Allerdings geht es ihm in seiner „Methodenlehre der philologischen Wissenschaften“ nur um die Feststellung des Textes, nicht um dessen Verstehen. Boeck fragt in seiner Methodenlehre nicht warum und betreibt hier darum keine Wissenschaft im engeren Sinne, sondern eine, in der Klassischen Philologie natürlich höchst notwendige, wissenschaftliche Propädeutik. Wenn für den sensus historicus der geschichtliche Hintergrund für Sacherklärungen herangezogen wird, für den sensus grammaticus Sprachbedeutungen rekonstruiert werden, für den sensus individualis die Persönlichkeit des Autors rekonstruiert wird und für den sensus geneticus der Bezug zur Gattungstradition hergestellt wird, dann liegen hier genau die vier Warums vor, allerdings in gleichsam kastrierter Form, denn sie sind um ihre Episteme, um ihre Erkenntnispotenz gebracht und auf ein Wissen vom Text bzw. das Kennen des Textes reduziert.

Als drittes und letztes Vorbild möchte ich Schopenhauers Frühschrift von der „Vierfachen Wurzel des Satzes vom Zureichenden Grunde“ anführen. Hier wurde der Versuch unternommen, die Vierzahl nicht nur zu behaupten, sondern nach Kriterien auseinanderzulegen, indem er die Rede davon, etwas habe einen Grund, ihrem Sinn nach differenziert. So kommt er zu den vier Wurzeln dieser scheinbar einen Frage: der Kausalität, dem Erkennen bzw. der Rationalität, der Motivation bzw. Finalität und dem Seinsgrund. In dieser Reihenfolge präsentiert Schopenhauer seine zureichenden Gründe, und zwar in Abweichung von ihrer Systematik, die lautet: erst Seinsgrund, dann Kausalität, dann Motivation und schließlich Erkennen. Die andere Reihenfolge der Präsentation geschehe der Deutlichkeit wegen, es werde das vorausgeschickt, was das übrige am wenigsten voraussetze.

Dem schließe ich mich an, denn der Text begegnet zunächst als das, was im aktuellen Wissenschaftsmodell, dem der Neuzeit, den höchsten Rang einnimmt, und das ist die Kausalität. Sie verknüpft die Denotate und entspricht also dem historischen Warum. Als zweites begegnet der Text heutzutage vermittels der immanenten Analyse seiner Verfahren technisch. Das Mittel zu dieser Analyse ist die Rationalität. Sie nahm im Wissenschaftsmodell des Mittelalters den höchsten Rang ein. Die Analyse ermöglicht dann die Deutung des Textes, die, wie wir gesehen haben, finalistisch auf den Abstrakten Autor oder auf Gott gerichtet ist. Dieses ästhetische oder philosophische Warum nahm im Wissenschaftsmodell des Altertums den höchsten Rang ein. Zuletzt begegnet uns der Text heutzutage kulturell, und die zeitlich verstandene Kultur gibt ihm seinen Seinsgrund. Das hier wirksame assoziativ grenzüberschreitende Verstehen nahm im Wissenschaftsmodell der archaischen Zeit, im Schamanismus und Totemismus, den höchsten Rang ein. Schopenhauers Systematik geht vom Seinsgrund aus, weil dieser das reine Zeitschema enthalte. Wenn das reine Zeitschema das früheste Fragen, das früheste Verstehen war, dann dokumentiert der Verlust der Zeitlichkeit im 20. Jahrhundert 
das Ende eines langen Abbauprozesses, an dessen Ende die Wiederentdeckung der Zeit und damit der Kultur stehen könnte.

Nun zu meinem Beispiel: Čechovs Erzählung Tolstyj $i$ tonkij, „Der Dicke und der Dünne" ist ganz offensichtlich historisch, psychologisch und soziologisch relevant. Es lohnt sich also, an sie das historische Warum zu richten. Sie thematisiert erstens die sozial trennende Funktion der Rangtabelle der zaristischen Verwaltung, sie demonstriert, wie diese Tabelle die alte „gottgegebene“ ständische Ordnung zu ersetzen vermag, sie zeigt zweitens die psychisch deformierende Verinnerlichung dieser Rangtabelle und drittens die „Abhängigkeit“ Čechovs vom Motiv des „,kleinen Beamten" in der russischen Literatur. Auch der technische Aspekt dieser kleinen Erzählung gibt viel her. Durch leitmotivische Lautverkettungen und durch Metonymien werden eine dicke und eine dünne Welt einander gegenübergestellt. Das gilt nicht nur für das $h i-h i-h i$ des Dünnen und das ho-ho-ho des Dicken, sondern die kartonki, die der Dünne mit sich führt, enthalten z.B. anagrammatisch ihn selbst, den tonkij, während der Dicke, tolstyj, lautlich in to- und l-Ketten repräsentiert ist. Ja, man kann die Nähe und Differenz der beiden Beamten, die sich auf dem Bahnhof begegnen, fast in phonetischen Minimalpaaren beschreiben. Die Erzählung verweist durchweg auf die lautliche Seite der Sprache und durch die Symmetrien auch auf ihren im höchsten Maße konstruktiven Charakter und damit auf ihr „Gemachtsein“. Auf der technischen Ebene ist zudem festzustellen, dass der Erwartungshintergrund der Rezipienten, nämlich das Mitleid mit dem kleinen Beamten, systematisch negiert wird - denn der Ranghöhere ist der sympathischere. Auch durch diese Verfremdung wird die Wahrnehmbarkeit und damit der Selbstverweis des ästhetischen Zeichens gesteigert.

Die hermeneutische Rekonstruktion des Abstrakten Autors und damit die Antwort auf das ästhetische Warum ist aufwendiger, ich kann sie nur skizzieren. Die Identität der beiden Figuren als Schulkameraden und ihre Differenz als rangverschiedene Beamte verweisen nicht, wie man technisch annehmen müsste, auf eine Verschiebung, einen sdvig. Die Spitznamen der beiden als Schüler - Herostrat und Ephialtes - legen vielmehr eine charakterologische Konstanz nahe, für die der unterschiedliche Rang nur Symptom ist - hier liegen Ursache und Wirkung also genau entgegengesetzt zur thematischen Kausalität des historischen Warum. Auch die Analogie zwischen dem Dünnen und den leeren Zigarrenkisten, die er produziert, suggeriert eine Aufgeblasenheit, mit der der Dünne seinen Unterschied zum Dicken kompensieren will. Als der Dünne den Rangunterschied bemerkt und vor dem Dicken zu kriechen beginnt, entweicht aus ihm und auch aus seinem Gepäck in grotesker Realisierung der Metaphorik die Luft seiner Aufgeblasenheit. Der Abstrakte Autor begründet das Scheitern von Kommunikation im Narzissmus einer Figur und nicht in den „objektiven sozialen Verhältnissen“.

Auch dem kulturellen Warum hat unser kleiner Text einiges zu bieten. Hier steht dem Lebensgenuss, den der Dicke verkörpert, die protestantisch-kapitalistische Askese des Dünnen gegenüber. Es wird nicht nur zweimal erwähnt, dass die Frau des Dünnen Lutheranerin ist, der Dünne ist auch über seinen Beamten-Dienst 
hinaus als Kleinfabrikant von Zigarrenkisten tätig, deren Preis einzeln und im Zehnerpack zu erwähnen in einer so kurzen Erzählung schon recht merkmalhaft ist. Der Name Mischa für den Dicken macht ihn zur Personifikation Russlands, während der Name des Sohnes des Dünnen, Nathanael, über die Intertextualität zu E. T. A. Hoffmanns Sandmann wiederum deutsche und über die alttestamentlichen Herkunft des Namens auch hebräische Bezüge hat. Wir haben es mit einer nicht nur räumlich motivierten Kulturtypologie zu tun (orthodoxes Russland protestantisches Deutschland), sondern auch mit einer kulturgeschichtlichen, wenn man mit Max Weber im Protestantismus das Aufgreifen alter jüdischer Kulturmodelle als Grundlage für die neuzeitlichen Wertevorstellungen sieht. Diesem Typus steht mit dem Genussmenschen Mischa gleichsam der mittelalterliche Mensch gegenüber, der als Zeitgenosse des Dünnen mit Vorliebe als Konsument von dessen kapitalistischen Produkten in Erscheinung tritt - eine Situation, die wir auch in der heutigen Beziehung Russlands zu Westeuropa noch beobachten. Ihre gemeinsamen Wurzeln haben beide Kulturmodelle in der Antike, weswegen der Dicke und der Dünne in ihrer gemeinsamen Schulzeit griechische Spitznamen hatten. Zu den Spitznamen selbst. Den Dicken nannte man Herostrat nach dem Tempelbrandstifter. Das verweist auf das zerstörerische Potential einer im Grunde mittelalterlichen Genuss-Kultur in einer sonst kapitalistischen Welt, auf das revolutionäre Potential einer Gesellschaft, die in ihrer Masse zu keiner Askese zugunsten späteren Gewinns bereit ist. Der Tempel des protestantischen Kapitalismus wird in Brand gesteckt. Der Dünne hieß Ephialtes nach dem Verräter der Spartaner an den Perserkönig Xerxes. Verriet jedoch Ephialtes den Okzident an den Orient, so ist es nunmehr, bei dem Dünnen, umgekehrt. Durch den Import des Protestantismus nach Russland verrät er den Orient an den Okzident.

\section{Anmerkungen}

${ }^{1}$ Mittelstraß, J.: 2004, Transdisziplinarität, wissenschaftliche Zukunft und institutionelle Wirklichkeit, Konstanz. 



\section{„Moja harfa je ceło ślónsko zém“ Zur lachischen Poesie von Óndra Łysohorsky aus der Euroregion Schlesien}

Kollege Walter Kroll erzählte mal in der Teestube unseres Slavischen Seminars, wie zu ihm zur Studienberatung eine polnische Studentin erschien - aus dem gleichen oberschlesischen Dorf Horneck bei Gliwice im Regierungsbezirk Opole, wo er am 10. Oktober 1941 geboren war. Und das es hier noch Einheimische gibt, die sich an den Walterek im Kinderwagen erinner können. Er saugte also mit der Muttermilch neben Polnisch und Deutsch auch „po naszemu“/,po našému“ ein, in Polnisch-Schlesien gwara śląska und im tschechischen Teil Schlesiens Lachisch genannt, manchmal als „Wasserpolakisch“ belächelt. Walter Kroll ist also ein idealer Rezipient der lachischen Poesie von Óndra Łysohorsky (Dr. Erwin Goj, geb. in Friedek/Frýdek, 6. Juli $1905-\dagger 19$. Dezember 1989, Bratislava), der in seinem Debüt Spiwajuco piaść (1934, 60; Nachdichtung von Ewald Osers in Łysohorsky 1989, 66) offenbarte: 
Moja harfa je ceło ślónsko zém: chałupky w Beskydach a šumne řéky, kolónije, pola, lesy, fabryk a šachty a hamry a krew a dym.

Moja harfa mo struny po cełym swěće: od obzora ku obzoru struny śe pnu kaj robotnicy padaju a mřu kaj oči teskňo po pérwšim kwěće.
Meine Harfe ist das ganze schlesische Land:

beskidische Hütten, Berge und Wälder,

Fabriken, Ströme, Rauch und Brand

und Qualm und Blut und Schächte und Felder.

Meine Harfe umspannt den Norden und Süden, Meine Harfe hat Saiten in aller Welt wo eben ein Arbeiter stirbt und fällt und wo man sich sehnt nach den ersten Blüten.

Wilhelm Szewczyk, der Óndra Łysohorsky auf der Flucht am 2. September 1939, als die Flaks gegen deutsche Flugzeuge feuerten, seine lachischen Gedichte im Radio Katowice vortragen ließ, fasst seine Bewunderung über die lachische Poesie zusammen:

\begin{abstract}
Niektóre liryki Ondry można zaliczyć do najlepszych osiągnięć współczesnej poezji słowiańskiej. Na ich przykładzie równocześnie się widzi, jak dojrzała, bogata i soczysta jest gwara śląska, jak cudnie umie oddawać najintymniejsze drgnienia serca poety. Poezja Łysohorskiego to nie tylko triumf samego poety, to triumf języka nadostrawskiego, tych dźwięków śląskich, które siłą uczucia i melodii sylab przewyższają niewątpliwie wykształcone, zmechanizowane języki tzw. literackie słowiańskie. Jużeśmy u Kubisza podziwiali ten język, ale tam jeszcze krępowało go zbyt inteligenckie myślenie. U Ondry jest żywioł, sam żywioł. Nie widzimy różnicy między myśleniem poety, a między jego językiem, wszystko się stapia $\mathrm{w}$ jedną całość, w jeden szum, w jeden dzwon. (Szewczyk 2001, 150)
\end{abstract}

Wie habe ich diesen verborgenen lachischen Schatz entdeckt? Und was ist mit Óndra Łysohorsky geschehen, nachdem er am dritten Tag des Weltkrieges vor der heranrückenden Wehrmacht aus Katowice in den Osten getrieben wurde in die Arme der Roten Armee, welche mit ihrem Hitler-Stalin-Pakt den Polen in den Rücken fiel? Und was hatte Łysohorsky als Ślónzok/Ślązak/Slezan/Schlesier während der Teilung der Welt 1943-1944 in Moskau vor, als er im Frühjahr 1944 Stalin in einem Brief um die ,lachische bzw. schlesische Autonomie“ gebeten hatte? Mit der edlen Absicht, alle Schlesier in Schlesien leben zu lassen und somit die Vertreibung der deutschen Schlesier zu vermeiden?

Mein Abenteuer mit Óndra Łysohorsky fing im Wintersemester 1955-1956 an. Ich sollte an der Philosophischen Fakultät der Masaryk-Universität in Brno eine Seminararbeit über lachisch schreibende Autoren verfassen, weil ich am tschechischpolnischen Grenzfluss Olza/Olše in Český Těšín/Ciezsyn/Teschen aufgewachsen bin und da seit meiner Kindheit auch ,po našému“/lachisch gesprochen habe. Bei der Lektüre der lachischen Gedichte und Prosatexte der 30er Jahre geriet ich bald ins Staunen: Denn die Sonne, um die in dem multinationalen antifaschistischen 
literarischen Zirkel Lašsko perspektywa in Ostrau 1937 die lachischen Autoren Jozeff Šénowsky, Jan Stónawsky und Jura Hanys kreisten, trug den Namen Óndra Łysohorsky. Ich habe von ihm nie gehört, dachte, er sei gestorben, also fing ich an, nach seinem Grab zu suchen.

Ich hatte Glück, dass um uns herum das politische „Tauwetter" ausgebrochen war und dass uns - „Osmsil“ (Acht Kräfte), acht Adepten der Literaturwissenschaft - unser Dekan, Prof. Hrabák, im April 1956 zum II. Schriftstellerkongress ins Parlament nach Prag geschickt hatte. (Nach dem Ausbruch des Volksaufstandes in Ungarn im Herbst 1956 hat die kommunistische Propaganda den Prager Schriftstellerkongress beschuldigt, er habe als geistiger Funke diesen Aufstand entfacht.) Ich rührte mich eine Woche lang nicht von der Galerie des Parlaments, erlebte unten unvorstellbar kritische Auftritte, vor allem die von Jaroslav Seifert und František Hrubín. Und auch ein versteinertes Gesicht des Möchtegern-Schriftstellers Antonín Zápotocký unter mir in der Präsidentenloge, wie er auf die Fakten über den Selbstmord des Dichters Konstantin Biebl und über die Schriftsteller reagierte, die hinter den Stacheldraht der Arbeitslager und der Gefängnisse verbannt wurden. Und so schrieb ich da mein Epigramm Pohled s galerie, das im Bulletin des Kongresses und mit anderen Epigrammen in der Zeitschrift Host do domu (1956) veröffentlicht wurde: Svědomi národa/tam dole posedalo./ Soudě dle prázných mist -/ není ho nějak málo?

Jemand sagte mir, dass jenes „soudě dle prázdných mist" während des Kongresses in dem Sinne gelesen wurde, dass es um Autoren gehe, die das totalitäre Regime in den Tod getrieben oder lebendig begraben hatte. Und weil zu ihnen auch der von mir gesuchte schlesische Dichter Óndra Łysohorsky gehörte, fragte ich auf den Korridoren nach ihm. Und erhielt von dem slowakischen Akademiemitglied Karol Rosenbaum die Auskunft: „Ale ved’ on žije u nás v Bratislave. A je vedúcim katedry cudzich jazykóv."

$\mathrm{Zu}$ meiner ersten Begegnung mit Łysohorsky kam es dann im rauschenden Mai in Bratislava. Er ging mit mir in der Altstadt spazieren, zeigte mir alles von den romanischen Fundamenten bis zum Barock und der jüdischen Altstadt und sondierte vorsichtig, ob ich nicht Agent seiner Erzfeinde aus Moskau sei, des Kultusministers Zdeněk Nejedlý und des Informationsministers Václav Kopecký. Als ich aber anfing, lachisch, deutsch, polnisch, tschechisch, russisch, ukrainisch und slowakisch zu sprechen, und erzählte, was ich da beim Schriftstellerkongress in Prag so erlebt hatte und dass ich mich danach sehnte, mit meiner Arbeit zur Wiederauferstehung des totgeschwiegenen schlesischen Dichters Óndra Łysohorsky beizutragen, gewann ich sein Vertrauen - und den Zugang zu seinem Privatarchiv, zu Materialien bis zu seiner Emigration im Spätsommer 1939 und den ,sowjetischen“ Dokumenten von 1940 bis 1946. Fast alles (bis auf den russischen Brief an Stalin von 1944) durfte ich dann im Herbst 1956 für mich fotografieren. Danach schickte mir Óndra Łysohorsky autorisierte Texte aller seiner lachischen Gedichte nach Brno, auch jener, die 1940-1946 in Moskau und in Taškent, Samarkand und Buchara entstanden waren. 
Auf meine Bitte, sich an Łysohorsky zu erinnern, antwortete mir am 6. November 1956 Petr Bezruč überraschend mit einem vier Seite langen Brief. Er offenbarte: „Mám básně Łysohorského. Je pravý básník, slezská duše. Thema jste si vybral velmi švarné. Ó. Ł. zůstává nepochopen, jako před 58 lety zůstal nepochopen v Praze jistý P. B.“

Im Winter 1956-1957 hatte ich fast alle lachischen Gedichte Eysohorskys zur Verfügung, mit Nachdichtungen und Übersetzungen in viele Sprachen, sowie deren Widerhall in der Tschechoslowakei bis 1939 und danach in Sowjetrussland (einschließlich einer für Radio Moskva 1944 bestimmten und verbotenen Rezension von Jiří Taufer). Ich konnte mir also vorstellen, wie sich mein lachischer Dichter in der Tschechoslowakei und im sowjetischen Exil entwickelt hatte:

Óndra Łysohorsky (Pseudonym nach dem Räuber Óndra und der Eyso hora), geboren noch in Österreich-Ungarn, war das siebte Kind eines Bergmanns, später Gärtners, und einer Hebamme. Mit 15 Jahren, beim Plebiszit 1920, hat er schmerzhaft die Teilung Oberschlesiens in einen tschechischen und einen polnischen Teil miterleben müssen. In seiner Familie sprach man Lachisch, Deutsch und nur wenig Tschechisch. Um dem sich extrem verstärkenden tschechischen Nationalismus zu entkommen (einer der Professoren am tschechischen Gymnasium hatte ihn 1920 wegen seines Lachischen und Deutschen sehr verletzt), entschloss sich Erwin Goj, an das deutsche Gymnasium in Ostrau zu gehen, wo er 1924 maturierte. Schon damals schrieb er deutsche Gedichte. Nach 1924 studierte er dann an der Deutschen Universität in Prag, wo er 1928 über Rilke promovierte. An der Karlsuniversität studierte er zugleich Slawistik und tschechische Literatur bei Prof. F. X. Šlda.

Nach der Promotion träumte Dr. Erwin Goj von einer Hochschulprofessur, worauf ihn - in der Weltwirtschaftskrise nach 1929 - das Schicksal der Arbeitslosen ereilte. Er fuhr nun in Europa per Autostop herum. Zu Hause wanderte er dann entlang der Oder bis nach Raciborz und entlang der Ostravica in die Beskiden, die lachischen Volkslieder sammelnd - mit Janáčeks Lašské tance im Hintergrund, sich des Humanismus von Angelus Silesius und der sozial rebellierenden Epigramme des Schlesiers Friedrich von Logau bewusst.

Um in der Sprache seiner Mutter und seines Vaters zu dichten, die auch die Landsleute entlang der Oder bis nach Raciborz und Opole verstehen können sollten, gab Óndra Łysohorsky die rein phonetische Transkription der lokalen ostlachischen Dialekte auf und schuf die lachische Literatursprache. Am 18. März 1930 schickte er seine Visitenkarte an Petr Bezruč nach Brno, noch mit tschechischem Text: „Mistře! Jsem Slezan. Dlouho jsem čekal na příležitost Vám říci, čím mně jsou Vaše Písně. Bylo by možno s Vámi také promluviti o některých problémech našeho Těšínska? Jsem dneska a zítra v Brně. Dr. Ervín Goj." Zwischen den beiden schlesischen Dichtern beginnt eine Korrespondenz. Im September 1932 schickt der achtundzwanzigjährige Landsmann an Bezruč - schon als Óndra Łysohorsky seine ersten 16 lachischen Gedichte, mit der Bitte, er möge ein paar Zeilen als Vorwort verfassen. Unter den ersten lyrisch intimen sowie sozial geprägten Balladen sind die (noch mit tschechischem $V$ verfassten) Texte Leto, Ślónsko balada, Óndraš, 
Mamě, Odpovedź, Peter Bezruč, Spěv deśići milijard tón uhlo, V letněj nocy a Jan Hus und das Bekenntnis vom 21. 7. 1932 Kaj nórod mój? (siehe Łysohorsky 1989, 34): Joch noród mój hledot żivot cety/a přyšełch zaś v beskydsky mrak./Z knih polskych cudze vélny hřměly,/ Aj v Praze žilech osamèly./ A včil? Do Moskvy idźe zrak.

Wegen jenem Do Moskvy idźe zrak hat Bezruč das Vorwort zu Łysohorskys Gedichtsammlung nicht verfasst. Er schrieb ihm aber im Oktober 1932: „Vše, co jste napisali, je krásné a básnicky řečeno, s pravopisem souhlasím. (...) Ale vydáte-li to, propadne to konfiskaci - nevím všimate-li si, jak řádí pražská censura proti opozičnímu tisku v Praze. Myslím, že ani Bach nebyl tak krutý. (...) Možná, že se mýlím, ale nečítal jste Puškina a Lermontova v originále? Rhytmus v některých písních je připomíná.“

Als Bezruč sich nicht mehr gemeldet und auch nicht auf den Brief vom 8. 12. 1932 geantwortet hatte: „Co śe tyko dedykacyje Spiv. P. «Petru Bezručovi» nic mi ňepišu. Móm čitać odmitnući v Jejich mlčéňu?", entscheidet sich der ehemalige Student der Bohemistik an der Karlsuniversität und nun debütierende lachische Dichter, seinen Professor F. X. Šalda in seinem Sommerhaus am Fluß Sázava zu besuchen. Er hat Glück - Šalda ist von den rezitierten lachischen Gedichten fasziniert (auch von den intimeren, die im zweiten Gedichtband Hłos hrudy 1935 erschienen waren) und verfasst zu Łysohorskys Debüt Spiwajuco piaść am 3. September 1933 ein Vorwort, was er bisher für keinen debütierenden Dichter getan hatte:

SPIWAJuco Piaść je poesie převážně obžalobná, poesie žalující na vládnoucí Prahu, poesie žalující na nový režim, jako poesie Berzučova žalovala kdysi na režim starý. (... ) Ale je tu i zájem druhý, hlubší, vnitřní: jak vlil své vidění života do kadlubu slova zcela nového, panenského, které nemělo posud literárního otisku; jak vyrovnal a zasnoubil svůj vnitřní rytmus duševní s vnějškovou melodií řeči odposlouchané k tomu účelu se rtů žijících; jak ztvárnil své básnické představy a vtiskl je do vzdorné nedotčené prsti. (...) V jeho knížce básnické jsou čísla veliké výraznosti a síly slovné, která zachycují životní situace v nezapomenutelných postojích plastických, hutně, tvrdě, spádně, jak tomu má být v skutečných baladách; a jiná, která dotvářejí odposlouchaný material slovně zvukový v skutečnou uměleckou monumentálnost širého zvlnění. Poesie Łysohorského může býti dobrou protiváhou jisté části dnešní přeumělkované poesie české, která se ráda uhýbá prostotě a ráda se zabíhá do formálních schválností a plochých zvětralých hř́iček.

Damit wurde über Nacht die Himmelspforte der tschechischen und europäischen Literatur für die lachische Poesie geöffnet. Die Jagd nach dem unbekannten Pseudonym potenzierte diese dichterische und soziale Tat. Bald darauf kommt Hitler an der Macht. Łysohorskys Balladen und lyrische Gedichte werden nun in deutschen Nachdichtungen in Zeitschriften in der Schweiz, Österreich, Holland, London veröffentlicht, vor allem dank den jüdisch-deutschen Prager Intellektuellen Pavel Eisner und Rudolf Fuchs. Bis zu den Moskauer Prozessen erscheinen sie auch in der Zeitschrift Internationale Literatur in Moskau. 
Nach der Gründung der multikulturellen literarischen Gruppe BLOK in Brno 1936 entsteht dazu in Ostrau, wo Łysohorsky 1937 ein Jahr lang als Mittelschulprofessor arbeitet, seine literarische Gruppe Lašsko perspektywa. Hier beginnt das Erwachen des schlesisch-lachischen Dichters aus seinem purpurroten Traum von der Völkerfreiheit in der Sowjetunion. Denn im Jahr 1937, während Stalin in Spanien die Republikaner in Stich läßt und daheim einen blutigen Terror gegen die Revolutionäre der ersten Stunden entfacht, kehrt von dort ernüchtert der französische Schriftsteller André Gide zurück. Sein Buch erscheint in der Tschechoslowakei unter dem Titel Návrat ze Sovětského svazu. Im BLOK beginnt daraufhin eine grundsätzliche Diskussion zwischen dem Dichter S. K. Neuman, einem Fanatiker des Stalinismus, und seinen Gegnern, wie dem Dichter Jan Noha. Über Stalins blutigen Kommunismus wurde auch in Bratislava diskutiert, wo Łysohorsky seit Anfang des Schuljahres als Professor für Französisch und Deutsch am Deutschen Gymnasium tätig war und zu dem linksintellektuellen Zirkel des Rechtsanwalts Vlado Clementis gehörte. Diesem gelang es 1939 noch, nach England zu emigrieren. Łysohorsky blieb dagegen auf dem Weg nach Warszawa (wo er hoffte, ein britisches Visum zu erhalten) vor dem Mikrofon von Radio Katowice am 2. September 1939 im Flakfeuer stecken und mußte vor der Wehrmacht ostwärts flüchten (womit er sich in der Versreflexion Polsky podźim 1939 auseinandersetzt, verfasst in Moskau, 5.-23. Oktober 1945, s. Łysohorsky 1988, 732-759).

Für den Dichter Łysohorsky Glück im Unglück. Er wird zuerst mit den internierten Tschechen und Slowaken (der späteren Tschechoslowakischen Brigade des Oberst Svoboda) neun Monate lang von einem Internierungslager zum anderen bis an die Wolga transportiert, 1940 holt man ihn dann als ,proletarischen Dichter“ nach Moskau und quartiert ihn im Hotel Metropol ein. In Moskau begegnet er Boris Pasternak, mit dem er - wie mir Łysohorsky erzählt hat - spazieren ging und auf deutsch über ihr Idol Rilke schwärmte. Pasternak empfahl darauf Marina Cvetajeva, fünf lachische Texte zu übersetzen. Balada o křywej budźe, Cvetajevas Ballada o krivoj chatě (Lysogorskij 1946, 13) gehört ersichtlich zu ihren letzten genialen Nachdichtungen. Sie soll sich ein Jahr später, im Winter 1941, am Fuße des Urals in einer ähnlichen Hütte wie die Kolorka aufgehängt haben:

\section{Za městém přy ceśće budka křywo. \\ Kołorka předowo piwo.}

Před tym tu a tam śe zastavili śedlocy na wozach a trochu popili.

Časy su złe. Aj śedlocy ňémaju.

Na Kołorku hérbatu śe flašky dźiwaju

a škarboł z uřadu śe dźiwo na ňe: Kołorka pod trestém zapłaćić mo daňe.
Pod ivoj chata pritknulas' krivo.

$\mathrm{V}$ toj chate babka varila pivo.

Vchodili parni v lochmatych šapkach, Chvalili pivo, chvalili babku.

No den'gi splyli, i parni splyli. Odna Kolorka sredi butylej.

Sognulas' babka preniže ivy: Kuda kak strašen nalog na pivo! 
Pět dni, pět nocy ňejedła, ňepiła

a před tym, co přyndźe, śe wdowa hroziła.

W potek skónčili čěkani ji hrozne.

Kołorka została w budźe prozne.

Wšecko, aj špunty, ji pozbirali.

Én křyž na śćéne ji smutny ňechali.

Kołorce własy na hłavě stowaju, Oči ji ohňém poźiwnym horaju.

A na roz křyž térho a o zém s nim rube

A na roz fĕrtuch se sebe škube

A do prowoza ho w potu krući, na hřebik, kaj křyž był, zufale ho nući.

Śedlocy jedu z města od sudu A piwém chcu złość zmyć před křywu budu.

Šak w budźe Kołorky je wšecko na ruby. Z własów střapatych śe ščiřo zuby.
Pjat' dolgich dnej ne pila, ne ela, -

Vsë na nalogovoj list gljadela!

Prišël den' pjatyj, nastal den' platy:

Ostalas' babka odna s raspjat'jem.

U babki dybom vstajut volos'ja!

Glaza, čto ugli u perenosja.

Sryvaet babka iz sil podlednich

S gvozdja raspjat'je, s sebja perednik.

Rvët na poloski perednik staryj,

Iz tech loskut'jev - verëvka stala!

I na gvozde - kakova obnovka!

Gde ran'še krest byl, teper' - verëvka.

Krest'jane edut s suda, čut' živy,

Zalit' obidu rešili pivom.

- Prostite, drugi, za skaz moj grubyj -

Visit Kolorka i skalit zuby.

Nach Hitlers Überfall auf die Sowjetunion - so erzählte mir Łysohorsky - irrte er mit Pasternak in Moskau herum und die beiden beschlossen, mit der Harmonie ihrer Sonette der Barbarei der Deutschen zu begegnen. In jenem Sommer 1941 wurde Łysohorsky von Aleksej Tolstoj ins Slavische Komitee eingeladen. Dort bat der Moskauer Rundfunk alle Vertreter der slawischen Völker ans Mikrofon und nahm ihre Aufrufe zum Kampf gegen den Faschismus auf. Für die Tschechen sprach Prof. Zdeněk Nejedlý, für die Slowaken der Dichter Laco Novomeský - und für das ,lachische Volk“ forderte dessen Dichter Óndra Łysohorsky auf lachisch zum Partisanenkampf in Schlesien auf! An diese Sendung erinnert sich Ewald Osers, der jüngste Dichter der Gruppe BLOK, welcher 1938 aus der Tschechoslowakei nach Grossbritannien emigrierte und in Reading bei der BBC tätig war:

There was a major event staged in Moskow in connection with the setting-up of an All-Slav Committee for the pursuit of the war against Fascism and the liberation of the contries over-run by the Nazis, and I was, together with others, listening to their broadcasts. My specific duty was to listen to the Czech broadcast within the program, and to my enormous surprise there, suddenly, was Óndra with a very moving contribution, not in Czech but in Lachian. To this day I remember the moving line „Cełu Ewropu zaleśnili šibenicami“. (Łysohorsky 1989, 816) 
Von einem anderen Ereignis erzählte mir Josef Rummler, Autor des Nachwortes zu Łysohorskys Antologie Aj lašske řéky płunu do mořa, während des III. Schriftstellerkongresses in Prag 1967: Er hörte 1943 eine Sendung des Moskauer Rundfunks, in der die „lachische Autonomie“ verkündet wurde - und danach ein Dementi. Ich habe Łysohorsky dazu schon 1957 in Bratislava gefragt. Er erzählte mir, dass nach seiner Rückkehr aus Taškent nach Moskau im Februar 1943, als dort, nach Stalingrad, die Teilung der Welt in Angriff genommen wurde, die tschechische kommunistische Emigration mit Prof. Zdeněk Nejedlý der polnischen kommunistischen Emigration den größten Teil Schlesiens zu entreißen versuchte, und umgekehrt. Prof. Nejedlý und Václav Kopecký forderten dabei Łysohorsky auf - der kein Mitglied der Tschechoslowakischen KP war, sonst hätte er es als Parteiauftrag ausführen müssen -, er solle aufhören, lachische Gedichte mit $W$ zu verfassen und zum tschechischen $V$ zurückkehren. Denn das $W$ käme den Forderungen der Polen bei der Teilung Schlesiens entgegen, weil dort, wo man $W$ benutze, das Territorium zu Polen gehöre! Pavel Wodecki hat im Archiv des Zentralkomitees der KP der Tschechoslowakei Anfang der 90er Jahre die Korrespondenz der tschecholowakischen Parteiführung mit Ufa und Moskau von Januar bis März 1943 zu dieser Frage entdeckt, wonach sich Łysohorsky in Moskau geweigert habe, die tschechische kommunistische Propaganda zu übersetzen, so dass: „Musime to tady vzíti zatím vlastnimi silami, protože (...) Eysohorsky jen blázní a básni." (in: Gan $1992,69)$

Łysohorsky war von Nejedlýs Chauvinismus schockiert, besonders, als er erfuhr, dass ihn die tschechoslowakischen Kommunisten zur Tschechoslowakischen Brigade des Oberst Svodoba abkommandieren wollten, damit er an der Front als Held fällt. Boris Pasternak, Aleksander Dovženko und Łysohorskys Moskauer Frau und Übersetzerin Nina Sokolova haben ihm in dieser Lage geraten, er solle sich mit einem russischen Brief an Stalin wenden, weil dieser den Mazedoniern eine Autonomie mit einem kodifizierten Mazedonisch im Rahmen der Jugoslawischen Föderation zugesagt hatte. Ich habe dazu Łysohorsky gefragt (nachdem er mir nicht erlaubt hatte, den rusischen Brief an Stalin vom Frühjahr $1944 \mathrm{zu}$ fotografieren), wie er sich 1943 in Moskau die ,lachische Autonomie“ vorgestellt hat. Dabei erinnerte ich Łysohorsky an seinen lachischen Dosłów in Spiwajuco piaść (1934, 92), wo er offenbarte:

S pojmém „lašsky“, aj tam, kaj wóbec je znómy, śe spojuje ňejasno filologicko předstawa, kěre śe ňedo subzumować nic kónkretneho. Bodej śe wi, že słowo „lašsky“ ňeznači žoden prozny pojém katedry, ale že označuje wšeljakymi ménami (na př lašsky, morawsky, ślónsky a. t. d.) jazyk, kěreho užiwaju přybližňe dwa milijóny ludźi. Bodej śe wi, že a z jakych přyčin jazyku tému ze wšeckych swětowych jazyków śe ňejwic wysmiwali a že ho, kěj už muśeli o nim młuwić s jistu rezerwu, označowali jednoduchym ,přechodém“ jazyka českeho ku jazyku polskému. Bodej śe wi, že prawě noród tén je zakořéňény na jednym z rozhodujucych mist Europy, na přechodu mezy Sudetami a Karpatami, na wérchnim běhu Odry a jejich přypływów a na wérchnim běhu Wisły. 
Łysohorsky sagte mir dazu schon 1957 in Bratislava, dass Schlesien nach dem Krieg eine östliche multikulturelle Schweiz hätte werden können: mit polnischen, tschechischen, deutschen Schlesiern und den einheimischen Ślonzaken. Ein kühner, humaner Traum. Denn Il'ja Ėrenburg verlangte damals von Stalin, er möge für die Verbrechen des Faschismus das ganze deutsche Volk vernichten. Łysohorsky stellte sich dagegen vor, dass die „unschuldigen“ deutschen Schlesier nach dem Krieg in Schlesien bleiben dürfen sollten.

Nachdem Łysohorsky den Brief an Stalin im Frühjahr 1944 abgeschickt hatte, lud ihn der Sekretär des Zentralkomitees der KPdSU, Dmitrij Manuil'skij, Absolvent der Sorbonne von 1911, zu zwei Gesprächen ein. Dabei ließ er sich die Grenzen Schlesiens auf einer historischen Karte zeigen und (auf französisch?) erklären, wie er sich die „lachische Autonomie“ vorstellt. Łysohorskys Lettre a Josef Staline. Printemps 1944 (Übersetzung ins Französische in Lysohorsky 1970, 80-85) fängt eigentlich mit der gleichen Argumentation wie im lachischen Dosłów von 1934 an:

Je me permets de me tourner vers vous et de vous demander conseil au sujet d'une question nationale.

Dans cette région de transition entre les Sudètes et les Carpates, entre les sources de l'Oder et celles de la Vistule, il y a un pays situé au carrefour de quatre peuples : les Tchèques, les Slovaques, les Allemands, les Polonais. La population de ce pays appartient à la branche des Slaves de l'Ouest et on l'appelle silésienne, moravienne ou laque. La plus grande part de ce pays se trouve en Tchéchoslovaquie.

Les langues slaves sont plus proches les unes des autres que, par exemple, les langues germaniques; on passe de l'une à l'autre par de nuances d'arc-en-ciel. La première population moravo-silésienne qui habite ce pays parle une langue que la linguistique désigne du vieux mot slave laque et qu'elle dit être un dialecte de transition entre le tchèque et le polonais. Cette langue est parlée par environ un million et demi à deux millions de personnes.

Nach den zwei Gesprächen bei Manuil'skij mußten die tschechoslowakischen Kommunisten mit ihren Intrigen gegen Łysohorsky aufhören und durften ihn nicht an die Front in die Karpaten abkommandieren. Er wurde beauftragt, in Moskau die Dolmetscher der Roten Armee in Tschechisch und Deutsch zu unterrichten. Mit Łysohorsky solidarisierten sich in dieser Zeit über 30 Dichterinnen und Dichter, die seine lachische Poesie ins Russische übersetzten und sie in zwei Sammlungen herausgaben: Pesni o solnce i zemle (Moskva 1945, 151 Seiten, mit Vorwort von Viktor Šklovskij) und Stichotvorenija (Leningrad 1946, 87 Seiten). Vorher kam es im Herbst 1944 im Moskauer Schriftstellerklub - auf Initiative von Petr Bogatyrëv, Professor für Bohemistik und Slovakistik an der Lomonosov-Universität, bis 1939 in Bratislava - zum Avtorskij večer čechoslovackogo poeta Ondry Lysogorskogo. Den Abend leitete Viktor Šklovskij ein, dann trugen u. a. Boris Pasternak, Nikolaj Aseev, Samuil Maršak ihre Nachdichtungen der lachischen Gedichte vor, die Łysohorsky - wie vor zehn Jahren bei F. X. Salda - in Lachisch rezitierte.

Łysohorsky hätte mit dieser Solidarität in Moskau zufrieden sein können. Als ich aber in Łysohorskys Lašsko poezyja 1931 - 1977 (1988, 723 - 725) die Datierungen 
unter seinen letzten lachischen Gedichten in Moskau verfolgte (er hatte wie Rilke immer eine Kerze und einen Bleistift am Bett), ahnte ich, warum ausgerechnet 1944 in Moskau der mächtige Strom seiner lachischen Lyrik und der Balladen versickert war und er wieder Deutsch dichtete. Die Welt wurde bereits geteilt ohne seine erträumte ,lachische Autonomie“ akzeptiert zu haben.

Als Łysohorsky im Sommer 1946 aus Moskau (mit einem „Schutzbrief“ von Dimitrov) in die Tschechoslowakei zurückgekehrt war, stellte er fest, dass die Restexemplare seiner Gedichtsammlungen aus den 30er Jahren aus dem Verlag Družstevní práce abgeholt und verschwunden waren. Er bat den Generalsekretär der Kommunistischen Partei der Tschechoslowakei, Rudolf Slánský, den er aus Moskau kannte, ihn zu empfangen. Der legte ihm erneut ans Herz, mit Lachisch aufzuhören, vor allem mit dem ,polnischen“ $W$, und nur noch tschechisch zu dichten. Dafür möge er sich eine Botschaft in der Schweiz, Paris oder in den USA aussuchen. Der sture schlesische Dichter Eysohorsky ging aber auf dieses Angebot nicht ein. Der „Londoner" Kommunist Vlado Clementis, stellvertretender Außenminister, versuchte ihm noch zu helfen, die „Moskauer" Statthalter hatten jedoch schon das Sagen. Nach ihrem Staatsputsch 1948 fing die Zeit der politischen Prozesse und der Galgen an, denen auch der Generalsekretär Slánský und der Außenminister Clementis zum Opfer fielen. Für den schlesischen Dichter Óndra Łysohorsky, den man zuvor in die slavistische Abteilung der Universitätsbibliothek in Bratislava abgeschoben hatte, ein stilles Begräbnis zu Lebzeiten.

Von all dem erfuhr ich vor allem bei meinen Gesprächen mit Óndra Łysohorsky in Bratislava im Winter 1956-1957. Im Sommer 1957 konnte ich dann meine Dissertation Óndra Eysohorsky - básník verteidigen (Gan 1957).

Meine Abenteuer mit Łysohorsky sollten nicht enden. 1958 durfte in Prag - noch in der „Tauwetterzeit" - eine Auswahl der lachischen Poesie Łysohorskys Aj lašske řéky płynu do mořa erscheinen: mit seinem lachischen Kommentar zu einigen Gedichten, dem Nachwort von Josef Rummler, der Šaldas Nachwort aus dem Jahr 1933 zitierte, auch die tabuisierte Rezension von Jiří Taufer zu Łysohorskys Lesung im Schriftstellerklub in Moskau 1944, Bezručs Brief an Pavel Gan 1956 und das Bekenntnis von Boris Pasternak im Vorwort Slavjanskij poèt zu seinen ersten 5 Nachdichtungen der lachischen Poesie (in: Literatura $i$ iskusstvo, 21. 8. 1943):

S Lysogorskim menja sbližaet obščnost' poètičeskich privjazannostej i ispytannych vlijanij. Mne v nëm dorog krupnyj sovremennyj poèt s interesnymi mysljami i nezaurjadnym živopisnym vkusom.

Was für ein Gefühl für mich, die Stille um den zu Lebzeiten beerdigten schlesischen Dichter gesprengt und seiner lachischen Poesie den Weg zurück in die europäischen Literaturen geebnet zu haben! Denn 1966 bekam ich plötzlich aus der Schweiz die 20. Nummer der Zeitschrift poésie vivante, Tribune Internationale de Poésie éditée à Genève, die exklusiv Óndra Łysohorsky gewidmet war und ihn für den 
Nobelpreis nominiert hatte! Ich war damals in Prag, ging zu Eduard Goldstücker, Germanistikprofessor an der Karlsuniversität, und fragte ihn, ob man sich hier nicht der Erforschung des Phänomens des bilingualen lachisch-deutschen schlesischen Dichters Óndra Łysohorsky widmen könnte? (Ich habe darauf später in den Überlegungen Zur Genesis der Themen und Motive der deutschen und lachischen Poesie des schlesischen Dichters Óndra Eysohorsky aufmerksam gemacht, s. Gan 1996, 4-19.) Wie ich nach meinem Gespräch mit Prof. Goldstücker in Prag jedoch erfuhr, schrieb er umgehend nach Oslo - der „Prager Frühling“ stand vor der Tür -, dass man Łysohorsky den Nobelpreis nicht verleihen solle. Als ich vor den „brüderlichen“ Armeen im Herbst 1968 in den Westen „umgezogen“ war, erhielt ich 1971 die Nachricht, dass die poésie vivante Łysohorsky zum zweiten Mal für den Nobelpreis nominiert hatte - als den schlesischen Mistral!

Im Frühjahr 1984 ergab sich eine neue Gelegenheit, als bei uns am Slavischen Seminar in Göttingen der Linguist Prof. Jiří Marvan von der Monash University aus Australien, dem einzigen slavistischen Institut auf der südlichen Hemisphäre, zu einem Vortrag eintraf (bevor er nach Australien berufen wurde, unterrichtete er in Uppsala den künftigen Sekretär der Nobelpreisstiftung.) Nach den Vorträgen gingen wir gewöhnlich vom Blauen Turm in die nahe Kneipe im Berliner Hof, wo unser Prof. Andrzej de Vincenz vorher bei der Wirtin ein slawisches Gericht bestellte. An jenem Abend war es eine Linsensuppe mit Würstchen. Beim Bier brillierte dann Prof. Marvan mit Anekdoten in allen slawischen Sprachen. Ich wartete, bis seine amerikanisch-australische Show zu Ende war - und rückte mit den Anekdoten „po našému“ über Antek und Jósek raus. Als Prof. Marvan erfuhr, dass ich aus Český Těšín war, an der Masaryk-Universität über Óndra Łysohorsky promoviert hatte und dass man diesen zweimal in der Schweiz für den Nobelpreis nominiert hatte, beflügelte ihn offensichtlich der Gedanke an eine dritte Chance.

Wir überlegten darauf im Blauen Turm, wie man im Westen in einem Band chronologisch alle lachischen Gedichte Łysohorskys herausgeben könnte, und in weiteren Bänden alle deutschen und ,sowjetischen“ (ostslavischen, turkotatarischen und kaukasischen) Nachdichtungen, vor allem aber die englischen, um die sich Ewald Osers in England gekümmert hatte; ohne englische Nachdichtungen, wie die von Ewald Osers im Fall von Jaroslav Seifert im Herbst 1984, würde man einen Nobelpreis ohnehin nicht verleihen). Die Bohemistikstudentin Felicitas Rohder besuchte danach Łysohorsky wiederholt in Bratislava (ich durfte dort als „Republikflüchtling" nicht hin) und schmuggelte die von ihm autorisierten Texte nach Göttingen. 1989 verfasste sie bei uns am Slavischen Seminar ihre Magisterarbeit Die Rolle von Óndra Eysohorskys lachischer Poesie im čechischen literarischen und kulturellen Leben. Die Fotokopien von etwa 550 lachischen Gedichten schickte ich laufend an Prof. Marvan nach Australien, wohin ich Ende August 1986 zur Endredaktion des Textcorpus eingeladen war.

Das von uns redigierte lachische Textcorpus wurde anschließend in einen Computer der Monash University eingegeben und schon per Satellit (noch mit großen Lettern) an Prof. Peter Scherber von der Gesellschaft für Wissenschaftliche 
Datenverarbeitung gesendet. Hier hat es Felicitas Rohder für den Druck vorbereitet (Eysohorsky 1988). Einige Autorenexemplare konnten wir noch im gleichen Jahr Óndra Łysohorsky und seiner Frau Olga Kuchtová-Gojová zwischen den Weinbergen in Trumau bei Wien überreichen. Dabei waren anwesend ein Slavist von der Wiener Universität, Prof. Günter Wytrzens, Landsmann aus Karviná in Tschechisch-Schlesien, und der Slavist Jiří Marvan von der Monash University aus Australien. Was für ein Gefühl für den schlesischen europäischen Dichter Óndra Łysohorsky, kurz vor seinem Tod den ersten Band seiner lachischen Poesie zu erblicken!

Als ein Jahr danach die Berliner Mauer fiel und ich (nach einundzwanzig Jahren) zu Weihnachten in die Tschechoslowakei fahren durfte, kam ich nur noch zu Łysohorskys Bestattung im Krematorium in Bratislava an. Vorher habe ich in seinem Schreibtisch die (in Eysohorsky 1988 nicht vorhandene) Balada o Janu Palachovi, študéntovi a kacyřovi entdeckt und sie, mit Janáčeks Lachischen Tänzen als musikalischem Hintergrund, bei der Trauerfeier vorgetragen. Der Witwe Olga Kuchtová-Gojová überreichte ich zusammen mit Prof. Marvan den zweiten Band (Łysohorsky 1989).

Nachdem im September 1990 - in der Euphorie nach der „Samtenen Revolution“ - in Łysohorskys Geburtstadt Frýdek-Místek seine Rehabilitierung in Angriff genommen wurde, schrieb ich darüber in den Informationen der Universität Göttingen (Januar/Februar 1991, 14-15) und fügte dem Faksimile der russischen Abschiedswidmung von Boris Pasternak aus Moskau vom 11. Mai 1946 und einem Foto von Łysohorsky in Bratislava aus dem Jahre 1987 auch die kürzeste lachische Ballade bei. Sie entstand in Taškent am 5. Dezember 1942 und wurde in Russisch von Samuil Maršak bei Łysohorskys Lesung im Schriftstellerklub in Moskau 1944 vorgetragen (Lysogorskij 1946, 8):

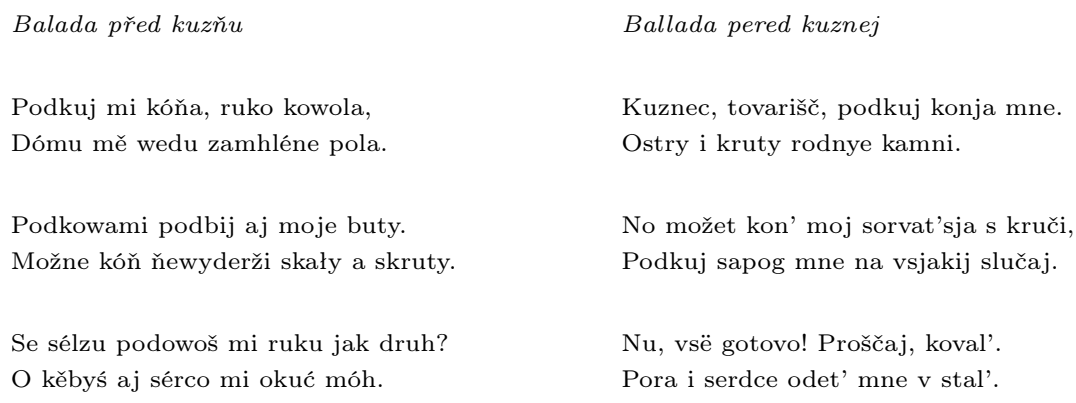

An all das erinnerten wir uns gemeinsam mit Jiří Marvan während der Konferenz zum 100. Geburtstag Óndra Łysohorskys in Frýdek. Jiří Marvan veröffentlichte dazu in seinem Buch Brána jazykem otvíraná aneb o češtině světovédas Kapitel „Łysohorského lašský projekt - daň době minulé, či odkaz pro budoucnost. Příspěvek k záchraně jazykového euroregionu“(Marvan 2004) und überlegte, wie man Łysohorskys dichterisches Werk in der sprachlichen Euroregion Schlesien 
vor dem Vergessen retten könnte. (Zu diesem Problem präsentierte in Frýdek der Hochschullehrer Bohumír Zlý Ergebnisse seiner Umfrage. Er hatte 2005 an der Obchodni podnikatelská fakulta SU a Ekonomická fakulty VŠB-TU in Ostrava und Karviná 567 Studenten befragt, ob sie schon einmal von Óndra Łysohorsky gehört hätten - mit dem Ergebnis, dass nur einer einzigen Studentin Łysohorsky bekannt war.) Ich gab also in Frýdek die „Lachistik-Staffel“ weiter: An Grażyna Balowska, welche 2001 in Opole ihre Magisterarbeit über Łysohorskys lachische Literatursprache verteidigt hatte; an Libor Martínek von der Slezská univerzita in Opava, bei dem 2004 Markéta Pfeiferová ihre Diplomarbeit über Łysohorsky geschrieben hatte; und an Prof. Aleksandr Duličenko in Tartu, spezialisiert u. a. auf slawische Mikroliteratursprachen, der den dritten Band mit Nachdichtungen von Eysohorsky in ostslavischen, mittelasiatischen und kaukasischen Sprachen aus den Jahren 1940 - 1946 und danach herausgeben möchte.

Möge also der lachische Mistral Óndra Łysohorsky aus der Euroregion Schlesien auch den Schlesier Walter Kroll am Kaminfeuer begeistern.

\section{Literatur}

Balowska, G.: 2001, Próby Óndry Eysogorskiego utworzenia laskiego języka literackiego, Dissertation, Uniwerzytet Opolski.

Duličenko, A. D.: 1981, Slavjanskie literaturnye mikrojazyki, Tallinn.

Duličenko, A. D.: 1992, ,Fenomen Ondry Lysogorskogo: Odin čelovek - odin jazyk. In: Umělecký a lidský odkaz Óndry Eysohorského, Hg. K. Bogar, Frýdek-Místek, 104-117.

Gan, P.: 1957: Óndra Eysohorsky - básnikk. Filosofická fakulta MU, Brno.

Gan, P.: 1992, , «W řéku rozšiřił mě kraj rusky», Úvahy ke vztahu Óndry Łysohorského a Borise Pasternaka v Sovětském svazu 1941 - 1946', in: Umělecký a lidský odkaz básnika Óndry Eysohorského, Hg. K. Bogar, Frýdek-Místek, 61-70.

Gan, P.: 1995, ,Ein Plädoyer für die Lachistik‘, in: „Ite meis manibus gestati saepe libelli". Studia Slavica Ioanni Schultze bibliothecario eminentissimo, librorum peritissimo slavicorum, qui decimo tertio lustro completo mense marte exeunte accipit vacationem muneris ab omnibus qui hoc in Georgiae Augustae seminario linguis litterisque slavicis se dedere solent, dedicata, edidit Werner Lehfeldt, Göttingen, 169-175.

Gan, P.: 1996, ,Zur Genesis der Themen und Motive der deutschen und lachischen Poesie des schlesischen Dichters Óndra Łysohorsky. Vorüberlegungen zum komparatistischen Erforschen des mehrsprachigen poetischen Werkes', in: Óndra Eysohorsky 1905 - 1989, Frýdek-Místek, 4-19.

Łysohorsky, Ó.: 1934, Spiwajuco piaść, úvodní slovo F. X. Šalda, Praha.

Łysohorsky, Ó.: 1935, Hłos hrudy, Praha.

Lysogorskij, O.: 1945, Pesni o solnce i zemle, 1931 - 1943, Moskva.

Lysogorskij, O.: 1946, Stichotvorenija, Leningrad. 
Łysohorsky, Ó.: 1958, Aj lašske řéky płynu do mořa, doslov Josef Rumler, Praha, $243 \mathrm{~S}$.

Lysohorsky, O.: 1966, poésie vivante, Journée Internationale de Poesie 20 (zu Lysohorskys Nominierung für den Nobelpreis), Genève.

Lysohorsky, O.: 1970, Une étude de Pierre Garnier. Documents iconographiques, Genève (poésie vivante).

Łysohorsky, Ó.: 1988, Lašsko poezyja 1931 - 1977, Hg. J. Marvan u. P. Gan, Schriften des Komitees der Bundesrepublik Deutschland zur Förderung der Slawischen Studien, Bd. 1, Köln - Wien.

Łysohorsky, Ó.: 1989, Lachische Poesie 1931 - 1976 in deutschen Übersetzungen und Nachdichtungen, Hg. P. Gan (Vorwort), J. Marvan und F. Rohder, Schriften des Komitees der Bundesrepublik Deutschland zur Förderung der Slawischen Studien, Bd. 2, Köln - Wien.

Marvan, J.: 2004, ,Łysohorského lašský projekt - daň době minulé, či odkaz pro budoucnost? Př́spěvek k záchraně jazykového euroregionu', in: Brána jazykem otvíraná aneb o češtině světové, Praha, 275-285.

Marvan, J. (Hg.): 2005, Poručénstwo. Óndra Eysohorský. Odkaz. České parafráze a doslov Zdenka Bergrová, Acta Slavica et Baltica 3, Karlova universita.

Osers, E.: 1971, Selected Poems of Ondra Lysohorsky, London.

Rohder, F.: 1989, Die Rolle von Óndra Eysohorskys lachischer Poesie im čechischen literarischen und kulturellen Leben. Magisterarbeit, Seminar für Slavische Philologie der Universität Göttingen.

Szewczyk, W.: 2001, Wspomnienia. Hg. G. Szewczyk u. W. Janota, Katowice, 149-153. 


\section{Lehren, Übersetzen und Forschen in Jeletz (1887- 1891). Ein Kapitel aus Wassili Rosanows Biographie ${ }^{1}$}

Im Jahr 1887 wurde der Lehrer Wassili Rosanow auf eigenen Wunsch von Brjansk in die $250 \mathrm{~km}$ südöstlich gelegene Kleinstadt Jeletz versetzt. Der Unterricht am dortigen Gymnasium, hoffte der Einunddreißigjährige, entspräche seinen denkerischen Fähigkeiten und wissenschaftlichen Ambitionen mehr als die Arbeit im Brjansker Progymnasium. Auch erwartete er, der Ortswechsel könne seine Ehe mit Apollinaria Suslowa retten. Wie hat er sich getäuscht!

Das Jeletzer Gymnasium hatte zuvor (1880-84) der spätere Literaturnobelpreisträger von 1933, Iwan A. Bunin (1870-1953) besucht; er war jedoch wegen ausstehenden Schulgeldes ausgeschlossen worden. Michail M. Príschwin (18731954), gleichfalls später bekannter russischer Schriftsteller, besuchte die Schule von 1883 bis 1889. Er hatte als Zwölfjähriger mit Kameraden die Flucht in den „wilden Osten“, nach Asien geplant. Rosanow unterrichtete ihn seit 1887 und 
nahm ihn gegen den Spottvers der Mitschüler - ,sie flohen einst nach Asien und kamen in Gymnasien“ - mit dem Einwand in Schutz „Das war lobenswert, denn es war ungewöhnlich" (Prišvin 1994, 365). 1889 ereilte Prischwin dann doch das Consilium abeundi: Er hatte just den Lehrer Rosanow beleidigt; er hatte sich wohl über ihn lustig gemacht, weil der Lehrer gewohnheitsgemäß mit dem Bein wippte. Das war Anlaß für anzügliche Bemerkungen der Gymnasiasten. Rosanow gab zu Protokoll, der Schüler habe ihn wegen einer unzureichenden, die Versetzung gefährdenden Note in Geographie bedroht: „Es wird dann weder Sie noch mich geben". Wahrscheinlich hat sich Rosanow gerade deshalb zu dieser Zeit einen Revolver besorgt. Im autobiographischen Roman Kastschejs Kette (1923-1954) hat Prischwin (Prišvin 1954) dem Lehrer „Ziegenbock“ (d. i. Rosanow) die alleinige Schuld am Schulverweis gegeben ${ }^{2}$. Den Sommer 1889 über suchte Rosanow Heilung von seinen infolge der Trennung von Apollinaria Suslowa und des Konflikts mit dem Schüler Prischwin überreizten Nerven in Lipezk (Fateev 2002, 83).

Schließlich lernte Rosanow in Jeletz auch den Schüler Sergej Bulgakow (18711944) kennen, der 1890 die Universität Moskau bezog und später als Religionsphilosoph von sich reden machte. Bulgakow hatte den Besuch des Priesterseminars abgebrochen und war zum Gymnasium gewechselt, wo ihn Rosanow ohne Erfolg von Materialismus und Marxismus abzubringen suchte. Erst nach Jahrhundertwechsel und Revolution von 1905 hat Bulgakov dann dem Materialismus abgeschworen. Schließlich muß Rosanow in Jeletz auch dem Schüler N. A. Semaschko (1874-1949) begegnet sein, der Revolutionär wurde, 1895 in Moskau verhaftet und verbannt wurde und es später bis zum Gesundheitsminister der Sowjetunion brachte.

In Jeletz hatte der Inspektor Penkin, der wie Rosanow aus Brjansk übergewechselt war, unter den Lehrern die Kunde gestreut, der neue Kollege habe in Brjansk nicht nur eigenhändig ein ,ganzes dickes“ Buch geschrieben, sondern es sogar auf eigene Kosten drucken lassen. Auf Nachfragen mußte Penkin einräumen, das Werk nicht gelesen zu haben; jedenfalls handle es von Philosophie und heiße Über das Verstehen. „Das muß ein wundersamer Vogel sein“, ereiferten sich die neuen Kollegen, „ein ganzes Jahresgehalt für den Druck eines Buches aufzuwenden!“ Fragen kamen auf: „Wovon hat er gelebt?“ „Wie kann man überhaupt ein ganzes Buch über das Verstehen schreiben!“ „Und was ist das überhaupt: Verstehen?“ Penkin nahmen sie die Auskünfte nicht recht ab, aber den Autor des sagenhaften Werkes mochten sie auch nicht fragen. Schließlich teilte Penkin mit, er werde Rosanow zur bevorstehenden Familienfeier einladen; dann werde man schon sehen, was es mit dem Buch auf sich habe.

Das Fest hatte den ersten Geburtstag der Tochter zum Anlaß, die der stockkonservative, karrierebewußte Vater, einer Regel des Alten Testamentes getreu, bis zu diesem Tag nicht auf dem Arm getragen hatte. Um den Tisch, auf dem ein Stör gewaltiger Größe aufgetragen war, saßen die Lehrer mit ihren Frauen. Die Gemahlin des Inspektors trug die in Spitzen gewickelte Tochter ins Zimmer, und der Vater suchte sie unter den Glückwünschen der Gäste mit den Händen zu halten. Toaste wurden ausgebracht, und man stieß an. Als der Fisch verspeist war, 
kam das Gespräch mit dem neuen Lehrer wie zufällig auf sein Leben in Brjansk und sein Werk. Rosanow erzählte leutselig: „Es ist mein erstes Buch, handelt vom Verstehen und ist mehr als 600 Seiten stark. Ich habe es bei Lissner und Roman in Moskau drucken lassen, mit einer Auflage von 600 Stück." Man staunte: „Und diese Weisheit über das Verstehen hat ein Mann zu Papier gebracht, der mitten unter uns sitzt und zuvor Lehrer war am Brjansker Progymnasium!“

Bald bekamen die Lehrer das Buch auch leibhaftig zu Gesicht. Wenige Wochen später fragten sie beim Autor nach, wohin er die Bücher denn zum Verkauf geschickt habe, was eines koste und wie viele inzwischen abgesetzt worden seien. Rosanow nannte den Preis von fünf Rubeln, flüchtete sich im übrigen in Späße. Wie sollte er auch einräumen, daß in den ersten beiden Jahren weder in Moskau noch in Jeletz auch nur ein einziges Exemplar über den Ladentisch gegangen war! Die Kollegen rechneten eifrig nach: Der Autor hatte bei diesem Preis selber an die zweitausend Rubel berappen müssen. „Woher hat er diese Unsumme bloß genommen?“ Penkin „unterrichtete“ sie: Rosanow sei Sohn einer armen Beamtenwitwe, sie habe die Familie durch Wäschewaschen über Wasser gehalten. Er habe im Studium vom Stundengeben gelebt und zu guter Letzt seine Zimmerwirtin geheiratet. Die Schwester dieser Frau sei eine dieser berühmten Damen, die im Ausland studiert hätten und als erste in Rußland Ärztinnen geworden seien. Rosanow habe sich aber schon im ersten Ehejahr von seiner Frau getrennt. Die Gerüchte blühten und verkürzten eine zeitlang die Langeweile der Kleinstädter.

Auf den Inhalt seines Buches wurde Rosanow nicht angesprochen. Unterdessen kamen hinter seinem Rücken wilde Vermutungen in Umlauf; Spekulationen zielten auf den Tatbestand, daß die Arbeit kaum Zitate und Fußnoten aufwies. Einer der Lehrer versuchte sie gar zu lesen, doch zu mehr als hilflosem Blättern in den vielen Seiten reichte es nicht. Da kam einem der Gedanke: „Er hat diese Hunderte von Seiten gewiß aus irgendwelchen Büchern abgeschrieben. Man muß nur herausfinden, aus welchen!" Mit Unschuldsmiene fragten sie den Kollegen, welche Fremdsprachen er denn beherrsche. Sie verdächtigten ihn nämlich, sein Buch überwiegend durch Übertragung aus dem Werk eines ausländischen Philosophen zusammengestellt zu haben. Es ergab sich jedoch: Rosanow beherrschte Fremdsprachen nicht über das Maß hinaus, wie es jeder Oberstufenschüler im Gymnasium erwarb.

Niemandem gelang es zu unterscheiden, was in der dicken Schwarte vom Autor selbst stammte und was nicht, und doch alle waren überzeugt: Das meiste hat er gestohlen. Der Verfasser aber saß wie eh und je daheim und hielt sich in seiner freien Zeit von den anderen Lehrern fern. Gesprächen entwand er sich mit Späßen. Und so entschieden die Kollegen einmütig: „Das ist keine Beere von unserem Feld.“ Die Gehässigkeiten nahmen zu. Kollegen begannen, ihn spöttisch „den Philosophen“ und „den Verstehenden“ zu nennen. Der Lehrer alter Sprachen Desnítzki, ein leidenschaftlicher Spieler, gab - auf Rosanow gemünzt - ab und an voll Hohn von sich: „Es hat sich ein Verstehender unter lauter Nichtsverstehenden gefunden“. Die Verleumdungen hinter Rosanows Rücken verstummten auch nicht, als er bei einigen Lehrern zu Namenstagen und Abendeinladungen erschien. Einmal geriet er 
sogar auf ein Trinkgelage von Junggesellen beim Lehrer des Mädchengymnasiums Schelúdkow. Hier entspann sich ein Streitgespräch mit Desnitzki, der mächtig gegen Philosophie und Philosophen vom Leder zog und eifernd schrie: „Auch wir verstehen etwas!" Auf dem Gipfel des Streits griff er das Buch Vom Verstehen, das Rosanow Scheludkow feierlich überreicht hatte, vom Regal knöpfte seine Hose auf und bepinkelte es unter allgemeinem Gelächter: „Und ihr Verstehen, Wassíli Wasílitsch, das ist es, was es wert ist." (Pervov 1995, 95).

Dieses Buch war ein Wagnis, richtete es sich doch offen gegen die russische Kathederphilosophie. Rosanow griff unverblümt die von Professor Troitzki vertretene englische Erfahrungspsychologie an - zumal Bacon und die induktive Logik. Die Studie untersucht, was Rosanow die „Seiten der Welt" nannte. Sie entsprechen Kants „Kategorien“. Die „Schemata des Verstandes“" werden hier jedoch weder rein logisch noch psychologisch, sondern kosmologisch gefaßst. Es geht im Kern wie in Aristoteles' Metaphysik nicht um „Ursache" oder "Zweckmäßigkeit" im Sinne begrifflicher Kategorien; es ist dem Verfasser nicht um den Begriff des Zweckhaften zu tun, sondern um das Gefüge, die Bauweise der natürlichen zweckmäßigen Vorgänge selbst. In dem, was er mit der Kompaktheit eines Wörterbuchs auf den ersten siebzig Seiten darzulegen suchte, gab es, wie Rosanow auch später noch überzeugt war, neben dem von anderen ,lange entdeckten Amerika“" auch eine Menge „sympathischer Inseln“, auf die noch nie der Blick des menschlichen Auges gefallen war (Rozanov 2001, 18).

Eine wiederentdeckte Insel ist für die Neuzeit die Beschränkung der wissenschaftsfähigen Kenntnis auf das keiner Veränderung unterworfene Dauerhafte, auf das Ewige. Rosanow nennt Wissenschaft nämlich im Anschluß an Aristoteles nur die Kenntnis, die sich auf ewig Seiendes bezieht. Das Veränderliche schließst er aus der Wissenschaft völlig aus. Das Gesetzmäßige, das Veränderungen hervorruft, steigt nur, sofern es Bestand hat, selbst auf zum Gegenstand der Wissenschaft. Zeitlich ist, was geschieht; dauerhaft ist, was dieses Geschehen hervorruft, was es erschafft. Da ewig Seiendes aber nicht vor Augen liegt, muß sich die Wissenschaft dieses Ewige aus dem Sichtbaren, aus eben den Erscheinungen erschließen, die selbst dem Wechsel unterliegen. So sind ewige Kräfte zwar nicht sichtbar, rufen aber wahrnehmbare vergängliche Erscheinungen wie die Bewegung hervor, aus denen sie sich dann herleiten lassen. Dieses Herleiten ist das im Titel benannte „Verstehen".

Philosophiegeschichtlich schließt das Scheiden des Beständigen, des „Seienden“, vom Unbeständigen, von der „Erscheinung“ an das Abheben der veränderlichen Welt gegenüber der unveränderlichen beim Griechen Parmenides an. Wie Parmenides dem Heraklitischen Verstehen der Welt als stetem Werden die eleatische Lehre von der Welt als ewigem Sein entgegensetzte, so hat Rosanow dem positivistischen Weltentwurf der Entwicklung die Idee der Wahrheit als Ewigkeit entgegengehalten. Wo Platon im Phaidon Leben und vollkommenes Sein als Bewegung zu fassen suchte, hat Aristoteles in seiner Metaphysik die begriffliche Gegenüberstellung von Nichtbewegung und Bewegung der Bestimmung Gottes als unbeweglichen Bewegers 
gipfeln lassen. Gerade diesen Text aber sollte Rosanow nach Erscheinen seines Buches gemeinsam mit seinem Lehrerkollegen Perwow ins Russische übersetzten.

Während anderenorts, gespeist auch von Hegels Entwurf der Welt als der Bewegung des Weltgeistes, Entwicklungstheorien sprudeln, entscheidet sich der junge russische Philosoph im Gegenzug für die Gleichung von Wahrheit und Ewigkeit. Das sich Entwickelnde verwirft er mit Blick auf seine Vergänglichkeit als nicht wahrheitsfähig. Die Entscheidung für das Dauerhafte, für das, was allem Wechsel unveränderlich zugrunde liegt, mag nur zu begreiflich scheinen bei einem Menschen, in dessen Lebenserfahrung der aus jähen Veränderungen erwachsende Schmerz überwog: Wenn das Leben einen Sinn hatte, konnte der nicht in den verschiedenen Einzelzuständen liegen, die unabsehbar und unvermittelt aufeinander folgten und durch die tiefe Pein unwiederbringlicher Verluste voneinander abgeschnitten waren. Sinn konnte allenfalls diesen Veränderungen zugrunde liegen. Dies war der innere Beweggrund, der Dauer Wahrheit zuzusprechen. Nicht weniger stieß Wassili die Verherrlichung des Wechsels in den Entwicklungstheorien des Positivismus dazu an, den entgegengesetzten Standpunkt zu vertreten; da sie seine Umgebung beherrschte, forderte sie seinen Widerspruch heraus. Ein Vorbild für solche Widerborstigkeit konnte er sich an Dostojewskis Essay von 1873 Das Milieu nehmen, das gegen die Freisprüche von Tätern Einspruch erhob, deren Vergehen mit ihrer sozialen Umgebung begründet wurden (Dostoevskij 1980).

Nicht den aus den Naturwissenschaften, zumal aus der Physik kommenden Grundsatz der Ursächlichkeit wählt Rosanow zum zeitlichen Band der Erscheinungen, sondern die in der philosophischen Überlieferung heimische Zweckmäßigkeit; er faßst sie als Zielgerichtetheit und stellt sie so auch dem Millschen Utilitarismus entgegen. Wo Kausalität die Herrschaft des Früheren über das Spätere und damit auch des Gegenwärtigen über das Künftige voraussetzt, hat für die Teleologie das Danach Vorrang über das Vorher. Hier gebietet das Nicht-Sein, genauer: das Noch-Nicht-Sein über das Sein. Das Sein erlangt seinen Zweck, sein Ziel aus dem, was noch nicht ist, indem es das Nicht-Seiende in Seiendes überzuführen hilft.

Bei Rosanow kommt der im Vergleich zur Räumlichkeit geringe Entwicklungsstand des Nachdenkens über die Zeit, über die Zeitlichkeit, zur Sprache. Mit dem Bezug auf zeitliche Stetigkeit steht sein Blick auf die Ganzheit der Welt statt auf ihre Teile im Einklang. Rosanow fügt das Nachdenken über das Verstehen in eine Kosmologie, in den Entwurf des Weltganzen ein, wie es das westliche Philosophieren im Gegensatz zum russischen kaum kennt:

Die Lehre vom Kosmos als Ganzem hat die Aufgabe zu bestimmen, welchen endgültigen Sinn das ganze Weltgebäude und die ganze Weltentwicklung hat und zugleich den tiefsten und wahren Grund seiner Entstehung und seines Bestehens zu erkennen. Wie eine Antwort auf diese Frage zu suchen ist, das kann alles weiter oben über das Finden der Ziele der einzelnen Dinge und Erscheinungen Gesagte zeigen, aber darüber etwas zu sagen, was darauf geantwortet werden kann, ist schwer. (Rozanov 1996, 344) 
Eine andere von Rosanow entdeckte Insel können wir „Philosophie der Stimmung“ taufen. Diese Entdeckung liegt bei der besonderen Prägnanz von Stimmungslagen in der russischen Kultur nahe. Wir erinnern nur an Toská, die mit ,Schwermut' nur unzulänglich ins Deutsche übersetzt ist; der Maler Horst Janssen hat ihr ein ganzes Buch mit Porträts und Werkausschnitten russischer Dichter und Schriftsteller gewidmet. Rosanow beschreibt - lange vor Freuds Abhandlung über Melancholie am Beispiel der von ihm erfahrenen Abschiedstrauer den Übergang einer starken Empfindung in eine Stimmung. Und anders als Freud verurteilt er Stimmungen nicht als irrational, sondern erhebt sie zum Kennzeichen ,großer Charaktere“:
Stimmungen sind Gefühle von außergewöhnlich allgemeinem Charakter, die ent- weder überhaupt kein Objekt haben oder einmal eines hatten, und zu dieser Zeit Aufwallungen waren und sie dann einbüßten, selbst aber erhalten blieben, wobei sie ihre Natur unverändert bewahrten. So trauert ein Mensch, der einen Naheste- henden verloren hat, zunächst um den Verlorengegangen, doch dann, wenn sogar das Verlorengegangene vergessen wird, bleibt das Gefühl unbestimmter Trauer in ihm erhalten, ergießst sich gleichsam über seinen Geist und verwandelt sich in eine beständige Stimmung, die bereits grund- und gegenstandslos ist. Doch öfter noch sind Stimmungen reine Geistesformen, die entweder nur erregt werden und durch äußere einmalige Fälle (wie den Tod von Luthers Freund) bekräftigt werden oder sogar solcher Fälle gar nicht bedürfen, und sei es nur, um geweckt zu werden. So war Dante nie ein fröhlicher Mensch und konnte es auch nicht sein, war Schiller nie zynisch und konnte es nicht sein, konnte sich Rousseau nie freuen. Das Bewußtsein dieser Grundlosigkeit der Stimmung, oder, was dasselbe ist, ihre Rein- heit als Geisteswerk, hat auch in der Sprache seinen Ausdruck gefunden: ,grämt sich", ,freut sich", „,wird unzufrieden“, ,ist leid um alles" sagen ganz gewöhnliche Menschen, wenn bei ihnen zeitweise eine Stimmung auftritt, die im Grunde nur großen Charakteren eignet. (Rozanov 1996, 403)

Das Beispiel Luthers, der nach dem Tod des Freundes durch Blitzschlag ins Kloster gegangen sein soll, ist klug gewählt; es leitet die auf Dauer angelegte Lebenshaltung überzeugend aus einer einzelnen Erfahrung her. Nur hat Rosanow es unterlassen, darzulegen, aus welchen Erfahrungen Luther später das Kloster nicht nur verließ, sondern es überhaupt abschaffte.

Der kulturgeschichtliche Blick auf die Gemütslage berührt sich mit Lew Tolstojs Ansicht, die Kunst übermittle nicht Kenntnis, sondern Gefühl. Die Bedeutung der Stimmung in der Geschichte kann Rosanow zufolge gar nicht hoch genug geschätzt werden. Religion und Revolution, Kunst und Literatur, Leben und Philosophie erlangten ihre Eigenart in der Stimmung derjenigen, die sie hervorbrächten. Den Buddhismus sieht er vom Gefühl der Hoffnungslosigkeit und Verzweiflung geprägt, die Lehre Zaroasters von der Empfindung der Machtlosigkeit im Kampf mit dem Bösen. Die Kunst erlange durch dieses oder jenes Gefühl ihr Gepräge, während ihr Gegenstand - die schönen Formen - stets ein und derselbe bleibe. Das Gefühl, zur Erde niedergedrückt zu sein und die Hoffnung, im Himmel Zuflucht und Erleichterung zu finden, hätten sich in der gotischen Architektur ausgedrückt, in der flämischen Malerei das Gefühl der Zufriedenheit mit dem Leben, in spanischer 
Erregtheit und Asketismus, in italienischer religiöse Freude. Das Muster einer Kulturgeschichte aus Stimmungen zeichnet sich ab, und es widerrät in seiner Begründung auf Gefühlslagen aufs Schärfste wie dem Rationalismus, so auch Hegels Entwurf der ästhetischen Geschichte als geistigen Stadien des sich fühllos verwirklichenden Weltgeistes.

Bei den Dichtern erfaßst Rosanow Stimmung als alles durchdringendes Gefühl: Sie präge sich allen Bildern ein, erklinge in jeder Lyrik, ob bei Dante, Schiller, Byron oder Heine. Die großen Schriftsteller schließlich brächten ihre Gemütslage in der Gestalt ihrer Sprache zum Ausdruck: Wenn ein und dasselbe Geschehnis mit gleicher Kunstfertigkeit von Herodot oder Thukydides, von Livius oder Tacitus erzählt werde, sei der Eindruck, den der Leser gewänne, doch ganz verschieden. Dies rühre von der unfaßbaren, sich keiner Analyse beugenden Verknüpfung der Wörter her, die der Autor unbewußt gebraucht habe, der sich der Leser auf unbestimmbare Weise unterwirft und die bei den Russen tiefer als in anderen Sprachen „Geist des Schriftstellers" genannt werde. Wassili irrt zwar, wo er den „Geist der Schriftsteller" der russischen Kultur zugute hält, aber es verdient Beachtung, daß dieser Topos der deutschen Romantik in der russischen Kultur mehr Boden gewonnen hat als in englischsprachigen Ländern oder in Frankreich.

Die Gemütslage zeitigt für Rosanow auch in der Philosophie Wirkung: Malebranche, Spinoza und Berkeley, Schopenhauer und Schelling sowie in der alten Zeit die Epikuräer und Stoiker hätten, ohne es selbst zu wissen - „unbewußt“! - unter dem starken Drang ihrer Stimmung gedacht und ihre Gedanken unwillkürlich dem Gefühl unterworfen, indem sie die einen Wahrheiten den anderen vorzogen. Aufschlußreich ist an dieser Gedankenfolge zunächst das Ersetzen der im Positivismus gängigen Überzeugung, die Umwelt - bei Taine: Rasse, Klima und Milieu - bedinge Denken und Schöpfen, durch den Blick auf die Wirkung des inneren Zustandes des Denkenden oder Schaffenden. Bezeichnender noch ist der Umstand, daß der Mensch diesen Stimmungen Rosanow zufolge unwillkürlich ausgesetzt ist. Sie kommen über ihn wie das Wetter, ohne daß er sich gegen sie zur Wehr setzen kann. Leider hat Rosanow in seinem Buch nicht verraten, auf welche vorherrschende Stimmung sein eigenes Philosophieren zurückgeht; daß er als ,starker Charakter“ Stimmungen hatte, versteht sich von selbst.

Rosanow hat seine Schellinglektüre später in Stillschweigen gehüllt. In dessen „System des transcendentalen Idealismus“ konnte er den Versuch kennenlernen, das Kernstück allen Wissens, die Übereinstimmung von Subjekt, also Geist oder Intellekt und Objekt, d.h. Natur als seinsgegebene Polarität zu erfassen. In der menschlichen Vernunft, lehrte die Schellingsche Naturphilosophie, kehre die Natur zu sich selbst zurück und kongruiere mit dem Intellekt. Hier fragt Schelling, wie zum Subjekt als Absolutem die Welt der Objekte hinzutrete. Historisch beginnt die Erkenntnis mit der ursprünglichen Empfindung, die noch nicht weiß, daß sie die Anschauung selbst hervorruft. In der Reflexion wird das Subjekt sich seiner eigenen Tätigkeit bewußt, als das Hervorbringen der mit dem Potenzreich der Natur in seinen Eigenschaften gleichwertige Formen des Objektbewußtseins in 
Form von Kategorien und Begriffen. Im Mittelpunkt steht die Ursächlichkeit, in die außer Zeit und Raum alle anderen Kategorien eingehen. Am Organischen zeigt Schelling, wie das Subjekt vom Objekt berührt wird. Die höchste Stufe des theoretischen Bewußtseins ist dann der absolute Willensakt, in dem sich die intellektuelle Anschauung auf sich selbst richtet und erkennt, daß es die Welt der Objekte unbewußt erschaffen hat. Es dürfte Rosanow bei all dem heftigen russischen Schellingianertum nicht entgangen sein, daß Schellings absolutes Ich ein auf es bezogenes Sein voraussetzt, das als Gott in Christus Mensch geworden ist. Dabei ermöglicht das Walten Gottes nach einem sinnhaften Plan dem Menschen auch die Möglichkeit freier Entscheidung im Sinne des Sittengesetzes. Dieses Freiheitsprinzip bestimme auch die Offenbarung. Gott wird entworfen als Einheit des unmittelbar „Seinkönnenden“ (als causa materialis, Wirkursache) mit dem rein Seienden (bewußt gewordener Wille als causa efficiens) und dem „Überseienden“ (Einheit der beiden als causa finalis). In Christus sei die zweite Potenz geopfert worden; auf die Petrinische Kirche des Katholizismus und die Paulinische Kirche des Protestantismus werde die „Johanniskirche der Zukunft“ als Verwirklichung des reinen Logos folgen. Die Offenbarung übersteigt die Mythologie, in welcher Schelling philosophisch erkennbares Weltschöpfungswissen ausmacht, mit dem Gott sich im Menschen realisiere; allegorische Deutungen des Mythos führen dagegen unausweichlich zu Widersprüchen. Der mythische Prozeß verläuft als Gang zunehmender Monotheisierung: Von der Großen Mutter geht es zu ägyptischen und indischen Götterhierarchien, bis es zur reflektierten griechischen Mythologie kommt. Gott ist Inbegriff der drei Seinspotenzen Natur, Form und Geist. Der Übergang vom potentiellen zum aktuellen Sein bilde den theogonischen Prozeß, der gleichermaßen subjektiv (im Geist des Menschen) und objektiv (in Gestalt der mythischen Götter) ablaufe.

In einer bereits vom Fortschrittsdenken geprägten Zeit richtete Rosanow das Augenmerk auf die Beständigkeit der Formen - wie der Natur so auch der Geschichte. Es geht ihm abermals nicht so sehr um die gegenwärtig bestehenden wie um diejenigen Formen, die alles Lebende unmerklich anstrebt. Im Zugriff auf Natur und Geschichte nach ein und demselben Grundsatz ist Wassili weniger der zeitgenössischen Übertragung naturwissenschaftlicher Verfahrenswiesen auf die Geisteswissenschaften verpflichtet als einem ganzheitlichen Vorgehen. Immerhin hat er die geistigen Erscheinungen, wohl ohne schon Windelbands Arbeiten zu kennen, von den natürlichen auf der Grundlage abgesetzt, daß sie menschliche Schöpfungen sind.

In seinem Grund ganz und gar idealistisch, erhebt Wassilis Denken gegen allen „Nihilismus“ und Materialismus seiner Gegenwart, Einspruch. Anders als dem Geist eignen Körpern keine Ziele an und für sich, sind sie nur Berührungspunkte des Geistes mit der materiellen Welt:

So besteht die Rolle des Körpers im Verhältnis zum Geist in dem, was sich auf die Bestimmung des Menschen bezieht. Es ist unzweifelhaft, daß nur der Geist als ewig sich vervollkommnende und ewig strebende Form im Menschen eine 
Bestimmung hat; sein Körper aber, der überall und immer unverändert bleibt, hat keinen Bezug auf diese Bestimmung. Und dennoch verweilt der Geist im Körper, und nur durch ihn, sich mit der physischen Welt berührend, kann er einige Teile seiner allgemeinen Bestimmung erfüllen. Vielleicht wäre es richtiger, derartige Tatsachen und Erscheinungen unvollkommene Zweckmäßigkeit zu nennen [...]. (Rozanov 1996, 344)

Im neunten Abschnitt des fünften Kapitels entwirft Rosanow das neben Nichtsein, sich bildendes Sein und reales Sein gestellte ,potentielle Sein“ (Rozanov 1996, 144-147). Er umreißt eine fünfgliedrige Typologie des Möglichseins und greift zum Beispiel jenes Samens, in dem der Baum als Möglichkeit angelegt ist. Der Same sei das potentielle Sein des Baums: Von ihm muß etwas fortgenommen und ihm muß etwas beigefügt werden, damit der Baum entsteht. Hier klingen mit den Leitmotiven Baum und Samen zwei der wichtigsten Bildkerne von Rosanows späterem Denken an. Aber auch seine Sicht auf Gogol' als Erfinder der russischen Prosa und Dostojewski als Entdecker der (russischen) Seele ist hier vorgeprägt. In diesem Sinne ruht in Rosanows Buch Über das Verstehen selbst das ,potentielle Sein" seiner späteren Arbeiten. Letztlich ist alles bisherige Sein für ihn nur das potentielle Sein eines künftigen endgültigen, eben des ewigen Weltzustandes. Das Moment der Möglichkeit war freilich bereits in Herzens Äußerung „In potentia enthält die russische Seele sehr viel" (Malia 1961, 233) zumal in besonderer Bindung ans Russische herausgestellt worden.

Anders als bei Hegel kommt bei Rosanow nicht der Weltgeist (im Kopf des preußischen Staatsphilosophen) zu sich und das Denken damit zu seinem Ende. Kein Prozeß des sich entfremdenden und zu sich kommenden Weltgeistes bestimmt und bildet den Weltprozeß, vielmehr ist es bei Rosanow die ewige und unabänderliche Wahrheit selbst, die dem Weltall Grund und Bestimmung verleiht. Das menschliche Meinen in Wissenschaft und Philosophie bleibt dagegen stets Stückwerk, es ereignet sich vielfach, wo das (richtige) Verstehen einmalig ist. Wissenschaft und Philosophie sind zeitlich, ja, „zwischenzeitlich“, da sie von der Wissensentwicklung stets wieder überholt werden. Was sich in der Erkenntnistheorie des zwanzigsten Jahrhunderts, etwa in Poppers Entwurf von Wahrheit als Widerlegung jeweils geltender Annahmen, als stets vorläufiger Charakter eines jeden Wissens entfaltet hat, beklagt Rosanow hier als Mangel:

Wissenschaft und Philosophie sind teilhaft, vielfach und zwischenzeitlich: In ihnen kommt die Tätigkeit des menschlichen Verstandes nicht zu ihrem Ende; sie sind ein Umherstreifen, das hierhin und dorthin gelangt, nicht aber zum Ziel; ihrer gibt es viele, und in all ihrer Vielheit erforschen sie weder das ganze Sein und seine Ganzheitlichkeit noch dasjenige Teilhafte, das in all seiner Fülle darin liegt: Nur Einiges erkennen sie in Einigem, nicht aber Alles in Allem, was darin dann auch [nur] dem Verstehen zugänglich ist; gerade am erschöpfenden Charakter mangelt es ihnen. (Rozanov 1996, 654f.)

Im Unterschied zu Popper stellt Rosanow der zeitgebundenen Wissenschaft und Philosophie das überzeitliche, aufs Ganze zugreifende Verstehen gegenüber. Wie 
bei Hegel ist bei ihm das Wahre nur das Ganze, doch hat hier, anders als beim Enzyklopädisten des Geistes, nicht der Verstehende das Verstehen in der Hand, sondern das Verstehen den Verstehenden. Das Zurückdrängen des autonom denkenden Subjekts ist die Brücke, die Rosanow zum kommenden Jahrhundert schlägt. Gegen objektivierende Wissenschaft und empiristische Philosophie grenzt er das Verstehen als hermeneutischen Vorgang, als zielgerichteten Austausch des Verstehenden mit dem Weltganzen ab. Dieses geistige Erfassen macht das Weltall zum Horizont des Verstehenden, ist monoman: Es wirft sein Licht auf nur eine angemessene Weise auf seinen Gegenstand, und es ist final: Was einmal verstanden ist, ist ein und für alle mal begriffen:

Im Gegenteil dazu eignet dem Verstehen dieser erschöpfende Charakter. Außerhalb von ihm gibt es keine erkennbaren Objekte, und in jedem einzelnen Objekt keine erkennbaren Seiten. Zudem ist es allein: Nicht nur in der Gegenwart, sondern auch in der Zukunft als möglicher läßt es keine Vielheit in sich zu; es kann kein zweites Verstehen auftreten, und wenn sich sogar der Verstand der Menschen selbst in seinem Aufbau, wenn in ihm andere Schemata des Erkennens aufkämen als gegenwärtig bestehen, - so hätte sich das Verstehen nicht verändert, sich nicht umgestaltet, sondern es fügte sich zu den sieben Lehren von den Seiten des Kosmos in ihm nur gleichsam noch etwas Achtes oder Neuntes hinzu. Auf diese Weise ist es das Letzte in der Tätigkeit des Verstandes, dasjenige, in dem er seine Ruhe finden kann, was in ihm den Schmerz des Nichtverstehens tilgen kann, was zur Vernichtung gerade dieses Bösen - des Teils eines Anderen und Umfassenderen, das in der menschlichen Natur angelegt ist - mit der Fähigkeit begabt zu sein scheint, es durch das Heil der Betrachtung der in ihrem Inhalt unveränderlichen und endgültigen Wahrheit vom Unvergänglichen zu ersetzen. (Rozanov 1996, 655)

Als Wassili diesen Gedanken gedacht, als er diese Passage geschrieben hatte, schwindelte ihm: Ihm war, als habe er im Begreifen selbst den Stein der Weisen gefunden, den Weg vom Erfassen der Dinge zum Verstehen der Wahrheit. Und es war ein Motiv östlichen Denkens, das ihm vorschwebte, wenn er durch das Verstehen den Verstand zur Ruhe bringen wollte.

Die Provinzstadt Jeletz ist am linken, hügligen Ufer des Flusses Sosná gelegen. Sie war in Rußland bekannt für ihre Spitzenstoffe und die Gutmütigkeit ihrer Bewohner. Dennoch fürchtete Rosanow nach dieser Erfahrung, in diesem Nest zugrunde zu gehen, und so bemühte er sich bald um eine Arbeit in Petersburg. Auf seinen Brandbrief an den späteren Freund, den Kritiker und Philosophen Strachow (1828-1896), erhielt er eine enttäuschende Antwort:

Sie wollen Jeletz verlassen, aber ich stelle es mir vor wie Belgorod, die Stadt, in der ich geboren bin. Das sind gesegnete Orte, wo Sonne und Luft und Holz so gut sind. Und Sie wollen nach Petersburg, wo ich seit 1844 lebe, und ich kann mich seither an diese Widerlichkeit, an diese Menschen und diese Natur nicht gewöhnen. Und was werden Sie hier tun? Hier unterrichten die Lehrer täglich fünf bis sechs Stunden. Ihr wahrer Platz ist es, an Zeitschriften mitzuarbeiten, wenn sie dazu 
fähig sind; doch Sie werden wohl kaum mit sich selbst und mit den Zeitschriften zurechtkommen. (Rozanov 1913, 147)

Alexander Herzen hatte schon Mitte des Jahrhunderts, wenngleich aus anderen, nämlich politischen Gründen davor gewarnt, die Provinzstädte zugunsten der Metropolen zu verlassen. Ihm schien die politische Kontrolle dort weniger durchzugreifen, und ihm war daran gelegen, demokratisch-revolutionäre Gesinnung möglichst gleichmäßig über das Land zu verteilen.

Die Weihnachtsferien 1888-1889 verbrachte Rosanow in St. Petersburg. Er lernte den Freundeskreis Strachows kennen. Dazu gehörten der Dichter Apollon Majkov, dessen Bruder, der Literarhistoriker L. N. Majkow. Er machte auch die Bekanntschaft des Vorsitzenden des Wissenschaftlichen Rates des Ministeriums für Volksbildung A. I. Georgíjewski, der eine Tätigkeit als Lehrer in St. Petersburg anriet.

Die Jeletzer Schüler schätzten die Gepflogenheit des neuen Geschichtslehrers, das Thema der Stunde links liegenzulassen und spannende Erzählungen aus ganz anderen Epochen oder gar aus Fachgebieten zum Besten zu geben, die den Schülern oft völlig unbekannt waren. Er sprach mit den ihnen wie mit Seinesgleichen und ging mit ihnen ungewöhnlich familiär um.

Sein Vorgänger hatte im Erdkundeunterricht keine hohen Maßstäbe gesetzt. Beim Abschlußexamen der vierten Klasse, das für alle Parallelklassen gemeinsam abgenommen wurde, hatte er den Schülern in Geographie mit Fragen der Art Erfolgserlebnisse beschert: „Wie heißt die Hauptstadt des Gouvernements Wladímir? Wie die des Kasaner Gouvernements? Welches Volk lebt in Frankreich? Welches in der Schweiz?" Ein Schüler vermutete hinter den schlichten Fragen eine Falle und gab zum Entsetzen der Beisitzer unzutreffende Antworten. Taranówski begann zu toben, die Assistenten entließen den Prüfling rasch. Der Schüler Samochwálow, der vier Jahre Geographieunterricht bei Taranowski genossen hatte, zeigte sich außerstande, auf der Karte Festland vom Meer zu unterscheiden. Nach der Aufforderung, irgendeinen Staat zu zeigen, fuhr er unbestimmt mit der Hand durch die Luft. Als die Noten erteilt wurden, zeigte sich: Taranowski hatte einen Haufen Vieren und Fünfen gestreut. Schließlich ist es gelungen, ihn davon zu überzeugen, allen ohne Unterschied eine Drei zu geben.

Bis hinein in die Stadt rühmten die Gymnasiasten den Nachfolger Desnitzkis ob seiner Gelehrsamkeit, und die Schülerinnen des Mädchengymnasiums beneideten sie um einen so gelehrten Historiker. Ihr eigner Geschichtslehrer konnte nur unanständige Witze über die Zarinnen Elisabeth und Katharina reißen und den jungen Damen selbstgemalte Bilder verehren. Als Pawel Perwow, dem wir diese Schilderungen verdanken, den vier Jahre älteren Rosanow zu Hause aufsuchte, traf er ihn in seinem Zimmer an. Vor den Sichtschirmen und an den Wänden erhoben sich Türme von Bücherregalen. Die Stellagen waren von unten bis oben vollgestopft mit Büchern aller Formate in alten Ledereinbänden mit Schmuckoder Goldschnitt und verblichenen goldenen Rückenaufschriften. Es fanden sich die großen Pergamentfolianten von Diderots Enzyklopädie, das kirchenkritische 
Dictionnaire historique et critique von Pierre Bayle, vielbändige französische Werkausgaben Voltaires, Rousseaus und vieler anderer Schriftsteller und Philosophen des 18. Jahrhunderts. Da standen die Erstausgaben russischer Klassiker neben manchen antiquarischen Raritäten in Latein und den neuen Sprachen. Auf einem eigenen kleinen Regal drängten sich die einbandlosen zerlesenen Werke der wenigen russischen Philosophen aus den geistlichen Seminaren und Akademien. Perwow vergrub sich viele Stunden in diese "Schätze des Denkens und Wissens“ (Pervov 1995, 95). Auch boten die durchgesehenen und gelesenen Bücher manchen Anlaß zu langen Gesprächen. Rosanows geschmeidiger und zugleich tiefschürfender Geist, seine klar und unverhohlen geäußerten Sympathien und Antipathien gegenüber Menschen und Meinungen steigerten diese Wechselreden nicht selten zu Wortgefechten.

Eines Tages stieß Perwow in Rosanows Regalen auf Renans (1862) Broschüre Über den Anteil der semitischen Völker in der Geschichte der Zivilisation. Er übertrug die Schrift ins Russische und schickte die Übersetzung dem Verleger Maranzujew nach Moskau. Dort ist sie $1888^{3}$ unter dem Titel Der Ort der semitischen Völker in der Geschichte der Zivilisation erschienen (Renan 1888). Rosanow, der Renans Mängel geißeln und ihm eine Abfuhr erteilen wollte, wählte für die Festrede im Gymnasium zum 1.10. 1888 aus Anlaß der Neunhundertjahrfeier der Taufe Rußlands das Gegenthema „Der Ort des Christentums in der Geschichte der Zivilisation". Diese vielbeachtete Rede erschien im Januar 1890 im Russischen Boten sowie als Büchlein mit dem anziehenderen Titel Der Ort des Christentums in der Geschichte und war rasch vergriffen ${ }^{4}$. Rosanow hatte zum erstenmal Erfolg beim Publikum. Der Vergleich der semitischen Weltwahrnehmung mit der christlichen setzte weitere Untersuchungen dieser Art in Gang, die in der Folgezeit zum Angelpunkt seiner philosophischen Arbeit wurde.

Rosanow stellt ganz im Geiste der Kulturgeschichte des 19. Jahrhunderts den lichten objektiven, experimentalen, und beobachtenden Geist der ,arischen Rasse“, der sich, vom Willen geleitet, nach außen, aufs Gegenwärtige, auf die Wahrnehmung der Wirklichkeit, richte, dem subjektiven, nach innen gewandten, von Vorstellung geleiteten Geist der semitischen Völker gegenüber ${ }^{5}$. Den semitischen Völkern fehlten demnach Initiative und Organisationsvermögen, Originalität und das Interesse für die sie umgebende Welt. Hier sei in den Wissenschaften die Abstraktheit Folge des Mangels an Beobachtung. In den Künsten blühten bei ihnen demnach nur die subjektivsten, Musik und Lyrik, nie aber wirklichkeitsgesättigte Epik. Seien Wissenschaft, Kunst und Staat Früchte arischer Willensanstrengung, so würden den semitischen Völkern die göttliche Offenbarung und damit die Religion zuteil, weil sie sich auf den Innenraum ihrer Seele richteten. Und diese Seele sieht Rosanow nicht für ein organisches Geschöpf an, sondern für das Ebenbild und den Atem Gottes.

Die semitischen Völker haben für Rosanow nun ihren Mangel gerade in ihrem Vorzug, in der Introversion. Sie gestatte es ihnen nicht, ihre Religion der Selbstoffenbarung Gottes mit anderen Völkern zu teilen. Gott habe sich daher den Menschen 
erneut in Christus zu erkennen geben müssen, und diese Offenbarung sei nun nicht vom jüdischen Volk, sondern von den arischen Völkern angenommen worden: „Die historische und die religiöse Bedeutung des jüdischen Volkes ging zuende“ (Rozanov 1990, 18). Wie Hegel überzeugt, daß sich alles in der Geschichte mit innerer Notwendigkeit vollziehe, sieht Rosanow die Juden des Alten Testaments als auserwähltes, die des Neuen dagegen als verworfenes Volk. Die Vergebung, die sich im Opfertod Christi ereignete, habe den anderen Völkern nicht durch das introvertierte Volk zuteil werden können. Und diese „schreckliche Notwendigkeit“ müsse „tiefes Mitgefühl mit dem jüdischen Stamm“ (Rozanov 1990, 20) einflößen. Wenn Rosanow schreibt, das altes Testament sei geprägt vom Geist der Auserwähltheit und Strenge, von Größe und Schrecken, die Evangelien dagegen zeigten den „Geist heller Freude, den Geist der Vergebung und der Versöhnung“" (Rozanov 1990, 21), wertet er jüdische und christliche Kultur als einander ergänzende Größen. Jetzt komme die Einstellung nach Außen den arischen Völkern zupaß, sie spürten in diesem hellen und freudigen Geist etwas ihnen Verwandtes. Sokrates habe die extravertierten Kräfte der Arier nach innen gekehrt zur Aufforderung „Erkenne dich selbst!, und so die Heraufkunft des Christentums vorbereitet.

Ziel der Weltgeschichte sei die Synthese von subjektgerichtetem, religiösem Judentum und objektgerichtetem, wissenschaftlichem Ariertum. Auf das Podest des Vorbilds für diese Einheit hebt Rosanow den polnischen Astronomen Kopernikus, der ungeachtet seiner wissenschaftlichen Einsichten von seinem Glauben nicht abgefallen sei. Rosanow stellt hier zunächst dem elitären alttestamentlichen religiösen Programm des auserwählten Volkes den egalitären neutestamentlichen Entwurf der Allvölkerreligion gegenüber. Kein Zweifel: Die Einstellung auf Erfahrung bei den englischen Empiristen stand ihm für die Mentalität der ,arischen Rasse“" ebenso Modell wie die Binnenschau des Psalmensängers David für die „semitische“. Wo Wladímir Solowjów das gottlose Menschentum des Westens dem menschenlosen Gottum des Ostens religionsgeographisch entgegensetzte, bildet Rosanow die religionsgeschichtliche Folge von introvertiertem Judentum und extravertierter Christenheit. Mit Blick auf die Kultur als Folge gegensätzlicher Typen wandelte er in den Fußstapfen Hegels. Rosanow rechnete es sich selber als den größten Erfolg an, in dieser Arbeit zum erstenmal den arischen und den semitischen Geist als „Produzenten der Menschheitsschicksale“ (Rozanov 1913, 202) und somit eine psychologische Erklärung der Geschichte vorgeführt zu haben ${ }^{6}$.

Der in die Augen springende Gegensatz zwischen dem Fehlschlag seiner philosophischen Monographie und dem Erfolg der populärwissenschaftlichen Rede war Wassilij eine Lehre. Anders als die Magisterarbeit Wladimir Solowjows von 1874, Die Krise der westlichen Philosophie (gegen die Positivisten) (Solov'ev 1974), und dessen Doktorarbeit von 1880, Die Kritik der abstrakten Prinzipien (Solov'ev 1980) - gemeint sind Idealismus und Materialismus zugleich - hatte die Öffentlichkeit Rosanows fachwissenschaftliches Buch ohne Echo gelassen. Nicht einmal der Vorwurf der Effekthascherei ist ihm erspart geblieben ${ }^{7}$. Der unerwartete Erfolg der Broschüre gab ihm freilich nun endlich recht. 
Mit der Schrift Altes und Neues (1891-92) suchte er an den Erfolg anzuknüpfen. Darin ging es allgemein um den geschichtlichen Wandel, im besonderen aber um das Ablösen der Volkstümler und der „Sechziger“, einer Richtung demokratischrevolutionär eingestellter russischer Intellektueller. Für den Kritiker trat die Absicht dieser, sich für das Volk verantwortlich fühlender Angehörigen der Vätergeneration in Widerspruch zu ihren Ergebnissen - sie vermehrten das Unheil nur, das sie zu bekämpfen suchten. Haß und Chaos hätten sie in die Seele des Volkes getragen und dabei ihre eigenen Schwächen der wahrgenommenen Welt zugesprochen: „Die Welt offenbart sich uns in dem Maße, das wir mit uns in diese Welt tragen." (Rozanov 1899a, 14) Dem ästhetischen Blick Rosanows schien die Welt verwickelt, die Traktate der Revolutionäre stellten sie als einfach dar.

In seinem Essay Katkow als „Staatsmann“ (1897) hat Rosanow an dem überaus einflußreichen russischen Kritiker zunächst vor allem „die Sättigung der Seele mit empirischem Wirklichkeitsgehalt" (Rozanov 1899b, 127) bemängelt: Die bestehende Welt habe sein Inneres überwältigt. Den überaus wirkungsvollen Kritiker, der auf manches ministeriale Ressort mehr Einfluß genommen hatte als die Fachminister, schlägt er unter den beiden von ihm unterschiedenen Menschentypen, den die Menschen führenden aktiven Welterrichtern in Gestalt von Narren in Christo und Feldherren und allen übrigen, die sich führen lassen (unter ihnen Gesetzgeber, Diplomaten, Politiker und Fürsten), den „Geführten“ zu. Katkow war eben doch kein Visionär. Keine Frage, Rosanow sah sich selbst gern unter den wenigen, die führen.

Belinskij hat Rosanow weniger kritisch beleuchtet als die Mehrheit der revolutionären Demokraten auf der einen und den staatsnahen Kritiker Katkov auf der anderen Seite. Dies lag gewiß daran, daß er dessen frühe Schrift Literarischer Träumereien als visionär einschätzte. Und so kam Belinskij in seinem Jubiläumsaufsatz 50 Jahre Einfluß (Das Jubiläum Belinskijs) auffällig gut weg. Rosanow zeigte Mitgefühl mit dem einsamen Denker und Achtung vor dessen Lebenslauf ohne Universitätsdiplom und irgendwelche Posten. Und manche Bemerkung schien mehr auf den Verfasser als auf seinen Helden gemünzt: „Er fragt ewig nach und lernt ewig." Dieser unbegrenzte Lernwille und diese Jugendlichkeit kennzeichne auch seine Aufsätze. Später zieh Rosanow Herzen unsolidarischen Gebarens; er habe trotz allem ideologischen Gleichklang den bitterarmen Kollegen nicht unterstützt.

Die beiden Brjansker Lehrer stießen beim Erwägen der philosophischen Zukunft Rußlands auf einen schwerwiegenden Mangel: Grundlegende Einsichten großer Philosophen waren in der russischen Kultur noch nicht heimisch. Dabei geriet sogleich Aristoteles in den Blick: Er hatte im Gegensatz zu Platon - ganz anders als im mittel- und westeuropäischen philosophischen Denken - in der russischen Kultur keine Heimat. Platons Philosophie war, von den Neuplatonikern ins christliche Denken getragen, über Byzanz tief in die russische Kultur eingedrungen. Die Aristoteles-Renaissance, die durch arabische Vermittlung über Spanien im späten Mittelalter in Gang gekommen war, hatte zwar West- und Mitteleuropa, nicht aber Rußland erreicht. 
Rosanow und Perwow einigten sich rasch auf die Übersetzung der aristotelischen Metaphysik ins Russische. Dies war eine kluge, aber auch gewagte Wahl. Den Realien näher als Platon, hat Aristoteles gerade in seiner Metaphysik die theoretische Probe auf sein Philosophieren geliefert (eigentlich hieß das Buch „prōtē philosophia“" - erste Philosophie). Hier ging es nicht nur um das Verhältnis des Allgemeinem zum Besonderen, um Stoff und Form, sondern auch um die Rosanow fesselnde Frage nach dem Bezug von Möglichkeit und Wirklichkeit. Der Grieche deutet das Werden als entelechetische Verwirklichung der in Stoff und Form selbst liegenden Möglichkeiten.

Die russische Geistlichkeit, die - alter Tradition gemäß - noch immer die Hand auf der Philosophie hatte und sich gerade anschickte, den bedeutendsten russischen Philosophen dieser Zeit, Wladimir Solowjow, aus der Universität zu werfen, konnte gegen die Aristotelische Metaphysik wohl die geringsten Einwände erheben. Kühn war die Aufgabe, weil die Metaphysik ein dunkles, schlecht überliefertes und schon von daher ungeheuer schwer zu übersetzendes Werk ist. Vielleicht aber wollte Rosanow den Russen auch nur die Voraussetzungen zum Verstehen seiner Monographie Über das Verstehen liefern...

Die beiden Übersetzer hatten keinerlei einschlägige Erfahrung, und die Provinzstadt bot kaum Literatur zu Aristoteles. In der Gymnasiumsbibliothek fanden sich nur das Lateinwörterbuch Thesaurus totius latinitatis und die griechischen Folianten des Aristoteles-Textes in der stereotypen Ausgabe von A.-F. Didot, allerdings ohne jeden Kommentar. Das Übersetzergespann bestellte bei Gotier in Moskau hoffnungsfroh die französische Fassung der Metaphysik aus der Hand Jules Barthélemy-Saint Hilaires (1805-1895). Doch die dreibändige Ausgabe leistete ihnen, wie sie behaupteten, kaum Hilfe: Sie kam ihnen vor wie unzusammenhängendes und unbegreifliches Gerede. Um sich davon nicht beeinflussen zu lassen, verbannten sie das Buch auf ein entlegenes Regalbrett, und sie haben es, wie Perwow wenig glaubhaft behauptete, in keinem Fall zu Rate gezogen.

Auch das zeitraubende Lesen der russischen Abrisse philosophischer Lehren für Seminarzwecke sowie aller russischen philosophischen Aristoteles-Darstellungen bot wenig Hilfe. Bei der philosophischen Terminologie wäre aber Beistand höchst willkommen gewesen, gerade sie kam in den Veröffentlichungen daher wie Kraut und Rüben: Für ein und denselben griechischen Terminus gab es Dutzende russische Übersetzungen, während die verschiedensten griechischen Ausdrücke mit ein und demselben russischen Wort wiedergegeben wurden. Die neuesten philosophischen Begriffswörter waren in die alten Texte hineingelegt worden, und die Wiedergaben strotzten zum Leidwesen der beiden nur so von Ausdrücken wie „Seiendes“, und „Wesen“, „Sein", „Substrat", und „Form“. Kurzerhand entschlossen sie sich, ohne alle Voraussetzungen ans Werk zu gehen, geleitet allein vom griechischen Text und vom eigenen Denken!

Hier tat sich eine weitere Schwierigkeit auf: Rosanow beherrschte die griechische Sprache kaum besser als jeder durchschnittliche Abiturient. Da er seinen philologischen Kenntnissen zurecht nicht traute, sah er nur ab und an in den 
griechischen Text. Und doch war er ein scharfsinniger Deuter des Originals, das Perwow ihm in wörtlicher Übersetzung vortrug, bisweilen sogar auf Lateinisch. Perwows Griechischkenntnisse verbanden sich so mit dem philosophischen Wissen und Vermögen Rosanows zu einer schöpferischen Gemeinschaftsleistung, die in der russischen Kulturgeschichte ihresgleichen sucht. Sie widerlegt auch das Vorurteil, Rosanow sei ein notorischer Einzelgänger gewesen ${ }^{8}$.

Manche Wörter und Begriffe, Ausdrücke und Phrasen wurden abendelang hin und her gewendet. Die Arbeit forderte tiefes Eindringen in den griechischen Wortlaut, abstraktes philosophisches Denken von hohem Rang und Erfindungsgabe bei der Wiedergabe von Feinheiten der Gedanken. Die beiden arbeiteten, die Ferien ausgenommen, ein ganzes Jahr lang und schwangen sich nach ödem Unterricht wieder und wieder auf zu philosophischer Begeisterung: Die Bewegung auf dem Höhenkamm des Denkens löste Schwindel aus, die Prosa des Alltags fiel von ihnen ab wie ein Albtraum. Für Perwow „die beste Zeit meines Lebens“ (Pervov 1995, 98), half das Miteinander Wassilij, den Gram über den Mißerfolg des ersten Werkes und die Unbill seiner Ehe zu verwinden.

Kaum hatten sie drei der dreizehn Bücher der Metaphysik übersetzt, gingen die beiden aufs Geratewohl in Nishni Nowgorods einzige Druckerei. Kotschergins Typographie druckte fast ausnahmslos Binden zum Verpacken von Tabak (Machorka) der gewaltigen Fabrik Saussálows. Auf die Frage, ob seine Druckerei auch Bücher herstelle, antwortete der Eigentümer: „Wir drucken Rechnungen, Mahnungen, können aber auch Bücher herstellen. Gehen Sie zum Setzer; der wird Ihnen alles sagen." Sie besprachen sich eine Stunde lang mit dem Setzer, schätzten, wie viele Buchstaben eine Buchseite aufnimmt, rechneten zusammen, vervielfachten, addierten Rubel und Kopeken. Diese Tätigkeit war dem hilfsbereiten Setzer offenkundig vollkommen neu; die Druckerei hatte noch nie ein Buch hergestellt. Als Perwow und Rosanow ihre Handschrift wieder eingewickelt hatten und aufbrechen wollten, hielt er sie einen Augenblick zurück und sagte im vertraulichsten Tone: „Sie sind, wie ich sehe, gute Menschen, meine Herren, und ich möchte Ihnen überflüssige Kosten ersparen. Mein Rat lautet: Statt zu drucken, ist es viel vorteilhafter, das fertige Buch in Moskau zu kaufen, es kostet wahrscheinlich nicht mehr als drei Rubel." (Pervov 1995, 98)

$\mathrm{Zu}$ dieser Zeit gab es in Rußland noch keine rein philosophische Zeitschrift, und in den Reihen der geistlichen Akademien waren nur religionsphilosophische Abhandlungen willkommen. Zuflucht bot dank N. N. Strachows Hilfe schließlich die Zeitschrift des Ministeriums für Volksaufklärung mit ihrer Abteilung für Klassische Philologie. Dorthin sandten die beiden den fertigen Teil ihrer Übersetzung, und dort wurde er bereitwillig zum Druck angenommen. Da die Übertragung von einem fortlaufenden philosophischen Kommentar begleitet war, der mehr Raum einnahm als die Wiedergabe des Originals, hat man sie nicht mit dem geringeren Honorar einer Übersetzung, sondern wie ein Original vergütet.

Nach dem Druck der ersten Bücher der Metaphysik setzten die beiden die Arbeit voller Eifer in Jeletz fort, und die Übersetzung erschien im Laufe von sechs 
Jahren, zwischen 1890 und 1895, in der ministeriellen Zeitschrift ${ }^{9}$. Während dieser Zeit kam es zwischen den beiden einzig zu Reibereien um das Erstlingsrecht bei der Namensnennung: Während Übersetzer und Kommentator meist in alphabetischer Reihenfolge „Perwow, Rosanow“ angegeben wurden, erwirkte Rosanow einige Male doch die umgekehrte Namensfolge. Die beiden haben sich letztlich darüber aber nicht zerstritten.

Als Lehrer war Rosanow weder besonders leidenschaftlich noch, wie andere Kollegen, wegen der Wahrnehmung seiner Urteilsmacht gefürchtet. Indes suchte ihn einmal der Vater eines Schülers auf, dem Rosanow womöglich aus Zerstreutheit zu Unrecht eine schlechte Note erteilt hatte. Dieser Mitarbeiter der Polizei entschuldigte sich für das schlechte Lernen seines Sohns, erbat aber - und erhielt die Zusicherung, diese Zensur werde nicht für die Endnote im Zeugnis zählen. Der Lehrer folgte, vom Mittagstisch abgehalten, sichtlich gelangweilt der umständlichen Rede des Verwaltungsbeamten, bis ihn unversehens ein Kinnhaken aus seiner Verträumtheit riß. Der aus der Haut gefahrene, bekümmerte Vater ließ sich seinen Entschuldingsbrief, den er dem Lehrer folgenden Tags übersandte, freilich noch zurückgeben, ehe es Nacht war. Erneut mokierten sich die Schüler über des Lehrers Angewohnheit, beim Sitzen eine Hand in der Hosentasche zu vergraben und rhythmisch ein Bein zu schaukeln...

\section{Anmerkungen}

${ }^{1}$ Dieses Kapitel wurde ausgewählt in Erinnerung an gemeinsames Lernen und Lehren, Übersetzen und Forschen in Göttingen. Da die Biographie, aus dem es stammt, wie diese Festgabe auch für den nichtslavistischen Leser geschrieben wird, nutzt es im Haupttext leichterer Lesbarkeit halber die Duden-Transliteration. Die für den Slavisten bestimmten Fußnoten und Quellennachweise entsprechen dagegen der wissenschaftlichen Umschrift.

${ }^{2}$ Im Oktober 1919 wird Prišvin $(1990,97)$ - Ironie der Geschichte - in eben dem Gymnasium Geographielehrer, aus dem ihn als Gymnasiasten der Geographie- und Geschichtslehrer Rozanov ausgeschlossen hatte.

3 Pervov $(1995,95)$ nennt in seinen Erinnerungen wohl irrtümlich die Jahreszahl 1898.

4 Später war die Abhandlung Teil von Rozanovs (1899) Buch Religion und Kultur.

${ }^{5}$ Rozanov stützte sich dabei auch auf das Buch Semiten und Indogermanen in ihrer Beziehung zu Religion und Wissenschaft. Eine Apologie des Christentums vom Standpunkte der Völkerpsychologie des protestantischen, in Königsberg wirkenden Theologen Rudolf Friedrich Grau (1835-1893).

6 Der Wert dieses Aufsatzes wurde von Vl. Solov'ev $(1911,55)$ in einem Brief an Leont'ev betont.

7 So A. Losev $(1994,45)$ : „Dem anarchistischen Dekadenzler Rozanov war ganz gleich, was er sagte, wenn es nur eine Sensation bildete."

8 Rozanovs Version, er habe die ersten sechs Kapitel der Aristotelischen Metaphysik bereits in Brjansk übersetzt (Brief an Strachov vom 15.2.1888), ist nicht belegbar.

9 Žurnal ministerstva narodnago prosveščenija. 1890, Nr. 2, 3; 1891, Nr. 1; 1893, Nr. 7-9; 1895, Nr. 1-2.

\section{Literatur}

Dostoevskij, F.: 1980, ,Sreda‘, in: ders., Polnoe sobranie sočinenij, Bd. XXI, 13-23. 
Fateev, V. A.: 1991, V. V. Rozanov. Žizn'. Tvorčestvo. Ličnost', Leningrad.

Fateev, V. A. (Hrg.): 1995, V. V. Rozanov: pro et contra. 2 Bde, Sankt-Peterburg.

Fateev, V. A.: 2002, S russkoj bezdnoj v duše. Žizneopisanie Vasilija Rozanova, Moskva.

Grau, R. F.: 1864, Semiten und Indogermanen in ihrer Beziehung zu Religion und Wissenschaft. Eine Apologie des Christentums vom Standpunkte der Völkerpsychologie (2. Aufl. 1867), Gütersloh.

Grübel, R.: 2003, An den Grenzen der Moderne. Das Denken und Schreiben Vasilij Rozanovs, München.

Losev, A.: 1994, Vladimir Solov'ev, Moskva.

Nikoljukin, A.: 2001, Rozanov, Moskva.

Malia, M.: 1961, Alexander Herzen and the Birth of Russian Socialism, Cambridge.

Pervov, P. D.: 1995, ,Filosof v provincii (iz literaturnych vospominanij)', in: Fateev, V. A. (Hrg.), Rozanov. Pro et contra, Bd. 1, 88-101.

Prišvin, M.: 1982, ,Kaščeeva cep' (1928-1954)', in: ders., Sobranie sočinenij v vos'mi tomach. Bd. 2, Moskva, 6-213, besonders 66-69, 87f., 93f., 96-99.

Prišvin, M.: 1990, Dnevniki, Moskva.

Prišvin, M.: 1994, Dnevniki. 1918-1919. Moskva.

Renan, E.: 1862, De la Part des Peuples Sémitiques dans l'histoire de la civilisation. Discours d'ouverture du cours de langues hébraïque, chaldä̈que et syriaque au Collège de France, Paris.

Renan, E.: 1888, Mesto semitskich narodov v istorii civilizacii, Moskva.

Rozanov, V. V.: 1886, O ponimanii. Opyt issledovanija prirody, granic i vnutrenneog stroenija nauki kak cel'nogo znanija, Moskva.

Rozanov, V. V.: 1888, Mesto christianstva $v$ istorii, Moskva.

Rozanov, V. V.: 1899, Religija i kul'tura, Sankt-Peterburg.

Rozanov, V. V.: 1899a, ,Staroe i novoe', in: ders., Literaturnye očerki, SanktPeterburg, 13-15.

Rozanov, V. V.: 1899b, ,Katkov kak „gosudarstevennyj čelovek“", in: ders., Literaturnye očerki, Sankt-Peterburg, 126-128.

Rozanov, V. V.: 1913, Literaturnye izgnanniki, Sankt-Peterburg.

Rozanov, V. V.: 1990, Mesto christianstva v istorii, Moskva.

Rozanov, V. V.: 1996, O ponimanii, Moskva.

Rosanow, V. V.: 2001, Literaturnye izgnanniki, Moskva.

Rozanov, V.: 2005, ,Sladkoe i gor'koe na Rusi (k istorii prof. M.M. Tareeva', in: ders., Zagadki russkoj provokacii. (Stat'i i očerki 1910 g.), Moskva, 260-278.

Solov'ev, V.: 1911, Pis'ma. Bd. III, Sankt-Peterburg.

Solov'ev, V.: 1874, Krizis zapadnoj filosofii (protiv pozitivistov), Moskva.

Solov'ev, V.: 1880, Kritika otvlečennych načal, Moskva.

Sukač, V. G., 1991/92. ,Žizn' Vasilija Vasil'eviža Rozanova „kak ona est““, in: Moskva 1991, 10: 137-170; 11: 141-153; 1992, 1: 108-131; 2-4: 120-128; 7-8: 121-141. 


\section{„Der Tod und das Mädchen“ in den Versionen Mak- sim Gor'kijs und Nikolaj Zabolockijs}

„Der Tod und das Mädchen“ gehört zu den grundlegenden und viel verwendeten Motiven der europäischen Kultur des Mittelalters und der Neuzeit. In seinen Anfängen steht es vielfach nicht allein für sich, sondern erscheint - meist in der bildenden Kunst und Malerei - als eine der Episoden des berühmten mittelalterlichen „Totentanzes“, der die Begegnungen des Todes mit Figuren aller Stände und Altersstufen zeigt. Der bis ins 20. Jahrhundert hinein in immer neuen Varianten aktualisierte und rezipierte „Totentanz" war dabei nicht nur eine Gattung der Malerei, bildenden Kunst und Graphik, sondern auch eine Text- bzw. Text-BildSorte, die seit dem 15. und 16. Jahrhundert in Handschriften und Frühdrucken weite Verbreitung gefunden und verschiedene regionale Traditionen ausgebildet hatte. Darunter nahm das 1485 zum ersten Mal herausgegebene Blockbuch von Guyot Marchant aufgrund seines europaweiten Erfolges eine Sonderstellung ein, indem es, bis ins 18. Jahrhundert hinein ständig nachgedruckt, die Vorstellungen weiter Kreise vom „Totentanz“ prägte (Layet 2000, 27). Eingebettet war diese 
Gattung im Kontext der „Sterbeliteratur“, der ,ars moriendi“, ihre Funktion war das „memento mori“ durch die häufig auch satirische Zurschaustellung der Begegnung des Menschen mit dem Tod. Wenn die ältesten Totentänze in der Regel bimediale Texte waren (Wunderlich 2000, 137), so entstanden im Laufe der Zeit auch rein graphische oder rein literarische Versionen. Dabei kam es auch zu einer Isolierung einzelner Episoden des Totentanzes, die allein für sich entwickelt und vorgestellt wurden. Ein Beispiel für die Verselbständigung einer solchen Episode im 18. Jahrhundert ist das Gedicht „Der Tod und das Mädchen“ von Matthias Claudius. Der Autor ging hier von denjenigen zu seiner Zeit in Kunst und Malerei weit verbreiteten Darstellungen des „Totentanzes" aus, die das Treffen von Tod und Mädchen in erotischer Färbung, als Werbung eine Kavaliers bzw. Liebhabers, präsentierten (Adlerhold 2000): Claudius zeigt das Treffen des sich fürchtenden und um Schonung bittenden Mädchens mit einem als sanften Tröster und Liebenden auftretenden Tod. Weithin bekannt geworden ist dieses Gedicht durch die Vertonung Franz Schuberts im Jahre 1817, dessen Musik das Erschrecken, die Erregung des Mädchens und die aus der Kunst bekannte Konzeption der Annäherung des Todes an das Mädchen als ein Liebender zum Ausdruck brachte (Adlerhold 2000). ${ }^{1}$ Schuberts Vertonung wird hier als Beispiel erstens für das ungebrochene Interesse am Totentanz und zweitens für die Aussonderung des Motivs „Der Tod und das Mädchen“ angeführt, das im 19. und beginnenden 20. Jahrhundert als ,Tod der schönen Frau" zu einem weitverbreiteten Topos der europäischen Kunst, Literatur und Musik avancierte (Bronfen 1994). ${ }^{2}$

Walter Kroll hat der Verarbeitung dieses Motivs in der kroatischen Literatur der Moderne - in Verbindung mit Schuberts Musik - einen Vortrag gewidmet, an den ich mit der folgenden Betrachtung zweier bzw. dreier russischer Texte des späten 19. und 20. Jahrhunderts anknüpfen möchte. Es handelt sich um Maksim Gor'kijs Versmärchen „Девушка и смерть“ und um Nikolaj Zabolockijs in zwei Varianten vorliegendes Gedicht „Искушение“.

Das von Maksim Gor'kij 1892 in Tiflis geschriebene kleine Poem „Девушка и смерть. Сказка“" gehört zu seinen ersten literarischen Werken (Горький 1968, 1, 512). ${ }^{3}$ Eine Veröffentlichung war in zaristischer Zeit aus Zensurgründen nicht möglich; als es im Jahre 1917 gedruckt wurde, fand es im Kontext der Revolutionsereignisse kaum Resonanz. ${ }^{4}$ Erst in den dreißiger Jahren, nachdem Gor'kij den Text Stalin vorgelesen und dieser mit Beifall reagiert hatte, ${ }^{5}$ wurde es allgemein bekannt.

Gor'kijs „Märchen“ entwickelt den Mythos über den Anfang, das Zustandekommen der für unzerstörbar erklärten Verbindung von Liebe und Tod. Der Text besteht aus 250 gereimten Versen im trochäischen Versmaß, wobei die Anzahl der Versfüße pro Zeile wechselt (der einzelne Vers kann zwischen sechs und zehn Silben umfassen). Das Märchen ist in sieben Kapitel untergliedert, die mit arabischen Ziffern gekennzeichnet und im Prinzip den einzelnen chronologisch geordneten Stationen der Handlung gewidmet sind. Der Handlungsablauf sieht, der Gliederung der Kapitel gemäß, so aus: 1. Der im Felde geschlagene Zar ist auf dem Rückweg 
in die Hauptstadt, um neue Truppen für den Krieg zu sammeln; auf dieser Reise hört er im Gebüsch neben der Straße das Lachen eines Mädchens, das seinen Zorn erweckt. Das Mädchen, glücklich über die erste Nacht mit ihrem Liebsten, weigert sich, das Unglück des Zaren und seiner gefallenen Ritter zu beklagen. Der Zar befiehlt, es zu töten. 2. Der Tod erscheint als alte Frau, als „Tödin“, die zur Zeit „nicht in Stimmung“, „böse“ ist und über die Angst der Menschen vor ihr klagt. 3. Der Tod bzw. die Tödin beginnt ein Gespräch mit dem Mädchen, das sie um eine kurze Frist bittet, um noch einmal seinen Liebsten zu küssen; die Alte, verwundert über die ihr neue Furchtlosigkeit des Mädchens, erfüllt diese Bitte und gewährt ihm eine Frist bis zum nächsten Morgen. Dann soll es vor ihr erscheinen. 4. Der Tod, die Alte, schläft in der Sonne ein, sie träumt von ihrem Vorvater Kain und von Judas, die den Erzengel Michail um die Vermittlung der Verzeihung ihrer Sünden durch Gott und um die Befreiung aus der Hölle bitten. Michail überliefert ihnen Absage und Urteil Gottes. 5. Die Tödin wacht am nächsten Morgen auf und sieht, daß das Mädchen nicht erschienen ist, sie wartet und vertreibt sich die Zeit mit einem Lied. 6. Die Tödin beginnt zornig zu werden, sucht das Mädchen und findet es in den Armen ihres Liebsten. Das Mädchen gesteht seine Schuld ein, verweist auf die sichtbaren roten Zeichen der Liebe an ihrem Körper und bittet um einen letzten Kuß. Die Tödin sieht diesem Kuß zu. 7. Die Tödin entschließt sich zu einem Wunder: Sie erlaubt dem Mädchen, die Liebe mit ihrem Liebsten weiterzuleben, unter der Bedingung, daß sie von nun an und für immer mit ihr zusammen bleiben werde. So geschieht es:

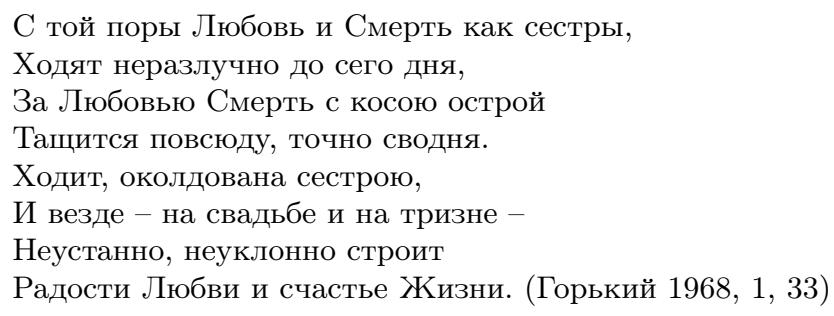

Wie alle Werke dieser Schaffensphase ist auch dieser Text durch eine „Romantik“ gekennzeichnet, deren Ausgangspunkt Arnim Knigge als Gor'kijs ,schwärmerischunbestimmte Sehnsucht nach dem Ungewöhnlichen, Großartigen, nach Schönheit, Kraft und Bewegung“" (Knigge 1994, 34) beschrieben hat. „Девушка и смерть“ beruht auf der Opposition von Liebe und Tod und zeigt den Ursprung ihrer Verbindung im Leben und in der Kraft der Liebe: Dem Mädchen als Verkörperung von Lebenskraft, Jugend, Schönheit und Mut steht die Tödin als böse alte Frau gegenüber, der die Angst, mit der ihr die Menschen begegnen, längst langweilig und zuwider wurde, und die sich nach etwas Neuem und einem Gefährten ihrer Einsamkeit sehnt. Das Mädchen wird entworfen als schöne, unabhängige, kühne und furchtlose Jungfrau, die ganz und gar dem Entzücken der Liebe hingegeben ist, allein für den Augenblick der Verwirklichung ihrer Liebe lebt. Alles andere ist für sie unwichtig geworden. In der Gewalt dieses starken Gefühls fürchtet sie weder 
den Zaren noch den Tod, obwohl sie deren Macht kennt; doch sie ist bereit, für ihr normwidriges Verhalten, ihr Lachen im Krieg, und ihre Liebe mit dem Leben zu bezahlen. Damit gehört sie zu den für Gor'kijs frühe Texte charakteristischen Figuren starker und schöner Menschen, die den zugleich von ihm entwickelten „босяки" sehr nahe stehen. Diese zeichnen sich durch Stolz und Unabhängigkeit aus, ihre Verbindung zu F. Nietzsches Konzept des Übermenschen hat Hans Günther deutlich herausgestellt (Günther 1993, 14-58). Arnim Knigge hat diese Werke als „Legenden von Kraft und Schönheit“" (Knigge 1994, 37) bezeichnet.

In diesem frühen Text repräsentiert das schöne und starke Mädchen die Verkörperung von Liebe und Leben. Gor'kij stellt es in den Rahmen eines als mythische Erzählung angelegten Versmärchens, er erzählt den Mythos des Anfangs, den Mythos darüber, wie der unzerbrechliche Bund von Liebe und Tod einst zustandekam. Mit seiner Wahl des Motivs steht Gor'kij durchaus im Kontext der Strömungen seiner Epoche, denn das Mythem der Verbindung von Liebe und Tod kann als einer der grundlegenden Kulturmythen des frühen Symbolismus bezeichnet werden. Dieser stellte - allerdings im Geiste der Dekadenz - den „Liebestod“ und den „Tod der Liebe“ (Hansen-Löve 1989, 395-407) ins Zentrum seiner Aufmerksamkeit und entwickelte ihn in verschiedenen Varianten. Gor'kij wählte also ein in dieser Zeit aktuelles Mythem und gestaltete es in Abgrenzung vom Symbolismus und in Übereinstimmung mit seiner Konzeption der Beziehung von Leben und Tod, wobei er den Tod als Gegenpart zu Vitalität und Leidenschaft der Liebe und des Lebens faßt. Damit nimmt Gor'kij die von den Symbolisten in anderer Weise entwickelte Konzeption der Austauschbarkeit und Äquivalenz des Oppositionspaares Liebe und Tod vorweg. Obwohl er weit entfernt ist von der Erotisierung des Todes oder vom Todeskult, wie er z.B. bei V. Brjusov oder F. Sologub anzutreffen ist, kann in der Wahl des Themas eine gewisse Nähe zu symbolistischen Auffassungen konstatiert werden: Diese Nähe ist am ehesten zu D. Merežkovskijs religiöser Konzeption des Todes zusehen, die die Opposition von Leben und Tod neutralisiert, indem der Tod als Rückkehr in den Schoß der Mutter, der Natur, zu Gott entworfen wird (Hansen-Löve 1993, 403-405). Bei Gor'kij tritt der Tod nicht als Mutter Natur oder verständnisvoller, großer Tröster auf, sondern als böse alte Frau und Mörderin des Lebens, die ihr Handwerk längst satt hat, und die nun von der Schönheit und Furchtlosigkeit des Mädchens als etwas für sie Neuem angezogen wird.

Der Text zeichnet sich aber nicht nur durch seine Nähe zu symbolistischen Diskursen aus. Gor'kij entwickelt den aktuellen literarischen Mythos von der Vereinigung von Liebe und Tod unter Verwendung auch volksliterarischer Traditionen und Motive. „Девушка и смерть“ galt vor allem der sowjetischen Literaturwissenschaft als erster Versuch Gor'kijs, sich in die Muster der Volksdichtung einzuschreiben. So hat S. V. Kastorskij (M. Горький и поэты „Знания“, 1958, 7-9) darauf hingewiesen, daß das Bild des launenhaft agierenden Zaren im Geist satirischer Volksmärchen gehalten sei, daß der Tod bzw. die Tödin zum ständigen Figurenrepertoire der Volksliteratur gehöre; er hat ferner auf volksnahe, „realistische" Details der Charakterisierung des Todes als Tödin aufmerksam gemacht: Der 
Tod werde auf der Ebene der Alltagswelt gezeigt, als eine alte Frau in Fußlappen, die sich an der Sonne wärme und Sonnenblumenkerne knabbere usw. L. A. Evstigneeva erkärt, daß Gor'kij hier „Elemente des Volksmärchens über Zaren auf originelle Weise verwende und interpretiere“, eine „materialistische Phantastik, dem Volkstümlichen nahestehende Bilder" entwickle und die Darstellung Gottes (in der Kain- und Judas-Episode) „christliche Traditionen der russischen Ikonenkunst und Apokryphen wiedererwecke“ (Kommentare zum Text, Горький 1968, 1, 513). Genauere Angaben zu möglichen Prätexten Gor'kijs werden allerdings nicht gemacht. Ergänzend kann man darauf verweisen, daß Gor'kij in seiner Kindheit die russischen Bylinen las und hörte, daß seine Großmutter ihm christliche Legenden und biblische Geschichten erzählte, der Großvater mit ihm das Gebetbuch, die Kirchenväter und Heiligenviten las. Gor'kij interessierte sich in seinen jungen Jahren sehr für Probleme der Kirche, Religion und Religiosität und unternahm im Jahre 1890 eine Reise durch russische Klöster auf der Suche nach geistiger Wahrheit (Kjetsaa 1996, 23-26), las theologische Schriften (Kjetsaa 1996, 28) und besuchte den damals als Prediger berühmten Mönch Ioann von Kronstadt (Kjetsaa 1996, 63). So ist es nicht unwahrscheinlich, daß Gor'kij auch die weitverbreiteten Texte der russischen geistlichen Lieder bekannt waren. Der Untertitel seines Poems bezeichnet den Text als „Märchen“, und sein Märchen trägt deutliche Züge dieser im Volk weitergegebenen geistlichen Legenden und Gesänge. Gor'kij könnte sie von der Großmutter gehört haben, er hätte sie auch in damaligen ethnographischen Veröffentlichungen lesen können, wie z.B. in der sechsbändigen Sammlung „Калеки перехожие“ des Ethnographen Pavel Bessonov (Бессонов 1861-4). Auch dort läßt sich zwar kein direkter Prätext finden, aber es sind verschiedene Varianten des „Taubenbuches" abgedruckt, einer Volkslegende über die Verbannung der Wahrheit auf den Meeresboden und die damit beginnende Herrschaft der Lüge auf der Erde. Ebenso sind dort mehrere Varianten von Liedern über den Sündenfall Adams, über Kain und Judas, die die Sünde, den Tod und den Verrat in die Welt trugen, zu finden. Gor'kijs Märchen kann demnach als ein eigenständiger literarischer Text über die Verbindung von Liebe und Tod unter Verwendung volksliterarischer Motive angesehen werden, die er gemäß seiner Vorliebe für Vitalismus und Heroismus in lebensbejahender Perspektive entwirft.

Ganz anders geht Nikolaj Zabolockij mit diesem Motiv um, obwohl auch er auf die geistlichen Lieder zurückgreift und seine Bekanntschaft mit den Bänden der „Калеки перехожие“ belegt ist. Als er im Jahre 1956 sein literarisches Werk abschließend redigierte, nahm er auch den von ihm auf das Jahr 1929 datierten Text „Искушение“ in die Abteilung „Смешанные столбцы“ auf (Text nach: Заболоцкий 2002, 376-379). Zugleich veränderte er das Gedicht und schuf eine zweite Variante, die sich radikal von der ersten unterscheidet. Die erste, im Archiv des Dichters A. Sergeev erhalten gebliebene Version (Заболоцкий 2002, 718) ist in zwei Teile untergliedert, die zwei Bilder der Begegnung mit dem Tod zeigen, zuerst die des Mädchens, dann die des Mannes, hier eines alten Bauern und Krüppels. Mit dieser Reihung von zwei Bildern knüpft der Text bereits an die Darstellungen der 
bildenden Kunst, an die Zyklen des „Totentanzes“, an. Die beiden Treffen verlaufen auf sehr unterschiedliche Weise, der Tod tritt in jeweils anderer Gestalt auf. Zu dem Mädchen, dessen Klage (plaš) hinter dem Berg hörbar wird, kommt er als „Смex“6, womit der im Russischen durch das grammatische Geschlecht weiblich konnotierte Tod männliche Züge erhält. Das „Lachen“ - so heißt es - „kommt als Feind“, der sich über die Klage und Sehnsucht des Mädchens lustig macht, als ,lustiger Verführer" auftritt, der sie zur Sünde, zur Ausschweifung verführt. Der über den Wortklang mit dem ,Lachen' (смех) identifizierte ,Tod‘ (смерть) wird über den Klang weiter mit ,Sünde' (грех) verbunden (man denke auch an die Redensart „и смех, и грех“), diese ist als Todsünde, die Ursünde der von der Schlange bzw. dem Teufel verführten Eva markiert. Zweimal versucht „Lachen“ das Mädchen, das zweite Mal mit Erfolg:

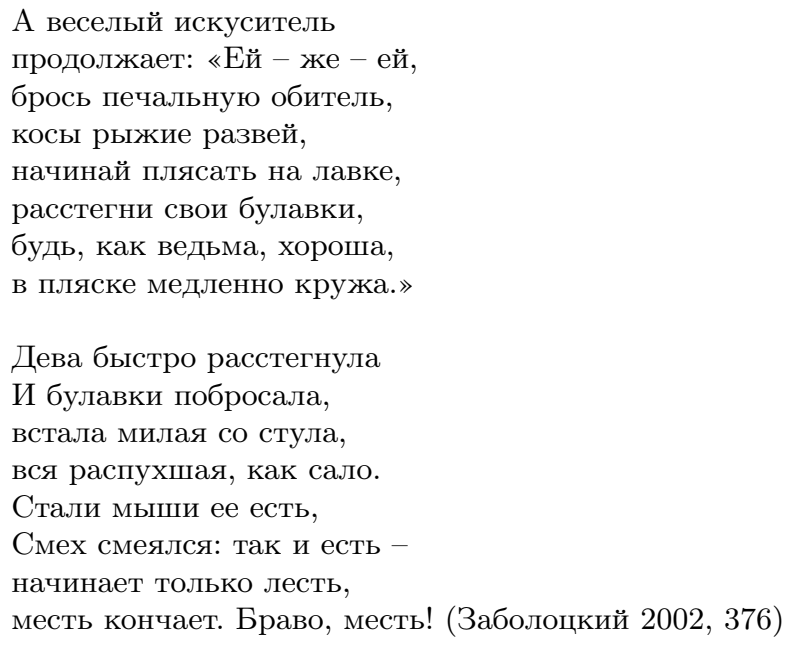

Das von der Lustigkeit und Schmeichelei des „Lachens“ verführte Mädchen ist dem Tode verfallen und stirbt durch seine Öffnung für die Ausschweifung, es fällt seinem „angeschwollenen“ Leib zum Opfer: Die Schwangerschaft als Folge der Verführung und der eventuelle Selbstmord sind in der Beschreibung nur angedeutet bzw. ausgespart. Die nächste Szene zeigt das Mädchen bereits im Grab, als schon zerfallenden und verwesenden Leichnam, der jedoch sein Bewußtsein bewahrt hat und über den Verlust der Schönheit und des ,lieben Freundes“ klagt. Als schließlich das „Lachen“ sich der jungen Frau zu erbarmen scheint, ihr das Ende ihrer „unterirdischen Fastenzeit" verheißt und die Auferstehung aus dem Grabe befiehlt, erweist sich dies als Täuschung und Betrug. Denn nun hat sie ihre Gestalt verloren, sie kann nicht mehr springen, sondern nur noch ,fließen“:

И течет, течет бедняжка

в виде маленьких кишок.

Где была ее рубашка,

там остался порошок. 
Изо весх отверстий тела

червяки глядят несмело, вроде маленьких малют

жидкость розовую пьют.

Была дева, стала щи... (Заболоцкий 2002, 377)

Der Tod verwirklicht sich hier in mehreren Phasen, die man als Vorbereitungsphasen - das Mädchen klagt, macht damit „Smech“ auf sich aufmerksam und öffnet sich ihm, damit geht es ins Grab - und Endphase bezeichnen kann: Der Körper zerfällt, das Mädchen scheint nicht mehr zu existieren, der Tod über das Leben zu triumphieren. Aber damit sind die Metamorphosen des Mädchens noch nicht beendet, denn nun greift der Erzähler des Textes ein und sagt die nächste Verwandlung voraus:

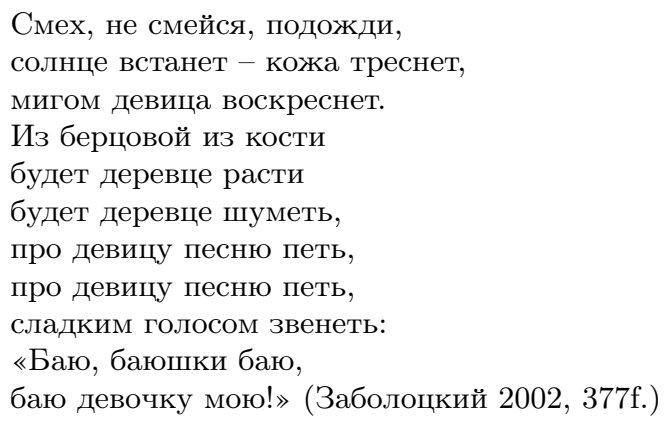

Das Mädchen wird aus ihrem Körper als Baum wiedererstehen, die Beschreibung des Treffens zwischen dem Mädchen und dem Lachen bzw. Tod endet mit dem Wiegenlied des aus ihr entstehenden Baumes für und über das Mädchen. Das Wiegenlied kann dabei sowohl der (Selbst-)Beruhigung des gestorbenen und verwesten Mädchens als auch eines neugeborenen Mädchens gelten - der Kreislauf von Leben und Tod beginnt von neuem. Der von Zabolockij entworfene Phasenverlauf des Mädchentodes weist dabei Parallelen zu Ol'ga Frejdenbergs Beschreibung der Rolle von Klage und Lachen im Totenritual der antiken Kultur auf. Frejdenberg schreibt:

„Плач' и ,смех' - две метафоры смерти в двух аспектах; ,плач' - это начальный акт умирания, ,смех - конечный. Обряд плача дублирует обряд похорон и потому занимает все первое действие страстей; обряд смеха дублирует акт воспроизведения и выливается во втором действии страстей в метафору радости [...]. (Фрейденберг 1997, 105)

Im zweiten Teil des Gedichtes „Искушение“ wird die Begegnung des Todes mit dem alten Mann dargestellt. Der Tod wendet sich an den Mann als an einen „хозяин“, erinnert ihn an seine Krüppelhaftigkeit und versucht, ihn durch die Beschreibung der Stille, Ruhe und Ordnung des Grabes zum Mitkommen zu überreden. Hier 
tritt er auf als Verführer zum Tode, zum stillen Schlaf, als Tröster und Freund des Alten. Der Mann jedoch weist die Verführung des Todes zurück, er strebt vielmehr nach der Erkenntnis der Geheimnisse der Natur, des Lebens und allen Seins, er arbeitet an der Zerstörung des Kreislaufes von Leben und Tod, an der Vernichtung der „Kasematten der Natur". „Das Gefängnis der Natur“ (,темница природы“") die ewige Wiederkehr von Leben und Tod, Geburt und Sterben - ist eines der grundlegenden Motive des Frühwerks von Nikolaj Zabolockij, insbesondere seiner „Смешанные столбцы“. Der Gedanke von der Befreiung des Menschen aus diesem Gefängnis geht bei ihm auf die Lehre des Philosophen Nikolaj Fedorov zurück, auf sein Konzept der „gemeinsamen Sache“ der Menschheit - der Erringung der Unsterblichkeit des Menschen und der darauf folgenden Auferweckung der Toten (zu Fedorovs Philosophie s. Hagemeister 1989, zu Zabolockij und Fedorov s. Goldstein 1993, 123-134), auf die wir in diesem Rahmen nicht näher eingehen können. Hier soll vielmehr die Aufmerksamkeit auf die Unterschiede der beschriebenen Begegnungen mit dem Tode gelenkt werden: Jedes Treffen wird in Entsprechung zum Geschlecht des jeweiligen menschlichen Partners des Todes entwickelt. Das Mädchen wird als Teil der Natur beschrieben, sie wird verführt durch den als „Lachen“ auftretenden Tod, ist verbunden mit der Ursünde, auf die der Tod als ihr Lohn folgt. Der alte Mann erscheint als Krüppel, aber zugleich als denkendes Wesen, er widmet sich der Wissenschaft, um den ewigen Wechsel von Leben und Tod zu zerstören und diesen dadurch zu besiegen. Der Text entwirft somit eine traditionelle Konzeption der Geschlechterrollen.

Die zweite, späte Variante des Textes „Искушение“ aus dem Jahr 1956, ist auf einen Teil reduziert worden, der die beiden menschlichen Figuren verbindet. Der alte verkrüppelte Mann und das Mädchen treten nun als Vater und Tochter auf. Der Tod kommt zuerst zu dem Alten und verspricht ihm Ruhe und Frieden im Grabe, doch dieser bittet um Schonung „um seines armen Alters willen“ und bietet ihm seine Tochter zum Tausch an. Der Tod erfüllt die Bitte des Alten und führt das Mädchen - das nicht gefragt wird - ins Grab. Dort erfährt das Mädchen dieselben Metamorphosen wie in der ersten Variante. In dieser Redaktion ist das Mädchen nicht mehr mit Ausschweifung und Sünde verbunden, sondern wird ohne ihre Schuld zum Opfer des Todes und ihres Vaters, den sie damit zugleich errettet. Der Tod tritt nicht als „Lachen“ auf, sondern stellt sich dem Alten als Freund und Tröster vor, dem Mädchen begegnet er als ihr Mörder. Schuberts erotische Beziehung von Tod und Mädchen ist hier zu einer Begegnung von sich gegenseitig achtenden Männern geworden, das Mädchen wird zum Opfer der beiden Männer. Als ein weiterer eventueller musikalischer Prätext könnte in Bezug auf den Tod und das Mädchen hier Igor' Stravinskijs „Le Sacre du Printemps“ angenommen werden, in dem die rituelle Auswahl und Darbringung eines jungen Mädchens als Opfer für den Gott des Frühlings gestaltet wird (Steegmann 2000, 107-117).

Wenn wir abschließend die Texte Gor'kijs und Zabolockijs miteinander vergleichen, erweist sich, daß beide Autoren das traditionelle Motiv vom Tod und dem Mädchen auf völlig unterschiedliche Weise modelliert haben - obwohl beide Volks- 
legenden und geistliche Lieder verwenden. Gor'kij stellt das Motiv in den Kontext sozialer bzw. feudaler Machtverhältnisse - das Mädchen wird auf Befehl des Zaren getötet - und verwandelt es in den Mythos von der alles besiegenden Kraft der Liebe, des Lebens und der furchtlosen Jugend, die selbst die alte Tödin anrührt. Er weist damit die im 19. Jahrhundert verbreitete Erotisierung des Todes einer schönen Frau zurück und rückt stattdessen die Erotik von Jugend und Vitalität ins Zentrum, die er als Kräfte faßst, die - wenn auch nur für kurze Zeit - den Tod besiegen können. Zabolockij entwickelt das Motiv ganz anders: Er kontrastiert dem Tod nicht ein Paar, sondern die Einzelfiguren des Alten und des Mädchens und stellt dem Leser damit gleichsam zwei Episoden des „Totentanzes“ vor Augen. Bei ihm wird das Mädchen in der ersten Variante zum bereits durch ihr Geschlecht, ihre Weiblichkeit vorherbestimmten Opfer des Todes, des „lachenden Verführers“ zur Sünde, in der zweiten Variante ist sie ungefragtes Opfer ihres Vaters und des Todes. In beiden Fällen erscheint sie als unabtrennbarer Teil der Natur. Sie aktualisiert und verwirklicht die Gesetze der Natur, sie ist unwiderruflich dem ewigen Kreislauf von Leben und Tod unterworfen. Ihr gegenüber steht der Mann, der Alte, in der ersten Variante der denkende Mensch, der an der Überwindung dieses Naturgesetzes arbeitet, an der Verwirklichung der Unsterblichkeit der Menschen und alles Lebendigen. In der zweiten Variante erscheint er als Vater, der seine Tochter opfert, um sein ,armes Alter“ weiter zu leben.

Können wir Zabolockijs „Искушение“ als direkte Replik auf Gor'kijs „Девушка и смерть" bezeichnen? Meines Wissens gibt es keine Daten darüber, daß Zabolockij Gor'kijs Text bereits 1929 bei der Niederschrift der ersten Version kannte, obwohl wir es als wahrscheinlich annehmen können: 1928 war in der Sowjetunion eine große Ausgabe der Gesammelten Werke Gor'kijs erschienen, in deren erstem Band der Text abgedruckt war. Unzweifelhaft scheint, daß Zabolockij den Text spätestens in den dreißiger Jahren, als er aufgrund der Reaktion Stalins eine weite Verbreitung fand, kennengelernt haben muß, aber falls es so war, wäre die erste Variante ohne die Kenntnis von Gor'kijs Poem geschrieben worden. Wenn wir dennoch die beiden Texte Zabolockijs als Dialog mit dem Märchen Gor'kijs lesen, wird deutlich, daß Zabolockij eine oppositionelle Position einnimmt: Der Tod tötet jeden, niemand entkommt ihm, Leben ohne Tod existiert (noch) nicht. In der letzten Formulierung seines Standpunkts wären die beiden Autoren dann bereits trotz ihrer gegenteiligen Fassung des Motivs nicht mehr weit voneinander entfernt. In Bezug auf den Hintergrund der jeweiligen Bearbeitung aber muß vermerkt werden, daß es Gor'kij um die Darstellung des starken und stolzen Menschen geht, der den Tod nicht scheut, während Zabolockij auf die Traditionen des Totentanzes zurückgeht. Seine Texte nehmen eher einen Dialog mit Schubert und Stravinskij sowie den Darstellungen der Malerei und Graphik auf: Er entwertet in der ersten Variante die erotische Beziehung zwischen Tod und Mädchen zu einer Verführung zur Sünde, deren Lohn der Tod ist; der alte Mann und der Tod erscheinen dagegen fast gleichrangig. In der zweiten Variante wird das Mädchen von ihrem Vater dem Tod geopfert, hier ist jede Erotik getilgt, auch der Vater ist nicht mehr der 
denkende Mensch, der an der Überwindung des Todes arbeitet. Die heroischen und utopischen Entwürfe aus dem ersten Drittel des 20. Jahrhunderts sind damit im Jahre 1956, als Zabolockij seine erste Textversion aufgreift und redigiert, Vergangenheit geworden.

\section{Anmerkungen}

1 Auf dasselbe Thema schrieb Schubert einige Jahre später, 1824, das gleichnamige Streichquartett d-moll (D 810).

2 Bronfen untersucht die Ausstellung des Todes bzw. des toten Körpers der schönen Frau im patriarchalen Blick der europäischen Kultur.

3 Die Verse Gor'kijs wurden von der zeitgenössischen und späteren Literaturkritik wenig beachtet. Einen Überblick über Gor'kijs Versschaffen bietet die Ausgabe М. Горький и поэты „Знания“, eine Einschätzung Volkov 1969, der das Poem Девушка и смерть als den ersten bedeutenden Verstext Gor'kijs bezeichnet (Волков 1969, 29).

${ }^{4}$ Eine Ausnahme stellt der Komponist German Galynin dar, der den Text zu einem Oratorium umformte (Горький 1968, 1, 513f.).

5 Stalin schrieb nach dem Vorleseerlebnis unter das in der Werkausgabe Gor'kijs von 1928 gedruckte Werk: „Эта штука сильнее, чем Фауст Гете (Любовь побеждает смерть). И. Сталин.“ (М. Горький и поэты „Знания" 1958, 370).

6 Zur Konzeption des „Lachens“ bei den Obèriuten s. Gerasimova 1988 (speziell bei Заболоцкий: 59-64).

\section{Literatur}

Бессонов, П.: 1861-64, Калеки перехожие. Сборник стихов и исследований, т. 1-6, Москва.

Волков, А. А.: 1969, Путь художника. М. Горъкий до Октября, Москва.

Герасимова, А.: 1988, ,Обэриу. (Проблема смешного)', Вопросы литературы, 4, 48-79.

Горький, М.: 1968, Полное собрание сочинений в двадиати пяти томах, т. 1, Москва, 513f.

Заболоцкий, Н. А.: 2002, Полное собрание стихотворений и поэм, (НБП), Санкт- Петербург.

M. Горъжий и поэты «Знания», вступительная статья, подготовка текста и примечания С.В. Касторского (БПБ), Ленинград 1958.

Фрейденберг, О. М.: 1997, Поэтика сюжета и жанра (1936), подготовка текста и общая ред. Н.В. Брагинской, Москва.

Aderhold, W.: 2000, ,Der Tod und das Mädchen in Schuberts „Veränderungen“ oder: Der Tod als Geliebter', in: Jung-Kaiser, U. (Hg.), „.. . das poetischste Thema der Welt"? Der Tod einer schönen Frau in Musik, Literatur, Kunst, Religion und Tanz, Bern, Berlin usw., 81-90.

Bronfen, E.: 1994, Nur über ihre Leiche. Tod, Weiblichkeit und Ästhetik, deutsch v. Thomas Lindquist, München 1994.

Goldstein, D.: 1993, Nikolai Zabolotsky. Play for Mortal Stakes, Cambridge. 
Günther, H.: 1993, Der sozialistische Übermensch. Maksim Gor'kij und der sowjetische Heldenmythos, Stuttgart.

Hagemeister, M.: 1989, Nikolaj Fedorov. Studien zu Leben, Werk und Wirkung, München.

Hansen-Löve, A. A.: 1989, Der russische Symbolismus. System und Entfaltung der poetischen Motive, Bd. 1: Diabolischer Symbolismus, Wien.

Kjetsaa, G.: 1996, Maxim Gorki. Eine Biographie, aus dem Norwegischen v. I. Sack, Hildesheim 1996.

Knigge, A.: 1994, Maksim Gor'kij. Das literarische Werk, München.

Layet, P.: 2000, ,La Danse macabre des Hommes‘, in: Frey, W., Freytag, H. (Hgg.), „Ihr müßt alle nach meiner Pfeife tanzen". Totentänze vom 15. bis 20. Jahrhundert aus den Beständen der Herzog August Bibliothek Wolfenbüttel und der Bibliothek Otto Schäfer Schweinfurt, Wiesbaden, 27-34.

Steegmann, M.: 2000, ,Strawinsky's Sacre du Printemps als sanktionierte Tötung einer schönen Frau oder: Das Alibi für rituellen Mord', in: Jung-Kaiser, U. (Hg.), ...,das poetischste Thema der Welt“? Der Tod einer schönen Frau in Musik, Literatur, Kunst, Religion und Tanz, Bern usw.

Wunderlich, U.: 2000, ,Zwischen Kontinuität und Innovation - Totentänze in illustrierten Büchern der Neuzeit', in: Frey, W., Freytag, H. (Hgg.), „Ihr müßt alle nach meiner Pfeife tanzen". Totentänze vom 15. bis 20. Jahrhundert aus den Beständen der Herzog August Bibliothek Wolfenbüttel und der Bibliothek Otto Schäfer Schweinfurt, Wiesbaden, 137-202. 



\section{Göttinger Elegien}

In mein Gedächtnis, in meine Seele

dringen neue Böden, neue Wände ein, indessen

ein bekanntes Klima. Die Teppichbodenfarbe, das Weiß

der Flächen, die Anordnung der Betten, der Stühle, die Farben der Stoffe, die Lichter der Arbeitstische, siedeln sich in mir an, wie neue Gespenster, Merkmale des Unterschiedes. Die Wärme der Lampen, die Radioklänge, die Anordnung der Heizung, Himmelsrichtungen, die Sonne. Die leere Wohnung, der tiefe Mond im Dachgeschoßfenster.

Neue Wörter in meiner Aussprache, andere Ausdrücke. Nach und nach, immer gründlicher bewältige ich den Raum: Jeansfarbene Vorhänge, Papierkerzen, Kleinigkeiten. Langsam 
trete ich in die Sachen, ich gewöhne mich. Nur die Meldungen aus der Heimat sind immer entsetzlicher, immer unverständlicher, fremd. Verwirrung und Furcht, auf den Lippen.

II.

Immer intensiver fühle ich meinen Körper, das Jucken am Rücken, unter der rechten Schulter.

Meine Nägel schälen sich, das Haar fällt mir ab, ich nässe unklar. In mir steht eine aufrechte Kiefer, gegenüber. Ich zähle Geld, zähle Tage und Jahre zusammen. Ich fühle das Sediment auf den Schränken, die Schichten der Vergangenheit in Ereignissen.

In mir existiert Geschichte im Überfluss, mit mir geht sie Hand in Hand, wie im Klassenzimmer, im Atlas. Mit dem feuchten Mittelfinger blättere ich die Seiten um: Altertum, Mittelalter, das vorige Jahrhundert. Mitten in der Nacht, Meldungen vom Kriegsfeld. In unserer Heimat schlachtet man Schweine, es ist Schlachtfest, man kocht Kohl, und begießt es mit Wein.

Ich wache auf, ohne Geschlecht, unecht.

IV.

Morgens macht mein Blick auf den Wolken des fremden Himmels halt, Zerstreuung des Lichtes, allerdings habe ich völlig die ungewöhnliche Unordnung auf dem Schreibtisch überwunden. In der ovalen Einteilung der Fläche herrscht ein gleichmäßiges Durcheinander von Stiften, Büchern, Papieren. Ich grenze Wörter ab: monokulturell, multikulturell, interkulturell.

Europa, alle Himmel über unterschiedlichem Klima, alles Bangen, alles Regen. Ich schließe meine Augen, erlösche, ertrinke im Ton. Die Musik spielt auch mit ihren Klängen, Flaute. Oboe. Trübe Vermutung vom Krieg, vom Feuer. 
VI.

Du gesegnetes Europa, ich mag den Stein von Dubrovnik, ich zittere beim Anblick der Küste, der warmen Erde des Südens (wo das Rauschen des Meeres aufs Neue das Rauschen des kaputten Wasserbehälters, der Kaserne und des Gefängnisses, des schäbigen Hotels, betäubt). Ich schreite durch deine Kirche, durch dein Hauptschiff, voller Verehrung und Buße steige ich zum Glockenturm, in mir tickt die Uhr. Tauben, Möwen, verbergen sich in mir, Salz bestreut mich, Jod umschlingt mich ganz. Ich gehe, durch deine Kirche, durch dein Hauptschiff, du Vaterland, du Europa. Ich liebe den Stein von Dubrovnik, wie die Drau, die Heimat und die Pforte.

VII.

Ich steige in dich hinab, Meer, wie in die Tiefe des Sinnes, den Schaum der Liebe, ich reiche dir die Hände: du beweinst mich unbarmherzig, ich wasche mir das Gesicht in dir, frech dringst du in meine Schuhe ein, bis zum Knie bin ich in der Welle, auf den Knien flehe ich dich an. Vergib mir, ich habe an dein Dasein nicht geglaubt Gott, und dieses Meer ist mächtig, weise bis zur Weiße, wir spielen in nächtlicher Begeisterung und Einsamkeit, wie zwei alte, endlose Kameraden, wie Ebbe und Flut, wie der Mond hinter den Wolken. Regen naht, nervös zünde ich Feuer im Wind, vergeblich, beharrlich. Ich berühre die Steine, hier ist die Küste der Heimat, der Murinsel. Hier, wenn du meine Brust mit Schluchzern füllst, wenn ich dich trübe durch Tränen beobachte, weine ich, mich waschend und wasche mich im Weinen, vor dem Gesicht der Ewigkeit, ich trotze dem Wind, aber übergebe mich dem Meer. Und es steigt zu mir hinauf, „Nacht, Meer!“ 
VIII.

Dubravko K. gewidmet

Wenn sie mit ihren Kokarden kommen,

unsere Brüder, Barbaren, um unsere Häuser zu zerstören,

um uns zu berauben, um unsere Frauen zu entehren und unsere Töchter fortzu-

führen,

werden wir nicht töten. Unser Meer

wird uns aufnehmen, wir werden Pfahlbauten aufbauen, Segelboote,

Flöße, wir werden uns Wind und Stürmen übergeben,

werden die Inseln zu Festungen bauen, zu Burgen

aus Stein und Sonne, aus Dämmerung und Traum.

Wir werden sie mit Schweigen verfluchen, mit furchtbarem

kroatischem Schweigen, das lauter ist als der Blitz,

fruchtbarer als die Erde, als das Übel.

Wenn sie mit ihren Gewehrkolben kommen,

unsere Brüder, unsere Barbaren, um uns unser Land,

um uns unsere Häuser zu nehmen, werden wir Boote bauen,

und Masten wie Türme, werden uns unserem Meer übergeben,

unserem Himmel, dem Glauben, dem Gelübde.

Doch wenn wir zurückkehren,

zu unseren Brandstätten, zu unseren Höfen,

werden wir Frühlinge suchen, doch Messer finden, und Blut.

Dubrovnik, 1991.

$\mathrm{X}$.

Guten Morgen Kirschbaum, im fremden Garten

des weiten, vertrauten Europa. Dein Erblühen

in kleinen Büschen, weckt mich mit langem Sonnenschatten,

dein Alter beruhigt mich. Vielleicht sind wir Altersgenossen,

du blühst so prachtvoll fruchtbar, überlässt dich

dem Himmel und den Bienen. In deiner Krone nistet

eine Turteltaube. Ich stehe, unruhig am Fenster,

während mir dein Geäst Frieden bietet,

guten Morgen fremder Kirschbaum, alter Kirschbaum,

berauschend ist der Geruch deines Blütenstaubes, berauschend

ist auch die Weiße deiner Blüte. Ich sehe dich an, mit Augen

voller Wehmut, Besorgnis, Verzweiflung. Guten Morgen

alter Kirschbaum, echter Kirschbaum, ich wachse

in deinen Stamm hinein, verschwinde in deinem Kreis 
aus Blüten und Himmel, aus Frühling. Der Platz, den du besetzt hast und der Raum meines Geistes berühren sich ganz natürlich, wie Küste und Meer, wie Blüte und Frucht. Guten Morgen sage ich, im Tau, im Glanz, im Reichtum der Weiße bist du.

Guten Morgen alter Kirschbaum, fremder Kirschbaum, heimischer.

XI.

Heute morgen landete eine Taube auf meinem Schreibtisch, scheu und grau.

Der Vogel versucht durch die andere Dachluke hinauszufliegen, ich öffne die Fenster im Nebenzimmer, verberge den Kaffee, etwas ängstlich gehe ich zu ihm heran. Er versucht wieder durch die Scheibe zu fliegen, auch dieses Fenster öffne ich ganz in Furcht, um seine Unfreiheit besorgt, die ich nicht verursacht habe. Nach einigen Versuchen fürchtet er sich den gleichen Weg erneut zu fliegen, beruhigt sich auf meinem Arbeitstisch. Ich nähere mich ganz beunruhigt, will ihm helfen, seinen Weg zum Himmel zu finden. Warum habe ich Angst vor einer Taube? Vielleicht war es ein Weibchen. Wie soll ich in den Krieg, wenn ich mich vor einem Vogel fürchte, welche Nachrichten hat er wohl mitgebracht, was hat er sagen wollen? Du Himmelsvogel, danke dir für das Bild einer Taube auf meinem Schreibtisch. Danke dir für das frohe Omen.

XIII.

Gott, wie Trauer mich umfasst, wie Wehmut mich ganzen greift, wegen meines Volkes, kroatischen. Mitten im weißen Hain, über dem blauen Meer, küssen sich freie Vögel, und die Maschinengewehre sind schwer, Wunden sind grob. Wir gehen, mit bloßen Händen auf Panzer, zu Fuß, Raupenspuren, Bluttropfen, Frauen singen Himmelslieder, Brot zerkrümelt in der Faust, Salz flimmert durch die Finger. Wie ein Segel wächst die Fahne, flattert, eine Arche schifft, mein Volk wandert im Schlaf, wir sind alle Narren, Nachtwandler. Sie haben uns verlockt, werden uns berauben, Dummheit, Gaukler. Mich umschlingt Trauer, Schwäche, Bangen, Angst. Kroaten, Seefahrer, 
XIV.

O, sei geduldig mit deiner Natur, mit deinem unruhigem Herzen. Geduldig sammle ich Scherben der Seele (wie es in einem schlechten Vers heißt), beschäftigt mit Schmerzensgefühl, mit Demut. Alle Güte die du besessen hast, alle Großzügigkeit deiner Hände, ist vergessen, unvergolten. Ich träume erschrocken in meiner Naivität, wie man leichthin zu lügen pflegt, wie man betrügt, schlecht träumt, entsetzlich lästert. $\mathrm{O}$, sei geduldig mit deiner verletzen Seele in deinen Melancholien: der Tag ist sonnig, der Wald belaubt, die Glocke klar, hell. Wir beschäftigen uns nämlich nur mit Wörtern, Erfahrungen.

XVI.

Hier gibt es jetzt keine Historie, die trampelt, hier geht Geschichte auf Zehenspitzen, damit sie die Tauben unter dem Vordach nicht aufweckt, damit sie die Eichhörnchen aus den Gärten nicht vertreibt. Hier ist es gleich, wenn sie von Opfern aus Kroatien oder vom Militärputsch in Äthiopien melden. Hier spricht die Sprecherstimme gleichförmig über den Tod von Gandhi, wie auch über die Nichtwahlen eines Präsidenten irgendeines vergessenen Landes. Hier sind fremde Vaterländer gleich überflutet, gleich zerstört von Dummheiten der Eingeborenen, ihren Mitmenschen. Hier sind alle Bürgerkriege ein attraktiver Anlass für eine gute Reportage, mit ersten Meldungen über eine höhere Zahl von Toten, damit sie dann sinkt oder nicht mehr erwähnt wird. Geschieht etwas davon vor eurer Haustür, beruhigt ihr euch, es wird vorbeigehen, gut, dass ihr hier seid, denn dort ist es grausam, alles absurd, alles närrisch und ungebildet (fürchterlich, sinnlos, verrückt... scheiße, entschuldigen Sie, schade, ne?) 


\section{XVII.}

Ich erwache, mit dem Gurren der Tauben, dem Geknarre ihrer Unterkünfte, sie küssen sich, wälzen sich, Gestank ist in meinen Mund, ich fühle die überfüllte Blase (Tee von gestern Abend), sie ist wach, aber schlummert, ich bin unausgeschlafen faul. Ich erwache im Alptraum, wie vor einer Reise, welche Meldungen kommen aus der Heimat? Ich gehe aufrecht, wasche mein Gesicht im kalten Wasser (Gewohnheit aus dem Wehrdienst), ermuntere mich, im Übrigen pinkle ich, ziehe mich an, spüle mir die Zähne aus. Sie ist schon in der Küche, setzt die Milch auf, wir bereiten Wasser für Tee und Kaffee (sie mag ihn süß, ein wenig), wir wecken die Kinder, frühstücken, brechen auf, ich komme zurück, schreibe Gedichte, lese Andrić, übersetze, schreibe sog. wissenschaftliche Artikel über, gehe zur Post, in die Bibliothek. Wir wachen mit dem Gurren der Tauben, mit dem Bild des zerstörten heimischen Herdes, einem Alptraum auf. Wir schweigen, verrichten unsere Aufgaben, nach Vereinbarung, in dauernder Unruhe, im Vertrauen.

XVIII.

Im Morgendunkel, in der Wärme des Sommers, bin ich unerträglich reizbar. Ich ertrage mich kaum, in der Machtlosigkeit des Briefes, in den Bitten. Weit ist die Heimat, vielleicht am weitesten bis jetzt, durch mich rauscht das Meer, gehen unwegsame Wege, Kroatisch bleibt mir wie eine Gräte im Hals stecken. Ich fühle mich wie ein Nervenbündel, wie ein steriler Hengst, überfüllt mit unfruchtbarem Samen.

Alles was du unternommen, alles was du geträumt hast, zerstreut sich wie Minze, wie Samen der feinsten Kraut, Getreidepflanze. In der Faust. Alles entrinnt, als schüttetest du einen Kübel Luft, von einem Gefäß ins andere. Als wenn du Wasser mit Händen schöpftest, porös ist es zwischen den Fingern. Halb wahnsinnig, halb besonnen, bete ich zu Wörtern, damit sie meinen Schmerz erhören, mein Sterben. Ich gehe zugrunde wie damals Gutsherren, würdevoll und ruhig, auf meinem einzigen Besitz des Gedichtes, auf dem Wall des Verses. Unerschütterlich ausdauernd, im Atmen, im Erobern der Festung des Zeichen und des Sinnes. 
LIV.

Judita K. gewidmet

Seit wir in unsere Schneeweihnachtsgeschichte eingetreten sind, und diese Tanne, die wir zusammen gekauft haben, und der Schnee, der auftaut, seit wir in die diesjährige Weihnachtsgeschichte eingetreten sind, und dein bescheidenes Zimmer, und übriggebliebene Spielsachen, und Spiele, bist du munter wie der Inselhorizont, lebhaft wie eine schwarze Schwalbe, überm Fluss. Seit wir hierher angekommen sind, bist du ganz wach und ganz verschlafen, ganz verspielt und aufgeräumt, bist du dir mehr aller Dinge ganz bewusst.

Hier wirst du, zwischen reichlichem weißem Schnee und der Pfütze des Südens, zwischen tiefblauer Heiterkeit des Himmels oder Meeres und trüben Nachtmittagen oder Nebel, ganz in Smog und Unsauberkeit, deine liebe Unordnung aus Spielzeug und Papierchen halten, die Ordnung von Puppen und Noten, immer aufs Neue kämpfend um eine neue Reihenfolge, in dir und um dich, nochmaliges Aufräumen, Wiederherstellen des Einklangs, im Pianoklang, in Farben. Hier wirst du, in Kämpfen der inneren Widersprüche, aufwachsen, wahrnehmen, dich enttäuschen, Erfolg haben, Kroatisch sprechen.

In der Harmonie der Musik, vielleicht im Lied, wirst du jenen höheren, gelernten Sinn einhalten, obwohl alles entgegen stehen wird: Ansteckungen und Beschaffungen, Beschwerden und Vergnügungen, Kinder, Kochen, nochmaliges Aufräumen, Spiele, Tanz und Gesang. Hier wirst, du wie Tausende Kroatinnen, deine Weihnachtsgeschichte, deine Neujahrserzählung, mitten in schrecklichen Schüssen über Schnee und Wärme erzählen, das Zuhause und die Fremde. Hier werden wir ausharren. 


\section{Arkadij Bartov, Muchiniada. Ein fiktiver Kindler-Artikel}

Arkadij Bartov (eigtl. Arkadij Anatol'evič Šejnblat), geboren am 18.12.1940 in Leningrad (Sowjetunion). 1967 Abschluß an der Leningrader Technischen Hochschule, 1972 an der Leningrader Universität; technischer Zeichner, Photograph, Ingenieur und Leiter eines EDV-Zentrums bis Ende der 1980er Jahre, danach Nachtwächter, Fabrikarbeiter, Radiokorrespondent und Gymnasiallehrer; Publikationen in Samizdat-Zeitschriften und in Periodika russischer Emigranten; Mitglied des Klub 81 von seiner Gründung bis Ende der 1980er Jahre; lebt in Sankt Petersburg (Rußland). Bedeutender Autor konzeptualistischer Erzählungen und Dramen.

Bartovs konzeptualistischer Erzählzyklus über Muchin, der im Laufe von mehreren Jahrzehnten entstanden ist und bei jeder Ausgabe zahlreiche Änderungen erfährt, weist eine explizit streng durchdachte Struktur auf. Der erste der sechs Teile der Muchiniada, ,Кое-что о Мухине‘ (,Einiges über Muchin`), Ende der 1970er Jahre geschrieben und 1982 in der Leningrader Samizdat-Zeitschrift $\check{C}$ asy erstveröffentlicht (Бартов 1982), besteht aus neun Kapiteln, von denen jedes wiederum aus neun 
anekdotenhaften, meist um die zehn Zeilen kurzen Texten besteht, die bestimmten Themen zugeordnet sind, etwa ,Несколько историй, случившихся с Мухиным во время тушения пожаров“ (,Einige Begebnisse, die Muchin beim Feuerlöschen widerfuhren'), ,Некоторые встречи Мухина с людьми, ему неизвестными, но, возможно, имеющими преступные намерения‘ (,Einige Begegnungen Muchins mit ihm unbekannten, möglicherweise jedoch verbrecherische Absichten hegenden Personen') oder ,Чуть-чуть о поведении Мухина в дороге' (,Ein wenig über Muchins Verhalten auf Reisen'). Darin werden Variationen von Ereignissen aneinandergereiht, von denen manche vollkommen banal, andere wiederum von existenzieller Tragweite sind. Elemente „klassischen“ Erzählens wie die schlüssige Handlung oder die psychologische Charakterzeichnung mit unterstützender Naturbeschreibung und realistischem Dialog werden dabei mit großer Präzision vorgeführt und demontiert.

Das Geschehen entzieht sich einer gängigen Logik. So steht eines schönen Sommertages Kuz'ma Stepanovič Koromyslov, der Bruder von Muchins Freund Ivan Stepanovič Koromyslov, unterwegs zur Heumahd, auf der Brücke über dem Fluß Makar'evka und bemerkt dabei einen Hecht im Wasser. Da er ein leidenschaftlicher Angler ist, zieht er instinktiv am Griff der Sense, die über seine Schulter hängt, und schlägt sich dabei versehentlich den Kopf ab. Seitdem liegt er ohne Kopf auf dem Friedhof, der Kopf ist fortgeschwommen, keiner weiß wohin. Koromyslovs Bruder war, kommentiert der Erzähler, kein schlechter Mensch, jedoch unbeherrscht. In einer späteren Geschichte steht Koromyslovs Bruder, unterwegs zur Heumahd, auf der Brücke über der Makar'evka, bemerkt dabei einen Hecht im Wasser und zieht, da er ein leidenschaftlicher Angler ist, instinktiv am Griff der Sense, die über seine Schulter hängt, verletzt sich jedoch glücklicherweise nicht, sondern schneidet nur einige Haare am Scheitel ab. Später ertrinkt er - so heißt es am Ende des Berichts über diesen Vorfall - doch das ist ein anderes Mal passiert.

Weitere Figuren kommen nur bedingt in Muchins Leben vor. Fedor Vorob'ev ist ein Kindheitsfreund Muchins, der mal als Kind, mal als Jugendlicher tödlich verunglückt, mal ist er gar Muchins Mörder. Muchin hat einen Onkel, den er seit seiner Kindheit nicht getroffen hat und zu dem er mehrmals nach Moskau zu Besuch fährt, doch leider ist dieser jedesmal gerade verreist oder kürzlich verzogen. Ein einziges Mal trifft Muchin seinen Onkel tatsächlich, er findet ihn in seiner eigenen Wohnung vor, dazu ist er mit einer Zigarette in der Hand eingeschlafen und muß mit schweren Verbrennungen ins Krankenhaus gebracht werden. Ansonsten trifft Muchin auf zahlreiche unbekannte Männer, die als potentielle Opfer oder Verbrecher beschrieben werden. Sie erscheinen urplötzlich, nur um gleich wieder $\mathrm{zu}$ verschwinden, meistens wird die Endgültigkeit ihres Verschwindens jedoch relativiert, denn immer wieder findet, wie im Fall des Onkels, eine weitere Begegnung doch noch statt, als dies bereits vollkommen aussichtslos geworden ist.

Bartovs Figuren sind ohne faßbare Eigenschaften und grundsätzlich gegeneinander austauschbar. Über Muchins Charakter, sein Aussehen, sein Alter oder seinen Beruf fehlt lange jede Information, auch sein vollständiger Name ist un- 
bekannt. Sein Freund und Nachbar, Koromyslov, heißt immerhin mit Vor- und Vatersnamen Ivan Stepanovič, er hat einen Bruder (gehabt?), Kuz'ma Stepanovič, und schenkt Getränke in einer Kantine aus. Viel mehr weiß man jedoch auch über ihn nicht: Koromyslov ist meistens betrunken - die trüben Augen sind das einzige Leitmotiv in seiner Charakteristik -, und seine Rolle besteht vor allem darin, Wodka auszuschenken oder auch nicht, mit jemandem zusammen zu trinken oder eben nicht. Auch er wird, ähnlich wie Muchin, in merkwürdige Vorgänge einbezogen, die zumeist in keinem Zusammenhang mit seiner Persönlichkeit und seinen Absichten stehen.

Die sprechenden Namen signalisieren Banalität und Eigenschaftslosigkeit: Muchin ist nach dem alltäglichsten aller Insekten, der „муха“ „Fliege“, genannt, Vorob'ev nach dem alltäglichsten Vogel, dem „воробей“ „Spatzen“, und auch der Flußname „Макарьевка“" weist auf Einförmigkeit und Namenlosigkeit hin, denn er erinnert an jene Bauern, die, als sie erfahren, daß Peter der Große den Namen Makar amüsant findet, plötzlich alle behaupten, sie hießen Makar. Ein Hinweis auf Schicksalsergebenheit und Eintönigkeit auf niedrigem Niveau ist in diesem Kontext auch in Koromyslovs Namen enthalten, der von „коромысло“ ,Tragjoch“ stammt. Eigenschaftslosigkeit kennzeichnet schließlich auch die präzise, klare, stilistisch weitgehend neutrale, steril wirkende Sprache der Texte.

Die parodistische Tendenz der Muchiniada ist besonders in einer Reihe verhältnismäßig längerer Texte im Rahmen der restlichen fünf Teile des Zyklus spürbar, die ,O Мухине чуть-чуть подробнее (,Über Muchin etwas ausführlicher'), ,O Мухине совсем коротко' (,̈̈ber Muchin ganz kurz'), ,Жизнь вне сада (описания)` (,Das Leben außerhalb des Gartens (Schilderungen)`), ,Жизнь в саду“ (,Das Leben im Garten') und „Вместо послесловия' (,Anstelle eines Schlußworts') betitelt sind. In diesen Episoden, die im Laufe der 1980er und 1990er Jahre entstanden sind, erfolgt eine Zeichnung von Mensch und Natur von beinah Turgenevscher Detailliertheit. Es wird Spannung aufgebaut, Gefühle werden aufwendig zum Ausdruck gebracht, doch all dies erweist sich als sinnlos, da die einzelnen Elemente kein kohärentes Ganzes bilden und nicht mit der Nichtigkeit des Geschehens zu vereinbaren sind.

So ist die Information, daß der Säufer Koromyslov ebenmäßige, feine Züge hat und daß die matte Haut seiner Wangen von leichter Röte umspielt wird oder daß Muchin groß und schwarzhaarig ist und sein Gang nicht zum Gesichtsausdruck paßt, vollkommen belanglos, ebenso die psychologische Tiefe in der Darstellung ihrer Erlebnisse angesichts der Tatsache, daß das gesamte Geschehen in diesem Kapitel darin besteht, daß Muchin sich mit Vorob'ev und Koromyslov auf einer Wiese trifft, wo die beiden gespannt auf ihn warten, und aus einer Wasserflasche trinkt, die Koromyslov mitgebracht hat. Von Erinnerungen überwältigt, bricht Muchin in Tränen aus und verabredet mit den Freunden, sich jede Stunde am selben Ort zu treffen.

Ein Hauptthema der Muchiniada ist der Zweifel am Sinn menschlichen Handelns angesichts der Statik, die die dargestellte Welt dominiert. Zwar werden 
Veränderungen wiederholt thematisiert, etwa wenn der Erzähler behauptet, über Muchins Wesen könne keine Aussage getroffen werden, weil es sich stündlich verändere. Die Zurücknahme der Statik wird jedoch sogleich ad absurdum geführt, indem betont wird, daß sich bei Muchin Knochen, Zähne und Sehnen stündlich bis zur Unkenntlichkeit verändern („Состав организма не остается постоянным, обновлению подвергаются все его части, в том числе кости, зубы и сухожилия.").

Gewalt ist ein weiteres zentrales Thema, das spielerisch eingeführt wird. Muchin werde, so der Erzähler, tagtäglich Opfer von Verbrechen: „Из сильного, полного жизни человека он превратился в запуганную тень.“ „Aus dem kräftigen, lebensfrohen Menschen ist ein scheuer Schatten geworden. 'Selbstverständlich wird auch hier das, was eine endgültige Aussage zu sein scheint, relativiert, denn sie klingt nicht nur klischeehaft, sondern kulminiert schließlich in eine waghalsige Übertreibung: „Преступники оставляют на своем пути следы - вещественные свидетельства преступлений: черепа убитых, остатки мешков, веревочные петли, протезы, шпильки для волос и искусственный глаз.“ „Die Verbrecher hinterlassen auf ihrem Weg Spuren, sie hinterlassen Beweismaterial für die Verbrechen: Schädel von Ermordeten, Reste von Säcken, Schlingen, Prothesen, Haarnadeln, ein Glasauge'.

In seinen ebenfalls über mehrere Jahrzehnte verfaßten Essays, die eine Art Einführung in die poststrukturalistische Literaturtheorie darstellen, plädiert Bartov für eine radikale Mechanisierung des Verfahrens und für eine konsequente Sinnentleerung aller Zeichen, durch die die vollständige Aufgabe der Individualität des Autors zugunsten einer Literatur erreicht werden soll, welche allein aus Versatzstücken des Massenbewußtseins besteht (Бартов 2006). Der russische Konzeptualismus hat für Bartov seine Wurzeln zum einen in den Theorien eines Roland Barthes oder Jacques Derrida und im westeuropäischen Konzeptualismus der 1960er Jahre. Zum anderen verweist Bartov ironisch auf die Literatur der sozialistischen Periode als Beispiel für Dekonstruktion der Sprache schlechthin oder auf den, so der Autor, „,bedingten“, „relativen“ Charakter der Zivilisation in Rußland (,условный характер российской цивилизации“") mit der Stadt Petersburg als dem Ursprung postmoderner Simulation und Eklektizismus.

Die durchgehend eingesetzten Elemente konzeptualistischen Umgangs mit Literatur fügen sich in Bartovs Erzähltexten zu einer sehr persönlichen und bewegenden Darstellung einer trostlos statischen Gesellschaft zusammen, in der sinnlose Gewalt herrscht und die Menschen einer unbekannten Macht ausgeliefert sind. Bartov schildert einen Polizeistaat, in dem die Gewalt vor allem in den zwischenmenschlichen Beziehungen stattfindet und die Funktion von uniformierten Vertretern einer Institution, die über Leben und Tod entscheidet und sich in ein Geheimnis hüllt, von den Ärzten übernommen wird. Und obwohl der Autor in seinen absurden Katastrophengeschichten fast gänzlich ohne Lokalkolorit auskommt, gibt es deutliche, ironisch auf Stereotype zurückgreifende Hinweise darauf, daß in diesen 
Texten eine Karikatur der sowjetischen und der postsowjetischen Gesellschaft enthalten ist.

Neben Lev Rubinštejn wird Arkadij Bartov, nicht zuletzt auch von seinen konzeptualistischen Weggefährten, häufig als einer der wenigen rigorosen Konzeptualisten wahrgenommen, was dem Selbstverständnis des Autors der Muchiniada allerdings nicht entspricht. Eine der möglichen Umschreibungen konzeptualistischen Schreibens ist, daß die Texte den Eindruck erwecken, einer bestimmten Gattung anzugehören, ohne daß sich dies wirklich so verhält. Umgekehrt läßt sich aber auch, insbesondere im Zusammenhang mit einem Werk wie der Muchiniada sowie den Bartovschen Kurzdramen, den sogenannten „речевые акты“ (,Sprechakte'), behaupten, daßs die Konzeptualisten den Eindruck erwecken, Konzeptualisten zu sein, was sie in der Regel bewußt nicht hundertprozentig sind.

\section{Literatur}

Бартов, А.: 1982, ,Кое-что о Мухине', Часы 36, март-апрель 1982, 31-57.

Бартов, А.: 1991, Прогулки с Мухиным, Ленинград.

Бартов, А.: 1999, Мухиниада, Санкт-Петербург.

Бартов, А.: 2005, ,О Мухине чуть-чуть подробнее. Из цикла «Мухиниада» ', Нева 7, 92-103.

Бартов, А.: 2006, Эпоха и стиль, Москва.

Bartow, A.: 1995, Unterwegs mit Muchin. Konzeptuelle Miniaturen, Klagenfurt.

Бутырин, К., Кривулин, В.: 1983-1984, „Разговор о творчестве Бартова', Обводный канал 5, ноябрь 1983 - декабрь 1984, 145-156.

Кривулин, В.: 1994, ,Вавилонская башня Аркадия Бартова' знакомство, Санкт-Петербург, 105-107.

Langner, B.: 1996, ,Die Welt in Zahlen. Russische Momentaufnahmen von Arkadij Bartow', Süddeutsche Zeitung 154, 06.-07.07.1996, IV.

Пикач, А.: 1995, ,От Ролана Барта - к Аркадию Бартову“, Звезда 8, 89-91. 



\section{Grundlegung der Metametrik}

Sapienti sat.

Die Gesetzmäßigkeiten, die den Verstext beherrschen, beschreibt die Metrik, deren höhere Regularität wieder legt die Metametrik (сверхметрика) nieder. Sie bildet, wie bei der Triade Text - Literaturwissenschaft - Turkologistik, die dritte Abstraktionsebene, auf der sich Operationen mit unabsehbaren Folgen denken und ausführen lassen.

Ausgangspunkt der Metametrik war bekanntlich ein Diskurs in den 1980er Jahren, der unter dem Namen FUNDID (d. i. Fundamentaldidaktik) längst in die Wissenschaftsgeschichte eingegangen ist. Er wurde mit dem Ziel geführt, komplexe wissenschaftliche Begrifflichkeiten in handfeste Formeln zu transformieren. Einem analogen Zweck widmete sich etwa gleichzeitig in Rußland das von Kassian Kassianovič Bessmyslov begründete Forschungskollektiv Фундаментальные эдукативно-генеративные элементы русской терминологии.

Am Anfang stand ein mnemotechnisches Kalkül. Während nämlich die Bezeichnungen der dreiteiligen Versfüße Daktylus $(-\cup \cup)$ und Anapäst ( UU-) 
identisch mit ihrer rhythmischen Formel waren, strebten diese Kategorien bei den zweiteiligen Versfüßen, Trochäus (russ. хорей) und Jambus (russ. ямб), offensichtlich auseinander. Als erste metametrische Transformation schlug deshalb der französische Literaturtheoretiker Baudouin de Nonsens eine edukativ-generative Umbenennung der klassischen Versfüße vor. Um die genannte Divergenz aufzuheben, sollte der Trochäus (russ. хорей) künftig Tróchus, der Jambus (russ. ямб) Jambús heißen. Im Falle katalektischer Versfüße sollten, wie in der klassischen Metrik, die iktenlosen Silben einfach entfallen, also Troch statt Tróchus, Dak oder Dákty statt Dáktylos gesprochen werden.

Einwände der inzwischen einflußreichen Gruppe der Paläometametriker, hier sei unbedingt das im Urslavischen gültige Gesetz der offenen Silbe zu berücksichtigen; die Transformationstermini müßten also lauten: Dáktylu, Anapä, Tróchu und Jambú, konnten mit überlegenen synchronistischen Argumenten vom Tisch gefegt werden. Die kolumbianische Wende der Metametrik, nun oft auch Transformationsmetrik genannt, erfolgte am 11. November 1983. Von nun an war es möglich, jegliche Verszeile auf ihre rhythmischen Universalkonstituenten zurückzuführen und nach dem metametrischen Code zu transformieren. Ein vierfüßiger Trochäus lautete jetzt:

Tróchus Tróchus Tróchus Tróchus,

ein Pentameter:

\section{Dáktylos Dáktylos Dák Dáktylos Dáktylos Dák.}

Gerade die schlanke Transformation einfacher Metren wurde indes von Fachkreisen in Zweifel gezogen. Man wandte ein, die semantische Ebene der Verse werde zu wenig berücksichtigt, das für alle Wissenschaft konstitutive Gesetz der Verallgemeinerung $\mathrm{zu}$ weit getrieben.

Ihren Durchbruch erlebte die Metametrik auf dem Ersten Weltkongreß der inzwischen ins Leben getretenen Internationalen Gesellschaft für Metametrik (IGM). Nach langen, ziellosen Diskussionen um Sinn und Methode der neuen metametrischen Richtung trat endlich der französische Germanist Renard Reual ans Rednerpult und bat darum, Goethes bekanntes Gedicht „Wanderers Nachtlied“ in metametrischer Transformation vortragen und interpretieren zu dürfen. Monsieur Reual hub an: 
Tróchus Tróchus Tróchus

Jambús,

Amphíbrach Tróchus

Dáktylus

Dáktylus Tróch:

Amphíbrach Dáktylus Tróchus

Dáktylus Tróchus

Tróchus Jambús.

Dann wies er auf, daß die Ruhe über den Wipfeln durch das wiederholte Tróchus viel deutlicher modelliert werde, als es Goethe gelinge. Auch das „kaum einen Hauch“ werde durch das katalektische Tróch hautnäher empfunden als im Original. Am stärksten wirke die metametrische Transformation jedoch am Schluß. Bei Goethe sei durch „ruhest du auch“, neben dem baldigen zu-Bett-gehen, die ewige Ruhe zwar mitgedacht, bleibe aber im ganzen vage. Nicht so bei der schwungvollen Formel "Tróchus Jambús". Sie wirke wie der Absprung von einer Skisprungschanze in die Transzendenz, ja, bis zum lieben Gott, und bringe die metaphysische Dimension des Textes erst angemessen zum Ausdruck.

Reuals inzwischen legendäre Deklamation brachte alle ästhetischen Einwände ebenso zum Schweigen, wie seine Interpretation die Überlegenheit der metametrischen Methode endgültig bestätigte. So geschehen am 11. Februar 1994. In der Zwischenzeit hat sich die Metametrik zur zentralen Methode der Literaturwissenschaften entwickelt. Dabei haben zwei Erkenntniswege in den letzten Jahren den metametrischen Diskurs bestimmt:

die Translationsmetametrik: sie geht auf die von de Nonsens aufgestellte These zurück, daß die Poesie jeglicher Zunge, sobald sie nach dem metametrischen Code transformiert wird, die Probleme der Lyrikübersetzung radikal löse. Lyrikübersetzungen sind danach überflüssig. Auch hier schafft die Universalisierung übrigens ein höheres, bisher ungeahntes Poesieverständnis. Große Gruppen von Metametrikern arbeiten bereits systematisch an der Transformation sämtlicher Korpora der Weltlyrik.

die Redutionsmetametrik: sie nimmt den Gedanken des polnischen Philologen Włodzimierz Lechpolski auf, daß jeder isometrische Text durch ein sog. metametrisches Differenzial $x=_{M M}$ yn auf eine einzige Zeile zu reduzieren sei. Ein Sonett, bestehend aus 14 fünffüßigen Jamben, reduziert sich nach der metametrischen Operation ebenso auf eine Zeile wie die 8000 vierfüßigen Jamben von Puškins „Evgenij Onegin“ oder sämtliche Endecasillabi der "Göttlichen Komödie“" von Dante. Auf diese Weise läßt sich die gesamte Versdichtung einer Nationalliteratur auf eine geringe Zahl metametrischer Formeln reduzieren. Beispielsweise könnte die russische Versdichtung, die etwa ein Drittel des Gesamtkorpus der russischen Literatur ausmacht, durch metametrische Differenziale auf höchstens 2-3 Druckseiten heruntergefahren werden. 
Die Aussichten, die sich dank die Reduktionsmetametrik abzeichnen, sind wahrhaft revolutionär. Alles was gegenwärtig über Verschlankung und/oder Verkürzung der Studiengänge diskutiert wird, ist dagegen erbärmliches Stückwerk. Denn es muß gesagt werden, daß, parallel zu den metametrischen Ansätzen, auch in der Prosatheorie bereits ähnliche Pfade begangen werden. Der serbische Prosaforscher Vuk Kovačević arbeitet mit Volldampf an einem Reduktionsmodell für Prosatexte, mit dem er, ähnlich wie die Metametriker in der Poesie, zu einen Nullstatus der Prosa gelangen will.

Würden diese Forschungsanstrengungen von Erfolg gekrönt, so würden sich die Lebensprobleme vieler Philologen, darunter nicht zuletzt der Slavisten, wesentlich leichter lösen lassen als bisher, allein schon deswegen, weil die lästige literarische Belesenheit endgültig entfiele. Doch weit darüber hinaus gehend taucht nichts Geringere als die Annullierung der Philologien am Horizont auf. Sie würde überflüssiges Lehren und Lernen beenden, durch die Aufhebung ganzer Studiengänge die Studentenzahlen drastisch verringern und durch die Schließung von Universitätsund Forschungsinstituten dem Fiskus erhebliche Einsparungen erbringen. In gesamtwirtschaftlichem wie in individualpsychologischem Belang hält die Metametrik also beträchtliche Trümpfe in der Hand. 


\section{Moltke über Polen}

Walter Kroll, dem die vorliegende Festschrift gewidmet ist, ist seiner Herkunft nach Schlesier. Während des II. Weltkrieges ward er in dem oberschlesischen Ort Horneck geboren, nach dem Ende des Krieges besuchte er in seiner nunmehr von Polen annektierten Heimat die polnische Schule, bevor er im Jahre 1958 mit seiner Familie nach Deutschland übersiedelte. Polen, die polnische Sprache und die polnische Literatur hat Walter Kroll also als Kind und Jugendlicher zuerst aus schlesischer Warte kennengelernt. Daher liegt es nahe, ihm zu seinem arbeitsrechtlich erzwungenen und allseits bedauerten Ausscheiden aus langjähriger slavistischer Forschungs- und Lehrtätigkeit an der Universität Göttingen einen Beitrag zu widmen, in dem es gleichfalls um einen Blick auf Polen aus jedenfalls partiell schlesischer Warte gehen soll. Die Rede ist von einem kleinen Buch, das 1832 unter der Verfasserangabe „Durch H. von Moltke“ in Berlin bei G. Fincke erschienen ist und folgenden Titel trägt: „Darstellung der innern Verhältnisse und des gesellschaftlichen Zustandes in Polen". Soweit sich hat ermitteln lassen, hat diese Abhandlung zum Zeitpunkt ihres Erscheinens kaum Aufmerksamkeit gefunden und 
ist in dem folgenden halben Jahrhundert so gründlich in Vergessenheit geraten, daß sich Gustav Karpeles, der sie 1884 wiederveröffentlichte, ,,als der Schliemann des vorstehenden Essays“ bezeichnete, „den ich aus einer Million von Büchern glücklich ausgegraben" (Moltke 1884, 17). Allerdings hatte sich bereits 1873 der Breslauer Professor Caro bei Moltke danach erkundigt, ob er der Verfasser der uns interessierenden Abhandlung sei. ,Dieser bestätigte umgehend seine Autorschaft und fügte hinzu, ,daß auch er die Schrift zu der unerschöpflichen Spreu rechne; sie sei zumeist aus besseren Werken excerpirt, und er sehe sie gern der Vergessenheit anheimgegeben" (Moltke 1892, 64).

Die erste Wiederveröffentlichung des uns beschäftigenden Textes geschah unter dem Titel „Ueber Polen“ in der Zeitschrift „Vom Fels zum Meer“. Die Frage, weshalb eine vorher weitgehend unbeachtet gebliebene historische Darstellung in „Spemann's Illustrirter Zeitschrift für das Deutsche Haus" vor einem breiten Leserpublikum gleichsam wiederauferstehen konnte, beantwortet sich, wenn wir die Verfasserangabe von 1832 mit der von 1884 vergleichen. Aus dem bescheidenen Hinweis „Durch H. von Moltke“ ist mehr als 50 Jahre später ein klangvolles „General-Feldmarschall Graf Moltke" geworden, das, wie G. Karpeles es formuliert hat, auf „,den hohen Träger eines glänzenden Namens“ (Moltke 1884, 17) verweist.

Bei diesem nunmehr so berühmten Autor handelt es sich um niemanden anders als um den preußischen Generalfeldmarschall Helmuth Karl Bernhard Graf von Moltke (1800-1891), der seit 1858 Chef des Generalstabs der preußischen Armee war und dessen Operationspläne die Grundlage für den siegreichen Verlauf der Einheitskriege von 1864, 1866 und 1870/71 gebildet hatten. In den Grafenstand war er im Oktober 1870 erhoben worden. Es ist gewiß die Frage, ob der Text, mit dem wir uns beschäftigen wollen, auch dann als ,einer der glänzendsten historisch=politischen Essays unserer Litteratur" (so G. Karpeles in Moltke 1884, 17) bezeichnet worden wäre, der ,nach Inhalt und Form einen Ehrenplatz in der Litteratur unserer geschichtlichen Essays einnehmen würde“ (Stern 1884, 95), wenn sein Verfasser nicht den langen Weg von einem in dürftigen Verhältnissen lebenden preußischen Sekondelieutenant bis an die Spitze der stärksten Armee des damaligen Europa zurückgelegt hätte.

Aus welchem Anlaß ist nun die Schrift über die ,innern Verhältnisse und den gesellschaftlichen Zustand in Polen" zustandegekommen? Diese Frage beantwortet sich wie folgt: „Als junger Offizier war er in freundschaftlichen, Jahre lang gepflegten Verkehr mit einer polnischen vornehmen Familie getreten" (so der Herausgeber von Moltke 1892,63). Und zwar hatte Moltke 1825 während eines Kuraufenthaltes in dem niederschlesischen Badeort Salzbrunn ,die Familie des polnischen Grafen Rafael Obieziersky von Imbier kennen- und schätzengelernt, insbesondere die Gräfin Apolonia geb. Zaremba" (Biewer 1990, 9). Welchen Eindruck der Umgang mit der Familie Obieziersky auf Moltke machte, hat dieser selbst in einem Brief an seine Mutter geschildert: „Ich weiß nicht, ob Du früher Gelegenheit gehabt hast, mit Polen umzugehen. Nichts kann angenehmer sein. Man ist gleich eingeführt, gleich bekannt und gleich vertraut. Die Leute überschütten einen mit Güte und 
Artigkeit, die man bei Deutschen Aufdringlichkeit nennen würde. Aber so sind sie Alle, dabei äußerst feingebildet, unterhaltend und lustig, [... ]“ (Moltke 1891, 7; 1990, 64).

Im September 1825 hielt sich Moltke zum erstenmal auf dem im Kreis Jaroschin gelegenen Gut Rusko auf, das der Familie Obieziersky gehörte und von dieser bewohnt wurde. Nach Berlin zurückgekehrt, nahm er mit der Gräfin Obiezierska einen in französischer Sprache geführten Briefwechsel auf, der bis in den Juli 1832 aufrechterhalten wurde (vgl. die Publikation von Moltkes Briefen an die Gräfin Obiezierska in Moltke 1990).

Von 1828 bis 1830 (so Bigge 1901, 32; in der Vorbemerkung zu der Wiederveröffentlichung von 1892 werden nur die Jahre 1829 und 1830 genannt) war Helmuth von Moltke zu den Feldarbeiten des topographischen Bureaus des preußischen Generalstabs nach Schlesien und nach Posen abkommandiert. Während seines dienstlichen Aufenthaltes im Großherzogtum Posen wohnte er wieder, diesmal monatelang, in Rusko und hatte so Gelegenheit, die Lebensart, die Gastfreundschaft und die politische Haltung des polnischen Adels gründlicher kennenzulernen. Diese Versetzung sowie die topographischen Arbeiten, die in Schlesien und Posen durchzuführen waren, „,mögen seiner Zeit wohl die nächste Veranlassung“ (Karpeles in Moltke 1884, 17) für die Abfassung der kleinen Schrift über die Zustände Polens gewesen sein, wie es der Generalfeldmarschall selbst dem "Schliemann“ seiner Abhandlung bestätigte (vgl. hierzu auch Moltkes Briefe an die Gräfin Obiezierska vom 24. 3. 1831 bzw. vom 1. 1. 1832; Moltke 1990, 66, 68). Wie unbeschwert, ja glücklich sich Moltke in Rusko gefühlt hat, bezeugen die an seine Gastgeberin gerichteten Briefe eindrücklich.

Bereits während seines ersten Aufenthaltes in Rusko hat es sich Moltke angelegen sein lassen, sich polnische Wörter und Wendungen anzueignen. Davon zeugt sein an die Gräfin Obiezierska gerichteter Brief vom 26. 10. 1825, in dem es u.a. heißt: „Aussi je Vous prie [...] de remercier Mademoiselle Clotylde de la peine qu'elle a été m'apprendre quelque [sic] mots polonnais“" (Moltke 1990, 30). In demselben Brief erwähnt Moltke die Absicht, seine Beschäftigung mit der polnischen Sprache fortzusetzen und zu vertiefen: „Je c[omm*]ençerais à présent de prendre des leçons en Polo[nais pour*] Vous fatiguer un jour de mon polonnais, comme je vous ai fatigué de mon français“" (Moltke 1990, 30). Wie weit Moltke diesen Wunsch verwirklicht hat, hat sich nicht eindeutig ermitteln lassen. Immerhin tauchen in seiner mit der Gräfin Obiezierska geführten Korrespondenz mehrfach polnische Redewendungen auf, die sich Moltke in Rusko eingeprägt zu haben scheint; vgl. in seinem Brief vom 20. 2. 1826: „Mille complimens à la petite Elise que m'a si bien pourvue de tout (day mu [?] nu troche herbate) [...]" (Moltke 1990, 44; , , ? [" so in der Publikation) oder am 24. 3. 1831: „Je vois la petite Elise, qui sera bientôt la grande Elise distribuante du vodky au milieu d'une trentaine de upaddam do nog" (Moltke 1990, 64).

Es versteht sich, daß auch in dem Buch von 1832 mehrfach polnische Wörter und Redewendungen begegnen. In einer „Abschweifung“ geht der Verfasser u.a. auf 
die Beschaffenheit des Polnischen ein, von dem er erstaunlicherweise behauptet, es besitze keine Dialekte: „Allein im eigentlichen Polen wird durchgängig dieselbe Sprache von Allen gleich geredet, selbst vom gemeinen Mann; denn es giebt hier kein Platt oder Patois, und das wirkliche Polnisch ist in Polen ohne Dialect" (Moltke 1832, 93).

Bevor wir uns der „Darstellung der innern Verhältnisse und des gesellschaftlichen Zustandes in Polen" zuwenden, sind einige Worte über die weitere Publikationsgeschichte dieser Abhandlung angebracht.

Aus der redaktionellen Nachbemerkung von Gustav Karpeles zu der ersten Wiederveröffentlichung von Moltkes Frühschrift kann, ja muß der Leser den Eindruck gewinnen, er habe hier eine unveränderte und ungekürzte Wiedergabe des Originaltextes vor sich. Tatsächlich ist aber dieser Text in der Zeitschrift „Vom Fels zum Meer" mit Auslassungen abgedruckt worden, die von dem Autor selbst veranlaßst gewesen sein müssen. „Denn wer anders dürfte es gewagt haben sich an seinem Werke zu vergreifen als er selbst?“ (Stern 1884, 96). Die Passagen, deren Streichung Moltke 1884 zur Bedingung seines Einverständnisses mit einem Wiederabdruck machte, waren ihm offenbar peinlich geworden, und so wollte er sie dem Vergessen anheimgeben. Und zwar hatte Moltke 1832 ,sich dazu verführen“ lassen, ,über die Juden im allgemeinen und die polnischen insbesondere Nachrichten in Umlauf zu setzen, die er nur aus den trübsten Quellen geschöpft haben konnte. Dahin gehört die Versicherung, die Juden ständen unter einem «ungekannten Oberhaupte, welches in Asien hauset, durch das Gesetz zum beständigen Umherirren von Ort zu Ort verpflichtet, den sie den Fürsten der Sklaverei nennen». Auch manche ehrenrührige, in ihrer Allgemeinheit sehr ungerechte Beschuldigung wird gegen diese vermeintlichen Unterthanen des ungekannten asiatischen Oberhauptes geschleudert" (Stern 1914, 188). „Ohne jeden Ansatz von Kritik gibt er an Vorurteilen wieder, was an anderer Stelle 1830 in Paris veröffentlicht worden war, nämlich bei Malte Brun: Tableau de Pologne ancienne et moderne, refondu par Leonard Chodzko. Die Quelle, die keine ist, sondern vielmehr eine böse und billige Polemik gegen fremdartig wirkende Menschen, gab Moltke freilich auch in einer Fußnote an; er folgte ihr auch fast wörtlich" (Biewer 1990, 13).

Als 1892 Moltkes Frühschrift im 2. Band der „Gesammelten Schriften“ des ein Jahr zuvor verstorbenen Feldmarschalls ein weiteresmal wiederveröffentlicht wurde, wurde die Streichungsverfügung des Autors ignoriert, vorgeblich deshalb, weil dem Herausgeber „nimmermehr“ das Recht zustehe, „manchen Tagesanschauungen zu Liebe auch nur das Geringste [...] zu kürzen" (so v. Leszczynski auf S. VII der Vorrede zum 2. Band) - ein Vorgehen, das Alfred Stern $(1914,199)$ nicht zuletzt deshalb als ,falsche Pietät" tadelte, weil der antisemitische Oberhofprediger Stöcker „nachmals aus diesen Äußerungen jugendlicher Unkenntnis und Leichtgläubigkeit Kapital zu schlagen gesucht" (Stern 1914, 198) habe (vgl. dazu auch Stern 1884, 96).

In der Wiederveröffentlichung von 1892 wurden aber nicht nur die erwähnten Passagen über die in Polen lebenden Juden restituiert, sondern auch alle anderen 
Abschnitte, die Moltke 1884 nicht hatte abgedruckt sehen wollen. In der Publikation von 1884 endet der Text mit einem hoffnungsvollen Ausblick auf die Entwicklung in dem zu Preußen gehörenden Teil Polens. In dem Originalwerk folgen hier aber noch ganze elf Seiten, die im wesentlichen eine Betrachtung der Verhältnisse in Kongreßpolen zwischen 1815 und dem Aufstand von 1830/31 enthalten sowie eine Schlußbetrachtung über „die auffallendsten Widersprüche“, die nach Meinung Moltkes von jeher das Dasein des polnischen Volkes bezeichnet haben. In dem Abschnitt über Kongreßpolen finden sich zahlreiche kritische Bemerkungen über Rußland, die wiederzuveröffentlichen dem Generalfeldmarschall zur Zeit des deutsch-russischen Bündnisses nicht opportun erschienen sein mag - eine Vermutung, die freilich Spekulation bleiben muß (über das Verhältnis zwischen dem Original von 1832 und dem Wiederabdruck von 1884 vgl. Stern 1884).

1885 erschien unter dem Titel „O Polsce“ bei F. A. Brockhaus eine polnische Übersetzung, die von dem bereits erwähnten Gustav (Gerschon) Karpeles (1848-1909) angefertigt und von Moltke selbst autorisiert worden war: „Przekład z upoważnienia autora dokonany“, wie es auf dem Titelblatt heißt. Der aus Mähren stammende G. Karpeles hatte in Breslau studiert und dort den philosophischen Doktorgrad erworben. Später war er als Schriftsteller, Publizist und Journalist tätig. Neben einer zweibändigen „Geschichte der jüdischen Literatur" (1886) entstammen seiner Feder u.a. auch Arbeiten zu slavischen Literaturen, so etwa "Goethe in Polen“ (1880) und "Slawische Wanderungen“ (1905). 1996 erschien in Warschau in der Serie „MARS“ ein photomechanischer Abdruck von G. Karpeles' polnischer Übersetzung der Frühschrift H. von Moltkes. In der Einleitung zu dieser Ausgabe findet sich ein Hinweis auf einen ,parustronicowy druk po angielsku pt. «Field Marshal Moltke on Poland»", über den sich aber bisher keine näheren bibliographischen Angaben haben ermitteln lassen.

Wenn man sich mit Moltkes Frühschrift beschäftigt und verstehen will, weshalb Moltke als preußischer Offizier sein Interesse auf Polen gerichtet hat, muß man den Zeitpunkt der Entstehung dieser Abhandlung beachten. Als Reaktion auf die französische Julirevolution von 1830 und die Loslösung Belgiens von den Niederlanden hatte sich in Polen die Überzeugung verbreitet, daß es möglich sei, sich von der russischen Herrschaft zu befreien. Am 29. November 1830 kam es in Warschau zu einem Aufstand, dessen Gelingen die Russen dazu zwang, das Land zu räumen, das sich nunmehr für unabhängig erklärte und sich eine vorläufige Regierung gab. Der Zar war allerdings nicht bereit, Polens Unabhängigkeit hinzunehmen, und so begann im Februar 1831 ein Feldzug gegen die polnischen Streitkräfte, der am 26. Mai 1831 zu deren Niederlage in der Schlacht bei Ostrożęka führte.

Den Ereignissen in Polen gegenüber konnte Preußen nicht gleichgültig bleiben. Es mußte mit der Möglichkeit rechnen, daß der Aufstand auf die eigenen polnischen Gebiete übergreifen würde, und es hatte ferner die Eventualität in Rechnung zu stellen, daß sich Frankreich zugunsten der polnischen Aufständischen einmischen würde. Um eine Ausbreitung des Aufstandes auf das eigene Staatsgebiet zu verhindern, wurde unter dem Oberbefehl Gneisenaus an der östlichen Grenze eine 
Observationsarmee aufgestellt und wurde eine scharfe Bewachung der Grenze angeordnet.

An all diesen politischen und militärischen Ereignissen nahm Moltke lebhaften Anteil. So schrieb er am 25. 12. 1830 an die Gräfin Obiezierska: „Vous pouvez Vous imaginer que je prends un intérêt très vif à la tournure que les affaires de Pologne prendront, surtout à cause qu'illes pourront avoir sur Vos affaires" (Moltke 1990, 60). Dieses Interesse wurde noch dadurch gesteigert, daß das militärische Geschehen Auswirkungen für Moltkes Karriere im preußischen Heer haben konnte. Sollte es zum Krieg kommen, wäre er in den Generalstab versetzt worden, wie er aus einer an ihn gerichteten Anfrage wußte (vgl. Bigge 1901, 40). Schließlich darf auch nicht vergessen werden, daß Moltke in den Anfangsjahren seines Dienstes in der preußischen Armee in äußerst bescheidenen, ja dürftigen finanziellen Verhältnissen lebte und daher durch schriftstellerische Tätigkeit sein Einkommen aufzubessern suchte. So waren es also ganz persönliche Beweggründe und Motive allgemeiner Natur, die Moltke dazu veranlaßten, sich als Schriftsteller mit den „innern Verhältnissen und dem gesellschaftlichen Zustand“ Polens zu beschäftigen.

Wenn man das Zustandekommen und den Inhalt von Moltkes Abhandlung über Polen gründlich verstehen und beurteilen will, so ist es erforderlich, die Quellen zu studieren, auf die sich der Autor bei seiner Arbeit gestützt hat und die er in Anmerkungen namhaft macht. Nur so ist es möglich, herauszufinden, wie weit Moltke seinen Vorlagen gefolgt ist und in welchem Maße er möglicherweise von ihnen abgewichen ist. Diese anspruchvolle Arbeit ist, soweit bekannt, bisher noch von niemandem unternommen worden. Auch in dem vorliegenden Beitrag kann diese Aufgabe nicht gelöst werden, und so besteht der Zweck dieses Beitrages nicht zuletzt darin, auf Moltkes halbvergessene Schrift hinzuweisen und zu ihrem vertiefenden Studium anzuregen.

Wenden wir uns nun Moltkes Schrift von $1832 \mathrm{zu}$ und versuchen, uns ihren Aufbau und die Grundzüge ihres Inhalts zu vergegenwärtigen (vgl. hierzu auch die Zitatenauswahl von Biewer 1990). Alle Zitate entstammen dem Originalwerk. Hinter der entsprechenden Seitenangabe wird nach einem Schrägstrich die Seite aus der Wiederveröffentlichung von 1892 angegeben, da diese leichter zugänglich ist als die Erstausgabe. Die bereits zitierte Angabe des Herausgebers, Moltkes Text sei nicht um „das Geringste“ gekürzt worden, trifft im übrigen nicht zu, wenn man es ganz genau nimmt. Vielfach sind die Schreibweise von Wörtern und die Interpunktion, bisweilen auch grammatische Formen geändert worden. Ein vollständiger Textvergleich ist allerdings nicht durchgeführt worden.

Im ersten Teil gibt Moltke eine „Darstellung der innern Verhältnisse und des gesellschaftlichen Zustandes", wie sie sich in der polnischen Adelsrepublik des 16. des 17. und des 18. Jahrhunderts herausgebildet hatten. Die Vorgeschichte dieser Situation wird nur gelegentlich und nur kurz gestreift. Das Erkenntnisinteresse, das sämtlichen Ausführungen dieses ersten Teils zugrundeliegt, ist die Suche nach einer Antwort auf die Frage, worin die „Ursachen des endlichen Sturzes dieser Republik“ (S. 50/S. 113) bestanden haben. Bei dieser Suche richtet der Verfasser 
seine Aufmerksamkeit gleich zu Anfang und dann immer wieder auf den Adel. Dieser ,war im ausschließlichen Besitz aller politischen Rechte, er allein bildete den Staat" (S. 5/S. 66), es ,wohnte die eigentliche Souverainetät in dem Gesamtkörper des Adels" (S. 12/S. 73). Eine Wurzel des Untergangs des polnischen Staates erblickt Moltke in dem „Recht des unbedingten Nein! (des liberum veto)“ (S. 67), das ,in seinem Misbrauch so verderblich“ (S. 7/ 67) gewesen sei. Es ist für ihn eines der „Hauptübel, an welchem die Republik verblutete“ (S. 23/S. 86).

„Eine der hauptsächlichen Ursachen des Verfalles der Republik war ferner die fortgesetzte Verminderung der königlichen Gewalt im Staate“ (S. 19/S. 80). „Das Uebergewicht des Adels blieb im beständigen Steigen“ (S. 23/S. 85), und das auf diese Weise entstandene Unheil wurde noch vermehrt durch die Glaubensspaltungen. „Die Dissidenten wurden eine gefährliche Wunde des Staates“ (S. 29/S. 91), und zwar deshalb, weil ,sie nachmals einen verderblichen Vorwand und Stützpunct für die Einmischungen des Auslands“ (S. 29/S. 91) abgaben.

Bei der Suche nach „den Gründen, welche den Untergang der Republik verbreiteten“ (S. 29/S. 91), richtet Moltke sodann seinen Blick auf die Lage der Bauern. Deren ,glücklicher Zustand“ „endete, als mit dem Aussterben der Jagellonen der Adel seinen immer mächtiger werdenden Einfluß auf Kosten der Krone und des Bauernstands erweiterte“ (S. 32/S. 94). „Jeder Edelmann war unumschränkter Alleinherrscher auf seinem Gut" (S. 33/S. 95), und aus dieser Situation absoluter Rechtlosigkeit erklären sich „die furchtbaren Bauernaufstände, deren Androhung schon den Adel erzittern machte. Daher aber auch der tiefe Verfall des Grundeigenthums und das Versiegen der Quellen, aus welchen die Nation ihren Wohlstand und ihre Kraft schöpfen sollte" (S. 33/S. 95).

Außer dem Adel und den Bauern sind als letzte Schicht noch die Juden zu berücksichtigen, denen man das „Wenige, was in Polen noch vom Handel übrig blieb“ (S. 38/S. 100), zu verdanken gehabt habe und die ,nächst dem Adel die angesehenste und mächtigste Körperschaft im Lande" (S. 42/S. 105) gebildet hätten.

Die Darlegungen des ersten Teils münden in folgendes Resümee: „Wir haben jetzt die widerstrebenden Elemente betrachtet, welche in ihrer Verbindung den Staat bildeten. Einen kraftlosen König, einen übermächtigen democratischen Adel, der in seinen Interessen und religiösen Meinungen unter sich zerfallen war, einen Mittelstand, welcher im Staate wucherte ohne dem Staate anzugehören, und den die Masse der Nation bildenden Landmann ohne politische fast ohne Menschenrechte ins tiefste Elend versunken" (S. 44/S.k 107).

Auf den eher statischen ersten Teil folgt eine Beschreibung und Analyse der Ereignisse, die im 18. Jahrhundert das Ende der staatlichen Selbständigkeit Polens herbeiführen sollten. Diese Ereignisse stellen sich Moltke als Paradoxon dar: Als sich endlich Männer fanden, die nach ,einer Verbesserung des geselligen Zustands ihres Vaterlands" (S. 48/S. 111) strebten, indem sie sich an die Aufgabe machten, „die alten Grundsäulen zu zertrümmern und neue unterzuschieben“ (S. 50/S. 113), da waren es „eben diese Versuche, eine bessere Ordnung der Dinge herbei zu führen“" 
(S. 50/S. 113), die ,als die letzten Ursachen des endlichen Sturzes dieser Republik genannt werden" (S. 50/S. 113) müssen. Unter dem Schutz russischer Truppen, die sie ins Land gerufen hatte, setzte die Partei der Fürsten Czartoryski auf dem Krönungsreichstag von 1764 weitgehende Veränderungen des Staatsaufbaus durch, gab Polen ,eine andere Verfassung“ (S. 68/S. 133), legte den „Grund zu einer kräftigen Monarchie“ (S. 133). Wenn „dieses unglaubliche Ereigniß“" (S. 68/S. 133) dem Staat schließlich doch nicht die erhoffte Rettung brachte, so vornehmlich deshalb, weil der neue König, Stanislaus August Poniatowski, der ihm von seinen Oheimen, den Czartoryski, zugedachten schweren Aufgabe nicht gewachsen war: „Er erschrack vor dem Gedanken, einem Krieg mit Rußland und einer Revolution des unzufriedenen Adels die Stirn bieten zu müssen. Indem er sich von dem Interesse seiner Oheime trennte, gab er ihre Schöpfung und Polen auf, und indem er alle seine Hoffnung auf die Großmuth der russischen Kaiserin setzte, wurde er ein Opfer ihrer Politik" (S. 68/S. 133).

In der Sicht des jungen Moltke waren der Untergang der Adelsrepublik und die mit ihm verbundenen Teilungen des Staatsgebiets in erster Linie „die natürliche Folge des ganzen innern Zustandes dieses Staats, dessen Fortbestehen unmöglich geworden, und bei dem man nur bewundern kann, daß er so lange hat dauern können" (S. 68/S. 133). Auf eine Beschreibung der Teilungsvorgänge und der mit diesen verknüpften außenpolitischen Konstellationen verzichtet Moltke gänzlich. Er übersieht allerdings nicht, daß es letztlich Rußland und Preußen gewesen sind, die im Verein mit Österreich dem polnischen Staat den Todesstoß versetzt haben, zwei Nachbarstaaten, denen „Polen durch seine Weltstellung selbst [...] durchaus hindern im Wege stand, welche beide in den letzten hundert Jahren einen beispiellos schnellen Aufschwung nahmen, und in ihrer raschen Entwicklung selbst untergehen oder die Schranken, die sich ihnen entgegenstellten, niederwerfen mußten“ (S. 69/S. 134). Moltke erkennt deutlich, daß Preußen Polen „vom Meere, von der Welt" (S. 70/S. 134) abschnitt und damit in seiner Existenz gewissermaßen einschnürte. Aus eben diesem Grund konnte er als Verfechter der preußischen Staatsraison auch nicht an einer Wiederherstellung der polnischen Staatlichkeit interessiert sein; denn, wie er später bemerkt hat: „Ein selbständiges Polen wird natürlich nach dem Meer streben" (Moltke 1940, 39). Dieser Gedanke kommt bereits in seiner Schrift von 1832 zum Ausdruck: „In der That, man sieht nicht wohl ein, wie Polen ohne Preußen selbstständig bestehen soll“ (S. 70/S. 135). Hier wie an zahlreichen anderen Stellen wird erkennbar, daß Moltke sich dem Gegenstand seiner Darstellung mit einigem Einfühlungsvermögen zuzuwenden vermag, ohne das preußische Staatsinteresse, so wie er es sah, auch nur ansatzweise aus dem Auge zu verlieren. An diesem Punkt seiner Darstellung überschreitet er für einen Moment den Rahmen der Beschreibung und Analyse faktischer historischer Zustände und Ereignisse, indem er bemerkt, daß es interessant sei, ,zu denken, welches das wahrscheinliche Schicksal dieses Staates geworden sein möchte, wenn es das brandenburgische statt des sächsischen Hauses auf seinen Thron gerufen hätte“ (S. 70/S. 135). 
Im letzten Teil seiner Schrift geht Moltke auf das Schicksal der polnischen Nation in der Napoleonischen Epoche und unter der Herrschaft der drei Teilungsmächte ein. Seine Darstellung reicht bis zu dem antirussischen Aufstand von 1830/31. Sie ist von einem charakteristischen Einerseits-andrerseits geprägt. Einerseits hat der Verfasser Verständnis dafür, daß ,sich Niemand gern zwingen“ läßt, ,auch nicht einmal zwingen glücklich zu sein“" (S. 76/S. 141), und dafür, daß ,der Adel [...] besonders schmerzlich [...] den Untergang des Vaterlands empfand, und [...] bei einer ungemein tief eingeprägten Nationalität sein Interesse mit seinem Patriotismus zugleich verwundet ward“ (S. 76 f./S. 142), andererseits ist es ihm ,gewiß, daß der Masse der Nation, in administrativer, polizeilicher und commerzieller Hinsicht, unermeßliche Vortheile erwuchsen, indem sie Staaten unmittelbar untergeordnet wurden, welche ihnen in allen diesen Zweigen so weit vorausgeeilt waren" (S. 76/S. 141). Dieser letztere Gesichtspunkt prägt insbesondere die Beschreibung der Verhältnisse in der zu Preußen gehörenden Provinz Posen. Hier wurde das 1811 erlassene Edikt über die Regulierung der gutsherrlichen und bäuerlichen Verhältnisse nach dem Ende der Freiheitskriege angewandt. „Weder Oestreich noch Rußland konnten eine so durchgreifende Reform, wie die Befreiung der Masse der Nation, in ihren polnischen Ländern wagen“ (S. 92 f./S. 159). Durch diesen Schritt gewann der preußische Staat ,eine neue zahlreiche und schätzbare Klasse von Eigenthum besitzenden Unterthanen, die eben dadurch, und weil sie durch ihr Interesse an die Regierung geknüpft, auch zuverlässige und treue Unterthanen waren" (S. 91/S. 158).

Ganz anders die Lage in dem unter russische Herrschaft gelangten Teil Polens. „Zum Besten des Bauern geschah nichts“ (S. 97/S. 165), weil die Verhältnisse in Rußland selbst der Bauernbefreiung entgegenstanden. „Rußlands Adel zählt noch jetzt seinen Reichthum nach der Seelenzahl seiner leibeignen Bauern, und konnte daher eine Annäherung zur Befreiung des Landmanns im Nachbarstaat nur mit Abscheu betrachten" (S. 96/S. 163). Da die Regierung es auch nicht vermochte, den Adel an sich zu binden, und ,eine übertriebene, strenge Censur jeden geschriebenen Gedanken, und zahlreiche Agenten der Polizei jede Rede bewachten" (S. 100/S. 167), trat schließlich eine Situation ein, in der eine an sich „geringfügige Ursach“ zum Funken wurde, „der in dem [sic] von allen Seiten angesammelten Brennstoffe der Unzufriedenheit fiel, dessen Explosion jede andere Zufälligkeit, etwas früher oder später, eben so gut bewirkt hätte“ (S. 100/S. 168).

Aus der Sicht eines Lesers, dem der spätere Verlauf der Geschichte bekannt ist, erscheint es einigermaßen merkwürdig, daß Moltke bei einer Betrachtung des von russischen Truppen niedergeworfene Polen mit einem erwartungsvollen Ausblick endet, der sich ausgerechnet auf Nikolaus I. richtet, jenen ,jungen Kaiser, von welchem die Geschichte in einer kurzen Reihe von Regierungs=Jahren, so außerordentliche Thaten aufzuzeichnen hat" (S. 102/S. 169). Ihm sei es „,orbehalten Polen in das umzuschaffen, was es künftig in Europa sein soll" (S. 102/S. 169). Erinnern wir uns daran, daß in der ersten Wiederveröffentlichung von Moltkes Schrift im Jahre 1884 der gesamte abschließende Abschnitt über die Entwicklung 
in Kongreßpolen kommentarlos weggelassen worden ist. Vielleicht hat dazu auch beigetragen, daß Moltke seine Erwartungen an den zum "Gendarmen Europas" gewordenen Zaren enttäuscht gesehen hatte. „Manches Urtheil, das für den Standpunkt des Jahres 1832 giltig zu sein schien, wird 1884 nicht wiederholt" (Stern 1884, 96), so auch hier.

Zum Abschluß charakterisiert Moltke die Lage Polens zum Zeitpunkt der Arbeit an seiner Schrift über dieses Land. Ebenso, wie in der Geschichte des polnischen Volkes von jeher die ,auffallendsten Widersprüche“ (S. 102/S. 169) zu beobachten gewesen seien, ebenso widerspruchsvoll sei die gegenwärtige Situation: „Das Uebermaas der Freiheit und das der Sklaverei haben das selbstständige Polen vernichtet, aber in seinen Trümmern selbst bewahrt es die Mischung des Widerstrebenden. Ein constitutioneller Staat, dessen König unbeschränkter Selbstherrscher von 40 Millionen Russen ist, - ungeheure Reichthümer und drückende Armuth, - ein fruchtbarer Boden und ungebaute Felder, - prachtvolle Paläste, umgeben von den elendesten Hütten, die wohl je von Menschen bewohnt wurden, - so erblicken wir Polen, den Staat, welcher auf die vollkommene Gleichheit Aller gegründet wurde, noch heute als das Land der Ungleichheit, der Gegensätze und Widersprüche“ (S. 103/S. 170).

Wir wollen - und können - uns nicht mit der Frage beschäftigen, inwieweit das Bild, das Moltke von den Ursachen des Untergangs der staatlichen Selbständigkeit Polens zeichnet, dem Urteil der Geschichtswissenschaft standhält. Versuchen wir statt dessen, uns Moltkes Einstellung gegenüber dem polnischen Volk und dem untergegangenen polnischen Staat zu verdeutlichen, soweit diese sich aus der von uns betrachteten Schrift ermitteln läßt. Es fällt auf, daß in dieser Schrift nichts von der Polenbegeisterung zu spüren ist, die sich nach dem Aufstand von 1830/1831 in Deutschland verbreitete, ihren Niederschlag in der damaligen deutschen Literatur fand und sich wohl am deutlichsten zu Pfingsten 1832 beim Hambacher Fest kundgab, an dem zahlreiche polnische Emigranten teilnahmen und bei dem neben der schwar-rot-goldenen Fahne der demokratischen Bewegung die Fahne mit dem polnischen Silberadler hing. In unverkennbarer Distanz zu dem Enthusiasmus für die Sache eines selbständigen Polens, der sich vielfach mit dem Ruf nach der Einheit Deutschlands und einer republikanischen Staatsverfassung verband, bewahrt Moltke den ,innern Verhältnissen und dem gesellschaftlichen Zustand in Polen" gegenüber den nüchternen Blick eines preußischen Offiziers, der stets die Interessen des Staates im Auge behält, dem er dient. Nüchternheit und das mit ihm gepaarte Bemühen um rationale Erkenntnis sind indes nicht mit Gleichgültigkeit zu verwechseln. An mehreren Stellen der Abhandlung von 1832 kommen Moltkes Bereitschaft und Fähigkeit zum Ausdruck, sich in die Situation des polnischen Adels nach dem Untergang des eigenen Staates hineinzudenken und hineinzufühlen, wenngleich ihn dies nicht davon abbringen kann, diesem Adel die Hauptschuld für das „finis Poloniae“ zuzuschreiben. Dieses Bemühen um Verständnis hat Moltke übrigens in seiner Korrespondenz mit der Gräfin Obiezierska mehrfach ausdrücklich bekundet. So schreibt er seiner Briefpartnerin am Neujahrstag 1832: „[. . ], j’ai 
été assez occupé aussi d'un petit [...] ouvrage sur - Votre Patrie, qui paraitra en 8 jours. [...] Mais enfin j'ai tâché d'être juste et vrai - et d'ailleurs il faut se souvenir que c'est un Nimiez qui l'a écrit" (Moltke 1990, 68). Schon gar nicht finden wir in Moltkes Buch irgendwelche Spuren nationalistischer Überheblichkeit gegenüber dem polnischen Volk. Diejenigen Passagen der Originalschrift, in denen die in Polen lebenden Juden in einer Weise charakterisiert werden, die man nur als Schmähung bezeichnen kann, hat Moltke in der Wiederveröffentlichung von 1884 entweder gänzlich weggelassen oder stark abgemildert - ein unübersehbarer Hinweis darauf, daß er über die Bereitschaft und die Fähigkeit verfügte, eigene Ansichten in Frage zu stellen und zu revidieren, wenn sie sich ihm als unhaltbar erwiesen hatten.

Kehren wir zum Schluß an den Anfang unserer Darlegungen zurück. Dort war die Rede von der schlesischen Warte, von der aus Moltke zum erstenmal seinen Blick auf Polen gerichtet hat. Den unmittelbaren Anlaß hierfür bildete, wie wir gesehen haben, die Bekanntschaft mit der Familie Obieziersky, zu der es während eines Kuraufenthaltes Moltkes in dem niederschlesischen Badeort Salzbrunn gekommen war. Moltkes Beziehung zu Schlesien hat dann Jahrzehnte nach diesem Aufenthalt eine Fortsetzung und Vertiefung erfahren. Nach dem siegreich verlaufenen Feldzug von 1866 erhielt der Heerführer eine Dotation zugesprochen, mit der er 1868 das von König Wilhelm I. bestätigte Familienfidiekommiß Kreisau im schlesischen Kreis Schweidnitz errichtete. Kreisau wurde zu Moltkes „Tuskulum“, „an dem er selbst mit so inniger Liebe hing“ (Moltke 1940, 191). In Kreisau wurde der Generalfeldmarschall 1891 auch beigesetzt.

\section{Bibliographie}

Biewer, L. 1990, ,Moltkes Verhältnis zum polnischen Volk', Moltke Almanach, Band 2, München, 4-18.

Bigge, W.: 1901, Feldmarschall Graf Moltke. Ein militärisches Lebensbild, Erster Band 1800-185\%, München.

Blume, W. v.: 1905, Moltke, Leipzig, Oldenburg i. Gr., Berlin.

Kessel, E.: 1957, Moltke, Stuttgart.

Köppen, F. v.: 1888, Helmut von Moltke. Ein Lebensbild für das deutsche Volk, insbesondere für die deutsche Jugend, Glogau.

Moltke, H. v.: 1832, Darstellung der innern Verhältnisse und des gesellschaftlichen Zustandes in Polen, Berlin.

Moltke, H. v.: 1884, ,Ueber Polen', Vom Fels zum Meer, Heft 8, 1-18, 153-162, $270-278$.

Moltke, H. v.: 1885, O Polsce. Napisal generalfeldmarszalek hr. Moltke. Przeklad z upowaznienia autora dokonany, Lipsk.

Moltke, H. v.: 1892, ,Darstellung der inneren Verhältnisse und des gesellschaftlichen Zustandes in Polen', Gesammelte Schriften und Denkwürdigkeiten des 
General=Feldmarschalls Grafen Helmuth von Moltke, Zweiter Band. Vermischte Schriften, Berlin, 61-170.

Moltke, H. v.: 1891: ,Briefe an die Mutter. 1823 bis 1837', Gesammelte Schriften und Denkwürdigkeiten des General=Feldmarschalls Grafen Helmuth von Moltke, Vierter Band. Briefe; erste Sammlung, Berlin, 1-104.

Moltke, H. v.: 1940, Moltke. Gespräche. Herausgegeben von Eberhard Kessel, Hamburg.

Moltke, H. v.: 1990, ,Der Briefwechsel Moltkes mit der Gräfin Obiezierska', Moltke Almanach, Band 2, München, 21-93.

Moltke, H. v.: 1996, O Polsce, Warszawa.

Stern, A.: 1884, ,Moltke als Historiker', Die Nation. Wochenschrift für Politik, Volkswirtschaft und Literatur, Bd. 2, Heft 8, 95-96.

Stern, A.: 1914, ,Moltke als Historiker', Reden, Vorträge und Abhandlungen von Alfred Stern, Stuttgart und Berlin, 189-210. 


\section{Friedrich Hölderlin u prijevodu Dragutina Tadija- novića na hrvatski jezik}

Za ovaj prilog u povodu 65-godišnjice Waltera Krolla i prestanka njegove sveučilišne djelatnosti odlučio sam se iz dva razloga. Slavističkom svijetu je poznato da je W. Kroll uz znanstveni interes i ljubav za polonistiku svoju privrženost pokazivao i prema kroatistici, ili djelujući kao pedagog, za vrijeme lektorata na Zagrebačkom sveučilištu, ili znanstveno, zanimajući se za hrvatsku književnost i njezine predstavnike. Drugi je razlog da Dragutin Tadijanović, nestor hrvatskoga pjesništva, 2005. godine napunja stotu obljetnicu života. Počeo je pisati u trinaestoj godini, a prva pjesma „Golubinja krila“ objelodanjena je u časopisu Književnik 1928. god., pod pseudonimom Tadeon. Njegov opus sadržava više od petsto objavljenih pjesama, preko četrdeset pojedinačnih zbirki (Skok 2004, 354). Tomu treba dodati još tri književna područja: prozu, književnu povijest i prevođenje. Proza je tiskana u tri knjige: Knjiga o svojima i sebi, Knjiga o hrvatskim piscima i Razgovori. Kao povjesničar hrvatske književnosti bio je urednik i priređivač kritičkih izdanja djela hrvatskih pisaca: S. Str. Kranjčevića, A. G. Matoša, Vl. Vidrića, J. Polića Kamova, 
T. Ujevića i niza drugih (Kaštelan 2004, 59). Izdano je petnaest posebnih knjiga njegovih pjesama na stranim jezicima, a brojne su mu pjesme uvrštene u strane i domaće antologije ili su u prijevodu objavljene u različitim književnim časopisima. I sam je prevodio poeziju sa stranih jezika: njemačkoga, francuskoga, talijanskoga, češkoga, te prozu sa slovenskoga (Cankara, Vodnika, Kocbeka). Od njemačkih pjesnika prevodio je J. W. Goethea (20 pjesama), F. Hölderlina (24 pjesme), Novalisa (4 pjesme), H. Heinea (1 pjesmu), J. van Hoddisa (1 pjesmu) (Tadijanović, Aus der Deutschen Lyrik 3-164). U svojim „Napomenama o prijevodima“ ovih pjesnika za Hölderlina Tadijanović kaže: „Djelo velikoga Hörderlina, davne moje poetske ljubavi, nije mi u razdoblju između dva rata bilo mnogo znano, nego mi se u potpunosti otkrilo ujesen 1941, u Rimu, kad sam nabavio njegova sabrana djela (Sämtliche Werke, im Insel Verlag, Leipzig. Text der kritisch-historischen Ausgabe von Franz Zinkernagel ... Str. 1044); danima sam ih čitao (Tadijanović 2004, 156-158). Nije poznato kad je Tadijanović počeo prevoditi njemačkoga pjesnika, ali znademo iz Tadijanovićevih „Napomena“ da je časopis Republika u dvobroju (kolovoz-rujan) posvećenom stranoj poeziji 1950. g. objavio pjesmu „Mladost“, prijevod originala „Die Jugend“. U drugoj polovici iste godine Tadijanović nastavlja s prevođenjem Hölderlina, pa je u Hrvatskom kolu 1950 tiskano osam prijevoda, a 1956, povodom izdanja Antologije svjetske lirike urednici Ježić-Krklec uvrstili su sedam prevedenih pjesama njemačkoga pjesnika.Tadijanović je i sljedećih godina prevodio, ali tek dvadest godina kasnije predstavlja javnosti rezultate prevođenja u izdanju zbirke svojih pjesama pod naslovom Sabrane pjesme, 1975. g. Prema podacima kojima raspolažem, Tadijanović je preveo dvadeset i četiri pjesme F. Hölderlina. Naslove prevedenih pjesama donosim prema originalu rukopisa, koji posjedujem, AUs DER DEUTSCHEN LYRIK, ins Kroatische übersetzt von Dragutin Tadijanović: Noćni putnik - „Der nächtliche Wanderer“, Mojim prijateljicama „An meine Freundinnen“, Luizi Nastovoj - „An Luise Nast", Himna geniju Grčke - „Hymne an Genius Griechenlands", Hrastovi - „Die Eichbäume“, Buonaparte „Buonaparte“, Mladim pjesnicima - „An die jungen Dichter“, Parkama - „An die Parken“, Diotima - „Diotima (Erste Fassung)", Nekad $i$ sad - „Ehmals und jetzt", Tok života - «Lebenslauf“〉, Kratkoća - „Die Kurze“, Dobra vjera - „Der gute Glaube“, Zapad sunca - „Sonnenuntergang“, Sokrat i Alkibijad - „Sokrates und Alcibiades", Pjesma sudbine - „Schicksalslied“, Mladost - 〈„Die Jugend“〉, Večernja fantazija - „Abendphantasie“, Domovina - „Die Heimat (Zweite Fassung)“, Ž $i$ votna dob - „Lebensalter“, Polovina života - „Hälfte des Lebens“, Uspomena „Andenken“, Doba žetve - 〈,Erntezeit"〉, Dodijalost života - „Lebensüberdruss“ (Tadijanović 79-133). Naprijed je rečeno da se Tadijanovića duboko doimao njemački pjesnik. Nije stoga nikakvo čudo što se poneke teme i određeni motivi, slučajno ili neslučajno, javljaju i u poeziji hrvatskoga poete. Poziv i sudbina pjesnika, pa i smisao pjesništva postale su osnovnom temom u pjesmama nesretnoga njemačkog pjesnika. Bio je to za njega snažan poriv nadahnuća, a djelomice i uzrok životne nesreće (ludilo). Ponosan i vrlo osjetljiv, oskudijevajući u svačemu, morao je podnositi poniženja i omalovažavanja od najbližih prijatelja. Klasično obrazovan, 
žalio je za drevnom Heladom, tugovao za nestalim zajedništvom bogova i ljudi, tim idealnim razdobljem ljudske povijesti: Slava! Slava ti u visini, / Prvorođeni / Velike prirode! / Iz dvorane Kronosa / Silaziš / Ljubazno i veličanstveno / Na nova, posvećena stvaranja. - „Himna geniju Grčke“. Poezija je Hölderlinu značila bijeg iz sadašnjosti u bolji, pravedniji i uzvišeniji svijet, u svijet ne bes ke slasti: Al da sam svoje srce čestito i vjerno, $i$ čisto / U metežu svijeta, medu opadačima / Vjerno i čisto zadržao, to je / Nebeska slast patniku. - „Mojim prijateljicama“. U „Pjesmi sudbine“ izbija osjećaj čovjekove osamljenosti i nemoći u usporedbi s „blaženim genijima“. ...: U snu, dišu nebesnici; / Sačuvan čist / U skromnu pupoljku, / Vječno cvjeta / Njihov duh ... Al nama nije dano / Mirovat na ikojem mjestu; / Nestaju, padaju / Ljudi patnici ... / Ko voda s hridi / Na hrid bacana / Godinama u neizvjesno. Slično i u pjesmi „Mladost“, gdje o sebi kazuje: O, svi vi vjerni / Ljubazni bozi! / Da ste znali / Kako vas duša moja ljubljaše!/... / Ipak poznavah vas bolje / No što sam ikad poznavao ljude, / Razumjeh tišinu etera, / Riječi čovjeka ne razumjeh nikad!. Otuđenost, samoća, ponekad suzdržana i blaga, drugi puta očitovana snažnim i reskim tonom zle slutnje o nesretnoj sudbini, koja je dosuđena pjesniku, pretkazana je, na primjer, u stihovima treće i četvrte strofe pjesme „Večernja fantazija“: „Na večernjem nebu rascvalo proljeće, / nebrojene ruže cvatu, i miran se čini / Zlatni cvijet; o, tamo me uzmite / Grimizni oblaci! I nek mi se gore... / U Svjetlu i zraku razidu ljubav i bol! - / No, kao zaplašen ludom molbom, nestade / Čar; tamno posta, i osamljen sam / Pod nebom, kao $i$ uvijek. Još slikovitije i jasnije pokazuje pjesnikovo raspoloženje pjesma od četiri stiha sa simboličkim naslovom „Dodijalost života“: Uživao sam slasti ovoga svijeta, / Mladosti nesta pred mnogo, mnogo ljeta! / Travanj se, i svibanj, i lipanj udaljiše, / sad nisam ništa, rado ne živim više! Snažan osjećaj napuštenosti i životne gorčine otkrivaju stihovi: Ti šutiš i trpiš, $i$ oni te ne razumiju, / Živote sveti! Nestajěs i šutiš, / jer, ah! zaludu tražǐ̌ kod Barbara / Svoje u sunčanom svjetlu. - „Diotima“. Takvo raspoloženje često prerasta u duboku depresiju, na primjer kad on, pjesmotvorac ne bude više mogao stvarati, bez kraja „pjevati“, kao nekoć u mladosti. Jer, sva njegova sreća bila je pjesma: Zašto si tako kratak? Ne voliš li više / Pjesmu kao negda? A kao mladić, / U danima nade, kad si pjevao, / Nikada nisi znao kraja? / . . / Kao moja sreća moja je pjesma. - Hoćěs li se veseo / Okupati u ruju zapada? Prošlo je, i zemlja je hladna. - „Kratkoća“. Kao utjeha teške životne sudbine pjesniku ostaje nada da će njegova pjesma nadživjeti njegov „odlazak“. Zato upućuje molbu „Parkama“: Samo mi je dn o poklonite ljeto, vi silne / I jednu jesen za zrelo pjevanje, / Da bi mi srce, zasićeno / Slatkom igrom, voljnije umrlo. U motiv prolaznosti utkan je ponekad i osjećaj vedrine, kad se bude približio posljednji čas. U kratkoj i vrlo dobro komponiranoj pjesmici pod naslovom „Nekad i sad“ priopćeno je: U mladim danima bijah veseo jutrom, / U veče plakah, Sada kad stariji sam, / Sa sumnjom počinjem dan svoj; ali / Svet mi je $i$ vedar njegov svršetak. Međutim postoji nešto što daje pjesniku nadu da će ostati zauvijek u nezaboravnom sjećanju i poslije njegove smrti, to nešto je ljubav, pojam koji vječno traje: Nek prijete oluje, neka patnje / razdvajaju 
- godine rastanka. / One nas razdvajaju! / One nas ne razdvajaju! / Jer ti si moja! I preko groba / Nek traje nerazdvojna ljubav. - „Lujzi Nastovoj“. U pjesmi „Domovina“, u kojoj se isprepliće više motiva, značajnih za ovu liriku, pjesnik se vraća rodnome kraju, gdje u mladosti: Na hladnom potoku gledah valova igru, / ... drage bregove / Koji me čuvaste negda, domovine / Štovane sigurne granice, kuću majčinu / I zagrljaju ljubljene braće / Pozdravit ću uskoro; a vi me zagrlite / Da mi srce, kao zavito u melem, ozdravi. Pjesmu počinje s predodžbom o mornaru koji se veseo vraća kući / . . na tihu rijeku / S otoka dalekih, kad je dovršio žetvu; Tako bih i ja došao doma, da sam / Požnjeo toliko dobara koliko bola. Znači, pjesnik se nema čemu veseliti. Njegov bol ništa ne može ublažiti: ni povratak u rodni zavičaj, ni doživljaj prirode iz mladenačkih dana, ni majčin dom, ni zagrljaj voljene braće, pa završni stihovi imaju upravo fatalistički prizvuk: Jer oni koji nam posuduju nebeski žar, / Bogovi, darivaju nam takoder sveti bol, / Zato nek ostane tako. Sin zemlje, čini se / Da sam: za ljubav stvoren, za trpnju. Jedino doživljaj prirode ostavlja dojam (sjetne) ljepote i radosti. Opisi prirode više puta pružaju jedno čudesno oblikovano jedinstvo. Slike životnih boja postaju čistom muzikom, skladanom od duboko osjećajnih doživljenosti veličajnoga krajolika i njegove idile: Iz vrtova dolazim $k$ vama, sinovi brijega! / Iz vrtova, gdje priroda živi strpljivo i domaće, / $S$ marljivim čovjekom, uzgajajući i uzgajana. / A vi, vi divni stojite kao narod titana / U pitomijem svijetu i pripadate samo sebi i nebu / Koje vas hrani i podiže, i zemlji koja vas rada. - „Hrastovi“, ili: Na večernjem nebu rascvalo proljeće. / Nebrojene ruže cvatu, i miran se čini / Zlatni cvijet; o, tamo me uzmite / Grimizni oblaci! I nek mi se gore / ... / U svjetlu i zraku razidu ljubav $i$ bol! - „Večernja fantazija“. Ne samo čovjek nego i druga živa bića služe autoru da opis prirode bude zbiljskiji, slikovitiji, privlačniji: Sa žutim kruškama / I divljih ruža puno / Naginje se kopno nad jezero; / Mili labudi, / I pjani od poljubaca / Uranjate glavu / Usvetu trijeznu vodu. - „Polovina života“. Upoznavši se s poezijom F. Hölderlina, dugo je trajalo Tadijanovićevo druženje s njemačkim pjesnikom. Što povezuje prevoditelja s „djelom velikoga Hölderlina“? Tematska analiza dvaju pjesnika upućuje na (ne)izravne srodnosti opjevanih doživljaja i pobuda o ljubavi, zavičaju, samoći, otuđenosti, prolaznosti, smrti. Ljubav je bila jedno od prvih nadahnuća hrvatskoga poete. U mladenačkom zanosu, a i kasnije u zreloj dobi, pjesnikove se misli često okreću ljubljenoj: Ja stojim na mjesečini, pod jablanom / I mislim na tebe. - „Večer"; Ali i od te ljubavi goleme / Još je snažnija misao na tebe. - „Misao na tebe“. U ranim pjesmama željan je radosti i životne sreće da bi trajno mogao biti „s njom": Moju dušu obuzme // Silna radost života; / Izvadivši ludo srce / Na dlanu bih ga pružio / Tebi ... - „Susret“. Djevojka mu nije objekt, sredstvo pohote, nego utjelovljenje ženstva, ideal koji „u srcu nosi“: Mladić $i$ djevojka nose / U srcu mladost vedrine... / Oči su im pune radosti. / Oči su im ogledala sreće. - „Ogledala sreće“. Bez ljubavi, bez djevojke on biva nesretan, tužan, ,žalostan": U trsju stoji mladić / I gleda rijeku daleku. I gleda oblak lak. / Sam, i žalostan. - „Mladić u trsju tužan“. Kad ljubavnu sreću pomuti iskustvo neispunjenih nada, pjesnika obuzima osjećaj otuđenosti, samoće: Nigdje 
nikog nema: Ni čovjeka, ni ptice. Prolazim kroz tišinu. / Pusto mi je srce. Iskrsava pustoš, javlja se osjećaj prolaznosti: Jesen je, Lelijo, jesen: / Kišna i siva jesen, / I treba da se tiho rastanemo. / . . . / Zaboravi vedro ljeto: $i$ sunce, $i$ žito zrelo; / Zaboravi milovanja u večeri meke, / Sreću srdaca naših. - „Rastanak u jesen“. Vrlo jednostavno i neposredno isto nam kazuju, u tonu narodne pjesme, sljedeći stihovi: Uvenuše rujni cvjetovi / Tvoje i moje ljubavi. / . . / Nikad više / neću gledati / Tvoja dva oka / Duboka. - „Nikad više“. Na kraju ostaje gorka spoznaja da će iza pjesnikove smrti u sjećanju djevojke ostati jedina uspomena - pročitana pjesma: Svakog dana sunce zapada. Doći će / Dan od kojeg će se znati: mene / Više nema. Neće se ništa desiti što nije bilo / Za moga vijeka . . . / . . / Djevojka će šapnuti sjajnom mjesecu: Sanjam li / Ili čitam pjesnika / Koji je pjevao o mojoj ljubavi? - „Kad mene više ne bude?" Svijest o prolaznosti i tjeskoba smrti javljaju se vrlo rano, bivaju glavnim motivom pjesnikove vizije svijeta. U ciklusu „Intimna izložba crteža s Raba“" već naslovi pjesama podsjećaju na neminovnu prisutnost smrti, npr.: „Hiljade mrtvih i ja“, „Dva groblja“, „Tiho plakanje“, „Bio sam kao i ti". Čovjek dolazi, prolazi i odlazi, i ništa se ne mijenja. Sve ostaje kako je i bilo: zemlja, sunce, vjetar, žita, oranice ... a „njega nema“. Impresivno lirski nastajao je poetski svijet Tadijanovićevih nadahnuća i u ciklusu pjesama pod naslovom „Dani djetinjstva“. O njegovu nastanku pjesnik je zapisao između ostaloga i ovo: Videći da od onoga što sam kanio reći nije kazano ni polovina, trećeg sam popodneva nastavio i napisao četiri nove pjesme ne iscrpivši svu gradu. Trebala su mi još tri popodneva ... da se kaže sve što je ležalo na srcu, da se ciklus zaokruži s dvanaest pjesama. A trinaesta, završna pjesma ... napisana je upravo mjesec dana poslije nastanka prvih pjesama ciklusa. Treba li napominjati da sam bio vjeran svom kraju, da sam vjerno prikazao svoje doživljaje? (Tadijanović 1969, 316) Ciklus je pravi inventar pjesnikovih sjećanja na djetinjske dane, na rodni zavičaj: „Moje igračke“, „Djevojčica i ja“, „Računska zadaća“, „Lov na dugu“. Doživljaji su protkani realnim i slikovitim opisima prirode: zelena polja, zrela žita, sunce nad oranicama, kiša, duga, potok, rodno Rastušje, zatim prikazima dječjih nestašluka: „Nosim sve torbe a nisam magarac", „Da sam ja učiteljica“, vjerskih i tradicijskih običaja: „Moja majka blagosilja žita" te ratnih zbivanja: „Dopisnica na ratište“. I kasnije se pjesnik okreće svome djetinjstvu i zavičaju, ali ponajviše s čuvstvom potištenosti, samoće, prolaznosti, stalnog nastajanja svega što postoji: Znam, kad mene više ne bude, / Neće ni bunara pokraj potoka, / Jedino on je zlato / Što blista iz moje mladosti, / I sjaj će mu biti ugašen / Kad moja svijeća dogori. - „Vrijeme je da se još jednom“. U pjesmi „Danas trideset i pete“ mrtvi su djed, baka, otac i brat Đuro: ... /Svi odoše, / Svi sad šute / ... / Bijah li JA doista taj dječak / Koji je slušao njihov govor? / Šuti, srce, u samoći, / Kad naviru uspomene. Autor ovdje i u mnogim drugim stihovima jednostavno prepričava događaje, govori o zbivanjima u rodnome Rastušju, o doživljajima na putovanjima, o svome postojanju u gradu, o razmišljanjima o životu i vlastitoj sudbini.

Uz sličnosti i slučajne podudarnosti opjevanih motiva poeti pokazuju zajedničku liniju i na formalnoj razini: uporabu nevezanog stiha. Ova podudarnost ne znači 
da je Tadijanoviću uzorom bio Hölderlin budući da je poznanstvo s njemačkim pjesnikom uslijedilo kasno, tek pedesetih godina prošlog stoljeća, a ne na početku Tadijanovićeva pisanja. Tadijanović je već prve pjesme stvarao u slobodnom stihu, držeći takav stih jedinom mogućom i logičnom formom u poetskom procesu. Pjesništvo je za njega slobodno kazivanje, govor o doživljajima i pojavama, koji se ne daju uokviriti rimama, strofama u posebne modele. Osnovi ovog stiha služi govorna struktura jezika, tradicija pučkog izraza, bogatstvo narodnog izričaja, protkano dubokom težnjom za jednostavnošću, za skladom i harmonijom. U širem značenju pjesma postaje biografija čovjekova života, biografija jezika i naroda iz kojega je on ponikao. Kritika tvrdi da ova lirika u hrvatskoj književnosti predstavlja najsubjektivnije svjedočanstvo, najautentičniji nadnevak pjesnikova života. To potvrđuje i sam Tadijanović porukom čitatelju: Pišući od petnaeste godine, nastalo je više od tri stotine pjesama (pjesnik govori 1987. g., m. nap.), i ja sam o njihovu nastanku, u različitim prigodama, i govorio i pisao, a poveći njihov broj objavljen je u pojedinim publikacijama kao faksimil mog autografa ... Još bih kazao i ovo: od najmladih dana bilježio sam uz pjesmu i podatak o njezinu nastanku, mjesto $i$ datum ... da bi čitalac uzmogao, donekle, naslutiti put kojim se kretao autor pjesama u svome vijeku (Tadijanović 2004, 220).

Što i kako je Tadijanović prevodio? Kod izbora pjesama i odluke da prevede upravo ovaj a ne drugi tekst, sigurno je pri tome značajnu ulogu igrao i prevoditeljev afinitet. Slušajući svoj unutrašnji glas, glas svojeg uha i diktat vlastitoga jezičnog osjećaja.Tadijanović je u potpunosti primjenjivao zakonitosti i načela hrvatskoga jezika kakva jesu i kako postoje. Provedba tih načela temeljila se je na suptilnom odabiru adekvatnih riječi, na primjeni odgovarajućeg suglasja vanjskoga i unutarnjeg ritma jezika. Pogledajmo zadnja tri stiha pjesme

\footnotetext{
PARKAMA

Zadovoljan sam, i ako me svirka mojih

Struna ne bude pratila dolje; j ed n o m

Življah, kao bozi, više i ne treba
}

\author{
AN DIE PARKEN \\ Zufrieden bin ich, wenn auch auch mein Seitenspiel \\ Mich nicht hinabgeleitet; einmal \\ Lebt ich, wie Götter, und mehr bedarfs nicht.
}

Prvo što pada u oči jest da su sva tri stiha dvanaesterci. Stih je to kojim se prevoditelj najviše približio metrici i ritmu narodne pjesme. Riječi i njihovi oblici $\mathrm{u}$ prijevodu su posve primjereni: svirka, struna, bozi, življah na najsavršeniji način izazivaju dojam onoga što je autor originala htio iskazati. Ne samo za Tadijanovićevo pjesništvo nego i za njegovo prevođenje neprijeporna je činjenica da on rabi riječ u onome obliku u kome ona dolazi u svakidašnjem govoru. On 
ju unosi u stih, računajući s njezinim akustičnim svojstvima, koja su manje više svakom dostupna. Njezin akustični efekt pjesnik ne prilagođuje nekim izmišljenim pravilima, nego nastoji da se riječ u stihu doima zvučno sama po sebi, vlastitom snagom, a ne naknadnim umetanjem elemenata kojih nema. U prijevodu, pjesma „Nekad i sad“, oživljava dojam male priče, u kojoj ni jedna riječ nije prekomjerna, ni jedan oblik neobičan. Kazivanje je to jednostavno, neposredno, skladno.

\author{
NEKAD I SAD \\ U mlađim danima bijah veseo jutrom \\ U veče plakah. Sada kada stariji sam \\ Sa sumnjom počinjem dan svoj; ali \\ Svet mi je i vedar njegov svršetak.
}

\title{
EHEMALS UND JETZT
}

In jüngeren Tagen war ich des Morgens froh

Des Abends weint ich; jetzt, da ich älter bin,

Beginn ich zweifelnd meinen Tag, doch

Heilig und heiter ist mir sein Ende.

I naglasak, i oblici, i red riječi, i melodika stiha, sve to ovdje dolazi u svome punom i naravnom obliku. Prijevod je i ovdje svojom ritmičkom strukturom sukladan originalu. Naprijed je rečeno da Tadijanović u prijevodima upotrebljava stih narodne pjesme, ponajviše dvanaesterac, deseterac, osmerac. U pjesmi „Tok života“" prva dva stiha su dvanaesterci, kao i u originalu, treći i četvrti deseterci.

\section{TOK ŽIVOTA}

Uvis je moj duh težio, ali ga ljubav

Uskoro obori; žalost ga snažnije savi!

Tako prolazim kroza životni

Luk i vraćam se, odakle dođoh.

\section{LEBENSLAUF}

Hochauf strebte mein Geist, aber die Liebe zog

Bald ihn nieder; das Lied beugt ihn gewaltiger;

So durchlauf ich des Lebens

Bogen und kehre, woher ich kann.

Da je prevoditelj ovdje htio realizirati stih narodne pjesme, dokazuju stihovi originala, čiji treći stih ima sedam a četvrti devet članaka, to jest slogova. Glede strukturalne forme prevedenih pjesama prevoditelj se gotovo u stopu drži njemačkog izvornika, bez obzira radi li se o cezuri ili o ukupnom broju stihova odnosno strofa. 
Odstupanja ipak ima, nešto češće u pogledu cezure, a samo jednom u odnosu na strofnu strukturu. U pjesmi „Himna geniju Grčke“ sjedinjene su peta i šesta, također sedma i osma strofa, pa prijevod sadržava šest a original osam strofa. Razlog ovakvu postupku može biti semantičke prirode, naime namjera prevoditelja da postigne čvršću semantičku cjelost. U svezi s redom riječi, nije potrebno isticati, da su razlike između dvaju jezika znatne. Nasuprot njemačkome u hrvatskome jeziku red riječi je više manje slobodan. Dakako, Tadijanović koristi jezičnu slobodu i u smislu litentiae poeticae, ali nastoji zadržati i red riječi originala, kad to drži potrebnim. Od brojnih primjera, navodim zadnju strofu pjesme

\author{
USPOMENA \\ Ali nek pruži mi netko \\ Mirisavi pehar, \\ Tamne svjetlosti pun, \\ Da bih mogao mirovati; jer sladak \\ Pod sjenama bio bi san.
}

\author{
ANDENKEN \\ Es reichte aber, \\ Des dunklen Lichtes voll, \\ Mir einer der duftenden Becher, \\ Damit ich ruhig möge, den süß \\ Wär unter Schatten der Schlummer.
}

Dok se prva tri stiha u prijevodu razlikuju od teksta originala (red riječi, izmjena u poretku drugoga i trećega stiha), u zadnja dva stiha, prevoditelj slijedi gotovo doslovno njemački uzorak. Usuglašenost se očituje čak i na konsonantskoj razini, tj. Pojavi sibilantnog fonema ,,": sladak, sjenama, san: süß, Schatten, Schlummer. Tadijanović uglavnom usvaja uporabu nevezanog stiha u jeziku izvorniku. Dokazuje to, na primjer, prva strofa pjesme

\title{
VEČERnJA FANTAZIJA
}

Pred kolibom svojom mirno u hladu sjedi

Orač, skromnome se dimi njegovo ognjište. Gostoljubljivo zvoni putniku

Večernje zvono u tihom selu.

\author{
Abendphantasie \\ Vor seiner Hütte ruhig im Schatten sitzt \\ Der Pflüger, dem Genügsamen raucht sein Herd \\ Gastfreundlich töntdem Wanderer im \\ Friedlichen Dorfe die Abendglocke.
}


U nekim, međutim primjerima struktura Hölderlinove pjesme biva izmijenjena $\mathrm{u}$ korist vezanoga stiha. Slijedeći melodičnost svoga materinskog jezika, prevoditelj je ustrojio drukčije intoran stih, svoj način kazivanja, „pjevanja“ pjesme. Ovakvu prevoditeljevu postupku neka posluži, naprijed već citirana, prva strofa pjesme

\section{PARKAMA}

Samo mi je d no poklonite ljeto, vi silne, I jednu jesen za zrelo pjevanje

Da bi mi srce, zasićeno

Slatkom igrom, voljnije umrlo.

\section{An DIE PARKEN}

Nur einen Sommer gönnt, ihr Gewaltigen!

Und einen Herbst zu reifem Gesange mir,

Daß williger mein Herz, vom süßen

Spiele gesättigt, dann mir sterbe.

Za razliku od originala $u$ prijevodu se stih rimuje prema shemi: a a; b b. Na drugačiji način postupanja upućuje primjer jednostrofne pjesme, gdje se rima prijevoda posvema poklapa s rimom originala.

\section{DodiJALOST ŽIVOTA}

Uživao sam slasti ovoga svijeta,

Mladost nesta pred mnogo, mnogo ljeta!

Travanj se, i svibanj, i lipanj udaljiše,

Sad nisam ništa, rado ne živim više!

\section{LEBENSÜBERDRUSS}

Das Angenehme dieser Welt hab ich genossen

Die Jugendstunden sind, wie lang! Wie lang! verflossen,

April und Mai und Julius sind ferne,

Ich bin nichts mehr, ich habe nicht mehr gerne!

Što nam u ovi primjeri govore? Dosljednost u prevođenju i očitost prevoditeljeve želje da ostvari takav stih koji će najpreciznije ispoljiti njegovu predodžbu i u duši čitatelja izazvati najviše odjeka. Bez obzira na to, kakve je oblikovne izmjene Tadijanović vršio u svojim prijevodima, one odaju jedno: težnju za jednostavnošću izraza, za jasnoćom predodžbe, za melodikom stiha, za ostvarenjem osobnoga stila. 


\section{Bibliografija}

Kaštelan, J.: 2004, Dragutin Tadijanović (Neprolaznost prolaznosti. Predgovori i pogovori u knjigama Dragutina Tadijanovića), Zagreb.

Schmidt, J.: 1992, Gedichte (Friedrich Hölderlin, Sämtliche Werke und Briefe, Bd. 1), Frankfurt.

Skok, J.: 2004, Pogovor ili mala glosa o lirici Dragutina Tadijanovića (Neprolaznost prolaznosti. Predgovori i pogovori u knjigama Dragutina Tadijanovića), Zagreb.

Tadijanović, D.:. Goethe, Hoelderlin, Novalis, von Hoddis, ins Kroatische übersetzt von D. Tadijanović (Aus der Deutschen Lyrik). Manuskript, Hirschberg.

Tadijanović, D.: 1969, O ciklusu pjesama dani djetinjstva (Kaštelan J., Dragutin Tadijanović), Zagreb.

Tadijanović, D.: 2004, Napomena (Neprolaznost prolaznosti. Predgovori i pogovori u knjigama Dragutina Tadijanovića), Zagreb.

Tadijanović, D.: Anmerkung für die Übersetzung (Aus der Deutschen Lyrik). Manuskript, Hirschberg. 
PETER MEYER

\section{Ist Herr Kroll ein Gehirn im Tank?}

\section{Willkommen in der Matrix}

Die überaus erfolgreiche Filmtrilogie Matrix der Brüder Laurence und Andrew Wachowski (Wachowski, Wachowski 1999-2003) stellt jeden aufmerksamen Kinogänger und Leser dieser Zeilen vor eine schwerwiegende Frage: Existiert das dicke Buch, die Festschrift für Walter Kroll, die ich gerade in Händen zu halten glaube, überhaupt? Bevor die soeben aufgeworfenen Bedenken einen Sturm der Entrüstung bei den Leserinnen und Lesern auslösen, die dieses Buch lesen und womöglich Herrn Kroll mit einem eigenen Beitrag eine Freude bereitet haben, sei kurz die wenig erfreuliche Vision skizziert, die in Matrix cineastisch verarbeitet wurde: Unfreundliche Mächte haben die Kontrolle über die Erde und ihre Bewohner übernommen. Der Planet ist übersät mit riesigen Türmen, in denen die Körper der Menschen in flüssigkeitsgefüllten Tanks aufbewahrt werden, damit besagte böse Mächte die menschliche Körperwärme als Energiequelle anzapfen können. Das Nervensystem eines jeden dieser menschlichen Körper ist an einen Supercomputer angeschlossen und wird von ihm mit Sinnesreizen versorgt, die den 
eingetankten Menschen auf perfekte Weise vorgaukeln, sich in einer ,normalen“ Welt zu bewegen, in der es zum Beispiel Bäume, slavistische Seminare, universitäre Evaluationsverfahren und Mobiltelefone gibt und man morgens zur Arbeit in den Wolkenkratzer nebenan geht - während doch der Körper mitsamt dem Gehirn, das dies alles glaubt, in Wirklichkeit regungslos im finsteren Tank schwimmt.

Eine besonders beliebte akademische Variation über diese makabren Filmideen stammt von dem Harvard-Philosophen Hilary Putnam, der indes wohl nicht die Inspirationsquelle der Wachowskis - die es da eher mit Baudrillard halten - gewesen ist. Putnam hat in seinem Buch Reason, Truth and History (1982) eine zeitgemäße Version des cartesianischen Skeptizismus vorgelegt: Woher wissen wir, woher weiß der Leser dieser Zeilen, daß wir nicht nur Gehirne im Tank sind, daß es also die von uns wahrgenommene Außenwelt wirklich gibt? Nach Voraussetzung des Gedankenexperiments sollen die vom Supercomputer produzierten Nervensignale für die angeschlossenen Gehirne nicht von solchen unterscheidbar sein, die eine reale Außenwelt, vermittelt über Sinnesorgane, hervorbringt. Demnach könnten alle Überzeugungen, die wir über die Welt um uns herum haben, falsch sein - ohne daß wir die Möglichkeit haben, dies jemals herauszufinden! Daß die Wachowskischen oder Putnamschen Gedankenexperimente möglicherweise nicht einmal im Prinzip realisierbar sind (Dennett 1991), hilft nicht weiter; sie sind denkbar, das genügt. Für die nachfolgenden Überlegungen ist es dabei nicht relevant, ob man, wie Putnam oder die Wachowskis, davon ausgeht, daß es viele eingetankte Gehirne gibt, die, etwas verkürzt ausgedrückt, in der ihnen allen vom Supercomputer vorgegaukelten Welt als virtuelle Menschen interagieren, oder ob man nur ein einzelnes um die reale Welt betrogenes Gehirn annimmt, so daß die Handlungen und Entscheidungen aller anderen Menschen in der virtuellen Welt dieses Gehirn bloße Erfindung des Computers oder vielleicht der Programmierer dieses Computers sind. Daß es in den Überlegungen des amerikanischen Starphilosophen um eingetankte Gehirne und nicht, wie bei den Filmemachern, um ganze eingetankte Körper geht, ist in unserem Zusammenhang ebenfalls unerheblich. In allen genannten Varianten ist die vom einzelnen eingetankten Individuum, um dessen Standpunkt es im folgenden gehen wird, erfahrene Wahrnehmung nämlich dieselbe.

\section{Warum Gehirne-im-Tank keine Gehirne-im-Tank sind}

Zum Glück will uns Putnam nicht nur die skeptische Bedrohung, die von niemals wirklich gedruckten Festschriften ausgeht, liefern, sondern auch die endgültige Destruktion dieser Art von Skeptizismus. Sein Argument hat eine sprachlogischbegriffliche, genauer referenztheoretische Grundlage, es prüft also, worauf wir uns mit den Wörtern unserer Sprache - in erster Linie Substantive wie „Baum“, „Wolkenkratzer" oder eben auch „Gehirn" - beziehen.

Putnams Argument läßt sich ungefähr wie folgt zusammenfassen. In unserer Sprache beziehen sich Wörter wie die eben genannten auf Dinge der Außenwelt wie eben Bäume, Wolkenkratzer bzw. Gehirne. Es handelt sich um Objekte, mit denen wir in irgendeiner hinreichend spezifischen Form in kausalen Kontakt treten 
können oder zumindest theoretisch treten könnten. Nur deswegen läßt sich, so Putnam, überhaupt sinnvoll sagen, wir könnten sprachlich auf sie Bezug nehmen. In der Sprache eines Gehirns im Tank, vornehmlich wenn dieses immer schon im Tank war und nicht erst von fiesen Wissenschaftlern eingetankt worden ist, beziehen sich die genannten Wörter jedoch nicht auf „reale“ Bäume, Wolkenkratzer oder Gehirne, denn das Gehirn kann keinerlei kausale Verbindung zu solchen Gegenständen aufnehmen. Wenn sich diese Wörter, so sagt Putnam, in der Sprache eines Tankgehirns überhaupt auf etwas beziehen, dann beispielsweise auf jene elektronischen Konfigurationen im Simulations-Supercomputer, die jeweils den Wahrnehmungseindruck der fraglichen Objekte im Gehirn kausal erzeugen. Die genaue Bestimmung des jeweiligen Referenzobjektes bzw. der jeweiligen Klasse von Referenzobjekten hängt von den sprachtheoretischen Vorlieben des Betrachters ab und ist hier für uns nicht von Interesse. Im folgenden bezeichnen wir die elektronischen Computerkonfigurationen, die im eingetankten Gehirn Sinneseindrücke erzeugen, die von realen Bäumen, Gehirnen, Tanks... ununterscheidbar sind, abgekürzt als Bäume*, Gehirne*, Tanks* und so weiter. Ein Gehirn im Tank bezieht sich daher mit dem Wort „Gehirn" nicht auf Gehirne, sondern auf Gehirne*, und mit dem Wort „Tank“ nicht auf einen Tank, sondern auf einen Tank*. Nehmen wir nun an, jemand äußere den Satz „Ich bin ein Gehirn im Tank“. Dann gibt es zwei Möglichkeiten: Entweder das betreffende Individuum ist kein Gehirn; dann ist seine Äußerung falsch. Oder aber die Person ist ein Gehirn im Tank; dann behauptet sie mit ihrer Äußerung aus den gerade genannten referenztheoretischen Gründen, daß sie ein Gehirn* im Tank* ist, was ebenfalls falsch ist: In seiner computersimulierten Welt ist dieser Mensch nämlich kein Gehirn* im Tank*, sondern schlicht ein Mensch* unter vielen anderen Menschen*. Also ist die Äußerung „Ich bin ein Gehirn im Tank" in jedem Falle falsch. Also sind wir alle keine Gehirne im Tank; quod erat demonstrandum.

Putnams Argument, das durchaus seine von Fachkollegen heiß debattierten Fallstricke hat, klingt zunächst recht paradox und wirkt ein wenig wie philosophischer Budenzauber. Würde ein echtes Gehirn im Tank aufgrund philosophischer Überlegungen à la Putnam zu dem Ergebnis kommen: „Ich bin offensichtlich kein Gehirn im Tank", dann hätte es damit Putnam zufolge sehr wohl recht, obwohl ein außenstehender Beobachter mit genau so gutem Recht gerade das (übrigens, wie zu zeigen sein wird, nur scheinbare) Gegenteil behaupten dürfte.

Aus der Sicht des Gehirns im Tank beziehen sich die Wörter „Gehirn“ und „Tank" auf Objekte in der für es selbst realen, aber, wie wir wissen, lediglich simulierten Welt. Der Person mit einem Gehirn im Tank genügt daher schon der morgendliche Blick in den virtuellen Rasierspiegel, um zu erkennen, daß es kein Gehirn im Tank ist. $\mathrm{Zu}$ dem tatsächlichen Gehirn im Tank hat die Person, zu der eben dieses Gehirn gehört, keinen hinreichenden kausalen Kontakt. Würde sie beispielsweise versuchen, in ihrer simulierten Welt mit dem Kopf durch die Wand zu rennen, dann würde damit das tatsächlich vorhandene Gehirn im Tank keinen Schaden nehmen können; die Kopfschmerzen blieben rein virtuell. Ähnlich kann Fernsehkommissar 
Derrick zwar jede Menge Fernsehapparate bei dem Versuch, den Täter im TVLaden zu fassen, zerschießen, aber ganz sicher nicht den Fernseher, auf dem wir am Samstagabend seine Verfolgungsjagd quer durch den Multimediatempel verfolgen. Daher kann Derrick auch nicht unseren Fernsehapparat meinen, wenn er das Wort „Fernseher“ verwendet, sondern nur Fernsehgeräte* in seiner, nur im Film existierenden, Welt. Entsprechend kann sich ein Gehirn im Tank denn auch nicht auf das reale Gehirn im Tank beziehen, wenn es in seiner simulierten Welt behauptet, es sei ein Gehirn* im Tank*. Das Gehirn im Tank hat mit seiner kühnen Mutmaßung, ein Gehirn im Tank zu sein, nicht nur aus seiner eigenen Rasierspiegelperspektive unrecht, auch aus der Außenperspektive eines Supercomputer-Programmierers betrachtet ergibt sich: Das Gehirn behauptet mit seiner Äußerung, ein Gehirn-Bitmuster im Tank-Bitmuster (ein Gehirn* im Tank*) zu sein - was immer das auch genau heißen mag! -, während es doch in Wirklichkeit ein Gehirn im Tank ist.

Für den außenstehenden Beobachter ist es also durchaus korrekt, zu sagen, die betreffende Person sei ein Gehirn im Tank, und zugleich der in der simulierten Welt von der betreffenden Person getroffenen Mutmaßung, sie sei kein Gehirn im Tank, zuzustimmen. Außenstehender Beobachter und Gehirn im Tank sprechen, in einem bestimmten Sinne, zwei verschiedene Sprachen, auch wenn sich beide „der deutschen Sprache“ bedienen. Selbst wenn sie dieselben Wörter verwenden, ist es daher nicht der Fall, daß sie sich damit auf dieselben Dinge und Sachverhalte beziehen. Auch daher können wir keine Gehirne in Tanks sein: Wir sprechen nicht die Sprache eines Gehirns im Tank (vgl. Wright 1994)!

Der Tenor von Putnams Überlegung läßt sich, ganz unabhängig von eher technischen Fragen einer Theorie der sprachlichen Bezugnahme, als Warnung vor einer unzulässigen Vermischung zweier Perspektiven verstehen. Wir können bei dem Namen von Fernsehkommissar Derrick einerseits an eine Person denken, die auf Fernseher schießt und den Polizeikollegen Harry bittet, schon mal den Wagen zu holen; oder aber wir können darunter ein kompliziertes, von einem Elektronenstrahl produziertes bewegtes Punktemuster auf einem Bildschirm verstehen. Auch wenn es eine offensichtliche inhaltliche Verbindung zwischen den beiden Perspektiven gibt, dürfen sie nicht miteinander vermengt werden. Bewegliche Punktemuster auf einer Mattscheibe lassen keinen Harry einen Wagen holen; Kommissare werden nicht von Elektronenstrahlen erzeugt. Wer auch nur mutmaßt, er könne ein Gehirn im Tank sein, der produziert, wenn Putnam denn recht hat, vergleichbaren semantischen Unfug - ebensogut könnte Derrick dem Fernsehzuschauer erklären, er werde gleich dessen Fernsehgerät mit einem gezielten Schuß aus der Dienstwaffe zur Implosion bringen. Ob eine solche, sehr vernünftige, Forderung nach einer Unterscheidung von Betrachtungsebenen allerdings durch die sprachphilosophische Einkleidung bei Putnam wirklich an Überzeugungskraft oder Wissenschaftlichkeit gewinnt, wird wohl auch für manchen erklärten Gegner skeptischen Gedankengutes fraglich bleiben. 
Als wir oben versuchten, aus der Außenstehenden-Perspektive zu verstehen, warum das Gehirn im Tank mit dem Satz „Ich bin ein Gehirn im Tank" unrecht hat, haben wir übrigens, wie mir scheint, selber bereits eine unzulässige Vermischung zweier Begriffsebenen vorgenommen, wie sich erneut leicht anhand unserer KrimiAnalogie erläutern läßst. Wenn wir uns darauf eingelassen haben, die bewegten, schalluntermalten Punktemuster auf der wohnzimmerlichen Mattscheibe als Bilder von Derrick (also als Bilder einer Person, die in einer wie auch immer gearteten Welt agiert und sprachlich handelt) zu interpretieren, haben wir uns auf eine begriffliche Ebene begeben, die es uns nicht mehr gestattet zu sagen, Derrick beziehe sich, wenn er das Wort „Wagen“ benutzt, nicht auf einen Wagen, sondern in Wirklichkeit bloß auf Bildpunktmuster auf Fernsehbildschirmen. Derrick bezieht sich mit dem Wort „Wagen“ auf Wagen „seiner" Welt, einer Welt, die wir bereits (samt Derrick selbst) vorausgesetzt haben, als wir anfingen, von Derrick und seinen Abenteuern zu reden. Wir können nicht, außer im Scherz, eine bestimmte Betrachtungsweise einnehmen (im wahrgenommenen, bewegten Bild die Handlungen einer Person Derrick sehen) und sie im selben Moment wieder zurückziehen (Derricks Sprache sich auf Bildpunkte auf Fernsehapparaten beziehen lassen); damit verwickeln wir uns in einen sinnlogischen Widerspruch. Ganz entsprechend dürfen wir nicht die elektrochemischen Aktivitäten eines Gehirns, das vor unseren Augen im Tank schwimmt, als neuronalen Ausdruck der psychischen Prozesse einer Person verstehen, die in einer wie auch immer gearteten Welt agiert, und im selben Atemzug behaupten, die Worte, die diese Person in dieser Welt verwendet, bezögen sich nicht auf Dinge in dieser Welt, sondern zum Beispiel auf elektronische Konfigurationen in einem Computer, der die elektrochemischen Aktivitäten des besagten Gehirns beeinflußt. Putnams Argument bleibt von meiner soeben angestellten kritischen Überlegung jedoch unangetastet: Die Person, deren Gehirn im Tank schwimmt, bezieht sich mit ihren Worten auf Gegenstände ,ihrer" Welt. Sie ist aber, in dieser ihrer Welt, kein Gehirn im Tank, sondern eine gewöhnliche lebende Person. Daher hat sie, in ihrer Welt, recht damit, zu sagen, sie sei kein Gehirn im Tank. Hat Herr Kroll also Glück gehabt? Wir werden sehen.

\section{Metaphilosophie im Tank}

Interessierte Leser, die nicht dem Stand des modernen Berufsphilosophentums angehören, werden möglicherweise geneigt sein zu vermuten, Putnams Überlegungen seien als kuriose Randbemerkung in der Nähe einer Wieviele-Engel-passen-aufeine-Nadelspitze-Scholastik anzusiedeln. Weit gefehlt! Es gibt mittlerweile eine umfangreiche Debatte zu diesem Thema; immer wieder wird „Wie hältst Du's mit den Tankhirnen?" beinahe zur Gretchenfrage für ganze Theoriegebäude in den Disziplinen Metaphysik, Sprachphilosophie und ach! manch anderem erhoben. Sogar Gegenstand einer Göttinger Habilitationsschrift ist Putnams filmogene Überlegung schon gewesen (vgl. Müller 2003). Man beobachtet in der Literatur ein durchaus charakteristisches argumentatives Wettrennen: Die einen versuchen, in den mittlerweile zahlreichen Ausformulierungen der eher nachlässigen Argumentation 
Putnams einen philosophischen oder logischen Argumentationsfehler zu finden, die anderen - unter ihnen auch z.B. Müller - bemühen sich darum, die eine oder andere Variation über die Widerlegung der Möglichkeit eines Tankhirn-Skeptizismus so zu modifizieren und wasserdicht zu machen, daß kein Platz mehr für besagte Argumentationsfehler bleibt.

Am skizzierten Wettrennen möchte ich hier nicht teilnehmen, sondern mich eher jener Fraktion anschließen, die - wie z. B. Thomas Nagel (1986) - der Auffassung ist, daß Putnams Argument kein hinreichendes antiskeptisches Potential hat, unabhängig davon, ob Putnams Argumentation Gültigkeit beanspruchen kann oder nicht. Tatsächlich geht es mir im vorliegenden Essay nicht einmal um einen Beitrag zur Skeptizismus-Diskussion, sondern ich möchte versuchshalber den von Putnam initiierten philosophischen Diskurs von einem metasprachlichen Standpunkt aus betrachten und auf zwei eng miteinander verwobene Probleme hinweisen. Zum einen möchte ich darauf hinweisen, wie sehr die saloppe Art der Putnamschen Fragestellung uns in die Gefahr bringt, unsere eigene sprachliche Ausdrucksweise mißzuverstehen und deswegen zu unbrauchbaren Analysen zu gelangen, eine Gefahr, vor der etwa der spätere Wittgenstein uns immer wieder gewarnt hat. Zum anderen ist Putnam, wie mir scheint, in seiner Beantwortung der Fragestellung Opfer eines zu einfachen, reduktiven Bildes von Sprache geworden, eines Bildes, dem zufolge Wörter wie „Gehirn“ und „Tiger", unabhängig vom Äußerungskontext und vom Satz, in dem sie stehen, immer dieselbe „Funktion" haben, indem sie die Aufgabe haben, sich - in welcher Weise auch - auf bestimmte "Gegenstände“ zu beziehen; auf welche Gegenstände sie sich jeweils beziehen, hängt natürlich sehr wohl vom Ko- und Kontext ab. Hierbei geht es mir also, anders als so vielen anderen Kommentatoren, überhaupt nicht darum, die spezielle, oft irreführend als „,kausal" bezeichnete, Referenzauffassung von Putnam zu kritisieren, die dieser in seiner Argumentation voraussetzt. Es geht mir um eine viel generellere Überzeugung, die wohl die allermeisten Kombattanten in der philosophischen Schlacht um Tankhirne teilen, nämlich diese: „Um die Bedeutung und den Wahrheitswert einer beliebigen Äußerung, also auch der Äußerung «Ich bin ein Gehirn im Tank», angeben zu können, müssen wir stets den Beitrag analysieren, den die einzelnen Bestandteile der Äußerung (im gegebenen Beispiel unter anderem die Wörter «Gehirn» und «Tank») zur Gesamtbedeutung des Satzes liefern." Das Problematische an der gerade referierten Überzeugung ist aus meiner Sicht gerade die Präsupposition, daß es einen solchen isoliert bestimmbaren Beitrag von Äußerungs-/Satzbestandteilen zum Äußerungs-/Satzganzen immer geben muß. Mit dieser Bemerkung soll übrigens nicht pauschal das semantische Kompositionalitätsprinzip - demzufolge sich die Bedeutung eines komplexen sprachlichen Ausdruckes aus der Bedeutung seiner Teilausdrucke ergibt - mit dem sprachphilosophischen Bade ausgeschüttet werden; als normatives methodisches und begriffliches Leitprinzip ist es vermutlich, in was für einer theoretischen Präzisierung auch immer, als eine Grundlage für jegliche Art von Bedeutungsanalyse unterhalb der Satzebene unverzichtbar. 
Beginnen wir mit einer scheinbar harmlosen Frage. Von welchen Entitäten kann man überhaupt sinnvoll (wenngleich auch möglicherweise zu Unrecht) sagen, sie könnten möglicherweise Gehirne im Tank sein? Etwas technischer ausgedrückt: Auf welche Objekte im Diskursuniversum läßt sich das Prädikat ist ein Gehirn im Tank überhaupt anwenden, unabhängig davon, ob sich bei einer solchen Anwendung eine wahre oder eine falsche Aussage ergibt? Reflexartig möchte man antworten: „Das Prädikat läßst sich offenbar sinnvoll auf Gehirne aller Art anwenden“; man liest das Prädikat ist ein Gehirn im Tank dann also in dem naheliegenden Sinne gehört zur Klasse der eingetankten Gehirne. Die Kopula hat in dieser Lesart eine ganz gewöhnliche subsumptive Funktion. Die spontane Antwort ist indes falsch. Um dies einzusehen, genügt eigentlich schon ein Blick auf den Titel dieses Aufsatzes, in dem das besagte Prädikat auf den Ausdruck „Herr Kroll“ angewendet wird. Herr Kroll ist aber kein Gehirn; er ist eine Person, die ein Gehirn hat. Und wenn wir in unseren bisherigen Überlegungen immer wieder von Gehirnen im Tank gesprochen haben, die sich in ihrer virtuellen Welt im Rasierspiegel sehen, sich philosophische Gedanken machen usw., dann stand der Ausdruck „Gehirn im Tank“ jeweils pars pro toto für eine Person, deren Gehirn in Wirklichkeit in einem Tank schwimmt und an einen Simulationscomputer angeschlossen ist. Statt von „Personen“ kann man, je nach den eigenen philosophischen Vorlieben, etwa auch von „Bewußtseinen“ o.ä. reden; dies ist für unsere weitere Argumentation unerheblich. Im folgenden verwende ich den hoffentlich hinreichend neutralen Ausdruck „Person“, um mich auf diejenige Art von Entität zu beziehen, von der wir sagen würden, sie habe Wahrnehmungen, ein Bewußtsein, (jedenfalls ihrer eigenen Überzeugung nach) einen menschlichen Körper usw.

In der philosophischen Argumentation von Putnam ist das Gehirn, das dort im Tank schwimmt, nicht nur ein beliebiger Haufen Nervenzellen in einer Nährlösung, der elektrochemisch mit einem externen Computer verbunden ist. Das Gehirn muß, so unterstellen Putnam ebenso wie die Wachowski-Brüder, ,Verursacher' oder ,Träger' einer Person im gerade erläuterten Sinne sein. Wenn Putnam annimmt, daß es da außer dem Gehirn im Tank noch eine damit irgendwie ,verbundene' Person gibt, dann aufgrund eines philosophisch durchaus raffinierten Analogieschlusses der folgenden Art: „Die elektrochemischen Prozesse, die man an dem Gehirn im Tank beobachten kann, sind dieselben, die bei einem Gehirn vorliegen, das sich im realen Körper eines Menschen «aus Fleisch und Blut» befindet, z.B. eines Menschen, der gerade im Café sitzt und sich unterhält; also gibt es auch jetzt eine Person «hinter» dem Gehirn in diesem Tank, eine Person, die sich, in ihrer Welt, gerade in einem Café in eine Konversation vertieft wähnt."

Daß wir bei der Formulierung des Putnamschen Gedankenexperimentes davon ausgehen, daß es eine Person ,hinter' dem Gehirn im Tank gibt, ist ein verständlicher und unter Umständen sehr sinnvoller, aber keineswegs banaler Analogieschluß, der sich nicht alleine durch irgendeine kausale oder, wie man richtiger sagen sollte, historisch erklärende Referenztheorie à la Putnam abdecken läßt: Hinter dem Begriff der Person steht in diesem Fall offenbar keine kausal wirksame Entität, 
die unabhängig von unseren Begriffsprojektionen existieren würde. Mit solchen Analogien (wenn man nicht gleich von Metaphern oder begrifflichen Projektionen sprechen möchte) erschließen wir uns ganz allgemein auf sprachlichem Wege konzeptuelles und epistemisches Neuland, auch in wissenschaftlichen Kontexten. Es gibt keinen logisch zwingenden argumentativen Weg, der uns überzeugen könnte, daß es da immer noch eine Person ,hinter' oder gar ,in' diesem Gehirn im Tank mitsamt seinen immens komplexen neuronalen Prozessen gibt, denn unsere gewöhnlichen, alltäglichen Kriterien für den Personenstatus finden sämtlich keine Anwendung mehr; man denke hier an die schwierige Frage der Beurteilung des Personenstatus etwa bei Wachkomapatienten, bei denen ebenfalls keine Verhaltensmuster mehr unseren Entscheidungsrastern klar entsprechen. Dennoch verlassen wir, und dies muß eben auch Putnam in seinen antiskeptischen Überlegungen unterstellen, nicht den Bereich sinnvoller Rede, wenn wir für eine neue Situation - lebendes, funktionierendes menschliches Gehirn in passender elektrochemischer Umgebung, aber ohne normalen Körper - neue Kriterien aufstellen oder erfinden, obwohl wir nicht in die Rolle oder Perspektive des Gehirns im Tank schlüpfen können, um zu prüfen, ob wir damit richtig liegen. Wir verwenden bei diesem Analogieschluß vertraute Wörter und Begriffe - etwa den Personennamen Herr Kroll -, die in unserem alltagsweltlichen Handeln hinreichend (auch kausal) verankert sind, in einem neuen Bereich und sind im besten Fall sogar in der Lage, die begriffliche Projektion mit Argumenten zu stützen.

Halten wir daher fest: Wenn wir mit Blick auf ein konkret vor uns stehendes, eingetanktes und verdrahtetes Gehirn sagen würden, dies sei (im Putnamschen Sinne) ein Gehirn im Tank, und zwar handele es sich um einen gewissen Herrn Schein, der sich gerade, wie der Computer anzeige, in einem Café in ein Gespräch mit einer charmanten jungen Dame verwickelt glaubt - dann würden wir das Prädikat ein Gehirn im Tank sein etwa in folgender, durch komplexe Analogieschlüsse gerechtfertigten, Bedeutung verwenden: eine Person sein, die sich, ohne es zu wissen, in einer virtuellen Welt von Wahrnehmungen und Überzeugungen befindet, die kausal von dem vor uns stehenden, eingetankten und an einen Simulationscomputer angeschlossenen Gehirn erzeugt wird.

Stellen wir uns nun vor, Herr Kroll würde nach der Lektüre dieser unmaßgeblichen Zeilen ins philosophische Grübeln verfallen und denken: „Vielleicht bin ich ja tatsächlich auch ein Gehirn im Tank". Was würde er damit nach der bisherigen begrifflichen Analyse meinen? Auf jeden Fall nicht folgende Behauptung: „Ich bin vielleicht - ein Gehirn (unter anderen Gehirnen von Lebewesen in meiner Welt) in einem Tank (unter anderen Tanks in meiner Welt, die ich, zumindest theoretisch, sehen und berühren kann)." Das will der dem Skeptizismus verfallene Herr Kroll ganz sicher nicht sagen; es ist ja ganz offenkundig falsch, ganz gleich, ob er nun „,in Wirklichkeit" ein Gehirn im Tank ist oder nicht. Aber nur diese triviale Lesart von ein Gehirn im Tank sein wird von Putnams Argument überhaupt erfaßst! Was Herr Kroll tatsächlich meint, ließe sich etwa wie folgt paraphrasieren: „Meine Situation könnte der des armen Herrn Schein vergleichbar sein." Erneut werden in 
dieser Äußerung Wörter wie „Situation“ und „,vergleichbar“, deren alltagsweltliche und -sprachliche Verankerung auch in der Welt eines Gehirnes im Tank nicht bestritten werden könnte, in einem neuen Kontext genutzt, und wieder fehlt die Möglichkeit, mit einem apriorischen Argument die neue Verwendung als sinnlos zu brandmarken. Wir verstehen ja, nach Voraussetzung des Argumentes von Putnam, was es heift, sich in der Situation des Herrn Schein zu befinden. Und nun machen wir - oder eben der nachdenkliche Herr Kroll - nichts anderes, als, gewissermaßen probeweise, das Prädikat ein Gehirn im Tank sein in einer neuen Weise, nämlich diesmal auf die eigene Person, anzuwenden. Wieder entfallen bei dieser sprachlichen Übertragungsleistung geradezu per definitionem sämtliche erdenklichen Kriterien, die uns bislang für die Feststellung der korrekten Anwendbarkeit des Prädikats zu Verfügung gestanden haben, ganz genau so, wie dies oben für den Begriff der Person der Fall war. Erneut fehlt aber auch die Möglichkeit, die Ausdehnung der Verwendungssphäre des Prädikats aufgrund von a priori gegebenen Kriterien zu verbieten, solange es gute Gründe gibt, diese Ausdehnung in Betracht zu ziehen. Wenn wir eine uns im herkömmlichen Sinne epistemisch unzugängliche Person „hinter" Herrn Scheins Gehirn unterstellen dürfen, können wir, und damit auch Herr Kroll, in vergleichbarer Weise, also auf dem Weg einer vergleichbaren begrifflichen Projektion, einen epistemisch unzugängliche Befindlichkeitszustand, den wir bei anderen Personen als möglich unterstellen, für uns selbst als Möglichkeit in Erwägung ziehen. Damit nehmen wir nicht das ein, was Putnam in seiner Kritik eines herkömmlichen - wie er es nennt: metaphysischen - Realismus als „Gottesgesichtspunkt" bezeichnet: Wir treten mit den zugegebenermaßen mutigen begrifflichen Projektionen nicht aus den uns zur Verfügung stehenden Sprache-Welt-Zusammenhängen heraus, da die von uns verwendeten Wörter und Bezeichnungen bereits eine Verankerung in eben diesen Zusammenhängen haben.

Herr Kroll erzeugt also keinen semantischen Unfug, wenn er sagt: „Meine Situation könnte der von Herrn Schein vergleichbar sein." Denselben Gedanken könnte er aber natürlich auch so ausdrücken: „Ich bin - vielleicht - ein Gehirn im Tank." Hier würde er das Prädikat ein Gehirn im Tank sein natürlich in der gerade explizierten, nichttrivialen Lesart verwenden. Für Herrn Kroll heißt „ein Gehirn im Tank sein" also soviel wie ,sich in einer Situation befinden, die derjenigen der Person Herrn Scheins ähnelt, von dem wir auch sagen, er sei ein Gehirn im Tank, d.h. in einer Situation, die von dem Gehirn hervorgebracht wird, das hier verkabelt in einem Tank schwimmt“. Nicht die einzelnen Wörter „Gehirn“, „Tank“ und so weiter müssen betrachtet werden, um die fragliche Lesart des Ausdruckes „ein Gehirn im Tank sein“ erläutern zu können, sondern der gesamte Ausdruck ist aus einem Kontext, in dem er semantisch noch einigermaßen zerlegbar war (als es nämlich um Herrn Schein als Person sowie um sein Gehirn ging), in einen neuen Kontext übertragen worden (in dem es um die Person von Herrn Kroll geht, deren Existenz wir nicht erst, anders als bei Herrn Schein, aufgrund einer schwierigen naturwissenschaftlichen Analogie postulieren müssen - da steht er ja vor uns und hält gerührt seine Festschrift in der Hand!). Entsprechend komplex muß dann 
die daraus ableitbare „Referenzleistung“ der einzelnen Substantive, die in ihm vorkommen, beschrieben werden.

Mit den vorstehenden Überlegungen kann abschließend noch eine interessante Brücke zu Herrn Krolls großem Betätigungsfeld, der Literaturwissenschaft, geschlagen werden. Wenn wir nämlich verstehen wollen, wie die menschliche Sprache beispielsweise in fiktionalen Kontexten „funktioniert", sind Überlegungen ähnlich denen, die wir gerade angestellt haben, ganz unumgänglich. Wie die Matrix-Trilogie und zahlreiche andere Filme zeigen, ist die Grenze zwischen literarischer und cineastischer Fiktion einerseits und philosophischen hypothetischen Szenarien durchaus fließend. Die metasprachlichen Beobachtungen, die ich oben angestellt habe, lassen sich entsprechend auch an viel elementareren Szenarien anstellen. So gibt es in einem bestimmten Sinne weder den Weihnachtsmann noch den Hauptkommissar Derrick, und dennoch machten wir es uns ja offensichtlich zu einfach, wenn wir ungerührt behaupten würden, wir bezögen uns schlicht auf nichts, wenn wir die Wörter „Weihnachtsmann“ bzw. „Derrick“ in den Mund nehmen. Vielmehr ruht unsere Rede von Weihnachtsmännern und Derricks gewissermaßen parasitär auf unserer alltagssprachlichen Verwendung von Personenbezeichnungen für „reale“ Menschen auf. Auch hier liegen bemerkenswert komplexe, aber trotzdem schon von Kindern mühelos beherrschte, sprachliche Übertragungsprozesse vor, die sich solchen sozusagen atomistischen Fragestellungen wie „Auf welche Entitäten beziehen sich denn nun die Wörter «Weihnachtsmann» und «Derrick»?" sehr erfolgreich widersetzen, weil sie nur auf einer holistischen Ebene der Betrachtung einer ganzen Praxis der sozialen Konstitution von und der Rede über Personen verständlich zu machen sind. Vielleicht hätte Putnam also das eine oder andere Seminar bei Herrn Kroll besuchen sollen?! Dann wäre er vielleicht auch über ein weiteres Problem gestolpert, das ich weiter oben geflissentlich unterschlagen habe, als behauptet wurde, Derrick könne sich mit dem Wort „Fernseher“ nicht auf die Fernsehapparate der zahlreichen TV-Serien-Konsumenten beziehen. Selbstverständlich kann er dies, genau so, wie sich der Bühnenschauspieler urplötzlich an die Theaterzuschauer wenden kann, um sich bei ihnen über die unzureichende Ausbildung seiner Kollegen oder das langweilige Stück zu beklagen. Solche autoreflexiven Wendungen sind gewissermaßen noch einmal eine Potenzierung der Übertragungsleistungen, die bei der Produktion und Rezeption literarischer Texte, Kinofilme, Dramen usw. erforderlich sind und die zu beschreiben und zu erklären offenbar ein gemeinsames Anliegen von Literatur- und Sprachwissenschaftlern sowie Philosophen sein muß. Nur am Rande sei erwähnt, daß Begriffsprojektionen der hier betrachteten Art offenbar auch notwendige Voraussetzung für jeglichen wissenschaftlichen Erkenntniszuwachs sind.

\section{Rein in den Tank, raus aus dem Tank}

Wenn nun aber Putnams mutiger Versuch der Destruktion eines der großen gedanklichen Herausforderungen der abendländischen Philosophie nicht gefruchtet haben sollte (was auf diesen wenigen Seiten ganz sicher nicht wasserdicht gezeigt wurde) 
- was sollen wir dann unternehmen, um das cartesische Skeptizismus-Gespenst zu vertreiben? Eine schlichte Antwort könnte lauten: nichts. Die von philosophischer Seite ausdrücklich artikulierte Möglichkeit, wir könnten „in Wirklichkeit“ bloß Gehirne im Simulationstank sein, ist in unser Praxis des Lebens, Redens und Handelns ein Unterschied, der keinen Unterschied macht. Es scheint mir, daß es ganz einfach in der begrifflichen Struktur skeptischen Argumentierens liegt, daß eine logische Widerlegung nie, die skeptische Unterwanderung selber hingegen immer möglich ist. Dem Skeptizismus können wir daher nur begegnen, indem wir unseren argumentativen Umgang mit skeptischen Strategien auf einer Metaebene selber zum Gegenstand philosophischen Nachdenkens werden lassen und skeptische Szenarien auf diese Weise zum Schweigen bringen. Gehirne im Tank lassen sich nicht wirkungsvoll begriffslogisch bestreiten. Aber die mit noch so großer Überzeugungskraft vorgetragene Behauptung, der Leser dieser Zeilen sei bloß ein Gehirn im Tank, wird den Leser vermutlich nicht dazu bringen, sein Verhalten oder Denken zu revidieren (gegenteilige Fälle sind angeblich tatsächlich bekannt geworden; man würde in solchen Fällen allerdings eher die Psychiatrie als die Philosophie als Remedium empfehlen wollen). Die skeptische Behauptung steht außerhalb unserer Lebenszusammenhänge; sie kann aber als leer drehendes Rad, gewissermaßen als rhetorische Floskel, an jede empirische Behauptung angehängt werden. In der Praxis unseres Lebens könnten wir einen konsequent skeptischen Standpunkt, der uns ja von jeglicher Ethik, von jeglichen Bindungen ablösen würde, gar nicht durchhalten. Vielleicht ist es nicht einmal möglich, sich konsistent vorzustellen, was das heißen könnte: einen konsequent skeptischen Standpunkt durchhalten. Auch wenn es begrifflich durchaus verständlich zu machen ist, was es heißen könnte, ein Gehirn im Tank zu sein - praktisch läuft die Überlegung leer. Glück - nicht nur - für Herrn Kroll!

\section{Zwei Fragen, zwei Antworten}

Am Ende dieses Aufsatzes sollen die Leserinnen und Leser nun endlich zu ihrem guten Recht einer Antwort auf ihre beiden drängendsten Fragen kommen.

Zum ersten: Warum wird - ausgerechnet in dieser Festgabe für Herrn Kroll! - unser geschätzter Kollege selber in der Überschrift dem Verdacht ausgesetzt, lediglich ein Gehirn im Tank zu sein? Hätte man nicht jemanden anderes für diese zweifelhafte Rolle vorsehen können? Den Autor dieser Zeilen etwa? Eben dieser muß aber sogleich den naheliegenden Verdacht zurückweisen, er habe die Überschrift einfach als reißerischen Aufmacher ausgewählt, und das auch noch auf Kosten des Geehrten. Vielmehr zwang gerade umgekehrt die gebotene Höflichkeit zu dieser Wahl: Hätte der besagte Autor dieses Aufsatzes etwa sich selber im Gedankenexperiment zum Tankhirn erkoren, dann wäre am Ende nicht nur die vorliegende Festgabe, sondern auch der in ihr Gefeierte bloß eine Fiktion des Supercomputers, gar ein Phantasieprodukt skrupelloser Programmierer gewesen! Und wer will schon in seiner eigenen Festschrift lesen müssen, ihn selbst, den Befestschriebenen, gebe es womöglich gar nicht? Dann doch lieber die Matrix, 
denn da gibt's unseren Kroll immerhin gleich doppelt: Als Gehirn im Tank und als von den uns simulierten Mitarbeitern hochgeschätzten Kollegen in unseren (selbstredend virtuellen) Gemäuern...

Und zum zweiten: Ist Herr Kroll denn nun ein Gehirn im Tank oder nicht? Aber selbstverständlich! Walter Kroll ist ein - und durchaus nicht nur irgendein Gehirn im illustren (Think-)Tank des Göttinger slavistischen Seminars. War doch - Philosophie hin oder her - sowieso klar. Oder?

Keine Widerrede....!

\section{Literatur}

Müller, Olaf L.: 2003, Hilary Putnam und der Abschied vom Skeptizismus: oder warum die Welt keine Computersimulation sein kann $[=$ Wirklichkeit ohne Illusionen, Band I], Paderborn.

Dennett, D. C.: 1991, Consciousness Explained, Boston.

Nagel, Th.: 1986, The View from Nowhere, Cambridge

Putnam, H.: 1982, Reason, Truth and History, Cambridge.

Wachowski, L., Wachowski, A. (Buch und Regie): 1999-2003, The Matrix: Kinotrilogie. Erster Teil 1999: The Matrix; zweiter Teil 2003: The Matrix Reloaded; dritter Teil 2003: The Matrix Revolutions [vgl. die offizielle Internet-Homepage http://whatisthematrix.warnerbros.com/].

Wright, C.: 1994, ,On Putnam's Proof that we cannot be Brains in a Vat', in: P. Clark, B. Hale (eds.), Reading Putnam, Oxford. 


\section{Zur Rezeption deutschsprachiger Literatur bei den Kroaten in den 30er Jahren des 20. Jahrhunderts}

I.

Es ist allgemein bekannt, daß im 19. Jahrhundert Übersetzungen aus dem Deutschen für die Entwicklung der kroatischen Literatur keine Hauptrolle spielten. Wichtiger als Goethe, Schiller oder Fontane, die man ohnehin im Original lesen konnte, waren slavische Autoren: die eigene ragusanische und dalmatinische Tradition, tschechische und slowakische Vertreter der Wiedergeburtsbewegung, Mickiewicz, Puškin und Lermontov, schließlich Turgenev. Erst zu Beginn des 20. Jahrhunderts tritt die kroatische Lyrik in Dialog mit der Wiener Moderne; später arbeiten kroatische Expressionisten mit Zeitschriften wie „Die Aktion“ und „Der Sturm" zusammen.

Der Expressionismus war von Anfang an sozial engagiert, und seine Vertreter gehörten überwiegend der politischen Linken an. Daher ist es nicht verwunderlich, daß die größte Aufmerksamkeit der Literaten zu Beginn der 30er Jahre weiterhin der Linken galt. Dieses Interesse steigerte sich, als im Mai 1933 im nationalsoziali- 
stischen Deutschland die Bücher unliebsamer Schriftsteller verbrannt wurden. Das besondere Interesse für diese Autoren drückte sich im Sammelband „Desetorica s lomače" (1933) aus, einer Anthologie von Texten zehn ausgewählter verfolgter Schriftsteller, aus. Die einzige kroatische Rezeption dieses Buches (Horvat 1933) erschien in der serbischen Zeitschrift „Život i rad“ und hat einen rein informativen Charakter.

Nicht nur zeitgenössische deutschsprachige Autoren wurden übersetzt oder von der Literaturkritik berücksichtigt, sondern auch Klassiker wie Goethe, Kleist und Heine. Wenn man jedoch die Kritik jener Zeit verfolgt, ist festzustellen, daß sich das damalige Klassikerverständnis mit der Ideologisierung des literarischen Lebens deckte. Davon zeugen etwa Krležas Kleist-Rezeption oder Rezensionen zu Nazors Heine-Übersetzungen, in denen sie als zu ,klassisch“ für den in den dreißiger Jahren postum unterdrückten Autor bemängelt werden. In der Zeitschrift „Vidik“ fordert Zlatko Gašparovič (1932) geradezu eine zeitgenössische, d.h. ideologische Interpretation des deutschen Klassikers Goethe.

Von den damals zeitgenössischen Autoren sollen im folgenden einige für die Rezeption deutschsprachiger Literatur paradigmatische Beispiele aus einer bedeutend größeren tatsächlich rezipierten Menge ausgewählt werden: die Brüder Mann, Ernst Toller, Erich Kästner und Ödön von Horvath. Die Brüder Mann galten damals bereits als Klassiker der modernen deutschen Literatur, Toller wurde besonders als Vertreter einer unabhängigen Linken rezipiert, Kästner erfreute sich der größten Popularität sowohl als Kinderautor als auch als Schriftsteller für Erwachsene, und für Horvath begannen sich schließlich Ende der dreißiger Jahre einige bedeutendere Vertreter der kroatischen Literatur zu interessieren.

\section{II.}

Heinrich und Thomas Mann waren dem kroatischen Publikum bereits seit längerem bekannt. Erste Übersetzungen des Werks von Thomas Mann, der 1929 den Nobelpreis für Literatur erhalten hatte, erschienen jedoch erst nach 1945, und zwar in der serbischen Variante. Anläßlich der Verleihung des Nobelpreises schreiben Ivan Esih (1929/30) in der Zeitschrift „Omladina“ und Ivo Lendić (1929/30) in der katholischen Zeitschrift „Luč“ Aufsätze über Leben und Werk von Thomas Mann. 1930 stellt Petar Preradović im deutschsprachigen „Morgenblatt“ Manns neue Novelle „Mario und der Zauberer“ vor, und 1933, nach der Verleihung des Nobelpreises an Ivan Bunin, schreibt derselbe Kritiker über die Begegnung zwischen Thomas Mann und dem Russen in Paris 1927, bei der Mann im Gespräch mit Bunin vor dem Totalitarismus in Ost und West gewarnt hatte. Dagegen warf Leon Bornik 1937 Mann vor, er habe, obwohl seine Bücher 1933 verbrannt wurden, nicht ausreichend gegen das nationalsozialistische Deutschland protestiert, sondern weiter in Deutschland publiziert. Dabei hat der Verfasser offensichtlich nicht im Blick gehabt, daß Mann durch seine fortgesetzten Publikationen in Deutschland nicht nur sein eigenes Werk für eine kurze Zeit weiterhin einem deutschsprachigen Publikum vorlegen, sondern gleichzeitig den bedrohten Fischer Verlag als einer der meistgelesenen Autoren unterstützen konnte. In derselben Zeitschrift „Književnik“ 
wurde 1939 Manns berühmter Vortrag „The Conscience of Mankind“, den er 1938 in mehreren amerikanischen Städten gehalten hatte, in kroatischer Übersetzung abgedruckt. Der Autor erläutert in ihm Manns Vorstellungen von Demokratie und Freiheit und prangert den Verlust der Menschenwürde in den Diktaturen, vor allem in Deutschland, an.

Daß Mann damals beinahe als Verräter der verbotenen Schriftsteller galt, hängt möglicherweise damit zusammen, daß sein Werk im Gegensatz zu dem seines Bruders Heinrich weniger stark sozial engagiert ist. Jedoch gerade aufgrund seiner sozialkritischen Werke interessierte sich Tin Ujević besonders für Heinrich Mann. Im Aufsatz „Umjetnik u djelu Heinricha Manna“ stellt er die grundlegende Frage: „Was bedeutet der Künstler als Mitglied der Gesellschaft? Und wieviel trägt die Kunst in ihrer sozialen Funktion, als Faktor des nationalen Lebens bei?" (Ujević 1931, 200), um anschließend darzulegen, wie Heinrich Mann sich im Roman „Jagd auf die Liebe“ dieser Frage widmet. Im Gegensatz zu Thomas Mann, der sich vor allem mit allgemeinen Fragestellungen des menschlichen Lebens beschäftigt hat, schrieb sein älterer Bruder scharfe Satiren auf das damalige Deutschland und das Wilhelminische Kaiserreich. 1933 hat der kroatische Literat Gustav Krklec den Roman „Der Untertan“ für den Belgrader Nolit Verlag in ekavischer Variante übersetzt. Obwohl Ivo Hergešić 1931 bemerkt hatte, daß Thomas Mann populärer sei als Heinrich, erfuhr gerade letzterer weitaus mehr Aufmerksamkeit in der kroatischen Kritik, nicht zuletzt deshalb, weil wenigstens eine Übersetzung vorlag. Zudem ließ sich Heinrich Manns Werk leichter in ideologische Kategorien einordnen. Aufgrund seiner scharfen Kritik an der politischen Rechten bereits lange vor 1933 dürfte er auch in den Sammelband „Desetorica s lomače“ aufgenommen worden sein. In einer Rezension dieses Bandes von Mladen Horvat (1933, 1408) wird ausgerechnet Mann „der schärfste Protest in diesem Buch“ zugeschrieben. Heinrich Mann verdankt seine Popularität in Kroatien nicht allein seinem literarischen Werk, sondern auch dem damals auch dort außergewöhnlich erfolgreichen Film „Der blaue Engel“ mit Marlene Dietrich in der Hauptrolle, der nach Manns Roman „Professor Unrat" gedreht worden war.

Die Trilogie „Das Kaiserreich“, von der „Der Untertan“ lediglich einen Teil darstellt, hatte vor der Übersetzung des „Untertans“ bereits 1931 Miliovoj Magdić in der Zeitschrift „Riječ“ vorgestellt; dabei vergleicht er Heinrich Mann mit Galsworthy, Rolland und Zola. Das Erscheinen des „Untertans“ hat nicht nur die literarische Linke beschäftigt, die die Gesellschaftssatire positiv aufgenommen hatte und in ihr eine Erklärung für die aktuelle politische Situation in Deutschland fand (so z.B. Ivo Kun (1934) in „Književnik“ oder Mirko Kus Nikolajev (1933a) in ,Socialna misao“), sondern auch die äußerste Rechte. So diffamierte Vinko Rieger $(1933,377)$ in „Hrvatska smotra“ Manns Position als sozialistische Propaganda und behauptete, daß jeder wahre Nationalismus auch eine soziale Komponente enthalte, wie „Hitlers und Mussolinis Bewegungen“ zeigten. Ein anderer Journalist ereiferte sich 1939 in der Zeitschrift „Hrvatsko jedinstvo“ in einem Bericht über einen Vortrag von Ivo Horvat darüber, daß Heinrich Mann fehlerhaft über Dalmatien geschrieben habe. 
Sowohl Heinrich als auch Thomas Mann haben die kroatischen Kritiker also weniger als Schriftsteller denn als Vertreter bestimmter ideologischer Werte interessiert, die die literarische Situation im damaligen Jugoslavien prägten.

\section{III.}

Die Brüder Mann haben mehr - Heinrich - oder weniger - Thomas - explizit gesellschaftliche Phänomene in ihren Werken kritisiert, waren aber politisch nicht aktiv. Im Gegensatz dazu war Ernst Toller nicht nur ein sozial engagierter Literat, sondern 1918 auch politisch in der Bayerischen Räterepublik tätig gewesen, wofür er mit fünf Jahren Festungshaft im Zuchthaus Niederschönenfeld bestraft worden war. Die meisten seiner literarischen Werke schrieb er in Gefangenschaft; seine expressionistischen Stücke wurden in Abwesenheit des Autors uraufgeführt. Trotz seiner Teilnahme an der bayerischen Revolution gehörte Toller niemals einer Partei an. Mirko Kus Nikolajev (1925) hattte ihn in der Zeitschrift „Vijenac" schon in den zwanziger Jahren als humanen Sozialrevolutionär vorgestellt; in demselben Geist schrieb er ein umfangreicheres Porträt in "Socialna Misao“ 1931. Selbst ein unabhängiger Linker, konnte sich Kus Nikolajev offenbar in vieler Hinsicht mit den Positionen des deutschen Autors identifizieren. Beide korrespondierten miteinander, und als Toller nach dem Dubrovniker PEN-Kongreß von 1933 nach Zagreb kam, lernten sie sich persönlich kennen. So wurde Kus Nikolajev zum wichtigsten Vermittler Tollers in Jugoslavien: Er schrieb über ihn zahlreiche Artikel und übersetzte einige seiner Texte.

Tollers Rede auf dem Dubrovniker PEN-Kongreß hatte nach Wolfgang Rothe $(1983,109)$ einen bedeutenden Einfluß auf die Haltung des Klubs. Zuvor hatten die Versammlungen mehr oder weniger Gespräche am (gedeckten) Tisch dargestellt; nach Tollers Auftritt und der Reaktion der deutschen Delegierten hatten die Mitglieder des PENs offenbar die Ernsthaftigkeit der Lage begriffen, in der sich die deutsche Literatur befand, und formulierten eine Resolution, in der sie Geistesfreiheit forderten. Damit konnten sie in Deutschland jedoch nichts mehr bewirken. Toller, der sich bereits vor dem Reichstagsbrand in der Schweiz aufgehalten hatte, verlor unmittelbar nach der Bücherverbrennung die deutsche Staatsbürgerschaft (zusammen mit Tucholsky, Heinrich Mann, Lion Feuchtwanger u.a.). Nach seiner Jugoslavienreise fand er Asyl in England, später in den USA.

Toller trat in Ljubljana, Zagreb, Sarajevo und Belgrad auf. Von seiner Lesung in Zagreb zeugen Artikel in verschiedenen Zeitungen und Zeitschriften. Das deutschsprachige „Morgenblatt“ schrieb über den Abend im „Gradski podrum“ verhalten (vgl. V. 1933, Vernić 1933), während Ivan Esih (1933) in „Jutarnji list“ den deutschen Autor begeistert als ausgezeichneten Redner vorstellte, der das Publikum in seinen Bann zu ziehen vermocht habe. Der Artikel von Kus Nikolajev (1933b) vermittelt vertiefte Informationen über die Lage in Deutschland und Tollers Position gegenüber dem Nationalsozialismus sowie der Literatur im allgemeinen. Kus Nikolajev übersetzte auch eine Sammlung von Tollers Reiseberichten, die unter dem Titel „Moskva - New York - Madrid“ 1933 im Verlag „Epoha“ erschien (Toller 1933c). Einige Texte waren bereits in „Desetorica s lomača“ erschienen. Im 
selben Jahr gibt Kus Nikolajev auch Tollers Büchlein „Kulturne posljedice požara Rajhstaga“ (Toller 1933d) heraus, und in Belgrad erscheint Tollers Autobiographie „Jedna mladost u Nemačkoj“ in der Übersetzung von Gustav Krklec (Toller 1933e), noch bevor sie in Amsterdam auf deutsch herauskommt. Auf diese Weise wurde Toller nicht nur durch seine Rede auf dem PEN-Kongreß, sondern auch durch sein literarisches Werk bekannt. Übersetzt wurde jedoch nur die autobiographische und die faktographische Prosa, nicht aber seine expressionistischen Dramen, deren Zeit anfang der dreißiger Jahre offenbar vorbei war. Ein Beitrag Tollers, in welchem er recht naiv die stalinistische Kulturpolitik verteidigt (Toller 1935), findet sich auch in der kroatischen Publikation des Gesprächs zwischen H. D. Wells und Stalin. In einer Rezension seiner Reiseberichte in „Stožer“" lobt ein gewisser N. K. den Abschnitt, der Moskau gewidmet ist:

[...] o svemu tome priča nam Toler živo i uvjerljivo. Tu nema nikakvih suvišnih naklapanja niti neinteresantnosti. Tu također nema dosadnih opisa boja i mirisa, pri ulazu u Moskvu u centralni grad velike i moćne sovjetske proleterske države. (N. K. 1934: 235).

Der dogmatische Rezensent hat offensichtlich Tollers Position nicht begriffen, insbesondere, wenn er ihm am Ende eine „Übertreibung bei den allgemein menschlichen Empfindungen und Pathos, von dem ihn nicht einmal die gröbste Wirklichkeit abhalten konnte" (N.K. 1934: 236), vorwirft. Offensichtlich polemisiert er gleichzeitig mit Krležas „Izlet u Rusiju“, in welchem eingangs die Farben und Gerüche Moskaus geschildert werden. Den Reportagenstil von Tollers Reiseberichten hebt auch einer der Herausgeber der Zeitschrift „Književni horizonti“, Ladislav Žimbrek (1934), in seiner Rezension hervor. Wichtiger als die Bedeutung von Tollers literarischen Texten ist ihm jedoch die Tatsache, daß der Autor im Lande gewesen war. Aus dessen Brief aus London zitiert er:

Za mene je naročito veselje da u vrijeme kada se moje knjige pale u Njemačkoj, mogu publicirati ovu svesku u Jugoslaviji. Ja sam upoznao narod o kome sam kao i mnogi zapadni Evropejci imao čudne i nastrane pojmove. Još više, zavolio sam ga. To je jedan od naroda, koji su sačuvali san o istini i dostojanstvu čovjeka i čovječnosti (Toller nach Žimbrek 1934, 55).

Dennoch waren die Reaktionen auf Tollers Besuch in Zagreb und auf seine Bücher nicht nur positiv. Ein gewisser Dragan Dawidovsky $(1934,126)$ greift mit antisemitischen Argumenten Toller und dessen Reiseberichte an, indem er dem Autor vorwirft, er kämpfe nur deshalb gegen den Nationalsozialismus, weil er den Markt für seine Bücher verloren habe. Eine solche ultrarechte Position ist jedoch ein Einzelfall in der insgesamt positiven Toller-Rezeption in Jugoslavien und insbesondere in Kroatien. Davon zeugen zahlreiche Nachrufe auf ihn, die nach seinem Selbstmord erschienen. An erster Stelle ist derjenige seines Freundes Kus Nikolajev (1939) zu nennen, der sich auf sehr persönliche Weise Tollers erinnert. Allzu pathetisch gerät der Nekrolog von Vilko Ivanuša (1939a) in den „Varaždinske novosti“, der später unter dem Pseudonym V. Rubin ein zweites Mal in „Slobodna 
riječ" erschien. Dieser Nachruf zog einen kleinen Kampf auf der literarischen Linken nach sich: Jovan Popović (1939) reagierte polemisch auf Ivanušas Bemerkung, Toller sei von links und von rechts bespuckt worden, worauf Ivanuša (1939b) wiederum in „Slobodna riječ zurückschlug. Tollers Tod wurde auch in der Zeitung „Židov" erwähnt, möglicherweise deshalb, weil der ,Stürmer" anläßlich von Tollers Selbstmord dessen Judentum besonders hervorgehoben hatte (vgl. Distl 1993, 177). Möglicherweise hat eben deswegen Ivanuša seinen Nachruf mit dem Titel „Čovjek Ernst Toller je mrtav" versehen.

Toller war einer der herausragendsten Vertreter der deutschen Schriftsteller im Exil. Die Tatsache, daß man über den Verstorbenen sehr einfühlsam geschrieben hat, zeugt von dem tiefen Eindruck, den sein Aufenthalt im Land hinterlassen haben muß.

IV.

Die größte Popularität genoß in den dreißiger Jahren zweifellos Erich Kästner. Als Autor für Kinder war er damals im ganzen Staatsgebiet bekannt: 1931 veröffentlichte der kroatische Literat Gustav Krklec in Belgrad seine Übersetzung von „Emil und die Detektive“ (Kästner 1931); „Pünktchen und Anton“ (Kästner 1933a) erschien in der Übersetzung von Tomislav Prpić im Zagreber Verlag Binoza. Beide Romane wurden in der dramatisierten Fassung des Autors auf Zagreber Bühnen aufgeführt: „Tonček i Točkica“ wurde zwischen 1933 und 1935 sechsundzwanzig Mal am HNK gespielt (vgl. Hećimović 1990), „Emil i detektivi“ 1935 am Omladinsko kazalište, ebenfalls in Zagreb. Das erstere Stück inszenierte Alfons Verli mit dem Bühnenbild von Pavel Froman, einem russischen Emigranten, der offensichtlich mit Mejerchol'ds Prinzipien vertraut war. Die Handlung beider Stücke wurde räumlich nach Zagreb verlegt. Über die Inszenierung von „Emil i detektivi“ hat sich positiv Kästners zeitgenössischer Kollege, der ebenso populäre kroatische Kinderbuchautor Mato Lovrak (1936: 23-24) geäußert.

Kästners Kinderromane riefen aufgrund ihres innovativen Charakters großes Interesse bei der Kritik hervor. In beinahe jeder Rezension konnte man lesen, daß phantastische Erzählungen schädlich für die Kinder seien und daß man den Kindern Bücher geben solle, in denen die Welt dargestellt wird, wie sie wirklich ist. In einer Zeit, als der Realismus und eine sozial engagierte Literatur besonders geschätzt wurden, erweist sich ein solches Denken als wenig verwunderlich. Nur in wenigen Ausnahmefällen sind Kritiker der Meinung, daß Kästners Bücher insbesondere für kroatische Kinder weniger geeignet seien. Ihr Argument lautet, Kästner schreibe für Großstadtkinder, in Kroatien gebe es aber keine Großstadt (vgl. z.B. Tomasović 1934). Vaso Bogdanov ist der Ansicht, daß der Roman „Emil und die Detektive“ eigentlich „ein richtiger, hundertprozentiger Kriminalroman“ sei (Bogdanov 1932, 82) und daher für Kinder ungeeignet. Solche Argumente gelten sicherlich nicht für „Hrabri razred profesora Justusa“ („Das fliegende Klassenzimmer“), übersetzt und veröffentlicht in Zagreb 1934 (Kästner 1934).

Doch das kroatische Publikum hat Kästner als Autor nicht nur für Kinder, sondern auch für Erwachsene kennengelernt. 1933, bereits nach der Bücherverbren- 
nung und dem Ausspruch des Publikationsverbots für Kästner in Deutschland, erschien sein Roman „Fabian“ von 1932 in der Übersetzung von Stanislav Šimić, dem Bruder des expressionistischen Lyrikers Antun Branko Simić, und fand größten Widerhall (Kästner 1933b). In seinem Vorwort hebt Šimić die Modernität des Themas und der Erzähltechnik hervor, die an Filmtechniken erinnere (vgl. Kästner 1933b: 3-7). Dieser humoristische, teilweise auch sarkastische Roman mit zahlreichen erotischen Szenen wurde von der Kritik ausnahmslos positiv aufgenommen. Über seine Qualitäten waren sich Kritiker wie Ivan Kozarčanin (1933), Novak Šimić (1934) und Ivo Hergešić (1933) einig.

Positiv wurde auch der Roman „Drei Männer im Schnee“, ebenfalls in der Übersetzung von Stanislav Šimić 1936 in Zagreb erschienen, aufgenommen (Kästner 1936b). Die anonymen Kritiker der „Narodne novine“ (Ag. 1936) lobten Kästner für seine ideologieferne Gesellschaftskritik und hoben den heiteren Humor der „Drei Männer im Schnee“ gegenüber dem Roman „Fabian“ hervor, der tragisch endet. Wie bereits S. Šmić in seinem Vorwort zu „Fabian", so betonen sie die filmischen Qualitäten von Kästners Prosa.

\section{V.}

1939 entdeckt Ivan Goran Kovačić Ödön von Horvaths Roman „Jugend ohne Gott“, jedoch noch nicht in der Übersetzung von Mladen Leskovac und Hijacint Petris. Kovačić hatte die französische Übersetzung gelesen und dies zum Anlaß genommen, den Autor dem kroatischen Publikum vorzustellen. Horvath war damals vorwiegend als Dramenautor bekannt, daher vermutete Kovačić, Horvath habe diesen Roman, der ,in sich alle Merkmale eines Theaterstücks vereint, in Romanform geschrieben, weil man ein Drama in einem fremden Land schlechter plazieren kann" (Kovačić 1939, 328). Nach dem Anschluß Österreichs war Horvath nämlich nach Paris ins Exil gegangen. Ivan Kozarčanin (1940) rühmte das Erscheinen der kroatischen Übersetzung als „Ereignis in unserer Übersetzungsliteratur“, aber er schätzte die Thematik höher ein als die literarische Qualität des Romans. Er konzentrierte sich in seiner Kritik vor allem auf das Problem der Erziehung junger Menschen in der Diktatur und ihres damit verbundenen moralischen Verfalls. Ähnlich urteilt m.o. (1940) in der „Hrvatska revija“, indem er den Sarkasmus des Autors hervorhebt, der in diesem Buch zum Ausdruck komme.

\section{VI.}

Besonders am Anfang der dreißiger Jahre spielte die ideologische Position eine bedeutende Rolle bei der Beurteilung deutscher Literatur in der kroatischen Kritik. Es zählte vor allem die politische Haltung des Autors. Dies galt sowohl für bürgerliche Autoren wie Thomas Mann, dessen Bruder Heinrich auf ein breiteres Interesse stieß, weil man sein Werk ideologisch eindeutiger festlegen konnte, als auch für den „Revolutionär" Ernst Toller. Sogar in den Kinderromanen Erich Kästners wurde nach Realismus gesucht, während die Kritiker seiner Romane für Erwachsene gerade seine antiideologische Position hervorhoben - ein Zeichen dafür, daß es dennoch eine gewisse Sehnsucht nach einer Literatur außerhalb ideologischer 
Polarisierung gab, vor allem in der zweiten Hälfte der dreißiger Jahre. Im übrigen wurde in den Nachrufen zu Toller der revolutionäre Charakter seiner Person und seines Werks kaum noch hervorgehoben, sondern im Mittelpunkt stand er selbst als Mensch und als Schriftsteller. In den Rezensionen zu Ödön von Horvath wird weder eine linke Position des Autors noch eine solche des Rezensenten zum Ausdruck gebracht, ein Symptom der politischen Veränderungen gegen Ende der dreißiger Jahre.

Alles in allem wurden in den dreißiger Jahren überwiegend solche Autoren rezipiert, die im nationalsozialistischen Deutschland verboten waren. Schriftsteller, die im Hitlerdeutschland gedruckt wurden, wie etwa der „Klassiker“ Gerhart Hauptmann, haben die Öffentlichkeit kaum interessiert. So wurde dessen Drama „Vor Sonnenaufgang“, wie Hećimović (1990) verzeichnet, am HNK Sarajevo in der Übersetzung Mihovil Kombols erst am 17. 11. 1941 zum ersten Mal gespielt, als Bosnien bereits der NDH eingegliedert worden war.

\section{Literatur}

Ag.: 1936, ,Roman o trojici u snijegu', Narodne novine 102/135, 2.

Bogdanov, V.: 1932, ,Knjiga gospodina Kästnera', Literatura 2/2, 78-84.

Bornik, L.: 1937, ,Iz zaštićene pozadine u otvoreni front', Književnik 10/5, 199-203.

Bosanac, H.: 1932, ,Erich Kästner: Emil i detektivi. Roman za decu. Izdanje Nolit, Beograd.', Napredak i savremena škola, 73/ 67-8, 247-250.

Dawidovsky, D.: 1934, ,Toller se pravi važnim', Hrvatska smotra 2/3, 126-127.

Desetorica s lomače, 1933. Zagreb.

Distl, D.: 1993, Ernst Toller. Eine politische Biographie, Schrobenhausen.

Durman, M.: 1932, ,Najnovija Nolitova izdanja‘, Književnik 5/2, 69-72.

,Erich Kästner. Trojica u snijegu. Humoristični roman.':1936, Narodne novine $\mathbf{1 0 2} / 121,4$.

Esih, I.: 1929/30, ,Thomas Mann i njegova dva romana', Omladina 13/6, 111-112.

Esih, I.: 1933, ,Dolazak Ernsta Tollera u Zagreb', Jutarnji list 22/7679, 9.

Frühwald, W.: 1978, ,Einleitung،, in: Toller, E., Gesammelte Werke. Band 1, hg. v. J.M. Spalek u. W. Frühwald. München.

Gašparović, Z.: 1932, ,Goethe i suvremena Njemačka‘, Vidik I/6, 182-185.

Hećimović, B.: 1990, Repertoar hrvatskih kazališta 1840-1860-1980. Sv. 1-2, Zagreb.

Hergešić, I.: 1931, ,Heinrich Mann (O šesdesetogodišnjici rodjenja)', Obzor 72/ 95, $2-3$.

Hergešić, I. 1933, ,Erich Kästner: Fabijan. Zabavna biblioteka br. 553, prev. Stanislav Simić', Obzor 74/248, 3.

Horvat, M.: 1933, ,Desetorica s lomače. Zagreb 1933‘, Život i rad 6/XVII/102, 1407-1408. 
Horvat, I.: 1939, ,Hrvati u njemačkoj književnosti. Heinrich Mann', Hrvatsko jedinstvo 3/107, 1-3.

Horvath, Ö. v.: 1939, Mladež bez Boga. Prev. M. Leskovac i H. Petris, Zagreb.

Ivanuša, V.: 1939a, ,Čovjek Ernst Toller je mrtav', Varaždinske novosti 10/497, 1-3; textgleich in: Slobodna riječ IV (1939) 21, 4-5 (unter dem Pseudonym V. Rubiner)

Ivanuša, V.: 1939b, ,Umjesto odgovora', Slobodna riječ IV/47, 2-3.

Kästner, E.: 1931, Emil i detektivi. Prev. G. Krklec, Beograd.

Kästner, E.: 1933a, Tonček i Točkica. Prev. T. Prpić, Zagreb.

Kästner, E.: 1933b, Fabian. Prev. S. Šimić, Zagreb.

Kästner, E.: 1934, Hrabri razred profesora Justusa. Prev. J. Bogner, Zagreb.

Kästner, E.: 1936, Trojica u snijegu. Humoristični roman za mladež od 18 do 80 godina. Prev. S. Simić, Zagreb.

Kovačić, I. G.: 1939, ,Iz svjetske književnosti', Hrvatska revija 12/6, 327-330.

Kozarčanin, I.: 1933, ,Erich Kästner: Fabian', Srpski književni glasnik, NS, 40/18, 624.

Kozarčanin, I.: 1934a, ,Erich Kästner: Tonček i Točkica', Savremena škola 8/3-4, 72-73.

Kozarčanin, I.: 1934b, ,Erich Kästner: Hrabri razred profesora Justusa', Savremena škola 8, 154.

Kozarčanin, I.: 1940, ,Pregled novih prijevoda', Hrvatski dnevnik 5/1344, 11.

Kun, I.: 1934, ,Heinrich Mann: Podanik. Izd. Nolit. Beograd 1933', Književnik 7/1, 46-47.

Kus Nikolajev, M.: 1925, ,Ernst Toller i Leonhard Frank', Vijenac 3/475, 153-155.

Kus Nikolajev, M.: 1931, ,Sakrament zemlje. O Ernstu Tolleru, čoveku i borcu', Socialna misao 4/5, 69-72.

Kus Nikolajev, M.: 1933a, ,Heinrich Mann: Podanik', Socialna misao 6/7/9, 183-184.

Kus Nikolajev, M.: 1933b, ,Ernst Toller u Zagrebu', Socialna misao 65/6, 111-115.

Kus Nikolajev, M.: 1939, ,Sjećanja na Ernsta Tollera', Jutarnji list 28/9824, 11.

Lendić, I.: 1929/30, ,Ovogodišnji nosioci Nobelovih nagrada', Luč 25/5, 161-162.

Lovrak, M.: 1936, ,Pregled. „Emil i detektivi“ i „Maturant Wagner“", Savremeni pogledi 2/1, 23-25.

Magdić, M.: 1931, ,Roman o prvom carstvu', Riječ 27/50, 15-17.

Mann, H.: 1933, Podanik. Preveo G. Krklec, Beograd.

Mann, T.: 1939, ,Savjest čovječanstva‘, Književnik 12/1, 1-10.

Matan, B.: 1993, Speak Now or Never. The 1933 Dubrovnik PEN Club Congress. Volume I: A Reader, Zagreb-Dubrovnik.

Meyer-Fraatz, A.: 2001, ,Nazorov Heine', in: Komparativna povijest hrvatske književnosti. Zbornik radova. III. Vladimir Nazor. Hg. v. M. Tomasović u. V. GlunčićBužanić, Split, 53-63. 
Meyer-Fraatz, A.: 2002, Die slavische Moderne und Heinrich von Kleist. Zur zeitbedingten Rezeption eines Unzeitgemäßen in Rußland, Polen und Kroatien. Wiesbaden.

m.o.: 1940, ,Iz prijevodne omladinske književnosti. Ödön von Horvath. Mladež bez Boga. Roman. Zagreb 1939‘, Hrvatska revija 13/7, 384-385.

N. K.: 1934, ,Moskva - New York - Madrid. S predgovorom N. K. Nikolajeva. Izdanje „Epoha“, Zagreb, Stožer 5/6, 235-236.

Peroš, V.: 1936-37, ,Iz prijevodne omladinske književnosti‘, Omladina 20/5, 195-197.

Popović, J.: 1932, ,Erich Kästner, Emil i detektivi', Stožer 3/1, 36-37.

Popović, J.: 1939, ,Plač Vilka Ivanuše nad mrtvim Tolerom', Umetnost i kritika 4-5, 280-282.

Preradović, P. v., Heyling, E. v.: 1930, ,Die neue Thomas Mann-Novelle „Mario und der Zauberer"“, Morgenblatt 45/191, 6.

Preradović, P. v.: 1933, ,Thomas Mann und Ivan Bunin. Ihre prophetische Begegnung im Jahre 1926, Morgenblatt 48/318, 10.

Rieger, V.: 1933, „,Podanik“ Heinricha Manna“, Hrvatska smotra I/8/9, 375-377.

Rothe, W.: 1983, Ernst Toller in Selbstzeugnissen und Bilddokumenten, Reinbek bei Hamburg.

,Samoubojstvo Ernsta Tollera‘, Židov 23/21, 9.

Šimić, N.: 1934, ,Erich Kästner. Povodom prevoda „Fabiana“ na naš jezik. Zabavna biblioteka. Knj. 551', Književnik 7/5, 224-226.

Toller, E.: 1933a, ,Govor na kongresu PEN-klubova u Dubrovniku', Socialna misao 6/5/6, 103-105.

Toller, E.: 1933b, Moskva - Newyork - Madrid. Preveo M. Kus Nikolajev, Zagreb.

Toller, E.: 1933c, ,Dolazak u Ameriku i dr.', Desetorica s lomače. Zagreb-Beograd, 131-134

Toller, E.: 1933d, Kulturne posljedice požara Rajhstaga. Govor u Londonskom protuprocesu. Preveo M. Kus Nikolajev, Zagreb.

Toller, E.: 1933e, Jedna mladost u Nemačkoj. Preveo G. Krklec, Beograd.

Toller, E.: 1935, ,Komentar Ernsta Tollera', in: Razgovor izmedju Staljina $i$ Velsa. Doslovni zapisnik. Diskusija izmedju G. Bernarda Šo-a, H. G. Velsa, J. M. Kejnza, Ernesta Tollera i drugih. Februar 1935. Zagreb, 32-34.

Tomasović, J.: 1934, ,K jednoj knjizi za omladinu', Jadranska vila 7/1, 15-16.

Ujević, T.: 1931, ,Umjetnik u djelu Heinricha Manna', Mlada Bosna 4/9/10, 199-205.

V.: 1933, ,Vortrag Ernst Tollers in Zagreb', Morgenblatt, Br. 167, 4.

Vernić, Z.: 1933, ,Ernst-Toller-Vorlesung', Morgenblatt, Br. 170, 4.

Vučica, D.: 1935, ,Erich Kästner o omladinskoj književnosti‘, 15 dana3/20, 307-308.

Vučić, D.: 1935, ,O dječjoj književnosti‘, Jadranski dnevnik 2/4, 9.

Zima, D.: 2001, ,Dječji romani tridesetih godina: Mato Lovrak i Erich Kästner‘, Umjetnost riječi 45/3-4, 251-265. 
Žimbrek, V.: 1934, ,Ernest [!] Toller: Moskva, New York, Madrid. Izdanje biblioteke „Epoha“, Zagreb“, Književni horizonti 1/2, 54-55. 



\section{Philippopolis - Filibe - Plovdiv: Plovdivbilder in der bulgarischen Literatur}

Seit einiger Zeit besteht eine Institutspartnerschaft zwischen dem Seminar für Slavische Philologie der Georg-August-Universität Göttingen und dem Lehrstuhl für Slavische Philologie der Universität „Paisij Chilendarski“ Plovdiv. Dieser wiederum ist dadurch, dass ein Germanistikstudium in Plovdiv nur in Kombination mit einem Russistik- und/oder Bulgaristikstudium möglich ist, eng verbunden mit dem Lehrstuhl für Deutsche Philologie, an dem ich fünf Jahre - von 1999 bis 2004 - als DAAD-Lektorin tätig war. Da Sie, verehrter Herr Kroll, selbst einst DAAD-Lektor waren und außerdem bulgaristische Literaturwissenschaft in Göttingen unterrichtet haben, möchte ich Ihnen das ,literarische Plovdiv“ vorstellen.

Bulgaren geraten ausnahmslos in Schwärmen, wenn sie über Plovdiv sprechen: die schönste bulgarische Stadt, am Fuße der Rhodopen auf sieben Hügeln erbaut, die heimliche Hauptstadt mit ihrer 8000-jährigen Geschichte, dem römischen Amphitheater, der Moschee Džumaja, den opulent verzierten Wiedergeburtshäusern, den Restaurants, Cafés und Bars in der historischen Altstadt und der prächtigen 
Fußgängerzone, die einem Catwalk gleicht, wenn die stolzen Plovdivčanki dort aufund abflanieren. Plovdiv: Kultur-, Wissenschafts- und Messestadt, die obendrein den international erfolgreichen Fußballer Christo Stoičkov hervorgebracht hat. Entsprechend leidenschaftlich stellen Plovdiver Germanistikstudenten ihre Stadt den ausländischen Kommilitonen vor: ${ }^{1}$

Plovdiv ist die zweitgrößte Stadt Bulgariens und hat etwa 500000 Einwohner. Man nennt Plovdiv auch „Stadt der Hügel“, weil es ursprünglich auf sieben Hügeln lag. Diese Hügel sind ein wichtiger Teil der Stadtgeschichte und die Plovdiver sind stolz auf sie. (...) Plovdiv ist die Kulturhauptstadt von Bulgarien. In der Altstadt mischen sich Baustile der römischen, griechischen und türkischen Kultur. Die Sehenswürdigkeiten in der Altstadt sind zahlreich: das Amphitheater, die Kirche der Heiligen Mutter Gottes, die Wiedergeburtshäuser, die Ruinen auf dem Rachat Tepe oder die Mosaikfliesen an den Wänden der Häuser. Parks gibt es in Plovdiv zwar nicht viele, aber die wenigen sind sehr schön. Sehr berühmt ist der Bunardschika-Park, wo eine große Statue namens Aljoscha, die während der Zeit des Kommunismus gebaut wurde, steht. Die Statue war einst das Wahrzeichen von Plovdiv. Jetzt ist sie inmitten des Parks ein Ort der Jugend, wohin die Studenten und Schüler mit Vergnügen gehen.

$(\ldots)$

Plovdiv ist eine der schönsten Städte Bulgariens. Es gibt viel zu sehen. Die Stadt ist groß und sie bietet viele Unterhaltungsmöglichkeiten: Kinos, Diskos, Klubs und Cafés, die von vielen Studenten besucht werden. (...) Es ist aber unmöglich, dies alles zu beschreiben - das muss man mit eigenen Augen sehen!

$(\ldots)$

Plovdiv liegt im Süden Bulgariens, daher ist das Klima relativ günstig. Die Winter sind kalt und schneereich, die Sommer dagegen sehr heiß und trocken, weshalb die Cafés voller Leute sind, die kalte Getränke und das Leben im Schatten genießen. Eine andere „Rettung“ vor der Hitze ist der Gebirgszug Rhodopen, der in der Nähe liegt und wo sich immer mehr junge Leute erholen. In den Rhodopen liegt Batschkovo - eine malerische Stadt, wo sich das zweitberühmteste Kloster Bulgariens befindet. Für die ausländischen Touristen und die Studenten gibt es weitere interessante Sehenswürdigkeiten, wie das Beinhaus und die schönen Wasserfälle in der Nähe. Zwischen Batschkovo und Plovdiv befindet sich die Stadt Assenovgrad, die durch ihre Burg berühmt ist. Das sind die interessantesten Orte, die man in der Umgebung von Plovdiv besuchen kann. (...) (García, 2006)

All diese und noch mehr Sehenswürdigkeiten ${ }^{2}$ sind auch in der bulgarischen Literatur $^{3}$ zu finden: Die sieben Hügel, der Aljoša, der ,provinziell-luxuriöse Barockbahnhof“, das ,zyklopische Fundament des Hotels Trimontium“, die Hauptstraße mit ihren „dicht aneinander gedrängten Häusern“, die Säulen des Antiken Theaters, die archäologischen Ausgrabungen beim Postamt, die Fußgängerzone mit ihrem „lasziv-knackenden Rückgrat“, auf dem „die verführerischen Silhouetten der Frauenleiber" zu bewundern sind, die Kaufhäuser, Banken, Apotheken in Zlatomir Zlatanovs (*1953) Roman Храмови свнища (Tempelträuте), die Plovdiver Messe, 
regionale Spezialitäten und die Plovdiver Weine in Georgi Rajčevskis $(* 1939)$ Roman Bреме на надежди (Zeit der Hoffnung), „die Kapana ${ }^{4}$ mit den sich unausweichlich kreuzenden lustigen Gassen und Ecken und ihren kleinen Läden in bibliothekarischer Reihe“, die Džumaja und „das Wunder von Weinlauben auf der Straße, das in eigener und wilder, antiker Schönheit Kränze auf einer Terrasse inmitten von Dächern flicht", in Ivan Teofilovs (*1931) Gedichtband Богатство на време (Reichtum an Zeit), die Verkaufsstände auf der Maricabrücke, wo „billige Waren mit Etiketten in lateinischer Schrift" feilgeboten und „nächtens die Karren mit eisernen Ketten an die Geländer angeschlossenen werden", in Jordan Velčevs (*1949) Gedichtband Милиони малки убийства (Millionen kleine Morde) - und immer wieder in den verschiedensten Schilderungen die Altstadt und der heiße Sommer von Plovdiv.

Im Folgenden sollen die imagotypen Strukturen in literarischen PlovdivDarstellungen von bulgarischen Autoren aus verschiedenen Epochen untersucht werden. Es handelt sich insofern um literarische Eigenbilder, als Plovdiv nicht nur eine Stadt in Bulgarien, sondern auch ein Symbol im kulturellen Selbstverständnis der Bulgaren ist. ${ }^{5}$ Diese aber sind, auch wenn sie noch so ,realistisch ${ }^{6}$, geradezu dokumentarisch erscheinen mögen, keine mimetische Abbildung der empirischen Realität, sondern subjektabhängige Reflexion und Konstruktion von Wirklichkeitsvorstellungen oder, um mit Goodman (1984) zu sprechen, eine „Weise der Welterzeugung“. Da die „Welt" in den zu untersuchenden Texten mit den Mitteln und Techniken der Literatur ,erzeugt" wird, sind auch deren imagotype Strukturen nicht nur als „Produktionstechniken von ideologischen Fiktionen, Wahrnehmungs-, Denk- und Empfindungsmustern“ (Egger 2002, 2) zu verstehen, sondern auch und vor allem „Elemente ästhetischer Kontexte“ (Bleicher 1980, 20). Sie befinden sich in einem Wechselverhältnis zur Geschichte und zum Kulturwandel (s. Wierlacher 1993, 34) und sind doch von zumindest ,partieller Substanz und Universalität" (Bleicher, 1980, 18).

\section{Thrakiens ruhmreiche Vergangenheit}

Lukian konstruiert in seiner satirischen Erzählung Die entlaufenen Sklaven ein Gespräch zwischen Merkur, Herkules und der Philosophie:

Herkules: Seht ihr die zwei Berge dort, die größten und schönsten unter allen, die vor uns liegen? Der größere ist der Haemus [= Balkan] und der andere gegenüber die Rhodope. Sehr ihr die herrliche Landschaft, die sich an ihnen beiden hinzieht? Und die drei wunderschönen Hügel dort, die sich, sanft emporsteigend, wie drei Burgen über die unter ihnen liegende Stadt erheben? Auch die Stadt selbst wird bereits sichtbar.

Merkur: Und beim Jupiter! - eine der größten und schönsten im ganzen Lande! Das leuchtet sogar aus dieser Ferne in die Augen. Und der große Fluß, der hart an ihren Mauern hinfließt... 
Herkules: Ist der Hebrus [= Marica], die Stadt selbst aber ein Werk des berühmten

Philippus (...). (Zit. n. Oppermann 1984, 8)

In der bulgarischen Literatur wiederholt sich das Lob der mythenreichen Landschaft Thrakiens, in der Orpheus, „ein Sohn des Appoll und der Klio“ (vgl. Вазов 1977, XI, 131), geboren sein soll; Plovdiv jedoch, das „Werk des berühmten Philippus“, wird nicht bedacht. ${ }^{6}$ Von patriotischem Geist erfüllt, listet Ivan Vazov (1850-1921) wenige Jahre nach der Befreiung Bulgariens von der osmanischen Fremdherrschaft ${ }^{7}$ namhafte Dichter auf, welche die „herrliche, nahezu unberührte Landschaft" (vgl. ebd., 199) besungen haben: Vergil, Ovid, Gundulić, Križanić, aber auch Kaufleute aus Dubrovnik und ein Gesandter Deshayes. Immer wieder wird der Zusammenhang mit Orpheus hergestellt, „nannten“ doch schon „die alten Griechen die Rhodopen ,das Gebirge des Orpheus“" (vgl. ebd., 131), des Musikgenies, das später von Gundulić eindeutig als Bulgare identifiziert wird: ${ }^{8}$

Според него, Орфей бил българин, създател на оня род мелодични песни в сръбските земи, които са известни там под името бугаркиня бугарщица. (Vgl. ebd., 258, Hervorhebung im Original)

Durch das Lob fremder Autoritäten auf die bulgarische Heimat, das wie zur Bescheinigung der Echtheit und Glaubwürdigkeit in den Originalsprachen (Lateinisch, Kroatisch) zitiert wird, „wird das Eigenbild mit einem positiven Teil des Fremdbilds komplementiert" (Bleicher 1980, 14), was vor dem Hintergrund der fast fünfhundertjährigen kulturellen Isolation, die bei den Bulgaren das schmerzhafte Bewusstsein von zivilisatorischer und kultureller Rückständigkeit gegenüber dem ,aufgeklärten Europa“" hinterlassen hat, geradezu als Nachweis der nationalen Würde erscheint. Die Denkfigur der Abwesenheit (,the morbid awareness of the absence of a whole civilizational model" [Kiossev [o.J.], Hervorhebung im Original]) wird umgedreht in eine der Anwesenheit, wobei die Botschaft, ,alles zu haben und nichts zu brauchen" ${ }^{9}$ durch die zivilisationskritischen Klagen ( Странно нарущава поезията на мястото присъствието на тия груби мащини. [Vgl. Вазов 1977, XI, 150]), die sich immer wieder in die pathetische Schilderung der Vollkommenheit des bulgarischen Idylls mischen, bestärkt wird.

Bei Penčo Slavejkov (1869-1914), dem ärgsten Rivalen Vazovs, ist es nicht mehr Orpheus, „die poetischste aller Gestalten der griechischen Antike“ (vgl. ebd., 131), sondern der große Deutsche, Goethe, der beim Anblick eines ,kräftige[n], alte[n] Ahornbaum[s] im Plovdiver Dorf Belaštica, am Fuße der Rhodopen" (vgl. Славейков 1959, VII, 107) aufscheint. Das hat mit Slavejkovs tiefer Sehnsucht nach einer bulgarischen Klassik zu tun, die von seiner uneingeschränkten GoetheVerehrung stets aufs Neue bestärkt wird. Der alte Baum wird, ähnlich Goethes Charakterisierung des Klassischen, das „nicht klassisch [ist], weil es alt, sondern weil es stark, frisch, froh und gesund ist" (Eckermann 1997, 310), als stark, unbeugsam, tief verwurzelt im heimatlichen Boden und widerstandsfähig gegen äußere Einflüsse beschrieben; er steht symbolisch für das Leben des Klassikers 
als stilles und erhabenes Sein im „Geist der Ewigkeit“ (s. Middeke 2006). - Und deshalb am Fuße der Rhodopen: der Heimat der Poesie.

In einen Alptraum von Verschmähungen, furioser Rache und Tod verwandelt werden die Vazovsche Idylle und die Slavejkovsche klassische Harmonie in Georgi Rupčevs (*1957) Тракийски пасторал (Thrakisches Pastorale), in dem Orpheus als ,selbstverliebter Hirte“ erscheint, der nach dem langen Abschied (von der mythologischen Vergangenheit[?]) „,gedächtnislos“ in einem ,ganz gewöhnlichen Zimmer" mit „Bett, Aschenbecher, Lampe, Rekorder“ (in der Gegenwart[!]) erwacht, einem Gedicht, das entgegen seinem Titel kein Pastorale ist, sondern eins wäre, wenn Orpheus zu seinen Herden zurückgekehrt wäre (s. Рупчев 1986, 52-56). Hier findet in einem Akt individualisierenden Überschreibens der Mythologie eine autoreflexive Thematisierung des eigenen Schicksals statt. Eine ähnliche tropische Wendung gegen den mythologischen Prätext - jedoch aus weiblicher Perspektive enthält Mirela Ivanovas $\left({ }^{*} 1962\right)$ Gedicht Евридика (Eurydike), in dem in einer Weise „verhalten melancholischen Selbst-Sein Wollen[s]" (Burneva 2000, 49) ${ }^{10}$ gezeigt wird, „daß auch Eurydike eine Stimme hat, mit der sie aus ihrem Schatten hinausbegehrt" (Randow 1994, 180):

Не искам да съм вече сянка между сенките,

не искам да съм даже сянката, вградена в скръбната ти песен.

Не искам да се върна в мъртвата жена (...). (Иванова 1999, 266)

\section{Das provinzielle und das morbide Plovdiv}

Als Provinzstadt präsentiert sich „das Werk des berühmten Philippus“ in Vera Mutafčievas (*1919) historischem Roman Сәединението прави силата (Die Vereinigung macht stark), der in der Zeit zwischen der Staatsgründung (1978) und der Vereinigung Westbulgariens und Ostrumeliens (1885) spielt, d.h. nur wenige Jahre nach der Ernennung Sofias zur Hauptstadt (1979). Trotzdem erscheint Plovdiv, das bis dahin das kulturelle Zentrum Bulgariens war, bereits als verschlafenes Nest, etwa in der Beschreibung des Bahnhofs, an dem der Schriftsteller Zachari Stojanov, „den jeder Bulgare, der etwas auf sich hält, kennen sollte“ (vgl. Мутафчиева 1989, 26), und seine Frau ankommen: (...) редки влакчета с редки пәтници и посрещачи, муден персонал, тищина и леност - благодатна провини,и, тлгста земл. (Ebd.)

Die Plovdiver Episode macht an Stojanovs persönlicher misslicher Lage, im Unterschied zu anderen berühmten Zeitgenossen wie „Opa Slavejkov und Petko Karavelov" (vgl. ebd., 27), die ein Diplom und deshalb eine Anstellung als Lehrer gefunden haben, noch arbeitssuchend zu sein, die tiefgreifende politische, wirtschaftliche und soziale Umbruchsituation deutlich, in der sich das Land befindet: Ostrumelien ist noch unter türkischem Protektorat - „Аз в държава без конституция не живявам“, bemerkt Stojanov bezüglich seines Aufenthaltes in der provisorischen Hauptstadt Plovdiv (vgl. ebd.) -, der Aufbau eines modernen Staates und einer modernen Gesellschaft mit autonomen Subbereichen steht noch 
ganz am Anfang, die Menschen sind desorientiert, auf der Suche nach ihrem Platz in der sich formierenden neuen Ordnung.

Auch Georgi Rajčevski wirft einen historischen Blick auf Plovdiv und beschreibt in Време на надежди die erste bulgarische Landwirtschafts- und Industrieausstellung, die 1892 ,in Gegenwart seiner königlichen Majestät“ (vgl. Райчевски 1995, 5) persönlich eröffnet wird. Sie steht synekdochisch für die bulgarische Gesamtsituation: das Buhlen der Aussteller um „die herrschaftliche Aufmerksamkeit" (vgl. ebd., 8) für das Streben des Staates nach der Anerkennung der politischen Großmächte, das Interesse für den österreichischen Pavillon für die Abwendung Bulgariens von der bisherigen Schutzmacht Russland ${ }^{11}$ und die Hinwendung zu Österreich-Ungarn. Die Beschreibung der Messe wird von einem leisen Unterton der Scham über die unroutinierte Aufgeregtheit und rustikale Unbeholfenheit der Plovdiver Gastgeber begleitet, im Ganzen aber ist sie, wie der Untertitel Тоя щарен и симпатичен Пловдив (Dieses bunte und sympathische Plovdiv) erwarten lässt, grundsätzlich positiv und stellenweise liebevoll ironisch.

In Zlatomir Zlatanovs postmodernem Roman Храмови сънища wird wieder einmal der Plovdiver Bahnhof, beschrieben als ,eine bescheidene Barockkopie mit Ziegelsäulen und unansehnlichen Verzierungen am oberen Teil der Fassade, die seit ihrem Bau unerschütterlich die verschiedenen Stadien der Individualität durchlief“ (vgl. Златанов, 1992, 63), zum Symbol der Provinzialität Plovdivs. Plovdiv selbst erscheint als „balkanische Kopie der Ewigen Stadt“ (vgl. ebd., 65), deren gepflegter Provinzialismus sich im unabwendbaren Verfall befindet.

Белееха се мрарморните капители на Античния театъп, изглозганият им мрамор се нанасяще с безславно режисиран мизансцен, по-скоро примирено да означи проекцията на погубен веднъж завинаги блясък и величие. // Археологическите разкопки покрай Пощенската палата бяха секнали в нещо като галеря на открито с добре поддържана морава, из която се валяха късове мрамор, стелни, глинени делви и оброчни плочки. Обилната светлина приобщаваще непатетично лапидариума към промененото обкръжение. Онтичната реалност на подръчния човещки свят, тази неспирна работилница, поразена от синдрома на Пигмалион да се самовъзпроизвежда във все нови и нови изкуствтени форми и отражения, сега бе застинала в излищен фрагмент с непотребни оръдия на труда. (Ebd., 67)

Das Bild vermittelt jenes Gefühl des „Schrecken[s] vor der öden, sinnentleerten, allem Menschlichen gleichgültig gegenüberstehenden Geschichte", das Pentschev als ein elementares ,konzeptuale[s] Motiv“ in der bulgarischen Literatur nach 1989 ausmacht, in deren Mittelpunkt ,nicht mehr die ,große nationale Tradition und die Großen der Geschichte, sondern die ehemals in die Sprachlosigkeit abgeschobenen, marginalisierten Existenzen und das metaphysische Leiden des Menschen in einer ihrer teleologischen Ordnung beraubten, indifferenten Welt" stehen (Pentschev 1999, 124f.) - einer Welt, die keinen „Zugang zum Rätsel des Todes und zum Sinn des menschlichen Strebens nach einem finalen Ziel" mehr offen lässt (Zlatanov 1992, 67). 
Ontologische Reflexionen liegen auch Jordan Velčevs und Aleksandăr Sekulovs (1960) Plovdiv-Gedichten in ihren Gedichtbänden Милиони малки убийства (Millionen kleine Morde) und Bсичко, над далечината (Alles, über der Ferne) zugrunde. In Velčevs Gedicht Cepzuume (Verkaufsstände) etwa werden die Verkaufsstände auf der Maricabrücke, „die zwei Ufer verbindet, die unmöglich verbunden sein können, zwei Worte, welche nicht nebeneinander ausgesprochen werden dürfen“, als „Verkaufsstände des Lebens“ (vgl. Велчев 1997, 17) bezeichnet. ,Leben' und ,Verkauf' sind diese Worte, bezogen auf einen Ort, an dem der Mensch, bemüht, in der Armut seine menschliche Würde zu bewahren, doch nur ,nur ein Jäger von Blicken“" (ebd. 18) ist und selten etwas kauft oder verkauft.

Сергии с евтитини стоки с етикети на латиница символ на модерност, мислеща в индекс: плюс, минус. Сергии, къедето грижата - от портфейла на ясновидеца до фенерчето на слепеца - е изгладила мозъчните гънки в пързалка на бедни провинциялисти. (ebd., 17)

Dieser Ort, an dem der Mensch nicht ist, „weil er dort sein will, sondern einfach nur weil es keinen Heimweg für ihn gibt" (vgl. ebd., 18), besitzt ebenso wenig jene von Barthes beschriebene „Erotik" bzw. „Sozialität", Schnittpunkt der menschlichen Interaktion, des Kaufs und des Spiels zu sein (s. Barthes 1988, 207f.), wie der in Sekulovs Gedicht Пловдив (Plovdiv):

В този град вече всичко е минало.

Нощем мъртвите викат от джамии и църкви

и осъмват с очи, полудели от взиране -

стращно самотни и завинаги мъртви. (Секулов 1997, 21)

Auch hier erscheint Plovdiv als Provinzstadt, ,in der man nicht leben kann“ (vgl. ebd.), weil „das Leben Asche und Ton, / die Luft - ein Fischknochen zum Füttern, / die Erinnerung - eine nostalgische Heimat" (vgl. ebd., 22).

,Provinziell', ,morbide', ,tot' sind die Eigenschaften, die nicht nur das Plovdivbild dominieren, sondern auch das - aus der Lebenswelt gewonnene und literarisch auf sie reprojizierte - Lebensgefühl der „Nach-Wende“-Dichter, die sich der Poetik des Wörtlichen zuwenden und die als hässlich und kalt empfundene Wirklichkeit hässlich und kalt beschreiben.

Die über weite Strecken in Plovdiv spielende Familiensaga Engelszungen des in Bulgarien aufgewachsenen und in Wien lebenden bulgarischen Schriftstellers Dimitré Dinev (* 1968) unterscheidet sich dadurch von den anderen literarischen Texten, dass sie auf Deutsch geschrieben wurde und zur so genannten Migrantenliteratur zählt, in welcher der Binarismus ,Eigen- vs. Fremdbilder' zugunsten einer kulturellen Synthese, „die nicht nur profunde Kenntnisse beider Kulturen, sondern auch gleichsam eine ,Fleischwerdung des Lebens mit der [fremden] Kultur voraussetzt", überwunden wird. (S. Heinze 1986, 62) Bei ihrer ersten Begegnung auf dem Wiener Zentralfriedhof am Grab eines gewissen Miro, von dem es heißt, dass er ein Engel sei und Wünsche erfüllen könne, stellen die in Wien gestrandeten bulgarischen Protagonisten Svetljo und Iskren fest, dass sie beide aus Plovdiv kom- 
men, erinner[te]n sich an ihre Stadt, erzähl[t]en einander von ihr, von den Hügeln, dem Antiken, den Lokalen, der Frechheit der Kellner und der Taxifahrer, von der Länge der Schlangen, der Milde des Winters und den glühend heißen Sommern (...) (Dinev 2006, 586f.), und davon, was sich in den Jahren nach der Wende, welche die beiden nicht mehr in Bulgarien erlebt haben, geändert hat. In der für Gespräche unter bulgarischen Landsmännern, die sich im Ausland kennen lernen, symptomatischen Vertraulichkeit (Ich war mal bei einer Prostituierten. Weißt Du, wo sie gewohnt hat? Beim Messegelände. Auf dem Boulevard Moskau. Jetzt heißt der Boulevard übrigens Bulgarien... [ebd., 587]) entsteht ein mit individuellen Erinnerungen bestücktes, aber insgesamt in Stereotypen verhaftetes Plovdivbild. Anders, als Jahre zuvor - zu kommunistischen Zeiten - Iskrens vor 1944 nach Jerusalem emigrierte Tante Rosa auf einen Besuch nach Plovdiv zurückkehrt und sich die persönlichen Erinnerungsschauplätze ihrer Kindheit selbst anschaut:

(...) vieles hatte sich geändert. Überall waren entweder neue Gebäude und Denkmäler entstanden, nicht einmal die Straßen hießen so wie früher. Anstelle ihres Vaterhauses stand jetzt ein neuer Wohnblock. (...//) Anschließend wollte Rosa die alte Synagoge besuchen, das hätte sie ihrem gestorbenen Schwiegervater Jojakim versprochen. Das Gebäude war noch da. Dasselbe Dach, dieselben Ziegeln, dieselbe Form, nur der Inhalt hatte sich dazwischen geändert. Aus der Synagoge war eine Bäckerei geworden. (...) Das Manna, das einmal vom Himmel gefallen war, wurde jetzt sozialistisch geplant und produziert. (ebd., 264f.)

Ist Rosa anfangs bestürzt, so muss sie bei dem Gedanken, „dass es nicht einmal Gott in dieser Zeit besser ergangen [ist]" (ebd.) lachen und freundet sich schließlich mit dem neuen Plovdiv an - hauptsächlich, weil ,sie auf der Straße keinen einzigen Bettler gesehen hat." (Ebd., 266)

In allen diesen Texten geht es um historische Umbruchsituationen - sei es die Zeit nach der Befreiung von der osmanischen Fremdherrschaft, die kommunistische Ära oder die Zeit nach der „Wende“ 1989 -, die oft mit einem Transformationsschmerz verbunden sind. Dieser schlägt sich im Zweifel der Menschen an der Beständigkeit, Verlässlichkeit und Funktionalität ihres kulturellen Orientierungssystems nieder, sodass die Beschreibung Plovdivs, das ja eines der Symbole in diesem System ist, als schutzlos den Launen der Geschichte ausgesetzt, als brüchig und morbide vor allem ein Ausdruck jener menschlichen und gesellschaftlichen Verunsicherung ist.

\section{Plovdiv mit fremden Augen}

Plovdiv, das von Thrakern gegründet wurde, unter Philipp II. mazedonische Hauptstadt, dann römisch, byzantinisch, slavisch, türkisch, griechisch war und heute bulgarisch und eigentlich multiethnisch ist, ist nicht nur in historischer, sondern auch geographischer Hinsicht ein Knotenpunkt zwischen Okzident und Orient. Darüber berichtet etwa Vazov in seinem kurzen Überblick über die Geschichte der 
Rhodopen (Един бърз поглед към миналото на Родопите) in den Пътеписи (Reisebeschreibungen) (Вазов 1977, XI, 151-153).

Wird Plovdiv aus der imaginierten Sicht jener Fremden, seien es Krieger, Eroberer und Fremdherrscher (wie bei Vazov und Rajčevski), Durchreisende (wie bei Zlatanov), Entsandte (wie bei Karastojanov), beschrieben, liegt ein Metabild vor: ein Bild vom Fremdbild des Anderen, welches zeigt, wie man glaubt, dass der Andere einen sieht.

In Georgi Karastojanovs (*1931) historischem Roman Куюмджиевата коща (Das Haus des Goldschmieds) reflektiert der griechische Metropolit Nikifor seine Rolle und Mission in der Stadt, die zwar noch türkisch ist und ,Filibe' heißt, in der jedoch „die geflohenen Bulgaren die Herrschaft zu übernehmen beginnen." (Vgl. Карастоянов 1972, 31) Er lässt sich von seinem bulgarischen Gehilfen berichten, was über ihn, den Sultan und den Patriarchen, d.h. über die Fremden, die gekommen sind, um die Emanzipation der Bulgaren aufzuhalten, gesprochen wird. In dieser raffinierten Perspektivik, die noch verfeinert wird, indem er sich das bereits zitierte berühmte Gespräch aus Lukians Entlaufenem Sklaven vorlesen lässt, entstehen Eigen-, Fremd- und Metabilder und sogar das Metabild des Metabildes. So wird ein „dialektischer Verweisungszusammenhang zwischen [den] Images" aufgebaut, deren ,Synthetisierung (...) einen Versuch der umfassenden Wirklichkeitserklärung dar[stellt]." (Bleicher 1980, 16)

Auch in Georgi Rajčevskis historischem Roman Време на надежди kommt das Verfahren der Erkenntnisstrukturierung durch die Relativierung einzelner Perspektiven anhand von mehreren Images zum Tragen. Wird zunächst in altes bulgarisches Ritual, das traditionelle Choro-Tanzen ${ }^{12}$, zum Objekt des fürstlichen Spottes (беще си спомнил тромавото подскачане на преситените от обилния обяд и размекващото вино столични гости и пловдиски пгрвенци, наловени в кргг, докато музиката сечеще с ритмичните си звуци горещия въздух [Райчевски 1995, 11), so wird der Spott sogleich entschärft, indem der Spötter - beim blasiert-eitlen Betrachten eines lebensgroßen Gemäldes, auf dem er als Reiter abgebildet ist - selbst als lächerliche Figur erscheint und seinerseits von einem höher Gestellten, dem Kaiser höchstpersönlich, diskreditiert wird: Oткљде Фердинанд би могъл да знае, че няколко години по-кбсно самият император Франи, Йосиф ще каже по адрес на своя бивщ, поручник: „Винаги е бил лощ, кавалерист.' (Ebd., 12)

Nicht durch Gegenbilder ausbalanciert bzw. harmonisiert wird die nationale Bloßstellung in Zlatanovs Roman Храмови сънища, in dem der Ich-Erzähler, „,versunken in einem süßen orientalischen Traum“ seinen „Lieblingsdichter, Alexander Preis, auf dem Weg in den Orient" (vgl. Златанов 1992, 70) in Plovdiv Halt machen lässt. Anders als bei Karastojanov und Rajčevski wird hier das (negative) Bulgarien- bzw. Plovdivbild nicht über die Konstruktion eines Metabildes vermittelt - im Gegenteil: Was der Fremde sehen und denken könnte, wird in diesem Tagtraum, der symbolisch für den Traum von „einem ungehinderten Dialog der Kulturen jenseits der Ideologie [und] geheimnisvolle[r] Verständigung 
an der Peripherie“" steht, ausgespart (ebd., 65). Der Ich-Erzähler selbst ist es, der, nicht mehr träumend, beschreibt, wie Bulgarien sich den Fremden, die - wie einst Alexander Preis - mit dem Orient-Express nach Istanbul fahren, präsentiert:

Бях прочел, че под прозорците висели опънати върлините за прането на живеещите тук със семействата си чиновници от железницата. Чужденците се забаляавали от Ориент-експреса да заничат по развяващите се долни гащи от най-различен калибър. (Vgl. Златанов 1992, 63)

Dieses Bild knüpft an eine Szene aus Aleko Konstantinovs (1863-1897) Roman Бай Ганъо (Baj Ganjo) an, der, weil er die wichtigsten nationalen Symbole und traditionellen patriotischen Werte in Frage stellt, bis heute als das provokativste Werk der bulgarischen Literatur gilt. Dort fährt eine Gruppe von Bulgaren, stolz, in einem eigenen - bulgarischen - Zug zu sitzen, auf eine Ausstellung nach Prag: Нека да видят, казвахме си, европейиите, че Бглгаря не спи. Но най-вече се надувахме с новата, с модерната конструкция и с чистотата на вагоните. (Константинов 1971, 39)

Doch was passiert bereits am zweiten Tag mit den schönen sauberen Waggons?

$(\ldots)$ клозетите бяха се превърнали и в перачници (...), а коридорите на вагоните се превърнаха в сущилници за това пране: проточиха въжета и простряха не дотам изпраните гащички; те заменяваха флаговете, с които трябваще да украсим нащия трен; вместо трикольор - бяло, зелено и червено - у нас лъщяха на слънцето множество двукольори - бяло и жълто. (Ebd., 45)

In beiden Romanen ergeben sich die negativen Eigenbilder aus dem Kontrast zum Fremdbild, dem Bild des aufgeklärten, zivilisierten und fortschrittlichen Europa, unterscheiden sich aber darin, dass es in Бай Ганъо eine narrative Instanz gibt, welche die Aufgabe der Scham und der ,Bereinigung' des nationalen Makels übernimmt, wohingegen in Храмови сънища der Ich-Erzähler unbeteiligt, geradezu gleichgültig erscheint, was wieder auf das von Pentschev beschriebene poetologische Konzept der „Kritik der ,großen Narrative““ (Pentschev 1999, 123) jener desillusionierten Dichter zurückzuführen ist, welche die Dichterin Miglena Nikolčina so treffend „die unterschlagene Generation der 80er Jahre“ nennt. (S. Gospodinov 1999, 33)

\section{Ins innere Plovdiv reisen}

Die Formulierung ist Fornoff (2006) entliehen, der in seinem Aufsatz Ins innere Bulgarien reisen sich auf psychoanalytischem Weg dem Fremden nähert und es in Anlehnung an Freud und Kristeva nicht als das Unbekannte, sondern als das fremd gewordene Bekannte, das verdrängte Eigene beschreibt. Plovdiv ist für Dimčo Debeljanov (1887-1916), der seine Kindheit dort verbracht hat, keineswegs ein unbekannter Ort, aber einer, den er aus seinem Gedächtnis verdrängen will - und nicht kann. In seinem Sonett Пловдив (Plovdiv), einem während eines Kurzbesuchs 1910 entstandenen Kasualgedicht, erinnert er sich an die unglücklichen Kindertage 
in Plovdiv, obwohl er - anders als Iskren, Sevtljo und Rosa in den Engelszungen sich gerade nicht erinnern möchte:

Как бяха скръбни моите детски дни!

О, колко, много сълзи спотаени!

$(\ldots)$

И толкоз черни мисли ми тежат,

че аз не искам да си спомна. (Дебелянов 1974, 131)

Ausgerechnet in dem berühmtesten Plovdiv-Gedicht - und das ist Debeljanovs Sonett zweifelsohne - wird kein Plovdivbild, sondern eine individuelle Gemütslage, die möglicherweise nicht einmal mit dem Ort zusammenhängt, affektiv-ästhetisch (re)konstruiert und festgeschrieben. ${ }^{13}$ Diese individualisierende Überführung des nationalen Symbols in den Bereich des Privaten und Intimen, die auch in den Gedichten von Aleksandăr Sekulov, Georgi Rupčev, Mirela Ivanova und Ivan Teofilov vorherrscht, ist gattungs- und epochenbedingt. Sie kann aufgrund der monologischen Organisation lyrischen Sprechens sowie des fragmentierten Ichund Weltempfindens der Schriftsteller seit dem Beginn der literarischen Moderne stattfinden, in der Literatur als Form- und Sinngebungsstrategie nicht nur zur Bewältigung von zeithistorischen und kulturellen, sondern auch und vor allem von persönlichen Erfahrungen wichtig wird. Auch Stefan Canevs $\left({ }^{*} 1936\right)$ Gedicht Altstadtgeliebte - geliebte Altstadt ${ }^{14}$ ist ein modernes Gedicht, in dem eine persönliche, geradezu intime Beziehung zur Plovdiver Altstadt beschrieben wird. Es ist aber auch eine Art versöhnliches Gegenstück zu Debeljanovs (an)klagendem Plovdiv-Sonett. Mit diesem so konzilianten Gedicht möchte ich meine „literarische Führung durch Plovdiv" beenden, dabei noch einmal an die anfangs zitierten einladenden Worte der Plovdiver Germanistikstudenten erinnern und Sie, lieber Herr Kroll, ermuntern, diese vielseitige, schöne und sympathische Stadt - „moя щарени симпатичен Пловдив" - einmal selbst zu besuchen. Es lohnt sich:

\author{
Altstadtgeliebte - geliebte Altstadt \\ Ich kehre in Plovdivs Altstadt zurück \\ wie zu einer alten Geliebten: \\ Alles erscheint bis zum Überdruß bekannt, \\ und doch will ich es wieder erleben. \\ Es bedarf keiner Liebes- und Treuebeschwörungen, \\ keiner Versprechungen, \\ verschwunden die falsche Scham des ersten Entkleidens. \\ Nur die Freude, nichts als die Freude, \\ wieder zusammen zu sein! \\ Nur die Liebe, die alle Bedenken überwunden hat... \\ Danach das stille Schuldgefühl, ständiges Fragen \\ und sich nicht erinnern können: \\ warum haben wir uns getrennt \\ und warum trennen wir uns wieder,
}


wenn es so schön ist.

Ich kehre in Plovdivs Altstadt zurück. (Zit. n. Jäger/Sitzmann 1999, 109)

\section{Anmerkungen}

${ }^{1}$ In einem Unterrichtsprojekt im Rahmen der Germanistischen Institutspartnerschaft zwischen der U Plovdiv und der TU Dresden haben die Plovdiver Germanistikstudenten eine Website für ihre Dresdner Kommilitonen angefertigt, auf der sie ihre Lebenswelt vorstellen. (S. García 2006")

2 Barthes nennt sie „diskrete Einheiten“, die zu semantischen Kategorien werden können: Wege, Zäune, Viertel, Knoten- und Bezugspunkte usw. (S. Barthes 1988, 201).

3 Bulgarische Zitate, die in die deutsche Satzstruktur eingegliedert sind, werden in deutscher Übersetzung wiedergebeben, die Quellenangabe bezieht sich aber auf das bulgarische Original. Alle anderen Zitate werden im Original wiedergeben.

4 Die ,Kapana', wörtlich übersetzt, die Falle', ist ein wegen der vielen kleinen Geschäfte und gemütlichen Kneipen besonders hübscher und beliebter Teil der Plovdiver Altstadt.

${ }^{5}$ Hofstede versteht Kultur als ,Software des Geistes“ und meint, dass sich die eine Kultur von einer anderen durch bestimmte Phänomene unterscheidet, die immer einer der vier Kategorien den Symbolen, Helden/Vorbildern, Ritualen oder den Werten - zugeordnet werden können. Diese vier Kategorien lassen sich in einem Diagramm wie die Schalen einer Zwiebel von außen nach innen beschreiben, wobei die Symbole (sprachliche, Farb-, Statussymbole, kulturelle Artefakte, Monumente, Wahrzeichen usw.) die äußerste (und sichtbare) Schale und die Werte, ,der rote Faden der Lebensorientierung“, den (unsichtbaren) Kern bilden. Durch alle Schichten hindurch reichen die Praktiken der jeweiligen Kultur. (S. Zeuner 1998)

${ }^{6}$ In Vazovs Pătepisi (Reisebeschreibungen) etwa kommt Plovdiv zwar an etlichen Stellen vor, wird aber nicht gerühmt. S. dazu Hranova $(2002,54 f$.$) , „[. . . ist es], als habe der ,Plovdiver Geist$ die Schriftsteller dazu genötigt vorbeizugehen und, wenn sie können, ganz zu gehen. Ivan Vazov, der große Schriftsteller des ausgehenden 19. Jahrhunderts, auch ,Patriarch der bulgarischen Literatur' genannt, lebte Anfang der 80er Jahre des 19. Jahrhunderts in Plovdiv und schrieb dort klassische, chrestomathische Texte, aber nie hat er Plovdiv ,besungen'. Der bedeutende Symbolist Dimčo Debeljanov verbrachte einige Jahre seiner Kindheit in Plovdiv, um dann im reifen Alter sein Sonett ,Plovdiv' zu schreiben, das mit den Worten, ich will mich an nichts erinnern' endet. (...) Es gibt etwas an diesem ,Geist des Ortes', das die Worte unterdrückt."

7 Vazovs bekanntester Roman heißt Pod igoto (Unter dem Joch) und handelt von der osmanischen Fremdherrschaft.

8 S. auch im „Dumont-Reiseführer“ Weiß $(2001,14)$ : „In Bulgarien sind sinnesfreudige Gottheiten und Musikgenies wie Dionysos und Orpheus beheimatet. Das hat Auswirkungen bis in die Gegenwart: Fast jeden Monat findet irgendwo ein Musikfestival statt, oder es werden weinselige Bräuche wieder belebt."

9 S. dazu Kiossev (1997, 42).

10 Burneva weist diese Figur in weiteren Gedichten Ivanovas nach (Burneva 2000, 44-49).

11 Russland hat sich nach der Abdankung des Fürsten Alexander von Battenberg (1868), der Bulgarien mit russischen Beratern regiert hatte, gegen die Wahl des „,westlichen” Kandidaten, Ferdinand von Sachsen-Coburg-Gotha, zum neuen Fürsten des Landes eingesetzt. Ferdinand söhnt sich erst nach der Entlassung des russophoben Ministerpräsidenten Stefan Stambolov mit Russland aus (1894).

12 S. dazu Frahm (2005, 5): „Gemeinsames Element [der vielfältigen Folklore] war allen der Reigen. Tänze waren also nicht, wie in den Ländern Westeuropas, Paartänze, sondern Reihen, in denen sich Männer und Frauen, nach Geschlechtern getrennt, im Schulterschluß zu Ketten verbanden und einander gegenüberstanden. Dies war das gemeinschaftsstiftende Element in allen bulgarischen Dörfern (und wohl auch sonst auf dem Balkan), und es hat sich bis in die heutige Zeit erhalten. Darum: keine Sentimentalität, kein Patriotismus, wenn sich Bulgaren (...) um die Schultern fassen, sondern Rekonstituierung einer stets bedrohten Identität." 
13 S. Hranova (2002, 54 f., wie Anm. 4).

14 Dieses Gedicht ist leider in keiner deutschen Bibliothek auf Bulgarisch vorhanden, sodass auf die deutsche Übersetzung von Valeria Jäger in Jäger/Sitzmann (1999, 209) zurückgegriffen werden musste.

\section{Primärliteratur}

Дебелянов, Д.: 1974, Съчинения в два тома, Т. 1: Стихотворения. Преводи.

Dinev, D.: 2006, Engelszungen, München.

Eckermann, J. P.: 1997, Gespräche mit Goethe in den letzten Jahren seines Lebens, 7. Aufl., Baden-Baden.

Иванова, М.: 1999, „Евридика', Randow, N. (Hg.), Eurydike singt, Köln, 266.

Jäger, V., Sitzmann, A. (Hg.): 1999, Europa Erlesen. Plovdiv. Klagenfurt/Celovec.

Карастоянов, Г.: 1972, Куюмджиевата квща, София.

Константинов, А.: 1971, Бай Ганъо, София.

Мутафчиева, В.: 1972, Свединението прави силата, София.

Райчевски, Г.: 1995, Време на надежди. Тоя щарен и симпатичен Пловдив, Пловдив.

Рупчев, Г.: 1986, Смяна на нощната стража, Пловдив.

Секулов, А.: 1996, Всичко, над далечината, Пловдив.

Славейков, П.П.: 1959, Събрани съчинения в осем тома, Т. VII: „Преводи', София, 105-260.

Теофилов, И.: 1981, Богатството от време, София.

Вазов, И.: 1977, Събрани съчинения в двадесет и два тома, Т. ХІ: „Пътеписи', София.

Велчев, Й.: 1997, Милиони малки убийства, Пловдив.

Златанов, З.: 1992, Храмови сънища, София.

\section{Sekundärliteratur}

Barthes, R.: 1988, ,Semiologie und Stadtplanung', Das semiologische Abenteuer, Frankfurt a.M., 199-209.

Bleicher, Th.: 1980, ,Elemente einer komparatistischen Imagologie', Komparatistische Hefte 2: ,Literarische Imagologie - Formen nationaler Stereotype in der Literatur', $12-24$.

Burneva, N.: 2000, , «Die warten auf Godot, und wir jagen nach dem Wind.» Bulgarische Literatur nach der Wende', Scholz, H., Merkel, S. et al. (Hg.), ZeitStimmen. Betrachtungen zur Wende-Literatur, Berlin.

Egger, S.: 2002, ,Komparatistische Imagologie im interkulturellen Literaturunterricht', Zeitschrift für Interkulturellen Fremdsprachenunterricht [Online], 6(3), http://www.ualberta.ca/ german/ejournal/imagologie.htm (Stand: 01.05.2005).

Fornoff, R.: 2006 (im Druck), ,Ins innere Bulgarien reisen. Zum psychoanalytischen Verständnis von Fremdheit', Lercher, M.-Ch., Middeke, A. (Hg.), Wider Raster 
und Schranken: Deutschland - Bulgarien - Österreich in der gegenseitigen Wahrnehmung, Göttingen.

Frahm, Th.: 2005, ,Wirklichkeit ist Vereinbarungssache. Bulgarische Erfahrungen', Der Hammer 9 (Nov. 05), 5-7.

García, A.C.: 2006 (im Druck), ,Projektdokumentation: Bilder im Kopf oder die verflixte selektive Wahrnehmung', Lercher, M.-Ch., Middeke, A. (Hg.), Wider Raster und Schranken: Deutschland - Bulgarien - Österreich in der gegenseitigen Wahrnehmung, Göttingen.

Goodman, N.: 1984, Weisen der Welterzeugung, Frankfurt a.M.

Gospodinov, G.: 1999, ,Karnevalisierung statt orthodoxer Postmoderne', Zeitschrift für Querverbindungen, 1 (N.F.): ,Maskenspiele. Bulgarien in der Literatur', 33-35.

Hranova, A.: 2002, ,Plovdiv - Erzählung ohne Sujet', Lichtungen, 91, 53-55.

Heinze, H.: 1986, Migrantenliteratur in der Bundesrepublik Deutschland, Berlin.

Kiossev, A. 1997, ,Homo scriptor und Homo academicus. Zwei Arten von Literaturgeschichtsschreibung', Lauer, R. in Verbindung mit A. Kiossev und Th.M. Martin (Hg.), Die bulgarische Literatur in alter und neuer Sicht, Wiesbaden, 37-58. (=Opera Slavica, N.F. 26.)

Kiossev, A.: ,Notes on the Self-colonising Cultures', http://www.online.bg/kultura/my_html/biblioteka/bgvntgrd/e_ak.htm (Stand: 25.09.2005).

Ликова, P.: 1994, Поезия на седемдесетте и осемдесетте години, София.

Middeke, A.: 2006 (im Druck), ,Zur literarischen Persönlichkeit Penčo Slavejkovs: Autokonstruktion und -inszenierung als bulgarischer Goethe', Lercher, M.-Ch., Middeke, A. (Hg.), Wider Raster und Schranken: Deutschland - Bulgarien Österreich in der gegenseitigen Wahrnehmung, Göttingen.

Oppermann, M.: 1984, Plovdiv - Antike Dreihügelstadt, Leipzig, Jena, Berlin.

Pentschev, B.: 1999, ,Die bulgarische Literatur der 90er Jahre im Überblick', Zeitschrift für Querverbindungen 1 (N.F.): ,Maskenspiele. Bulgarien in der Literatur', 121-129.

Randow, N.: 1994, ,Unter dem Regenschirm Daltschews.' Nachwort zu Laschen, G. (Hg.), Hör den Weg der Erde. Poesie aus Bulgarien, Bremerhaven, 176-181.

Weiß, H.: 2001, Bulgarien (Dumont-Reisetaschenbuch), Köln.

Wierlacher, A: 1993, ,Kulturwissenschaftliche Xenologie. Ausgangslage, Leitbegriffe und Problemfelder', Wierlacher, A. (Hg.), Kulturthema Fremdheit: Leitbegriffe und Problemfelder kulturwissenschaftlicher Fremdheitsforschung, München, 19112.

Zeuner, U.: 1998, Kursbuch: Interkulturelle Bewusstheit, http://www.tudresden.de/sulifg/daf/mailproj/inhalt.htm. (Stand: 01.02.2006) 


\section{Gewalt und Gewaltvorstellungen im russischen und osmanisch-südosteuropäischen Raum vom späten Mittelalter bis ins 19. Jahrhundert}

Mit welchem Gegenstand haben wir es zu tun? Bisher hat die Forschung, welcher Fachrichtung auch immer, zu keinem allseits akzeptierten Interpretationskonzept im Sinne einer plausiblen Definition von "Gewalt" gefunden (Platt 2002, 11ff.). Dies kommt nicht von ungefähr, zeigt doch schon die vielfach von Attributen gekennzeichnete Begrifflichkeit im deutschen Sprachraum (Imbusch 2000, 24), dass wir hier bei einer näheren Überprüfung auf eine überaus ambivalente, komplexe Erscheinung stoßen. Schon der Blick ins Grimmsche Wörterbuch verdeutlicht nicht ohne Grund eine erhebliche Ausdehnung des Bedeutungsumfangs im Verlauf der Jahrhunderte bis heute. Hieß im Beowulf „Gewalt“" noch „Kraft haben, Macht haben, über etwas verfügen, etwas beherrschen", so zeigt sich bald eine starke Bedeutungsteilung in Form massenhaft aufkommender Komposita wie „Gottesgewalt", „Christusgewalt", „Teufelsgewalt", aber auch konkret politisch in der 
Wortfügung „Kriegsgewalt", „Römergewalt", „Türkengewalt" bis zur noch heute analytisch wichtigen Prägung „Staatsgewalt", ausgehend von dem hier zugehörigen Begriff der „Fürstengewalt“. Schon seit dem Beginn der Neuzeit beobachten wir abweichend von dem ja ursprünglich vom nicht zwangsläufig unfriedlichen „Walten“ (Hugger 1995, 21) abgeleiteten Begriffsinhalt einen deutlichen Trend zu einer radikalisierten Auffassung, und zwar mit dem Auftreten der Begriffe „gewaltsam“ und „gewalttätig“ im Umfeld der Semantik staatlicher Macht- und Herrschaftsausübung (Lindenberger/Lüdtke 1995, 9, 10). Damit verengte sich nicht nur der Blickwinkel durch Fokussierung auf eine Herrschaftsansprüche reklamierende gewalt- und machtausübende Instanz, sondern es begründete sich auch der zwiespältige Doppelcharakter eines solchen Gewaltbegriffs. Dieser ist mit den lateinischen Wörtern potestas als legitime, aber auch mit dem Recht auf Tötung ausgestattete rechtssetzende Herrschaft auf der einen, und violentia als illegitime, rohe, ungebändigte und zerstörerisch gedachte „Gegengewalt" auf der anderen Seite beschrieben worden. Die einer solchen einfachen schematischen Gewaltvorstellung inhärenten Probleme sind bekannt und benannt (Brock 1995, 167ff.). Dieses antipodische Begriffspaar wird in der Forschung des franko- und des anglophonen Sprachraums dennoch bis heute im analytisch verwendeten Gegensatz von power, ggf. auch might auf der einen und violence auf der anderen Seite (Hook 1950, 264-267; Levine/Rosich 1996), bzw. franz. pouvoir und violence (Rauch 1991, 221-223; Corbin 1991, 224-236) benutzt, wobei der benachbarte Begriff force eher die Macht- und Gewaltmittel konnotiert (Elliot 1950, 338-341). Damit wird offensichtlich, dass "Gewalt" in diesem Sinne in einer Zweck-Mittel-Relation zu verorten ist, worauf schon Hannah Arendt beispielhaft hingewiesen hat (Arendt 1985, 8). Nun lehrt der Blick auf die allgemeine europäische Geschichte der letzten Jahrhunderte, dass die Fronten keineswegs so klar gesetzt sind, dass ein derartiges Gegensatzpaar in jeweils sauber voneinander abgegrenzter Form der konkreten Analyse historischer Gewalt als erkenntnisvermittelnder modus operandi dienen kann. In der Geschichte erscheint es vielmehr in einem eng ineinander verwobenen dialektischen Verhältnis. Lothar Brock hat das Problem folgendermaßen definiert: „Gewalt bleibt auch in der Gestalt der potestas Gewalt, sie verharrt am Rande des Abgrunds, ist stets gefährdet, in die violentia abzustürzen. Umgekehrt kann violentia in potestas umschlagen. Sie tut dies, wo sie siegreich ist, und auch dort, wo sie zur Institution wird" (Brock 1995, 167). Dieses Umschlagen, das gleichzeitig zumindest aus der Sicht des oder der Gewaltausübenden mit einer Übertragung von Legitimität verbunden ist, tritt im historischen Kontext besonders bei Regimewechseln als Ergebnis sozialer und politischer Revolutionen zutage. Das russische und das französische Beispiel drängt sich hier geradezu auf.

Abgesehen von der Erkenntnis dieses Zusammenhanges in der Wirkungsweise der u.U. ein staatliches Gemeinwesen präformierenden, ggf. neuschaffenden oder zerstörenden Form öffentlicher Gewalt, Gewaltausübung und -tätigkeit, hat die historische, soziologisch-politologische, kulturanthropologische oder ethnologische Forschung versucht, theoretische und methodische Ansätze zu finden, die geeignet 
sind, einen allgemeinen und generalisierbaren theoretischen Begründungszusammenhang für die bisher beobachtbaren Formen gesellschaftlich wirksamer Gewalt zu liefern. Hierfür sind Konzeptionen der beispielsweise strukturellen, also indirekt wirkenden Gewalt (Galtung 1975), der ,symbolischen“ bzw. „sanften Gewalt" (Bourdieu 1976, 369f., 377), der sog. „Sozialverhältnisgewalt" als „unabdingbare Gegebenheit aller Vergesellschaftung“" in der Geschichte (Papcke 1983, 24) oder der legitimen bzw. illegitimen „progressiven“ und „reaktionären“ Gewalt (Sieferle, 1998, 21), der psychischen, physischen oder kulturellen Gewalt, Gewalt gegen Personen sowie gegen Sachen etc. (Liell 1999, 34) formuliert worden.

Im Sinne größtmöglicher Operationalisierbarkeit des Gewaltbegriffs anhand der speziellen Verhältnisse Ost- und Südosteuropas erscheint es zweckmäßig, eine Beschränkung des Begriffs der Gewalt zwar auf deren physische Erscheinungsformen (Neidhardt 1986, 123) vorzunehmen, gleichzeitig aber auch auf den Ort ihrer Wirkungsweise, nämlich den öffentlichen - eben nicht familialen oder privaten Raum sowie ferner auf den kollektiven Charakter dieser Erscheinung zu beziehen. Aber noch eine dritte Einschränkung sei erlaubt: Nur diejenigen historischen Gewaltformen Osteuropas sollen im folgenden untersucht werden, die für das Staats- bzw. Gemeinwesen, in dem sie entstanden, von besonderer Bedeutung waren, ja dieses prägten oder ggf. auch bedrohten. Dies gilt besonders dann, wenn sie in einer gewalttätigen politischen Herrschaft und ihren Institutionen selbst oder aber in der Etablierung eines eigenen Machtmonopols in Konkurrenz zum Staat den Zusammenfall von potestas und violentia dokumentierten. Bei der Analyse von gewaltsamen Vollzugsakten staatlicher Organe oder sonstiger öffentlich agierender „Gewalt" ausübender Gruppen ist zudem der inhärenten Codierung der Gewalttätigkeit und ihres ggf. lange Zeiträume umfassenden Auftretens jeweils nachzugehen. Mit Recht ist gerade auch von Historikern darauf verwiesen worden, dass das Phänomen, um das es geht, in seinen speziellen historischen, sozialen und kulturellen Kontexten zu verstehen ist und daher nur in einer Kombination von sowohl struktur- wie auch kulturgeschichtlichen und akteursbezogenen Ansätzen adäquat bewertet werden kann (Höpken/Riekenberg 2001, 57). Dabei versteht sich das Folgende nicht als Beitrag zur Gewaltursachenforschung, sondern als eine in erster Linie phänomenologische Betrachtung gewalttätigen Handelns sozusagen aus der Perspektive des Täters. Nicht die passiven Wahrnehmungen von Gewalt, wohl aber die aktiv umsetzbaren Vorstellungen von ihr sind deshalb das Thema.

Zum Krieg als spezifischer Form extremer Gewaltausübung seien ebenfalls vorweg ein paar grundsätzliche Bemerkungen erlaubt, ist doch der Begriff des Krieges als analytische Kategorie spezifischer Gewalttätigkeit ebenso verwaschen wie der der "Gewalt" im allgemeinen. So wundert es nicht, dass auch hier bisher keine einheitliche und weithin akzeptierte wissenschaftliche Definition entwickelt wurde (Wegner 2000, 17). Dennoch bietet sich eine Möglichkeit an, Krieg als spezifische Art der kollektiven, organisierten und mechanisierten absoluten Gewalt, auch am Beispiel der Verhältnisse unter den verschiedenen soziokulturellen Kontexten der osteuropäischen Länder und Regionen, analytisch zu fassen. Hierfür 
erscheint ein von Lutz von Trotha entwickelter Ansatz fruchtbar, der eine Typologie der Kriege entwickelt hat und diese aus einem Dreieck unterschiedlicher Komponenten ableitet, nämlich den gesellschaftlich und kulturell vermittelten verschiedenen Formen des Krieges, in denen sich bestimmte Merkmale ausprägen, zweitens den Bedeutungen, die diese Merkmale für den jeweiligen Krieg haben, sowie schließlich auch den Zielen, mit denen die bewaffneten Auseinandersetzungen geführt werden. So gelangt er zunächst zum sog. „totalen Krieg“ als Form traditioneller frontaler bewaffneter Gewaltaktion zwischen Staaten oder auch nur Stämmen. Zweitens nennt Trotha den sog. „Pazifizierungskrieg“, den er einerseits in den Zusammenhang mit den Waffengängen der europäischen Großmächte zum Zwecke der Eroberung und dauerhaften Beherrschung kolonialer Gebiete stellt. Andererseits sieht er diesen Kriegstypus auch als Antriebskraft zur Bildung „territorialstaatlicher Herrschaft" mit genereller Bedeutung für Staatsbildungsprozesse auch in anderen Räumen und Zeiten (Russland!). Das dritte Glied der Typologie ist der sog. „Neo-Hobbessche“ oder „Kleine Krieg“, der in diesem Konzept für eine lokal begrenzte bewaffnete Auseinandersetzung steht und u.a. mit Etiketten wie „Grenz"-, „Partisanen“-, „Guerilla“-, „Banden“- und „Bürgerkrieg" versehen werden kann (Trotha 1999, 73-93).

Für die sich in Russland im Verlauf der Geschichte entwickelnden Gewaltverhältnisse hat Vladimir Kantor ein modelltheoretisches Konzept entworfen, worin er einen Gewalttypus definiert, der sich nach dem „Prinzip des außerrechtlichen Zwangs und der Unfreiheit, der Verpflichtung zum Dienen bei fehlenden Persönlichkeitsrechten“ ausrichte. Dieser spezifische sog. „Moskauer Typ gesellschaftlicher Beziehungen", auf den sich dieser Gewalttyp gründe, sei eine Folge der Unterbrechung der in rechtlich-zivilisatorischer Hinsicht „organischen Weiterentwicklung“ des mittelalterlichen Kiever Staates durch den Tatarensturm des 13. Jahrhunderts. Die Tataren seien mit der unterworfenen Rus' lediglich durch ihre Tributeinnehmer sowie bei Raubzügen oder Strafexpeditionen in Berührung gekommen. Sie hätten abseits gelebt, zuweilen die russischen Fürsten empfangen und mit den Händen des Eroberers, d.h. ohne verbindlichen Vertrag, das Recht auf die Herrschaft über dieses oder jenes Fürstentum verliehen. Hierdurch habe sich der Chan das Recht vorbehalten, das verliehene Privileg willkürlich, wann er wollte, wieder zu entziehen und auf einen anderen Fürsten zu übertragen. Damit sei nun ein tatarisches Ordnungsprinzip eingeführt worden, das einen prägenden dauerhaften Einfluss auf die gängigen Vorstellungen vom Regierungs- und Verwaltungshandeln der Russen genommen habe. Der Aufbau des Moskauer Staates habe sich deshalb unter Bedingungen vollzogen, die - so Kantor - „rechtlich gesicherte Beziehungen nicht begünstigten" und so auch spezifische, gewissermaßen nicht verrechtlichte Formen der Gewalt hervorgebracht hätten (Kantor 1997, 2, 3, 14). Als anschaulichen Beleg führt der Autor die quellenmäßig gut belegte Antwort des Großfürsten Ivan III. an. Dabei handelte es sich um eine an den Letztgenannten gerichtete Offerte der Novgoroder nach ihrer im Krieg gegen Moskau erlittenen militärischen Niederlage kurz vor der endgültigen totalen Angliederung und Gleichschaltung 
Groß-Novgorods durch den Moskauer Staat 1477. Bei dem Angebot der unterlegenen Handelsrepublik ging es um den Abschluss eines Unterwerfungsvertrags, der auf verbindlichen Abmachungen für beide Seiten gründete. Der Großfürst erklärte dazu: „Euch wurde gesagt, dass wir in Groß-Novgorod einen ebensolchen Staat wollen wie der Staat bei uns im Unterland an der Moskva ist; ihr aber weist mich jetzt selbst an, wie unser Staat bei Euch sein soll: Welcher Art wird danach denn mein Staat sein?“ (Kantor 1997, 15). Die Taten folgten: Die Novgoroder Bevölkerung wurde unter bewusstem Bruch eines Versprechens Ivans III. zwangsumgesiedelt, ihr Reichtum, gewachsen in einem regen Westhandel, von den Moskauer Adelsaufgeboten im Auftrag des Großfürsten geplündert. Somit erfüllte der Zug Moskaus gegen Novgorod und seine Folgen die Trothaschen Kriterien vom „totalen Krieg“, wie er durchaus auch für die Vormoderne definiert ist. Kantor zieht nun aus der zitierten Quelle eine entscheidende Schlussfolgerung: Schon die Vorstellungen der ersten Moskauer Herrscher zu Beginn der Neuzeit vom Wesen der obersten Staatsmacht bewiesen, „dass jeder beliebige staatliche Zwang jetzt zu widerrechtlicher, aber legitimer, d.h. staatlich sanktionierter Gewalt wurde" (Kantor 1997, 15). Auf der Basis des einleitend genannten wissenschaftlichen Instrumentariums der historisch-soziologischen Gewaltforschung bedeutet dies folgendes: Bereits vor der Definition der Herrschaftsgewalt des Moskauer Autokraten durch die Ideologen des „Dritten Roms“ zu Beginn des 16. Jahrhunderts kommt sowohl in den Vorstellungen wie auch in den Taten der Selbstherrscher ein Gewaltbild zum Tragen, das das tatsächliche Zusammenfallen von potestas und violentia im genannten Sinne verdeutlicht. Vor diesem Befund ist es auch nicht verwunderlich, dass in der russischen Sprache bei der begrifflichen Verwendung entsprechender Lexeme keine klare Trennung zwischen gesetzlicher und illegitimer öffentlicher, d.h. auch staatlicher Gewalt üblich wurde. Die Ausdrücke vlast', sila und moguščestvo können jeweils beide Begriffsinhalte von Gewalt umfassen, sila mehr noch in dem direkt abgeleiteten, stärker personenbezogenen Begriff nasilie für "gewalttätige Handlung“ - im besonderen eben gerade die rohe rechtsbrecherische Gewalt. Folgerichtig schreibt das russische, in den 90er Jahren des 19. Jahrhunderts erschienene „Enzyklopädische Wörterbuch“ unter dem Eintrag „vlast”, dass sich „als Resultat der Vermischung dieser Begriffe manchmal eine Identifizierung von vlast' und sila“ zeige, mit einem damit verbundenen „Verlust der sittlichen und progressiv-kulturellen Bedeutung", die dem Wort vlast' ursprünglich eigen gewesen sei (F.A. Brokgaus, I.A. Éfron 1892, 673; 1897, 638).

Die Vorstellungen von öffentlich sanktionierter Gewalt, bezogen auf Position und Legitimation des Selbstherrschers, wurden im Moskauer Zartum bekanntlich durch den Sieg der in der Forschung als „machtkirchliche Richtung“ bezeichneten Tendenz innerhalb der russischen Orthodoxie geprägt. Sie war durch die vom Abt Josif von Volokolamsk und seiner Anhänger Ende des 15., Anfang des 16. Jahrhunderts verfochtenen Zielvorstellung der Einheit von Staat und Kirche in einer "Civitas Dei" charakterisiert. In der Anlehnung an die byzantinische Herrschaftsideologie zeigte sich eine entsprechende kulturelle Codierung der herrscherlichen 
Gewalt, mit der Loslösung vom byzantinischen Patriarchat und der Entwicklung der Idee vom 3. Rom dann gleichsam die eigene ideologische Begründung der Gewalt des Selbstherrschers als unmittelbar von Gott verliehene. Ivan IV., „der Schreckliche", hat diese Gewaltvorstellung extrem zu seinen Gunsten instrumentalisiert. In seinem berühmten, 1573 verfassten Sendschreiben an den schwedischen König Johan III. formulierte er: „Der Obrigkeit widerstreben heißt Gott widerstreben [....]. Und dies ist gesagt von jeglicher Gewalt, auch wenn man sie mit Blut und im Kampf errungen hat. Bedenke aber, dass ich nicht durch Raub das Zartum erworben habe. Darum nur umso mehr: Wer der Obrigkeit widerstrebt, widersetzt sich Gott" (Hellmann 1966, 70). So gesehen, war es nur konsequent, wenn in der sog. „Zeit der Wirren“ nach dem Tod Ivans IV. die nun auftretenden beiden falschen Zaren von den hochadligen Machtprätendenten vory (= Diebe, Räuber), nämlich Räuber der legitimen Herrschergewalt, genannt wurden. Die Verschmelzung von violentia und potestas zeigte sich gerade auch in diesen dynastischen Machtkämpfen: Die Rechtmäßigkeit einer Übernahme der potestas des Zaren maßen die hochadligen Prätendenten am Prinzip der eigenen genealogischen Würdigkeit, auch wenn diese in wilder violentia erworben sein sollte. Die „Räuber“ der Herrschaftsgewalt orientierten sich ihrerseits an der gleichfalls mit roher Gewalt durchzusetzenden Vorstellung von der höheren Wertigkeit der Stellung des angeblich noch existierenden legitimen Thronfolgers.

Auch die späteren russischen Zaren gründeten ihre Herrschaft auf jene unter Ivan IV. endgültig theoretisch untermauerte Gewaltvorstellung. Der Zusammenfall von power und violence war nur eine zwangsläufige Folge des Selbstverständnisses der Selbstherrschaft, wozu in Abwesenheit einer Einwirkung römisch-rechtlicher Verbindlichkeit willkürliche Handlungsweisen gewissermaßen dazugehörten. Die Vorstellung vom vor als dem Dieb herrscherlicher Gewaltrechte und kaiserlicher Legitimität blieb gleichfalls erhalten. Sie zeigte sich z.B. im Vokabular des Behördenund des militärischen Briefwechsels im Kontext des Kosakenaufstands Stenka Razins sowie auch in den Berichten der zaristischen Geheimpolizei während des sog. Bauernkriegs Pugačevs gegen Katharina II. Das Bild vom Räuber in dieser herausgehobenen Position verband sich dabei organisch mit der Vorstellung vom „einfachen“ gewalttätigen Gesetzesbrecher (Švecova 1976, 15, 17, 61; Wende 1990, 195).

Bei einer phänomenologischen Analyse erscheint die Beobachtung wichtig, dass die bäuerliche Bevölkerung auf sozioökonomische Veränderungen zu ihrem Nachteil, auch wenn sie vom Herrscher selbst initiiert wurden, nicht in Anwendung diffuser Gewalt mit der Aufgabe weit verbreiteter patrimonial-patriarchalischer Denkmuster bezüglich der Position und Gewalt des Zaren reagierten. Vielmehr flüchteten sie sich in Aktivierung dieser Vorstellungen vom guten und gerechten Herrscher dorthin, wo nach ihrer Meinung die Sicherung des ,guten alten Rechts“ gewährleistet war, nämlich in die staatlich kaum penetrierten Grenzsäume des Reiches bei den freien Kosakengemeinschaften. 
Damit kommen wir zu einer wichtigen Form nichtstaatlicher Gegengewalt, die in der Lage war, an den Peripherien des russischen Reichs konkurrierende Gewaltmonopole auszubilden. Die autonomen kosakischen Gemeinden am Dnepr, am Don, an der unteren Wolga, am Terek, am Kuban und am Jaik lebten in erster Linie von der Jagd, vom Fischfang sowie vom Raub, weshalb besonders auch die Dnepr-Kosaken, die Zaporoger, von der Forschung in den Kontext des Fernräubertums eingeordnet worden sind (Longworth 1973, 9). Gerade in der Ukraine war im Niemandsland zwischen Polen-Litauen im Westen, den Krimtataren im Osten und dem Moskauer Reich im Norden die Möglichkeit zu Raubzügen in die benachbarten Regionen gegeben. Gewalt tritt uns hier in einer basisdemokratisch organisierten Lebensordnung, die auf gemeinschaftlicher Wahl eines Obersten, gemeinsamen Entscheidungen, Kollektivhaftung und kollektivem Landbesitz beruhte, als besonderes Lebensordnungsprinzip entgegen: Sie äußerte sich sehr häufig als „inszenierte Plötzlichkeit“ (Elwert 1998, 1). Diese auf dem Überrumpelungseffekt des plötzlichen, dem Gegner wenig Zeit zur Gegenwehr einräumenden Angriffs beruhende Gewaltaktion entsprach der erfolgversprechenden Taktik des schnellen und mobilen Zugriffs und ggf. Rückzugs, wie sie auch für den Partisanenkampf typisch ist. Das verbreitete, für den betroffenen Gegner in seinem unmittelbaren Bevorstehen erst im letzten Augenblick erkennbare Erschlagen ordnet sich, im Gegensatz zum aufwendigeren Erschießen, gut in diese ,inszenierte Plötzlichkeit“ im Elwertschen Sinne ein. Diese ,primitive“ Form der Gewalt wird auch in den Zeugnissen über die Eroberung Sibiriens vom Ende des 16. bis zum Ende des 17. Jahrhunderts deutlich. Dies war ein langsamer und unregelmäßiger Waffengang, der, wenn man der genannten Trothaschen Terminologie folgt, teils in den Kontext des mitunter im Stil des Partisanenkampfes geführten sog. „Kleinen Krieges“ als eines Grenzkrieges halboffizieller paramilitärischer Gruppen einzuordnen ist, teils auch das Gepräge eines mit Soldaten des Zaren aktiv unterstützten kolonialen „Pazifizierungskrieges“ hatte. Extreme violentia einzelner Kosakenkommandanten, verbunden mit Geiselnahme und willkürlich angerichteten Massakern an den zu unterwerfenden Stämmen, gehörten dazu (Longworth 1973, 52, 59, 66/67).

Als exemplarische Beispiele für die Umsetzung kosakischer Gewaltvorstellungen in Einheit mit den patriarchalisch-bäuerlichen seien die von den Kosaken Stenka Razin 1669-71 und Emeljan Pugačev 1772-74 angeführten großen Bauernaufstände genannt. Auch hier war der schnelle, im Überrumpelungssangriff erzielte Tod durch Erschlagen oder Erstechen ein wichtiges Moment. Die in diesen Aufständen verbreitete kosakische Auffassung vom „primitiven“, billigen Töten (ohne Kugelverbrauch) ist sehr plastisch im folgenden Aufruf des falschen Zaren Pugačev an seine Getreuen belegt: „Dafür, dass ich Euch mit Land, Wasser und Salz, Glauben und Gebet, Gut und Geld belohnt habe, sollt ihr mir bis zum letzten Atemzug dienen. Wenn aber einer gegen mich auftreten und mir untreu sein will, dann werde ich keine Gnade kennen. Der Kopf wird ihm abgeschlagen und der Besitz eingezogen" (Wende 1990, 195). In dieser angedrohten Sanktion als zwangsläufiger Folge eines Verrats, die als Vorstellung legitimer Gewaltausübung über viele Generationen in der kosakischen 
Gemeinschaft tradiert und insofern soziokulturell codiert war, zeigte sich auch die zeremonielle Seite der kosakischen Strafgewalt. Dieser Tod in kurzer Handlung hier gedacht durch den Säbel - ereilte viele Repräsentanten des Staates, der Städte, Geistliche und Gutsbesitzer. Gegen letztere gingen die aufgewiegelten Bauern oftmals mit sehr einfachen Handwaffen (Spießen und Keulen) vor, um nach ihrer Auffassung gebrochenes Recht zu sühnen und in der Volksbewegung als ,gutes altes Recht" auch wiederherzustellen. In der Gegengewalt der Herrschenden zeigte sich regelmäßig jenes Zusammenfallen von potestas und violentia, ein Zustand, den der genannte Vladimir Kantor als „,konservativ-provokativen“, fortschrittsfeindlichen Gewalttyp „rechtswidriger“ Natur eingestuft hat (Kantor 1997, 11, 12): Wenn auch Stenka Razin nach einem damals durchaus rechtsüblichen standgerichtlichen Verfahren auf dem Roten Platz in Moskau durch das Beil starb, wurden viele seiner gefangenen Anhänger auf Befehl des Fürsten Dolgorukij noch in der Aufstandsprovinz an ihren Rippenbogen (!) aufgehängt (Wende 1990, 80). Dieser zeremonielle Charakter der schweren körperlichen Bestrafung als Repräsentation einer racheübenden Strafgewalt seitens der Selbstherrschaft oder ihrer Vollzugsorgane zeigte sich auch im Hinrichtungsurteil Pugačevs. Es lautete: „Vierteilen, den Kopf auf einen Pfahl spießen, die Körperteile in alle vier Himmelsrichtungen durch die Stadt fahren und mit den Karren verbrennen“. Überraschenderweise wurde dieses Urteil jedoch nicht in dieser Weise ausgeführt, sondern es wurde lediglich der Kopf abgeschlagen, wonach man diesen dann allerdings auf eine Radspeiche spießte und den bereits toten Körper räderte (Wende 1990, 205, 206).

Hinter diesen Gewaltvorstellungen und (staatlichen) Untaten stand ein Selbstverständnis selbstherrscherlicher Gewaltausübung, das in der 2. Hälfte des 19. Jahrhundert nach dem verlorenen, nicht nur nach der Trothaschen Terminologie als „total“ zu begreifenden Krimkrieg (Baumgart 2000, 191ff.), der Abschaffung der Leibeigenschaft sowie im verstärkten Zuzug westlich-oppositioneller politischphilosophischer Ideen eine Akzeptanzkrise erleben sollte. So war die nicht ethnonationalistisch codierte Gewalt der russischen Truppen im kolonialen „Pazifizierungskrieg“" zur Eroberung Mittelasiens in erster Linie eine Funktion des Wunsches nach Wiederherstellung des Prestiges der Selbstherrschaft (Geyer 1977, 72, 78, 80). Die Ressource Prestige bestimmte damit also nicht nur die Gewaltausübung bestimmter staatskonkurrierender Machtgruppen wie der Kosaken.

Die Gewalt und die Vorstellungen von ihr in der russischen Geschichte sollen nun historisch wirksamen Gewaltkonzepten in den bis ins 19. Jahrhundert, z.T. noch darüber hinaus, osmanisch beherrschten Gebieten Südosteuropas gegenübergestellt werden.

Die offizielle osmanische Herrschaftsauffassung machte einen grundsätzlichen Unterschied zwischen der muslimischen Bevölkerung und der unterworfenen raya (= nichtmuslim. Untertanen), wie alle Bevölkerungen nichtmuslimischen Glaubens im Reich genannt wurden. Es handelte sich hierbei um Untertanen grundsätzlich minderen Rechts, denen gegenüber uneingeschränkte staatliche Gewaltausübung soweit erlaubt war, wie es dem Sultan als weltlichem und religiösem Oberherrn 
aller Muslime angemessen erschien. In der Praxis bedeutete dies im Verlauf der Jahrhunderte allerdings keineswegs eine schrankenlose Gewaltherrschaft eines theokratischen Monarchen über die raya. So ist denn auch das in der früheren Forschung noch vielbeschworene dämonisierende Etikett vom „türkischen Joch“ inzwischen längst einem differenzierteren Bild gewichen. Die christliche oder jüdische Abkunft war zudem - im Gegensatz zu Russland - unerheblich, falls der Untertan zum Islam übertrat. Er konnte dann wie jeder geborene Moslem sogar bis zur Position des Wesirs aufsteigen und somit selbst zur Macht- und Gewaltinstanz werden. Auch waren der Macht des Sultans besonders infolge der Eigenmächtigkeit lokaler Notabeln, der Beglerbegs, Begs und Paşas als den Gouverneuren der zahlreichen Provinzen, deutliche Grenzen gesetzt. Die Geschichte der inneren Verwaltung des Reichs war schon lange vor den christlich-nationalen Befreiungsbewegungen des 19. Jahrhunderts eine der zahlreichen Auf- und Widerstände dieser örtlichen Potentaten gegen ihren Großherrn (Matuz 1985, 159-164, 210-213). Dabei kam es auch zur Gewaltform der schon wiederholt genannten „kleinen Kriege“, aber auch der vom Sultan in Ausübung seiner Gegengewalt geführten „Pazifizierungskriege“ mit durchaus kolonialem Charakter. Zum anderen vermochte es die osmanische Herrschaft auch in ihrer über die lokalen Machthaber vermittelten Form keineswegs, sämtliche Gebiete des großen Territoriums erfolgreich und vor allem dauerhaft zu beherrschen. Weite periphere Bereiche, besonders die kleinräumig besiedelten, für den Westbalkan typischen mobilitätsfeindlichen eng verkammerten Gebirgsstöcke, blieben vielmehr permanent staatlich unzureichend kontrolliert. So entstanden rechts- und herrschaftsfreie Räume, staatliche Gewaltvakua. Infolge der andauernden Abwesenheit des Faktors Staat konnte deshalb die dort ansässige Bevölkerung unter Neubelebung alten Gewohnheitsrechts archaische paraoder konkurrenzstaatliche Gewaltstrukturen wieder errichten und konservieren. Im Gebiet des heutigen Montenegros, der Westherzegowina sowie Nordalbaniens bewirkte die Abwesenheit staatlicher Strukturen sogar eine Revitalisierung der Stammesorganisation (Matl 1959, 107, 119). Diese Stämme bauten völlig selbstständige Gewaltmonopole auf, die sich gegenseitig blutig bekämpften, ja aus dieser streng ethisch codierten, agonal-archaischen Regeln folgenden Gewaltausübung sogar ihre Existenzberechtigung ableiteten. In jedem der einzelnen Stämme des nordalbanisch-montenegrinisch-westherzegowinischen Raums hieß das erste Gebot heldisch-ehrenhaftes Verhalten. Sämtliche Lebensbereiche waren von der Erfüllung dieser Grundqualifikation des Zusammenlebens geprägt und durchdrungen. Jeder Mann war in jedem Augenblick potentieller Krieger, bereit, sich bei einer Verletzung der Ehre seiner Sippe oder seiner eigenen mit der Waffe in der Hand zu wehren. So geriet auch das Waffentragen nie zur bloßen Attitüde. Es war vielmehr Ausdruck der alltäglichen Lebensauffassung und Weltsicht (Barjaktarović 1971, 147-150). Von der montenegrinschen Überlieferung wissen wir, dass daher eine Abgabe der Waffen z.B. an einen Feind nach einer Gefangennahme oder später an den Staat die völlige Entkleidung, ja Entmannung des Mannes bedeutete. In dieser Gesellschaft entwickelte sich in Jahrhunderten kriegerischen Lebens eine immer 
wieder neu tradierte und gefestigte Gewaltdisposition. Deshalb musste einer ggf. endlosen Schraube der Gewaltausübung mit verhaltensregulierenden moralischen Normen begegnet werden. Beleidigung, Verletzung des Gastrechts, Schändung einer Jungfrau, Treuebruch u.a., also „unrechtmäßige“ Violenz, zogen nämlich unweigerlich in Ausübung der althergebrachten potestas die Blutrache nach sich, manchmal in langdauernden Auseinandersetzungen zwischen den Stämmen mit Hunderten von Toten. Um dieses möglichst zu vermeiden, galt das Prinzip des Stolzes mehr als die Rachepflicht. Dies bedeutete, dass der ausersehene Blutschuldner, wenn dieser aufgrund seiner bisherigen Taten und des Status seiner Familie als nicht rachewürdig angesehen wurde, ein ebenbürtiges Blutopfer jedoch nicht erreichbar war, durchaus auf die Blutrache verzichten konnte (Gesemann 1943, 34, 204, 205, 200). So wirkte also das gesellschaftsbestimmende agonal-ethische Prinzip dieser kämpferischen Stammesgesellschaft auch als Gewaltregulativ.

Aber selbst die überwiegend bäuerliche christliche Bevölkerung der Ebenen war dem Zugriff und damit der Gewaltausübung der in den wenigen urbanen oder halburbanen Verwaltungszentren konzentrierten osmanischen Behörden und vor allem auch der ursprünglich auf dem Militärlehen aufbauenden Gutsherrschaft der Sıpahi nicht gleich- und regelmäßig ausgesetzt. Die in Dörfern außerhalb Herrschaft der Sıpahi siedelnden Serben, Griechen, Albaner, Bulgaren - vom Sonderfall der Rumänen und zeitweise dem Reich einverleibten Kroaten und Ungarn einmal abgesehen - bekamen die osmanische Gewalt nur fallweise zu spüren. Dies geschah etwa im Zuge von Strafexpeditionen, im Regelfall meist nur bei Gefährdung der öffentlichen Ordnung und Sicherheit, bei Streitigkeiten mit Muslimen sowie im Zuge der halbjährlichen Steuereinnahme. So war es möglich, dass sich auch auf dem „platten Land“ in den Dörfern und Landkreisen zunächst staatlich geduldete, später ausdrücklich gestattete Praxen der Selbstregulierung mit Gewaltvorstellungen nach den Maximen des althergebrachten Gewohnheitsrechts entwickeln konnten. Aus ethnographischen Untersuchungen wissen wir, dass z.B. in den Dörfern im serbischen Siedlungsgebiet beiderseits der Morava autonom Recht gesprochen wurde. Das „Dorf“ als Gemeinschaft aller erwachsenen Männer fällte als traditionale patriarchale Rechtsinstitution noch um 1830 sogar Todesurteile als Sanktion für Verstöße einzelner Dorfbewohner gegen die gewohnheitsrechtlichen Normen (Đorđević 1948, 267ff.). Diese segmentären einheimischen Gewaltstrukturen der untersten Ebenen erwiesen sich, neben Montenegro besonders auffällig in Serbien und Griechenland, als so stark, dass der Versuch ihrer Eliminierung seitens einer sich von den Osmanen schrittweise emanzipierenden nationalen Elite bis zum Ende des 19. Jahrhunderts zu andauernden Aufständen oder endemischem Banditismus zum Schaden der eigenen neuen, universalistisch orientierten Staatlichkeit führte (Boestfleisch 1987, V, VI, 3, 5; Koliopoulos, 1987). Es sei zudem in diesem Zusammenhang darauf verwiesen, dass sich gegen Ende der osmanischen Herrschaft, aber auch und gerade in der ersten Phase der Befreiungskämpfe, die Klagen der Mehrheit der christlich-othodoxen Bevölkerung charakteristischerweise nicht gegen die als zunächst durchaus legitim erachtete Gewalt des Sultans als solche richteten, 
sondern lediglich gegen deren gewohnheitsrechtlich missempfundene Pervertierung, d.h. den Gewaltmissbrauch seitens lokaler Machtorgane. Hier standen akzeptierte - wenn auch ggf. gewalttätige - potestas gegen eine als fremd und unrecht empfundene violentia.

Somit bestätigt sich, dass physische, öffentlich wirksame Gewalt als phänomenologische Erscheinung und die Vorstellungen von ihr sowohl in der Geschichte Russlands als auch der des osmanischen Südosteuropas im gegebenen Zeitraum in ihren Begründungszusammenhängen vornehmlich von sozialen und siedlungsgeographischen Faktoren, aber auch religiösen und kulturellen Kontexten abhängig waren. Die prinzipiell willkürlich gedachte autokratische Auffassung herrscherlicher Macht und Gewaltausübung in Russland und im osmanischen Reich führte aber eben gerade wegen der Verschiedenheit der auf die konkrete Umsetzung Einfluss nehmenden (kulturellen) Codierungen nur teilweise zu ähnlichen Erscheinungsformen von Gewalt. Die unterschiedliche Durchsetzungskraft von zentraler oder von ihr abgeleiteter lokaler Herrschaft bewirkte dabei im häufigen Zusammenfallen von potestas und violentia jeweils auch unterschiedliche Formen gesellschaftlich vermittelter Parallel- oder Gegengewalt ,,von unten“.

\section{Literatur}

Arendt, H.: 1985, Macht und Gewalt, München/Zürich.

Barjaktarović, M.: 1971, ,On some Ethnical Characteristics of Montenegrians', in: Ethnologia Slavica III, 147-150.

Baumgart, W.: 2000, ,Der Krimkrieg 1853-1856', in: B. Wegner (Hg.), Wie Kriege entstehen. Zum historischen Hintergrund von Staatenkonflikten, Paderborn u.a., 191-209.

Boestfleisch, H.-M.: 1987, Modernisierungsprobleme und Entwicklungskrisen: Die Auseinandersetzungen um die Bürokratie in Serbien 1839-1858, Frankfurt, Bern, New York.

Bourdieu, P.: 1976, Entwurf einer Theorie der Praxis auf der ethnologischen Grundlage der kabylischen Gesellschaft, Frankfurt/Main.

Brock, L.: 1995, ,Gewalt in den internationalen Beziehungen', in: P. Hugger, U. Stadler (Hg.), Gewalt. Kulturelle Formen in Geschichte und Gegenwart, Zürich, 167-187.

Corbin, A.: 1991, ,Histoire de la violence dans les campagnes françaises au XIXe siècle. Esquisse d'un bilan', Ethnologie francaise 21, 224-236.

Đorđević, T.: 1948, ,Selo kao sud u našem narodnom običajnom pravu', Zbornik filozofskog fakulteta, 1, 267-287.

Elliot, W.Y.: 1950, ,Force, Political', in: Encyclopaedia of the Social Sciences V, DAN-GOS, London, 338-341.

Galtung, J.: 1975, Strukturelle Gewalt. Beiträge zur Friedens- und Konfliktforschung, Reinbek. 
Gesemann, G.: 1943, Heroische Lebensform. Zur Literatur und Wesenskunde der balkanischen Patriarchalität, Berlin.

Geyer, D.: 1977, Der Russische Imperialismus. Studien über den Zusammenhang von innerer und auswärtiger Politik 1860-1914, Göttingen.

Hellmann, M.: 1966, Iwan der Schreckliche. Moskau an der Schwelle der Neuzeit, Göttingen u.a.

Hook, S.: 1950, ,Violence', in: Encyclopaedia of the Social Sciences, XV, TRA-ZWI, London, 264-267.

Höpken, W., Riekenberg, M.: 2001, ,Gewalt in Südosteuropa und Lateinamerika: Einleitende Bemerkungen zu einem Vergleich und seinen Tücken', in: W. Höpken und W. Riekenberg, Politische und ethnische Gewalt in Südosteuropa und Lateinamerika, Köln, Weimar, Wien, VII-XX.

Hugger, P.: 1995, ,Elemente einer Kulturanthropologie der Gewalt', in: P. Hugger, U. Stadler (Hg.), Gewalt. Kulturelle Formen in Geschichte und Gegenwart, Zürich, $17-27$.

Imbusch, P.: 2000, ,Gewalt - Stochern in unübersichtlichem Gelände', Mittelweg 36, 9,2, 24-40.

Kantor, W.: 1997, ,Gewalt und Zivilisation in Russland', Bericht des BIOst 11, 3-38.

Koliopoulos, John S.: 1987, Brigands with a Cause. Brigandage and Irridentism in Modern Greece 1821-1912, Oxford.

Levine, F.J.; Rosich, K.J.: 1996, Social Causes of Violence. Crafting a Science Agenda, Washington.

Liell, Ch.: 1999, ,Der Doppelcharakter von Gewalt: Diskursive Konstruktion und soziale Praxis', in: S. Neckel, M. Schwab-Trapp (Hg.), Ordnungen der Gewalt. Beiträge zu einer politischen Soziologie der Gewalt und des Krieges, Opladen, $33-54$

Lindenberger, Th., Lüdtke, A.: 1995, ,Einleitung: Physische Gewalt - eine Kontinuität der Moderne', in: Th. Lindenberger, A. Lüdtke (Hg.), Physische Gewalt. Studien zur Geschichte der Neuzeit, Frankfurt/Main, 7-38.

Longworth, Ph.: 1973, Die Kosaken. Legende und Geschichte, München.

Matl, J.: 1959, ,Hirtentum und Stammesverfassung als Kulturfaktor', in: W. Gülich (Hg.), Völker und Kulturen Südosteuropas. Kulturhistorische Beiträge. München, 104-123.

Matuz, J.: 1985, Das Osmanische Reich. Grundlinien seiner Geschichte, Darmstadt.

,Nasilie', in: F.A. Brokgaus, I.A. Ėfron (Hg.): 1897, Énciklopedičeskij slovar', T. $20^{\text {a }}$ (40), 638 .

Neidhardt, F.: 1986, ,Gewalt - Soziale Bedeutungen und wissenschaftliche Bestimmungen des Begriffs', in: Bundeskriminalamt (Hg.), Was ist Gewalt? Auseinandersetzungen mit einem Begriff. Bd. 1. Wiesbaden, 109-147.

Papcke, S.: 1983, ,Formen und Funktionen von Gewalt in historischer und systematischer Perspektive', in: J. Callies (Hg.), Gewalt in der Geschichte. Beiträge zur Gewaltaufklärung im Dienste des Friedens, Düsseldorf, 19-36.

Platt, K. (Hg.): 2002, Reden von Gewalt, München. 
Rauch, A.: 1991, ,Violence, brutalité et barbarie', Ethnologie française 21, 221-223.

Sieferle, R.P.: 1998, ,Einleitung', in: R.P. Sieferle, H. Breuninger (Hg.): Kulturen der Gewalt. Ritualisierung und Symbolisierung von Gewalt in der Geschichte, Frankfurt/Main, New York, 9-29.

S.M.: ,Vlast', in: F.A. Brokgaus, I.A. Ėfron (Hg.): 1892, Énciklopedičeskij slovar', T. 6 (12), 672-678.

Švecova, E.A.: 1976, Krest'janskaja vojna pod predvoditel'stvom Stepana Razina. Sbornik dokumentov, T. IV (Dopolnitel'nyj), Moskva.

Trotha, T. von: 1999, ,Formen des Krieges. Zur Typologie kriegerischer Aktionsmacht‘, in: S. Neckel, M. Schwab-Trapp (Hg.), Ordnungen der Gewalt. Beiträge zu einer politischen Soziologie der Gewalt und des Krieges, Opladen, 71-95.

Wegner, B.: 2000, ,Was kann historische Kriegsursachenforschung leisten?', in: B. Wegner (Hg.), Wie Kriege entstehen. Zum historischen Hintergrund von Staatenkonflikten, Paderborn u.a., 9-21. 



\section{Die Ansichten von Bolesław Prus zu Preußen und Deutschland (am Beispiel der Kroniki)}

\section{Einführung}

Das Bild der Deutschen und der Preußen wurde in den Jahren der Unfreiheit sowohl in der polnischen Publizistik als auch in der polnischen Literatur beständig fortgeschrieben, modifiziert, um neue Elemente ergänzt oder durch die Vergegenwärtigung bereits stereotypisierter Sichtweisen im kollektiven Gedächtnis lebendig gehalten. Bis zur Gründung des Deutschen Reiches im Jahr 1871 war das Bild der Deutschen in der polnischen Presse nicht so negativ, wie man dies erwarten könnte. Lange Zeit wurde nämlich zwischen Deutschen und Preußen unterschieden, wobei man in letzteren die Ursache allen Übels sah. Diese Differenzierungen begannen allerdings langsam zu verfließen, wenngleich es weiterhin Stimmen gab, die ihre Dankbarkeit gegenüber jenen Deutschen äußerten, die sich auf die Seite der Polen gestellt und ihren Respekt für ein Volk bekundet hatten, dessen Untergang gemeinhin für besiegelt gehalten wurde. Solche Ansichten waren freilich immer 
seltener zu vernehmen und wurden von Hunderten anderer, negativer Äußerungen nach und nach übertönt.

Ein beharrlicher Verteidiger des deutschen Volkes blieb in der Phase des polnischen Positivismus der Romanschriftsteller Bolesław Prus, der zwar die Germanisierungspolitik verurteilte, sich aber nicht davon abhalten ließ, die Deutschen als ein großes ,fleißiges, sparsames, ausdauerndes und von Grund auf tugendhaftes“ Volk anzusehen (B. Prus, in: „Kraj“, 1883, Nr. 45, S. 5-6). In seinen Kroniki (Chroniken) (B. Prus, Kroniki, Bd. 1-20, bearb. von Zygmunt Szweykowski, Warszawa 1956-1970), die er fast vierzig Jahre lang schrieb und in der präventiv zensierten Warschauer Presse publizierte, befasste er sich eingehend mit der Problematik der deutsch-polnischen Beziehungen. Den Deutschen und den mit ihnen verbundenen Fragen widmete er viele Fragmente, mitunter ganze Texte.

Die Konventionen, derer Prus sich bedient, sind vielfältig: kurze Dialoge mit fiktiven und authentischen Personen, Briefe, Interviews, Berichte oder Reiseberichte von Ausländern, polemische Auseinandersetzungen mit den Autoren von Büchern und Artikeln, Presseschauen und eigene Kommentare - dies ist nur ein Teil seiner reichen Palette von Verfahren. Die Erzählstrategien, mit denen er vielfach wichtige Probleme behandelt, bleiben jedoch im Hintergrund meiner Ausführungen. Im Mittelpunkt werden stattdessen seine Streifzüge durch Gebiete stehen, die mit Preußen, den Preußen und den Deutschen verbunden sind. Ungeachtet dieser klaren Eingrenzung empfiehlt sich eine Untergliederung der behandelten, wiederkehrenden, in ähnlicher inhaltlicher Gestalt fortgeschriebenen oder auch reinterpretierten Themenkomplexe. Die in den Kroniki enthaltenen Feuilletons zu deutschen Fragen ließen sich zu einem umfangreichen Buch mit folgenden Kapiteln zusammenfügen: die Deutschen und die Polen, die Deutschen und die Preußen, die Deutschen und andere Völker, die preußische Politik (mit den Unterkapiteln: die preußischen Vertreibungen, die Germanisierung, Bismarck und die Hakata ${ }^{1}$ ). Diese klare Untergliederung des großen Themas ,Deutschland' lässt sich allerdings nicht immer aufrechterhalten, da die entsprechenden Mikro- und Makro-Motive zu einem bunt gemusterten Gewebe verflochten sind. Die hellsten Stellen in diesem Geflecht sind die von Faszination und Begeisterung durchdrungenen Anmerkungen über die deutsche Zivilisation und die Vorzüge des deutschen Volkes. Die dunklen Farben dominieren dort, wo die Politik der preußischen Regierung und der Hakata beschrieben wird. Bismarck erscheint sowohl in negativem als auch in positivem Licht. Eine weitere Schicht bilden erzieherische Mahnungen, Empfehlungen und gute Ratschläge für die Polen. In den Diagnosen, die Prus sowohl den Deutschen als auch seinem eigenen Volk ausstellt, erfüllt er die Funktion eines Arztes, der die wunden Punkte feststellt, behandelt, prophylaktische Maßnahmen verordnet und jedem noch so zwielichtigen Patienten eine Orientierung gibt.

\section{Deutsche und Polen}

Das Bild und das Selbstbild der Deutschen, das Bild und das Selbstbild der Polen, die Eigen- und die Fremdwahrnehmung beider Seiten begleiteten die zwei Völker 
in der gesamten Zeit ihrer nicht immer harmonischen Koexistenz. Die Gegenüberstellung der nachahmungswürdigen deutschen Tugenden und der negativen Eigenschaften des polnischen Nationalcharakters war ein wiederkehrendes Element in den Bilanzen sowohl von polnischen Kritikern der eigenen Mentalität als auch von Außenstehenden. Schon im 18. Jahrhundert kamen negative Vorstellungen von Deutschen über die Polen in Umlauf: Die Polen wurden als „halbbarbarisches“ Volk bezeichnet und der Zügellosigkeit und moralischen Verdorbenheit bezichtigt. Neben ausgesprochen dunklen Bildern tauchten in der deutschen Geschichtsschreibung aber auch Aussagen auf, die die Vaterlandlandsliebe und den Mut der Polen rühmten. Heinrich Sybel schrieb den Polen Mut sowie ein ausgeprägtes Gefühl der eigenen Würde zu; zugleich jedoch hob er ihre übermäßige Emotionalität und ihren Hang zu geistiger wie sinnlicher Wollust hervor. Die Zeiten der Polen-Begeisterung, da der edle und ritterliche Pole die deutschen Vorstellungen beherrschte, gingen langsam dem Ende zu - um so unaufhaltsamer, je weiter der November-Aufstand in die Vergangenheit rückte. Wenn die Deutschen sich nach dem Jahr 1871 mit der polnischen Nation verglichen, bedienten sie sich eines Sets von charakteristischen Gegensatzpaaren. Auf der einen Seite standen Zuschreibungen des Typs: Sittlichkeit, Disziplin, eine hohe Kultur, eine humanistisch geprägte Zivilisation, begründeter Stolz, Stärke, Fleiß; auf der anderen Seite fanden sich, mit Blick auf die Polen, die negativen Entsprechungen: sittlicher Verfall, Anarchie, niedere Kultur, Barbarei, Armut, Schmutz, Zerstrittenheit. Dieses sich langsam verdunkelnde Bild, das am Ende zu einem vollkommen negativen wurde, rührte aus der Fokussierung auf die problematischen Seiten des polnischen Charakters. Ähnlicher Gegensatzpaare bediente sich Prus, der in seinen Kroniki bis zuletzt die positiven Eigenschaften der Deutschen rühmte und darin ausgesprochen konsequent war. Dementsprechend stimmte er schon im Jahr 1874 dem Verfasser eines Artikels zu, der in der Zeitschrift der russischen Liberalen, Vestnik Evropy, den deutschen Unternehmergeist lobte. Prus bemühte sich zwar um Aufhellung des dunklen Bildes, das der Publizist des Vestnik von den Polen entworfen hatte; in seinen späteren Feuilletons lieferte er jedoch eine ähnliche Charakteristik. Dabei ging es ihm weniger um die Brandmarkung der polnischen Schwächen als um das erzieherische Anliegen, die Vorzüge aufzuzeigen, an denen es dem polnischen Volk mangelte und die es von den Deutschen lernen könnte. Wenn er die ,ziellose Verausgabung von Muskel- und Geisteskraft für nichts" (Kroniki, Bd. 13, S. 28) geißelte, wenn er über die mangelnde Sparsamkeit, die Fixierung auf Äußerlichkeiten wie Kleidung spottete, dann gab er nebenbei denen Recht, die das polnische Volk auf ebensolche Weise wahrnahmen. Fasziniert von den Erfolgen der Deutschen, suchte er deren Geheimnis aufzudecken, das für ihn in guter Wirtschaftsführung, Bildung und ökonomischem Talent lag. Von den entgegengesetzten Eigenschaften war sein wenig lichtes Bild des Polen gekennzeichnet. Die wichtigsten Fragen fielen im November 1883 und lauteten: „Was sind die Deutschen und was sind die Polen?" Ohne Ironie schrieb Prus über die Deutschen: „Sie sind ein großes Volk, einer der Anführer der Zivilisation. Dieses Volk ist fleißig, sparsam, ruhig, 
ausdauernd und von Grund auf tugendhaft. Auf dem Gebiet der Kunst schuf es den gotischen Stil, brachte Beethoven, Mozart, Wagner, Schiller, Goethe hervor. Auf dem Gebiet der Wissenschaft machte es einige riesige Schritte: Man denke nur an Kant, Hegel und Schopenhauer, Kepler [...] und Leibniz. [...] Fügen wir noch ihre staatsmännischen und organisatorischen Fähigkeiten hinzu, ihre weltbeste Armee, ihre tadellosen Beamten, ihren Kaiser, [...] ihren genialen Strategen und ihren Minister Bismarck, einen der genialsten, die es jemals gab, und wir werden nur eine schwache Vorstellung von den Verdiensten, der Macht und der Würde der Deutschen haben" (Kroniki, Bd. 6, S. 366). Von dieser Hochschätzung der Vorzüge der deutschen Zivilisation rückte Prus niemals ab. Die Bewertung des eigenen Volkes fiel in dem Kontext blass aus, war das Gegenstück zum Konterfei der Deutschen. Die Polen erschienen dem Chronisten als ein ,zerschlagenes, geschwächtes Volk, das heute kaum mit der Zivilisation Schritt halten kann" (Kroniki, Bd. 6, S. 366). Die panegyrische Beschreibung der deutschen Zivilisation stellte nicht nur die Aureole in Prus' Porträt der Deutschen dar, sondern gehörte auch zu den kontinuierlich wiederkehrenden, niemals veränderten oder reinterpretierten Motiven der Kroniki. Prus' Überzeugungen wurden in dieser Hinsicht weder von den preußischen Vertreibungen noch von der Kolonialisierung, der Germanisierung, der Hakata erschüttert. Die deutsche Zivilisation bildete für ihn nicht nur das Gegenstück zur polnischen Rückständigkeit, sondern diente ihm indirekt auch dazu, der polnischen emotionalen Verdunkelung des Bildes des deutschen Volkes einen Riegel vorzuschieben. Die zivilisatorischen Errungenschaften der Deutschen stellten für Prus einen unerschütterlichen Beweis für den Besitz von Eigenschaften dar, die sowohl den Erfolg dieser Nation garantierten als auch von der Vornehmheit vieler ihrer Individuen zeugten. Zugleich halfen sie dem Schriftsteller, eine Demarkationslinie zwischen Preußen und Deutschen zu ziehen: „Wenn die Deutschen durch irgendein Wunder aus der Geschichte verschwänden, sähe die Zivilisation wie die Erde nach dem Erlöschen eines Drittels der Sonne aus. Dies sind die wahren Deutschen. Nicht die Hakatisten, die Jagd auf polnische Beete und Fibeln machen, nicht die Amtsphilosophen, die im Namen der ,Wissenschaft' die Bismarcksche Parole ,Ausrotten!' guthießen..." (Kroniki, Bd. 19, S. 136), schrieb Prus noch im Jahr 1907. Daneben setzte er sich mit der polnischen Vorliebe für Symbole auseinander. Diese verwarf er zwar nicht, bemühte sich aber, ihre übermäßig kompensatorische Funktion einzudämmen, die auf eine Verschleierung und Behinderung der alltäglichen, wenig effektvollen Arbeit für die Zukunft des Volkes hinauslief. Demgemäß trat er dafür ein, nicht immer wieder die von Deutschen zugefügten Leiden zu thematisieren, mit Kopernikus und der Schlacht bei Wien zu prahlen oder sich mit der Schlacht bei Tannenberg zu trösten (Kroniki, Bd. 19, S. 136). Insbesondere Tannenberg nahm in den Ausführungen von Prus eine symbolische Bedeutung an, da die Polen sich bei ihrer Geschichtspflege und ihrer Glorifizierung sowohl der eigenen Niederlagen als auch der Siege gern darauf beriefen. Der Chronist erinnerte an die lärmenden Umzüge der Deutschen zum Jahrestag der Schlacht von Sedan, die ganz Europa als ,geschmacklose parvenühafte Selbstdarstellung“ 
ansah. Auf diesem Hintergrund, so meinte Prus, sollte auch das Gedenken an in den jahrhundertealten Sieg bei Tannenberg zurückhaltender ausfallen (Kroniki, Bd. 19, S. 137). Eine Fortschreibung dieser Überlegungen waren seine Anmerkungen über die Neigung der Polen zum exzessiven Deklamieren und zum Schwelgen in den eigenen Träumereien (Kroniki, Bd. 20, S. 359).

\section{Deutsche und Preußen}

Auf der einen Seite standen also die edlen Deutschen mit ihren vortrefflichen Eigenschaften, ihrer großen Zivilisation und ihrem positiven Verhältnis zu den Polen, auf der anderen Seite die vom Hakatismus vergifteten Preußen, die unter „,dem Deckmantel der europäischen Aufklärung den Instinkt von Mongolen und Negern“ (Kroniki, Bd. 15, S. 121) verbargen. Mehr als einmal schrieb Prus expressiv verbis: „Etwas anderes sind die Preußen, und etwas anderes sind die Deutschen, etwas anderes ist Hartmann, der zur ,Ausrottung" rät, und etwas anderes Windhorst, der dagegen protestiert. Selbst die größten Auswüchse von Seiten der Deutschen sollten uns nicht die Augen davor verschließen, wie viele Dinge wir von ihnen lernen müssen. Lernen wir also ihre Philosophie, Musik, Ordnung, Arbeit, Sparsamkeit, und meiden wir - wie einen bösen Geist - ihre Überheblichkeit, ihren Hass und ihre Intoleranz. Wenn nämlich Weisheit und Tugend, selbst deutschen Ursprungs, in unseren Grund und Boden verpflanzt werden, werden sie reiche Früchte bringen“" (Kroniki, Bd. 8, S. 126 f.). Etwas später wiederholte er: „Immer habe ich zwei Dinge unterschieden, die im Kern ihres Wesens völlig unterschiedlich sind: die preußische Politik und die deutsche Zivilisation, die preußischen Hakatisten und die deutschen Männer der Tat" (Kroniki, Bd. 18, S. 134 f.). Bis zu den Siebzigerjahren des 19. Jahrhunderts betrachtete er aber selbst die Preußen als mannhaftes, gutes, tolerantes Volk, das die eigenen Dichter und Philosophen verehrt. Erst nach 1870 veränderte sich dieses Bild durch den ,Übermenschen' Bismarck, „nach dessen Vorbild sich alle zu formen begannen" (Kroniki, Bd. 17, S. 243). In einem umfangreichen Feuilleton, das der Problematik des Hakatismus gewidmet war, umriss Prus die unterschiedlichen Beziehungen, die die Polen mit dem deutschen Volk einerseits und der preußischen Regierung andererseits verbanden: „Mit dem deutschen Volk“, schrieb er im Jahr 1901, „waren unsere Beziehungen die bestmöglichen. Von ihnen übernahmen wir den gotischen Stil in der Architektur, die Schnitzkunst, zahlreiche Geräte, [...] die Industrie, den Handel, viele Sitten und Gebräuche [...]. Wir brauchen uns der Wahrheit nicht zu schämen: Diesem edlen Volk verdanken wir den größten Teil unserer Zivilisation" (Kroniki, Bd. 17, S. 35). Anders verhielt es sich mit den Preußen. Preußen und die Preußen assoziierte der Schriftsteller unvermeidlich mit dem eisernen Fürsten und dem Hakatismus. Er bemerkte den Hass der Preußen auf das polnische Volk, wobei selbst solche Reflektionen ihn nicht daran hinderten, seine Landsleute vor einer Ansteckung vom Hass auf die Feinde zu warnen. Als er 1908 die aktuelle Politik betrachtete, wandte er sich nicht ohne Befriedigung an jene Leser, die ihn für seine Differenzierung zwischen dem deutschen Volk und der preußischen Politik kritisiert hatten. Nicht 
alle Deutschen, so wiederholte er mit noch festerer Überzeugung, seien schließlich vom Hakatismus vergiftet (Kroniki, Bd. 19, S. 243). In derselben Chronik schrieb er einen prophetischen Satz, der sich erfüllen sollte: „Wer bürgt dafür, dass diese eitlen, zutiefst unmoralischen und rückständigen Preußen das 20. Jahrhundert überdauern werden?“ (Kroniki, Bd. 19, S. 246).

\section{Die preußische Politik (Droht den Polen die Entnationali- sierung?)}

Die Germanisierungsbestrebungen sah Prus sehr kritisch und verurteilte sie als moralisch verwerflich. Seine Meinung, dass der deutsche Staat mächtig, doch von einer Krankheit verzehrt sei, äußerte er viele Male. Skeptisch beurteilte er die Rhetorik deutscher Publizisten und Politiker, die lautstark ihren Verzicht auf eine Entnationalisierung beteuerten und diese raffiniert durch die Notwendigkeit einer Bindung der Polen an den Staat ersetzten. Solche Deklarationen zogen die Unterdrückung der polnischen Sprache, die preußischen Vertreibungen und die hakatistische Propaganda nach sich. Feste Bestandteile von Prus' Analyse der Politik der Teilungsmacht waren einerseits die Besänftigung der polnischen Ängste vor einer Entnationalisierung, andererseits die Warnung vor Intoleranz gegenüber der deutschen Sprache wie auch vor der Neigung, alle Deutschen gleichermaßen für die Vorgehensweise der Regierung verantwortlich zu machen. Beständig bemühte er sich, die polnischen Emotionen zu dämpfen und seine Landsleute davon zu überzeugen, dass niemand gegen seinen Willen entnationalisiert werden könne. Selbst vor dem Hintergrund zunehmender Germanisierungbestrebungen blieb er seiner fast obsessiven Neigung treu, die Deutschen als edel und gerecht darzustellen.

Wenn er sich zu dem Edikt äußerte, das die Polen ohne preußische Staatsbürgerschaft zum Verlassen des deutschen Staatsgebietes anwies, versuchte er die Wogen zu glätten und die polnische Gesellschaft von den Vergeltungswünschen abzubringen, die ihren Niederschlag in der Presse fanden. Er war nämlich fest davon überzeugt, dass ,Staaten, die auf Massenvertreibungen zurückgreifen, krank sind, [...] und dass das System der Abschiebungen diese Krankheit nicht heilt, sondern verschärft $[\ldots]$, dass schließlich die Ausgewiesenen nicht nur nicht untergehen, sondern tatkräftige neue Generationen hervorbringen und gewöhnlich ein Segen für die Regionen sind, in denen sie sich niederlassen" (Kroniki, Bd. 8, S. 172). Bei dieser Gelegenheit kritisierte er die deutsche Idee eines homogenen Nationalstaates, die keinen Raum für andere Sprachen und Kulturen ließ. Er schrieb: „Die Deutschen wollen ein monotones Einerlei einführen, und so stolpern sie über die Torheit" (Kroniki, Bd. 8, S. 172). Seine Fortführung fand dieser Gedanke in den Ansichten des fiktiven Helden eines des Feuilletons über den eisernen Baumeister der deutschen Großmacht, wobei diese Ansichten den aufrichtigen Überzeugungen des polnischen Schriftstellers über Bismarcks Absichten gegenüber dem polnischen Volk entsprachen: „Der Fürst möchte einen Staat aufbauen, der wie ein Denkmal ist: aus einem Stück, oder zumindest aus einem Material. Deshalb beseitigt er 
alles, was aus anderem Material ist. Er beginnt mit den Polen, dann geht er zu den Franzosen und Dänen über und schließlich [...] zum Rauswurf der Hannoveraner, Sachsen und Bayern..." (Kroniki, Bd. 9, S. 40). Noch einige Jahre später erinnerte er daran, dass die preußischen Vertreibungen ein Kampf gegen die Gesetze der Natur und pure Arroganz gewesen seien (Kroniki, Bd. 10, S. 161).

Einer antipolnischen Propaganda und Politik bezichtigte der Schriftsteller vor allem die Hakatisten, die er aber konsequent vom Rest des deutschen Volkes unterschied. Er war der Ansicht, dass dieser Verein ein krankhaftes Phänomen inmitten der Deutschen sei und dass der Hass seiner Mitglieder nicht nur eine gesellschaftliche, sondern eine mentale Krankheit darstelle. Ein gewisser Trost für die Polen sollte die Devise sein, dass „ungerechtfertigte Verfolgung die Menschen und Völker nur abhärtet"; damit einher ging die Warnung vor einer Gleichsetzung aller Deutschen mit den Hakatisten (Kroniki, Bd. 15, S. 66). Dem Schriftsteller war daran gelegen, dass das positive Bild des großen deutschen Volkes, das er aus tiefer Überzeugung geschaffen hatte, keinen Sprung, keinen noch so kleinen Riss erhielt, der immer drohte, wenn die Bewertung der antipolnischen Politik ins Spiel kam. Gebetsmühlenartig kehrten daher seine Verweise auf „die große Zahl edler Menschen unter den Deutschen“" wieder. Die Hakatisten - „habgierige, ehrgeizige und ordinäre Egoisten" (Kroniki, Bd. 15, S. 119) - betrachtete der Chronist als die geistigen Nachfahren Bismarcks, als einen Tumor, der auf dem Organismus des großen und sympathischen Volkes gewachsen sei (Kroniki, Bd. 15, S. 217). Noch im Jahr 1904 bezeichnete er den Hakatismus als schwere moralische Krankheit, die den deutschen Staat befallen habe (Kroniki, Bd. 18, S. 21), als eine Erkrankung, die „mit Falschheit und Hass die Seele des eigenen Volkes vergiftet“ (Kroniki, Bd. 18, S. 23).

\section{Bismarck}

Großen Raum nahm in den Ausführungen von Prus der Baumeister des Deutschen Reiches, Fürst Bismarck ein. Der Chronist analysierte seine Politik, besprach die Charakterzüge des Kanzlers, deutete seine Persönlichkeit. Der enge Zusammenhang zwischen den Vorgehensweisen des Fürsten und seinen privaten Vorlieben kommt in den folgenden Sätzen zum Ausdruck: „Er wollte, dass die Menschheit sich der gotischen Schrift bediene, weil er selbst eine Schwäche für die Gotik hatte; er wollte, dass sie Deutsch spreche, weil er selbst Deutsch sprach" (Kroniki, Bd. 10, S. 165). „Ein genialer Diplomat", „der beste Führer", „ein Mann aus Blut und Eisen“, ,einer der größten Menschen der Geschichte“, ,,er zählt zu den Größten, weil er die größte Leistung vollbrachte, zu der ein Mensch sich aufschwingen kann ... er schuf einen Staat“ (Kroniki, Bd. 12, S. 170), „ein Kürassier mit Löwengesicht und Diskantstimme“, ,ein großer Fischer", „ein Held von der Pickelhaube bis zu den Absätzen“ (Kroniki, Bd. 12, S. 172) - dies sind nur einige der Formulierungen, mit denen Prus den Baumeister des Deutschen Reiches in seinen Chroniken bedachte. Die genaueste und gelungenste Charakteristik, die nicht frei von ironischen Akzenten ist, erstellte er im Jahr der Entlassung des Kanzlers 
(1890). Diese glänzend geschriebene Biographie, die zwischen Bewunderung für den „Chefingenieur" der Deutschen und Verurteilung seiner menschlichen Schwächen oszillierte, vervollständigte das über Jahre geschaffene und ergänzte Konterfei der Deutschen, ihres Staates, ihrer Vorzüge und Politik: „Vom Giebel bis zum Kellergeschoss gab es in diesem Gebäude keine Säule, die nicht nach seinem Plan aufgerichtet worden war, keinen Balken, der nicht unter seinen Augen befestigt worden war, keinen unterirdischen Gang unter fremde Häuser, den er nicht erdacht hatte. Die Kriege mit Dänemark, Österreich, Frankreich, die Bündnisse mit Italien und den deutschen Kleinstaaten, die Neutralität Frankreichs im Jahr 1866 und Österreichs im Jahr 1870, die Proklamation in Versailles, und daneben: die Hetzpresse, Agenten und Provokateure, individuelle und kollektive Verfolgungen, das offenkundige und unmerkliche Belügen der ganzen Welt - dies alles tat Fürst Bismarck, um einen Staat zu bauen“ (Kroniki, Bd. 12, S. 171). Bei der Gelegenheit versäumte der Chronist es nicht, erneut die Vorzüge des deutschen Volkes zu loben, die der Genialität des Kanzlers bei seinen Vorhaben förderlich gewesen seien. Für eine der hervorstechenden Eigenschaften von Bismarcks scharfem Geist hielt er dessen Fähigkeit, die Zukunft vorherzusehen. Doch machte Prus auch keinen Hehl aus der Rücksichtslosigkeit des Fürsten: Bismarck, und nicht Darwin, war seiner Ansicht nach der eigentliche Schöpfer einer auf Kampf basierenden Moral. Zur Untermauerung dieser These zitierte der Schriftsteller einige der bekanntesten, wenngleich wenig rühmlichen Äußerungen von Bismarck: „Er war es doch“, schrieb Prus, „der anwies, den Feind zu würgen, bis seine Lippen bleich werden“, er nannte sich „einen Mann von Blut und Eisen“ (Kroniki, Bd. 12, S. 240). In Form von Fußnoten, kleinen Digressionen und beiläufig eingeflochtenen Anmerkungen vervollständigte der Autor dieses Bild. Im Jahr 1894 erinnerte er zum Beispiel an Bismarcks Klagen über die zu wenig blutdürstigen Instinkte des deutschen Soldaten (Kroniki, Bd. 14, S. 379). Drei Jahre später bot er eine metaphorische Darstellung der Errichtung eines homogenen deutschen Staates: Der Fürst habe unablässig die Risse zwischen den Kleinstaaten übertüncht (Kroniki, Bd. 15, S. 210). An anderer Stelle zeichnete er ein persönliches Porträt des Menschen Bismarck: Der eiserne Kanzler war anscheinend im Essen maßlos, „rauchte ständig, las nicht viel, besaß offenbar nur eine mäßige Bildung, war aber zu seinen Studentenzeiten ein berühmter Duellant, später war er ein leidenschaftlicher Bärenjäger, und immer trank er, begierig wie ein Schwamm, die stärksten Getränke, zum Beispiel einen Mix aus Porter und Champagner" (Kroniki, Bd. 15, S. 387). Aus der Sicht von Prus war das ausgesprochen kämpferische Naturell von Bismarck ein Grund für die fortwährenden Unruhen und Verfolgungen innerhalb des deutschen Staates.

Prus' Ausführungen zum Thema „Preußen, die Preußen und die Deutschen` gleichen den Stellungnahmen eines politischen Kommentators, der seine Urteile vom Standpunkt eines außerhalb der Teilungsgebiete befindlichen Menschen formuliert, eines Realisten, der - befreit von jenen Widrigkeiten des Alltags, mit denen die 
Bewohner des wilhelminischen Reichs zu kämpfen hatten - aus der Distanz auf die deutsch-polnische Frage schaut und noch in der Analyse von Details Synthesen vollzieht. Seine Beziehung zu Preußen und Deutschland lässt sich auf die Formel bringen: preußischer Imperialismus, Bürokratie und Militarismus - nein; deutsche Zivilisation - ja. Mit diesen Überzeugungen ging die unablässige Sorge um die tagtäglich auf die Probe gestellte polnische Toleranz einher.

\section{Anmerkungen}

1 ,Hakata' war die polnische Bezeichnung für den Ostmarkenverein, nach den Initialen seiner Gründer Hannemann, Kennemann und Thiedemann (Anm. d. Übers.).

Übersetzung aus dem Polnischen: Dörte Lütvogt 



\section{Ambivalente Aspekte des assertiven sozialen Ver- haltens, ausgedrückt durch türkische Lehnwörter im Bulgarischen}

\section{Die Ambivalenz als psychologisches Phänomen}

Das Wort Ambivalenz gehört zu denjenigen, bei denen genau bekannt ist, von wem sie geprägt wurden. Der „Vater“ des Wortes, der Schweizer Psychiater Eugen Bleuler (1857-1939), führte es in einem Artikel über emotiv-affektive Störungen bei schizophrenen Patienten ein: „Das Nebeneinander von Lachen und Weinen ist ein Teilsymptom der schizophrenen Ambivalenz" (Bleuler 1930, 382). Das krankhafte gleichzeitige Bestehen entgegengesetzter Gefühle ist der pathologische Extremfall eines Phänomens, das sich auch im täglichen Leben bei normalen Menschen zeigt.

Beim Phänomen der ambivalenten Emotion macht Weigert $(1991,88)$ folgende Unterscheidung: 
(i) Ambivalenz äußert sich im Erleben widersprüchlicher Gefühle, in der vagen Empfindung, in zwei entgegengesetzte Richtungen gerissen zu werden. Die Person ist nicht imstande, ihre Gefühle zu artikulieren, und diese bleiben in diesem Sinne vorsprachlicher Natur. Gleichzeitig ist die Person gehindert, eine Verhaltensentscheidung zu treffen, und das führt bei ihr $\mathrm{zu}$ innerer Unruhe und Unsicherheit.

(ii) Von Ambivalenz kann auch dann gesprochen werden, wenn nur die positive Seite der Emotion eine Bezeichnung findet. Der negative Pol der Emotion umgibt den positiven wie eine Aura und tritt als unausgesprochene Angst, als innere Unruhe zutage. Weigert führt das Beispiel des Verlobten ein, der schwören kann, dass er seine zukünftige Ehefrau unsterblich liebt, der aber hin und wieder unerklärliche Bauchschmerzen bekommt, die er weder sich noch anderen gestehen will.

(iii) Ambivalenz ist ebenfalls dann gegeben, wenn die Person die von ihr empfundenen widersprüchlichen Gefühle verbal benennen kann und sich im selben Moment von ihnen zu entgegengesetzten Entscheidungen oder Verhaltensweisen getrieben fühlt. Nach Weigert ist das Ambivalenz im eigentlichen Sinne. Bezeichnungen für diese Art von Ambivalenz sind im Deutschen Wörter wie Hassliebe und Schadenfreude.

\section{Innere Struktur der ambivalenten Emotionen}

Wörter wie Hassliebe, Zwangsbeglückung und besonders Schadenfreude sind in der Fachliteratur zu Emotion und Ambivalenz populär geworden, weil sie explizit das gleichzeitige Vorhandensein widersprüchlicher Gefühlen ausdrücken. In diesem Sinne sind Wörter wie diese als deskriptiv ambivalent zu bezeichnen. Es gibt aber auch ambivalente Wörter, die eher als expressiv ambivalent bezeichnet werden können, weil ihre innere Form ihre Ambivalenz nicht zum Ausdruck bringt. Dazu gehören eine Reihe türkischer Lehnwörter im Bulgarischen, wie z. В. сербез, ербаn, келеш, курназ, die unten näher behandelt werden sollen.

Obwohl Wörter wie Hassliebe, Zwangsbeglückung und Schadenfreude deskriptiv und explizit sind, zeigt eine genauere Analyse der jeweiligen Wortkomponenten, dass sie keinesfalls automatisch zwei Gefühlspole auf derselben emotionalen Skala bezeichnen (wie z.B. Hass und Liebe). Man kann m. a. W. nicht behaupten, dass Schaden und Freude zwei diametral entgegengesetzte Emotionen im Sinne der Sprachkonvention benennen. Diese Besonderheit macht eine genauere Beschreibung der Struktur ambivalenter Emotionen notwendig. In der Literatur (s. den Überblick bei Hascher 1994, 177-183) wird im allgemeinen von zwei Möglichkeiten der Modellierung der Struktur komplexer Emotionen gesprochen.

Laut dem ersten Modell entstehen bei ambivalenten Emotionen im emotionalaffektiven Raum zwei unabhängige Skalen, z. B. bei Schadenfreude: Schaden Nutzen; Freude - Trauer. Das Ergebnis dieser zweidimensionalen Aktivierung 
äußert sich sprachlich in einer Kombination aus dem negativen Pol der ersten Skala und dem positiven Pol der zweiten Skala. Das gebildete Kompositum täuscht bei der Annahme, es handle sich nur um eine einzige Skala.

Laut dem zweiten Modell werden die verschiedenen Skalen nicht völlig unabhängig voneinander aktiviert, d.h. sie stehen im emotional-affektiven Raum orthogonal zueinander. In diesem Fall wird die eine Skala von der anderen dominiert und von ihr eingeschlossen. Bei Schadenfreude scheint die Skala Schaden - Nutzen die Skala Freude - Trauer zu dominieren und zu umfassen. Im Unterschied zum ersten Modell berücksichtigt das zweite sowohl die Kombinierbarkeit sprachlicher Mittel zur Bezeichnung von Emotionen als auch das Zusammenfügen von Emotionen zu ambivalenten Emotionen.

Die Kombinierbarkeit von verschiedenen Komponenten oder Aspekten der ambivalenten Emotion hat jedoch u. E. eine innere Struktur, die sich nicht geometrisch darstellen lässt. Wie Charles Osgood (cf. Osgood et al. 1957) bereits vor 50 Jahren festgestellt hat, können emotional-affektiv entgegengesetzte oder inkompatible Wörter miteinander verbunden werden:

(1) honest prostitute

(2) lazy athlete

Jede dieser Wortkombinationen lässt je zwei entgegengesetzte Interpretationen zu:

(1) a. "honest but prostitute“

b. "prostitute but honest"

(2) a. "lazy but athlete“

b. ,athlete but lazy“

Der Vergleich dieser Beispiele zeigt, dass die Wortkombinationen (1)a und (2)b als ambivalent zu bewerten sind (bzw. Schadenfreude bewirken), während (1)b und (2)a eher eine abschwächende Nuance enthalten. Die Beispiele zeugen auch davon, dass die ambivalente Bedeutung nicht nur aus Komponenten besteht, sondern auch eine spezifische Struktur aufweist, die vereinfachend folgenderweise beschrieben werden kann:

1. sich als gut zu präsentieren versucht (honest),

2. erweist sich als schlecht (prostitute),

3. sogar als dubios (honest prostitute), weil er/sie/es nicht nur schlecht ist, sondern zu täuschen versucht und sich als besser präsentiert, als er/sie/es ist. 


\section{Ambiguität, Polysemie, Homonymie, Antonymie, Synony- mie und die Struktur der ambivalenten Bedeutung - ein Bei- spiel}

Wie bereits ausgeführt, hängt die genauere Identifizierung der ambivalenten Emotionen zumindest teilweise von den sprachlichen Ausdrucksmöglichkeiten ab, vor allem von der Antonymie, aber auch von anderen sprachlichen Phänomenen wie Polysemie, Ambiguität, Synonymie und Homonymie. Wir wollen deshalb im folgenden etwas näher auf die Relation zwischen ambivalenter Emotion und Sprache eingehen.

Unter Ambiguität wird in der Linguistik die Eigenschaft von Ausdrücken natürlicher Sprachen verstanden, mehrere Interpretationen zu erlauben. Je nach dem, ob Ambiguität auf der Verwendung spezieller Lexeme oder der syntaktischen Struktur von mehrgliedrigen Ausdrücken beruht, unterscheidet man zwischen lexikalischer und syntaktischer (struktureller) Ambiguität.

Die lexikalische Ambiguität erscheint als Polysemie oder Homonymie. Von Polysemie (= Mehrfachbedeutung) wird bekanntlich dann gesprochen, wenn ein und dasselbe Lexemmit identischer Form verschiedene Inhalte (oder Bedeutungen) zusammenfasst. Dabei lassen sich die verschiedenen Bedeutungen etymologisch auf eine gemeinsame Quelle zurückverfolgen.

Homonymie besteht bei Wörtern gleicher Laut- und Schreibweise, die aber dennoch unterschiedliche Bedeutungen haben. Wenn man die Ursprünge dieser Wörter und deren Bedeutungen zurückverfolgt, stößt man auf unterschiedliche Quellen.

Schließlich ist ein Wort ein Antonym, wenn es die gegenteilige Bedeutung eines anderen Wortes beinhaltet. Im einfachsten Fall stammen die beiden sprachlichen Ausdrücke aus demselben Bereich.

Die Komplexität der Beziehungen zwischen Ambiguität, Polysemie, Homonymie und Antonymie soll anhand des türkischen Wortes persischer Herkunft keleş veranschaulicht werden, das als Lehnwort auch zum bulgarischen Wortschatz gehört.

Keles 1. хубав, красив, представителен; 2. крастав, плешив, келяв (Романски 1952);

Keles юнак, храбрец; хубав, красив, представителен; крастав, плешив (Янчев 1992);

Keleş is. ve s. юнак, храбрец; хубав, красив, представителен; нар. крастав, плешив (Димитрова 2004);

Keleş 1. (dial.) schön, hübsch, nett, gut aussehend; 2. (abusiv) s. kel [2. grindköpfig; 3. kahle Stelle am Kopf; 4. kahlköpfig, haarlos ... ]; 3. mutig, tapfer; 4. dumm, idiotisch (Steuerwald 1988);

Keleş handsome; attractive; ringswormy, bald; dirty (Hony, Iz 1984); 


\begin{tabular}{|c|c|}
\hline Keleşlık & handsomeness (Hony, Iz 1984); \\
\hline Keleş & (partly) bald; bald-head; (fig.) idiot (Moran 1971); \\
\hline Keleşlık & (fig.) idiocy (Moran 1971); \\
\hline Keleş$^{1}$ & $\begin{array}{l}\text { 1. покрытый коростой (паршой); 2. плешивый, лысый; 3. идиот } \\
\text { (Баскаков и др. 1977); }\end{array}$ \\
\hline
\end{tabular}

Keleş ${ }^{2}$ (диал.) 1. красивый, пригожий; 2. смелый, отважный (Баскаков и др. 1977).

Die Durchsicht der von uns benutzten zweisprachigen Wörterbücher mit Türkisch als einer Sprache legt die Vermutung nahe, dass es auch in der einsprachigen türkischen Lexikographie nicht einfach war, die zwei entgegengesetzten Linien in der Bedeutung des Wortes in Relation zueinander zu bringen. Denn, was heißt eigentlich keleş - ,haarloser Schönling', ,mutiger Idiot', , attraktiver Knirps' oder ,hübscher Nichtsnutz'? Derartige Kombinationen von semantischen Merkmalen erscheinen in der Grundbedeutung als recht unglaubwürdig, deshalb stellt sich die Frage, ob sich keleş lexikographisch adäquater als polysemes oder homonymes Wort darstellen lässt. In fast allen zitierten Wörterbuchartikeln aus zweisprachigen Wörterbüchern mit Türkisch wird das Wort keleş als polysemantisch präsentiert, obwohl die einzige Gemeinsamkeit zwischen den zwei (bei Steuerwald sogar vier) Bedeutungen des Lexems in ihrer Gegensätzlichkeit besteht. Nur im türkisch-russischen Wörterbuch von Baskakov et al. (1977) wird keleş als homonym aufgefasst. Hier wird sozusagen die Nabelschnur zwischen den womöglich doch mysteriös zusammenhängenden Bedeutungselementen durchschnitten. Dabei geht allerdings der „Reiz" der Bedeutungsstruktur des Wortes verloren, weil die entgegengesetzten Bedeutungen zwei in ihrer Form zufällig identischen Wörtern zugeordnet werden. Es fällt ebenfalls auf, dass bei Moran (1971) die negative Komponente der Bedeutung von keleş Oberhand gewinnt - ,Kahlkopf', ,Idiot‘ .

Im Bulgarischen durchläuft das Wort seine eigene Entwicklung.

Келеш мальк на ръст, на бой (Геров 1975);

,klein von Wuchs, von Statur';

Келеш (тур.) 1. Келяв човек; 2. Прен. Презр. Презрян, нищожен човек (РСБКЕ 1959);

,(Türk) 1. erbärmlicher Mensch 2. abwertend, verächtlich verachtungswürdiger, nichtiger Mensch';

Келеш тур. 1. Прозвище на келяв; 2. презр. Неразбран, опърничав и незначителен човек Om такгв келеш ли се плашиш? (Андрейчин и др. 1976);

, Türk 1. Spottname für einen erbärmlichen Menschen; 2. verächtlich starrköpfiger, dickköpfiger, nichtiger Mensch Hast du Angst vor so einem Taugenichts?'; 
Келеш 1. Разг. Грубо. Обикновено за мъж - долен, презрян човек; негодник, никаквик; 2. Разг. Презр. Обикн. в обръщение. Мъж или младеж, който е или изглежда неопитен, негоден за нещо, но е самоуверен, наперен, дързък или своенравен, вироглав; 3. Рядко. Ирон. За съобразителен, ловък, оправен младеж; 4. Остар. Келяв, плешив човек; 5. Остар и диал. Дребен, нисък, човек (РБЕ 1977);

,1. umg, grob gewöhnlich von einem Mann - niedriger, verachtenswerter Mensch; Taugenichts, Nichtsnutz; 2. umgangssprachlich, verächtlich, oft als Anrede Mann oder Jugendlicher, der unerfahren ist oder so aussieht, der zu nichts taugt und trotzdem überheblich, selbstbewusst, dreist oder eigensinnig, querköpfig ist; 3. selten, ironisch pfiffiger, wendiger, geschickter junger Mann; 4. veraltet unansehnlicher, glatzköpfiger Mensch; 5. veraltet, dialektal; kleinwüchsiger Mann';

Келешлгк Разг. Поведение, присъщо на келеш (във 2 значение) - перчене, своенравие и под. (РБЕ 1977);

, umg typisches Verhalten für einen келеш (2.) - Angeberei; Eigensinn u. ä.';

Келеш Разг. 1. Презрян, долен човек; 2. Неопитен, незрял човек; 3. Дребен, нисък човек; 4. Остар. Плешив човек (Буров 2000). , umg 1. verachteter, niederträchtiger Mensch; 2. unerfahrener, unreifer Mensch; 3. kleinwüchsiger Mensch; 4. veraltet glatzköpfiger Mensch'.

In den untersuchten einsprachigen bulgarischen Wörterbüchern wird келеш als polysemes Wort dargestellt. Im Vergleich zum Türkischen ist allerdings eine gewisse Bedeutungsveränderung zu beobachten. Die Bedeutung ,Idiot' ist geschwunden. Als selten und archaisch ist die wahrscheinlich ursprüngliche Bedeutung des Wortes im Bulgarischen erhalten geblieben - ,glatzköpfiger kleinwüchsiger Mensch ${ }^{6}, \mathrm{~d}$. h. körperlich unansehnlich und dazu noch kahlköpfig und krank. Die Bedeutungen ,verachtenswerter, niedriger Mensch' und vor allem ,unerfahrener, unreifer Mensch haben sich auf bulgarischem Boden zusätzlich entwickelt, offensichtlich als Folge einer metaphorischen Übertragung äußerer körperlicher Merkmale auf deren charakterologische Äquivalente. Es ist eine Betonung der negativen Konnotationen der Bedeutung zu verzeichnen, die auch mit einer Veränderung des kognitiven Gehalts des Wortes verbunden ist.

Vor diesem Hintergrund fällt besonders auf, dass келеш im Bulgarischen auch als Admirativ verwendet werden kann: „3. selten, ironisch pfiffiger, wendiger, geschickter junger Mann" (РБЕ 1977). Einerseits beinhaltet diese Bedeutung Neid, andererseits ist sie explizit als ironisch markiert, d.h. es geht um ironischen Neid oder neidische Ironie. Dabei kann hier nicht von einer Neutralisierung der Ambivalenz und von der Aktualisierung nur des positiven Bedeutungsaspekts 
gesprochen werden. Vielmehr handelt es sich um eine besondere Umkehrung der Pole und auch um eine Umschichtung der Bedeutungskomponenten 1., 2. und 4.

In keinem der von uns untersuchten zweisprachigen Wörterbücher mit Bulgarisch ist es gelungen, die ambivalenten Aspekte der Bedeutung von bg. келеш wiederzugeben:

Келеш 1. conceited puppy; squirt; 2. (for a child) brat (Атанасова и др. 1993);

Келешлгк (coll.) showing off; empty bragging (Grannes et al. 2002);

Keлеш $\quad$ umg übertr räudiger Hund (Walter \& Endler 1994);

Келеш итg реј starsinniger Mensch, Starrkopf (Петков и др. 2001);

Келешлгк итg реј Starrsinn; om aus Starrsinn (Петков и др. 2001).

Zum Vergleich soll das Wörterbuch der Synonymie und Antonymie von Bulitta und Bulitta (1999) zitiert werden, das folgende Antonyme bzw. Synonyme des klassischen deutschen ambivalenten Wortes Schadenfreude angibt:

Antonyme: Erbarmen, Anteil(-nahme), Mitleid, Bedauern, Mitgefühl, Wohlwollen, Mitempfinden, Sympathie, Teilnahme;

Synonyme: Übelwollen, Bosheit, Rachsucht, boshafte Freude.

Es ist nicht zu übersehen, dass die aufgezählten Antonyme eindeutig positiv sind, während die Synonyme mit Ausnahme der Wortverbindung boshafte Freude (die ähnlich wie Schadenfreude selbst als ambivalent zu bestimmen ist) eindeutig negativ konnotieren. In Analogie dazu wären Liebe und Hass entsprechend Synonym und Antonym von Hassliebe, was offensichtlich nicht stimmt. M. a. W., es ist sehr schwierig, ohne weiteres sowohl Synonyme als auch Antonyme für ambivalente Wörter zu finden. Auch das oben angeführte Beispiel келеш zeigt, dass der Gegensatz zur ambivalenten Bedeutung nicht eindeutig positiv ausfällt, sondern eine viel komplexere semantische Struktur aufweist, die wir als ambivalenten Admirativ bezeichnen wollen.

\section{Assertives Verhalten, ausgedrückt durch einige türkische Lehnwörter im Bulgarischen}

Es ist bekannt, dass im Bereich des sozialen Verhaltens eine und dieselbe menschliche Handlung in der sozialen Interaktion gegensätzlich beurteilt werden kann nämlich positiv oder negativ. Dass betrifft vor allem Handlungen, die als aggressiv, assertiv und/oder vernachlässigend gegenüber anderen Interaktionspartnern interpretiert werden können. Weniger bewusst ist, dass es möglich ist, beide Einstellungen gleichzeitig zu haben, zumal es Wörter gibt, die das Ausdruckspotential besitzen, um diese widersprüchliche Kombination von Einstellungen „komplex“ zu erfassen. Die Fachliteratur hat sich bisher nicht mit der Tatsache befasst, dass Am- 
bivalenz infolge des Sprach- und Kulturkontakts aus einer Sprache in eine andere übernommen und modifiziert werden kann. Insbesondere wenn die Kultur, aus der Wörter entlehnt werden, als feindlich bzw. konträr empfunden wird, neigt die rezipierende Kultur zu Entlehnungen mit negativer oder ambivalenter Bedeutung. Das war der Fall mit vielen Lehnwörtern aus der osmanisch-türkischen Kultur, die in die bulgarische Sprache eingedrungen sind. Das pejorative Potential der türkischen Lehnwörter im Bulgarischen wurde bereits mehrfach thematisiert (siehe z. В. Мирчев 1952). Bisher unberücksichtigt geblieben sind jedoch die kulturellen, sozialen und individualpsychologischen Grundlagen dieses Phänomens. Hier kann nicht auf die komplexe Problematik der Kulturkonflikte und auf die Möglichkeiten, diese in der Sprache zu ,kodieren“, eingegangen werden. Es sei nur bemerkt, dass auch lange nach der Lösung eines Kulturkonflikts dessen Merkzeichen in der Sprache bestehenbleiben und dabei interessante Modifizierungen durchlaufen können. Dies betrifft eine Reihe von türkischen Lehnwörtern im Bulgarischen. Um diese Dynamik zu veranschaulichen, werden im folgenden die Bedeutungen von drei weiteren türkischen Lehnwörtern analysiert, wobei zum Vergleich zweisprachige Wörterbücher mit Türkisch und Bulgarisch sowie verschiedene Wörterbücher der bulgarischen Sprache herangezogen wurden.

\section{1. Курназ}

Türkisch - Bulgarisch, Deutsch, Russisch

Kurnaz хитър, лукав (Янчев 1992);

Kurnazlık хитрост, лукавство (Янчев 1992);

Kurnaz s. хитър, лукав (Димитрова 2004);

Kurnazlık is. хитрост, хитрина, лукавство (Димитрова 2004);

Kurnaz pfiffig, listig, schlau, gewitzt, gerissen (Steuerwald 1988);

Kurnaz хитрый, лукавый (Баскаков и др. 1973);

Kurnazlık хитрость, лукавство, плутовство (Баскаков и др. 1973).

Bulgarisch - Deutsch, Englisch

Курназ $\quad$ unveränd umg dreist, frech (Петков и др. 2001);

Курназ indecl adj (coll.) bold, cheeky; adv boldly, cheekily (Granes et al. 2002);

Курназ cocky, bumptuous, uppish, pert, perky, fresh, cheeky (Атанасова и др. 1993); 
Курназлбк cockiness, perkiness, cheek; продавам show off, be foolhardy (Атанасова и др. 1993).

$$
\text { Bulgarisch - verschiedene Deutungen }
$$

Курназ разгов. Горделив, надут, дързък (БЕР 1971);

, umg überheblich, eingebildet, dreist';

Курназлгк гордеене, перчене (БЕР 1971);

,Überheblichkeit, Prahlerei“;

Курназя се гордея се (БЕР 1971);

,überheblich sein';

Курназим (село Доброславци, Софийско) показвам се смел (БЕР 1971);

ce

Курназ неизм. прил. Разг. смел, дързък, решителен, наперен; (РБЕ 1977);

, unveränd Adj umg kühn, dreist, zielbewusst, unbeirrbar';

Курназ нареч. Разг. смело, дръзко, решително, наперено (РБЕ 1977); , $A d v$ umg kühn, dreist, zielbewusst, unbeirrt';

Курназене Р Разг. Отгл.същ. перчене, големеене (РБЕ 1977); , umg Verbalsubst Prahlerei, Wichtigtuerei';

Курназлия неизм. прил. Разг. Смел, решителен, дързък, наперен; курназ (РБE 1977);

, unveränd Adj umg kühn, zielbewusst, dreist, unbeirrt';

Курназлбк Разг. 1. Излишно, ненужно перчене или противопоставяне пред някого или с нещо, обикн. от инат; 2. само мн.ч. Буйни, леки, обикн. младежки постъпки; щуротии; $\diamond$ продавам Разг. Неодобр. Върша нещо, за да се покажа пред другите като смел, силен (РБЕ 1977);

, umg 1. unnötige Angeberei oder Widerstand gegen jdn oder etw, meistens aus Trotz ; 2. nur Pl törichte Streiche;

Курназя се несв. непрех. Разг. големея се, перча се (РБЕ 1977);

, imperfektiv intr umg überheblich sein, prahlen';

Курназ горделив, надут, дързък (Андрейчин и др. 1995);

,überheblich, eingebildet, dreist‘. 
Redewendungen mit курназ im Bulgarischen

(3) Курназ сбм и аз, че сбм на власт. [имам самочувствие, самонадеян съм];

,selbstbewusst, selbstsicher sein';

(4) Килна чалма над чело - да изглежда по-курназ. [оперен, наперен];

,aufgeplustert, wichtigtuerisch";

(5) Я виж, дребен като пале, пгк ... курназ ... [наперен]; ,wichtigtuerisch';

(6) Виждал сгмм и по-курназ от теб (а сетне омекват като помук и молят за милост). [самонадеян];

,selbstsicher';

(7) Много е курназ тази, но няма кво да бие човек по нея. [показвам характер];

,Charakter bekennen";

(8) За курназлгк [(цел) за перчене, за да се перча]; ,(Ziel) um anzugeben';

(9) От курназлгк [(причина, основание) от инат, от самонадеяно перчене];

,(Grund) aus Trotz, aus Protzerei';

Вбрша курназлбии [правя лудории, щуротии за показ пред някого];

,demonstrativ Dummheiten treiben“;

Курназя се [перча се със своето самочувствие];

,angeben, selbstsicher sein'.

Der Vergleich des semantischen Gehalts von kurnaz/курназ im Türkischen und im Bulgarischen zeigt Änderungen im kognitiven Gehalt und in der emotionalaffektiven Einschätzung dieses Wortes. Heute wird курназ im Bulgarischen am häufigsten in der Bedeutung демонстрирам самонадеяност, перча се с характер и/или самочувствие пред другите (,Selbstgefälligkeit demonstrieren, sich aufplustern') verwendet. 


\section{2. Ербап}

Türkisch - Bulgarisch, Russisch, Englisch, Deutsch

Erbap който знае, компетентен, спец (Романски 1952);

Erbap познавач, майстор (Янчев 1992);

Erbap, -bı is. познавачи; майстори; компетентни лица; специалисти (Димитрова 2004);

Erbap 1. компетентные, сведующие люди; специалисты; 2. специалист; знаток; мастер; знающий свое дело (Баскаков и др. 1977);

Erbap $\quad$ expert (Hony, Iz 1984);

Erbap 1. Sachkundig, Fachmann; 2. wer mit etwas beschäftigt ist oder in e-m best. Beruf tätig ist; besitzend, innehabend (Steuerwald 1988).

Bulgarisch - Deutsch, Englisch,

Epбan umg findig, gewitzt, pfiffig (Walter, Endler 1994).

Epбаn unveränd umg $\mathbf{1}$ (способен) tüchtig, geschickt, erfahren $\mathbf{2}$ (смел) kühn, dreist, hemmungslos $\mathbf{3}$ (подходящ) alt geeignet (Петков, Гутшмидт, Игла 2001);

Epбаn 1. (смел) bold, plucky; 2. (способен) smart, resourceful (Атанасова и др. 1983);

Toǔ e epбan he's full of beans; he can fend for himself; he's all there, he's got човек his wits about him, he's a smart lad (Атанасова и др. 1983);

Epбan indecl adj $\mathbf{1}$ (coll.) expert, skilful. $\mathbf{2}$ daring, plucky. 3 (dial.) suitable for someone or something (Granes et al. 2002);

Ербаплия $\quad$ adj (dial.) brave; capable (Granes et al. 2002);

Ербаплгк $m$ (coll.) competence, skilfulness (Granes et al. 2002). 
Bulgarisch - verschiedene Deutungen

\begin{tabular}{|c|c|}
\hline Ербаб & $\begin{array}{l}\text { сгоден, пригоден, вряден за нещо. Този човек е ербаб за такава } \\
\text { работа (Геров 1975); } \\
\text {,zu etwas das Zeug haben; }\end{array}$ \\
\hline Epбап & $\begin{array}{l}\text { (араб.) Разг. Който умее лесно да се справя с нещо; годен, } \\
\text { способен (РБСКЕ 1959); } \\
\text { (Arabisch) umg jemand, der Probleme schnell meistern kann; } \\
\text { tauglich, fähig'; }\end{array}$ \\
\hline Epбап & $\begin{array}{l}\text { разг. смел, способен, похватен (БЕР 1971); } \\
\text {, umg kühn, fähig, geschickt'; }\end{array}$ \\
\hline Epбап & $\begin{array}{l}\text { ap.myp. Разг. 1. Смел, доблестен, мъжествен; 2. Способен, го- } \\
\text { ден за нещо (Андрейчин и др. 1976); } \\
\text {,Arabisch/ Türkisch umg 1. kühn, heldenmütig, mutig; 2. fähig, } \\
\text { zu etwas tauglich“; }\end{array}$ \\
\hline Epбап & $\begin{array}{l}\text { неизм. Прил. Разг. 1. Който умее сполучливо да се справя } \\
\text { с нещо; годен, способен, опитен; 2. Който е смел, оперен; } 3 . \\
\text { Остар. и диал. Който е подходящ за някого или нещо (РБЕ } \\
\text { 1977); } \\
\text {, unveränd, Adjektiv, umg 1. jemand, der gut zurechtkommt; fähig, } \\
\text { erfahren; 2. kühn, kess; 3. veraltet, dialektal geeignet für jemanden } \\
\text { oder etwas'; }\end{array}$ \\
\hline Epбап & $\begin{array}{l}\text { прил. неизм. разг. 1. Смел, наперен, много си ербап; 2. Спосо- } \\
\text { бен, годен за нещо (Андрейчин и др. 1996); } \\
\text {, adj unveränd umg 1. kühn, heldenmütig, mutig; 2. fähig, zu etwas } \\
\text { tauglich'; }\end{array}$ \\
\hline Epбап & $\begin{array}{l}\text { неизм. Разг. Сръчен, способен, оперен (Буров 2000). } \\
\text {, unveränd umg geschickt, fähig, kess'. }\end{array}$ \\
\hline
\end{tabular}

Der Vergleich des semantischen Gehalts von erbap/epбan im Türkischen und im Bulgarischen zeigt zwei Aspekte des Bedeutungswandels. Der erste betrifft die Änderung des kognitiven Gehalts des Wortes. Der zweite hängt mit der Entstehung des Semems ,kess' und ,kühn` im Bulgarischen zusammen. Diese spezifische Entwicklung signalisiert, dass zwischen demonstrierten Möglichkeiten und eigentlichen Fähigkeiten Dissonanzen bestehen können oder dass bestimmte Fähigkeiten aus der Sicht verschiedener gesellschaftlicher Schichten und Sprecher unterschiedlich bewertet werden (können). Heute wird epбan im Bulgarischen am häufigsten in der Bedeutung демонстрирам напереност, опереност, самонадеяност, перча се с вгзможности и/или умения пред другите ('Selbstgefälligkeit demonstrieren, sich mit seinem Können aufplustern') verwendet. Mit anderen Wörtern, es handelt 
sich um eine ambivalente Mischung der in РБЕ (1977) oder Андрейчин и др. (1996) abgesonderten Bedeutungen 1. und 2.

\section{3. Сербез vs. дързък}

\subsubsection{Serbaz und serbest im Türkischen}

Das Wort serbaz, aus dem das Lehnwort сербез im Bulgarischen stammt (vgl. Granes et al. 2002), gilt im Türkischen als veraltet. Im aktiven Gebrauch ist dagegen bis heute das Wort serbest erhalten, das viele Derivative hat und in Wörterbüchern der türkischen Sprache phraseologisch sehr gut erfasst ist. Hier sollen die Bedeutungen der beiden Wörter serbaz und serbest angeführt werden, weil $\mathrm{u}$. E. anzunehmen ist, dass die gegenwärtige Bedeutung des bulgarischen Wortes сербез eine semantische Verschmelzung der Bedeutungen von serbaz und serbest darstellt.

Türkisch - Bulgarisch, Russisch, Englisch, Deutsch

Serbaz неустрашим, смел, храбър, решителен, безстрашен (Романски 1952)

Serbaz смелый, отважный, бесстрашный (Баскаков и др. 1977);

Serbaz bold, fearless (Hony, Iz 1984);

Serbaz $\quad$ audacious, reckless (Moran 1971);

Serbaz (veraltet) tollkühn, verwegen (Steuerwald 1988);

Serbest свободен, независим; волен, непринуден (Янчев 1992);

Serbest $\quad s$. свободен, независим; волен, непринуден, непритеснителен (Димитрова 2004);

Serbest 1) в разн. знач. свободный, вольный, 2) свободный, вольный, беспрепятственный, 3) непринужденный, несмущающийся (Баскаков и др. 1977);

Serbestlık 1) свобода, независимость, 2) непринужденность (Баскаков и др. 1977);

Serbest 1. frei, unabhängig 2. ungeniert, frei, fest, bestimmt (Steuerwald 1988).

Die Bedeutung von сербез im Bulgarischen lässt sich u. E. als Kombination aus den Bedeutungen serbaz ,бесстрашный, отважный‘ und serbest ,непринужденный, несмущающийся' (Баскаков и др. 1977) beschreiben und weist dabei eine ambivalente Struktur auf. 


\subsection{2. Сербез vs. дързък im Bulgarischen}

Der Vergleich des Lehnwortes сербез mit dem heimischen Wort дързгк ist sehr aufschlussreich, weil beide Wörter in Wörterbuchern wie Атанасова и др. (1993) als genaue Synonyme in ihren zwei entgegengesetzten Hauptbedeutungen angegeben werden. Es stellt sich jedoch die Frage, ob es sich hier tatsächlich um eine völlige inhaltliche Übereinstimmung handelt. Vielmehr ist von einem wichtigen semantischen Unterschied zwischen beiden Wörtern auszugehen, der den Aspekt der Ambivalenz betrifft.

$$
\text { Bulgarisch - Englisch }
$$

Сербез 1. audacious, bold, daring, fearless; 2. insolent, presumptuous, arrogant; (coll.) cocky (Atanasova et al. 1993);

Дгрзгк 1. audacious, bold, daring, fearless; 2. insolent, presumptuous, arrogant (Atanasova et al. 1993).

Bulgarisch - Deutsch

Сербез kühn, beherzt, verwegen (Walter, Endler 1994);

Сербез unver änd umg $\mathbf{1}$ (смел) beherzt, tapfer, wagemutig $\mathbf{2}$ (напет) schmuck, schön 3 (упорит) dickköpfig, starrsinnig (Петков и др. 2001);

Сербезлљк umg 1 (смелост) Beherztheit, Tapferkeit 2 (упоритост) Dickköpfigkeit, Starrsinn (Петков и др. 2001);

Продавам umg sich für kühn aus/geben od mit Kühnheit glänzen wollen сербезлбии (Петков и др. 2001);

Дәрзгк 1. (смел) kühn, wagemutig; 2. (нахален) frech, dreist (Walter, Endler 1994);

Дгрзост 1. nur sg Kühnheit, Wagemut 2. (нахалство) Frechheit, Dreistigkeit (Walter, Endler 1994);

Дәрзгк 1 (смел) wagemutig, verwegen 2 (нахален) dreist, unverfroren (Петков и др. 2001);

Дәрзост 1 Wagemut, Verwegenheit 2 (нахалство) Dreistigkeit (Петков и др. 2001). 
Bulgarisch - verschiedene Deutungen von $ә г р з љ к$

Дәрзгк 1. Предизвикателно смел, решителен; 2. Неуважително, оскърбително груб, нахален (Андрейчин и др. 1976);

,1. tollkühn, waghalsig; 2. in unhöflicher Weise barsch, schroff‘;

Дгрзбк 1. Който излиза извън пределите на това, което се диктува от условията, възможностите, и е свързано с риск; предизвикателно смел; 2. който проявява неуважение към околните и с поведението си ги засяга; груб, оскърбителен; 3. Който изразява, в който има предизвикателна смелост или явно неуважение, незачитане на околните (РБЕ 1977);

,1. von einem Wagemut, der die Gefahr nicht achtet; waghalsig 2. im Umgangston mit anderen Menschen unhöflich und barsch; grob, beleidigend; 3 . sehr waghalsig und die Menschen um such missachtend ';

Дгрзбк прил. 1. Който пренебрегва опасностите, подлага се на риск, проявява или изразява предизвикателна смелост. Дгрзбк човек, дрбзка поствпка. 2. Който преминава отвъд ограниченията, отвъд нормите на обществото, на приемливото; оскърбителен, груб. Дрбзко поведение. Дгрзгк тон (Буров 2000);

,1. einer, der die Gefahr nicht achtet, Risiken eingeht und sehr waghalsig ist; 2. wer die Schranken, die Normen der Gesellschaft, des Annehmbaren überschreitet; 3. barsch und brüsk '.

Bulgarisch - verschiedene Deutungen von сербез

Сербез юначен, мъжествен, смел. Бегликчиите са сербез (Геров 1975); ,heldenmutig, mutig, tapfer';

Сербез (перс.) Разг. Силен, дързък; Сербезлбк-(тур.) Разг. Смелост, дързост (РБСКЕ 1959);

,Persisch, umg stark, dreist';

Сербез пер.-тур. разг. 1. Смел, дързък; 2. Бикоглав, упорит Сербез кон; Сербезлбк - бикоглавщина, смелост, дързост (примерът е на Андрейчин и др. 1976);

,Persisch-Türkisch, umg 1. kühn, dreist; 2. starrköpfig, dickköpfig;;

Сербез Разг. Дьрзък, смел (Буров 2000).

,umg dreist, kühn'. 
Drei Beispiele mit verschiedenen Bedeutungen der Substantivierungen сербез/лия/лгк/лик

$$
\begin{aligned}
& \text { Мамо мари, не жени ма/ тази зима, таз година!/ Да похода, } \\
& \text { да полиба/ ергенете, сербезете (Народна песен от Коприв- } \\
& \text { щенско); } \\
& \text {,Männlichkeit, Kühnheit besitzend‘; }
\end{aligned}
$$

И турчингт може ли да има отгоре си юначество (Kühnheit)? Той има само сербезлик (Dreistigkeit), защото има иарщина (Захари Стоянов, Христо Ботйов. Опит за биография. София, 1976, с. 80) [юначество $\neq$ сербезлик]; ,Kühnheit (юначество) $\neq$ Dreistigkeit (сербезлик)';

Удряите бе! Какъв е тоя маскаралбк, един иарски дуиманин да продава комитаджийски сербезлғк в двора на конака? говореха мнозина (Захари Стоянов, Записки по бблгарските въстания, т. 3. София, 1976, с. 97) [да продава комитаджийски сербезлък = да показва характер, да демонстрира достоинство, да не скланя да преклони глава и да моли за пощада];

,Charakter bekennen, Würde zeigen, sich das Rückgrat nicht brechen lassen'.

Die Bedeutung des Wortes сербез im Bulgarischen kann am besten erklärt werden, wenn man das heimische Synonym дәрзгк zum Vergleich heranzieht. In diesem Sinne wurde die Ambivalenz von сербез im entsprechenden Wörterbuchartikel bei Атанасова и др. (1993) besonders gut erfasst und findet dort eine akzeptable Beschreibung. Es ist jedoch $\mathrm{zu}$ bemerken, dass sich bei der Verwendung von сербез nicht entweder Bedeutung ${ }^{1}$ oder Bedeutung ${ }^{2}$ aktivieren, sondern sowohl Bedeutung $^{1}$ als auch Bedeutung ${ }^{2}$. Damit erscheint das Wort nicht als polysem (wie man annehmen könnte), sondern als ambivalent. Noch deutlicher wird das, wenn man sich die Definition von дәрзбк bei Атанасова и др. ansieht. Sie ist jeweils Bedeutung $^{1}$ oder Bedeutung ${ }^{2}$ aus der Definition zu сербез zuzuordnen, nicht aber gleichzeitig beiden Bedeutungen. Дгрзгк kann nämlich nicht als ambivalent interpretiert werden. Im konkreten Kontext kann das Wort entweder nur positiv (дргзко нападение на вражеския стан) oder nur negativ (отговарям дргзко, нахакано някому) verwendet werden. Womöglich ist diese genaue Trennung dem Wort сербез zu verdanken, das einem sofort einfällt, wenn man sich ambivalent ausdrücken möchte.

Die oben angeführten drei Beispiele aus Texten des 19. Jahrhunderts zum Gebrauch der Substantivierungen сербез/лия/лгк/лик, die entweder einen Charakterzug oder eine abstrakte Klassifizierung eines entsprechenden Typs des menschlichen Verhaltens bezeichnen, zeigen eindeutig das Verwendungsspotential des Wortes сербез und seiner Derivative. Ganz besonders prägnant ist die Verwendung von 
сербезлбк in Beispiel (14) aus Zachari Stojanovs Text, die den Konflikts zwischen Türken und Bulgaren in der Zeit vor dem Aprilaufstand von 1876 widerspiegelt. Dieses Beispiel lenkt die Aufmerksamkeit auf eine weitere Eigenart des ambivalenten Gebrauchs von Wörtern, nämlich dass ein Wechsel von ambivalenter zu positiver Bewertung möglich ist, jedoch nur beim Wechsel der Perspektive der an der Kontroverse beteiligten Personen und/oder Kulturen. In dem zitierten Satz hat das Wort сербезлик aus der Perspektive der Türken eine negative oder ambivalente Bedeutung, während es vom Gesichtspunkt Zachari Stojanovs aus eindeutig positiv konnotiert, weil dessen Sympathie den bulgarischen Rebellen ( царски душмани) gilt.

Im Unterschied dazu werden in Beispiel (13) durch die ausdrückliche Gegenüberstellung des bulgarischen Wortes юначество (,Kühnheit') und des türkischen Lehnwortes сербезлик (,Dreistigkeit`) die entgegengesetzten Einstellungen explizit konfrontiert. In Beispiel (12) ist сербез nicht ambivalent verwendet. Hier wird die Bedeutungskomponente, angeben mit Männlichkeit und Kühnheit ‘ als normaler Modus männlichen Verhaltens vor dem anderen Geschlecht präsentiert. In diesem Zusammenhang ist auf ein weiteres Detail hinzuweisen, das den sozialen und geschlechtsspezifischen Aspekt der Verwendung von ербап, курназ und сербез betrifft und weitere Seiten des Bedeutungspotentials ambivalenter Wörter veranschaulicht. Diese drei türkische Lehnwörter eignen sich besonders gut, wenn eine Frau von einem Mann für Eigenschaften gelobt werden soll, die im zeitgenössischen Kulturkontext Männern zugeschrieben werden. So führt Burov (2000) als passendstes Beispiel zur Illustration der Bedeutung von ербап und сербез die Ausdrücke ербап жена ,geschickte, tatkräftige Frau' und сербез жена ,kühne, wagemutige Frau' an (dagegen ist die Verbindung келеш жена ungebräuchlich). Die potentiellen symmetrischen maskulinen Entsprechungen сербез мәж und ербап мбж existieren im Bulgarischen (noch) nicht oder sind zumindest äußerst ungewöhnlich. Gängig sind die neutralen Varianten ербап човек und сербез човек. Es ist kaum anzunehmen, dass Буров bewusst die Kombinierbarkeit der analysierten Turzismen mit жена ,Frau' in den Vordergrund treten lässt. Vielmehr handelt es sich u.E. um eine geschlechtspezifische Verwendung.

Es gäbe auch eine andere Erklärung für dieses Phänomen. Es ist nämlich davon ausgehen, dass die unmarkierte Verwendung der substantivierten Formen epбan, сербез und курназ an erster Stelle männliche „Tugenden“ bezeichnen (vgl. Beispiel (12), in dem sich diе ергени (,Junggesellen') als сербез, d.h. als ,männlich, stark, tapfer' zeigen wollen). Wenn eine Frau gemeint ist, muss der Geschlechtsklassifikator жена explizit eingesetzt werden.

\section{Das Verwendungspotential von Wörtern für assertives Ver- halten}

Bei Wörtern wie келеш, ербап, курназ und сербез, die assertives Verhalten ausdrücken, ist zu erwarten, dass sie eine vergleichbare Distribution aufweisen, die 
weitere und tiefere Unterschiede in ihrer Verwendung enthüllen kann. Aus Platzgründen ist hier keine detaillierte Analyse möglich, deshalb sei die Problematik an einigen wenigen Beispielen veranschaulicht. Sie sollen die Auswechselbarkeit der untersuchten Wörter in ausgewählten phraseologischen Wendungen prüfen, wobei unter a. der jeweilige Phraseologismus in seiner geläufigen Form (PБE 1977), unter b.-d. die Varianten des Phraseologismus, unter e. die Bedeutung der Grundform des Phraseologismus, unter e. eine Erklärung der Bedeutung auf bulgarisch und unter f. eine Übersetzung ins Deutsche angegeben wird:

(15) а. Много си курназ.

b. Много си сербез.

c. Много си ербап.

d. *Много си келеш.

е. Много си наперен. Много си самонадеян. Много се опитваш да покажеш характер, възможности, способности. Много си нафукан';

f. $\quad$,Du bist ein großer Angeber

Die Variante (d) ist blockiert, weil келеш die Bedeutungskomponente ,Nichtsnutz enthält und im Vergleich zu a., b. und c. hier eindeutig negativ ist.

(16) а. Правя се на курназ.

b. ?Правя се на сербез.

c. ?Правя се на ербап.

d. *Правя се на келеш.

е. ,Демонстрирам самонадеяност, безстрашие в проблематична за мен самия ситуация';

f. ,Selbstbewusstsein, Tapferkeit demonstrieren in einer Situation, die für mich selbst problematisch ist'.

Die Wortverbindung a. ist konventionalisiert, während die Varianten b. und c. möglich sind, jedoch selten gebraucht werden. Bei allen drei Wendungen realisiert sich die Möglichkeit, reflexiv eigene Handlungen und Benehmen zu kommentieren. (d) ist wieder blockiert, weil келеш als Bedeutungskomponente ,Nichtsnutz enthält.

(17) a. Продавам курназлъци.

b. Продавам сербезлъци.

c. * Продавам ербаплъци.

d. Продавам келешлъци.

e. Перча се, правя демонстрации на превъзходство в нещо. Правя се на бестрашен пред лицето на опасност пред някого';

f. ,angeben, Überlegenheit demonstrieren; sich tapfer stellen'. 
Bei a., b. und d. wird der Aspekt der Angeberei hervorgehoben. Nicht bildbar ist nur (c), weil sich das Adjektiv epбan nicht substantivieren lässt.

(18) а. От курназлък.

b. ?От сербезлък.

c. ${ }^{*}$ От ербапльк.

d. От келешлък.

e. , (мотив) За да се перчи, за да демонстрира нещо пред някого;

f. ,(Motiv) um anzugeben, um jemandem was zu zeigen'.

In diesem Beispiel kommt bei a. b. und d. der Aspekt der Angeberei als Motiv für ein bestimmtes Verhalten in den Vordergrund. (c) ist nicht bildbar, weil sich das Adjektiv epбan nicht substantivieren lässt.

(19) а. За курназльк.

b. ?За сербезльк.

c. *За ербаплък.

d. За келешлък.

е. ,(цел) За да се перчи, за да демонстрира превъзходство за нещо пред някого;

f. , ,Absicht) um anzugeben, um Überlegenheit zu demonstrieren`.

In diesem Beispiel dominiert bei a., b. und d. wieder der Aspekt der Angeberei, jedoch als Absicht für ein bestimmtes Verhalten. Die Bildung von (c) ist nicht möglich, weil das Adjektiv epбan nicht substantivierbar ist.

(20) а. Върши курназлъци.

b. Върши сербезлъци.

c. * *Върши ербаплъци.

d. Върши келешлъци.

е. ,Върши щуротии, лудории (най-вече на млади години)';

f. ,Unsinn machen (vor allem in jungen Jahren)`.

In diesen Beispiel dominiert in a., b. und d. die Bedeutung „Unfug anstellen und damit angeben". Die Bildung von (c) ist nicht möglich, weil das Adjektiv epбan nicht substantivierbar ist.

(21) а. Курнази се.

b. ??Сербези се.

c. *Ербапи се.

d. Келеши се.

е. ,Надува се, фука се, прави се на горделив“;

f. ,wichtig tun, angeben, prahlen'. 
Die Wendungen in Beispiel (21) enthalten von den Adjektiven курназ, сербез, ербап und келеш abgeleitete Verben. (a) and (d) können als sinnverwandt bestimmt werden. (c) ist ungewöhnlich und (b) ist in Analogie zum konventionellen (a) akzeptabel. Es ist eindeutig, dass die Komponente ,angeben' am eindeutigsten durch курназ und келеш ausgedrückt wird.

(22) a. От такъв келеш ли се плашиш?

b. $\quad$ *От такъв курназ ли се плашиш?

c. * * такъв сербез ли се плашиш?

d. * $\quad$ От такъв ербап ли се плашиш?

е. ,От такова фукливо нищожество ли се плашиш?;

f. ,Hast du etwa Angst vor so einem nichtsnutzigen Angeberi.

In a. wird келеш im Sinne von ,nichtsnutziger Angeber' verwendet. Eine analoge Verwendung der anderen drei Wörter ist nicht möglich.

(23) a. Не съм очаквал, че ще излезе такъв невъзпитан келеш (Кръстева 2000).

b. ?Не съм очаквал, че ще излезе такъв невъзпитан курназ(лия).

c. * Не съм очаквал, че ще излезе такъв невъзпитан ербап(лия).

d. ??Не съм очаквал, че ще излезе такъв невъзпитан сербез(лия).

е. Не съм очаквал, че ще излезе такъв невъзпитан фукльо;

f. Ich habe nie geglaubt, dass aus ihm so ein unerzogener Angeber wird'.

Kелеш wird in a. in der Bedeutung, unerzogener Angeber' verwendet. Eine analoge Verwendung der anderen drei Wörter ist nicht möglich.

Der Vergleich der Austauschbarkeit der untersuchten vier Wörter in verschiedenen Wortverbindungen und Ausdrücken gibt noch genauere Aufschlüsse über die Ähnlichkeiten und Unterschiede in ihren Bedeutungsstrukturen. Келеu, ербап, курназ und сербез weisen in Bezug auf die Komponente ,Angeberei ‘ Ähnlichkeiten im Gebrauch auf. Zugleich werden unterschiedliche Nuancen deutlich. Келеш markiert den wahren Charaktertyp, der hinter der Angeberei steckt, nämlich den Nichtsnutz; курназ betont das Ziel des Angebens und zwar die Absicht, sich vor anderen als mutig und selbständig zu präsentieren. Курназ und сербез sind vergleichbar, wenn die Komponente ,mit Selbstbewusstsein und Tapferkeit angeben zum Ausdruck kommen soll. Beide aber unterscheiden sich im Grad und in der Art der jemandem zugeschriebenen Angeberei. Веі сербез dominieren Tapferkeit, Mut, Selbständigkeit und bei курназ die Selbstsicherheit. Die Bedeutung von ербаn enthält insbesondere in der Wendung много си ербаn! die Komponente ,Angeber'. In Unterschied zu курназ und сербез ist aber diese Komponente mit den Komponenten ,Fähigkeiten und Möglichkeiten besitzen, um etwas zu tun 
und/oder zu erreichen' verbunden. Es ist ersichtlich, dass in den untersuchten vier Wörtern verschiedene Aspekte der Komponente ,Angeberei' thematisiert und in ihren Bedeutungsstrukturen ambivalent kodiert sind.

\section{Zusammenfassung}

Die Untersuchung und Modellierung von ambivalenten Emotionen ist von großer Bedeutung für das Verstehen des Wesens emotionaler Prozesse. Die genauere Kenntnis dieser Prozesse führt ihrerseits zu einer klareren Vorstellung davon, wie die Sprache zum Ausdruck von Emotionen eingesetzt wird. Ohne solche Kenntnisse es ist nicht möglich, emotiv-affektive Bedeutungskomponenten in einsprachigen und zweisprachigen Wörterbuchern präzise zu beschreiben. Das gilt insbesondere für die lexikographische Erfassung von ambivalenten Wörtern.

In diesem Beitrag wurde die Struktur der ambivalenten Bedeutung beschrieben und anhand der türkischen Lehnwörter im Bulgarischen келеш, ербап, курназ und сербез veranschaulicht. Die Analysen und Deutungen der angeführten Beispiele und ihr Vergleich mit der Darstellung der vier Wörter in verschiedenen Wörterbüchern zeigen, dass die ambivalente Bedeutungsstruktur eine große Herausforderung für die lexikologische Theorie und Praxis darstellt. Die Ambivalenz ist nicht mit Ambiguität, Polysemie, Omonymie oder Antonymie gleichzusetzen. Auch durch die Kombination dieser semantischer Relationen lässt sich die Struktur der ambivalenten Bedeutung nicht adäquat wiedergeben. Notwendig sind zusätzliche deskriptive Mittel, um die spezifischen Konnotationen, die mit der Ambivalenz verbunden sind, genau zu beschreiben.

Die ausführliche vergleichende semantischen Analyse der vier Wörter келеш, ербап, сербез und курназ erlaubt nun eine präzisere Bestimmung der ambivalenten Aspekte ihrer Bedeutungen. Im Kern der Ambivalenz aller vier Wörter steht die Komponente ,Angeberei', die in jedem einzelnen Fall unterschiedlich exponiert wird:

Келеш човек, който се прави на опитен, способен и/или можещ пред другите, а в действителност е фукливо нищожество; ,ein Mensch, der sich als erfahren, fähig und/oder begabt zeigt, in Wirklichkeit aber ein angebender Nichtsnutz ist';

Epбап човек, който се прави пред другите на можещ, компетентен, способен и готов да свърши нещо, но това не е сигурно, поскоро подлежи на съмнение;

,ein Mensch, der sich vor den anderen als fähig, kompetent, zum Handeln bereit zeigt, bei dem in Wirklichkeit aber diese Eigenschaften eher in Zweifel zu setzen sind'; 


\begin{abstract}
Сербез човек, който самонадеяно, самоизтъкващо се се прави пред другите на смел, безстрашен, горд; човек, който претендира за високо достоинство и надлежно отношение към себе си, но едва ли ги заслужава в пълна мяра; ,ein Mensch, der mit Tapferkeit, Kühnheit, Stolz angibt; jemand, der anerkannt und bewundert werden möchte, dies aber kaum verdient

Курназ човек, който изглежда в очите на другите на наперен и самонадеян, когато се изтъква пред тях като бестрашен и/или със самочувствие;

,ein Mensch, der in den Augen der anderen überheblich und selbstgefällig erscheint, weil er mit Tapferkeit und/oder Selbstbewusstsein angibt'.
\end{abstract}

In Bezug auf die Verwendung der vier Wörter kann aufgrund der vergleichenden Analyse eine Skala der Ambivalenz in ihrer semantischen Struktur aufgestellt werden. Келеш kann negativ, ambivalent oder als ambivalenter Admirativ verwendet werden; курназ enthält immer einen ambivalenten Aspekt. Bei Сербез und ербап besteht die Möglichkeit der positiven Verwendung, wobei im geeigneten Kontext und bei geeigneter Intonation die Ambivalenz fast völlig ausgeschlossen werden kann. Eine Aufgabe für die Zukunft ist die genaue Untersuchung der Bedingungen und Mechanismen, die zur Blockierung der Ambivalenz führen sowie der Möglichkeit, diese Bedingungen und Mechanismen als Teil des semantischen Potentials ambivalenter Wörter lexikographisch darzustellen.

\title{
Literatur
}

Андрейчин, Л. и др.: 1976, Български тблковен речник, трето издание, София.

Андрейчин, Л. и др.: 1996, Български тълковен речник, четвърто издание, допълнено и преработено от Димитър Попов, София.

Атанасова, Т. и др. 1993. Българско-английски речник. 4-о стереотипно издание с притурка, София.

Баскаков, А. Н. и др.: 1977, Турецко-русский словаръ, Москва.

БЕР 1971: Георгиев, В. (ред.), 1971-, Български етимологичен речник, София.

Буров, С.: 2000, Тълковен речник на българския език, Велико Търново.

Геров, Н.: 1975 (1895-1908), Речник на българския език, фототипно издание, Т. 1-6, София.

Димитрова, Л.: 2004, Турско-бглгарски и българско-турски речник, София.

Кръстева, В.: 2000, Речник на турските думи в съвременния български печат, София.

Мирчев, К.: 1952, ,За съдбата на турцизмите в българския език', Известия на Института за бглгарски език при БАН, кн. 2, стр. 117-127, София. 
Петков, П., Гутшмит, К., Игла, Б.: 2001, Българско-немски речник, София.

РБЕ 1977: Речник на българския език. 1977-, отг. редактор Кристалина Чолакова и др., Т. 1-, София.

РСБКЕ 1959: Речник на съвременния български книжовен език, 1955-1959, под ред. на Стоян Романски, Т. I-III, София.

Романски, С.: 1952, Турско-български речник, София.

Янчев, М.: 1992, Турско-български речник, София.

Bleuler, E.: 1930, Textbook of Psychiatry, trans. from German into English by A.A. Brill, New York.

Bulitta, E., Bulitta, H. (Hrsg.): 1999, Wörterbuch der Synonyme und Antonyme, Frankfurt a.M.

Granes, A., Hauge, K. R., Süleymanoğlu, H.: 2002, A Dictionary of Turkisms in Bulgarian, Oslo.

Hascher, T.: 1994, Emotionsbeschreibung und Emotionsverstehen. Zur Entwicklung des Emotionsvokabulars und des Ambivalenzverstehens im Kinderalter, Münster.

Hony, H.C., Iz, F. (eds.): 1984, The Oxford Turkish-English Dictionary, Oxford.

Moran, A. V. (ed.): 1971, A Turkish-English Dictionary, Istanbul.

Osgood, Ch. E., Suci, G., Tannenbaum, P.: 1957, The Measurement of Meaning, Urbana, Ill.

Steuerwald, K.: 1988, Türkisch-deutsches Wörterbuch, 2. Aufl., Wiesbaden.

Walter, H., Endler, D.: 1994, Wörterbuch Bulgarisch-Deutsch, München-Sofia.

Weigert, A. J.: 1991, Mixed Emotions: Certain steps toward understanding ambivalence, Albany. 

JÜRGEN UDOLPH

\title{
Anmerkungen zum Familiennamen Kroll
}

\begin{abstract}
Alte Erinnerungen
Die folgenden Bemerkungen zum Familiennamen des Jubilars lassen Erinnerungen aufsteigen; Erinnerungen an gemeinsame Studienjahre in Göttingen in dem damaligen Slavischen Seminar in der Hospitalstraße 10. Besonders heimelig waren die Übungen in einem kleinen Raum, der etwa nur 15 Plätze umfaßte, intimer ging es nicht. Damals interessierten mich weder Orts- noch Gewässernamen und erst recht nicht Familiennamen. Selbst über meinen eigenen Namen hatte ich noch nicht nachgedacht und natürlich auch nicht über den von Walter Kroll. Ich erinnere mich nur, daß Walter Kroll wohl aus Schlesien stammte, was Gemeinsamkeiten erzeugte, denn auch meine Eltern stammten daher.
\end{abstract}




\section{Familiennamen und ihre Verbreitung - Etappen der Entwick- lung}

Meine folgenden Bemerkungen möchten aber nicht nur an Altes erinnern, sondern auch deutlich machen, welch gewaltige Fortschritte die Untersuchung der Familiennamen im letzten Jahrzehnt gemacht hat. Einige der im folgenden vorgelegten Verbreitungskarten können sogar erst seit zwei Monaten (dieser Beitrag stammt vom Februar 2006) erzeugt werden. Doch dazu später mehr. Entscheidende Fortschritte hat die elektronische Datenverarbeitung erbracht, ohne die Verbreitungskarten von Familiennamen nicht erstellt werden könnten. Und so hätte dieser Aufsatz in den Jahren unseres gemeinsamen Studiums (etwa 1967-1970) noch gar nicht geschrieben werden können.

In einem grundlegenden Artikel haben Konrad und Richard Kunze (2003) zum erstenmal zusammenfassend gezeigt, welch wichtige Quelle elektronische Datenverzeichnisse wie Telephon-CDs für die Untersuchung der Familiennamen darstellen. Mit Hilfe zahlreicher Karten konnten die Autoren die Verbreitung der Apokope im Deutschen, etwa anhand der Differenz zwischen Namen wie Schütz und Schütze, Schulz und Schulze, umfassend untersuchen und der Familiennamenforschung neue und wichtige Impulse geben. Dabei stützen sich die Autoren auf von Richard Kunze entwickelte Auswertungsprogramme von EDV-Datenbanken und TelephonCDs. Dankenswerterweise hat sich die Deutsche Forschungsgemeinschaft dazu entschlossen, die wegweisenden Arbeiten von Konrad Kunze zu fördern, und ein Deutscher Familiennamen-Atlas ist im Entstehen begriffen (vgl. dazu im einzelnen Nübling, Kunze 2005).

Einen ähnlichen Weg ging Volkmar Hellfritzsch (vgl. z.B. Hellfritzsch 2000), dessen Entwicklung ich bei zwei Beiträgen zu den Namen Thüringen und Scheuermann $^{1}$ Udolph 2001, 2003) dankbar nutzen konnte.

Langjährige Erfahrungen mit den Medien ${ }^{2}$ haben mir gezeigt, daß der Namenforscher vor allem über die Familiennamen das Interesse der Menschen an der Onomastik wecken kann. Familiennamen bieten durch ihre z.T. einzigartigen Formen fast einen automatischen Anreiz zu der Frage: „Warum heißt ein Mensch eigentlich so?"“. Träger von Namen wie Rauchfuß, Bleifuß, Mehlhose, Willkommen, Geldmacher, Frauendienst, Buttersack, Kistenfeger, Rosentreter werden immer wieder mit der Frage konfrontiert, woher der Name denn komme. Kaum jemand kann aber darauf antworten, der Namenforscher ist aufgefordert, eine Auskunft zu geben.

Ein wichtiges Hilfsmittel bei der Behandlung der Familiennamen sind - wie schon gesagt - elektronische Datensammlungen, vorzugsweise Telephonanschlüsse in Form einer CD (vgl. dazu bereits Kunze 2003, 198-221). Inzwischen gibt es zahlreiche Verzeichnisse für europäische Staaten wie auch für die USA, Australien, Japan und andere Länder. Mit diesen Daten erhält man einen Überblick über das Vorkommen eines Familiennamens in einem bestimmten Land. Hinweise darauf, daß es eine Anzahl von Telephonnutzern gebe, die sich nicht in derartige Verzeichnisse eintragen lassen, und dadurch das Bild vielleicht verfälscht werden könnte, sind ohne 
Gewicht. Statistisch gesehen ist es eine Minderheit, die angesichts der Gesamtzahl der Telephonnutzer vernachlässigt werden kann. In letzter Zeit ist allerdings eine Entwicklung eingetreten, die zu größeren Störungen führen wird: die Zahl der Mobiltelephone („Handys") nimmt weiter zu, schon übersteigt ihre Zahl die der Festnetzanschlüsse. Dies wiederum führt dazu, daß die neuesten Telephon-CDs eine wachsende Zahl von Telephonnutzern nicht mehr erfassen und somit nicht mehr repräsentativ sein könnten.

Gerade noch rechtzeitig - so muß man konstatieren - hat dagegen der Zuwachs der Telephonanschlüsse in den neuen Bundesländern eingesetzt. Nach einer Mitteilung des Statistischen Bundesamtes vom Dezember 1999 ist „die Ausstattung mit Telefon nahezu flächendeckend (99\%). Bisherige Unterschiede zwischen alten und neuen Bundesländern sind inzwischen so gut wie aufgehoben“. Für den Familiennamenforscher sind daher Telephon-CDs aus den Jahren 1997-2000 für die Familiennamen in Deutschland die wohl beste Quelle.

Wie allerdings K. Kunze und V. Hellfritzsch gezeigt haben, geht die Bedeutung der Telephon-CDs über eine bloße Auflistung der Familiennamen noch hinaus. Es handelt sich vor allem darum, die Streuung und Verbreitung der Namen zu erfassen. Dabei half uns in Leipzig der Zufall: in einem Supermarkt kaufte der Leipziger Onomastik-Studenten Bert Liebau eine Telephon-CD „DT-Info \& Route 99“ und entdeckte, daß diese CD sozusagen einen „Webfehler“ enthält, der sie für Familiennamenforscher zu einer wahren Fundgrube werden läßt. Markiert man bis zu 999 Namen, so stellt diese CD auf einen Klick hin die jeweiligen Namen auf einer Deutschland-Karte dar. Diese CD ist nicht mehr im Handel. Ihre Daten waren widerrechtlich von Telekom-CDs kopiert worden, ein Firmenname ist auf der CD nicht eingetragen, die Telekom hat Prozesse geführt, um den Vertrieb zu untersagen.

Neueste Entwicklungen haben aber selbst diese „Wunder-CD“ fast überflüssig gemacht: der Potsdamer Informatiker Christoph Stöpel hat inzwischen im Internet eine eigene Entwicklung frei zugänglich gemacht, die über die Fähigkeiten dieser Telephon-CD weit hinausgeht und an die Versionen von K. Kunze und V. Hellfritzsch heranreicht: es lassen sich von den Streuungen der Namen sogenannte „absolute" wie auch „relative“ Versionen herstellen; eine revolutionäre Entwicklung (an einem Beispiel werde ich dieses unten demonstrieren).

Und noch ein letztes: die polnische Namenforschung, schon immer auf höchstem Niveau agierend, hat ein Instrumentarium entwickelt, das den Verbreitungskarten in Deutschland kaum nachsteht. Gemeint ist die Internetseite genpol.com, mit deren Hilfe exzellente Verbreitungskarten von Familiennamen in Polen erstellt werden können. Auch das werde ich demonstrieren.

\section{Der Familienname Kroll und Verwandtes in Deutschland}

Unter 40 Millionen Telephonteilnehmern (Stand: 1998) ist der Name Kroll in Deutschland 7.097-mal bezeugt (Telefon CD DT-Info\&Route). Seine Verbreitung 
in Deutschland in absoluter Methode erbringt für 1000 Namen $^{3}$ folgendes Bild (Abb. 1).

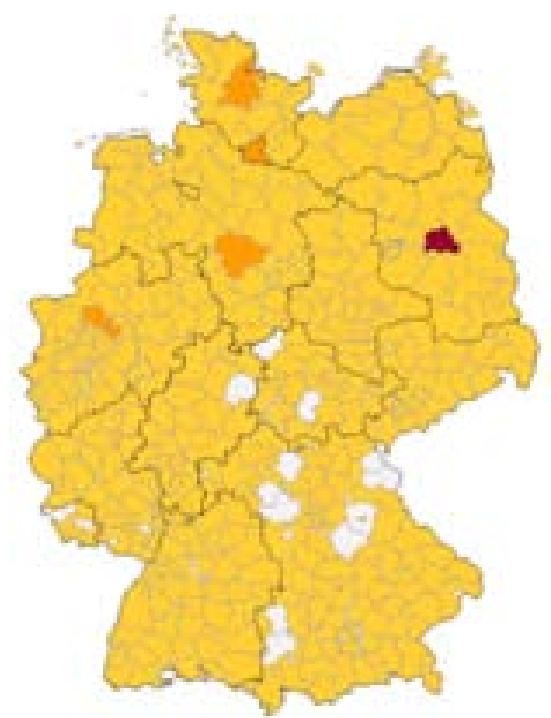

Abb. 1: Kroll - absolute Verbreitung

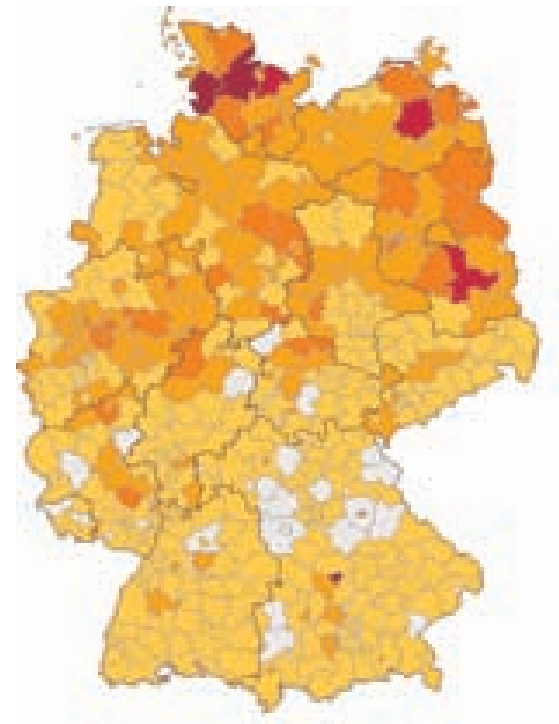

Abb. 2: Kroll - relative Verbreitung

Dabei scheinen bestimmte Regionen überdurchschnittlich beteiligt zu sein, so etwa Berlin, Hannover, Hamburg, das Ruhrgebiet. Eine Karte, die die relative Verbreitung zeigt (Abb. 2), bietet ein objektiveres Bild. Dazu ist zu bemerken, daß die absolute Verbreitung in Karten angibt, „wie oft ein Name pro Ort, Land, PLZ-Bezirk usw. auftritt ... Die[se] massenhaften Vorkommen v. a. in städtischen Ballungsräumen «erdrücken» im Kartenbild [aber] die geringeren Vorkommen auf dem Lande“ (Kunze, 2003, 2005). Relative Kartierungen berechnen dagegen, „wie groß der prozentuale Anteil des betr. Namens am Gesamtvolumen aller Namen eines PLZ-Bezirks ist (= relative Namendichte)" (ebd.). Relative Kartierungen bieten daher im allgemeinen ein objektiveres Bild als absolute.

Die Form Kroll ist aber nicht die einzige Form eines Familiennamens in Deutschland, die es zu beachten gibt. Es existiert auch die Variante Krol, nach DTInfo \& Route 438-mal nachgewiesen. Die Verbreitungskarte (Abb. 3) bietet einen bunten Flickenteppich, dessen Schwerpunkte in einem breiten Streifen von der Lausitz über Sachsen-Anhalt, Niedersachsen, Hessen bis nach Nordrhein-Westfalen reichen. Dabei ist zu bemerken, daß die verarbeiteten Telephon-CDs (leider) keinen Unterschied zwischen den Schreibungen Krol und Król machen, ein Faktum, das uns bei den Verhältnissen Polen gleich noch beschäftigen wird. 


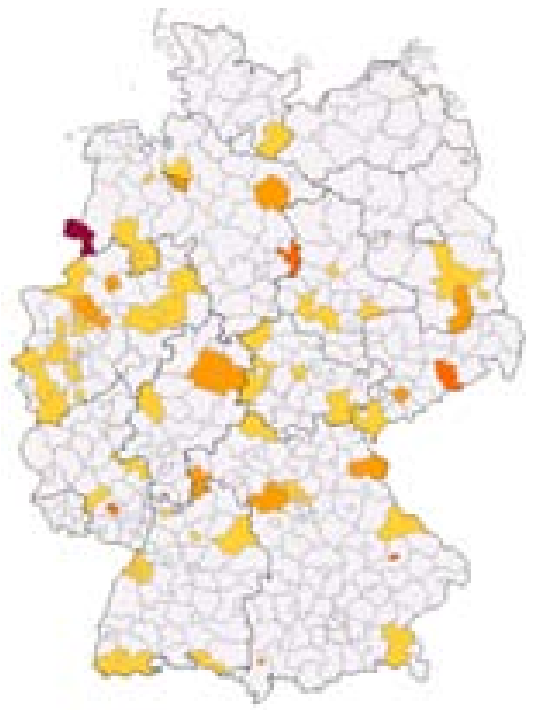

Abb. 3: Krol - absolute Verbreitung

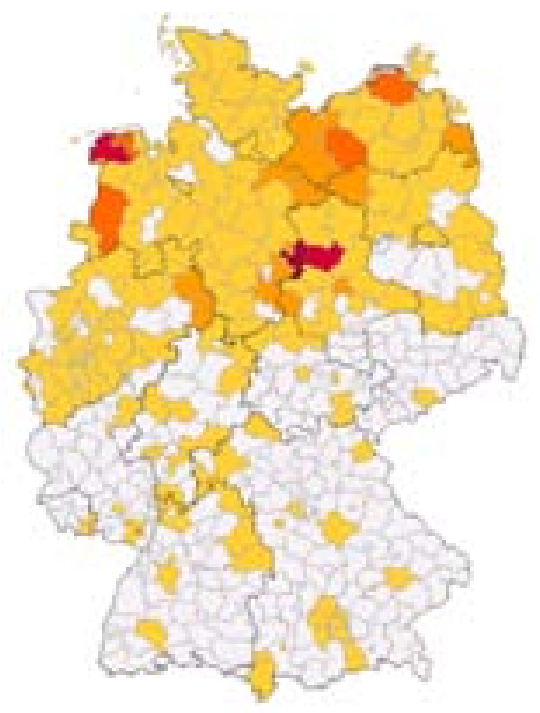

Abb. 4: Krull - relative Verbreitung

Abgesehen von Walter Kroll, den man vor allem im Slavischen Seminar der Universität Göttingen kennt, ist der Familienname Kroll einem größeren Publikum bekannt als der des belgischen Architekten Lucien Kroll, aber vor allem durch die Krolloper, in der nach dem Reichtagsbrand der Reichstag am 23.3.1933 tagte und dort das sogenannte „Ermächtigungsgesetz“ verabschiedete.

Es gibt aber eine Variante des Familiennamens, die vielleicht noch bekannter ist, und zwar durch den Roman von Thomas Mann Bekenntnisse des Hochstaplers Felix Krull. Nur ein Slavist und Polonist vermag die Verbindung zwischen Krol/Kroll und Krull zu erläutern, und auch hieraus erwächst die Erkenntnis, daß es sich bei den Familiennamen $\mathrm{Krol} / \mathrm{Kroll} / \mathrm{Krull}$ nicht um deutsche, sondern um ursprünglich polnische Namen handeln muß. Denn nur ein Slavist oder Polonist weiß, daß die Graphie von poln. Król als [krul] gesprochen wird (zu poln. Król, król s. unten).

Daraus ergibt sich, daß ein Familienname $\operatorname{Krul}(l)$ in Deutschland zwar auch auf eine polnische Vorlage Król zurückgeht, aber eine andere Form der Eindeutschung voraussetzt: Während Krol/Kroll die graphische Form von poln. Król zur Grundlage hat, liegt der Form Krul/Krull die sprachliche Realisierung, die Aussprache, die parole, zugrunde.

In Deutschland ist zwar ein Familienname Krul nur wenig bezeugt (12-mal nach DT-Info \& Route); wesentlich häufiger ist aber Krull: 1.988-mal. Die Streuung zeigt Abb. 4. Es gibt einige Unterschiede in der Streuung: Während Kroll vor allem im deutschen Nordosten (Mecklenburg-Vorpommern, Brandenburg) und im Norden (Schleswig-Holstein) vorkommt, läßt sich Krull vor allem im westlichen Niedersachsen, im Grenzgebiet zwischen Niedersachsen und Sachsen-Anhalt sowie zwischen Niedersachsen und Mecklenburg-Vorpommern nachweisen. 


\section{Krol, Król und Verwandtes in Polen}

Wie schon oben betont wurde, bietet die Namenforschung in Polen wichtige Hilfsmittel an, um die Herkunft eines Namens zu ermitteln. Das betrifft nicht nur die Etymologie der Familiennamen ${ }^{4}$, sondern auch deren Streuung. Man nutzte dazu die Einträge der Bürger Polens in der staatlichen Versicherung. Da es vor der politischen Wende nur eine Versicherung gab, war klar, daß in dieser faktisch jeder Bürger Polens verzeichnet sein würde. Die Krakauer Namenforscher um K. Rymut erkannten das sehr rasch und brachten zunächst in Buchform eine Sammlung der Familiennamen Polens heraus ${ }^{5}$. Sie enthält ca. 38 Millionen Namen, und schon nach dessen Erscheinen war dieses ein unentbehrliches Hilfsmittel.

Aber bald wurde diese Publikation noch verbessert, und zwar durch eine elektronische Ausgabe. Die Daten dieser Sammlung wurden im Internet frei zugänglich präsentiert und sind noch heute für jeden Nutzer abrufbar. Sie stehen auf der Internet-Seite genpol.com. Ich biete daraus eine Streuung des Familiennamens Krol, der nach dieser Sammlung in Polen 349-mal bezeugt ist (Abb. 5).

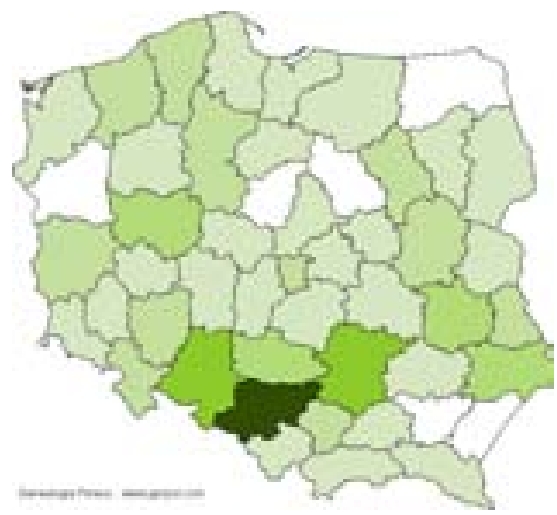

Abb. 5: Krol (aus genpol.com ${ }^{6}$ )

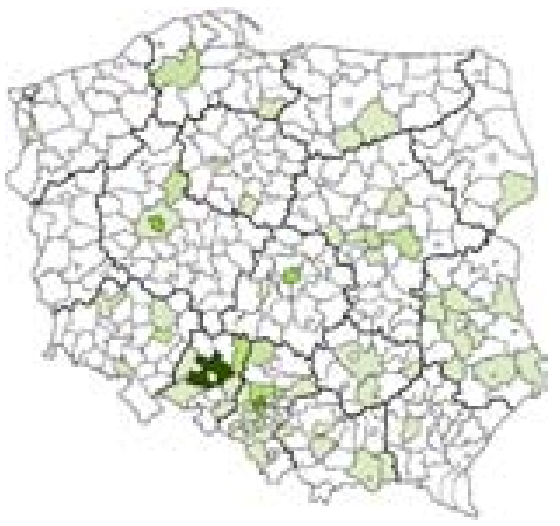

Abb. 6: Krol (CD von $2003+$ genpol.com $)^{7}$

Doch damit noch nicht genug! Im Jahr 2003 brachten die Krakauer Namenforscher eine weitere Verbesserung heraus. Es ist die CD Słownik nazwisk używanych w Polsce na poczatku XXI wieku, die unter der Leitung von K. Rymut erstellt worden ist. Das Material wird auf dieser CD in folgender Form geboten (hier Krol als Beispiel): 
Krol 170, WrPo: F. 1, WrTr: F. 1, WrWa: M. 1, WrmWr: M. 2, F. 1, ToRa: F. 1, TomBy: M. 1, F.
2, TomTo: F. 1, LuHr: F. 1, LuJa: F. 1, LuLr: F. 1, LuLu: M. 1, LuPu: M. 1, F. 1, LuSw: M. 1, F.
1, LuWł: M. 1, LuZa: F. 1, ZGmZG: M. 2, F. 5, ŁoZd: F. 1, ŁomŁo: M. 3, F. 4, KrGo: F. 1, KrMy:
M. 1, KrNS: F. 1, KrOś: M. 1, KrmKr: M. 1, F. 1, WaMi: M. 2, F. 2, WaPi: M. 1, WaSc: M. 1,
WaWa: M. 1, F. 2, WaWZ: M. 1, F. 1, WaWy: M. 1, OpBr: F. 1, PoKK: F. 1, OpNy: F. 1, OpOl:
M. 3, F. 3, OpOp: M. 9, F. 10, OpSt: M. 1, OpmOp: F. 1, RzRS: F. 1, BsHa: F. 1, GdBy: M. 1,
F. 2, GdKw: M. 1, F. 1, GdmGd: M. 1, KaBę: M. 1, F. 2, KaCi: F. 2, KaGl: M. 1, F. 1, KaKł: M.
2, F. 2, KaMi: M. 2, F. 2, KaPs: F. 1, KaTG: M. 3, F. 3, KaWo: M. 1, KaZa: F. 1, KamBy: M. 4,
F. 7, KamCh: M. 1, F. 1, KamGl: F. 1, KamKa: F. 1, KamMł: F. 1, KamRu: F. 2, KamRy: F. 1,
KamZb: M. 8, F. 5, KiBu: F. 2, KiKi: F. 1, KiSa: F. 1, OlNi: F. 1, OlSz: M. 1, PoPo: F. 1, PoWą:
M. 2, F. 2, PomPo: M. 4, F. 5, SzmSz: F. 2

Die Zahlen und Abkürzungen erklären sich schnell: Gesamtzahl der Familiennamen belege in Polen: 170; am Anfang stehen die Wojewodschaften, Wr für Wrocław, ZG für Zielona Góra usw., dahinter folgen die untergeordneten administrativen Einheiten, WrmWr = Wrocław, miasto Wrocław usw., M. = männliche Personen, F. = weibliche.

Diese Daten kann man in die schon erwähnte Web-Seite genpol.com übertragen, in die dort vorhandene Maske eingeben und erhält eine wesentlich deutlichere Kartierung (Abb. 6) als die der ,älteren“ Ausgabe. Man kann auch gesonderte Karten erzeugen für die männlichen bzw. weiblichen Bevölkerungsanteile. Zusätzlich erscheinen Nachweise für die einzelnen Kreise (powiaty) noch in einer Tabelle. Für Krol wird ausgewiesen: Opole 19, Stadt Zabrze 13, Stadt Bytom 11 usw.

Mit Hilfe dieser namenkundlichen Sammlungen und Editionen lassen sich nun die Spuren des Familiennamens $\mathrm{Krol} / \mathrm{Kroll} / \mathrm{Król} / \mathrm{Krul} / \mathrm{Krull}$ in Polen perfekt verfolgen. Wir begannen bei Krol, bei dem das erhöhte Vorkommen in Schlesien, speziell in Oberschlesien, deutlich erkennbar ist. Diese Konzentration beruht nicht auf Zufall, sondern hat tiefere Gründe: es handelt sich ja um keine „echt“ polnische Form, denn diese ist, graphisch zumindestens, Król, sondern es liegt - wie bei Krol und Kroll in Deutschland -, eine eingedeutschte Form vor.

Um so interessanter ist der Vergleich mit der eindeutig polnischen Form Król. Im folgenden biete ich nur noch Kartierungen, die mit Hilfe der erwähnten CD und der Internetseite genpol.com erstellt worden sind. Die echt polnische Form Król ist in Polen fast 400-mal häufiger anzutreffen als Krol: die CD zählt 54.396 Einträge. Ihre Verbreitung zeigt Abb. 7. 


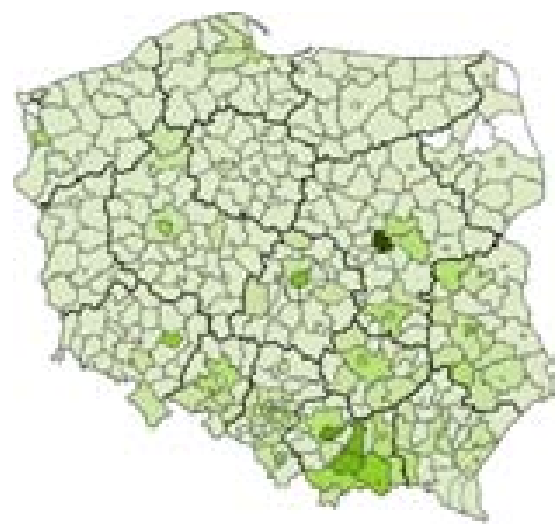

Abb. 7: Verbreitung der Namensform Król

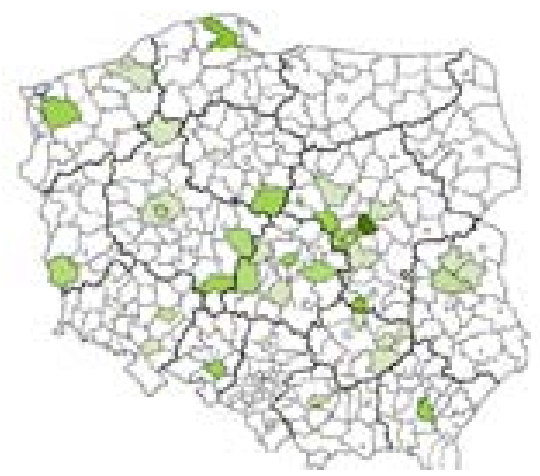

Abb. 8: Verbreitung der Namensform Krul

Es heben sich letzlich zwei Gebiete heraus: Warschau und der Raum um Krakau. Genauer fassen dieses die zusätzlichen Angaben über die Verbreitung der CD-ROM: Warschau 1.779 Eintragungen, Krakau 1.372 und Limanowa 1.198.

Es bietet sich an, diese Streuung mit der Bedeutung des Namens zu kombinieren: Man muß kein Namenforscher zu sein, um zu wissen, daß ein Familienname Król mit poln. król ,König' zu verbinden ist. Auch im Deutschen ist ein Familienname König, der sehr häufig ist (ca. 34.000 Telefonanschlüsse; vgl. Kunze 2003, 198), mit dem entsprechenden Wort zu kombinieren. Keineswegs aber handelt es sich um einen direkten Nachkommen eines Königs, vielmehr wird man in ihnen mit K. Kunze $(2003,151)$,großenteils Beziehungen zu einem entsprechenden Herrn als Höriger, Lehensträger usw. ansprechen, vgl. Zusammensetzungen wie Königslehner, Papenbur ( $\langle$ Klosterbauer $\rangle$ )“.

Von hier aus wird aber die Streuung des Namens Król in Polen durchaus interessant, denn die Häufungen bei Krakau und Warschau signalisieren offenbar alte Beziehungen zu den wechselnden Sitzen der polnischen Könige.

Es bleibt noch der Blick auf einige eingedeutschte Familiennamen wie Krul, Krull und natürlich Kroll. Krul ist 180-mal bezeugt, der Name ist vor allem im westlichen Umland von Warschau vertreten und und in den ehemals deutschen Ostgebieten (Abb. 8). Das ist nicht verwunderlich, denn er gibt ja die Eindeutschung eines polnischen -ó- wieder. Allerdings ist auch gelegentlich damit zu rechnen, daß er auch als polnischer Name von einem Administrator, Beamten, Pfarrer usw. dem Gehör nach notiert worden ist.

Krull ist selten, nur sieben Belege finden sich in der Umgebung von Zielona Góra/Grünberg, Gdańsk/Danzig und Poznań/Posen.

Bleibt noch Kroll. Dieser Name ist recht häufig, die CD-ROM enthält 1.194 Einträge. Die Streuung (Abb. 9) zeigt sehr deutlich, daß er in erster Linie in den ehemals deutschen Ostgebieten begegnet, in Oberschlesien und bei Posen etwas darüber hinausgreifend. Das zeigen auch die einzelnen Zahlen für die Kreise (powiaty), so etwa führt die Stadt Poznań/Posen die Liste klar mit 144 Einträgen 
an, es folgen Kartuzy/Karthaus 52, Złotów/Flatów 39 u.a. Im Südwesten des heutigen Polen hebt sich die Erhöhung der Einträge im schlesischen Industriegebiet heraus; in Schlesien liegen ja auch - wenn meine Erinnerung richtig ist - die Wurzeln von Walter Kroll.

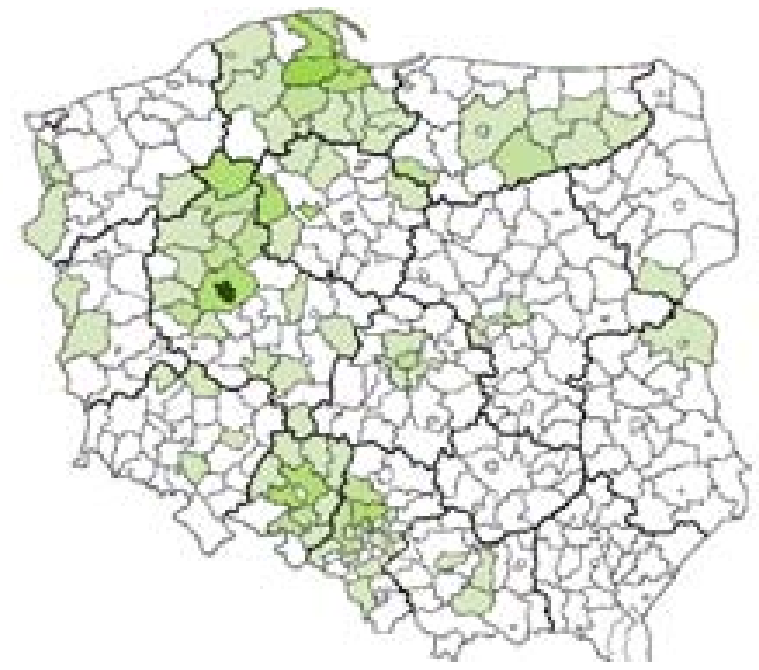

Abb. 9: Verbreitung der Namensform Kroll

\section{Zusammenfassung und Ausblick}

Dieser kleine Beitrag mag gezeigt haben, wie eng bei den Familiennamen die Verflechtungen zwischen der slavischen und der deutschen Welt sind. Und das betrifft auch den Kern der Etymologie von polnisch król ,König', den wir bisher noch gar nicht erörtert haben. Es ist schon seit mehr als einem Jahrhundert kein Geheimnis, daß das slavische Wort für den ,König', bezeugt in russ., ukr. koról', kirchenslav. kralb, bulg. králot, serb., kroat. kralj, sloven. králj, čech. král, slovak. král', poln. król, altsorb. krol, mit Liquidametathese aus dem Namen Karls des Großen, ahd. Karal, Karl, entlehnt worden ist. Verglichen werden kann damit auch der Name der Elbe, poln. Eaba, čech. Labe, polab. Låbi, obersorb. Eobjo, nsorb. Eobje.

Es ist daher auch nötig, noch ein Wort zur Etymologie des Namens Karl zu sagen, in dem ja letztlich die allerletzte Basis für den Nachnamen Kroll liegt. Und hier zeigt sich Überraschendes: Natürlich liegt hier ein alter Ruf-, Vorname zugrunde (er wird ja heute noch, wenn auch etwas selten, vergeben), und deutsch Kerl liegt doch auf der Hand, aber die Etymologie ist umstritten! Bei W. Seibicke (1998, 644), dem besten Kenner der deutschen Vornamen, heißt es unter Hinweis auf F. Kluge, E. Seebold (1995, 438): „Karl [ist] entgegen der allg[emeinen] Auffassung nicht identisch mit ahd., altnord. karl ,Mann, Ehemann` u. nhd. Kerl“. Man 
nimmt den Einfluß eines anderen Wortes an, das vielleicht mit der ursprünglichen Bedeutung von Kerl kombiniert wurde. A. Bach $(1954,34)$ hat hingewiesen auf die Bedeutungsvarianten für Kerl, Karl ,Mann, Liebhaber, vor allem Ehemann“, im Altnordischen auch ,Freier ohne Erbgut‘.

Hinzu kommt, daß Karl lange Zeit überhaupt kein beliebter Vorname war, „der heute gebräuchliche T[aufname] Karl ist jünger und geht auf kath. Seite in der Mehrzahl auf den hl. Karl Borromäus zurück“ (Bach 1954, 34).

Wie dem auch sei, sowohl Karl (der Große) und sein bedeutender Vorgänger Karl Martell wie auch der Name von Walter Kroll zeugen von dem lang anhaltenden engen Kontakt zwischen slavischen und germanischen bzw. deutschen Völkern, über den ich unlängst ausführlicher gehandelt habe (Udolph 2005, 44-50, 64-67, 69-73, 101-106). Beide großen indogermanischen Volksgruppen haben ihre Spuren im Familiennamen Kroll hinterlassen. Daß dieses in Schlesien geschah, fügt sich bestens auch in die Geschichte dieses Landes ein: der lange Kampf um den angeblich germanischen (Silinger) oder slavischen Namen des Landes (poln. *ślęgin ślegnać ,naß werden, anfeuchten' usw.) ist überwunden: Grundlage des Namens ist der Gewässername Ślęza, dessen alteuropäisch-indogermanischer Charakter den alten Gegensatz aufhebt, vgl. Udolph 1995; 1997/98. Es gibt eine gemeinsame Basis, aus der heraus sich das Germanische wie das Slavische entfaltet haben. Gerade Namen machen dies deutlich. Der Familienname Kroll allerdings reicht nicht so weit zurück, da Familiennamen kein so hohes Alter erreichen. Sie entstanden erst, nachdem sich slavische und germanische Sprachen entfaltet hatte. Aber in Schlesien trafen sie wieder aufeinander und hinterließen in Namen ihre vielfältigen und unterschiedlichen Spuren. Der Name Kroll zeugt davon.

\section{Anmerkungen}

1 J. Udolph, Der Name Thüringen. In: Namenkundliche Informationen 79-80,2001, S. 125-144; J. Udolph, Anmerkungen zum Familiennamen Scheuermann. In: Wörter und Namen. Festgabe f. U. Scheuermann, Bielefeld, S. 65-75.

2 Seit über acht Jahren werktägliche Sendung Numen - Nomen - Namen bei Radio Eins (Radio Berlin-Brandenburg); jetzt auch werktäglich in NDR I Niedersachsen.

3 Die Telefon CD DT-Info\&Route kartiert nur bis zu 1000 Namen, was für die generelle Streuung aber unerheblich ist. Moderne Umfragemethoden - etwa beim ZDF-Politbarometer arbeiten mit ca. 1500 befragten Personen und rechnen davon noch auf die Gesamtzahl von ca. 62 Millionen Wählern!

${ }^{4}$ Vgl. Rymut (1999-2001) und dazu meine Besprechungen Udolph (2001; 2004) sowie Stownik etymologiczno-motywacyjny staropolskich nazw osobowych, Teil 1ff., Kraków $2000 \mathrm{ff}$.

${ }^{5}$ Rymut (1992-1994); vgl. dazu meine Besprechung Udolph (1994/95).

6 Sozusagen „ältere Ausgabe“, allerdings - wie gesagt - frei zugänglich.

7 Erstellt mit Hilfe der Daten aus der CER-Rom von Rymut (2003) und der Internet-Seite genpol.com.

\section{Literatur}

Bach, A.: 1954, Deutsche Namenkunde. Die deutschen Ortsnamen, T. 2, Bd. 2, Heidelberg. 
Etymologisches Wörterbuch der deutschen Sprache, 1995. 23. Aufl., bearbeitet von E. Seebold, Berlin - New York, 438.

Hellfritzsch, V.: 2000, ,Lessig/Lässig - Lessing', Dialektgeographie im Ostmittel- und Ostniederdeutschen. Ergebnisse - Einsichten - Folgerungen, Beiträge, Teil III, hrsg. Von Rudolf Große (=Sächsische Akademie der Wissenschaften zu Leipzig. Arbeitsblätter der vorhabenbezogenen Kommission für die Mundartwörterbücher, Nr. 2, August 2000), 5-16.

Kunze, K., Kunze, R.: 2003, ,Computergestützte Familiennamen-Geographie', Beiträge zur Namenforschung, Neue Folge 38, 121-124.

Kunze, K.: 2003, dtv-Atlas Namenkunde. Vor- und Familiennamen im deutschen Sprachgebiet, 4. Aufl., München, 198-221.

Nübling, D., Kunze, K.: 2005, ,Familiennamenforschung morgen: Der deutsche Familiennamenatlas (DFA)', Namenforschung morgen, Hamburg, 141-151.

Rymut, K.: 1999-2001, Nazwiska Polaków, Bd. 1-2, Kraków.

Rymut, K.: 2003, Stownik nazwisk używanych w Polsce na początku XXI wieku, Kraków.

Seibicke, W.: 1998, Historisches deutsches Vornamenbuch, Bd. 2, Berlin - New York.

Stownik nazwisk wspótcześnie w Polsce używanych, 1992-1994. Hrsg. v. K. Rymut, Bd. 1-10, Kraków.

Stownik etymologiczno-motywacyjny staropolskich nazw osobowych, Teil 1ff., Kraków $2000 \mathrm{ff}$.

Udolph, J.: 1995, ,Der Name Schlesien', Studia Onomastica et Indogermanica. Festschrift f. F. Lochner v. Hüttenbach, Graz, 335-354.

Udolph, J.: 2001, ,Der Name Thüringen', Namenkundliche Informationen 79-80, 125-144.

Udolph, J.: 2003, ,Anmerkungen zur Familiennamen Scheuermann', Wörter und Namen, Festgabe für U. Scheuermann, Bielefeld, 65-75.

Udolph, J.: 2005, ,Slawen (Namenkundlich); Slavisch-Baltisch-Germanische Übereinstimmungen in Toponymie und Hydronymie; Germanisch-Slawische Sprachbeziehungen und Slawische Sprachen', Reallexikon der Germanischen Altertumskunde, Bd. 29, Berlin - New York, 44-50, 64-67, 69-73, 101-106. 

Stumme Poesie.

\section{Zur Poetik des nonverbalen Ausdrucks in der tsche- chischen experimentellen Literatur}

\section{Schweigen}

Schon der Volksmund weiß: „Reden ist Silber, Schweigen ist Gold“. So als wolle sich ausgerechnet die Literatur diesem Diktum unterwerfen, bemächtigt sie sich manchmal unter Bedingungen, die Verschwiegenheit fordern, der Verfahren anderer Künste, um sich dem Diktat des Wortes zu entziehen.

Die Geste des Verzichts des Dichters auf sein eigenes Instrument, die verbale Sprache, gilt als ein selbstbezügliches literarisches Verfahren der Moderne, das ihren eigentlichen Beginn markiert. Stéphane Mallarmé forderte, nachdem er 1897 in der Gedichtpartitur Un Coup de dés die weiße Fläche des Papiers als gleichberechtigten Bedeutungsträger und als Äquivalent des Schweigens eingesetzt hatte, das ,verschwiegene Gedicht, aus Weiße“. ${ }^{1}$ Analog dazu entledigten sich auch die anderen Künste ihrer Mittel. So fanden literarische Beispiele wie das 
allein aus Ikten- und Morenzeichen bestehende Gedicht Fisches Nachtgesang von Christian Morgenstern ${ }^{2}$ oder das aus Gedankenstrichen zusammengesetzte Dadaistische Lautgedicht von Man Ray ${ }^{3}$ ihr Pendant etwa in Erwin Schulhoffs Kompositionen aus Pausenzeichen ${ }^{4}$ oder in der monochromen Malerei Kazimir Malevičs ${ }^{5}$ und Władysław Strzemińskis. ${ }^{6}$ Gemeinsamer Nenner dieser Tendenz, die Eugen Gomringer 1954 als Paradoxon des Schweigens in einer Konstellation dargestellt hat (Abb. 1), ${ }^{7}$ ist das Bemühen, an die Stelle der Repräsentation von Welt durch allzu arbiträre Zeichen deren Präsentation zu setzen. Flankiert und angeregt durch sprachphilosophische, linguistische und zeichentheoretische Erkenntnisse führten die sprachanalytischen Verfahren der konkreten Poesie die Kritik an der Konventionalität des sprachlichen Ausdrucks und der Vermitteltheit der Wahrnehmung auf diese Weise direkt vor Augen. ${ }^{8}$

\section{schweigen schweigen schweigen schweigen schweigen schweigen schweigen schweigen schweigen schweigen schweigen schweigen schweigen schweigen}

Abb. 1: Eugen Gomringer: Schweigen, 1954 (Gomringer 1996, 58)

Doch bei aller Innovationskraft - und hier zeigt sich die Dialektik des Verfahrens geben selbst die unkonventionellen Gesten der Verweigerung immer wieder auch der Tradition in Form des mimetischen Ut-pictura-poesis-Postulats neue Nahrung. Was Simonides, der nicht zufällig in seiner Eigenschaft als Dichter zum Begründer der Gedächtniskunst wurde, ${ }^{9}$ metaphorisch über die Bildkunst ausgesagt haben soll, dass sie nämlich stumme Dichtung sei, wurde zuweilen schon in der sich als redende Malerei verstehenden Sprachkunst geradezu wörtlich realisiert. ${ }^{10}$ So konnten die bis auf Simias von Rhodos zurückzuführenden ideographischen Verfahren visueller Poesie auf verbale Elemente gänzlich verzichten, wenn sie durch rebusartigen Einsatz von Bildmaterialien eine Visualisierung des Begriffs leisteten, die den sprachlichen Ausdruck überflüssig machte. ${ }^{11}$ Der leeren schwarzen Seite in Sternes Tristram Shandy, ${ }^{12}$ den ausgelassenen Strophen in Puškins Evgenij Onegin ${ }^{13}$, 
der Aposiopese und dem nihilistischen Oxymoron (Mukařovský 1948, 115-116) in Máchas $M a j^{14}$ wohnte bereits eine gleichsam performative Kraft inne, die das Schweigen der Literatur zu einem autoreflexiven Mittel des Literarischen schlechthin machte. Und noch die sich als Sprachkritik gebende Philosophie spiegelt im Frühwerk Ludwig Wittgensteins die Tradition dieser Unsagbarkeitstopik, wenn sie der Autor nach dem letzten Satz des Tractatus mit negativem rhetorischen Pathos selbst umsetzt (Wittgenstein 1963, 115). Doch was man nicht mehr sagen kann - und dies ist eine Konsequenz, die gerade die Literatur des 20. Jahrhunderts aus einer solchen Sprachskepsis gezogen hat -, das kann man vielleicht besser zeigen...

\section{Experimentelle Poesie}

Als ein spezifischer Ausdruck einer nicht allein sprachphilosophisch, sondern auch dichtungslogisch und nicht zuletzt politisch motivierten Suche nach einer tragfähigen dichterischen Sprache kann die besondere Vielfalt visueller Gattungen in der tschechischen experimentellen Poesie von 1959-1969 gelten. ${ }^{15}$ Ausgehend von einer Kritik an der manipulierenden Sprache des Sozialistischen Realismus war in der nichtoffiziellen Literatur der 50er Jahre das dichterische Wort selbst ins Blickfeld geraten. Aus der quasi linguistischen Analyse entwickelten sich dann im Jahrzehnt vor der sowjetischen Invasion neuartige, bisweilen skurrile poetische Formen, die auf eine dualistische Sprachsituation reagierten, in der man dachte, was man nicht sagte, und sagte, was man nicht dachte. Schweigsam war diese Dichtung in zweierlei Hinsicht. Zum einen musste sie - trotz der ab 1963 einsetzenden Demokratisierung der Kulturpolitik, die dem Künstler in der Tschechoslowakei weitaus größere Freiheit gewährte als in der Sowjetunion, - immer noch dem Steuerungsinstrument der Zensur gehorchen, was oft einem Verstummen in der Öffentlichkeit gleichkam. Zum anderen schlugen manche Dichter in ihrer persönlichen Poetik den Weg einer Dichtung ohne Worte ein, die, in der Tradition visueller Poesie und im Kontext internationaler konkreter Dichtung stehend, mannigfaltige Grenzüberschreitungen zwischen künstlerischen Gattungen, literarischen Genres, Sprachen und Kulturen anstrebte.

Waren die Initiatoren experimenteller Poesie wie Jiří Kolář oder Ladislav Novák Ende der 50er Jahre noch unberührt von internationalen Entwicklungen, so versuchten die späteren Protagonisten Josef Hiršal und Bohumila Grögerová schon Anfang der 60er Jahre die kulturelle Isolation durch Kontaktaufnahme zunächst mit deutschen und österreichischen, bald mit französischen, italienischen, englischen und brasilianischen Literaten zu überwinden. In Zeiten relativer Liberalität wurde daraus ein weit verzweigtes Netzwerk, das Prag als „Mekka für Konkretisten“ (Ferdinand Kriwet) erscheinen ließ. Deutsche und österreichische Dichter aus dem Umkreis der konkreten Poesie wie Helmut Heißenbüttel, Hans Magnus Enzensberger, Reinhard Döhl, Ernst Jandl, Friederike Mayröcker, Heinz Gappmayr und Hans Carl Artmann suchten in Prag den Austausch und fanden Publikationsmöglichkeiten für Werke, die in einer konservativen heimischen Verlagslandschaft nicht 
gedruckt werden konnten. Französischen Vertretern wie Henri Chopin und Pierre Garnier wurde in halboffiziellen Lesungen ein Forum für phonische Poesie geboten. Manche Besucher konnten für Übersetzungen (Konrad Balder Schäuffelen), viele für Beiträge in den von Hiršal und Grögerová initiierten Sammelbänden gewonnen werden. ${ }^{16}$ Zwar konnte ihre Anthologie der tschechischen Vertreter erst mit über 30jähriger Verspätung erscheinen, ${ }^{17}$ doch durfte das Pendant, eine Anthologie internationaler experimenteller Poesie, schon in der Zeit als eine der umfassendsten Sammlungen im Weltmaßstab gelten (Hiršal, Grögerová 1967a). ${ }^{18}$

Es handelt sich damit um den seltenen Fall eines interkulturellen Dialogs, in dem nicht die kleinere Literatur die nehmende war, sondern in dem sie selbst einen innovativen Beitrag leistete und sogar die Entwicklung der anderen Literaturen förderte.

Beinahe folgerichtig scheint hier die ästhetische Verständigung über sprachliche Barrieren hinweg eine „,vorbabylonische“ Poesie hervorgebracht zu haben. Stellt man sich die Frage, wie dieser lebhafte Austausch zustande kam, so liegt die Vermutung nahe, dass er offenbar auf einem Korrelat in der Dichtung selbst beruhen muss. In der Tat tendieren gerade die Verfahren der Konkretion des sprachlichen Materials als Schrift- oder Lautwert zu einer asemantischen Poesie, die aufgrund der leistungsfähigeren Reproduktionsform des Buches vor allem die vielfältigen Varianten des Zusammenwirkens visueller Medien nutzte. „Schrift und Bild" lautete denn auch der Titel einer richtungweisenden Ausstellung, die Dietrich Mahlow 1963 (Mahlow 1963) in Deutschland initiierte und die, von dem Kunsthistoriker Jiří Padrta zu einem spezifisch tschechischen Konzept umgeformt, den entscheidenden Impuls für eine innovative Entfaltung tschechischer visueller Dichtung im halboffiziellen Raum lieferte. ${ }^{19}$

Vergleichbare Verfahren brachten ähnliche Gattungen hervor. So verzeichnet die tschechische Variante neben den Konstellationen und Typogrammen konkreter Poesie im Sinne Eugen Gomringers, die z. T. noch in der Reduktion auf einzelne Buchstaben eine dezidiert politische Aussage vermitteln (vgl. Abb. 2) ${ }^{20}$, ebenfalls visuell wirksame Piktogramme, Typographiecollagen und Figurengedichte. Daneben gingen aus einer starken Tendenz akustischer Poesie reine Lautgedichte, akustische Zeichnungen und Soundcollagen hervor. Hinzu kamen die vielfältigen Formen dreidimensionaler Gegenstandspoesie mit Gedicht-Objekten, Buch-Objekten, Ready-mades und Assemblagen. Auch konzeptuelle Gattungen wie die Aktionspoesie mit poetischen Gebrauchsanweisungen und Rezepten waren vertreten. Doch weist schon das explizite Bemühen um objektive Methoden auf eine Differenzqualität gegenüber den westlichen Ausprägungen hin. Der Einbezug mathematischer, logischer und - besonders unter dem Einfluss Max Benses (Bense 1967) - auch informationstheoretischer Verfahren, hinter denen oft die Überzeugung einer statistisch messbaren Ästhetik stand und denen Kybernetik und Computergraphik neue Gestaltungsmöglichkeiten eröffneten, führten zu einer besonderen Form der

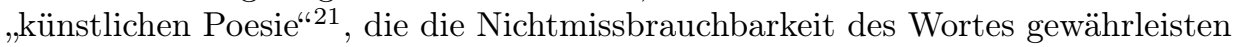


sollte. Wie sehr hier jedoch das Verständnis des scheinbar Inhaltlosen an den Kontext gebunden bleibt, soll an einigen Beispielen veranschaulicht werden.

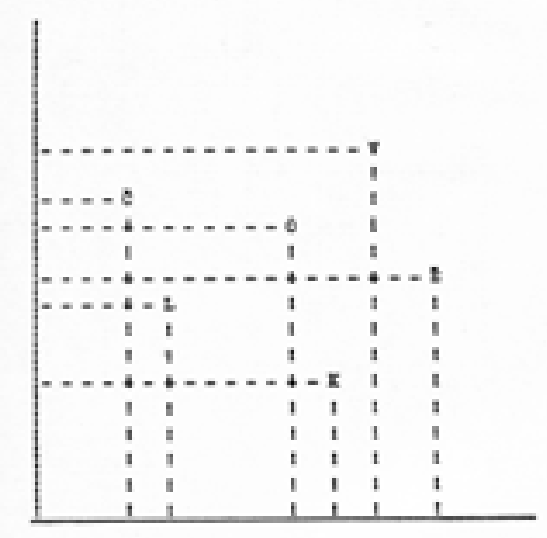

Abb. 2: Václav Havel: Člověk, 1966 (Havel 1993, o.S.)

\section{Beispiele}

Als erster Dichter zog Jiří Kolář aus der Situation seine poetologischen Schlüsse. Tiefe Zweifel an der Tragfähigkeit einer missbrauchten Sprache, maximale dichterische Ansprüche und das Gefühl ethischer Verantwortlichkeit veranlassten ihn, sein genuines Ausdrucksmedium zu wechseln, um sich ausschließlich der Herstellung verschiedenster Collageformen zu widmen. Ein kritischer Dichter, der für das freie Wort ins Gefängnis gegangen war, entledigte sich damit seines eigenen Instruments. Ausgehend von konkretistischen Typoskripten, die er bezeichnenderweise dem Schöpfer der malerischen Abstraktion, Kazimir Malevič, widmete, entwickelte Kolář Ende der 50er Jahre ungewöhnliche Varianten visueller Dichtung, die er „evidente Poesie“ nannte. Sie sind in der für die tschechische Literatur wohl bedeutendsten Sammlung dieser Art unter dem ebenso programmatischen wie sprechenden Titel Básně ticha, „Gedichte der Stille“, zusammengefasst (Kolár 1994). ${ }^{22}$ Darin bilden die der abstrakt-expressionistischen Kunst verwandten gestischen Skripturen (Abb. 3) den Auftakt zu nonverbalen Formen wie Knoten-, Blinden-, Duft-, Farben-, Bild- und Objektgedichten. Mit den gleichzeitig entwickelten vielfältigen Collagegattungen, die Kolář schon in den 60er Jahren als Künstler international bekannt machten, wird scheinbar die definitive Abkehr von 
der Literatur besiegelt. Doch hat er auch in seinem bildkünstlerischen (Euvre, dessen gattungsbildende Verfahren er später in „Wörterbüchern“ (Kolář 1999) ${ }^{23}$ systematisierte, das Gebiet der Dichtung nicht verlassen. ${ }^{24}$

Da Kolář die verbale und die visuelle Werkphase in einem deklarativen Akt durch das Moment des Poetischen zusammenschließt, können seine bildkünstlerischen Arbeiten - in Analogie zur Conceptual Art - auch unter dem Gattungsbegriff einer ,konzeptuellen Dichtung“" erfasst werden. Der Dichter hat offenbar die erst Ende der 60er Jahre entfaltete Kunstrichtung auf literarischem Gebiet antizipiert, so dass ihm eine Vorreiterrolle auch im europäischen Kontext zugesprochen werden muss. ${ }^{25}$

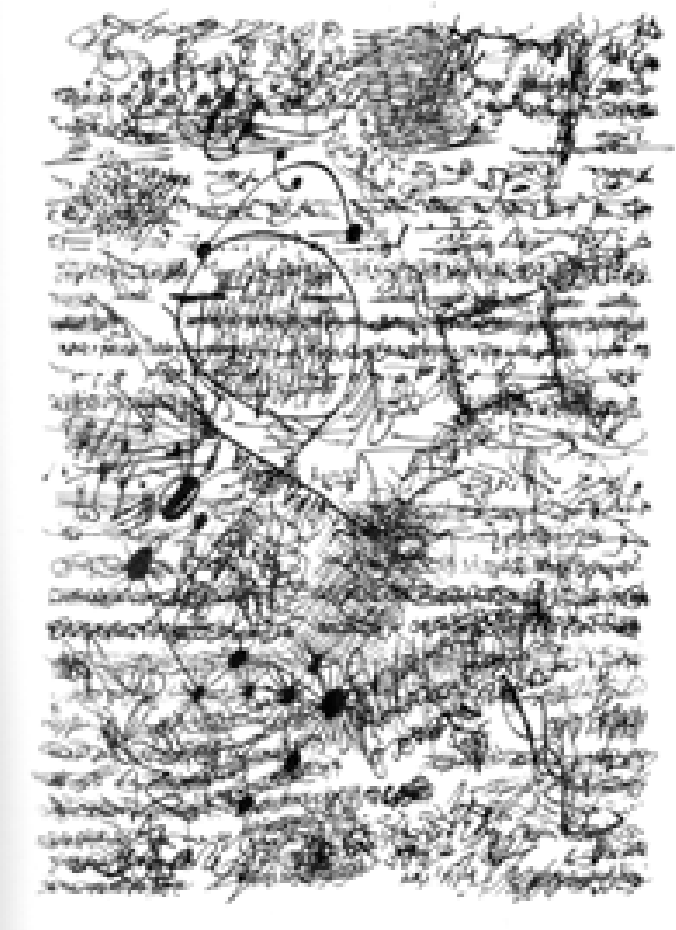

Abb. 3: Jiří Kolář: Cvokogram, 1962 (Kolář 2001, 40)

Während diese Kunstrichtung auf die stoffliche Gestalt zugunsten rein verbal formulierter Konzepte verzichtete, ohne dabei das Gebiet der Kunst zu verlassen, ${ }^{26}$ ersetzte Kolář das verbale Zeichensystem durch den semantischen Gehalt der produzierenden Geste. Gedicht ist, was als Gedicht dienen soll. Ähnlich wie in der künstlerischen Strömung sollen seine Werke auf die Vorstellung wirken, Erkenntnisprozesse in Gang setzten und für eine poetische Wahrnehmung der Welt sensibilisieren. Ein Anspruch auf Originalität wird nicht mehr gestellt, stattdessen ist es eine Poesie, die den Betrachter zum Mitspieler und Vollender macht. 
Den Beginn dieser Konzeptualisierung und Desemantisierung der Dichtung markieren 1961 „Analphabetogramme“, die den poetischen Ausdruckswillen eines Analphabeten wiedergeben wollen, und "Cvokogramme“ (Abb. 3), die ein Äquivalent für die stumme Geste des Geisteskranken bieten und so auf die alltägliche sprachliche Schizophrenie reagieren. ${ }^{27}$ Zwar verdanken sich diese graphischen Formen der Anregung durch surrealistische écriture automatique und informelle Malerei, die, spät rezipiert, eine starke Strömung tschechischer abstrakter Malerei ausbildete. ${ }^{28}$ Doch wird hier weder eine Psychographik des Unterbewussten angestrebt noch eine expressive abstrakte Malerei. Vielmehr ist in der reinen Schriftspur die Nullstufe der Literatur erreicht.Einem Seismogramm vergleichbar präsentiert sich die von der Alphabetschrift abstrahierte Handschrift als unmittelbarer Index des Autors, als geronnene Ausdrucksgeste ohne symbolische Vermittlung. Dabei weisen die unterschiedlichen Schraffuren und Verwischungen in zeiliger Anordnung, das Nebeneinander von kindlichem Hiebkritzeln und wohlgeformten Linienschwüngen mit der typischen Schriftneigung des Rechtshänders eine geradezu epische Breite verschiedener Ausdrucksmotive auf, die den Text wörtlich zur "Textur" machen. ${ }^{29}$ Da der Produzent aber weder Analphabet noch geistesgestört war, bleibt durch den Titel eine fiktive Ebene erhalten, so dass das Konzeptuelle hier in der als Rezeptionsanweisung fungierenden Gattungsbezeichnung besteht.

Die Unzufriedenheit über verbrauchte dichterische Mittel und literarische Schemata veranlassten auch Ladislav Novák 1958 - in der mährischen Provinz gänzlich unbeeinflusst vom internationalen Geschehen und angeregt durch Rundfunkberichte(!) über Ausstellungen von Jackson Pollock und Victor Vasarély -, die traditionelle Dichtung zu verlassen. Nach asemantischen onomatopoetischen Gedichten, die auf Anregungen mündlicher Eskimo-Poesie zurückgingen und die er bald direkt auf einem Tonträger realisierte (Novák 1970), begann Novák, WortKonstellationen nach dem vermuteten Vorbild des optischen Kinetismus zu schaffen, um durch wenige Verschiebungen im Graphembestand semantische Bewegungen zu erzeugen und zugleich überkommene literarische Gattungen zu ironisieren (Novák 1966, 1968a, 1968b). Daneben fragmentierte er in seinen präparierten Gedichten vorgefundene Texte nach aleatorischen Prinzipien bis zur Unlesbarkeit. Die Spontaneität der Geste, die ihn am amerikanischen Action painting faszinierte, führte auch zu quasibildkünstlerischen Verfahren wie Dripping, Abklatsch, Durchpausen oder Zerknüllung mit dem ehemaligen Träger der Schrift. So zeigten die „Froissagen“ in den Falten zufällig zerknüllten und geglätteten Papiers eine zeichenhaft stumme Schrift, die dann durch eine lavierend flächige Aquarellmalerei nachträglich wieder gegenständlich und oft mit grotesken Figurationen interpretiert wurde (Abb. 4). ${ }^{30}$ In seinem „Receptář“ versammelte er Beispiele der auch von Kolář entwickelten Gattung der Anweisung, einer Gedichtform also, die das Schweigen konzeptualisierte, indem sie, den ontologischen Status des Gedichts problematisierend, die Vollendung gänzlich der Rezipientenseite überantwortete (Novák 1992, 21-29). So entstanden etwa die „erotomagischen“ Tastgedichte (zwei Personen, eine aktive und eine passive, berühren sich in bestimmter Folge nach formulierten Regeln und 
dokumentieren ihre Assoziationen zugleich auf Tonband) erst durch die aktive Realisierung in der Empfindung und Vorstellung des Adressaten. Es handelt sich also um entmaterialisierte Gedichtformen, die den nonverbalen textus durch den tactus formen. ${ }^{31}$ Allerdings wandte sich Novák in diesen neuartigen Gattungen nicht mit der gleichen Radikalität vom dichterischen Wort ab wie Kolár, welcher später nur noch mittels Collagen korrespondierte und die dichterischen Tagebücher durch bildkünstlerische Wochenbücher ersetzte.

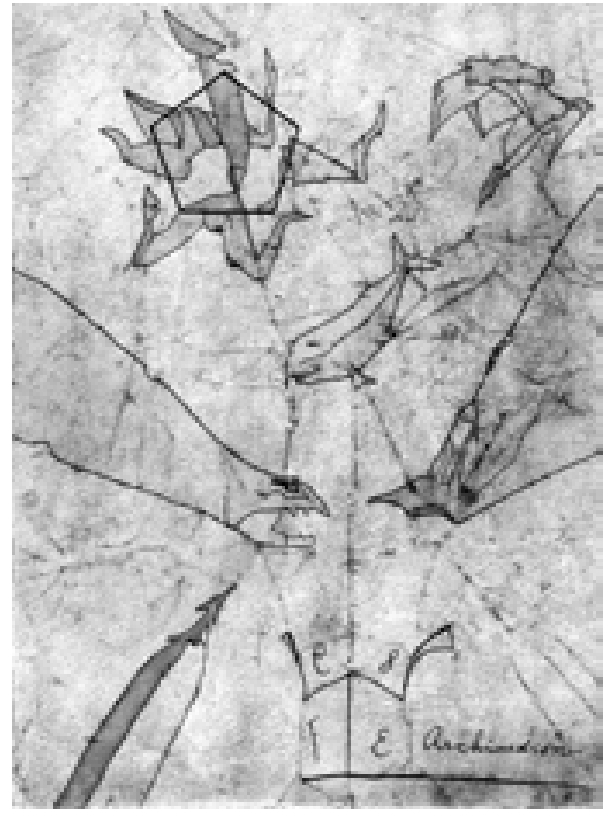

Abb. 4: Ladislav Novák: Archimedion, Froissage, 1968 (Novák 1992, Umschlag)

Im Unterschied zu den noch surrealistisch beeinflussten Versuchen Nováks hielt sich Ladislav Nebeský an die objektivierenden Prinzipien der neuen Wissenschaften und einen strengen Neokonstruktivismus. ${ }^{32}$ Als Computerlinguist entwickelte er numerische oder codierte Gedichte mit universalsprachlichem Ansatz, die, das Prinzip der mathematischen Permutation nutzend, jedoch nie eine ironische Distanz gegenüber der eigenen Profession verleugneten. So zeigt der „Kurs binärer Poesie", ${ }^{33}$ wie geschickt gewählte Buchstabensubstitute sogar für verschiedensprachige Lexeme dieselbe Codierung eines Begriffs ergeben können (Abb. 5). 


$\begin{array}{llll}\text { a } & 00 & \text { o } & \text { OIOOO } \\ \text { e } & \text { OOO } & \text { r } & \text { OOOIO } \\ \text { f } & \text { II } & \text { u } & \text { IOOOOOO } \\ \text { m } & \text { IOOO } & \text { w } & 1100 \\ \text { n } & 0 & \text { z } & \text { I10001000I }\end{array}$

\begin{tabular}{|c|c|}
\hline 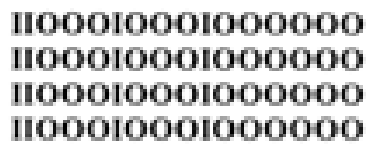 & Ľena \\
\hline 011101110011111 & $\begin{array}{l}\text { noman } \\
\text { femme } \\
\text { İena }\end{array}$ \\
\hline
\end{tabular}

$\begin{array}{llll}\text { n } & \text { I } & \text { z } & \text { OOIIIOHI } \\ \text { m } & \text { OIII } & \text { w } & \text { OOII } \\ \text { f } & \text { OO } & \text { v } & \text { OIIIIII } \\ \text { e } & \text { III } & \text { r } & \text { IIIOI } \\ \text { a } & \text { II } & \text { o } & \text { IOIII }\end{array}$

Abb. 5: Ladislav Nebeský: Kurs binární poezie, 1965 (Ausschnitt) (Hiršal, Grögerová 1993, 103)

Die Inspiration durch Schrifterfindung, wohl auch angeregt durch Knotengedichte, mit denen schon Kolář die peruanische Knotenschrift Quipu aufgegriffen hatte, ließ zahlreiche Entwürfe neuer Quasischriften entstehen. Josef Honys entwickelte groteske Zeichen, die an die Tradition der Figurengedichte erinnerten, ${ }^{34}$ Běla Kolářová bildete aus der Akkumulation gleichartiger Materialien (wie z.B. Kieselsteine, Rasierklingen, Werkzeuge, Haare) neue Muster, graphische Zeichen und wortanaloge Arrangements, die sie auch den natürlichen Veränderungsprozessen aussetzte (Kolářová 1993). Dagegen blieb bei Eduard Ovčáček der einzelne Alphabetbuchstabe erhalten und konnte, wie etwa in den „Lektionen des Großen A" allein durch typographische Gestaltung und visuelle Anordnung die narrativen Momente einer Fabel wiedergeben, politische Kritik zum Ausdruck bringen und sogar Miniaturdramen visualisieren (Ovčáček 1995). ${ }^{35}$

War hier der visuell genutzte, nicht mehr artikulierte Buchstabe der Akteur, so übernahm diese Funktion in den Werken Milan Grygars der zufällig erzeugte Laut. In kleinen Performances auf Papier hat er akustische Zeichnungen generiert (Valoch 1969, 27-28). Sie visualisierten den Klang kleiner mechanischer Gegenstände, oder sie dokumentierten die Bewegung der in Tinte getauchten Füßchen kleiner Küken, die über Notenpapier hüpfen. An diese ephemere Gedichtform erinnert im nachhinein nur das Zeugnis ihrer stummen Partitur (Abb. 6). 


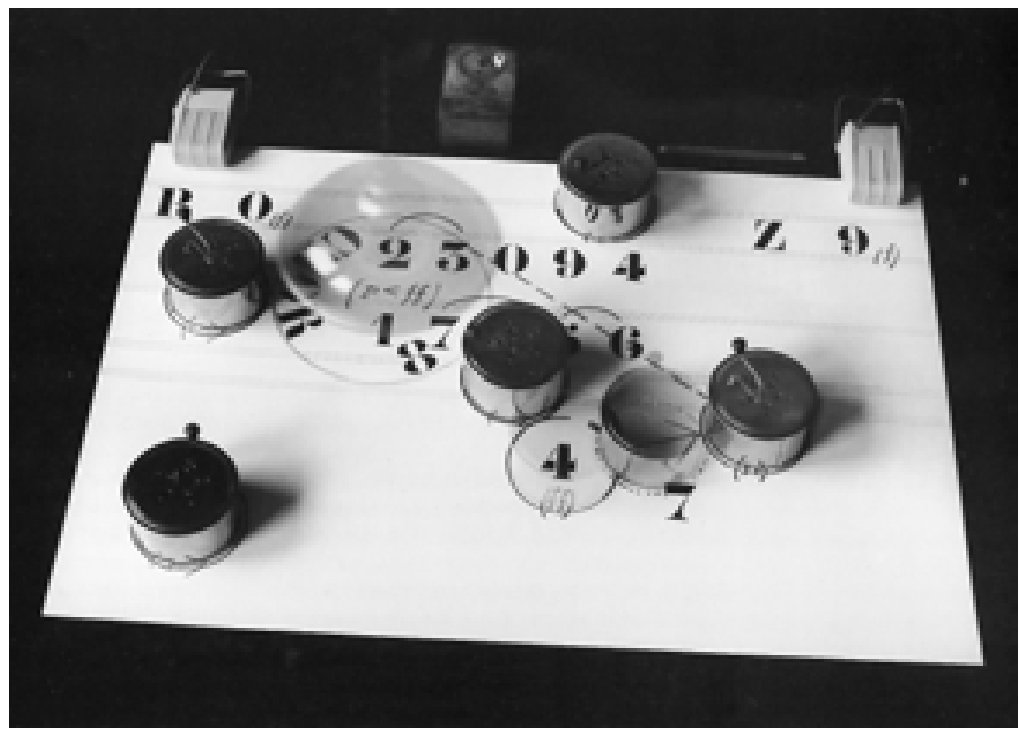

Abb. 6: Milan Grygar: Akustická kresba, 1968 (Thomas 1991, 50)

\section{Bedeutung}

Die dichterischen Reaktionen auf die dualistische Sprachregelung waren also vielfältig, und Kolářss unkonventionelle Lösung bildete gewiss keine Ausnahme, sie war aber, da er sich auch im Pariser Exil nicht mehr dem Wort zuwandte, eine der konsequentesten.

Ein komparatistischer Blick auf diese verschwiegene Strömung zeigt, wie sehr experimentelle Verfahren in ihrer Wirkung an das Gesellschaftssystem und den Zeitkontext gebunden bleiben, in dem sie aufgenommen werden: scheinbar unverbindliche Sprachspiele galten im totalitären System als brisanter Protest gegen politische Doktrinen, während sie in einer pluralistischen Kultur als selbstzweckhaftes Kuriosum aufgefasst werden konnten. So wird deutlich, dass es auch in einer erklärtermaßen rationalen Dichtungsart keine „objektiven“ Verfahren geben kann. Durch die pragmatische Einbindung in den ideologischen Diskurs war das Wort paradoxerweise sogar dann von großer Sprengkraft, wenn es, in seine Bestandteile zerlegt, keinen Inhalt mehr hatte. Daher erfordert gerade die asemantische Dichtung eine entschiedene Kontextualisierung. Dies beweist schon die Neurezeption der nichtedierten Werke: während noch die zeitgenössische Literaturkritik das in der Regel nur in Zeitschriften veröffentlichte Experiment äußerst kontrovers bewertete, wurde es in den 1990er Jahren in seiner Daseinsberechtigung niemals in Frage gestellt, wobei aber dem Bemühen um sachliche Darstellung häufig schon ein Gespür für die ungeheure Wirkungsmacht in seiner Zeit fehlte. An der westlichen Rezeption der Collagenkunst Kolářs, die eigentlich nonverbale Dichtung ist und sich gerade nicht durch explizite politische Stellungnahme, sondern durch die 
Betonung des Formseite dem Diktat sozialistischer Doktrinen widersetzte, wird das Missverständnis besonders deutlich. Die ethische Komponente des Schweigens macht denn auch den wichtigsten Unterschied der tschechischen gegenüber den westlichen Strömungen aus. Sie will für eine Poesie des Alltags sensibilisieren, die man nicht nur lesen, sondern auch sehen, hören, riechen, schmecken und „be-greifen“ kann. Im stillen Interesse am Poietischen an sich und am schöpferischen Prozess, selbst wenn er sich in der Isolation vollzieht, liegt die eigentliche Freiheit und das Subversive dieser ideologieresistenten künstlerischen Weltaneignung.

\section{Anmerkungen}

1 Stéphane Mallarmé: Crise du vers, zitiert nach Mallarmé 2000, 82. Siehe dazu auch SchmitzEmans 1995, 168-178.

2 Christian Morgenstern: Fisches Nachtgesang (Morgenstern 1972, 29).

3 Man Ray: Dadaistisches Lautgedicht, 1924 (Richter 1970, 123).

4 Erwin Schulhoff: Pittoresken für Klavier, 1919 (Bek 1994, 45).

5 Vgl. Kazimir Malevič, Weißes Quadrat auf weißem Grund, 1918 (Simmen 1999, 60-64).

6 Zur Monochromie siehe Riout 1996.

7 Eugen Gomringer: Schweigen, 1954 (Gomringer 1996, 58).

8 Zur Theorie der konkreten Poesie siehe z.B. Kopfermann 1981, Vollert 1999.

9 Vgl. zur Entstehungslegende Yates 1991, 34-35.

10 Die Tradition der wechselseitigen Erhellung und Horazrezeption beschreibt Lee 1998.

11 Zur allgemeinen Gattungsgeschichte des carmen figuratum siehe Ernst 1991.

12 Vgl. auch Nink 1993.

13 Vgl. Tynjanov 1977, 50-56.

14 Die Rezeption beschreibt Richterová 1991, 79-93.

15 Da noch keine umfassende Aufarbeitung der Strömung und ihrer teilweise bis heute unveröffentlichten Texte vorliegt, sei auf einige Aufsätze mit Überblickscharakter verwiesen: Valoch 1991, 74-84, Langerová 1998, 308-319, Abe 1999, 9.

16 Dokumente des internationalen Austauschs versammelt die Tagebuch-Trilogie Let let (Hiršal, Grögerová 1993-94).

17 Es handelt sich um die wichtigste Anthologie mit repräsentativem Anspruch (Hiršal, Grögerová 1993).

${ }^{18}$ Ein ebenfalls zusammengestellter Reader theoretischer Texte lieferte sogar den ersten Überblick zur Theorie dieser Dichtungsart, blieb allerdings aufgrund der Übersetzung ins Tschechische in der Wirksamkeit beschränkt (Hiršal, Grögerová 1967b).

19 Obraz a písmo, Špálova galerie, 1966. Vgl. Padrta 1964, 408-417, 447-453.

20 Václav Havel, Člověk, 1966 (Havel 1993, o.S.).

21 Hiršal und Grögerová informierten 1962 in Vorträgen über diese Strömungen, um sich dem direkten Zensurzugriff zu entziehen. Zugleich übertrugen sie die Kategorien der Texttheorie Benses auf ihre eigene Textproduktion. Vgl. Hiršal, Grögerová 1962, 1968. Missverständlich aufgenommen und ironisiert wurden die Verfahren von der Kritik (Milota 1966, 155-156).

${ }^{22}$ Die Sammlung wurde in Auszügen bereits in den 60er Jahren, vollständig aber erst 1994 veröffentlicht.

23 Vladimír Burda stellte die ersten Stichworte des Lexikons 1968 zusammen (Burda 1968, 428-436), darauf folgten zahlreiche weitere Redaktionen, die mit einer bedeutenden Ausweitung im Umfang verbunden waren.

24 Zum Medienwechsel siehe Winter 2006.

25 Einen ähnlichen Weg beschritt später Heinz Gappmayr (Simon 1995).

26 Vgl. z.B. Dreher 1992, Godfrey, 2005.

27 Vgl. die Ausgabe Kolář 2001, 40.

28 Vgl. den Ausstellungskatalog Nešlehová 1991. 
29 Zur Genealogie dieser poetologischen Metapher siehe Greber 2002.

30 Vgl. z.B. die Beispiele in Crispolti 1993.

31 Vgl. damit auch die Tastgedichte aus Knetmasse von Jan Švankmajer (Taktilní básně, 1988, Langerová 2002, 468-469), die freilich die Kenntnis der Tast- und Blindengedichte von Kolář aus den 60er Jahren voraussetzen.

32 Hier besteht eine deutliche Parallele zu den gleichzeitigen bildkünstlerischen Tendenzen (Hlaváček 1994, 55-57).

33 Ladislav Nebeský: Kurs binární poezie, 1966, bisher nicht vollständig veröffentlicht (Hiršal, Grögerová 1993, 92-106). Vgl. auch Nebeský 1997, 57-63.

34 Josef Honys: Text, 1970 (Valoch 1970, 27).

35 Mit der Majuskel A ist natürlich eine Allusion an den „Großen Bruder“ verbunden.

\section{Literatur}

Abe, K.: 1999, ,Česká vizuální poezie 60. let', Literární noviny 29, 9.

Bek, J.: 1994, Erwin Schulhoff. Leben und Werk, Hamburg.

Bense, M.: 1967, Teorie textu, Praha.

Burda, V.: 1968: ,Hesla z Kolářova slovníku', Výtvarné uměni 9-10, 428-436.

Crispolti, E. (ed.): 1993, Ladislav Novák, Bologna.

Dreher, T.: 1992, Konzeptuelle Kunst in Amerika und England, Frankfurt/M.

Ernst, U.: 1991, Carmen figuratum. Geschichte des Figurengedichts von den antiken Ursprüngen bis zum Ausgang des Mittelalters, Köln.

Godfrey, T.: 2005, Konzeptuelle Kunst, Berlin.

Gomringer, E. (ed.): 1996, Konkrete Poesie. Deutschsprachige Autoren. Anthologie, Stuttgart.

Greber, E.: 2002, Textile Texte. Poetologische Metaphorik und Literaturtheorie. Studien zur Tradition des Wortflechtens und der Kombinatorik, Köln.

Havel, V.: 1993, Anti-Kódy, Praha.

Hiršal, J., Grögerová, B.: 1962, O filozofii jazyka, statistické estetice a současném experimentu [Vortrag v. 20.12.1962], Lit. archiv Hiršal/Grögerová, LA PNP, Praha, 31 gtr. gez. Bl.

Hiršal, J., Grögerová, B. (eds.): 1967a, Experimentální poezie, Praha.

Hiršal, J., Grögerová, B. (eds.): 1967b, Slovo, písmo, akce, hlas. K estetice kultury technického věku, Praha.

Hiršal, J., Grögerová, B.: 1968, JOB-BOJ, Praha.

Hiršal, J., Grögerová, B. (eds.): 1993, Vrh kostek. Česká experimentální poezie, Praha.

Hiršal, J., Grögerová, B.: 1993-94, Let let. Pokus o rekapitulaci, sv. 1-3, Praha [u.a.].

Hlaváček, J.: 1994, Poesie racionality. Konstruktivní tendence v českém výtvarném uměni šedesátých let, Praha.

Kolář, J.: 1994, Básně ticha, Praha.

Kolář, J.: 1999, Slovník metod. Okř́dlený osel, Praha.

Kolár̆, J.: 2001, Snad nic, snad něco. Práce na papiře z let 1962-1963, Praha.

Kolářová, B.: 1993, Objekty a asambláže, Praha. 
Kopfermann, T.: 1981, Konkrete Poesie. Fundamentalpoetik und Textpraxis einer Neo-Avantgarde, Frankfurt/M.

Langerová, M.: 1998, „Experimentální poezie šedesátých let‘, Česká literatura 3, 308-319.

Langerová, M.: 2002 ,Vizuální aspekty básnického díla', Pohledy z blízka: zvuk, význam, obraz, Praha, 377-473.

Lee, R. W.: 1998, Ut pictura poesis. Humanisme et théorie de la peinture, XVe-XVIIIe siècle, 3. tir., Paris.

Mahlow, D. (ed.): 1963, Schrift und Bild, Baden-Baden [u.a.].

Mallarmé, S.: 2002, Un coup de dés jamais n'abolira le hazard. Ein Würfelwurf niemals tilgt den Zufall, Frankfurt/M.

Milota, K.: 1966, ,Systémová poezie přichází‘, Plamen 9, 155-156.

Morgenstern, C.: 1972, Sämtliche Dichtungen, Bd. 6, Basel.

Mukařovský, J.: 1948, Kapitoly z české poetiky. Díl třetí: Máchưv Máj, Praha.

Nebeský, L.: 1997, ,Prázdné místo‘, Česká literatura 45, 57-63.

Nešlehová, M.: 1991, Český informel, Praha.

Nink, R.: 1993, Literatur und Typographie. Wort-Bild-Synthesen in der englischen Prosa des 16. bis 20. Jahrhunderts, Wiesbaden.

Novák, L.: 1966, Pocta Jacksonu Pollockovi, Praha.

Novák, L.: 1968a, Závratě čili zdoufalství, Praha.

Novák, L.: 1968b, Textamenty, Brno.

Novák, L.: 1970, Phonetische Poesie, Neuwied [Schallplatte].

Novák, L.: 1992, Receptár̆, Praha.

Ovčáček,E.: 1995, Lekce velkého A, Praha.

Padrta, J.: 1964, ,Obraz a písmo II, II', Knižni kultura, 11-12, 408-417, 447-453.

Richter, H.: 1970, DADA - Kunst und Antikunst. Der Beitrag Dadas zur Kunst des 20. Jahrhunderts, 2., erw. Ausg, Köln.

Richterová, S.: 1991, ,Kontury ticha. Oxymóron v moderní české poezii‘, S. Richterová, Slova a ticho, Praha, 79-93.

Riout, D.: 1996, La peinture monochrome. Histoire et archéologie d'un genre, Nîmes.

Schmitz-Emans, M.: 1995, Schrift und Abwesenheit. Historische Paradigmen zu einer Poetik der Entzifferung und des Schreibens. München.

Simmen, J: 1999, Das schwarze Quadrat. Vom Anti-Bild zu Ikone der Moderne, Frankfurt/M.

Simon, I.: 1995, Vom Aussehen der Gedanken. Heinz Gappmayr und die konzeptuelle Kunst, Klagenfurt.

Thomas, K.: 1991, Tradition und Avantgarde in Prag, Köln.

Tynjanov, J. N.: 1977, Das Problem der Verssprache. Zur Semantik des poetischen Textes, München.

Valoch, J.: 1969, ,Akustické kresby', Host do domu 12, 27-28. 
Valoch, J.: 1970, ,Vizuální básně Josefa Honyse', Host do domu 5, 27.

Valoch, J.: 1991, ,České vizuální texty. Náčrt přehledu šedesátých až osmdesátých let', Rok 1, 74-84.

Vollert, L.: 1999, Rezeptions- und Funktionsebenen der Konkreten Poesie. Eine Untersuchung aus semiotischer, typographischer und linguistischer Perspektive, Würzburg.

Winter, A.: 2006, Metamorphosen des Wortes. Der Medienwechsel im Schaffen Jiř́ Kolářs, Göttingen.

Wittgenstein, L.: 1963, Tractatus logico-philosophicus, Frankfurt/M.

Yates, F. A.: 1991, Gedächtnis und Erinnern. Mnemonik von Aristoteles bis Shakespeare, Weinheim. 


\section{Wird die deutsche Sprache der tschechischen immer ähnlicher? \\ Beobachtungen beim Hörfunk}

Während meines Krimaufenthalts im Jahre 1985 sprach die des Deutschen durchaus kundige russische Dolmetscherin wiederholt von Vóroncov. Auf die diskrete Frage, ob der Graf und ehemalige Eigentümer des Palastes nicht Voroncóv hieße, bejahte sie dies zwar, begründete ihre Betonung jedoch damit, dass im Deutschen stets die erste Silbe akzentuiert würde. Welch ein Entgegenkommen gegenüber den deutschen Gästen!

Analysiert man mündliche Beiträge in Form von Nachrichten, Vorträgen, Kommentaren, Interviews etc., so lässt sich, besonders bei Fremdwörtern, eine Akzentverschiebung zur ersten Silbe beobachten. Nach meiner Erinnerung begegnet man wohl schon seit drei Jahrzehnten dem Adverb „úberhaupt“, obwohl der Duden dies auch in seiner neuesten Auflage (2006) noch nicht vorsieht. Es folgten Begriffe 
wie „Hórizont" und „Kónsens", letzterer vielleicht in Analogie zu „Nónsens". Das Míkrofon verdankt seine neue Betonung sicher der Abkürzung „Míkro“.

In diesem Jahr wurden in Rundfunksendungen zum Beispiel die folgenden ca. hundert Wörter auf der ersten Silbe betont:

\begin{tabular}{|c|c|c|}
\hline Afrikanistik & Reduzierung & konzentriert \\
\hline Alternative & Renaissance & kulturell \\
\hline August (Monat) & Solidarität & legal \\
\hline Dirigent & Solidität & lokal \\
\hline Finanzierung & Souveränität & materiell \\
\hline Infektion & Strategie & mental \\
\hline Information & Transfer & national \\
\hline Institut & & nationalistisch \\
\hline Integration & aggressiv & offensiv \\
\hline Islam & aktuell & offiziell \\
\hline Kalkulation & demographisch & ökonomisch \\
\hline Kombination & demokratisch & palästinensisch \\
\hline Kommunist & deplaciert & parallel \\
\hline Komponist & differenziert & populär \\
\hline Konsensdemokratie & effektiv & potentiell \\
\hline Konsolidierung & eruieren & prominent \\
\hline Kontinent & finanziell & renommiert \\
\hline Kontingent & finanzieren & routiniert \\
\hline Kontinuität & global & souverän \\
\hline Konzession & graduell & strapaziös \\
\hline Leviathan & humanitär & substantiell \\
\hline Manipulation & ideal & symptomatisch \\
\hline Marine & industriell & systematisch \\
\hline Modernisierung & intensiv & traditionell \\
\hline Organisation & international & turbulent \\
\hline Patriotismus & investieren & ultimativ \\
\hline Pessimist & kategorisch & umfassend \\
\hline Popularisierung & kommerziell & \\
\hline Qualifizierung & komplett & \\
\hline Qualität & konsequent & \\
\hline
\end{tabular}

alternative Energie

konvertierter Christ

anonyme Amtshilfe

galoppierende Preise

kriminelle Energie

massive Beteiligung

illustre Gesellschaft

nationale Ebene

kollektives Versagen

prosperierende Wirtschaft

kommunale Arbeitgeber

universelle Tragweite

komplizierter Abschluß

kontrollierte Heroinabgabe 
bisher

zuvor

insbesondere

zum Beispiel

Im Rahmen der Satzintonation ist die völlig unbegründete Hervorhebung einzelner Lexeme auffällig. Dies geschieht häufig in einer Weise, als solle ein gegenteiliger bzw. anderer Sachverhalt negiert werden (Beispiele: ein italienischer General, eine positive Bilanz, keine Opfer). Aber dies ist ein anderes Thema.

In letzter Zeit hat sich also u.a. auch der Wortrhythmus im Deutschen verändert, und zwar zugunsten der ersten Silbe, wie sich mühelos überprüfen lässt.

Mit eben dieser „tschechischen“ Betonung gratulieren wir zum Geburtstag und Ruhestand:

Ob króatisch, serbisch, russisch, bosnisch,

Herr Kroll spricht alles und auch polnisch:

Die ganze Breite unseres Faches

in Ost und West und Süd, er macht es.

Credit points, Module kennt er.

In Angerstein zum Bus hin rennt er

Und hält im Winter - ist es wahr? -

ein gar so nettes Séminar. (Sonett)

Bachelor, Master - all die Fragen

béantwortet ohne Zagen

unser Held vorm Ruhestand.

Fehlen wird er hierzuland.

Slávisten, auch Gérmanisten

und so viele andere -isten

wünschen Glück, des Lobes voll,

uns'rem Doktor Walter Kroll. 



\section{Aspekte der Verfremdung}

In dem Roman Povratak Filipa Latinovicza von Miroslav Krleža (1932) äußert sich eine Romangestalt über Seereisen und Befahren von Meeren im Allgemeinen. „More je prilično velika (za ljudske mjere naime) količina kisika i vodika, po kojoj se ljudi voze po nekakvim glupim splavima i na tim krčmama na splavima plaćaju mineralne vode i kosano meso mnogo skuplje nego po obichim krčmama na kopnu. [...] Po tim svojim korabljama ljudi vješaju smiješne raznobojne krpe i tako šarenim tkaninama nakićene splavi predstavljaju ,morske prevlasti ${ }^{6}$, a sve se to zapravo događa na jednom izvjenom kvantitetu izvjesnij plinova u tekućem stanju, što su se razlili po jednoj blatnoj lopti.“ (Nach dem Text der Erstausgabe, Zagreb 1932, S. 173)

Genau fünfzehn Jahre später hat Wolfgang Borchert in seiner Kurzgeschichte Die Kegelbahn etwas Vergleichbares unternommen. Geschildert wird, nahezu im Stil eines Schulaufsatzes, ein Kriegsvorgang. Von zwei Löchern (Frontlinien) ist die Rede sowie von Männern, die einander nicht kennen, aber voll damit beschäftigt 
sind, aufeinander zu schießen. Ein Kopf, der Parfum riechen, Brot essen und Inge sagen kann, wird aus dem andern Loch „kaputt" gemacht. Und umgekehrt.

Die Geschichte beruht auf einer durchaus kritischen Anschauung, doch die befremdende (und dadurch verfremdende) Perspektive besteht darin, daß die Kritik an militärischer Gewaltanwendung auf eine spielerische, gleichsam infantile Weise erfolgt. Wesentliche Bedingungen des Phänomens ,Krieg‘ werden nach dem Muster kindlicher Spiele oder auch anonymer Verwaltungsvorgänge modelliert. Etwa nach dem Motto: Krieg ist, wenn von einem Graben zum anderen hin scharf geschossen werden darf, unter der Bedingung, man kennt die Leute von drüben nicht; Hauptsache, sie tragen andere Farben, wie Sportler. Die literarische Absicht ist evident. Die Kontextverschiebung, ohne die es keine Verfremdung gibt, besteht darin, daßs ein bestimmtes Geschehen aus dem Zusammenhang mentaler Gewohnheiten herausgelöst und dieser Erscheinung das Vertraute genommen wird, das ihm seit altersher durch imperiale und agonale Überlieferung zugewachsen ist. Die ideologische Tradition läßt den absurden Vorgang, nämlich das quasi sportliche Töten von Menschen, als etwas Normales und Selbstverständliches erscheinen, jedenfalls als etwas, was nicht weiter in Frage gestellt wird. Stellt man den Vorgang jedoch anders dar, indem man ihm seine Selbstverständlichkeit nimmt, wird die Frage nach Sinn und Rechtmäßigkeit des Tuns wieder angemessen. Mit anderen Worten: die Fremdheit in der Anschauungsform lenkt unverhofft den Blick auf die Logik und die Motive des Geschehens.

Die beiden Beispiele verbindet keinerlei stoffliche Verwandtschaft. Um so deutlicher erkennt man, worauf es ankommt. Fremdheit wird hergestellt, indem die gewohnten gesellschaftlichen Deutungsmuster ästhetischer, politischer oder wirtschaftlicher Art beseitigt werden und die Beurteilung der Dinge ausschließlich von deren nackter Materialität ausgeht. Fremdheit durch Reduktion also: das Meer wird naturgeschichtlich gesehen, Technik auf Urformen reduziert, und von den Hoheitszeichen bleibt das übrig, was sich als betastbarer Rest darbietet. Hätte Krležas Figur etwa eine altertümliche Schlacht mit bunten Uniformen, Standarten und Wimpeln beschrieben, so wäre das Bild zweier Menschengruppen entstanden, die sich viel Mühe geben, einander die Köpfe einzuschlagen, und die dabei besondere Aufmerksamkeit Eisenplatten mit aufgemalten Tieren und Burgen widmen.

Wendet man sich der Theorie der Verfremdung zu, führt in der Sekundärliteratur kein Weg an Šklovskij und Brecht vorbei. Eben aus diesem Grund erscheint es ratsam, auf eine ausführliche Darstellung der weitgehend bekannten Positionen einmal zu verzichten. Die folgenden Ausführungen verstehen sich jedoch als Ergänzungen zu Šklovskijs Theorie.

Die Anfänge eines systematischen Verfremdungsdiskurses werden zumeist im 18. Jahrhundert gesucht, in Voltaires Erzählungen etwa. Übersehen wurde dabei ein Text der deutschen Romantik, der auf sehr einprägsame Weise bereits eine Verfemdungsästhetik in nuce enthält. Es handelt sich um eine Stelle aus Ludwig Tiecks 1795 erschienenen kleinen Roman Peter Lebrecht, einem weniger bekannten Werk aus der ersten Schaffensphase. Der Autor kündigt im Untertitel eine „Geschichte 
ohne Abenteuerlichkeiten" an. Der heutige Leser erkennt leicht, was als Ersatz für Abenteuer angeboten wird: jede Menge Metatextualität und Intertextualität. In einer Formulierung des Erzählers wird deutlich, wie klar der Verfasser eine Poetik der Verfremdung anvisiert (ohne indes das Wort selbst zu gebrauchen). Das 16. Kapitel beginnt folgendermaßen:

Ich kam zurück und mein alltägliches Vaterland kam mir nach meinen Reisen mit einem Male ganz neu vor. So wie ein altes Kleid, das wir verdrüßlich in den Schrank hängen und es in langer Zeit nicht ansehen, unns hernach wieder besser und neuer vorkommen kann: so ging es mir gerade mit meinen Landsleuten, mit ihren Sitten, ihrer Sprache, ihren Städten und Dörfern, Weibern und Töchtern. Das Alltägliche und Langweilige bestimmen und messen wir immer nach dem, was dicht um uns herum ist, das, was uns ergötzen soll, suchen wir immer in der Ferne. Von Jugend auf ist es unser Studium gewesen, uns alles Fremde, Sitten, Sprache, Kleidertrachten u.s.w. gewöhnlich zu machen; wir sollten es nur einmal versuchen, uns das Gewöhnliche fremd zu machen, und wir würden darüber erstaunen, wie nahe uns so manche Belehrung, so manche Ergötzung liegt, die wir in einer weiten, mühsamen Ferne suchen. Das wunderbare Utopien liegt oft dicht vor unseren Füßen, aber wir sehn mit unsern Teleskopen darüber hinweg." (L. Tieck: Frühe Erzählunqen und Romane. München 1978, S. 124 f.)

Bemerkenswert ist diese Stelle schon deswegen, weil sie zeigt, daß Auffassungen von Verfremdung ihren Ausgangspunkt in ganz unterschiedlichen Weltbildern haben können. Der romantische Wunsch nach der Entdeckung des Fremden im Alltäglichen ist kein Symptom einer Sinnkrise, sondern ein Zeichen der Hoffnung, daß das Wunderbare sich immer und überall offenbaren könne. Verfremdung ist hier in der Tat eine utopische Kategorie, denn es geht um die Entdeckung oder Wiedererlangung verlorener Erlebnisintensität. Das Teleskop (ein Instrument rationaler Welterfassung!) ist durch seine Zweckhaftigkeit gleichsam stumpf geworden für den spontanen Blick. Das Medium der Romantiker ist hingegen die kindliche, noch unverbrauchte Sicht der Dinge. Für Novalis ist daher die Kindheit im Allgemeinen fast eine geschichtsphilosophische Kategorie. „Wo Kinder sind, da ist ein goldnes Zeitalter", verkündet er in seinen Fragmenten (Werke und Briefe, hg. von A. Kelletat, München 1962, S. 362).

Die positiven Konnotationen der romantischen Vorstellung von paradoxer Fremdheit lassen sich gut hundert Jahre später in abgewandelten Denkmotiven erkennen. Wir geben hier ausnahmsweise die Šklovskij-Abstinenz auf und zitieren aus einem Text, der weniger bekannt ist als der berühmte Aufsatz über die Kunst als Verfahren von 1917. Gemeint ist die Schrift Literatura i kinematograf (1923), in der die Ausführungen zum Begriff ,ostranenie' keinen Zweifel daran lassen, daß dieser Begriff als das Theorem einer allgemeinen Ästhetik angelegt ist. (Da mir das Original z.Z. nicht zur Verfügung steht, zitiere ich aus der Übersetzung von R. Grübel und P. Scherber, veröffentlicht in: Formalismus, Strukturalismus und Geschichte, hg. von A. Flaker und V. Žmegač, Kronberg/Ts. 1974, S. 27.) 


\begin{abstract}
„Wir leben in einer armen, abgeschlossenen Welt. Wir fühlen die Welt nicht, in der wir leben, wie wir die Kleidung nicht fühlen, die wir tragen. ... Die Pythagoräer haben gesagt, daß wir die Sphärenmusik deshalb nicht hören, weil sie ununterbrochen fortdauert. So hören die Menschen, die am Meer leben, das Rauschen der Wellen nicht, wir hören aber nicht einmal die Wörter, die wir sagen. Wir sprechen eine armselige Sprache nicht zu Ende gesprochener Wörter. Wir sehen einander ins Gesicht, aber wir sehen einander nicht."
\end{abstract}

Hier springt die Kunst ein, erläutert Šklovskij; denn das Kunstwerk vermag den Mechanismus des Gewohnten zu stören. Die Fremdheit neuer Beziehungen verleiht der Wahrnehmung jene Spontaneität, die unter sogenannten normalen Bedingungen zumeist verkümmert. Mit anderen Worten, der Künstler sorgt dafür, daß wir das Rauschen der Wellen wieder hören und die Gesichter wahrhaftig sehen, nicht nur flüchtig erkennen. Mehrdeutig ist diese Theorie allerdings dort, wo es um die Frage geht, was die volle, spontane Perzeption der Realität eigentlich bewirken soll. Ist das unverbrauchte Sehen nur ein Akt sinnlicher Regeneration oder ein Vorgang komplexer, gesteigerter Erkenntnis? Überwiegt die ästhetische oder die intellektuelle Beschaffenheit? Bei Šklovskij weisen die rein theoretischen Äußerungen in die erste, die Beispiele (vor allem jene aus den Erzählwerken Tolstojs) eher in die zweite Richtung.

An dieser Stelle liegt es auf der Hand, die unterschiedlichen Aspekte verfremdender Schreibweise behelfsmäßig zu sortieren, ohne Anspruch auf eine geschlossene Typologie. Es erscheint sinnvoll, drei Tendenzen zu unterscheiden. Die Absicht, die Künstlichkeit von Konventionen erkennbar zu machen, Konventionen gleichsam zu dekonventionalisieren, liegt der ersten zugrunde; der Versuch, die Widersprüche menschlicher Handlungen in prägnanten Modellen anschaulich zu machen, der zweiten; die Neigung, die conditio humana ganz allgemein als eine Aporie zu begreifen und diese Erkenntnis in entsprechende Bilder zu bannen, der dritten. Es versteht sich, daß bei einem Verfahren, wie es die Verfremdung ist, die Grenzen nicht scharf gezogen werden können. Wenn die allgemeine Orientierung des Textes beispielsweise satirisch ist, wird die Konstellation der Stilelemente anders beschaffen sein als etwa bei einer Ausrichtung auf eine universale Groteske.

Am Anfang standen zwei Beispiele für das Verfremden von Konventionen. Ein drittes mag zeigen, wie bezeichnend gerade die infantile oder naive (bzw. gespielt naive) Sicht für diesen Typus ist. Es handelt sich um eines der Hauptwerke der amerikanischen Literatur, Mark Twains Roman The Adventures of Huckleberry Finn (1884). Eine eigentümliche Sicht der europäischen Geschichte kommt hier durch die kindlichen Vereinfachungen des kleinen Romanhelden zustande. Im Gespräch mit dem schwarzen Jungen Jim, der staunend zuhört, präsentiert Huckleberry seine bescheidene Mixtur aus Grundschulwissen und Trivialliteratur (zit. nach der Ausgabe: Washington Square Press, New York 1960, S. 99 f.):

I read considerable to Jim about kings and dukes and earls and such, and how gaudy they dressed, and how much style they put on, and called each other your 
majesty, and your grace, and your lordship, and so one, 'stead of mister; and Jim's eyes bugged out, and he was interested. He says:

- I didn' know dey was so many un um. I hain't hearn 'bout none un um, skasely, but ole King Sollermun, onless you counts dem kings dat's in a pack er k'yerds. How much do a king git?

- Get? I says; why, they get a thousand dollars a month if they want it; they can have just as much as they want; everything belongs to them.

- Ain' dat gay? En what dey got to do, Huck?

- They don't do nothing! Why, how joy talk! They just set around.

- No; is dat so?

- Of course it is. They just set around - except, maybe, when there's a war; then they go to the war. But other times they just lazy around; or go hawking - just hawking ... and other times, when things is dull, they fuss with the parlyment; and if everybody don't go just so he whacks their heads off. But mostly they hang round the harem.

Interpretiert man das infantile Schwadronieren in windschiefer Grammatik als einen Akt literarischer Verfremdung, so steckt mehr darin als ein gefälliger Scherz. Geschichte wird weder pathetisch-affirmativ noch kritisch gesehen, sie wird vielmehr aus jeglichem Begründungszusammenhang herausgenommen und auf etliche primitive Handlungen reduziert. Mit den Mitteln der Untertreibung wird indes zugleich karikaturistische Übertreibung erzeugt. Und darin liegt die eigentümliche Wahrheit des Textes. Die Verfremdung darin beruht auf einer Theorie des Kindermundes: Da dieser keine Ideologie und keine entsprechende Werteskala kennt, benennt er die Dinge drastisch, ohne die herkömmliche Aura und die schirmende Konvention. Die infantile Selektion ist Verzerrung, zweifellos. Doch darin liegt ihre verfremdende Evidenz. Man mag bei Mark Twains historischen Extrakten an folgenden Aphorismus von Karl Kraus denken: „Die Verzerrung der Realität im Bericht ist der wahrheitsgetreue Bericht über die Realität." (K. Kraus: Beim Wort genommen, München 1955, S. 229)

Wir legen keinen sehr weiten Weg zurück, wenn wir von der Bloßstellung von Konventionen zum Wahrnehmungsschock durch Widersprüche gelangen. Exemplarisch dafür ist eine Szene aus einem Roman, den man zu den klassischen Werken verfremdender Kunst zählen sollte: Flauberts Madame Bovary (1857). Im achten Kapitel des zweiten Teils bildet den Schauplatz die Jahresversammlung der Landwirte; Reden werden gehalten, Viehzüchter gepriesen, Preise verliehen. Doch der Leser erfährt auch, was Emma Bovary und ihr Liebhaber Rodolphe, die sich im akustischen Umkreis der Veranstaltung befinden, zu gleicher Zeit einander zu sagen haben. Verfremdung wird hier im kommentarlosen berichtenden Diskurs durch akustische Simultaneität erzeugt. Jeder Satz des Liebespaares (etwa die Beteuerung, man werde einander nie vergessen) erscheint unfreiwillig im Lichte 
landwirtschaftlicher Errungenschaften, ebenso wie jeder Satz über Merinoschafe oder Düngemittel unversehens in den Bedeutungszusammenhang eines Liebesgesprächs hineingerät und dort befremdliche Assoziationen weckt. Der Abschnitt besteht aus einer regelmäßigen Abfolge im Wechsel der Stimmen von beiden Seiten. Mit erlesener Bosheit setzt Flaubert seine Verfremdung in Szene: Durch Gleichzeitigkeit ruft er eine wechselseitige Spiegelung der Aussagen hervor, in der jeder der beiden disparaten Bereiche plötzlich fremd, sinnlos, bis zur Lächerlichkeit relativiert erscheint. Die Selbstverständlichkeit der sonst getrennten Vorgänge wird fragwürdig, und man glaubt auf einmal, verborgene Beziehungen zu entdecken; so etwa in den Sätzen des Liebesgeflüsters, in denen sich nun eine Korrespondenz mit der Rhetorik der Landwirte und Beamten abzeichnet. In Rodolphes Worten vernimmt man die verschleierte Unwahrhaftigkeit des eitlen Genießers, der erotische Erfolge sammelt wie andere Menschen Auszeichnungen und Trophäen.

Ein letzter Text führt ebenfalls die Gleichzeitigkeit des Beziehungslosen vor Augen, allerdings in einer Zusammenschau, die die milieuhaft-realistische Darstellung bei Flaubert hinter sich läßt und ins Allgemeine, Existenzielle vorstößt. Verfremdende Visionen dieser Art finden sich bei Krleža, besonders einprägsam abermals in dem Roman Povratak Filipa Latinovicza. In den ersten Kapiteln, in denen geschildert wird, wie der Romanheld nach vielen im Ausland verbrachten Jahren in seine ihm fremd gewordene Heimat zurückkehrt, gibt es eine besonders eindringliche Stelle. Sie findet sich im vierten Kapitel, wo Filip, der Maler ist, vom Fensterplatz eines Cafés aus das Treiben auf der Straße betrachtet, eigentlich teilnahmslos und dennoch mit einem durchdringenden Blick für die Gegensätze und Widersprüche des Daseins. Die verfremdende Sicht kommt zustande, indem der Beobachter am Fenster die Passanten in ungewohnten Zusammenhängen sieht. So isoliert er in seinen Gedanken etwa die Hände und gelangt in einem Zustand transzendentaler Schau zu einer Epiphanie der menschlichen Hand.

Ruke. Kako samo izgledaju te mase ljudskih ruku što se miču po gradskim ulicama? Te ljudske ruke kolju, puštaju krv drugim životinjama, stvaraju strojeve, bodu iglama, drže usjane pegle, svjetiljke, zastave, britve, instrumente, ljudi ih pronose ulicama i ne znaju što bi s njima? Skidaju suknene šešire, mašu palicama, nose u rukama predmete, cigarete, knjige, jedna ruka drži drugu ruku u magnetizmu tjelesnog dodira, tople su ruke ljudske, znoje se, krastsve su, ranjene, okupane, nafarbane [...] A ljudi vuku sobom svoje ruke, svoje dugove, svoje gnjile zube i brige, i žene, i djecu, i umorne noge, i nezdravo, žalosno tijelo, i tako se miču u bokovima i u zglobovima, otvaraju usta, govore, viču, a gdjegdje javlja se na usnama ljudskim smijeh. Još uvijek ima prašume u obrazima ljudskim i taj protuprirodan smijeh što se tu i tamo javlja među ljudima, taj smijeh zvoni kao srebrno zvonce nad tminama, ali u glavnom lica su ljudske umorna i nepomična, više drvena nego mesnata. Čudni su ti obrazi ljudski, ukočeni, tvrdi, kao dlijetom tesani, a lanci i tkanine i krzna sve to visi na ljudima kao suvišan ukras i plete se zajedno sa suknjama, sa grivom i dlakama, stakalcima i očima u čudnom neraspletivom kolopletu i zepletu; kratkovidno, umorno, zlobno i dosadnom uglavnom. (A.a.O., S. 27 f.) 
Krležas Romanfigur (und mit ihr, wie wir aus anderen, nichtfiktionalen Texten wissen, auch der Autor) schwankt zwischen einer geschichtlichen und einer ontologischen Sicht. Im genannten Kapitel ist im Hinblick auf das Aussehen der Passanten ganz allgemein vom „Leben in den westeuropäischen Städten in der Abenddämmerung einer alten Zivilisation" die Rede. Doch diese Aussage wird von verfremdenden Verallgemeinerungen wesentlich relativiert. Die historische Spätzeit ist, wie so oft bei Krleža, eines der eindringlichsten Symbole der conditio humana.

Die bei dem kroatischen Autor von Nietzsche und Schopenhauer beeinflußte Anschauung, daß das geschichtliche Tun der Hände stets auch transhistorische Züge offenbare, kann als Bestätigung unserer dritten Kategorie gelten. Diesmal ist der Wesensunterschied radikal. Hatten wir es in den vorigen Beispielen mit Darstellungsformen zu tun, die von konkreter Gesellschafts- und Sprachkritik bis zu humoristischer Persiflage reichten, führt Filips Zeiten und Räume verbindende Vision in die Bereiche existenzieller Problematik, wo das Disparate der Realität nicht mehr einheitlich gedeutet werden kann und sämtliche eingeschliffenen Wahrnehmungsformen in Frage gestellt werden. Es ist allerdings fraglich, ob die herkömmliche, wenn man so will: die klassische Auffassung von Verfremdung hier noch anwendbar ist. Wer von Brechts Poetik herkommt, wird die Kluft sicherlich als unüberbrückbar bezeichnen. Im Hinblick auf Šklovskijs Theorie dürfte die Antwort wohl weniger apodiktisch ausfallen. 



\section{Schriftenverzeichnis von Dr. Walter Kroll}

\section{Monographien}

1. Heraldische Dichtung bei den Slaven. Mit einer Bibliographie zur Rezeption der Heraldik und Emblematik bei den Slaven (16. - 18. Jh.). Wiesbaden 1986 (= Opera Slavica. N.F., Bd. 7). - 202 S.

2. Epochen der polnischen Literatur. Eine bibliographische Einführung. Göttingen 1996, 2. Aufl. 2000 (= Der Blaue Turm, Bd. 16). - 336 S.

3. Epochen der kroatischen Literatur. Eine bibliographische Einführung. Göttingen 1998 (= Der Blaue Turm, Bd. 20). - 272 S.

\section{Anthologien - Herausgebertätigkeit}

4. Literaturtheoretische Modelle und kommunikatives System. Zur aktuellen Situation in der polnischen Literaturwissenschaft. Hrsg. Walter Kroll und Aleksandar Flaker. Kronberg (Taunus) 1974. - 418 S. 
5. Književna komunikacija. Antologija poljske znanosti o književnosti. Hrsg. Walter Kroll. Themenheft der Zeitschrift „Umjetnost riječi“, 18 (1974), 2-4, Zagreb 1979. - S. $95-464$.

6. A.S. Puškin: Evgenij Onegin. Roman in Versen. Russisch-deutsche Parallelausgabe. Prosaübersetzung von Maximilian Braun. Hrsg. Vasilij Blok und Walter Kroll. Göttingen 1994, 2. Aufl. 1996, 3. Aufl. 2004 (= Der Blaue Turm, Bd. 14). - $191 \mathrm{~S}$.

7. Titov, Fedor: Tipografija Kievo-Pečerskoj Lavry. Die Druckerei des Kiever Höhlenklosters. Als Reprint herausgegeben und eingeleitet von Martin Erdmann und Walter Kroll. Köln - Weimar - Wien 2000 (= Bausteine zur Slavischen Philologie und Kulturgeschichte. Reihe B: Editionen. Neue Folge, Bd. 15). - LIII, $506 \mathrm{~S}$.

8. Slavische Literaturen im Dialog. Festschrift für Reinhard Lauer zum 65. Geburtstag. Hrsg. Ulrike Jekutsch und Walter Kroll. Wiesbaden 2000. - 561 S.

\section{Aufsätze}

9. Zur Einführung. In: Literaturtheoretische Modelle und kommunikatives System. Zur aktuellen Situation in der polnischen Literaturwissenschaft. Hrsg. Walter Kroll und Aleksandar Flaker. Kronberg (Taunus) 1974. - S. 3 -34 .

10. Poljska znanost o književnosti u kontekstu novije književnoteorijske diskusije. In: Književna komunikacija. Antologija poljske znanosti o književnosti. Hrsg. Walter Kroll. Themenheft der Zeitschrift „Umjetnost riječi“, 18 (1974), 2-4, Zagreb 1979. - S. 95-122.

11. Ares und Dionysos als Paradigmen der Mythosrezeption in den slavischen Literaturen des 19. und 20. Jahrhunderts. In: Ares und Dionysos. Das Furchtbare und Lächerliche in den europäischen Literaturen. Hrsg. H.-J. Horn und H. Laufhütte. Heidelberg 1980 (= Mannheimer Beiträge zur Sprach- und Literaturwissenschaft, Bd. 1). - S. $203-222$.

12. Die „Neue Ökonomische Politik“" in der sowjetischen Satire der zwanziger Jahre. In: Ökonomie. Sprachliche und literarische Aspekte eines 2000 Jahre alten Begriffs. Hrsg. Th. Stemmler. Tübingen 1985. - S. $127-141$.

13. Randbemerkungen zur Emblematik-Rezeption bei Jan Kochanowski. In: Jan Kochanowski. Ioannes Cochanovius $(1530-1584)$. Materialien des Freiburger Symposiums 1984. Hrsg. Rolf Fieguth. Freiburg (Schweiz) 1987. - S. $205-$ 219. 
14. Aspekti recepcije mita na primjeru „Hrvatske rapsodije“ Miroslava Krleže. In: Godišnjak Instituta za književnost, Bd. 15, Sarajevo 1985. - S. 9 - 42.

15. Aspekte der Mythos-Rezeption - am Beispiel der „Hrvatska rapsodija“. In: Künstlerische Dialektik und Identitätssuche. Literaturwissenschaftliche Studien zu Miroslav Krleža. Hrsg. Reinhard Lauer. Wiesbaden 1990 (= Opera Slavica. N.F., Bd. 19). - S. $41-89$.

16. Die Welt als Buch. Stefan Javorskij und seine Bibliothek. In: ,Ite eis manibus gestati saepe libelli“. Studia Slavica Ioanni Schultze bibliothecario eminentissimo librorum peritissimo slavicorum [...] dedicata. Edidit Werner Lehfeldt. Göttingen 1995. - S. 95 - 116.

17. Nova hrvatska proza. In: Republika, H. 1-2, Zagreb 1999. - S. 26 - 30.

18. Zur Aufnahme der slovakischen Literaturwissenschaft in Deutschland. In: Deutsche und slovakische Literatur. Beiträge von einem Komparatistischen Symposium 28. bis 29. Januar 1995 in Göttingen. Hrsg. Reinhard Lauer. Wiesbaden 2000. - S. 155 - 192.

19. Statt einer Literaturgeschichte. Titovs Darstellung der Buchdruckkunst des Kiever Höhlenklosters $(1606-1616-1721)$. In: Fedor Titov: Tipografija Kievo-Pečerskoj Lavry. Die Druckerei des Kiever Höhlenklosters. Als Reprint herausgegeben und eingeleitet von Martin Erdmann und Walter Kroll. Köln - Weimar - Wien 2000 (= Bausteine zur Slavischen Philologie und Kulturgeschichte. Reihe B: Editionen. N.F., Bd. 15). - S. VII - XXVIII.

20. Exkurs über die Emblem- und Emblematikrezeption in der Ukraine (17. Jahrhundert). In: Slavische Literaturen im Dialog. Festschrift für Reinhard Lauer zum 65. Geburtstag. Hrsg. Ulrike Jekutsch und Walter Kroll. Wiesbaden 2000. - S. $409-422$.

21. Göttingen. Ingarden und die Literaturwissenschaft. In: Göttinger Tage der polnischen Literatur. Wechselseitigkeit - Theorie - Interpretationen. Hrsg. R. Lauer und L. Żyliński. Göttingen 2004 (= Der Blaue Turm, Bd. 27). - S. $103-119$.

\section{Lexikonartikel}

22. Der Literatur-Brockhaus in drei Bänden (kroatische, serbische und polnische Literatur).

23. Harenbergs Literaturlexikon (kroatische und polnische Literatur).

24. Brockhaus-Enzyklopädie (slavische Philosophie).

25. Lexikon der Weltliteratur von Gero von Wilpert. 4. Auflage. 2004 (russische Literatur). 


\section{Bibliographien}

26. Bibliografija poljske znanosti o književnosti. In: Književna komunikacija. Antologija poljske znanosti o književnosti. Hrsg. Walter Kroll. Sonderheft der Zeitschrift „Umjetnost riječi“ 18 (1974), 2-4, Zagreb 1979. - S. 405 - 449.

27. Bibliographie zur polnischen Literaturwissenschaft. Literarische Kommunikation - Literatursoziologie - Phänomenologie der Literatur. In: Language, Literature \& Meaning II: Current Trends in Literary Research. Hrsg. J. Odmark. Amsterdam 1980. - S. 525 - 569.

28. M. Sedmidubský und W. Kroll: Bibliographie zum tschechischen und slovakischen literaturwissenschaftlichen Strukturalismus. In: Language, Literature \& Meaning II: Current Trends in Literary Research. Hrsg. J. Odmark. Amsterdam 1980. - S. $457-524$.

29. Bibliographie deutscher Arbeiten zur Rezeptionsästhetik, Semiotik der Literatur, Textlinguistik und zur neueren Rhetorikforschung. In: Rezeptionsästhetik und Literaturgeschichte. Sonderheft der Zeitschrift „Umjetnost riječi“. Zagreb 1977. - S. $221-275$.

30. Reinhard Lauer - Schriftenverzeichnis 1958 - 2000. Hrsg. Anke Bruhn und Walter Kroll. Göttingen 2000 (= Der Blaue Turm, Bd. 15).

\section{Übersetzungen aus dem Russischen, Polnischen und Kroati- schen}

31. Jurij M. Lotman: Die Struktur des künstlerischen Textes. Hrsg. R. Grübel. Übersetzt von R. Grübel, W. Kroll und H.-E. Seidel. Frankfurt am Main 1973.

32. Jurij M. Lotman: Zur Distinktion des linguistischen und literaturwissenschaftlichen Strukturbegriffs. In: Formalismus, Strukturalismus und Geschichte. Hrsg. Aleksandar Flaker und Viktor Žmegač. Kronberg (Taunus) 1974. - S. $105-120$.

33. Michail M. Bachtin: Das Wort im Roman. In: Formalismus, Strukturalismus und Geschichte. Hrsg. Aleksandar Flaker und Viktor Žmegač. Kronberg (Taunus) 1974. - S. $121-130$.

34. Edward Balczeran: Perspektiven der „Perzeptionspoetik“. In: Formalismus, Strukturalismus und Geschichte. Hrsg. Aleksandar Flaker und Viktor Žmegač. Kronberg (Taunus) 1974. - S. $186-210$.

35. Michał Głowiński: Die literarische Gattung und die Entwicklung der Literaturwissenschaft. In: Formalismus, Strukturalismus und Geschichte. Hrsg. Aleksandar Flaker und Viktor Žmegač. Kronberg (Taunus) 1974. - S. 155 185. 
36. Henryk Markiewicz: Das Werk Roman Ingardens und die Entwicklung der Literaturwissenschaft. In: Formalismus, Strukturalismus und Geschichte. Hrsg. Aleksandar Flaker und Viktor Žmegač. Kronberg (Taunus) 1974. - S. $221-246$.

37. Teresa Dobrzyńska: Metapher im Märchen. In: Literaturtheoretische Modelle und kommunikatives System. Zur aktuellen Situation in der polnischen Literaturwissenschaft. Hrsg. Walter Kroll und Aleksandar Flaker. Kronberg (Taunus) 1974. - S. $261-296$.

38. Zdenko Škreb: Ritterdichtung und frühe bürgerliche Kultur. In: V. Žmegač, Z. Škreb und Lj. Sekulić: Geschichte der deutschen Literatur. Königstein 1981. - S. $28-47$.

39. Dževad Karahasan: Die Angst vor dem Unterschied. In: Text + Kritik 10 (1994), 124. - S. $82-91$. 